\title{
SystEM-PLA: \\ um método sistemático para avaliação de arquitetura de linha de produto de software baseada em UML
}

Edson Alves de Oliveira Junior

Tese apresentada ao Instituto de Ciências Matemáticas e de Computação - ICMC-USP, como parte dos requisitos para obtenção do título de Doutor em Ciências - Ciências de Computação e Matemática Computacional.

Orientador: Prof. Dr. José Carlos Maldonado

USP - São Carlos

Julho de 2010 

Dedico este trabalho à MINHA FAMÍLIA: minha mãe Helena ( in memoriam), meu pai Edson e minhas irmãs Eliane e Rosane, fontes de toda a minha inspiração, dedicação, esforço, humildade e reconhecimento.

"Melhor do que todos os presentes por baixo da árvore de natal, é a presença de uma família feliz." 


\section{Agradecimentos}

Agradeço à minha mãe, Helena, fonte de toda a minha inspiração e humildade, ao meu pai, Edson, pelo amor e paciência demonstrados, às minhas irmãs, Eliane e Rosane, pelo amor incondicional, carinho e constante incentivo, ao meu cunhado, Itamar, pela ajuda, carinho e incentivo constantes e ao meu cunhado Luis, por toda ajuda e incentivo.

Agradeço ao Prof. Dr. José C. Maldonado pela oportunidade de tornar real algo pelo qual sonhei desde a graduação e por me incentivar a continuar o trabalho face às adversidades.

Agradeço, em especial e com muito carinho, à Profa. Dra. Itana M. S. Gimenes, orientadora e amiga, por ser uma referência como profissional para mim, a quem eu admiro e devo toda a minha formação, conhecimento e discernimento; por acreditar, mais uma vez, no meu potencial e no meu trabalho, por incentivar a minha carreira e pelos inúmeros conselhos profissionais. Muito obrigado por tudo, Itana. É impossível expressar o sentimento somente com palavras!

Agradeço à Profa. Dra. Sandra Ferrari pelo constante incentivo, respeito e carinho por mim e pela paciência e dedicação na revisão do texto desta tese. À minha irmã Eliane, Camila Leal, Edilson Castro e Edilaine Bondioli, por contribuírem com a revisão do texto desta tese. Agradeço ao meu grande amigo Iverson Barreto por toda a ajuda e paciência no desenho das figuras dos capítulos de revisão bibliográfica desta tese.

Agradeço aos amigos e futuros colegas Cristina e Ricardo Ciferri, Thelma Colanzi, Luciana Martimiano, Ademir Carniel, Ademir Constantino, Anderson Faustino, Donizete Bruzarosco, Elisa Huzita, Flávio Braga, Josiane Melchiori, Maria Madalena, Nardênio Martins, Osvaldo Santos, Ronaldo Gonçalves, Sérgio Silva, Valéria Feltrim, Tânia Tait, Wesley Romão e Tarcísio Trindade por contribuirem direta ou indiretamente com a realização deste trabalho. 
Agradeço carinhosamente aos meus amigos Michel e Mari, Rogério (Cabelo), Keity, Aline Vanso, Anderson e Magda, Iverson, Francielle Shimizu, Noemi Rocha, Letícia Lauzer, Julinho, Ju Bellato, Márcia Cristina dos Reis, Marcell Matheus, Késsia Marchi, Daniela Flôres, Rogério Pozza, Luiz Arthur e Keula, Igor Wiese, Igor Steinmacher, Aldo e Cláudia, Sérgio e Lucia Yamada, Emerson Rabelo, Marcius Gimenes, Camila Kozlovski, Marcella Letícia, Paulo Gabriel, Sandro Lopes, Erika Nina, Marco Aurélio Graciotto, Rodrigo Calvo, Vanessa Borges, Alessandra Chan, Juliana Azoia, André Vicente, Fabiano Ferrari, Katia Felizardo, Merley Conrado, Vivian Motti, Murilo, Nelson e Ana Gaspareto, Altair e Rosane, Eduardo Bertholdo que de alguma forma contribuíram para a realização deste trabalho.

Agradeço aos amigos que foram muito importantes durante o tempo que passei no Canadá: Diógenes Vedoy, Jazmin Romero, Paula, Mônica, Manoel, Arthur, Alberto e Ceci, Rafael e Erica, Thiago e Fran, Carlos (Sony Toronto Eaton Centre), Mehdi Amoui e Nousha, Mazeiar Salehie e Sepinood, Reza, Sen Li, Purya e Avin, Pooyan e Avid, Afsaneh, Ruby, Marcilio, Melissa Macdonald, Jennifer Laughlin (St. Paul's Residence), Elena Ruiz, Mark, Saurabh Tewari, Brenda, Nikkii e Serena. Agradecimento especial à Profa. Dra. Ladan Tahvildari, por me receber tão bem na University of Waterloo e por me fazer sentir parte da família Star Lab. Agradeço ao Prof. Dr. Krzysztof Czarnecki por permitir que alguns dos seus alunos participassem do estudo experimental realizado durante o doutorado-sanduíche em Waterloo. Agradeço à Katherine MacLean, minha tutora em língua inglesa na University of Waterloo.

Agradeço aos profissionais e alunos de mestrado e doutorado da University of Waterloo (UWaterloo), Universidade Estadual de Maringá (DIN-UEM) e Universidade de São Paulo (ICMC-USP) que participaram do estudo experimental de validação das métricas propostas.

Agradeço ao Prof. Dr. Avelino Zorzo por me receber na PUC-RS e por contribuir com o trabalho desenvolvido e com a realização do estudo experimental de viabilidade do método SystEM-PLA em uma das empresas da TecnoPUC. Agradeço aos profissionais que participaram do estudo experimental pela disposição e contribuições à tese. Agradeço à CAPES por financiar minha missão de estudo em Porto Alegre, por meio do Programa Nacional de Cooperação Acadêmica (Procad) entre o ICMC-USP, a UEM e a PUC-RS.

Agradeço ao Prof. Dr. Márcio Barros (Unirio) pela disponibilidade, paciência e por contribuir diretamente com o planejamento do estudo experimental para validação das métricas de complexidade e extensibilidade. 
Agradeço à colega e amiga Erika Nina Höhn pelas dicas e contribuições nos estudos experimentais realizados e a revisão dos protocolos das revisões sistemáticas conduzidas.

Agradeço ao Prof. Dr. Henrique Rozenfeld pela oportunidade de trabalhar, como bolsista CNPq-DTI, em um dos projetos da Escola de Engenharia de São Carlos (EESC), Departamento de Engenharia de Produção, Núcleo de Manufatura Avançada (NUMA).

Agradeço à Profa. Dra. Maria das Graças Campos Pimentel pela oportunidade de trabalhar, como bolsista FAPESP TT4a, no projeto TIDIA-Ae.

Agradeço ao Sr. Jürgen Wüst por conceder uma versão funcional sem restrições da ferramenta SDMetrics para a definição e coleta de métricas para modelos UML.

Agradeço ao pessoal do setor de pós-graduação do ICMC-USP, em especial à Laura, Ana Paula e Noemi Rocha, por toda a ajuda despendida nesses quatro anos. Agradeço a todos os profissionais da USP que direta ou indiretamente contribuíram para a realização deste trabalho.

Agradeço à CAPES pelo financiamento do doutorado-sanduíche em Waterloo-ON, Canadá e pelos meses concedidos de bolsa de doutorado. 
$\begin{array}{lll}\mathbf{1} & \text { Introdução } & \mathbf{1}\end{array}$

1.1 Contextualização $\ldots \ldots \ldots \ldots \ldots$. . . . . . . . . . . . . . 1

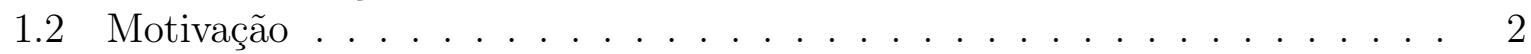

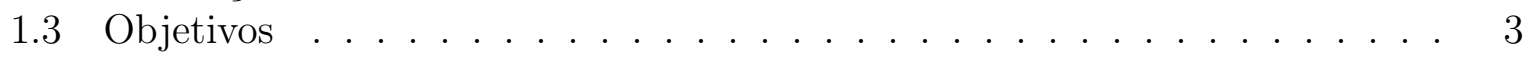

1.4 Organização do Trabalho . . . . . . . . . . . . . . . . . . . . . . . . . 4

\begin{tabular}{|lll}
\hline 2 & Linha de Produto de Software & 7
\end{tabular}

2.1 Caracterização de LP . . . . . . . . . . . . . . . . . . . . . . . . . . . . . . 8

2.2 Benefícios da Abordagem de LP . . . . . . . . . . . . . . . . . . . . . . 11

2.3 Atividades Essenciais de LP . . . . . . . . . . . . . . . . . . . . . . . . . . 13

2.3 .1 Desenvolvimento do Núcleo de Artefatos . . . . . . . . . . . . . . . 14

2.3 .2 Desenvolvimento do Produto . . . . . . . . . . . . . . 16

2.3 .3 Gerenciamento de Linha de Produto . . . . . . . . . . . . . . . . 17

2.4 Abordagens Existentes de LP . . . . . . . . . . . . . . . . . . . . . . . . . 18

2.5 Arquitetura de Sistemas Únicos vs. Arquitetura de LP . . . . . . . . . . 19

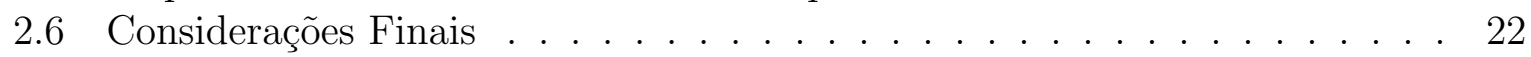

\begin{tabular}{|lll}
\hline & Avaliação de Linha de Produto de Software & 23
\end{tabular}

3.1 O Método ATAM . . . . . . . . . . . . . . . . . . . . . . . . 24

3.2 Conceitos sobre Avaliação de LP $\ldots \ldots \ldots$. . . . . . . . . . . . . . . . . . 29

3.3 Abordagens e Métricas para Avaliação de LP . . . . . . . . . . . . . . . . . 32

3.3.1 Avaliação de Atributos de Qualidade de Arquiteturas de LP . . . . 33

3.3.2 Avaliação Estrutural de Arquiteturas de LP . . . . . . . . . . . . . 40

3.3 .3 Definição e Avaliação de Escopo de LP . . . . . . . . . . . . . . . . . 43

3.4 Extensões do Método ATAM para a Avaliação de ALP . . . . . . . . . . . 51

3.4.1 EATAM (Extended ATAM) [. . . . . . . . . . . . . . . . . 51

3.4.2 HoPLSAA (Holistic Product Line Software Architecture Assessment) 55

3.5 Considerações Finais $\ldots \ldots \ldots \ldots \ldots \ldots$

4 SMarty: Uma Abordagem UML para Gerenciamento de Variabilidade 59

4.1 Abordagens Existentes de Gerenciamento de Variabilidade . . . . . . . . . 60

4.2 O Perfil UML SMartyProfile . . . . . . . . . . . . . . . . . . 63 
4.2.1 SMartyProfile e Outras Abordagens de Representação de Varia-

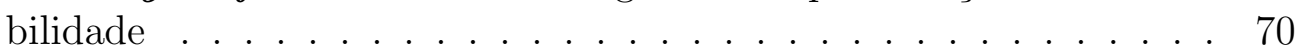

4.3 O Processo SMartyProcess . . . . . . . . . . . . . . . 75

4.3.1 Elaboração do Modelo de Rastreamento de Variabilidades . . . . . 78

$4.3 .2 \quad$ Identificacão de Variabilidades . . . . . . . . . . . . . . . . . . . 78

$4.3 .3 \quad$ Delimitação de Variabilidades $\ldots . . . . . . . . . .80$

4.3.4 Identificação de Mecanismos de Implementação de Variabilidade . . 80

$4.3 .5 \quad$ Rastreamento e Controle de Variabilidades . . . . . . . . . . . . . . 81

4.3 .6 Análise de Configuração de Produtos . . . . . . . . . . . . . . . . . 82

4.4 Exemplo de Aplicação da Abordagem SMarty . . . . . . . . . . . . . . . 83

4.5 Considerações Finais $\ldots \ldots \ldots$. . . . . . . . . . . . . . . . . . . . . . . . . 90

5 SystEM-PLA: Um Método de Avaliação de Arquitetura de LP $\quad 93$

5.1 Caracterização do Método SystEM-PLA . . . . . . . . . . . . . . . . . 94

$5.1 .1 \quad$ Fase de Planejamento . . . . . . . . . . . . . . . . . . . . . . 98

$5.1 .2 \quad$ Fase de Coleta de Dados . . . . . . . . . . . . . . . . . . . . . . . . 98

5.1 .3 Fase de Análise de Dados e Documentação . . . . . . . . . . . . . . 99

5.2 Metaprocesso de Avaliação (MPA) $\ldots \ldots$. . . . . . . . . . . . . . . . . . . 99

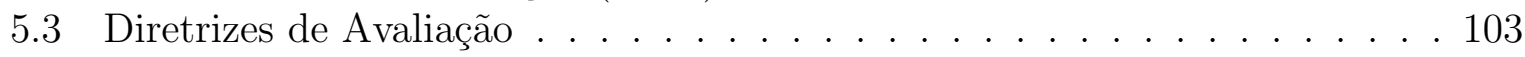

$5.3 .1 \quad$ Diretrizes de Planejamento (DP) . . . . . . . . . . . . . . . . . . . . . . . . . 104

$5.3 .2 \quad$ Diretrizes de Coleta de Dados (DC) . . . . . . . . . . . . . . . . . . 110

5.3.3 Diretrizes de Análise de Dados e Documentação (DA) . . . . . . . . . 111

5.4 Considerações Finais . . . . . . . . . . . . . . . . . . 117

6 Métricas para Avaliação de Arquitetura de LP 119

6.1 Métricas Básicas . . . . . . . . . . . . . . . . . . . 121

6.1 .1 Métricas Básicas de Classes e Interfaces. . . . . . . . . . . . . . . . 121

6.1 .2 Métricas Básicas de Diagramas . . . . . . . . . . . . . . . . 130

6.1.3 Métricas Básicas de Componentes e Modelos . . . . . . . . . . . . . . 135

6.2 Métricas para Atributos de Qualidade . . . . . . . . . . . . . . . . . 137

6.2 .1 Métricas de Complexidade . . . . . . . . . . . . . . . . . . . 138

6.2 .2 Métricas de Extensibilidade . . . . . . . . . . . . . . . . . . . . . . 140

6.3 Automatização das Métricas Usando a Ferramenta SDMetrics . . . . . . . . 143

6.4 Exemplo de Aplicação e Coleta de Métricas de Complexidade e Extensibi-

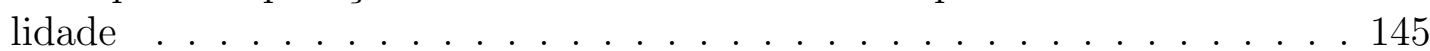

6.4.1 Config.1: Jogo Brickles com Características Restritas . . . . . . . . 145

6.4.2 Config.2: Jogos Brickles e Pong com Todas as Características . . . 149

6.4 .3 Análise Acerca do Exemplo . . . . . . . . . . . . . . . . . . . . 154

6.5 Considerações Finais . . . . . . . . . . . . . . . . . . . . . 155

\section{Validação Experimental das Métricas de Complexidade e Extensibili-} dade

7.1 Definição do Estudo Experimental.

7.2 Planejamento do Estudo Experimental . . . . . . . . . . . . . . . . . . . . 158

7.3 Execução do Estudo Experimental. . . . . . . . . . . . . . . . . . . . . . . 163

7.4 Análise e Interpretação dos Resultados do Estudo Experimental . . . . . . 166 
7.4.1 Testes de Normalidade para as Métricas CompPLA e ExtensPLA . 167

7.4.2 Correlação de Spearman para as Métricas CompPLA e ExtensPLA. 170

7.4 .3 Análise de Regressão Linear . . . . . . . . . . . . . . . . . . . . . . 173

7.5 Avaliação de Validade do Estudo Experimental . . . . . . . . . . . . . . . 177

7.5.1 Ameaças à Validade de Conclusão . . . . . . . . . . . . . . . . . . . 177

7.5 .2 Ameaças à Validade de Construção . . . . . . . . . . . . . . . . . . 177

7.5 .3 Ameaças à Validade Interna . . . . . . . . . . . . . . . . . . . . . . 178

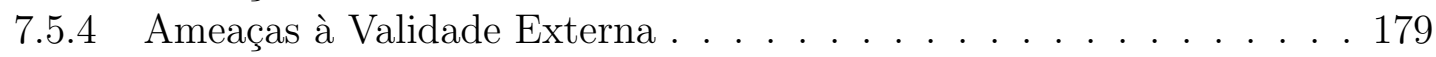

7.6 Apresentação e Empacotamento do Estudo Experimental . . . . . . . . . . . 179

7.7 Considerações Finais $\ldots \ldots \ldots$. . . . . . . . . . . . . . . . . . 179

8 Estudo Experimental de Viabilidade do Método SystEM-PLA 181

8.1 Definição do Estudo Experimental . . . . . . . . . . . . . . . . . . . . . . . 182

8.2 Planejamento do Estudo Experimental . . . . . . . . . . . . . . . . . . . . 182

$8.3 \quad$ Execução do Estudo Experimental. . . . . . . . . . . . . . . . . . . . . 186

8.4 Análise e Interpretação dos Resultados do Estudo Experimental . . . . . . 202

8.5 Avaliação de Validade do Estudo Experimental . . . . . . . . . . . . . . . 204

8.5.1 Ameaças à Validade de Conclusão . . . . . . . . . . . . . . . . . . . 204

8.5 .2 Ameaças à Validade de Construção . . . . . . . . . . . . . . . . . . 205

8.5 .3 Ameaças à Validade Interna . . . . . . . . . . . . . . . . . . . . . . 205

8.5.4 Ameaças à Validade Externa . . . . . . . . . . . . . . . . . . . . . . 206

8.6 Apresentação e Empacotamento do Estudo Experimental . . . . . . . . . . . 206

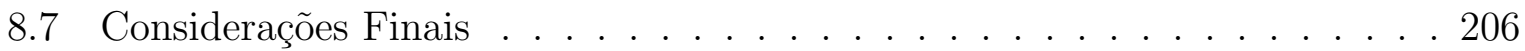

$\begin{array}{lll}9 & \text { Conclusões } & 209\end{array}$

9.1 Propósito da Pesquisa $\ldots \ldots \ldots$. . . . . . . . . . . . . . . . . . . . . . . 209

9.2 Resultados e Contribuições . . . . . . . . . . . . . . . . . . . . . . . . . . . 210

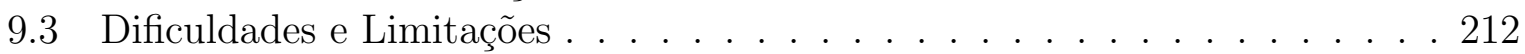

9.4 Trabalhos Futuros . . . . . . . . . . . . . . . . . . . . . . . . . . . . . . . . 213

\begin{tabular}{ll}
\hline Referências Bibliográficas & 215
\end{tabular}

A A Linha de Produto Arcade Game Maker 231

B Código XML das Métricas Básicas de Avaliação de ALP 239

B.1 Métricas Básicas de Classes . . . . . . . . . . . . . . . . . . . . . 239

B.2 Métricas Básicas de Interfaces . . . . . . . . . . . . . . . . . . . . . . . 244

B.3 Métricas Básicas de Diagramas . . . . . . . . . . . . . . . . . . . . . . . . 249

B.4 Métrica Básica de Componentes . . . . . . . . . . . . . . . . . . . . . . . . 253

B.5 Métricas Básicas de Modelos (LP) . . . . . . . . . . . . . . . . . 253

C Validação Experimental de Métricas de ALP: Instrumentação 257

D Estudo Experimental de Viabilidade do Método SystEM-PLA: Instrumentação 


\section{Lista de Figuras}

2.1 Exemplo de Modelo de Características para um Cliente de E-mail (Gurp

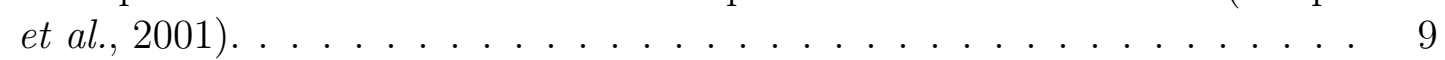

$2.2 \quad$ Atividades Essenciais de LP, adaptada de (SEI, 2010a). . . . . . . . . . . . . 14

2.3 Desenvolvimento do Núcleo de Artefatos, adaptada de (SEI, 2010a). . . . . 16

2.4 Desenvolvimento do Produto, adaptada de (SEI] 2010a). . . . . . . . . . 17

3.1 Decomposição de Metas e Avaliação de Domínios. . . . . . . . . . . . . . . 47

3.2 Etapas do Método MAP. . . . . . . . . . . . . . . . . . . . . . . . . . . 48

3.3 Os Interesses do Processo BAPO e seus Relacionamentos (Linden et al.,

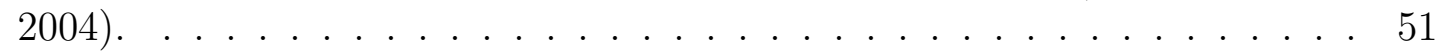

3.4 Estrutura do EATAM. . . . . . . . . . . . . . . . . . . . . . . 52

3.5 Exemplo de Aplicação das Marcações do EATAM em Atributos de Qualidade de um Forno de Microondas (Kim et al. [2008b). . . . . . . . . . . . . 54

3.6 Entradas e Saídas do Método HoPLSAA. . . . . . . . . . . . . . . . . . . . 55

4.1 Relacionamento dos Conceitos de Gerenciamento de Variabilidade e Modelos UML. . . . . . . . . . . . . . . . . . . . . . . . 64

4.2 Modelo de Casos de Uso da Característica "Ordenação de Elementos". . . . 65

4.3 Modelo de Classes da Característica "Ordenação de Elementos". . . . . . . . 66

4.4 SMartyProfile para Gerenciamento de Variabilidade em Linhas de Produto de Software Baseadas em UML. . . . . . . . . . . . . . . . . . . . . . 67

4.5 Representação de Pontos de Variação Usando a Notação em Triângulo (Halmans e Pohl, 2003). . . . . . . . . . . . . . . 70

4.6 Sistema de Reserva de Vôo de Acordo com a Abordagem de Halmans e

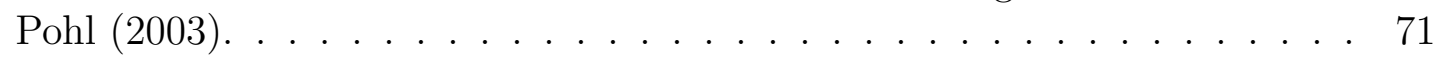

4.7 Sistema de Reserva de Vôo Segundo o Perfil SMartyProfile. . . . . . . . . . . 72

4.8 Característica "Check Out Customer" Segundo a Abordagem PLUS (Go-

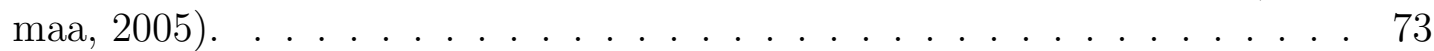

4.9 Característica "Check Out Customer" Segundo o SMartyProfile. . . . . . . 74

4.10 Interação entre as Atividades de Desenvolvimento de Linha de Produto e o SMartyProcess. . . . . . . . . . . . . . . . 76

4.11 Metamodelo de Variabilidade Usado para Rastrear e Controlar Variabilidades. 82 4.12 Modelo de Variabilidade para Casos de Uso da AGM de Acordo com SMarty. 85 
4.13 Modelo de Variabilidade para Classes da AGM de Acordo com SMarty. . . 87

4.14 Arquitetura Lógica de Componentes da AGM de Acordo com SMarty. . . . 89

$5.1 \quad$ Fases do Método SystEM-PLA. . . . . . . . . . . . . . . . . . . 95

5.2 Representação Gráfica do Método SystEM-PLA Contendo suas Fases, Diretrizes e Artefatos. . . . . . . . . . . . . . . . . . . . . . . . . 97

5.3 SystEM-PLA: Atividades do Metaprocesso de Avaliação (MPA). . . . . . . 101

5.4 Modelo Goal-Question-Metric para a LP AGM. . . . . . . . . . . . . . . . 110

5.5 Estatística Descritiva e Distribuição de Frequência dos Valores Observados da Métrica CompPLA. . . . . . . . . . . . . . . . . . . . . . . 113

5.6 Estatística Descritiva e Distribuição de Frequência dos Valores Observados da Métrica ExtensPLA. . . . . . . . . . . . . . . . . . . . . . . . . . . . . . 113

5.7 Histograma de Dispersão dos Valores Observados das Métricas CompPLA e ExtensPLA para as Configurações AGM. . . . . . . . . . . . . . . . . . . 116

6.1 Tela Principal da SDMetrics Versão 2.02. na Visão Tabular (Table View) 144

6.2 Exemplo de Coleta de Métricas Básicas de Classes Usando a Ferramenta SDMetrics. . . . . . . . . . . . . . . . . . . . 145

6.3 Modelo de Classes AGM Config. 1. . . . . . . . . . . . . . . . . . . . . . 146

6.4 Modelo de Classes AGM Config.2. . . . . . . . . . . . . . . . . . . . . . . . 150

7.1 Valores de Complexidade e Extensibilidade Associados pelos Participantes às Configurações AGM. . . . . . . . . . . . . . . . . . . . 163

7.2 Métrica CompPLA: Estatística Descritiva e Testes de Kolmogorov-Smirnov e Shapiro-Wilk. . . . . . . . . . . . . . . . . . 168

7.3 Métrica ExtensPLA: Estatística Descritiva e Testes de Kolmogorov-Smirnov e Shapiro-Wilk. . . . . . . . . . . . . . . . . . . . . . . . . . 169

7.4 Escalas da Correlação de Spearman. . . . . . . . . . . . . . . . . . . 170

7.5 Análise de Regressão Linear da Correlação Corr.1. . . . . . . . . . . . . . . . . 173

7.6 $\quad$ Escala de Complexidade Proposta para Medir Configurações de ALP. . . . 174

7.7 Análise de Regressão Linear da Correlação Corr.2. . . . . . . . . . . . . . . 175

7.8 $\quad$ Escala de Extensibilidade Proposta para Medir Configurações de ALP. . . 175

7.9 CompPLA vs. ExtensPLA: Análise de Regressão Linear. . . . . . . . . . . 176

7.10 ExtensPLA vs. CompPLA: Análise de Regressão Linear. . . . . . . . . . . . 176

8.1 Part.1: Gráfico de Dispersão para as Métricas CompPLA e ExtensPLA. . . 193

8.2 Part.2: Gráfico de Dispersão para as Métricas CompPLA e ExtensPLA. . . 197

8.3 Part.3: Gráfico de Dispersão para as Métricas CompPLA e ExtensPLA. . . 201

A.1 Modelo de Características da LP Arcade Game Maker (SEI, [2010b). . . . . . 232

A.2 Modelo de Casos de Uso da LP AGM (SEI [2010b). . . . . . . . . . . . . . 233

A.3 Modelo de Classes da LP AGM (SEI, 2010b). . . . . . . . . . . . . . . . . 238

A.4 Arquitetura Lógica de Componentes da AGM (SEI] 2010b). . . . . . . . . 238 


\section{Lista de Tabelas}

4.1 Comparação das Abordagens com Relação aos Principais Conceitos de

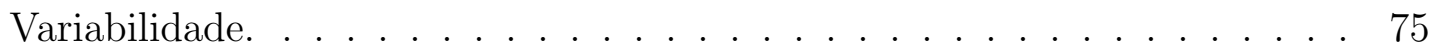

4.2 Relacionamentos Entre Atividades, Entradas e Saídas do Desenvolvimento de Linha de Produto e do SMartyProcess. . . . . . . . . . . . . . . . . . . 77

4.3 Exemplo de Modelo de Implementação para a Característica "Ordenação de Elementos". . . . . . . . . . . . . . . . . . . . 81

4.4 Modelo de Rastreamento da LP AGM. . . . . . . . . . . . . . . . . . . . . 84

4.5 Modelo de Implementação de Variabilidades da AGM. . . . . . . . . . . . . . . 89

5.1 Metaprocesso de Avaliação: Entradas e Saídas das Atividades. . . . . . . . . 103

5.2 Cenários Definidos para Complexidade de Produtos da AGM. . . . . . . . 105

5.3 Cenários Definidos para Extensibilidade de Produtos da AGM. . . . . . . . . . 105

5.4 Cenários AGM Classificados para Complexidade e Extensibilidade. . . . . . 106

5.5 Seleção de Atributos de Qualidade AGM. . . . . . . . . . . . . . . . . . . . 107

5.6 Questões Gerenciais e Técnicas para as Metas de Negócio AGM. . . . . . . . 108

5.7 Métricas AGM para os Atributos de Qualidade Complexidade e Extensibilidade. . . . . . . . . . . . . . . . . . . 109

5.8 Valores Observados das Métricas de Complexidade e Extensibilidade para Configurações AGM. . . . . . . . . . . . . . . . . . . . . . . . . 111

6.1 Siglas Usadas para Formar o Nome das Métricas Baseadas em UML. . . . 120

6.2 Métricas Básicas para Classes. . . . . . . . . . . . . . . . . 126

6.3 Métricas Básicas para Interfaces. . . . . . . . . . . . . . . . . . . . . . . . 130

6.4 Métricas Básicas para Diagramas. . . . . . . . . . . . . . . . . . . . . . . 135

6.5 Métricas Básicas para Componentes e Modelos. . . . . . . . . . . . . . . . 137

6.6 Métrica CompClass Aplicada às Classes e Interfaces da Config.1 . . . . . . 146

6.7 Métrica CompClass Aplicada às Classes e Interfaces da Config.2 . . . . . . 151

7.1 Dados Detalhados dos Participantes do Estudo Experimental. . . . . . . . . . 165

7.2 Arcade Game Maker: Métricas Coletadas e Estatística Descritiva. . . . . . . 166

7.3 Correlação de Spearman para Corr.1: CompPLA e o Valor de Complexidade Associado pelos Participantes. . . . . . . . . . . . . . . . . . 171 
7.4 Correlação de Spearman para Corr.2: ExtensPLA e o Valor de Extensibilidade Associado pelos Participantes. . . . . . . . . . . . . . . . . . . 172 7.5 Correlação de Spearman para Corr.3: CompPLA e ExtensPLA. . . . . . . . . 172

8.1 Dados Detalhados dos Participantes do Estudo. . . . . . . . . . . . . . . . 189

8.2 Part.1: Classificação dos Cenários. . . . . . . . . . . . . . . . . . . . 191

8.3 Part.1: Valores Observados para as Métricas CompPLA e ExtensPLA. . . . 192

8.4 Part.2: Classificação dos Cenários. . . . . . . . . . . . . . . . . 195

8.5 Part.2: Valores Observados para as Métricas CompPLA e ExtensPLA. . . . 196

8.6 Part.3: Classificação dos Cenários. . . . . . . . . . . . . . . . . . . . . 199

8.7 Part.3: Valores Observados para as Métricas CompPLA e ExtensPLA. . . . 200

A.1 Pacotes e Descrição das Classes da LP AGM. . . . . . . . . . . . . . . . . 237 


\section{Lista de Códigos-Fonte}

6.1 Exemplo de Definição de Métrica Usando a Ferramenta SDMetrics. . . . . . 143

B.1 Código XML da Métrica $C L S_{-} C L S_{-} B A S_{-} V P T_{-} I S A .7 . . . . . .239$

B.2 Código XML da Métrica $\left.C L S_{-} C L S_{-} B A S_{-} I N C_{-} I S A.\right]$. . . . . . . . . . . . . 239

B.3 Código XML da Métrica $C L S_{-} C L S_{-} B A S_{-} E X C_{-} I S A . ~ . . . . . . . . .240$

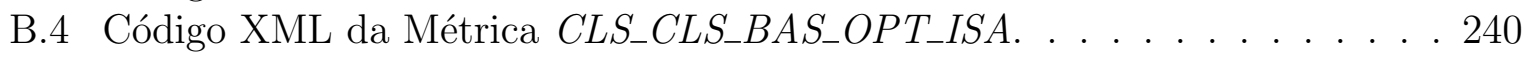

B.5 Código XML da Métrica $C L S_{-} C L S_{-} B A S_{-} M N D_{-} I S A$. . . . . . . . . . . . . . 240

B.6 Código XML da Métrica $C L S_{-} C L S_{-} B A S_{-} I N C_{-} N U M$.

B.7 Código XML da Métrica $C L S_{-} C L S_{-} B A S_{-} E X C_{-} N U M$. . . . . . . . . . . . . . 241

B.8 Código XML da Métrica $C L S_{-} C L S_{-} B A S_{-} O P T_{-} N U M$.

B.9 Código XML da Métrica $C L S_{-} C L S_{-} B A S_{-} M N D_{-} N U M$. . . . . . . . . . . . . . 242

B.10 Código XML da Métrica $C L S_{-} C L S_{-} B A S_{-} V P T_{-} N U M$. . . . . . . . . . . . . . 242

B.11 Código XML da Métrica $C L S_{-} I T F_{-} B A S_{-} I N C_{-} N U M$. . . . . . . . . . . . . . 242

B.12 Código XML da Métrica $C L S_{-} I T F_{-} B A S_{-} E X C_{-} N U M$. . . . . . . . . . . . . 243

B.13 Código XML da Métrica $C L S_{-} I T F_{-} B A S_{-} O P T_{-} N U M$.

B.14 Código XML da Métrica $C L S_{-} I T F_{-} B A S_{-} M N D_{-} N U M$. . . . . . . . . . . . . . 243

B.15 Código XML da Métrica $C L S_{-} I T F_{-} B A S_{-} V P T_{-} N U M$.

B.16 Código XML da Métrica $C L S_{-} C L S_{-} B A S_{-} V B T_{-} N U M$. . . . . . . . . . . . . 244

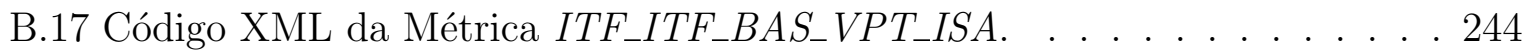

B.18 Código XML da Métrica $I T F_{-} I T F_{-} B A S_{-} I N C_{-} I S A$. . . . . . . . . . . . . . . 244

B.19 Código XML da Métrica $I T F_{-} I T F_{-} B A S_{-} E X C_{-} I S A$. . . . . . . . . . . . . . 245

B.20 Código XML da Métrica $I T F_{-} I T F_{-} B A S_{-} O P T_{-} I S A$.

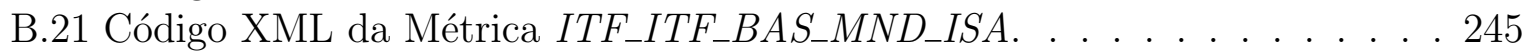

B.22 Código XML da Métrica $I T F_{-} I T F_{-} B A S_{-} I N C_{-} N U M$. . . . . . . . . . . . . . 246

B.23 Código XML da Métrica $I T F_{-} I T F_{-} B A S_{-} E X C_{-} N U M .$. . . . . . . . . . . . . 246

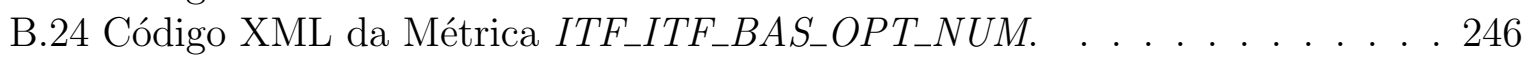

B.25 Código XML da Métrica $I T F_{-} I T F_{-} B A S_{-} M N D_{-} N U M$. . . . . . . . . . . . . 247

B.26 Código XML da Métrica $I T F_{-} I T F_{-} B A S_{-} V P T_{-} N U M . ~ \ldots . . . . . .247$

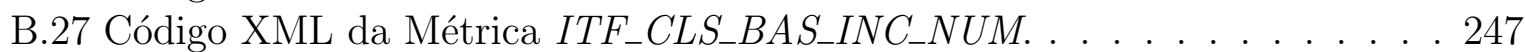

B.28 Código XML da Métrica $I T F_{-} C L S_{-} B A S_{-} E X C_{-} N U M$. . . . . . . . . . . . . . 247

B.29 Código XML da Métrica $I T F_{-} C L S_{-} B A S_{-} O P T_{-} N U M$. . . . . . . . . . . . . . 248

B.30 Código XML da Métrica $I T F_{-} C L S_{-} B A S_{-} M N D_{-} N U M$.

B.31 Código XML da Métrica $I T F_{-} C L S_{-} B A S_{-} V P T_{-} N U M$. 
B.32 Código XML da Métrica $I T F_{-} I T F_{-} B A S_{-} V B T_{-} N U M$.

B.33 Código XML da Métrica $D G M_{-} C L S_{-} B A S_{-} V P T_{-} T O T$. . . . . . . . . . . . . 249

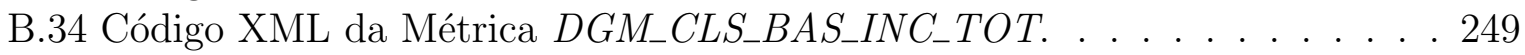

B.35 Código XML da Métrica $D G M_{-} C L S_{-} B A S_{-} E X C_{-} T O T$. . . . . . . . . . . . . 250

B.36 Código XML da Métrica $D G M_{-} C L S_{-} B A S_{-} O P T_{-} T O T$. . . . . . . . . . . . . 250

B.37 Código XML da Métrica $D G M_{-} C L S_{-} B A S_{-} M N D_{-} T O T$. . . . . . . . . . . . 250

B.38 Código XML da Métrica $D G M_{-} C L S_{-} B A S_{-} V B T_{-} T O T$. . . . . . . . . . . . . 250

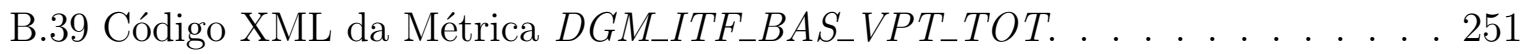

B.40 Código XML da Métrica $D G M_{-} I T F_{-} B A S_{-} I N C_{-} T O T . ~ . . . . . . .251$

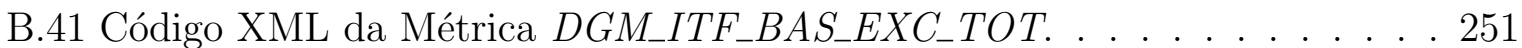

B.42 Código XML da Métrica $D G M_{-} I T F_{-} B A S_{-} O P T_{-} T O T$. . . . . . . . . . . . . 252

B.43 Código XML da Métrica $D G M_{-} I T F_{-} B A S_{-} M N D_{-} T O T$. . . . . . . . . . . . . 252

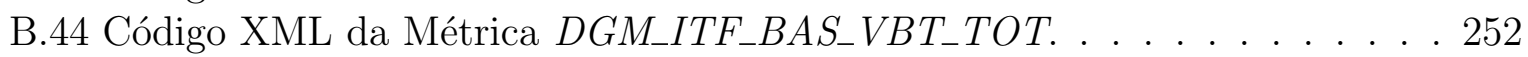

B.45 Código XML da Métrica $\left.D G M_{-} C P T_{-} B A S_{-} V B T_{-} T O T.\right]$. . . . . . . . . . . 253

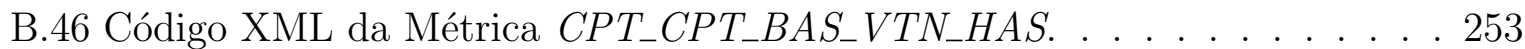

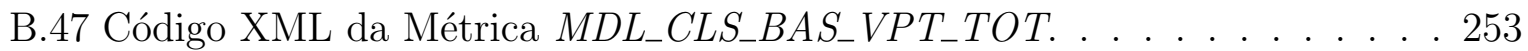

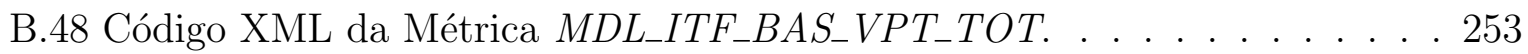

B.49 Código XML da Métrica $M D L_{-} M D L_{-} B A S_{-} V P T_{-} T O T$. . . . . . . . . . . . . 254

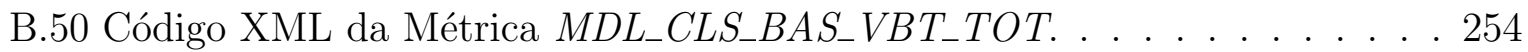

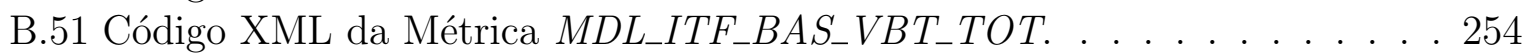

B.52 Código XML da Métrica $M D L_{-} M D L_{-} B A S_{-} V B T_{-} T O T$. . . . . . . . . . . . 255 
AGM Arcade Game Maker

ALP Arquitetura de Linha de Produto de Software

ATAM Architecture Tradeoff Analysis Method

DA Diretrizes de Análise de Dados e Documentação

DC Diretrizes de Coleta de Dados

DP Diretrizes de Planejamento

EATAM Extended ATAM

GQM Goal-Question-Metric

HoPLSAA Holistic Product Line Software Architecture Assessment

LP Linha de Produto de Software

MPA Metaprocesso de Avaliação

ROI Return on Investment

SEI Software Engineering Institute

SMarty Stereotype-based Management of Variability

SystEM-PLA Systematic Evaluation Method for UML-based Software Product Line A rchitectures

UML Unified Modeling Language 
A abordagem de linha de produto de software (LP) tem como objetivo principal promover a geração de produtos específicos de um determinado domínio com base na reutilização de uma infraestrutura central, chamada núcleo de artefatos. Um dos principais artefatos do núcleo de uma LP é a Arquitetura de LP (ALP), que representa a abstração de todas as arquiteturas de sistemas únicos que podem ser gerados, para um domínio específico. Avaliações de ALP são importantes, pois permitem aumentar a produtividade e a qualidade dos produtos da LP, bem como, seus resultados permitem a análise de metas de negócio e de retorno de investimento. Este trabalho propõe um método sistemático para avaliação de ALP, o SystEM-PLA ( a Systematic Evaluation Method for Software Product Line A rchitectures). Tal método considera modelos de ALP em UML, por ser uma notação amplamente conhecida e consolidada. SystEM-PLA é composto por um metaprocesso de avaliação, diretrizes que guiam o usuário em como avaliar uma ALP e métricas básicas para modelos UML e atributos de qualidade. O método utiliza a abordagem SMarty (Stereotype-based Management of Variability), para gerenciar variabilidades em LP baseadas em UML. Análises de trade-off com o objetivo de priorizar atributos de qualidade para o desenvolvimento e evolução dos produtos de uma LP são realizadas com base na aplicação e coleta das métricas do SystEM-PLA em configurações de uma ALP. As métricas propostas para os atributos de qualidade complexidade e extensibilidade foram validadas por meio de um estudo experimental. Evidências indicaram a viabilidade de aplicação do método SystEM-PLA na indústria com base em um estudo experimental realizado com profissionais de uma empresa de grande porte no setor de desenvolvimento de software. 
The software product line (PL) approach aims at promoting the generation of specific products from a particular domain based on the reuse of a central infra-structure, so-called core assets. One of the main assets of a PL is the PL Architecture (PLA) that represents the abstraction of all possible single-product architectures that can be generated for a particular domain. PLA evaluations are important due to allow the increasing of the productivity and the quality of PL products, as well as their results allow business drivers and return on investment analyzes. This work proposes a Systematic Evaluation Method for Software Product Line Architectures, the SystEM-PLA. This method takes into account UML models with PLA variability explicitly represented, since UML is a widely known and consolidated notation. SystEM-PLA is composed of an evaluation meta-process, guidelines that drive the user on how to evaluate a PLA, and basic and quality attribute metrics. This method uses the proposed approach Stereotype-based Management of Variability (SMarty) to manage variabilities in UML-based PLs. Trade-off analyses to prioritize quality attributes for the development and evolution of PL products are carried out based on the application and collection of the SystEM-PLA metrics from PLA configurations. The quality attribute metrics were validated trough an experimental study. Evidences indicated the SystEM-PLA application feasibility in industry based on an experimental study, planned and conducted with professionals from a large software development organization. 


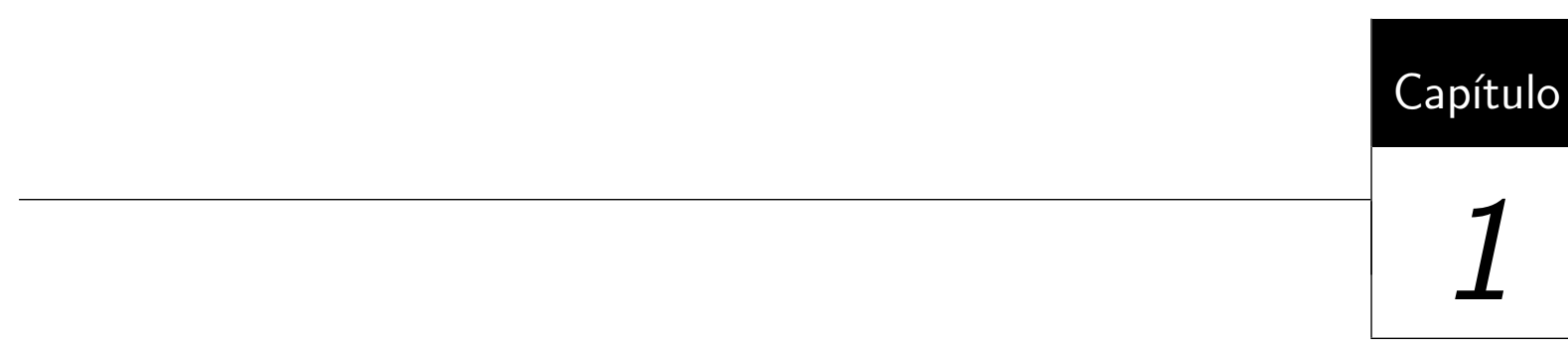

\section{Introdução}

"No meio de qualquer dificuldade
encontra-se a oportunidade."

Albert Einstein (1879 - 1955), Físico

Teórico, Prêmio Nobel (1921)

\subsection{Contextualização}

Os benefícios obtidos com a abordagem de linha de produto de software (LP) incluem: melhor compreensão dos domínios, mais artefatos reusáveis e menos tempo para o produto chegar ao mercado (Clements e Northrop, 2001; Linden et al., 2007; SEI, 2010a). Casos de sucesso na adoção de LP por várias organizações têm sido reportados na literatura, incluindo: Philips, Bosch, Nokia e Toshiba (Linden et al., 2007; SEI, 2010c). A adoção da abordagem de LP requer planejamento a longo prazo, pois os seus benefícios não são imediatamente obtidos. Assim, um grande número de produtos deve ser produzido para se obter retorno de investimento (ROI) (Böckle et al., 2004). Tais benefícios podem ser melhor compreendidos e alcançados por meio de avaliações de LP e dos seus principais artefatos. O mais importante desses artefatos é a Arquitetura de LP (ALP), pois é uma abstração de todas as possíveis arquiteturas dos produtos únicos de uma LP. Além disso, avaliações de ALP podem ser usadas como parâmetro para avaliar a qualidade de uma LP. Ao avaliar uma ALP, o arquiteto de LP pode analisar seus atributos de qualidade e 
priorizá-los com o objetivo de reduzir o esforço de manutenção de LP e sua evolução. O gerente de LP pode utilizar uma avaliação de ALP como uma forma de identificar riscos associados à LP, amenizá-los e justificar o retorno de investimento esperado.

Para avaliar uma ALP é necessário definir metas de negócio e relacioná-las aos seus atributos de qualidade. Métricas devem ser definidas para que se possam coletar dados sobre os potenciais produtos de uma LP, interpretá-los e permitir que análises de trade-off possam ser realizadas com relação aos atributos de qualidade da ALP à medida que produtos sejam gerados. As metas de negócio, os atributos de qualidade e as métricas devem considerar as variabilidades existentes na ALP. Para tanto, uma representação apropriada para as variabilidades deve ser considerada. Dentre as várias abordagens para representar variabilidade em LP existentes na literatura, a representação usando UML é uma das mais amplamente consideradas. Assim, modelos UML de uma LP são marcados com estereótipos específicos para representar variabilidade.

O contexto deste trabalho é a investigação e a proposta de um método para avaliar arquitetura de linha de produto de software (ALP) baseada em UML.

\subsection{Motivação}

A avaliação dos atributos de qualidade de uma ALP é importante uma vez que os resultados obtidos produzem informações que levam a um potencial aumento de produtividade e qualidade dos produtos de uma LP, redução do tempo para os produtos estarem disponíveis no mercado, melhoria da capacidade de produção (Linden et al., 2007) e uso da ALP como um parâmetro para a avaliação geral da LP (Etxeberria e Sagardui, 2008b).

Por meio da avaliação de uma ALP é possível ajustar o desenvolvimento e evolução dos produtos de uma LP de acordo com as metas de negócio previamente estabelecidas. A definição de cenários comportamentais (Brito et al. 2009) permite a realização de análises de trade-off com o objetivo de identificar quais atributos de qualidade influenciam diretamente as metas de negócio da LP, e quais desses atributos devem ser priorizados no desenvolvimento dos produtos de uma LP. Avaliações de ALP também podem ser vistas como uma forma de estabelecer valores limites para métricas específicas de ALP e de produtos para um determinado domínio.

A literatura existente apresenta vários métodos de avaliação de LP e/ou ALP, porém tais métodos não definem nem permitem a utilização de métricas de ALP como apoio à realização de análises de trade-off para priorização dos atributos de qualidade de uma ALP, e à análise de metas de negócio de uma LP. 
De forma geral, a avaliação de ALP é vista pelo gerente de LP e, especialmente, pelo arquiteto de LP como uma ferramenta para ajustar a ALP com base nas suas metas de negócio, visando aumentar a qualidade dos produtos desenvolvidos, prever os produtos gerados e justificar o retorno de investimento com relação à abordagem de LP.

Com base na motivação apresentada, acredita-se que a investigação e proposta de um método de avaliação de ALP que considere as variabilidades de uma LP, bem como metas de negócio, atributos de qualidade e análises de trade-off apoiadas por métricas para modelos UML e atributos de qualidade seja uma possível solução para avaliar ALPs baseadas em UML.

\subsection{Objetivos}

Este trabalho teve como objetivo investigar e melhorar a avaliação de LP baseada em UML por meio da avaliação de seu principal artefato, a ALP. Como uma solução para tal problema foi proposto um método de avaliação de ALP denominado SystEM-PLA. O método é composto por um metaprocesso de avaliação, um conjunto de diretrizes que guiam a realização das atividades do metaprocesso e um conjunto de métricas de apoio à avaliação de ALP. SystEM-PLA difere dos trabalhos existentes por fornecer uma forma sistemática de definir os artefatos necessários para uma avaliação de ALP considerando as metas de negócio da LP, atributos de qualidade da ALP, cenários comportamentais que exercitam as variabilidades da ALP e métricas para a priorização dos atributos por meio da realização de análise de trade-off, o que permite tanto análises quantitativas como qualitativas sobre uma ALP. A abordagem SMarty é proposta para gerenciar as variabilidades dos modelos UML do SystEM-PLA.

O metaprocesso é composto por um conjunto de atividades para a definição dos artefatos necessários para avaliação de ALP como, por exemplo, definição das metas de negócio de uma LP, definição e classificação de cenários que exercitam os atributos de qualidade e a definição de métricas para os atributos. Os conceitos relacionados a alguns desses artefatos como, por exemplo, metas de negócio, cenários e atributos de qualidade estão baseados no método ATAM (Architecture Tradeoff Analysis Method), por ser um método de avaliação de arquietura de software consolidado nos ambientes acadêmico e industrial.

Um conjunto de diretrizes deve guiar o usuário do método em como realizar as atividades do metaprocesso, aplicar e coletar as métricas definidas e realizar análise de trade-off com relação à priorização dos atributos de qualidade da ALP. 
SystEM-PLA está articulado com um conjunto de métricas básicas previamente definidas com o objetivo de medir modelos de ALP representados em UML. As métricas indicam, por exemplo, se uma classe ou interface é um ponto de variação ou variante, o número de variabilidades presente em um modelo de classes e o total de variabilidades presentes em uma ALP a partir de modelos UML com variabilidades gerenciados por SMarty. Duas métricas são fornecidas inicialmente pelo método proposto: complexidade e extensibilidade de ALP. Além dessas métricas, é possível estender o conjunto de métricas básicas ou definir métricas específicas para os atributos de qualidade de uma ALP.

A principal contribuição do SystEM-PLA é a possibilidade de gerentes e arquitetos de LP realizarem avaliações de ALP, cujos modelos são representados em uma notação padrão (UML), com o objetivo de verificar se as metas de negócio estabelecidas são respeitadas, analisando-se os potenciais produtos da LP e obtendo respaldo quantitativo e qualitativo - com o apoio de métricas para modelos UML e atributos de qualidade - para a tomada de decisões sobre a LP.

\subsection{Organização do Trabalho}

Neste capítulo foram apresentados o contexto no qual este trabalho está inserido, sua motivação e seus objetivos. Os Capítulos 2 e 3 apresentam, respectivamente, os conceitos básicos sobre LP e os fundamentos sobre avaliação de LP que norteiam este trabalho. Destaque especial para as revisões sistemáticas realizadas com o objetivo de apresentar um panorama da literatura existente sobre avaliação de LP. O Capítulo 4 apresenta a proposta de uma abordagem sistemática para o gerenciamento de variabilidades em LP, SMarty, composta por um perfil UML, o SMartyProfile, e um processo que possui diretrizes para o gerenciamento efetivo de variabilidades, o SMartyProcess. No Capítulo 5 é proposto um método sistemático para avaliar ALP baseadas em UML, SystEM-PLA, com o apoio da abordagem SMarty, composto por um metaprocesso de avaliação, diretrizes e métricas aplicadas a modelos UML de uma LP. O Capítulo6lista e descreve as métricas básicas e de atributos de qualidade definidas para a avaliação de ALP por meio do método SystEM-PLA. O Capítulo 7 demonstra como as métricas de complexidade e de extensibilidade foram validadas experimentalmente, por meio da geração de configurações da LP Arcade Game Maker (AGM), aplicação das métricas, testes de normalidade, correlação de Spearman e análise de regressão linear. O Capítulo 8 apresenta um estudo experimental com o objetivo de identificar indícios de viabilidade do método SystEM-PLA aplicado à indústria, em particular à uma organização de grande porte. No Capítulo 
9 estão sintetizados o propósito deste trabalho, seus resultados e contribuições, suas dificuldades e limitações e os trabalhos futuros. 


\section{Linha de Produto de Software}

"A grandeza não consiste em receber

honras, mas em merecê-las."

Aristóteles (384 A.C. - 322 A.C.), Filósofo Grego

A abordagem de linha de produto de software (LP) vem se consolidando com o passar dos anos como uma forma efetiva de reutilização de artefatos de software tanto na indústria quanto na academia (Etxeberria e Sagardui, 2008b; Gomaa, 2005, Linden et al., 2007; SEI, 2010c). Vários são os métodos existentes na literatura que visam à melhoria do processo de adoção e desenvolvimento de LP, com base em conceitos amplamente conhecidos, como desenvolvimento baseado em componentes e arcabouços (frameworks) (Gomaa, 2005; Olumofin, 2007).

Empresas de grande porte especializadas no desenvolvimento de sistemas de software complexos, como a Nokia, apresentam relatos de experiências no uso e adoção da abordagem de LP (SEI, 2010c). Em alguns relatos, a redução dos custos com desenvolvimento de sistemas de software chega a 50-75\%, diminuindo a densidade de defeitos e aumentando o número de produtos (Bosch e Bosch-Sijtsema, 2010).

As seções a seguir apresentam uma revisão bibliográfica dos conceitos fundamentais sobre LP. Os benefícios da adoção de LP são discutidos, o que motiva o entendimento dos conceitos gerais sobre LP, variabilidade e das atividades essenciais de LP. Além disso, conceitos sobre arquitetura de sistemas únicos e de LP são apresentados, pois são extremamente importantes para o entendimento deste trabalho. 


\subsection{Caracterização de LP}

Uma LP representa um conjunto de sistemas de software que compartilham características ${ }^{1}$ comuns e gerenciáveis, que satisfazem as necessidades de um segmento particular do mercado ou de uma missão (Clements e Northrop, 2001; Northrop, 2002). Esse conjunto de sistemas de software é também chamado de família de produtos. Os membros da família são produtos específicos desenvolvidos de maneira sistemática a partir da instanciação de uma infraestrutura comum de uma LP, chamada de núcleo de artefatos.

O núcleo de artefatos forma a base da LP e, normalmente, inclui a ALP, componentes reusáveis, modelos de domínios, requisitos da LP, planos de teste e modelos de características e de variabilidades.

O modelo de características é responsável por apresentar todas as características de uma LP e os seus inter-relacionamentos. O conceito de característica tem origem na engenharia de domínio e pode ser definida como uma capacidade do sistema que é relevante e visível para o usuário final (Kang et al., 1990). Uma característica pode ser obrigatória, opcional ou alternativa. A Figura 2.1 ilustra um exemplo de modelo de características para um cliente de e-mail.

Na Figura 2.1 observam-se várias características organizadas hierarquicamente. Por exemplo, a característica Receber Mensagem possui um relacionamento de especialização com as duas subcaracterísticas Pop3 e IMAP. Isso significa que o recebimento de mensagens por um cliente de e-mail pode ser feito por meio do protocolo Pop3 ou por meio do protocolo IMAP. Produtos derivados dessa LP podem conter qualquer combinação dessas características, respeitando as suas restrições de relacionamento.

De acordo com Gurp et al. (2001), o modelo de características representa as variabilidades iniciais de uma LP. As variabilidades podem estar associadas a diferentes níveis de abstração, dentre eles, a descrição da arquitetura, a documentação de projeto, o código fonte, o código compilado, o código ligado e o código executável. Segundo Weiss e Lai (1999), variabilidade é a forma como os membros de uma família de produtos podem se diferenciar entre si. A variabilidade é descrita por pontos de variação e variantes. Um ponto de variação é um local específico de um artefato em que uma decisão de projeto ainda não foi resolvida. A cada ponto de variação está associado um conjunto de variantes. Cada variante corresponde a uma alternativa de projeto para instanciar uma determinada variabilidade. A resolução de um ponto de variação se dá por meio da escolha de uma ou mais variantes do conjunto de variantes relacionado (Linden et al., 2007).

\footnotetext{
${ }^{1}$ Nesta tese usa-se característica como tradução direta do termo em inglês feature.
} 


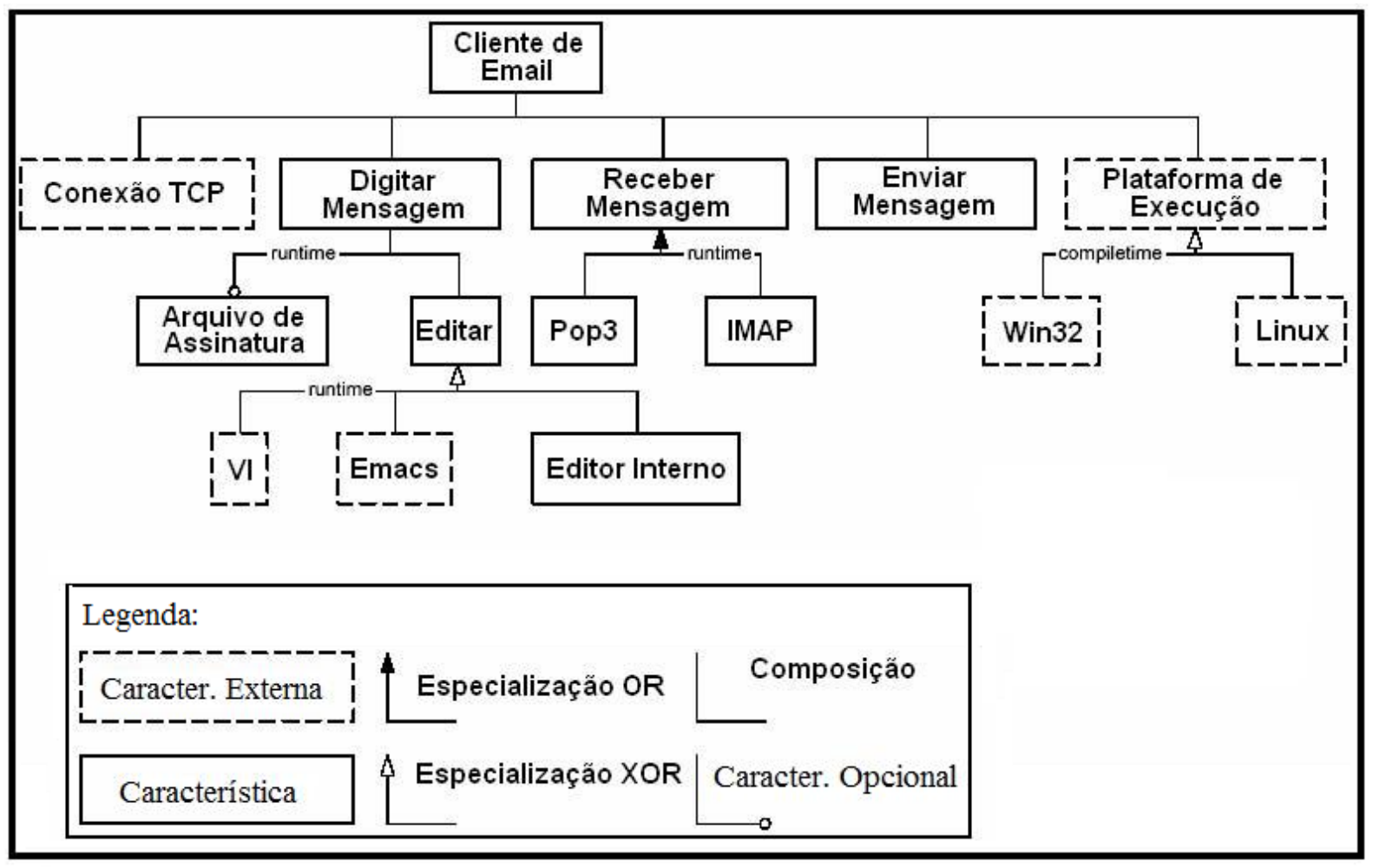

Figura 2.1: Exemplo de Modelo de Características para um Cliente de E-mail (Gurp et al. 2001).

A variabilidade surge do adiamento de certas decisões fundamentais ao projeto de produtos de software. Essas decisões, quando tomadas no início do projeto, restringem o domínio no qual o sistema pode ser aplicado. As decisões tomadas em fases iniciais do projeto de um sistema computacional correspondem à abordagem tradicional de desenvolvimento de um único produto e não à abordagem de LP. Assim, quanto maior o número de decisões de projeto adiadas, maior será o número de variabilidades de um produto de software (Halmans e Pohl, 2003).

O conceito de variabilidade provém do desenvolvimento e instanciação de arcabouços. Um arcabouço é o esqueleto de uma aplicação formado por um conjunto de classes que contêm um projeto abstrato de soluções para uma família de problemas relacionados (Parsons et al., 1999). De acordo com Pree (1995), um arcabouço possui:

- frozen spots (pontos fixos): definem a arquitetura geral de um sistema de software - componentes básicos e seus relacionamentos.

- hot spots (pontos variáveis): representam as partes do arcabouço que são específicas de sistemas únicos. 
Segundo Parsons et al. (1999), os arcabouços são instanciados por meio dos hot spots e podem estar localizados em interfaces ou classes abstratas e seus respectivos métodos. Assim, os hot spots representam os pontos de variação em um arcabouço e podem ser adaptados às necessidades de uma aplicação (Buschmann et al., 1996).

A representação explícita de variabilidades torna possível a geração de produtos específicos de uma LP. A variabilidade surge do adiamento de certas decisões fundamentais ao projeto de produtos de software. Essas decisões, quando tomadas no início do projeto, restringem o domínio no qual o sistema pode ser aplicado (Clements e Northrop, 2001).

As decisões tomadas em fases iniciais do projeto de um sistema computacional, correspondem à abordagem tradicional de desenvolvimento de um único produto e não à abordagem de LP. Assim, quanto maior o número de decisões de projeto adiadas, maior será o número de variabilidades de um produto de software (Halmans e Pohl, 2003).

Um fator importante no gerenciamento de variabilidade é o seu tempo de resolução, o qual indica, em qual momento uma ou mais variantes serão associadas a um determinado ponto de variação (Gurp et al., 2001).

Segundo Gacek e Anastasopoules (2001), o tempo de resolução de variabilidade pode ser classificado como:

- tempo de compilação: a variabilidade é resolvida antes do programa ser compilado ou durante a compilação, usando diretivas de pré-processamento, por exemplo;

- tempo de ligação: a variabilidade é resolvida durante a ligação do módulo ou da biblioteca, selecionando diferentes bibliotecas com diferentes versões das operações exportadas;

- tempo de execução: a variabilidade é resolvida durante a execução do programa; $\mathrm{e}$

- tempo de atualização: a variabilidade é resolvida durante a atualização de programas ou após o início da execução destes (por exemplo, um programa de atualização que adiciona funcionalidades como o Windows Update da Microsoft).

Fritsch et al. (2002), assim como Gacek e Anastasopoules (2001), classificam os tempos de resolução de variabilidade como compilação e tempo de execução, além de:

- programação: pode ser especializado em:

- desenvolvimento do núcleo de artefatos: durante a construção dos artefatos da LP; e 
- desenvolvimento do produto: durante a instanciação da arquitetura de LP (ALP) e de seus componentes.

- integração: pode ser especializado em:

- compilação; e

- seleção do código fonte.

\section{- montagem.}

Segundo Fritsch et al. (2002), o tempo de resolução de variabilidade restringe a escolha de mecanismos de implementação de variabilidade. Por exemplo, se uma variabilidade é resolvida em tempo de execução, não se pode implementá-la com um mecanismo que é definido em tempo de compilação.

\subsection{Benefícios da Abordagem de LP}

O desenvolvimento de software com base na adoção da abordagem de LP é motivado por uma série de fatores, como (Linden et al., 2007; Pohl et al., 2005):

- a redução dos custos de desenvolvimento: artefatos de um núcleo usados em diferentes tipos de sistemas causam a redução de custos para cada sistema. Porém, para alcançar tal redução é necessário que a organização invista na criação de um núcleo de artefatos que permita isso, antes mesmo de se reduzir efetivamente os custos;

- a melhoria da qualidade: os artefatos produzidos são revisados e testados em muitos produtos. O funcionamento correto de cada artefato deve ser provado em mais de um tipo de produto. Assim, a garantia de qualidade implica em uma chance maior de detectar falhas e corrigí-las, melhorando assim, a qualidade de todos os produtos;

- a redução do tempo de produção ${ }^{2}$ : um dos fatores críticos mais importantes para um produto é o seu tempo de produção. Para a abordagem de LP, o tempo de produção é inicialmente mais alto, já que os artefatos comuns devem ser construídos antes. Com o desenvolvimento desses artefatos, o tempo de produção pode ser reduzido para cada novo produto;

\footnotetext{
${ }^{2}$ Do inglês time to market.
} 
- a redução do esforço de manutenção: toda vez que um artefato de um núcleo é modificado, as modificações podem ser propagadas para todos os produtos nos quais o artefato está sendo usado. Isso pode ser explorado para reduzir o tempo de manutenção. Assim, procedimentos de testes de produtos isolados podem ser utilizados para testar uma LP;

- a contribuição para a evolução: ao introduzir um novo artefato no núcleo da LP, tem-se a oportunidade de evolução de todos os tipos de produtos derivados da LP. Portanto, é possível organizar melhor o desenvolvimento visando à evolução dos produtos e reduzir o esforço;

- a contribuição para reduzir a complexidade: por causa do crescente número de requisições dos clientes, a complexidade dos produtos aumenta. Assim, mais funcionalidades são incorporadas ao software. O fato de partes comuns serem reusadas por uma LP acarreta na redução significativa da complexidade;

- a melhoria de estimativa de custo: a organização pode se concentrar em promover produtos que são fáceis de ser gerados a partir da LP. Produtos que necessitam ser estendidos podem ser vendidos por preços mais altos do que aqueles construídos somente a partir da reutilização de artefatos de um núcleo; e

- benefícios específicos ao cliente: o cliente recebe produtos adaptados às suas necessidades e expectativas. Clientes podem comprar produtos a preços razoáveis, já que a abordagem de LP ajuda a reduzir os custos de desenvolvimento. Além disso, clientes recebem produtos com alta qualidade, visto que componentes reusáveis e suas configurações já foram testadas. Os requisitos são revistos frequentemente, não somente durante a engenharia de domínio, mas também durante a engenharia de aplicação. Produtos de uma mesma LP possuem vários aspectos em comum como, por exemplo, interfaces de usuário e funcionalidades iguais ou muito similares. Assim, o cliente não precisa aprender novas maneiras de usar outro produto derivado do mesmo núcleo.

Recentemente, tem-se percebido uma crescente adoção da abordagem de LP, por causa dos seus benefícios. Essa abordagem possibilita às organizações explorar as semelhanças entre seus produtos aumentando, assim, a reutilização de seus artefatos e, como consequência, uma diminuição dos custos e do tempo no desenvolvimento (Linden et al., 2007; SEI, 2010c).

A adoção de uma abordagem de LP leva em consideração fatores organizacionais (Clements e Northrop, 2001; Northrop, 2002, SEI, 2010a), a saber: a natureza dos produtos, o 
mercado ou missão, as metas de negócio, a estrutura organizacional, a cultura e as políticas organizacionais, as disciplinas de processo de software, a maturidade dos artefatos legados e a distribuição geográfica da equipe de trabalho. Segundo Clements e Northrop (2001) e Heymans e Trigaux (2003), os benefícios conseguidos com a adoção da abordagem de LP podem ser classificados em:

- organizacionais: melhor compreensão do domínio e aumento da qualidade dos produtos e da confiança do cliente; e

- de engenharia de software: melhor análise de domínio e aumento da reutilização dos requisitos e dos artefatos, melhor controle da qualidade dos produtos, estabelecimento de padrões e documentação reusável.

A obtenção dos benefícios indicados implica em contrapartida das organizações. Um exemplo disso é a mudança da visão de desenvolvimento de produtos específicos para uma abordagem de LP, que exige treinamento e adaptação de comportamento da equipe de desenvolvimento e gerenciamento (Clements e Northrop, 2001). A abordagem de LP requer gerenciamento a longo prazo, pois os benefícios não são imediatamente visíveis. Assim, alguns produtos devem ser produzidos para que a adoção dessa abordagem possa ser realmente consolidada e ofereça retorno de investimento (Linden et al., 2004, 2007; Pohl et al. 2005; Schmid e Verlage, 2002). Segundo McGregor et al. (2010), com um percentual médio de reutilização em torno de 50\%, uma organização recupera o investimento na adoção da abordagem de LP após produzir dois ou três produtos. Algumas das empresas que obtiveram sucesso com a adoção de LP foram: a Cummins (Decker e Dager, 2007), a Hewlett-Packard (HP) (Toft, 2004; Toft et al., 2000), a Hitachi (Takebe et al., 2009), a OverWatch (Jensen, 2003) e a SystemForge (Bell, 2007).

\subsection{Atividades Essenciais de LP}

O desenvolvimento de LP segue normalmente duas atividades principais: Engenharia de Domínio e Engenharia de Aplicação (Pohl et al., 2005).

O SEI (Software Engineering Institute), por meio da iniciativa PLP (Product Line Practice), estabeleceu as atividades essenciais de uma abordagem de LP (SEI, 2010a). Essas atividades são: o Desenvolvimento do Núcleo de Artefatoł? que corresponde à Engenharia de Domínio; o Desenvolvimento do Produtq 4 que corresponde à Engenharia

\footnotetext{
${ }^{3}$ do inglês Core Asset Development

${ }^{4}$ do inglês Product Development
} 
de Aplicação; e o Gerenciamento de Linha de Produtd5. A Figura 2.2 ilustra as interações entre essas atividades.

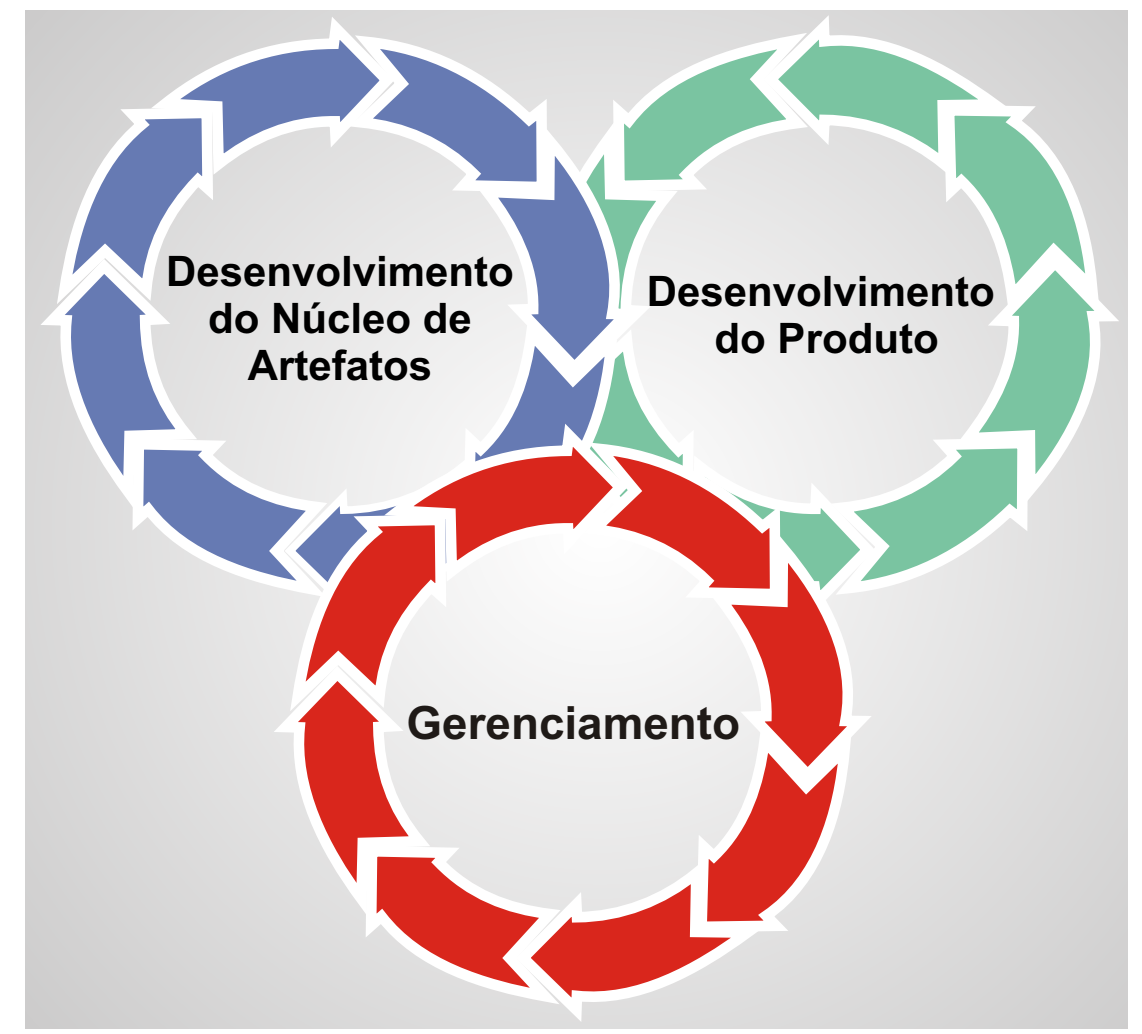

Figura 2.2: Atividades Essenciais de LP, adaptada de (SEI, 2010a).

Os três círculos da Figura 2.2 indicam que as atividades de uma LP são altamente interligadas e iterativas. As flechas rotativas indicam que, além dos artefatos gerados no desenvolvimento de produtos do núcleo, são também realizadas revisões dos artefatos ou até mesmo inclusão de novos artefatos.

À medida que os produtos são desenvolvidos, o núcleo de artefatos pode evoluir. Um exemplo disso ocorre quando se identifica um novo requisito relevante ao domínio que inicialmente não fazia parte da especificação de requisitos da LP. Assim, essa especificação evolui, incorporando o novo requisito identificado e o núcleo de artefatos é atualizado.

A seguir, é apresentada uma breve descrição das atividades essenciais de LP, segundo a abordagem PLP.

\subsubsection{Desenvolvimento do Núcleo de Artefatos}

O objetivo da atividade de desenvolvimento do núcleo de artefatos é estabelecer uma infraestrutura central que será reusada pelos produtos gerados a partir da LP.

\footnotetext{
${ }^{5}$ do inglês Management
} 
As entradas para essa atividade são:

- as restrições do produto: as semelhanças e as variações entre produtos que constituirão a LP, as normas que devem ser seguidas para definir as características dos produtos e os limites de desempenho;

- os estilos arquiteturais, padrões e arcabouços: utilizados para a construção da arquitetura de LP;

- as restrições de produção: os componentes COTS (Commercial-Off-The-Shelf) que serão utilizados, as normas que serão seguidas para a produção dos produtos e os componentes legados que serão reusados;

- a estratégia de produção: estratégia geral da abordagem para produzir os artefatos da LP; e

- o repositório dos artefatos pré-existentes: os artefatos existentes como, por exemplo, componentes, especificações ou partes legadas do domínio catalogadas para a sua futura reutilização.

Esta atividade tem como principais saídas:

- o escopo da LP: descrição dos produtos que constituirão a LP ou que esta é capaz de produzir. Essa descrição apresenta as semelhanças e as variações entre os produtos, além de incluir características e operações destes, tais como, desempenho e atributos de qualidade;

- o núcleo de artefatos da LP: base para a produção de produtos a partir da LP. Normalmente, o núcleo de artefatos inclui uma arquitetura a ser reusada pelos produtos, bem como os seus componentes; e

- o plano de produção dos produtos: descrição das decisões a serem tomadas para instanciar produtos específicos, a partir do núcleo de artefatos da LP.

A Figura 2.3 mostra as entradas e as saídas da atividade de desenvolvimento do núcleo de artefatos. 


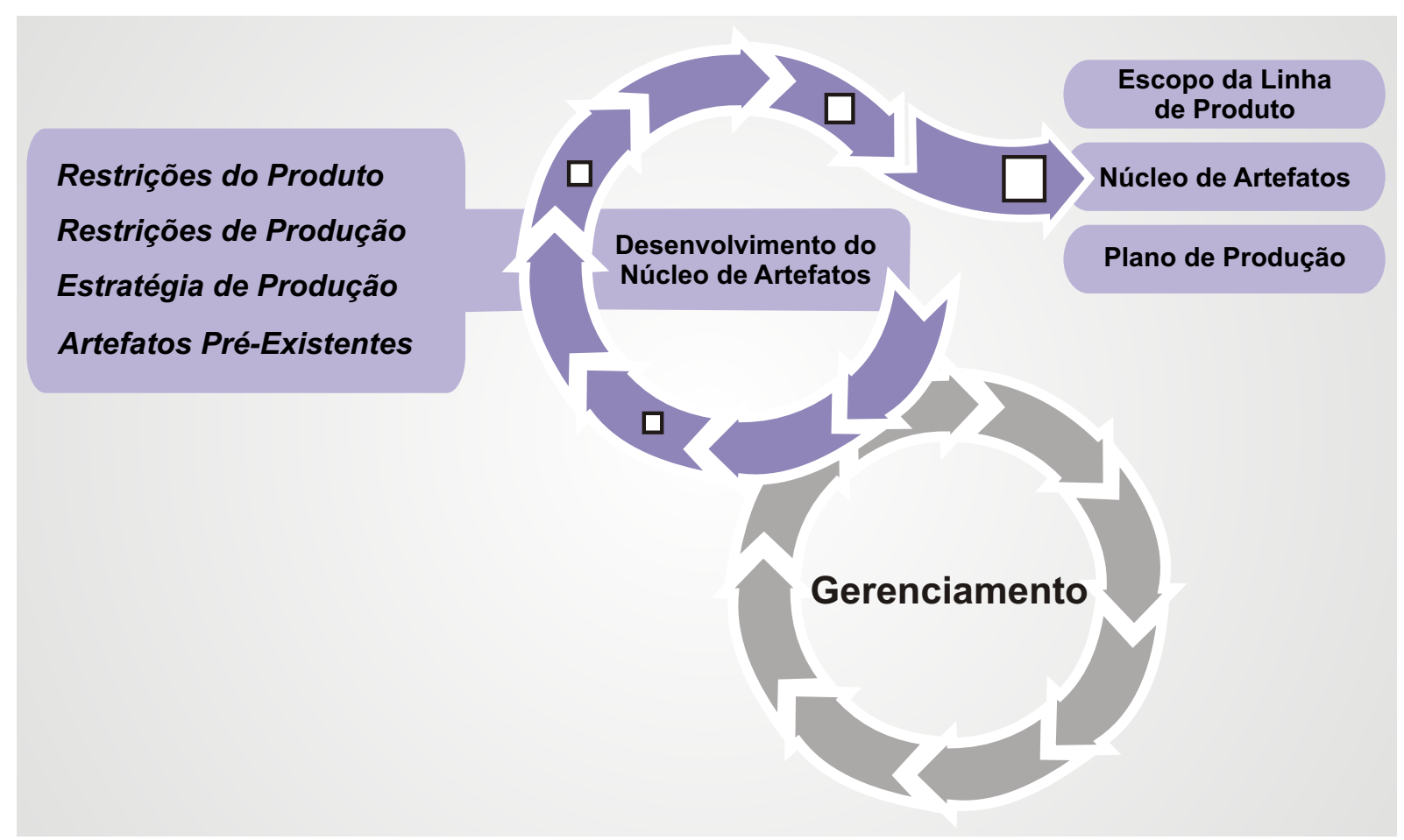

Figura 2.3: Desenvolvimento do Núcleo de Artefatos, adaptada de (SEI, 2010a).

\subsubsection{Desenvolvimento do Produto}

A atividade de desenvolvimento do produto tem como principal objetivo a geração de produtos de uma LP. Porém, é possível identificar requisitos que, inicialmente, não haviam sido especificados e, conseqüentemente, atualizar o núcleo de artefatos da LP.

Essa atividade depende substancialmente dos artefatos de saída da atividade anterior, que lhe servem como entrada. Esses artefatos são o escopo da LP, o núcleo de artefatos e o plano de produção. Além desses artefatos, são necessários também os requisitos para um produto específico.

As flechas rotativas indicam iteração e relacionamentos intrínsecos como, por exemplo, a existência e a disponibilidade de um produto específico podem afetar os requisitos de um produto subsequente.

A Figura 2.4 mostra os artefatos de entrada e saída da atividade de desenvolvimento do produto. 


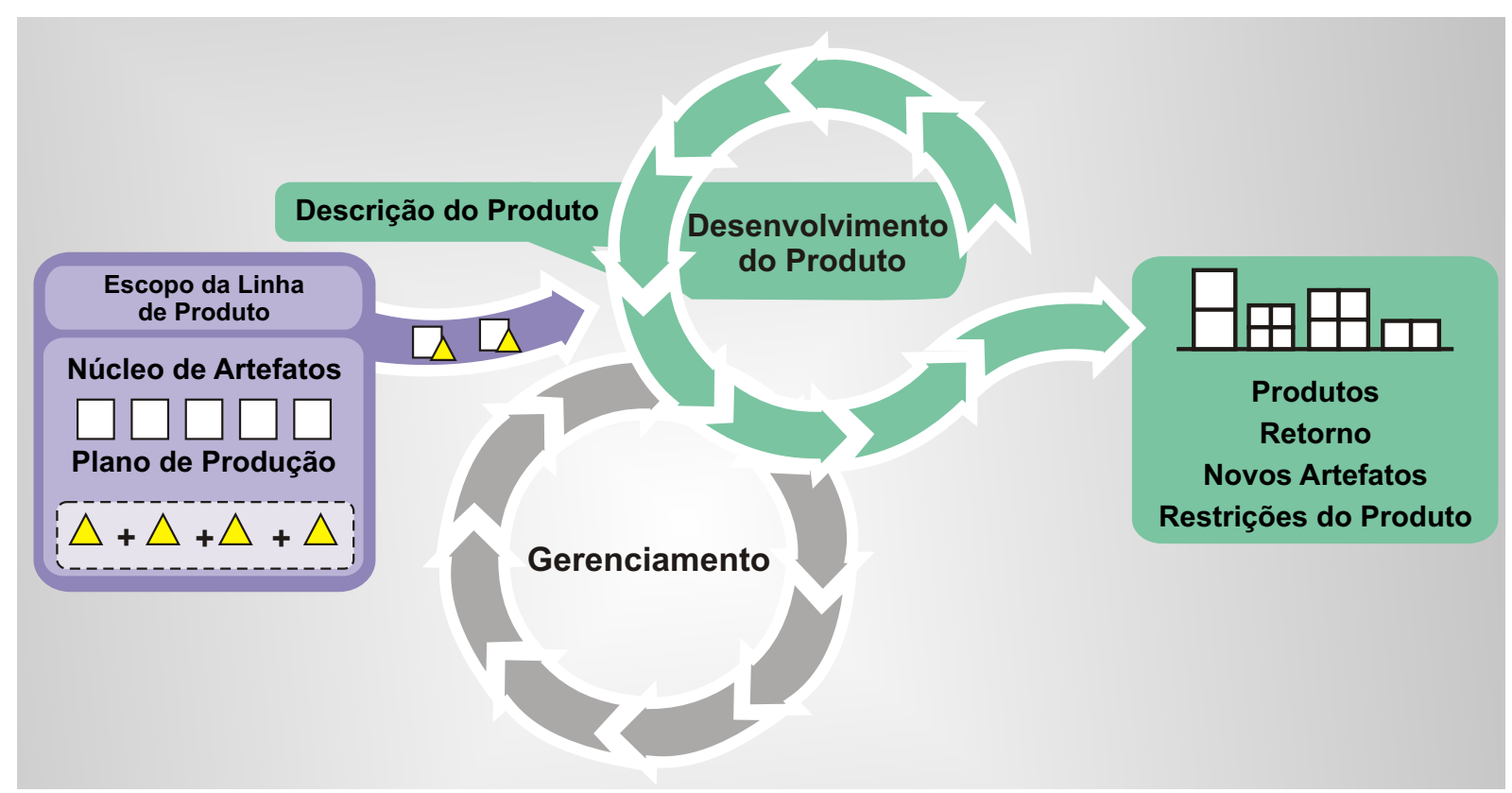

Figura 2.4: Desenvolvimento do Produto, adaptada de (SEI, 2010a).

\subsubsection{Gerenciamento de Linha de Produto}

A atividade de gerenciamento de LP deve garantir que todas as atividades técnicas sejam realizadas de acordo com um planejamento coordenado. Tal atividade pode ser dividida em duas categorias:

- gerenciamento técnico: coordena as atividades de desenvolvimento do núcleo de artefatos e desenvolvimento do produto, para garantir que as equipes de desenvolvimento sigam os processos definidos para a LP e coletem dados suficientes para acompanhar o progresso desta; e

- gerenciamento organizacional: garante que as unidades organizacionais recebam os recursos corretos (ex. treinamento) em quantidades suficientes.

Uma das ações mais importantes da atividade de gerenciamento de LP, é a criação de um plano de adoção que descreva o estado desejado da organização e uma estratégia para alcançar tal estado.

O gerenciamento de LP também deve estabelecer, como as atividades de desenvolvimento do núcleo de artefatos e de desenvolvimento do produto, devem interagir para permitir a evolução da LP e o gerenciamento das semelhanças e das variabilidades de cada artefato da LP. 
Um dos elementos principais do gerenciamento de uma LP é o gerenciamento de variabilidade (Becker, 2003; Gurp et al., 2001; Oliveira Junior, 2005; Oliveira Junior et al., 2005a b) que inicia na análise de requisitos e tem efeito na maioria dos artefatos da LP. A análise de impacto das variabilidades no desenvolvimento dos produtos de uma LP pode determinar o valor agregado para uma organização.

\subsection{Abordagens Existentes de LP}

A literatura existente apresenta várias abordagens de LP. Dentre elas, algumas são consideradas precursoras da abordagem de LP e fundamentais para o entendimento de LP, enquanto outras são consideradas importantes para este trabalho.

Feature-Oriented Domain Analysis (FODA), proposta por Kang et al. (1990), é um dos precursores da abordagem de LP. Essa abordagem foi desenvolvida no SEI como um método para análise de domínio e se destaca pela introdução do modelo de característica: 5 amplamente utilizado nas abordagens de LP. Em seguida, foi desenvolvida uma extensão dessa abordagem, chamada FORM (Kang et al., 1990) que inclui questões arquiteturais e de componentes.

As abordagens Family-Oriented Abstraction, Specification and Translation (FAST), proposta por Weiss e Lai (1999), e Synthesis, proposta por SPC (1993), tratam de questões abrangentes de LP. Tais abordagens são precursoras e serviram de base para possibilitar a definição de um contexto mais geral para LP, como o definido na iniciativa PLP, porém não possuem influência direta neste trabalho.

A iniciativa Product Line Practice (PLP), proposta por Clements e Northrop (2001), não contém um método de construção de LP, mas se destaca por caracterizar e uniformizar os vários conceitos de LP, bem como promover a sua utilização como citado na Seção 2.3. As atividades essenciais do PLP são importantes para este trabalho do ponto de vista da realização de suas atividades essenciais, principalmente a de gerenciamento de variabilidades e avaliação de ALP.

A abordagem Product Line UML-based Software Engineering (PLUS), proposta por Gomaa (2005), permite a sua integração com outros modelos de processo de software, tal como o Processo Unificado de Desenvolvimento de Software (Unified Software Development Process - USDP). Cada fase do PLUS possui os mesmos nomes dos workflows do USDP. A primeira fase do PLUS - concepção - envolve um estudo minucioso para determinar se a LP é viável ou não, o seu contexto, funcionalidades, grau de semelhanças e variabilidades e o número estimado de seus membros. Durante essa fase, são elaborados

\footnotetext{
${ }^{6}$ do inglês feature
} 
os casos de uso iniciais, um diagrama conceitual de classes e um modelo inicial de características. Na segunda etapa do PLUS - elaboração - o modelo de casos de uso e o modelo de características são revisados e elaborados em mais detalhes, identificando os seus pontos de variação. Nessa fase, a arquitetura da LP é expandida e incluem-se os componentes opcionais e variantes. Na fase seguinte do PLUS - construção - os componentes são desenvolvidos e testados; após essa fase, inicia-se a transição, na qual, os componentes são integrados e ficam disponíveis para os usuários poderem testar. As próximas iterações no processo permitem a integração de componentes opcionais e variantes. O método PLUS permite a identificação de componentes variantes por meio do uso de estereótipos para representar variabilidade, por isso essa abordagem é importante para este trabalho.

\subsection{Arquitetura de Sistemas Únicos vs. Arquitetura de LP}

A arquitetura de sistemas únicos define o sistema em termos de componentes computacionais e conexões entre esses componentes (Shaw e Garlan, 1996; Taylor et al., 2009). A arquitetura permite projetar e analisar antecipadamente o sistema com base nos seus atributos de qualidade (Bass et al. 2005 ). Consequentemente, o projeto da arquitetura do sistema ocorre nos estágios iniciais do ciclo de vida do sistema, sendo a primeira fase após a especificação dos requisitos.

Segundo Bass et al. (2005), uma arquitetura de sistemas únicos é a estrutura ou estruturas de um sistema formadas por componentes, suas propriedades externas visíveis e relacionamentos entre eles. A arquitetura de um software é extremamente importante, pois restringe os atributos de qualidade de um sistema. Quando uma arquitetura é projetada, valores mínimos e máximos são definidos para os seus atributos de qualidade como, por exemplo, desempenho, complexidade e extensibilidade.

A especificação explícita da arquitetura é importante para permitir a comunicação entre os stakeholders nas etapas iniciais do processo de desenvolvimento de software. $\mathrm{O}$ método ATAM (Architecture Trade-off Analysis Method) (Clements et al., 2002b), por exemplo, exige que os stakeholders participem da realização de várias fases do método com o objetivo de analisar uma arquitetura de software (Bosch, 2000).

A arquitetura de software é o resultado de um conjunto de decisões técnicas e de negócios, influenciando diretamente nas expectativas dos stakeholders (Bass et al., 2005).

Regras para um projeto adequado de uma arquitetura são apresentadas por Bass et al. (2005). Assim, uma arquitetura: 
- deve ser o produto de um ou vários arquitetos;

- deve possuir requisitos funcionais e um conjunto articulado e priorizado de atributos de qualidade, que espera-se, a arquitetura satisfaça;

- deve ser bem documentada, com pelo menos uma visão estática e uma dinâmica, usando uma notação que todos os stakeholders entendam com o mínimo de esforço. Clements et al. (2002a) argumentam que uma arquitetura de software deve ser documentada com base em suas interfaces, seus comportamentos e suas visões lógica, de processo, de desenvolvimento, física e de cenários (Jazayeri et al., 2000). Além disso, toda a documentação deve ser empacotada e compartilhada;

- deve ser analisada por medidas quantitativas (Taylor et al., 2009) e formalmente avaliada, com base em seus atributos de qualidade antes que seja tarde demais para efetuar mudanças. Segundo Clements et al. (2002b), a avaliação de uma arquitetura deve ser realizada para identificar problemas arquiteturais antes que o sistema comece a ser detalhado e problemas arquiteturais se propaguem por todos os componentes da arquitetura. Além disso, é possível avaliar os riscos das metas de qualidade especificadas para a arquitetura; e

- deve possuir atributos de qualidade que devem ser satisfeitos, seguindo uma estratégia arquitetural adequada para cada atributo.

Arquiteturas de software fornecem abstrações que permitem que variações e similaridades de uma LP sejam simultaneamente gerenciadas na forma de arquiteturas de LP (ALP). Uma ALP pode ser entendida com base na noção de arquiteturas de referência, que é um conjunto de decisões de projeto que são simultaneamente aplicáveis a múltiplos sistemas relacionados, sendo normalmente partes de um domínio, com pontos de variação explicitamente definidos (Taylor et al., 2009).

Uma ALP serve como a base para diferentes produtos de uma LP. Uma ALP difere de uma arquitetura de um sistema único por duas razões principais:

- escopo: em vez de descrever todas as possíveis arquiteturas dos produtos de um domínio, a ALP é especificada concentrando-se somente em um conjunto de produtos relacionados, normalmente desenvolvidos por uma organização; e

- completitude: ALP geralmente captura múltiplas arquiteturas de produtos únicos, não deixando partes sem especificações. 
Uma ALP pode ser projetada por meio da técnica de recuperação de arquitetura, em que as similaridades são analisadas e as variabilidades são propostas (Harsu, 2001). Bosch (2000) afirma que o projeto de uma ALP deve considerar os seguintes passos:

- análise dos casos de negócio: garante que a adoção de LP terá retorno de investimento;

- análise de escopo: usa os resultados do passo anterior como base para a seleção das características dos produtos que serão gerados pela LP;

- planejamento dos produtos e suas características: considera as características de versões subsequentes da ALP;

- projeto propriamente dito da ALP, com base em algumas abordagens existentes (Matinlassi, 2004a) para tal - por exemplo FAST (Weiss e Lai, 1999) e FORM (Kang et al., 1998) - consistindo das seguintes etapas:

- projeto arquitetural baseado em funcionalidades: define o contexto dos produtos no qual o software operará;

- análise arquitetural: avalia a ALP com relação aos seus atributos de qualidade. Algumas técnicas como, por exemplo, definição e classificação de cenários e simulação, podem ser aplicadas; e

- transformação arquitetural: concentra-se em melhorar os atributos de qualidade da ALP com relação à combinação de variantes e opcionalidades.

- especificação dos requisitos dos componentes: define quais componentes são usados por cada produto e como são instanciados; e

- avaliação da arquitetura: garante que a LP suporta as características definidas durante a análise de escopo, sendo instanciadas pelos produto.

A avaliação de arquiteturas únicas e de ALPs envolve muitos conceitos como, atributos de qualidade, cenários e métricas, com o objetivo de verificar se os atributos de qualidade são satisfeitos por uma ALP, bem como revelar potenciais riscos arquiteturais. O Capítulo 3 dedica-se exclusivamente a apresentar e ilustrar os conceitos sobre avaliação de LP e ALP, indispensáveis para o entendimento deste trabalho. 


\subsection{Considerações Finais}

Neste capítulo foram abordados os principais conceitos que regem a abordagem de LP, sua adoção, gerenciamento de variabilidades, abordagens de LP existentes, arquiteturas de sistemas únicos e ALP.

As principais atividades no desenvolvimento de LP são o Desenvolvimento do Núcleo de Artefatos, Desenvolvimento do Produto e Gerenciamento. Além disso, grande parte das abordagens tem como foco a atividade de gerenciamento de LP, dando ênfase ao gerenciamento de variabilidade e avaliação de ALP, entre outros assuntos importantes.

Várias abordagens de LP existentes na literatura corroboram com a necessidade de gerenciamento efetivo de variabilidade. As técnicas e métodos existentes para tal, visam solucionar problemas específicos de domínios distintos, o que dificulta a aplicação de tais abordagens em LP de contextos gerais como, por exemplo, LP modeladas usando notações como a UML e OCL (Object Constraint Language). Dessa forma, o Capítulo 4 apresenta a proposta de uma abordagem para o gerenciamento sistemático de variabilidades em LP com base na notação UML. Essa abordagem é composta por um perfil UML, utilizado para representar variabilidade e um processo contendo diretrizes que guiam o usuário em como identificar, delimitar, representar e gerenciar as variabilidades de uma LP.

Além do gerenciamento de variabilidades, a avaliação de uma ALP é um assunto extremamente importante, uma vez que a ALP é um dos ativos mais importantes do núcleo de artefatos, como visto neste capítulo. O capítulo a seguir apresenta uma revisão bibliográfica a respeito dos conceitos básicos sobre avaliação de LP e ALP, bem como abordagens existentes e métricas para tal. A revisão bibliográfica tomou como base os resultados obtidos com a realização de duas revisões sistemáticas sobre avaliação de LP (Oliveira Junior et al., 2007) e (Oliveira Junior et al., 2010). 


흘

\title{
Avaliação de Linha de Produto de Software
}

\author{
"Em última análise, o fator decisivo é \\ sempre a consciência." \\ Carl G. Jung (1875 - 1961), \\ Psiquiatra Suíço
}

Com a existência de métodos efetivos e possíveis de serem repetidos, a avaliação de arquiteturas de software torna-se viável a ponto de considerá-la uma atividade padrão do ciclo de vida do software. Porém, a avaliação de ALPs possui suas próprias peculiaridades como, por exemplo, o gerenciamento de variabilidades, pois a arquitetura assume um papel importante em dois níveis: a ALP e a arquitetura para cada produto gerado pela LP. A ALP deve ser avaliada, para garantir que serve como a base para os produtos derivados pela LP. As instâncias da ALP devem ser avaliadas para garantir que estão de acordo com os requisitos funcionais e de qualidade. Segundo Clements e Northrop (2001), a avaliação de LP deve concentrar-se nas variabilidades, garantindo assim, que sejam apropriadas, ofereçam flexibilidade suficiente para o escopo da LP, possam ser exercitadas para derivar os produtos específicos e não imponham custos de desempenho inaceitáveis em tempo de execução. A avaliação deve ser aplicada ao núcleo de artefatos, principalmente à ALP.

Os métodos de avaliação de arquiteturas de software (Dobrica e Niemelä, 2002) consideram representações da estrutura de um produto único. Já ALPs representam uma estrutura comum de um conjunto de produtos de um mesmo domínio e são formadas por elementos que estão presentes em todos os produtos e elementos que podem ou não estar 
presentes nos produtos de uma LP (Muccini e Hoek, 2003). Assim, a ALP representa a abstração do conjunto de todas as possíveis arquiteturas de produtos de uma LP.

As seções a seguir apresentam uma revisão bibliográfica sobre avaliação de LP, com destaque para: o método ATAM (Architecture Tradeoff Analysis Method) amplamente referenciado na literatura sobre avaliação de LP; os fundamentos sobre avaliação de LP; as abordagens e métricas existentes para avaliação de LP; e extensões do método ATAM para avaliação de ALP. Essa revisão bibliográfica é resultado da realização de duas revisões sistemáticas sobre avaliação de LP, planejadas e conduzidas por Oliveira Junior et al. (2007) e Oliveira Junior et al. (2010).

\subsection{O Método ATAM}

Nesta seção é apresentada a motivação para se avaliar arquiteturas de software, uma caracterização do método ATAM e a descrição de suas etapas com base nos conceitos apresentados por Clements et al. (2002a.b), Barbacci (2002); Barbacci et al. (2003) e Kazman e Bass (2005).

ATAM (Architecture Tradeoff Analysis Method) (Clements et al., 2002b) é o método de avaliação de arquitetura de software mais difundido na literatura e aplicado na indústria, sendo publicado um grande número de artigos, relatórios técnicos e relatos de experiência acerca de sua aplicação, adaptações e extensões. Esse método é extremamente importante para este trabalho, uma vez que vários dos seus principais conceitos e fundamentos são aplicados na proposta do método de avaliação de ALP do Capítulo 5.

Segundo Clements et al. (2002b), avaliações de arquitetura de software são motivadas principalmente por permitirem descobrir problemas em etapas iniciais do processo de desenvolvimento de software. O custo para corrigir um erro durante a análise de requisitos é muito mais baixo do que corrigir o mesmo erro em etapas mais avançadas, como na etapa de teste. Várias são as consequências de um projeto inadequado de uma arquitetura como: metas de desempenho não alcançadas, questões de segurança subestimadas e clientes insatisfeitos com relação à alguma funcionalidade que não esteja de acordo com o especificado.

Uma arquitetura de software determina a estrutura de um projeto. Problemas arquiteturais não identificados antecipadamente, podem acarretar sérios riscos ao projeto como um todo podendo, em alguns casos, causar o cancelamento de um projeto.

Avaliar uma arquitetura é uma maneira efetiva de evitar tais problemas. Tal avaliação deve ocorrer idealmente quando a arquitetura já tiver sido especificada, mas sua implementação ainda não iniciada. Para tanto, dois grupos de pessoas devem estar envolvidas em 
uma avaliação: a equipe de avaliação, formada pelas pessoas que conduzirão a avaliação; e os stakeholders, que são as pessoas que possuem um amplo interesse na arquitetura e no sistema. O cliente de uma avaliação de arquitetura será, normalmente, a pessoa responsável pela tomada de decisão em um projeto.

Uma avaliação de arquitetura produz como resultado um relatório, que varia em sua forma e conteúdo, respondendo a duas perguntas muito importantes: a arquitetura está adequada para o projeto para o qual foi especificada? e qual de duas ou mais arquiteturas é a mais adequada para o sistema em questão?

Vários são os benefícios alcançados com a avaliação de uma arquitetura, dentre os quais podem-se citar:

- stakeholders e equipe de desenvolvimento juntas em um mesmo local. Algumas vezes o primeiro encontro entre um arquiteto de software e o cliente acontece somente em estágios finais do desenvolvimento;

- força a articulação de atributos de qualidade específicos. Muitas vezes os atributos de qualidade não são capturados durante a análise de requisitos ou são capturadas de forma ambígua. Assim, cenários podem ser usados para capturar tais metas com a ajuda dos stakeholders;

- resulta na priorização de atributos de qualidade conflitantes;

- força uma clara especificação da arquitetura;

- melhora a qualidade da documentação da arquitetura; e

- resulta em melhoria das práticas de arquitetura.

\section{Caracterização do Método ATAM}

Os principais objetivos do método ATAM são: revelar de que maneira uma arquitetura de software satisfaz os seus atributos de qualidade; e fornecer maneiras de identificar como os atributos de qualidade interagem umas com as outras.

Pelo fato do método ATAM ser estruturado, é possível tornar análises de arquiteturas repetitíveis e garantir que as questões corretas a respeito da arquitetura sejam respondidas em estágios iniciais do desenvolvimento de software.

O ATAM pode ser usado para analisar sistemas legados, quando esses precisam passar por modificações e integrações com outros sistemas. 
Os princípios do método ATAM baseiam-se em três áreas: a noção de estilos arquiteturais; análises de atributos de qualidade; e o método SAAM (Software Architecture Analysis Method), que é o seu predecessor.

Um atributo de qualidade de qualquer sistema não-trivial é determinado por sua arquitetura. As decisões arquiteturais têm um profundo impacto sobre alcançar ou não os atributos de qualidade. Assim, um pré-requisito para avaliação de uma arquitetura é estabelecer claramente os atributos de qualidade, que são motivados pelas metas de negócio (business drivers) (Barbacci, 2002) e a especificação da arquitetura. Dessa forma, os três principais objetivos de uma avaliação de arquitetura são:

1. identificar e refinar os atributos de qualidade;

2. identificar e refinar as decisões arquiteturais de projeto; e

3. avaliar as decisões arquiteturais para determinar se satisfazem os atributos de qualidade.

Exemplos de atributos de qualidade são: desempenho, complexidade, extensibilidade, disponibilidade e portabilidade.

\section{Etapas do Método ATAM}

As etapas do método ATAM são separadas em quatro grupos:

- apresentação (etapas 1 a 3): envolvendo a troca de informação sobre como serão realizadas as apresentações do método ATAM, das metas de negócio e da arquitetura;

- investigação e análise (etapas 4 a 6): envolvendo a avaliação dos atributos chave de qualidade das abordagens arquiteturais;

- teste (etapas 7 e 8): envolvendo a verificação dos resultados com relação à necessidade de cada stakeholder; e

- documentação (etapa 9): envolvendo a apresentação dos resultados do ATAM.

Os itens a seguir apresentam uma descrição detalhada de cada etapa do método ATAM:

1. Apresentação do Método ATAM: o líder da avaliação deve apresentar o método ATAM aos stakeholders. O processo de avaliação é explicado a todos que irão 
participar, reservando um tempo para responder às questões pertinentes e definir o contexto e o que esperar das próximas atividades. O líder deve essencialmente descrever:

- brevemente os passos do método ATAM;

- as técnicas que serão usadas para a identificação e análise como, por exemplo, árvores de utilidade e priorização de cenários; e

- as saídas da avaliação como, por exemplo, os cenários identificados e priorizados, as árvores de utilidade e o conjunto de abordagens arquiteturais identificadas.

2. Apresentação das Metas de Negócio: os participantes de uma avaliação devem entender o contexto do sistema e as metas de negócio primárias que motivam o seu desenvolvimento. Nessa etapa, o gerente de projeto ou o cliente do sistema, apresenta um resumo do sistema do ponto de vista de negócio. A apresentação deve descrever:

- as funções mais importantes do sistema;

- qualquer restrição técnica, gerencial, econômica ou política relevante ao sistema;

- as metas de negócio e o contexto, pois são relevantes ao projeto;

- os stakeholders mais importantes envolvidos; e

- os atributos de qualidade mais importantes para a arquitetura.

3. Apresentação da Arquitetura: nessa etapa o arquiteto líder ou a equipe de arquitetos faz uma apresentação descrevendo a arquitetura em um nível apropriado de detalhes. O nível apropriado depende de vários fatores como: quanto a arquitetura já foi especificada e documentada e, a natureza dos atributos de qualidade e comportamentais. Normalmente, a equipe de avaliação pede informações adicionais antes que uma análise mais substancial possa ser feita. Nessa apresentação, o arquiteto deve cobrir:

- restrições técnicas como sistema operacional, hardware ou middleware que deverá ser usado;

- outros sistemas com os quais o sistema irá interagir; e

- abordagens arquiteturais usadas para satisfazer os atributos de qualidade estabelecidos. 
Visões arquiteturais devem ser usadas para apresentar a arquitetura como, por exemplo: concorrente, funcional, de código e física.

4. Identificação das Abordagens Arquiteturais: o método ATAM concentra-se em analisar uma arquitetura, entendendo as suas abordagens arquiteturais, que são capturadas pela equipe de avaliação, mas não são analisadas. O arquiteto deve nomear qualquer abordagem arquitetural utilizada. Além das abordagens arquiteturais, estilos arquiteturais também devem ser identificados, pois representam um meio de garantir que os atributos de qualidade críticos sejam satisfeitos de maneira previsível. Essas abordagens e estilos descrevem as formas com que a arquitetura pode crescer, responder a mudanças e ser integrada a outros sistemas.

5. Geração da Árvore de Utilidade dos Atributos de Qualidade: nessa etapa a equipe de avaliação trabalha junto com o gerente de projeto ou o cliente do sistema para identificar, priorizar e refinar os atributos de qualidade mais importantes do sistema. Para tanto, deve haver atenção total da equipe de avaliação nos aspectos da arquitetura que são os mais críticos para o sistema. Isso é alcançado por meio do conceito de árvore de utilidade. A árvore de utilidade serve para tornar concretos os atributos de qualidade, forçando o arquiteto e o cliente a definir os atributos de qualidade de forma precisa. A árvore fornece um mecanismo para traduzir direta e eficientemente, as metas de negócio em cenários concretos de atributos de qualidade. Tais cenários devem ser priorizados, gerando uma lista de atributos de qualidade priorizados.

6. Análise das Abordagens Arquiteturais (Fase 1): a equipe de avaliação deve verificar quais abordagens arquiteturais realizam os atributos de qualidade priorizados. Para tanto, deve-se documentar as decisões de projeto e identificar os riscos (risks), não-riscos (non-risks), pontos sensíveis (sensitive points) e trade-offs. Isso é feito para convencer a equipe de avaliação, que a instanciação de uma abordagem é apropriada para satisfazer os respectivos atributos de qualidade. Ao final dessa etapa, a equipe de avaliação pode testar o seu entendimento das representações arquiteturais que foram geradas.

7. Brainstorming e Priorização dos Cenários: os cenários dirigem a fase de teste do ATAM, são usados para representar os interesses dos stakeholders e para entender os atributos de qualidade. Os cenários são priorizados e comparados com os gerados na etapa de Análise das Abordagens Arquiteturais (Fase 1). Se os stakeholders concordarem, os cenários ficam estabelecidos. Se cenários adicionais 
forem descobertos, esses são incorporados aos já estabelecidos. Nessa etapa, três tipos de cenários são abordados:

- cenários de casos de uso: representam as formas nas quais os stakeholders esperam que o sistema será usado;

- cenários de crescimento: representam as formas nas quais a arquitetura pode acomodar mudanças em um prazo médio; e

- cenários exploratórios: representam formas extremas de crescimento, formas nas quais a arquitetura pode ser sobrecarregada por mudanças.

Os cenários são priorizados e, em seguida, são identificados os que mais representam comportamentos similares e mesclados. Cada stakeholder vota nos cenários que devem ser priorizados, sendo gerada uma lista final de cenários priorizados.

8. Análise das Abordagens Arquiteturais (Fase 2): a equipe de avaliação guia o arquiteto no processo de realização dos cenários melhor classificados. O arquiteto explica a relevância das decisões arquiteturais, contribuindo para realizar um cenário. A equipe de avaliação mapeia os cenários para os artefatos da arquitetura que ainda não foram cobertos, realizando a etapa 7 novamente, repetindo esse ciclo até que a etapa 7 não produza nenhum novo cenário de alta prioridade, para que a etapa 8 não precise ser repetida.

9. Apresentação dos Resultados: as informações coletadas precisam ser organizadas e apresentadas aos stakeholders. Essa apresentação é feita normalmente por alguém que se dirige aos stakeholders, acompanhado de um relatório completo das atividades realizadas, relacionando suas entradas e saídas.

\subsection{Conceitos sobre Avaliação de LP}

Segundo Etxeberria e Sagardui (2005), a avaliação de LP deve considerar alguns aspectos como:

- os atributos de qualidade relevantes à arquitetura de LP;

- o momento em que a LP é avaliada; e

- as técnicas e as métricas para avaliação de LP.

Os atributos relevantes para a avaliação de ALP podem ser classificados como: 
- Atributos de Qualidade de LP: são considerados a base para o conjunto de produtos relacionados, bem como, futuros produtos específicos da linha. Exemplos de atributos são: modificabilidade e configurabilidade;

- Atributos de Qualidade Relevantes ao Domínio: atributos de qualidade importantes para o domínio específico podendo englobar: confiabilidade (reliability), disponibilidade (availability), usabilidade (usability), entre outros; e

- Requisitos Funcionais: referem-se ao comportamento comum observado com relação aos vários membros da LP.

A maioria dos estudos não considera requisitos funcionais para a avaliação de LP, porém, um erro em um requisito pode afetar todos os produtos da LP.

Outro aspecto importante a ser considerado é o tempo ou momento em que a avaliação de LP deve ser realizada. Para tanto, Etxeberria e Sagardui (2005) definem vários momentos em que uma ALP pode ser avaliada, sendo:

- durante a Engenharia de Domínio: a avaliação nesse momento garante que a arquitetura satisfaz os atributos de qualidade da LP, relevantes ao domínio e de comportamentos comuns. Além disso, pode ser muito útil para detectar problemas e riscos ou comparar arquiteturas candidatas;

- durante a Engenharia de Aplicação: a avaliação nesse momento garante se os atributos de qualidade de produtos específicos e se suas arquiteturas estão de acordo com a ALP; e

- durante a Evolução da LP: nesse momento pode ser desejável adaptar a ALP para incluir novos requisitos. A avaliação pode ajudar a analisar a magnitude das mudanças exigidas na arquitetura e a garantir que ela continue de acordo com os atributos de qualidade relacionados.

Especificamente à LP, outros três momentos podem ser considerados para avaliação:

- antes da arquitetura de referência ser desenvolvida: acontece durante a Engenharia de Domínio e ajuda a analisar e comparar arquiteturas de produtos existentes, para usá-las como base para a ALP;

- durante a instanciação dos produtos: acontece durante a Engenharia de Aplicação e pode ajudar a comparar variantes alternativas que afetam os atributos de qualidade; e 
- durante a atualização da arquitetura: ajuda a identificar como as modificações e a manutenção da ALP afetam os produtos que já estão no mercado.

Outro aspecto importante que deve ser considerado são as técnicas utilizadas na avaliação de LP. Para tanto, Etxeberria e Sagardui (2005) classificam as técnicas em dois grupos:

- Técnicas de Questionários para Avaliação Qualitativa: incluem cenários comportamentais, questionários e checklists. Tais técnicas podem ser usadas para avaliar a qualidade de desenvolvimento ou operacional; e

- Técnicas de Medição para Avaliação Quantitativa: incluem simulação, prototipagem, modelos matemáticos e experimentais. Tais técnicas podem ser usadas para medir a aplicação de técnicas que englobam qualidades específicas, normalmente operacionais.

Os atributos de qualidade de LP não são considerados operacionais ou de desenvolvimento, assim, a avaliação é geralmente realizada qualitativamente. A maioria dos métodos é baseada em cenários, dado que tais métodos concretizam os atributos de qualidade que são abstratos em situações dependentes de contextos.

Apesar da avaliação qualitativa ser mais frequente, existem métricas definidas para avaliar atributos de qualidade específicos, como métricas de utilização de serviços, que podem ser usadas para avaliar a melhoria da ALP; e as métricas de Rahman (2004) para avaliação estrutural de arquiteturas de LP, baseada na medição de componentes.

A avaliação de atributos de qualidade relevantes ao domínio pode ser realizada por meio de cenários, mas algumas técnicas quantitativas como métricas, modelos matemáticos e experimentais também podem ser usados. Algumas comunidades desenvolveram técnicas e métodos específicos para avaliar atributos de qualidade (desempenho, segurança, confiabilidade, entre outros), porém, as abordagens não são específicas à LP necessitando, assim, de várias adaptações.

Para a avaliação de requisitos funcionais, outras técnicas podem ser usadas, tais como: Verificação de Modelo, Prova de Teorema, Verificação de Prova e Verificação de Equivalência. Os requisitos funcionais também podem ser analisados por técnicas manuais.

Etxeberria e Sagardui (2005) apresentam uma classificação das abordagens e métricas existentes para LP com relação: à meta, aos tipos de atributos, à etapa de avaliação, às técnicas de avaliação, à descrição do processo, ao método de avaliação e a outros 
métodos. O que se percebe é que a maioria das abordagens de avaliação está baseada na utilização de cenários, para avaliar atributos de qualidade, enquanto outros métodos, utilizam avaliações quantitativas por meio do uso de métricas, por exemplo.

\subsection{Abordagens e Métricas para Avaliação de LP}

Estudos sobre abordagens e métricas existentes para avaliação de LP foram realizados por Oliveira Junior et al. (2007) e Oliveira Junior et al. (2010) apresentando o estado da arte sobre o tema. Um panorama sobre os estudos realizados é apresentado nas seções a seguir, na forma de um agrupamento dos trabalhos pesquisados, com relação aos seus objetivos, identificados, a princípio, como sendo:

- Avaliação de Atributos de Qualidade de Arquiteturas de LP: estudos que consideram a avaliação de determinados atributos de qualidade de ALP como, por exemplo: desempenho, manutenibilidade, extensibilidade, reusabilidade, confiabilidade, portabilidade e interoperabilidade;

- Avaliação Estrutural de Arquiteturas de LP: estudos que consideram a avaliação de ALP, de acordo com a sua estrutura, em termos de métricas para componentes, interfaces, assinaturas de métodos, utilização de serviços, modelos de maturidade e teste de LP;

- Definição e Avaliação de Escopo de LP: estudos que consideram a análise de riscos e benefícios, adoção e melhoria do processo de LP, modelos econômicos e de estimativas, entre outros.

Montagud e Abrahão (2009) apresentam uma revisão sistemática extremamente importante sobre avaliação de LP. Os autores listam 39 estudos recuperados sobre avaliação de qualidade de LP dos últimos 10 anos. Desses 39 estudos, 23 foram recuperados pelas revisões sistemáticas realizadas por Oliveira Junior et al. (2007) e Oliveira Junior et al. (2010). Apesar da revisão sistemática conduzida por Montagud e Abrahão (2009) ser mais abrangente no que diz respeito à string de busca recuperando 16 trabalhos a mais, percebe-se que as revisões de Oliveira Junior et al. (2007) e Oliveira Junior et al. (2010) foram efetivas na busca pelos estudos. Assim, essas revisões podem contribuir para a revisão realizada por Montagud e Abrahão (2009) e vice-versa. 


\subsubsection{Avaliação de Atributos de Qualidade de Arquiteturas de LP}

A literatura sobre avaliação de atributos de qualidade de ALP considera vários métodos e técnicas que vão desde a utilização de cenários, passando pela aplicação da técnica GQM (Goal-Question-Metric) e BBN (Bayesian Belief Networks) até a extensão dos métodos ATAM (Seção 3.1) e SAAM (Software Architecture Analisys Method) e avaliações de ALP com base no atributo de qualidade variabilidade. Além disso, alguns desses métodos e técnicas utilizam ADL (Architectural Description Language) para a especificação das arquiteturas a serem avaliadas, bem como a utilização de casos de uso para apoiar a atividade de avaliação.

\section{Avaliação Baseada em Cenários}

Gannod e Lutz (2000); Lutz e Gannod (2003); Maccari (2002); Matinlassi (2004b); McGregor (2005); Olumofin e Misic (2005a); Riva e Rosso (2003); Rosso (2004, 2008) utilizam em seus estudos o conceito de cenários para a avaliação de ALP. Alguns desses autores especializam técnicas para resolver problemas específicos a um determinado domínio de aplicação de suas pesquisas. Além disso, fazem uso de cenários como forma de exercitar a ALP e descobrir se esta satisfaz os seus atributos de qualidade definidos.

Gannod e Lutz (2000) propõem um processo de análise repetitível que avalia uma ALP com relação aos atributos de qualidade exigidos para um determinado domínio. A análise da ALP é realizada de forma manual e automatizada, e compreende as seguintes etapas: (i) especificação formal da arquitetura em alto nível; (ii) análise manual de cenários; e (iii) verificação de modelo de comportamentos críticos. Para tanto, a ALP é descrita em ADL, para permitir a identificação de problemas arquiteturais e para a construção de uma baseline para subsequente análise automatizada.

Maccari (2002) apresenta uma abordagem de avaliação formada pela combinação de cenários com o método ATAM (Seção 3.1). Dois estudos de caso são apresentados para a avaliação de ALP de sistemas operacionais. O processo é composto pelas seguintes etapas: (i) criação dos cenários iniciais; (ii) refinamento dos cenários; (iii) classificação dos cenários; (iv) condução da avaliação; e (v) preparação de relatórios. Com a avaliação, é possível identificar potenciais problemas arquiteturais. Métricas são coletadas como resultado dos estudos de caso, porém não são apresentadas.

Riva e Rosso (2003) apresentam uma abordagem para avaliação de LP focando a sua evolução. Segundos os autores, a literatura sobre avaliação de LP é escassa e relatórios de experiências de organizações são raros. O artefato de entrada para a avaliação da ALP consiste da documentação e do conhecimento sobre a arquitetura. O principal artefato de 
saída é um relatório de avaliação. Para tanto, cenários são utilizados para a identificação de problemas arquiteturais e verificação dos atributos de qualidade relacionados. Porém, a abordagem não é apresentada em detalhes e não há informações sobre como os cenários são aplicados na avaliação.

Olumofin e Misic (2005a) afirmam que muitos métodos propostos de avaliação de arquiteturas consideram somente arquiteturas de produtos específicos. Assim, eles estendem o método ATAM (Seção 3.1) para considera tanto a avaliação de arquiteturas de produtos específicos quanto ALP. A abordagem HoPLSAA (Holistic Product Line Architecture Assessment) fornece uma análise qualitativa de variabilidades usando cenários e consiste em analisar os atributos de qualidade, usando o método ATAM. O método HoPLSAA prioriza os atributos de um determinado domínio e os classifica com base em cenários. Assim, o método HoPLSAA é dividido em duas etapas: a primeira, responsável por avaliar a arquitetura de referência da LP e a segunda, por avaliar as arquiteturas únicas dos produtos derivados. A primeira etapa é composta pelas seguintes atividades:

1. apresentar a primeira etapa do método HoPLSAA;

2. apresentar os objetivos arquiteturais da LP;

3. apresentar a arquitetura da LP;

4. identificar abordagens arquiteturais;

5. gerar, classificar e priorizar cenários de atributos de qualidade;

6. analisar cenários arquiteturais; e

7. apresentar os resultados.

A segunda etapa é idêntica ao método ATAM (Seção 3.1), pois considera a arquitetura dos produtos específicos derivados.

Matinlassi (2004b) apresenta um estudo de caso que ilustra o método QADA (Qualitydriven Architecture Design and quality Analysis), fortemente baseado em cenários, para sistemas de pedágio, visando avaliar a portabilidade e a manutenibilidade. O método QADA é composto pelas atividades de:

1. descrição da ALP com base em visões;

2. derivação de categorias de cenários de acordo com os problemas do domínio;

3. identificação dos cenários; 
4. associação de um peso para cada cenário;

5. avaliação dos efeitos dos cenários sobre os elementos da arquitetura; e

6. identificação de quais cenários afetam quais componentes (interação de cenários).

Categorias de cenários são criadas para cada atributo de qualidade a ser avaliado. Assim, é verificado quantos cenários afetam um determinado componente (fraca separação de interesse) e quantos componentes são afetados por um determinado cenário (ponto de risco na arquitetura).

Rosso (2004) apresenta um estudo de caso para avaliação de desempenho em uma LP para telefones celulares. As variabilidades são identificadas e os cenários mais importantes relacionados a desempenho são listados. Apesar do uso de cenários, o estudo não deixa claro como a avaliação é conduzida, nem como os cenários são elaborados e exercitados.

Lutz e Gannod (2003) apresentam experiências na especificação e avaliação automatizada de ALP. Para tanto, a abordagem é baseada em três etapas: (i) recuperação e especificação de arquiteturas; (ii) avaliação da arquitetura; e (iii) análise automatizada da arquitetura. A avaliação da ALP toma como base, a definição de cenários para a verificação de atributos de qualidade presentes na arquitetura. A análise automatizada da arquitetura envolve a sua descrição em ADL (ACME e Right), a especificação formal de comportamentos e a análise do comportamento, para determinar tolerância à falhas e robustez. A abordagem não deixa claro como os cenários são utilizados, nem como os resultados são interpretados com relação aos atributos de qualidade da arquitetura.

McGregor (2005) apresenta uma avaliação de ALP com base no método ATAM (Seção 3.1) e na definição de cenários, para a identificação de riscos associados com o desenvolvimento de produtos usando a ALP. Árvores de utilidade (Utility Trees) são usadas para traduzir as metas dos atributos de qualidade para os objetivos de negócio dos cenários. Assim, os cenários são priorizados e a geração de mais cenários pode ser realizada. O estudo não mostra como os resultados são obtidos e nem como são analisados.

Rosso (2008) utiliza cenários para realizar avaliações de desempenho e eficiência de gerenciamento de memória dinâmica da ALP de uma LP da Nokia. Dois estudos de caso são apresentados. Uma discussão a respeito de análises de trade-off entre desempenho e manutenibilidade em ALP, também é apresentada. O autor apresenta também um método para o ajuste de desempenho para ALP baseado em cenários, sendo as suas principais etapas:

- seleção dos cenários-chave de desempenho; 
- estabelecimento dos objetivos de desempenho e preparação de um plano de simulação;

- execução das simulações e modelos de desempenho;

- avaliação dos resultados da simulação e modelos de desempenho; e

- realização de análise de trade-off para a LP.

O primeiro estudo de caso concentra-se no ajuste de desempenho do núcleo de artefatos e suas características mais importantes. O segundo concentra-se na eficiência do gerenciamento de memória dinâmica e no impacto de características multimídia na ALP.

\section{Avaliação Baseada em GQM e BBN}

Kolb et al. (2006) apresentam suas experiências na avaliação de qualidade de LP para dispositivos portáteis. O desenvolvimento de LP adotado pelos autores segue a abordagem PuLSE (Product-Line Software Engineering) e o paradigma QIP (Quality Improvement Paradigm). A avaliação da LP é realizada usando cenários, assim como é feito no método ATAM, considerando os seguintes atributos de qualidade: manutenibilidade, reusabilidade, desempenho e confiabilidade. A qualidade da implementação da infraestrutura da LP é avaliada com base em métricas de código-fonte. Além disso, é feita uma verificação de conformidade entre os elementos arquiteturais e os elementos de código-fonte, em que esses são mapeados e classificados como:

- convergence: um determinado modelo existe tanto na arquitetura como no código-fonte;

- divergence: um determinado modelo existe somente no código-fonte; e

- abscence: um determinado modelo existe somente na arquitetura de LP.

Essa verificação é feita com o apoio do plugin SAVE para o IDE Eclipse. Desse modo, ao final da verificação, uma lista de adaptações da arquitetura é gerada para melhor apoiar a derivação de futuros produtos.

Zhang et al. (2003) apresentam uma abordagem para a avaliação de qualidade usando BBN (Bayesian Belief Networks), em que a rede é usada para representar o conhecimento de um domínio e as experiências acumuladas no desenvolvimento de outros projetos. A abordagem combina a utilização de BBN, com modelos de características para a modelagem das similaridades e das variabilidades de uma LP. Com redes BBN é possível criar uma relação entre os atributos de qualidade e, como esses podem ser medidos com base em uma ferramenta e algoritmos automatizados. Assim, é possível a partir da configuração de características de uma LP, estimar o seu custo e a sua qualidade. 


\section{Avaliação Baseada nos Métodos ATAM e SAAM}

Barbacci et al. (2003); Clements e Northrop (2001); Dolan et al. (2000); Ferber et al. (2002); Kim et al. (2008b); McGregor (2005) apresentam estudos baseados na utilização dos métodos ATAM e SAAM para avaliação de ALP. Esses métodos são fortemente baseados em cenários e casos de uso.

Ferber et al. (2002) discutem os resultados da aplicação do método ATAM em arquiteturas de software em uma organização. Uma comparação entre as arquiteturas é feita com base no uso de cenários. Com isso, uma série de melhorias é sugerida no domínio de sistemas automotivos, porém, o estudo não deixa claro como o processo é seguido, em particular para ALP, como sugere o tema abordado.

Dolan et al. (2000) apresentam um método para avaliação de ALP com base em seus atributos de qualidade como: extensibilidade (extensibility) e interoperabilidade (interoperability). O método é ilustrado com o desenvolvimento de uma ALP para sistemas médicos comerciais. O método é composto essencialmente por atividades baseadas no método SAAM e centrado no stakeholder. Utiliza casos de uso com o objetivo de analisar arquiteturas com relação a vários atributos de qualidade. O método é composto pelas seguintes atividades: (i) descrição da arquitetura candidata; (ii) desenvolvimento de cenários; (iii) avaliação de cada cenário; (iv) apresentação de cada interação de cenários; e (v) medição de cada cenário e suas interações. Apesar do método SAAM não ser projetado para LP, é possível avaliar extensibilidade e interoperabilidade de ALP, com pequenas modificações. Uma série de técnicas e ferramentas é utilizada para apoiar a realização das atividades do método.

McGregor (2005) apresenta os resultados da avaliação de uma ALP para jogos (Arcade Game Maker Product Line) com base no método ATAM (Seção 3.1), com o objetivo de identificar os riscos associados com o desenvolvimento de produtos. A abordagem usa árvores de utilidade para organizar os atributos de qualidade com relação aos cenários utilizados. O estudo mostra alguns resultados, mas não deixa claro como são alcançados.

Barbacci et al. (2003) apresentam um estudo de caso com a aplicação do método ATAM na avaliação da ALP para sistemas aviônicos. Para tanto, vários cenários, requisitos de negócio e abordagens arquiteturais são definidos. Além disso, árvores de utilidade também são construídas para organizar os atributos de qualidade e os cenários relacionados. Os resultados são apresentados, porém, de forma sucinta e sem muitos detalhes, não mostrando, por exemplo, como o processo é realizado.

Clements e Northrop (2001) apresentam conceitos fundamentais sobre avaliação de arquitetura de software e ALP. Mostram a importância e a possibilidade de se utilizar os métodos ATAM, SAAM e ARID para a avaliação de ALP e indícios de como estes 
podem ser modificados, para atender as arquiteturas de referência em LPs. Os autores consideram, também, os riscos da prática de avaliação, bem como os seus benefícios e ganhos quando realizada com sucesso e de forma correta. O estudo não entra em detalhes sobre as particularidades e os detalhes de cada método.

Kim et al. (2008b) apresentam o método EATAM (Extended ATAM) para avaliar ALP. O EATAM analisa os pontos de variação de atributos de qualidade usando modelagem de características, criando cenários de variabilidade para a derivação dos pontos de variação. Para isso, a tag PLUC (Product Line Use Cases) é utilizada. Assim, análises de trade-off são realizadas entre os cenários de variabilidade, com relação à ALP. Os autores ainda identificam quatro atributos de qualidade essenciais para uma LP: modificabilidade, escalabilidade, portabilidade e extensibilidade.

\section{Avaliação Baseada em ADL}

Gannod e Lutz (2000); Lutz e Gannod (2003) utilizam em suas pesquisas ADLs para a especificação de ALP. As ADLs podem ser usadas para especificar as ALPs em alto nível e formalmente, além de fornecer uma visão abstrata dos atributos de qualidade e a possibilidade de identificar problemas arquiteturais, antes mesmo do desenvolvimento de ALP.

\section{Avaliação Baseada no Atributo de Qualidade Variabilidade}

Deelstra et al. (2009); Etxeberria e Sagardui (2008a b) apresentam avaliações de ALP com base em variabilidade, já que o gerenciamento de variabilidade é a chave para a evolução de uma LP, em resposta às mudanças de mercado.

Deelstra et al. (2009) apresentam o método COSVAM (COVAMOF Software Variability Assessment Method) para a avaliação de variabilidade de LP. O processo de avaliação do COSVAM é composto pelas seguintes atividades:

1. identificar os objetivos da avaliação:

(a) identificar o contexto;

(b) definir as saídas da avaliação;

(c) selecionar o escopo da avaliação;

(d) identificar a equipe de avaliação; e

(e) planejar a avaliação. 
2. especificar as variabilidades fornecidas:

(a) identificar e obter fontes de informações para as variabilidades fornecidas;

(b) identificar pontos de variação;

(c) unificar pontos de variação;

(d) identificar variantes; e

(e) determinar realizações e dependências.

3. especificar as variabilidades requeridas:

(a) identificar e obter fontes de informações para as variabilidades requeridas;

(b) construir cenários de produtos; e

(c) construir modelos.

4. avaliar as variabilidades:

(a) identificar incompatibilidades diretas;

(b) identificar incompatibilidades indiretas;

(c) agrupar e priorizar incompatibilidades;

(d) sugerir um conjunto de cenários de solução; e

(e) determinar o impacto dos cenários de solução.

5. interpretar os resultados da avaliação:

(a) identificar metas de negócio e restrições;

(b) identificar vantagens e desvantagens das diferentes soluções; e

(c) selecionar soluções.

Etxeberria e Sagardui (2008b) e Etxeberria e Sagardui (2008a) apresentam um método para facilitar a avaliação efetiva de qualidade de ALP com base em variabilidade. Os autores propõem a extensão da modelagem de características, para permitir a avaliação, segundo o método proposto, sendo suas principais fases:

1. modelagem de variabilidade;

2. detecção de interações e quantificação de impacto; e

3. definição dos níveis para derivação dos produtos.

Os autores ilustram o método com a avaliação da LP Arcade Game Maker do SEI. 


\subsubsection{Avaliação Estrutural de Arquiteturas de LP}

Dincel et al. (2001); Eskenazi et al. (2004); Hoek et al. (2003); Kim (2008); Kim et al. (2008a); Kolb et al. (2006); Rahman (2004) concentram-se na avaliação estrutural de LP, com base na definição e uso de métricas para avaliação dos componentes de ALP e atributos de qualidade. Esse tipo de avaliação é vista como quantitativa, por causa do uso de métricas e, ainda, qualitativa por relacionarem as métricas coletadas com atributos de qualidade de ALP.

Eskenazi et al. (2004) apresentam o método APPEAR (Analysis and Prediction of Performance for Evolving Architectures) para a análise e estimativa de desempenho em ALP. O método visa coletar algumas métricas como: tempo de resposta entre chamadas de componentes, latência, média de utilização de CPU e tempo de execução. Essas métricas apoiam a avaliação de impacto de decisões arquiteturais e a seleção de versões mais apropriadas da ALP. Além disso, o método APPEAR utiliza técnicas estatísticas e de simulação para apoiar a análise de LP. Assim, arquitetos de LP podem analisar o desempenho de futuras versões de componentes durante a etapa inicial de desenvolvimento dos produtos. O desempenho é medido com base na análise das assinaturas dos componentes que fornecem informações. Para tanto, o desempenho é medido com base na métrica $\mathrm{P}$ ( $\mathrm{P}: \mathrm{S}->\mathrm{C})$, que é uma função em que $\mathrm{S}$ é um conjunto de elementos de tipos de assinaturas de um componente e $\mathrm{C}$ é uma métrica como, por exemplo, tempo de resposta. A estimativa é feita com base nos artefatos já implementados e em evolução.

Kolb et al. (2006) apresentam os resultados obtidos com a avaliação de qualidade de LP para dispositivos portáteis. O método ATAM é utilizado para avaliação de LP, após a geração de três produtos. A avaliação de conformidade visa comparar a arquitetura de referência com as arquiteturas dos produtos gerados. Um modelo estatístico é utilizado para tal. As métricas utilizadas para a avaliação foram definidas usando GQM.

Hoek et al. (2003) apresentam um conjunto de métricas para avaliação estrutural de LP, com base na utilização de serviços e componentes de ALP. Tais métricas visam avaliar a qualidade de um atributo de qualidade chamado structural soundness. As métricas convencionais, já conhecidas na literatura, não podem ser diretamente utilizadas em LP por causa das características da abordagem como opcionalidade e variabilidade. As métricas são dividas em duas categorias: componentes individuais e arquitetura como um todo. As métricas para componentes individuais são: PSU (Provided Service Utilization) e RSU (Required Service Utilization), definidas como:

$$
P S U_{x}=\frac{P_{a c t u a l}}{P_{\text {total }}} \text { e } R S U_{x}=\frac{R_{\text {actual }}}{R_{\text {total }}}
$$


$P_{\text {actual }}$ é o número de serviços fornecidos por um componente que é usado por outro(s) componente(s) na arquitetura e $P_{\text {total }}$ é o número total de serviços fornecidos por um determinado componente. $R_{\text {actual }}$ e $R_{\text {total }}$ possuem significados análogos, somente para serviços requeridos. Os valores de PSU e RSU são dependentes de domínio, assim, um componente pode ter valores diferentes para domínios diferentes. Componentes com valores RSU próximos a zero, indicam que podem não funcionar bem em uma arquitetura, enquanto valores de PSU próximos a zero, indicam a existência de funcionalidades extras que não são usadas por outro(s) componentes(s).

As métricas aplicadas à arquitetura como um todo são: CPSU (Compound PSU) e CRSU (Compound RSU), definidas como:

$$
C P S U=\frac{\sum_{i=1}^{n} P_{\text {actual }}^{i}}{\sum_{i=1}^{n} P_{\text {total }}^{i}} \text { e } C R S U=\frac{\sum_{i=1}^{n} R_{\text {actual }}^{i}}{\sum_{i=1}^{n} R_{\text {total }}^{i}}
$$

CPSU e CRSU são usadas para avaliar a coesão interna de uma arquitetura. Valores próximos a 1 indicam arquiteturas autocontidas, o que significa que são totalmente funcionais. Valores próximos a 0 indicam arquiteturas desbalanceadas. Valores baixos de CPSU combinados com valores altos de CRSU, implicam em uma arquitetura mais ampla, em termos de serviços, que o necessário. Altos valores de CPSU com baixos valores de CRSU indicam arquiteturas significativamente degradadas com relação às suas funcionalidades, o que significa que componentes devem ser adicionados para que todos os serviços requeridos estejam presentes. O cálculo dessas métricas só faz sentido, com relação à opcionalidade, quando o componente é incluído na arquitetura do produto final. Porém, as métricas não revelam as fraquezas de uma arquitetura, ao contrário, analisam possíveis soluções para problemas estruturais.

Rahman (2004) em sua dissertação de mestrado propõe um conjunto de métricas estruturais para componentes de ALP, para a medição de atributos como: observacionalidade, configuracionalidade, complexidade de interface, componentes autocontidos, modularidade, utilização de serviços fornecidos e maturidade. Um conjunto de métricas para cada atributo é definido com base em suas características e uma análise de correlação entre os atributos pode ser realizada. Testes de análises podem ser escolhidos para comparar os atributos e suas métricas coletadas, com relação à arquitetura.

Dincel et al. (2001) apresentam um conjunto de métricas para ALP para apoiar a análise de sua natureza incompleta, hierárquica e diversificada, com o objetivo de guiar decisões de projeto durante a evolução de sistemas. As métricas permitem ao arquiteto 
tomar decisões com base nos níveis de uso de uma ALP, sua coesão e a validade de tal arquitetura. Métricas já apresentadas como PSU e RSU são utilizadas pelos autores, além de métricas para:

- componentes primitivos;

- componentes complexos;

- média de componentes complexos; e

- média por arquitetura de LP.

As métricas sao apresentadas, contudo, sua utilização e suas definições não são consideradas.

Kim (2008) e Kim et al. (2008a) mostram como analisar ALP e melhorar o processo de LP, com resultados de experimentos. O estudo dos autores está baseado no projeto de atributos de qualidade e análise estática da implementação de uma ALP. A análise utiliza um modelo arquitetural de avaliação. Assim, o arcabouço FEF (Families Evaluation Framework) e o PuLSE (ProdUct Line Software Engineering) são estruturados em cinco níveis. Dessa forma, pode ser analisado o nível no qual uma ALP se encontra. O modelo de avaliação arquitetural é dividido em oito etapas:

1. elaborar o modelo de avaliação arquitetural propriamente dito;

2. especificar as similaridades e variabilidades;

3. especificar as camadas arquiteturais;

4. identificar os mecanismos de abstração;

5. especificar as interfaces padrão;

6. documentar a ALP;

7. classificar cada atributo de qualidade de acordo com uma escala; e

8. identificar as visões arquiteturais e aplicar métricas. 


\subsubsection{Definição e Avaliação de Escopo de LP}

Ahmed e Capretz (2010a)b); Ahmed et al. (2008); Böckle et al. (2004); Bernardo et al. (2009); Geppert e Weiss (2003); Kahsai et al. (2008); Lamine et al. (2005); Linden et al. (2004); Niemelä e Ihme (2001); Niemelä et al. (2004); Nobrega et al. (2008); Peter In et al. (2006); Schmid (2001); Schmid e John (2002); Segura et al. (2010); Silva e Soares (2009); Steger et al. (2004); Stoermer e O'Brien (2001); Yoshimura et al. (2006) desenvolvem suas pesquisas com base na análise e definição de escopo de LP, o que engloba: análise de riscos e benefícios de LP, adoção de LP, melhoria no processo de desenvolvimento e manutenção de LP, modelos econômicos e de estimativas e análise de domínios candidatos.

\section{Adoção de LP}

Schmid (2001) e Schmid e John (2002) apresentam uma abordagem para avaliação do planejamento de riscos no processo de adoção de LP. A abordagem, chamada PuLSE-Eco, concentra-se na análise de riscos e benefícios e de potencial reutilização de LP. O método PuLSE-Eco está estruturado nas seguintes etapas:

- mapeamento da LP: descrição em alto nível da LP em análise e de seus domínios relevantes; e

- definição do escopo do domínio: uma avaliação dos riscos e benefícios é realizada na LP e nos domínios relacionados.

A utilização de um modelo de maturidade para a avaliação como, por exemplo, o CMMI (Capability Maturity Model Improvement) não é recomendada, dado que deve-se especificar uma estrutura de referência flexível e, as áreas-chave do CMMI são estruturas fixas. Ao contrário, deve-se identificar uma estrutura que se adeque à LP em avaliação.

Para tanto, dois arcabouços são propostos pelos autores: um para o mapeamento de LP e outro para a avaliação de LP. O primeiro consiste em oito etapas que, de maneira geral, concentram-se em identificar produtos relevantes à LP, agrupar as suas características em áreas funcionais (domínios iniciais), garantir a consistência entre os produtos e desenvolver uma matriz produto final. O segundo, tem como objetivo determinar a avaliação real dos domínios ao longo de várias dimensões, sendo elas: maturidade, estabilidade, restrição de recursos e restrições organizacionais. A avaliação inicia com a definição de um conjunto de questões semelhantes ao GQM. Cada uma das dimensões é dividida em várias questões detalhadas, que por sua vez são respondidas de acordo com uma escala de quatro níveis: $\mathrm{F}=$ Fully, $\mathrm{L}=$ Largely, $\mathrm{P}=$ Partially e $\mathrm{N}=$ None. 
A avaliação toma como base o processo FAME e o SPICE, sendo que as principais saídas são: uma análise da contribuição dos domínios para a LP e uma lista de recomendações para o planejamento do desenvolvimento de LP.

A abordagem proposta pode ser utilizada para descobrir domínios para potenciais LP, assim, o esforço de definição de escopo é reduzido, não sendo necessária uma análise dos subdomínios.

Steger et al. (2004) apresentam conceitos e fatores fundamentais sobre arquitetura de LP e para a adoção da abordagem, bem como sobre o modelo CMMI adaptado à LP para melhoria do processo de desenvolvimento. O estudo não enfatiza diretamente avaliação de LP, porém apresenta uma comparação entre os modelos arquiteturais de LP e do CMMI adaptado para a melhoria das atividades de desenvolvimento de LP.

\section{Modelos de Custos e Estimativas}

Yoshimura et al. (2006) apresentam uma abordagem para avaliação da potencial incorporação de produtos de software embarcados em uma LP. Uma abordagem de LP considerada economicamente útil envolve dois principais tópicos de discussão: retorno esperado de investimento (ROI - Return on Investiment) de uma LP e entendimento do esforço necessário para a construção de artefatos reusáveis.

O cálculo de ROI é realizado com base em um plano de adoção de LP, em que os engenheiros estimam o ROI, considerando como controle, os produtos que serão gerados após a implantação do processo de LP. Nessa abordagem, o cálculo do ROI é feito utilizando o modelo de simulação Monte-Carlo. Assim, a similaridade entre produtos pode chegar a $60 \%$, o que torna a adoção viável e vantajosa.

Além disso, um processo de análise de viabilidade de potencial incorporação de produtos em uma LP é proposto, que consiste em: (i) listar os produtos desenvolvidos; (ii) incluir cada componente de cada produto em um repositório de artefatos reusáveis e (iii) testá-los. Caso sejam necessárias adaptações, devem ser feitas para cada nível de abstração, em busca de código-fonte equivalente ou duplicado. Para isso, uma métrica para análise de código equivalente é proposta, chamada Clone Coverage, sendo, assim, definida:

$$
\text { CloneCoverage }=\frac{\# L O C E q u i v a l e n t e s(J)}{\# L O C(K)} X 100
$$

Se o valor se aproximar de $100 \%$ significa que quase todas as linhas de código do componente $\mathrm{K}$ são equivalentes às linhas de código do componente J. Se o valor se 
aproximar de $0 \%$ significa que dificilmente existe alguma similaridade de $\mathrm{K}$ com relação a J.

Uma classificação de equivalência de código é proposta por Yoshimura et al. (2006):

- Tipo 1: cópias de interface e implementação exatas;

- Tipo 2: cópia de interface, mas implementação modificada para satisfazer requisitos específicos de um produto;

- Tipo 3: apenas a interface é copiada, mas a implementação difere muito, considerando implementações diferentes; e

- Tipo 4: a interface é renomeada, mas a implementação é clonada.

A ideia é identificar as partes comuns e variáveis dos produtos, de forma rápida para que possam ser incorporados em uma LP. A análise visa aumentar os tipos 1, reduzir os tipos 2, manter os tipos 3 e tornar os tipos 4 em tipos 1 .

Lamine et al. (2005) apresentam dois modelos de custo para LP: o modelo de custo integrado para reutilização e o modelo econômico de Poulin (1996). O primeiro é um modelo genérico e pode ser aplicado à LP após algumas adaptações, enquanto o segundo propõe uma fórmula global para estimar ROI em um projeto usando LP. O modelo SoCoEMo-PLE (Software Cost Estimation Model for Product Line Engineering) é proposto e alguns custos são estimados como: custo de investimento, custo periódico e benefício periódico para ciclos de desenvolvimento de componentes. Esses custos também são estimados para domínios, engenharia de aplicação e engenharia de organização. Para o cálculo desses custos, o modelo considera componentes COTS (Commercial-Off-The-Shelf).

Peter In et al. (2006) apresentam um modelo de estimativa de custo baseado em qualidade (qCOPLIMO) para a adoção de LP, considerando o cálculo de ROI. O modelo é derivado de outros dois: COPLIMO, que fornece uma baseline de modelo de custos para o ciclo de vida de LP, e o COQUALMO, que estima o número de defeitos residuais. Ambos modelos são extensões do modelo COCOMO. Assim, várias fórmulas são apresentadas para o cálculo dos custos e da qualidade, sendo utilizadas as seguintes métricas: custo relativo de escrever para reutilização e custo relativo para reutilização. O modelo permite estimar custo de qualidade de software, além de fornecer uma análise de custo-benefício de LP, aplicável somente ao ciclo de desenvolvimento de LP.

Böckle et al. (2004) apresentam um modelo de custos baseado na observação de engenheiros de LP e cenários gerais. O modelo permite o cálculo de quatro custos:

- custo para a organização adotar LP $\left(C_{\text {org }}\right)$; 
- custo para desenvolver um núcleo de artefatos de apoio à construção de $\operatorname{LP}\left(C_{c a b}\right)$;

- custo para desenvolver software específico que não é baseado em LP $\left(C_{\text {unique }}\right)$; e

- custo para reusar artefatos de um núcleo $\left(C_{\text {reuse }}\right)$.

O cálculo dos custos é realizado com base em cada cenário proposto. Contudo, o modelo precisa identificar os benefícios da adoção de LP.

Nobrega et al. (2008) apresentam um estudo que analisa os modelos de custo de LP mais efetivos, especificando um conjunto de características que torna um modelo efetivo. Além disso, apresentam um modelo de custo integrado (InCoME - Integrated Cost Model for Product Line Engineering) para LP e os seus principais elementos. O modelo é composto pelos seguintes elementos:

- fatores de custo (cost factors): encapsulam o conjunto de funções de custo (cost functions);

- camada de visão (viewpoint layer): composta por três visões, cada uma delas encapsula um conjunto de cenários de reutilização (reuse scenarios); e

- camada de análise de investimento (investment analysis layer): possui um conjunto de funções econômicas (economic functions) e uma camada de simulação (simulation layer).

Os autores realizaram experimentos baseados em hipóteses, aplicando o modelo à indústria. O método GQM foi aplicado para definir as métricas aplicadas no experimento.

\section{Análise de Domínios Candidatos}

Geppert e Weiss (2003) apresentam uma abordagem para avaliação de domínios, a qual define metas para avaliação de domínios e um modelo GQM para determinar as métricas para os domínios candidatos a serem avaliados. Cada meta é decomposta em critérios de seleção de domínios e subdomínios. Além disso, uma série de questões de entrevista é definida. A Figura 3.1, traduzida de Geppert e Weiss (2003), ilustra a decomposição.

Pode-se observar que a decomposição ocorre a partir dos critérios de seleção de domínios (Domain Selection Criteria) até chegar às questões de entrevistas (Interview Questions). Por outro lado, a avaliação acontece a partir das questões até chegar aos critérios satisfeitos para um determinado domínio. 


\section{Decomposição}

\section{Avaliação}

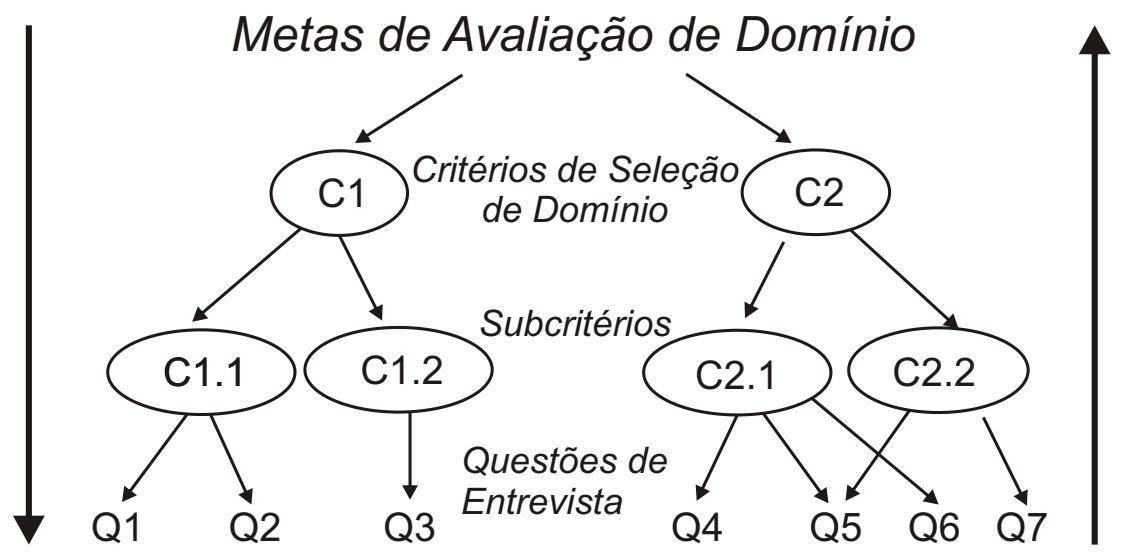

Figura 3.1: Decomposição de Metas e Avaliação de Domínios.

Stoermer e O'Brien (2001) apresentam um método para a captura de ALP (bottom-up) a partir de representações já existentes e para mapear estilos arquiteturais para LP candidatas (top-down). O método MAP (Mining Architectures for Product Lines) é formado pelas seguintes etapas:

- Preparação: todas as informações necessárias são fornecidas para garantir o sucesso da aplicação do método, como: entendimento comum de LP, aspectos técnicos e aspectos organizacionais;

- Reconstrução: consiste em três fases: extração de um modelo de implementação dos artefatos de origem, abstraindo-os para um modelo de arquitetura (composição) e mapeando tais estilos e atributos para um modelo arquitetural (qualificação);

- Avaliação: as arquiteturas dos produtos são comparadas com relação aos seus componentes, visões, estilos e atributos. Assim, a avaliação concentra-se na estrutura do sistema. As saídas da avaliação são as entradas para a etapa subsequente;

- Finalização: projeto baseado na arquitetura e, opcionalmente, um trade-off baseado no método ATAM.

A Figura 3.2, traduzida de Stoermer e O'Brien (2001), ilustra o método MAP e suas etapas. 


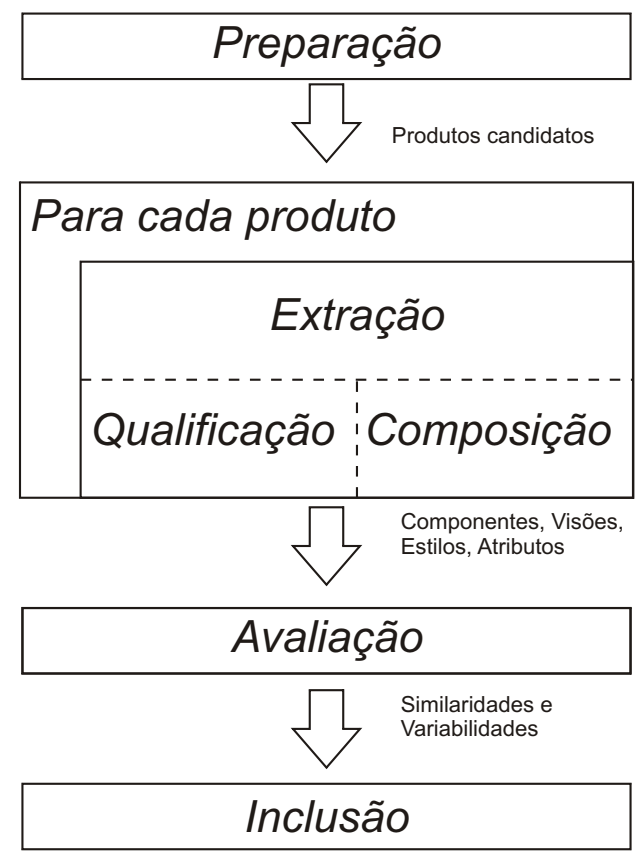

Figura 3.2: Etapas do Método MAP.

O método permite analisar vários produtos de forma disciplinada em uma organização e identificar as semelhanças e características de um determinado domínio. A avaliação ocorre em nível de arquiteturas de produtos específicos para a identificação de similaridades e variabilidades.

Niemelä e Ihme (2001) apresentam um conjunto de critérios de avaliação para o desenvolvimento de LP. Os critérios são definidos com base em um modelo de entrevistas e nas metas de negócio. O estudo enfatiza a avaliação de adoção de LP, por uma organização que tem como objetivo mostrar as diversas mudanças, tanto culturais quanto organizacionais, além de verificar se o ROI é alcançável. O estudo apresenta somente a estruturação para a aplicação dos critérios de avaliação.

\section{Modelos de Maturidade para Processos de LP}

Ahmed e Capretz (2010a.b); Ahmed et al. (2008) apresentam um modelo de maturidade organizacional para o desenvolvimento de LP, visando avaliar a maturidade de uma organização. O modelo leva em consideração que as teorias, comportamento e gerenciamento são os pilares da institucionalização do processo de desenvolvimento de LP em uma organização. Questionários de avaliação e métodos de classificação fazem parte do modelo proposto. O objetivo dos questionários é coletar informações sobre o processo de LP sob a perspectiva de comportamento e de gerenciamento. Para validar tal modelo, os autores 
apresentam dois estudos de caso e os resultados obtidos. Nesse modelo, o processo de LP (Software Product Line Engineering Process) envolve a identificação de vários fatores organizacionais (Organizational Factors) provenientes do gerenciamento organizacional. Apesar de proporem um modelo de maturidade, os autores não definem diretrizes para a melhoria do processo de LP.

\section{Teste de LP}

Bernardo et al. (2009) descrevem uma metodologia chamada Causal Analysis and Resolution (CAR) com base no método GQM. Para essa metodologia, indicadores são definidos com base nas métricas para o processo de tomada de decisão. O objetivo da metodologia é testar padrões de projeto em LP para sistemas de tempo real e embarcados. Um modelo de sistema de informação é criado para permitir a eliminação de defeitos, erros e falhas em um padrão de projeto chamado IO Manager, durante a fase de testes e antes de ser publicado em um repositório de componentes.

Segura et al. (2010) apresentam um conjunto de relações metamórficas entre modelos de características e os seus conjuntos de produtos e um gerador de dados de teste sobre tais produtos. Assim, vários modelos de características mais otimizados são propostos, diminuindo a complexidade dos produtos. O estudo foi avaliado utilizando teste de mutantes, o que revelou que muitas falhas podem ser detectadas automaticamente em poucos segundos.

Kahsai et al. (2008) propõem uma forma de teste baseado em especificação para o desenvolvimento de LP. Com base em casos de teste com relação às especificações formais, os autores desenvolvem o conceito de melhoria, permitindo a reutilização dos casos de teste no desenvolvimento de sistemas. A abordagem é ilustrada com um exemplo de LP para unidades de controle remoto para produtos de consumo.

Silva e Soares (2009) apresentam uma análise de cobertura de código e avaliação das principais diferenças entre técnicas de fluxo e controle de dados, considerando o uso de uma ferramenta de teste e a reutilização de ativos de teste em diferentes versões de uma LP.

\section{Abordagens Gerais para Avaliação de LP}

Niemelä et al. (2004) apresentam exemplos e resultados de avaliação de ALP com base em um modelo de avaliação. A ALP está relacionada a negócio, processo e organização. Assim, um método de avaliação de ALP é proposto e apoiado por um conjunto de dados empíricos coletados a partir de entrevistas realizadas em empresas. O método toma como 
base o modelo BAPO (Business, Architecture, Process, and Organization) (Linden et al., 2004), que categoriza o desenvolvimento de LP em: organização, cultura e processo; ALP; e gerenciamento de artefatos. O método possui quatro etapas:

- Arcabouço de Avaliação para Entrevistas: as questões são formuladas com base nos critérios de avaliação propostos por Niemelä e Ihme (2001). O número de questões limita-se a um tempo máximo de três horas. Os critérios são usados, pois o método classifica as questões em: negócio, domínio e tecnologias relacionadas ao desenvolvimento e à manutenção da arquitetura de LP;

- Revisão/Inspeção dos Artefatos da Arquitetura: o objetivo é compreender melhor o tipo de abordagem de LP que a organização está usando para desenvolver LP;

- Análise de Resultados: os resultados das entrevistas são coletados e reformulados, servindo como entrada para um arcabouço de comparação, que reconhece as questões de entrevista; e

- Arcabouço de Avaliação para Benchmark: são usados aspectos para identificar o nível de maturidade da ALP.

Linden et al. (2004) apresentam um arcabouço, BAPO, para a avaliação de LP em quatro dimensões (Figura 3.3): negócio, arquitetura, processo e organização. O arcabouço tem como propósito servir como benchmark para o desenvolvimento de LP, apoiar a avaliação de LP, e apoiar a melhoria de LP.

Com relação ao negócio, a avaliação cobre vários aspectos como: identidade, visão, objetivos e planejamento estratégico. No que tange a arquitetura, quatro aspectos são considerados: ALP, qualidade do produto, níveis de reutilização e gerenciamento de variabilidades. Em relação ao processo são enfatizados os cargos, produtos e responsabilidades e relações correspondentes ao desenvolvimento de software. Para a avaliação do processo podem ser utilizados o CMM e o CMMI. No âmbito da organização, os seguintes aspectos são considerados: distribuição geográfica, cultura, cargos e responsabilidades e ciclo de vida dos produtos. O arcabouço é apresentado em alto nível e o exemplo do estudo não detalha a realização da avaliação para cada nível citado. 


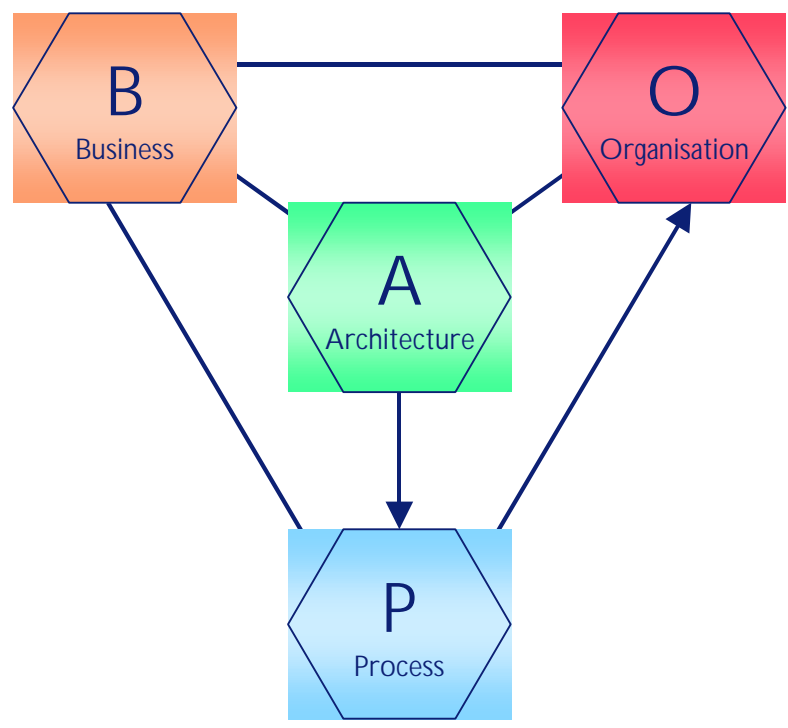

Figura 3.3: Os Interesses do Processo BAPO e seus Relacionamentos (Linden et al. 2004).

\subsection{Extensões do Método ATAM para a Avaliação de ALP}

Esta seção apresenta os conceitos fundamentais sobre duas extensões do método ATAM para avaliação de ALP: o método EATAM (Extended ATAM) e o método HoPLSAA (Holistic Product Line Software Architecture Assessment).

Os métodos EATAM (Kim et al., 2008a) e HoPLSAA Olumofin, 2007; Olumofin e Misic, 2005a) também são importantes para os fundamentos do método de avaliação de ALP, do Capítulo 5.

Assim, as subseções a seguir apresentam os principais conceitos desses dois métodos, com o objetivo de enriquecer o entendimento deste trabalho.

\subsubsection{EATAM (Extended ATAM)}

O EATAM, proposto por Kim et al. (2008b), é uma extensão do método ATAM, voltada para a avaliação de ALP. Tal avaliação está baseada em quatro métodos para avaliar uma ALP:

1. o primeiro identifica quatro atributos de qualidade comuns a uma ALP:

- modificabilidade: é a habilidade de compor vários elementos com várias combinações; 
- portabilidade: é a habilidade que permite usar vários elementos de hardware;

- escalabilidade: é a habilidade de um sistema crescer com base em modificações; e

- extensibilidade: é a habilidade de incorporar características à LP.

2. o segundo descobre as visões arquiteturais com base nos quatro atributos de qualidade mencionados acima;

3. o terceiro define marcações (tags) que indicam pontos de variação entre os quatro atributos de qualidade; e

4. o quarto repete as fases do método ATAM, para validar a arquitetura dos produtos.

O princípio básico do EATAM é estender o método ATAM em dois estágios: (i) avaliação da ALP; e (ii) avaliação dos seus produtos. A Figura 3.4 traduzida de Kim et al. (2008b), apresenta a estrutura do EATAM.

Estágio 1. Arquitetura de Linha de Produto (ALP)

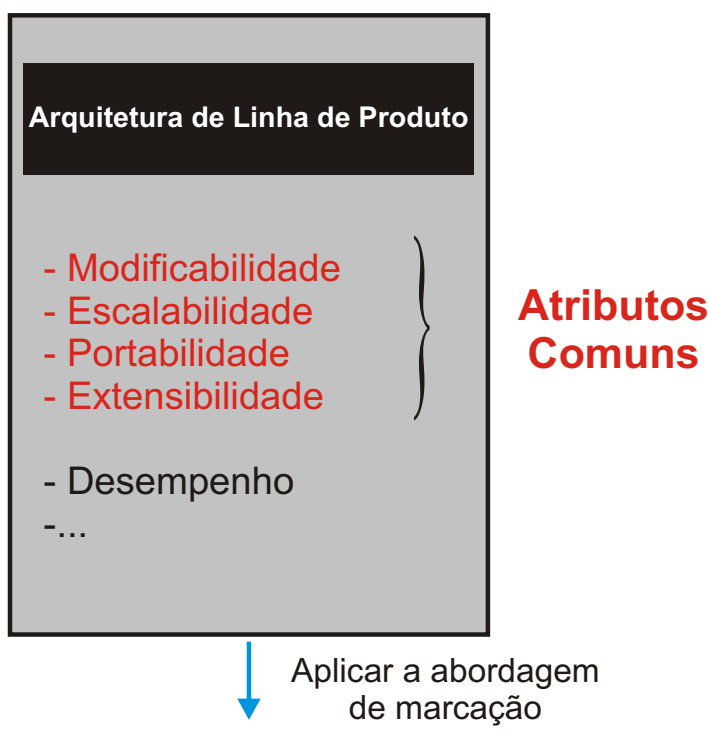

Avaliação da ALP
Estágio 2. Arquitetura do Produto (AP)

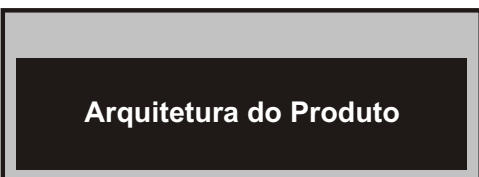

- Desempenho

- Segurança

- Disponibilidade

\section{Sinônimo para} aplicação

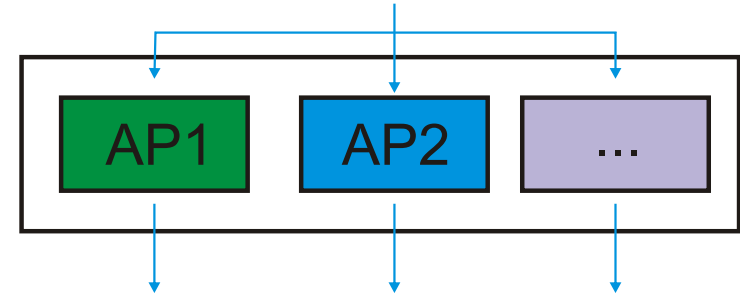

Avaliação das APs

Figura 3.4: Estrutura do EATAM. 
Como mostra a Figura 3.4, um estágio foi adicionado ao método ATAM, o Estágio 1 (Stage 1). Do lado direito da figura estão as arquiteturas dos produtos, sendo cada produto avaliado separadamente (Stage 2).

Os itens a seguir apresentam uma descrição de cada um dos quatro métodos do EATAM:

\section{Avaliação de ALP Considerando os Quatro Atributos de Qualidade}

A ALP deve concentrar-se em atributos de qualidade comuns a todos os seus produtos, enquanto a arquitetura de um produto específico, concentra-se em atributos de qualidade particulares a um produto.

Atributos de qualidade adicionais à ALP ou específicos aos produtos como, por exemplo, desempenho e segurança, podem ser adicionados. Para isso, o domínio e o modelo de características são analisados para determinar os pontos de variação.

\section{Análise de Pontos de Variação Usando Análise de Domínio e Modelo de Caracterís- ticas}

A visão conceitual da ALP está relacionada às similaridades e variabilidades, enquanto a visão de realização é necessária para determinar os quatro atributos de qualidade de uma ALP. A LP deve se concentrar nas suas visões arquiteturais, para obter os cenários relacionados aos atributos de qualidade formando, assim, a base para um modelo atual que revela os requisitos em um maior nível de detalhes.

Dessa forma, a visão conceitual é analisada para determinar os pontos de variação, incluindo as similaridades e variabilidades da LP. A visão de realização também é analisada para determinar as características da ALP, baseadas em seus atributos de qualidade.

\section{Definição da Marcação PLUC para Atributos de Qualidade}

Quando um método de avaliação é aplicado à uma ALP, esse deve considerar os pontos de variação da LP, para gerar cenários para os atributos de qualidade de forma precisa. Variabilidades e similaridades são derivadas de casos de uso, os quais são úteis para gerar a descrição dos requisitos funcionais de um sistema e para criar o modelo de características da LP. Assim, o EATAM define cinco tipos de marcações aplicadas aos atributos de qualidade, para apoiar a identificação de cenários:

- optional: características opcionais são aquelas que devem ser fornecidas por apenas alguns produtos da LP; 
Essas marcações também são usadas no Estágio 2 para definir a árvore de utilidade dos atributos de qualidade das arquiteturas dos produtos.

\section{Validação da Arquitetura dos Produtos da LP}

Com base na árvore de utilidade para os atributos de qualidade de cada produto, esses são avaliados separadamente, segundo os nove passos do método ATAM, apresentados na Seção 3.1

O EATAM ainda não foi validado e, portanto, continua em desenvolvimento.

\subsubsection{HoPLSAA (Holistic Product Line Software Architecture Assess-} ment)

O método HoPLSAA (Olumofin e Misic, 2005a b) é uma extensão do método ATAM, que cobre a avaliação tanto de ALP como de seus produtos, permitindo o tratamento qualitativo de pontos de variação usando cenários. O grande objetivo do método HoPLSAA é simplificar a análise dos atributos de qualidade e de suas interações, assim que decisões arquiteturais são tomadas nas etapas iniciais do desenvolvimento da ALP até o desenvolvimento de cada produto da LP. Isso é realizado em dois estágios, sendo que o primeiro se concentra na avaliação da ALP e o segundo na arquitetura de cada produto da LP.

Como o HoPLSAA é uma extensão do ATAM, as saídas são bem similares às geradas por cada etapa do método ATAM. As saídas do primeiro estágio como, por exemplo, abordagens arquiteturais e cenários, estão mais concentradas nos pontos de evolução, conforme ilustrado na Figura 3.6, traduzida de Olumofin e Misic (2005a).

Descrição da Arquitetura (ALP e APs)

e

Metas Arquiteturais

- metas de negócio

- contexto

- similaridade

- variabilidade

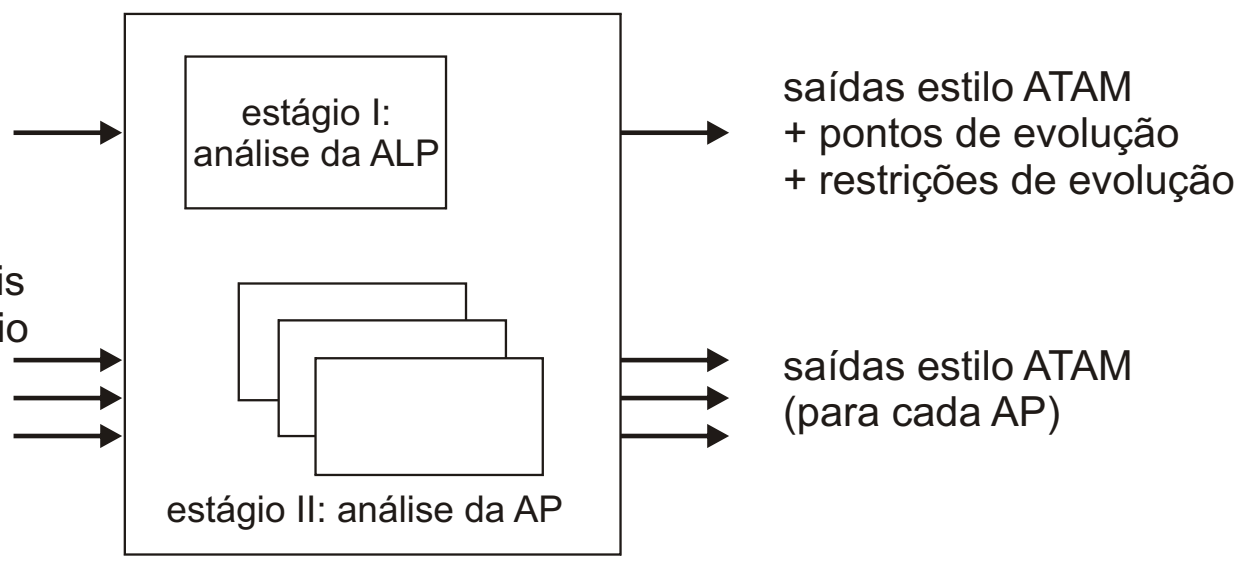

Figura 3.6: Entradas e Saídas do Método HoPLSAA. 
As principais características do método HoPLSAA são:

- extensão da análise de trade-off: a noção de análises de trade-off entre atributos de qualidade é a característica mais peculiar do método ATAM. Os atributos de qualidade não podem ser tratados de forma isolada, visto que as decisões de projeto em nível arquitetural influenciam estágios avançados no desenvolvimento de software. Análises de trade-off fazem parte da avaliação de uma ALP. Ao desenvolver a ALP, as decisões de projeto devem satisfazer os atributos de qualidade comuns à arquitetura e os que são específicos a certos produtos;

- tratamento de cenários dependentes de contexto: em muitos métodos de avaliação de arquitetura de software, cenários são empregados como uma forma de descrever a arquitetura e identificar atributos de qualidade. Como atributos de qualidade e cenários que os exercitam são identificados, é comum eliminar os redundantes e priorizar os restantes por meio de um sistema de votação. Assim, cenários comuns e específicos são gerados para atributos comuns de uma ALP. Cada estágio do HoPLSAA concentra-se na análise dos cenários do contexto, comuns para a ALP e específicos para os produtos; e

- tratamento qualitativo de pontos de variação: no método HoPLSAA, os pontos sensíveis definidos no método ATAM são chamados de pontos de evolução, que por sua vez, são identificados a partir dos pontos de variação de uma LP. Pontos de variação que podem alterar a qualidade, com base nos pontos de evolução, são tratados de forma diferenciada. Para isso, cada ponto de evolução possui um conjunto de diretrizes adequadas para restringir ou guiar as decisões de projeto de arquiteturas dos produtos subsequentes da LP. Dessa forma, os atributos de qualidade e as metas de negócio para uma ALP e seus produtos serão válidos.

O método HoPLSAA é composto pelas seguintes etapas:

- Estágio I - Avaliação da ALP: consiste de análises de trade-off para a ALP.

1. Apresentação do Método HoPLSAA (Estágio I): apresentação de um resumo das atividades do método HoPLSAA referentes ao Estágio I;

2. Apresentação das Metas de Negócio da ALP: descreve escopo, similaridades e variabilidades da LP, em termos de suas necessidades de negócio;

3. Apresentação da ALP: o arquiteto descreve a ALP; 
4. Apresentação das Abordagens Arquiteturais: a equipe de avaliação deve identificar as abordagens arquiteturais utilizadas para a construção da ALP;

5. Gerar, Classificar e Priorizar Cenários de Atributos de Qualidade

6. Analisar as Abordagens Arquiteturais e os Cenários Genéricos: analisa os cenários de maior prioridade definidos na etapa 5 para obter os pontos de evolução e riscos da ALP; e

7. Apresentar os Resultados: elaboração de um relatório contendo os resultados obtidos com a avaliação da ALP, referente ao Estágio I do HoPLSAA.

- Estágio II - Avaliação da Arquitetura dos Produtos Únicos: concentra-se na avaliação da arquitetura de cada produto da LP. Os passos 2 a 7 são os mesmos do método ATAM:

1. Apresentação do Método HoPLSAA: apresentação de um resumo das atividades do método HoPLSAA referentes ao Estágio II;

2. Apresentação das Metas de Negócio;

3. Apresentação da Arquitetura do Produto;

4. Apresentação das Abordagens Arquiteturais;

5. Gerar, Classificar e Priorizar os Cenários de Atributos de Qualidade;

6. Analisar as Abordagens Arquiteturais; e

7. Apresentar os Resultados.

O método HoPLSAA ainda não foi validado e, portanto, continua em desenvolvimento. Porém, um estudo de caso para avaliação da ALP da Arcade Game Maker (AGM) (SEI, 2010b) foi realizado.

\subsection{Considerações Finais}

Este capítulo apresentou os conceitos essenciais sobre avaliação de LP, com base nos estudos recuperados, lidos na íntegra e sintetizados a partir de duas revisões sistemáticas realizadas por Oliveira Junior et al. (2007) e Oliveira Junior et al. (2010). Essas revisões propiciaram a proposta de um panorama sobre avaliação de LP, permitindo que os principais conceitos e abordagens existentes pudessem ser utilizados para a proposta deste trabalho, além de contribuir para a obtenção do estado da arte sobre o assunto em questão. 
Por meio do panorama apresentado, percebe-se a existência de várias abordagens para avaliação de LP, a maioria delas baseada na avaliação de atributos de qualidade de ALP. Outras com base em métricas para avaliação estrutural e abordagens gerais.

Com base no estado da arte sobre avaliação de LP, apresentado neste capítulo, é possível constatar que existe uma certa carência por uma abordagem de avaliação de LP, que considere LP baseadas em componentes, modeladas em UML e que levem em conta as suas variabilidades existentes. Acredita-se que com base nas variabilidades, seja possível avaliar a qualidade de uma LP, bem como, realizar experimentos que permitam inferir sobre o esforço necessário para investir na incorporação de novas características em uma LP, além do esforço inerente da manutenção.

O método ATAM por si só mostra-se claramente incapaz de apoiar o planejamento e a condução de avaliações de ALP. Porém, dois métodos destacam-se por estendê-lo e permitir tais avaliações: EATAM e HoPLSAA. Ambos são muito interessantes do ponto de vista de usufruir de um arcabouço pré-existente para avaliar uma ALP. Apesar dos dois métodos levarem em consideração as variabilidades de uma LP para a avaliação de ALP, o método EATAM utiliza uma solução particular para representar os pontos de variação durante a avaliação de uma ALP, que são as chamadas marcações PLUC (Product Line Use Cases). Tais marcações são inseridas na descrição dos atributos de qualidade de uma ALP e exigem um tratamento particular para que possam ser consideradas em avaliações de ALP. A representação usando PLUC é muito interessante, mas exige que o usuário do método tenha que lidar com artefatos e técnicas diferentes das mais utilizadas no mercado. De uma forma geral, ambos os métodos permitem análises de trade-off entre os atributos de qualidade de uma ALP e análises qualitativas a respeito da priorização de atributos de qualidade. Contudo, tais análises não levam em consideração modelos arquiteturais da LP, representados em uma linguagem padrão como é, por exemplo, a UML. Além disso, métricas não são utilizadas para permitir análises estatísticas de uma ALP, com base em seus possíveis produtos.

De uma forma geral, percebe-se a necessidade de uma abordagem que permita a avaliação de ALP com base em suas variabilidades, modelos UML e métricas. Para tanto, os Capítulos 4 e 5 apresentam, respectivamente, a proposta de: uma abordagem para gerenciar variabilidades usando UML; e uma abordagem para avaliação de ALP que possa ser aplicada em um contexto mais geral, utilizando a notação UML. 


\section{SMarty: Uma Abordagem UML para Gerenciamento de Variabilidade}

"Se fossem escolher entre

alternativas, as decisões seriam

fáceis. Uma decisão inclui a seleção e a formulação de alternativas."

Edmund Burke (1729 - 1797), Filósofo Anglo-Irlandês

O gerenciamento de variabilidades inclui a identificação e representação de variabilidades, a resolução de variabilidades e a análise e controle de variabilidades. Para resolver uma variabilidade é necessário realizar uma ou mais decisões de projeto que foram adiadas (Gurp et al. 2001). Segundo Pohl et al. (2005, p. 58-59) e Linden et al. (2007, p. 8), o gerenciamento de variabilidades está relacionado a todas as atividades de desenvolvimento de LP e deve conter, pelo menos, as seguintes atividades:

1. identificação de variabilidade: consiste em apontar as diferenças entre produtos e onde elas ocorrem em artefatos de LP;

2. delimitação de variabilidade: define o tempo de resolução, que representa o momento em que uma variabilidade é resolvida, e a multiplicidade, que indica quantas variantes deverão ser escolhidas para resolver uma variabilidade; 
3. implementação de variabilidade: é a seleção dos mecanismos e estratégias utilizadas para realizar/codificar as variabilidades de uma LP; e

4. gerenciamento de variantes: controla as variantes e os seus pontos de variação, além de permitir uma análise acerca de potenciais produtos de uma LP.

Com base nas atividades e nos conceitos de variabilidade apresentados é proposta a abordagem SMarty (Stereotype-based Management of Variability), para o gerenciamento de variabilidades composta por um perfil UML, o SMartyProfile, e um processo, o SMartyProcess. A principal contribuição de SMarty, proposta neste trabalho, é permitir que as variabilidades de uma LP possam ser gerenciadas de forma efetiva em modelos UML e, com isso, definir e coletar métricas para apoiar a realização de avaliações de ALP.

O perfil SMartyProfile contém um conjunto de estereótipos e meta-atributos para representar variabilidade em modelos UML de LP (Seção 4.2). Basicamente, o SMartyProfile usa a notação orientada a objetos UML e seu mecanismo de perfil (UML, 2010) para fornecer uma extensão da UML e permitir a representação gráfica de conceitos de variabilidade.

O SMartyProcess é um processo sistemático que guia o usuário na identificação, delimitação, representação, rastreamento de variabilidades e análise de configurações de produtos de uma LP (Seção 4.3). O processo é apoiado por um conjunto de diretrizes que guiam o usuário na realização das suas atividades principais, bem como, pelo SMartyProfile.

As seções a seguir apresentam uma visão geral das abordagens existentes de gerenciamento de variabilidades, o SMartyProfile e o SMartyProcess, além de um exemplo completo da aplicação da abordagem SMarty em uma LP.

\subsection{Abordagens Existentes de Gerenciamento de Varia- bilidade}

A abordagem SMarty usa como fundamento trabalhos em LP existentes na literatura principalmente relacionados aos seguintes assuntos: atividades de gerenciamento, notação de artefatos, atributos de variabilidade e modelagem de metadados. As atividades de gerenciamento definidas pelo SMartyProcess estão de acordo com as atividades essenciais de desenvolvimento de LP (Linden et al., 2007; SEI, 2010a). Visto que o gerenciamento de variabilidades é considerado um subprocesso da atividade de gerenciamento de LP (Clements e Northrop, 2001), ele possui uma interação muito próxima de atividades de engenharia de domínio e de aplicação. 
As atividades definidas para a abordagem SMarty foram, inicialmente, propostas com base nas sugestões de atividades de gerenciamento de variabilidades de Linden et al. (2007) e de Pohl et al. (2005). Contudo, tais trabalhos somente listam essas atividades dentro do contexto de um processo bem definido com cargos, entradas e saídas. As atividades do SMartyProcess e seus cargos e artefatos associados, são especificados.

A abordagem SMarty usa o SMartyProfile como base para representar os conceitos de variabilidade e seus atributos em artefatos de LP e leva em consideração abordagens similares como, por exemplo, as propostas por Morisio et al. (2000), Bragança e Machado (2006), Ziadi et al. (2004), Korherr e List (2007), Clauss (2001) e Gomaa (2005). Chen et al. (2009) apresentam uma revisão sistemática com relação às abordagens existentes de gerenciamento de variabilidade, a qual inclui a maioria dos trabalhos relacionados à abordagem SMarty, mostrando-os em ordem cronológica.

Morisio et al. (2000) propõem uma extensão da UML para expressar variabilidade em análise de domínio. Tal extensão considera somente o nível de classes, mais precisamente atributos, métodos e relações estáticas e usa os estereótipos $\ll \mathrm{V} \gg$ e $\ll$ xorV》 para representar, respectivamente, variabilidade e variantes exclusivas. Elementos mutuamente exclusivos são detalhados no texto associado aos elementos UML. Apesar dessa extensão UML ser importante em termos de representação de variabilidades, não apresenta uma definição de um perfil UML e meta-atributos, que são essenciais para a compreensão dos conceitos de variabilidade nos níveis de metamodelo e objeto. Além disso, a extensão não guia o usuário sobre como identificar pontos de variação e variantes, como faz a SMarty.

Bragança e Machado (2006) apresentam uma extensão do metamodelo padrão da UML para a relação de extensão (extend) em modelos de casos de uso e sua formalização, usando diagramas de atividade. A extensão ocorre em nível de descrição dos passos em casos de uso, considerando o tipo de seqüência de passos. Para representar tais tipos, os autores propõem um conjunto de novas metaclasses e estereótipos UML, tais como: Location, Rejoin, ExtensionFragment, InclusionPoint, «before》, «after $\gg, ~ « r e j o i n \_p o i n t 》 \mathrm{e}$ «inclusion_point》. Apesar da abordagem SMarty também considerar a relação de extensão para representar variabilidades, não o faz em nível de descrição de passos em casos de uso, uma vez que considera que as informações relevantes sobre variabilidade em casos de uso, podem ser suficientemente representadas usando estereótipos e notas UML. A vantagem da abordagem SMarty é que não requer informações sobre variabilidades em baixos níveis de abstração como, por exemplo, passos de casos de uso.

Ziadi et al. (2004) propõem um perfil UML para representar variabilidade em diagramas de classes. Os estereótipos definidos em tal perfil são: «optional》 para especificar opcionalidade; «variation para especificar pontos de variação representados por clas- 
ses abstratas; e «variant》 para subclasses. O perfil SMartyProfile também define o estereótipo «optional». Além disso, considera o uso do estereótipo «variationPoint» não somente para classes abstratas, mas também para interfaces, uma vez que ambas podem representar o conceito de polimorfismo. Ainda, pelo fato de existir vários tipos de relacionamentos entre variantes e pontos de variação, o SMartyProfile define diferentes tipos de estereótipos para representar variantes em diagramas de classes. Como consequência, o usuário conta com um conjunto de soluções para resolver seus problemas de modelagem de variabilidade. Ziadi et al. (2004) propõem estereótipos, porém, esses não possuem meta-atributos, o que torna difícil representar os relacionamentos e restrições entre variabilidades, pontos de variação e variantes.

Korherr e List (2007) propõem um perfil UML para representar variabilidade em modelos de classe e um mapeamento entre seus estereótipos e diagramas de atividades. Os seguintes estereótipos fazem parte desse perfil: «variation point» para superclasses, $\ll v a r i a n t \gg$ para subclasses, «mandatory para variantes obrigatórias, «optional»e «alternative choice». Apesar desse perfil ser similar ao proposto nesta tese, o SMartyProfile permite representar explicitamente variantes inclusivas e exclusivas, por meio de diferentes estereótipos, o que fornece indícios de tornar a modelagem de variabilidade mais precisa e intuitiva. Além disso, o SMartyProfile representa variabilidades em modelos de casos de uso e de componentes.

Clauss (2001) apresenta uma abordagem para modelar variabilidade usando UML. Apesar do perfil SMartyProfile ser parcialmente baseado nesse trabalho, a abordagem de Clauss define dois estereótipos diferentes para variantes inclusivas e exclusivas, além de usar notas UML para diferenciá-los. O SMartyProfile se beneficia da notas UML para representar variabilidades e os seus atributos, tais como tempo de resolução e multiplicidade. Além disso, SMartyProfile não está definido apenas para o nível de classes, mas também para os níveis de casos de uso e componentes.

Gomaa (2005), em seu livro de LP, apresenta a abordagem Product Line UML-based Software Engineering (PLUS), que inclui atividades apoiadas por extensões da UML, para representar variabilidade em modelos de casos de uso, classes e colaboração. SMarty inclui, além de casos de uso e classes, modelos de componentes, uma vez que considera esses modelos os mais importantes para representar variabilidade. Porém, é sabido que a representação de variabilidade em diagramas de seqüência deve também ser considerada para analisar o impacto das variabilidades em modelos comportamentais de interação. A abordagem SMarty fornece diretrizes para a identificação de variabilidades, pontos de variação e variantes, bem como, para representá-las explicitamente, além de suas relações e restrições, de forma não ambígua. 


\subsection{O Perfil UML SMartyProfile}

O SMartyProfile baseia-se no inter-relacionamento dos principais conceitos de LP no que diz respeito ao gerenciamento de variabilidades (Gurp et al., 2001; Halmans e Pohl, 2003). Tais conceitos são:

- Variabilidade, de acordo com Weiss e Lai (1999), é a forma como os membros de uma família de produtos podem se diferenciar entre si. Apesar de uma variabilidade ocorrer em diferentes níveis de abstração e artefatos, a abordagem SMarty leva em consideração somente artefatos UML que resultam de atividades de desenvolvimento de LP, como mostrado em (Oliveira Junior et al., 2005a).

- Ponto de Variação é a representação de variabilidades em locais específicos de artefatos de uma LP. Segundo Jacobson et al. (1997), "um ponto de variação identifica um ou mais locais nos quais uma variabilidade ocorre." Assim, um ponto de variação pode ocorrer em artefatos genéricos e níveis diferentes de abstração. Basicamente, um ponto de variação responde a pergunta: O que varia em uma LP? (Pohl et al. 2005).

- Variante representa um artefato que possivelmente é escolhido para resolver um ponto de variação e, em alguns casos, pode também representar uma forma direta de resolver uma variabilidade associada. Basicamente, uma variante responde a questão: Como uma variabilidade ou um ponto de variação varia em uma LP? (Pohl et al. 2005).

- Restrição entre Variantes define os relacionamentos entre duas ou mais variantes para que seja possível resolver um ponto de variação ou uma variabilidade. Por exemplo, um gerente de LP decide não oferecer certas combinações de variantes mutuamente exclusivas para um conjunto de produtos. Assim, uma restrição mutuamente exclusiva deve ser definida entre tais variantes.

A Figura 4.1 mostra o relacionamento dos conceitos de gerenciamento de variabilidade com os elementos de interesse do metamodelo UML (UML, 2010), (Booch et al., 1999, Apêndice A). Um Modelo é classificado como Modelo Comportamental ou Modelo Estrutural. Um Modelo de Casos de Uso é um Modelo Comportamental formado por casos de uso e atores. Um Modelo de Classes é um Modelo Estrutural formado por classes e interfaces, enquanto um Modelo de Componentes, que também é um Modelo Estrutural, é formado por componentes. Tanto os modelos comportamentais como os estruturais podem conter Variabilidade. 


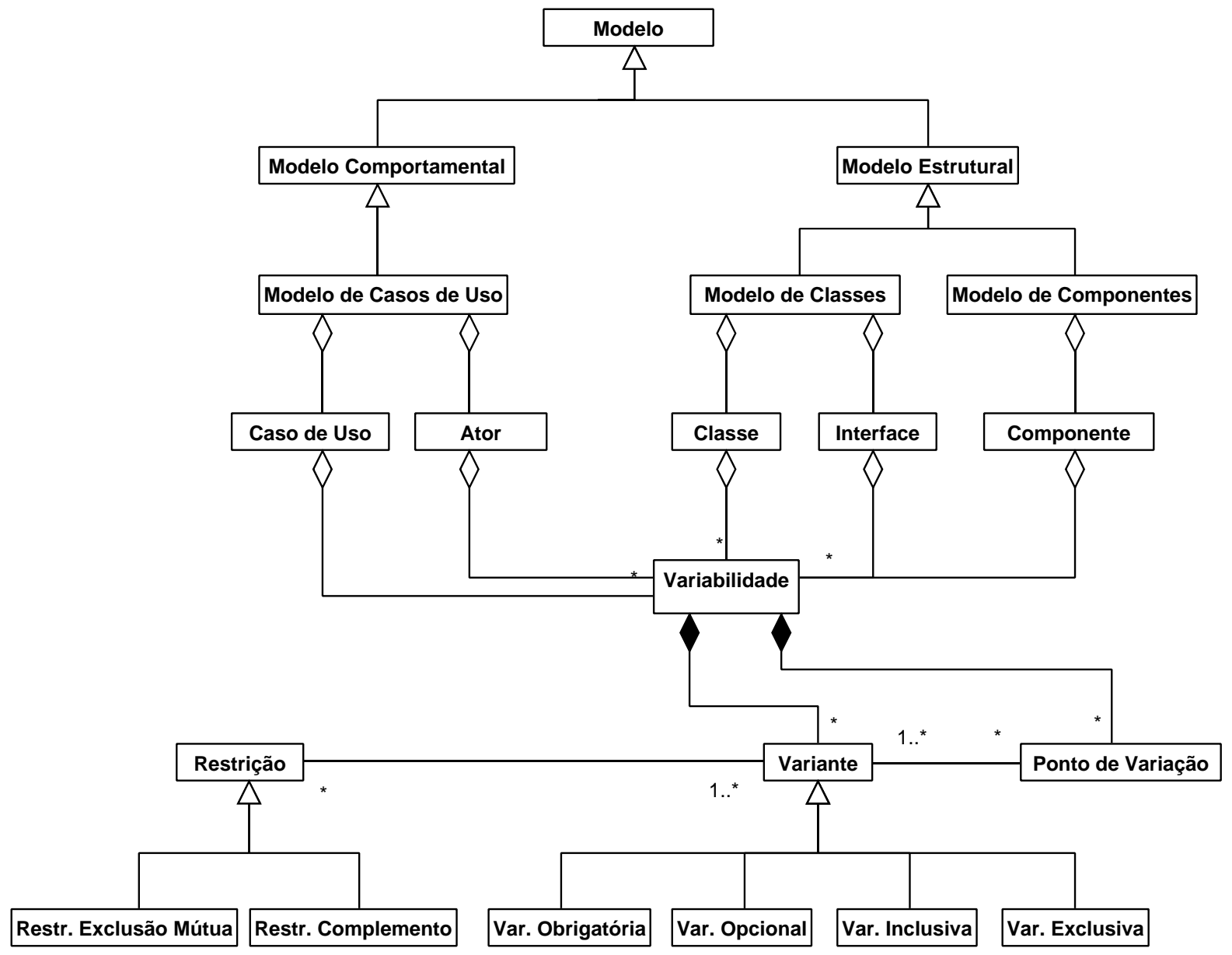

Figura 4.1: Relacionamento dos Conceitos de Gerenciamento de Variabilidade e Modelos UML.

Uma variabilidade é composta por:

- zero ou mais variantes, que podem ser do tipo obrigatória, opcional, inclusiva ou exclusiva. Variantes inclusivas representam escolhas a partir de um conjunto de alternativas, enquanto variantes exclusivas representam a escolha de uma única alternativa a partir de um conjunto; e/ou

- zero ou mais pontos de variação, que, por sua vez, possuam uma ou mais variantes associadas.

Uma Variante pode conter Restrição com relação à uma ou mais outras variantes. Tal restrição pode ser do tipo Exclusão Mútua ou Complemento.

Para exemplificar tais conceitos será considerada uma certa característica de uma LP que contém variabilidades relacionadas à ordenação de itens de uma coleção, denominada 
de "Ordenação de Elementos". As variabilidades dessa característica podem ser realizadas por dois pontos de variação:

- o tipo de elemento a ser ordenado, sendo as suas possíveis variantes, elementos do tipo string e numérico;

- o algoritmo de ordenação a ser aplicado ao conjunto de elementos, sendo as suas possíveis variantes: bubble sort, quick sort, heap sort, selection sort, insertion sort e shell sort.

As variantes são selecionadas para resolver os pontos de variação com o objetivo de gerar diferentes configurações da característica "Ordenação de Elementos". As configurações geradas são, então, utilizadas para compor possíveis produtos de uma LP.

As Figuras 4.2 e 4.3 apresentam, respectivamente, os modelos de caso de uso e de classes da característica "Ordenação de Elementos". Notas UML e estereótipos aplicados a esses modelos serão explicados em detalhe nas próximas seções.

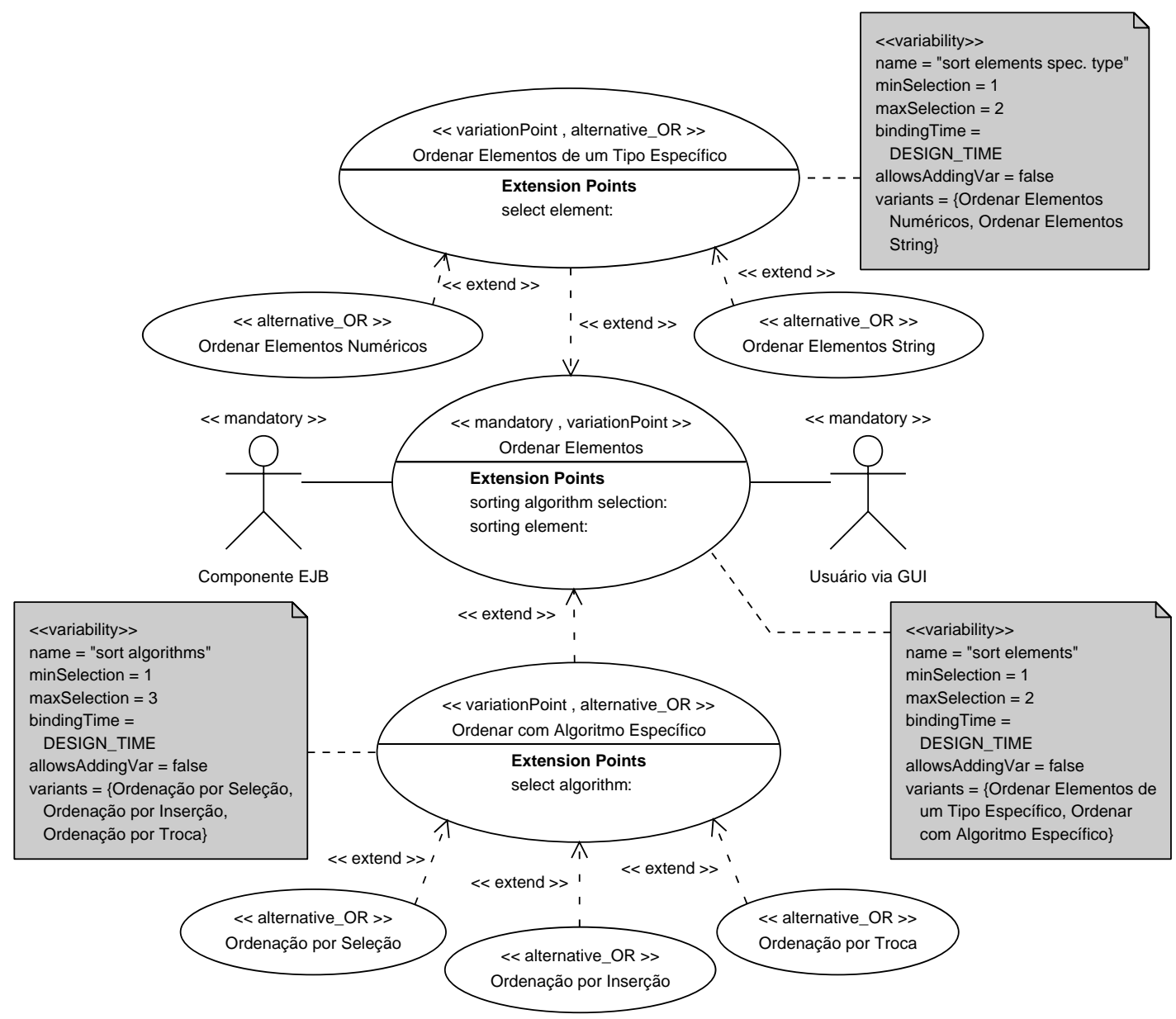

Figura 4.2: Modelo de Casos de Uso da Característica "Ordenação de Elementos". 
Basicamente, na Figura 4.2, a ordenação de elementos pode ser realizada por meio de um usuário via Graphical User Interface (GUI) ou de um componente Enterprise Java Bean (EJB). Um ator dispara o caso de uso Ordenar Elementos, o qual contém duas extensões Ordenar Elementos de um Tipo Específico, responsável por definir o tipo de elemento a ser ordenado, e Ordenar com Algoritmo Específico responsável por selecionar o algoritmo de ordenação apropriado.

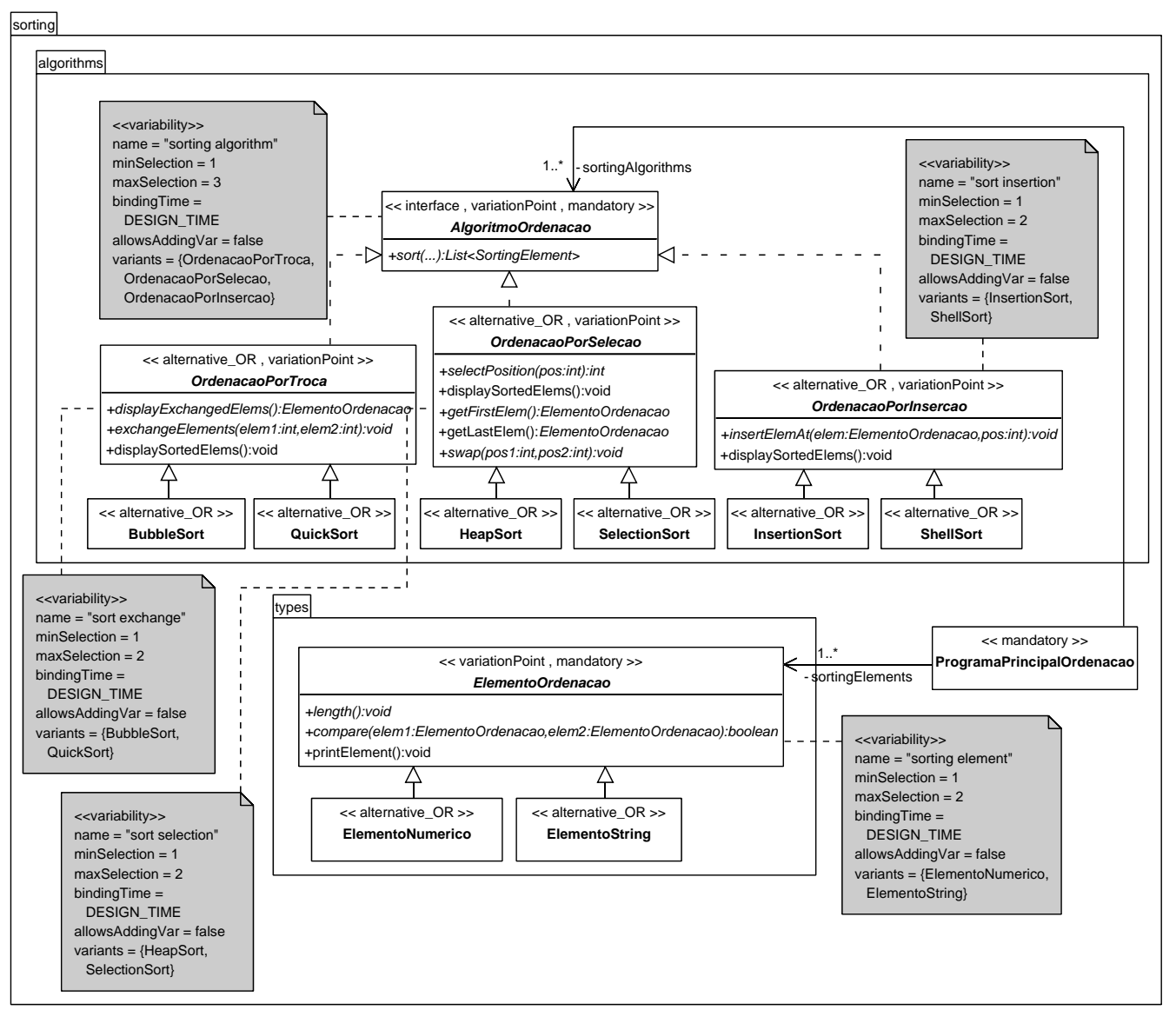

Figura 4.3: Modelo de Classes da Característica "Ordenação de Elementos".

Na Figura 4.3, a classe abstrata ElementoOrdenacao possui duas subclasses ElementoNumerico e ElementoString, representando, respectivamente, elementos numéricos e string a serem ordenados. A interface AlgoritmoOrdenacao possui três classes de implementação OrdenacaoPorTroca, OrdenacaoPorSelecao e OrdenacaoPorInsercao. Essas subclasses contêm os métodos polimórficos para as suas classes especializadas de ordenação.

Com base no relacionamento entre os conceitos de gerenciamento de variabilidades e modelos UML mostrado na Figura 4.1, a Figura 4.4 apresenta o perfil UML SMartyProfile, composto dos seguintes estereótipos e respectivos meta-atributos (tagged values): 


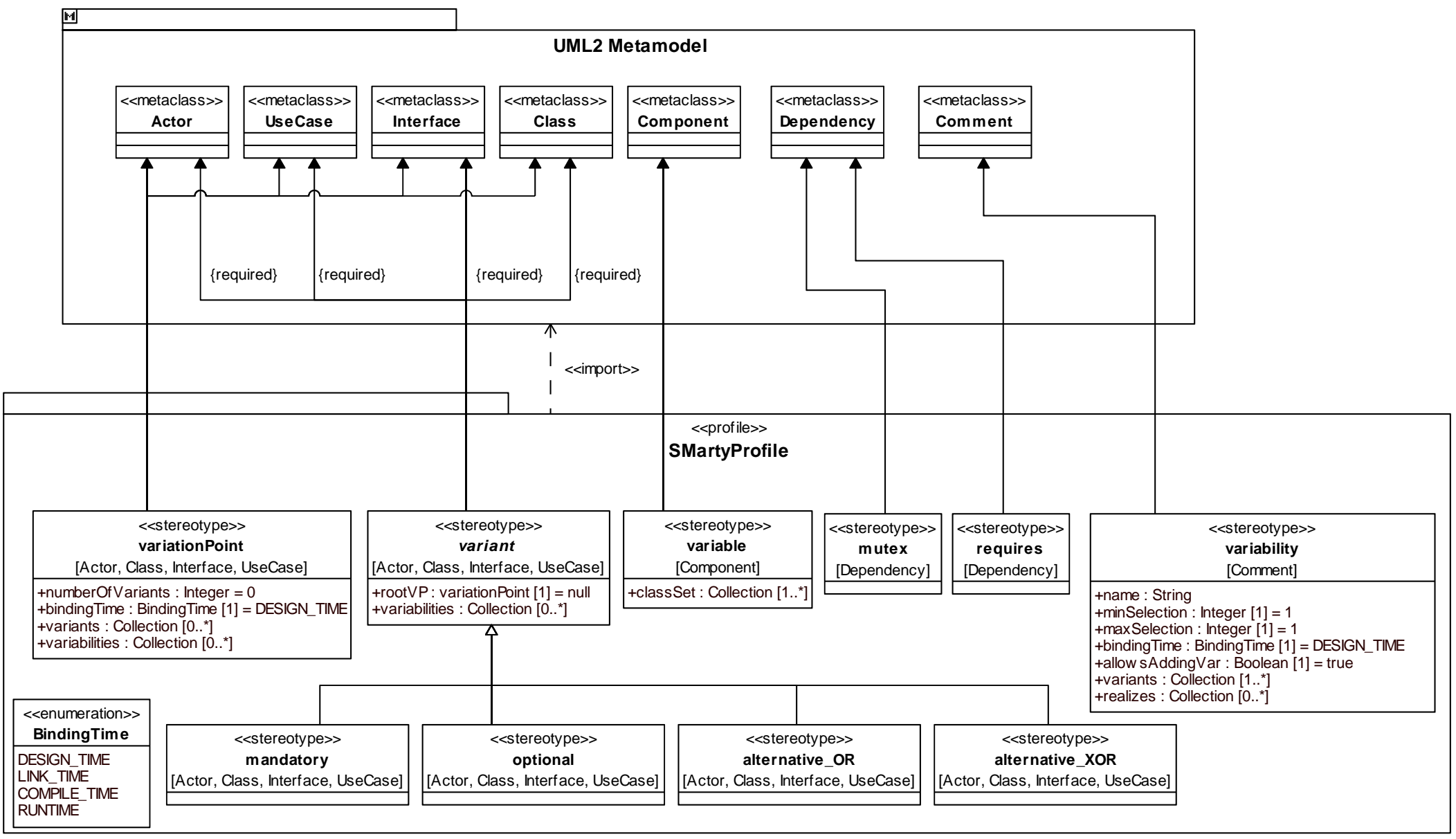

Figura 4.4: SMartyProfile para Gerenciamento de Variabilidade em Linhas de Produto de Software Baseadas em UML. 
- «variability» representa o conceito Variabilidade e é uma extensão da metaclasse UML Comment. Isso significa que esse estereótipo pode ser aplicado somente em notas UML. Esse possui os seguintes meta-atributos:

- name, o nome pelo qual uma variabilidade é referenciada;

- minSelection, representa o número mínimo de variantes a serem selecionadas para resolver um ponto de variação ou variabilidade;

- maxSelection, representa o número máximo de variantes a serem selecionadas para resolver um ponto de variação ou variabilidade;

- bindingTime, é o momento no qual uma variabilidade deve ser resolvida. Esse tempo é representado pela classe de enumeração BindingTime;

- allowsAdding Var, indica se é possível incluir novas variantes após uma variabilidade ser resolvida;

- variants, representa a coleção de instâncias associada à variabilidade; e

- realizes, representa a coleção de variabilidades de modelos de menor nível que realiza a variabilidade.

Por exemplo, a Figura 4.2 possui três variabilidades nomeadas: sort elements, sort algorithms e sort elements spec. type. Cada uma delas apresenta os valores de seus meta-atributos.

- 《variationPoint》 representa o conceito Ponto de Variação e é uma extensão das metaclasses UML Actor, UseCase, Interface e Class. Isso significa que esse estereótipo pode ser aplicado somente a atores, casos de uso, interfaces e classes. Esse estereótipo possui os seguintes meta-atributos:

- numberOfVariants, indica o número de variantes associadas que podem ser selecionadas para resolver esse ponto de variação;

- bindingTime, o momento no qual um ponto de variação deve ser resolvido. Esse tempo é respresentado pela classe de enumeração BindingTime;

- variants, representa a coleção de instâncias das variantes associadas a esse ponto de variação; e

- variabilities, representa a coleção de variabilidades com as quais esse ponto de variação está associado. 
Por exemplo, a Figura 4.3 possui cinco pontos de variação representados pelas classes /interfaces: AlgoritmoOrdenacao, OrdenacaoPorSelecao, OrdenacaoPorTroca, OrdenacaoPorInsercao e ElementoOrdenacao.

- «variant $\gg$ representa o conceito Variante e é uma extensão abstrata das metaclasses UML Actor, UseCase, Interface e Class. Por ser abstrato, esse estereótipo não pode ser aplicado em nenhum elemento UML, porém, suas especializações não abstratas podem ser aplicadas em atores, casos de uso, interfaces e classes.

Esse estereótipo é especializado em outros quatro estereótipos não abstratos, sendo eles: «mandatory $\gg, \ll$ optional $\gg, \ll$ alternative_OR $\gg$ e $\ll$ alternative_XOR $\gg$. O estereótipo «variant》 possui os seguintes meta-atributos:

- root $\boldsymbol{V P}$, representa o ponto de variação ao qual está associado; e

- variabilities, que é a coleção de variabilidades com as quais esta variante está associada.

- «mandatory» representa uma variante obrigatória que está presente em todos os produtos de uma LP. Por exemplo, na Figura 4.2, o caso de uso Ordenar Elementos é obrigatório;

- «optional» representa uma variante que pode ser escolhida para resolver uma variabilidade ou um ponto de variação;

- 《alternative_OR $\gg$ representa uma variante que faz parte de um grupo de variantes inclusivas. Diferentes combinações das variantes inclusivas podem resolver pontos de variação de diferentes maneiras, gerando assim, produtos distintos. Na Figura 4.3, a classe abstrata OrdenacaoPorTroca e as classes concretas BubbleSort e QuickSort são exemplos de variantes inclusivas;

- «alternative_XOR» representa uma variante que faz parte de um grupo de variantes exclusivas. Isso significa que apenas uma variante do grupo pode ser selecionada para resolver um ponto de variação;

- «mutex》 representa o conceito de restrição "Exclusão Mútua" e é um relacionamento mutuamente exclusivo entre variantes. Isso significa que para uma variante ser selecionada, a variante relacionada não pode ser selecionada;

- «requires» representa o conceito de restrição "Complemento" e é um relacionamento entre variantes, no qual a variante escolhida requer a escolha da variante relacionada; 
- «variable» é uma extensão da metaclasse UML Component. Este estereótipo indica que um componente é formado por um conjunto de classes com variabilidades explícitas. Este estereótipo possui o meta-atributo classSet, que é a coleção de instâncias das classes variáveis que formam o componente.

Todas as instâncias de casos de uso, atores, interfaces e classes devem ser marcadas com um dos estereótipos especializados de «variant». Porém, existe um caso especial no qual uma variante pode também ser marcada como «variationPoint». Por exemplo, na Figura 4.2, o caso de uso Ordenar com Algoritmo Específico é uma variante inclusiva do ponto de variação Ordenar Elementos; e também é um ponto de variação para as suas variantes Ordenação por Seleção, Ordenação por Inserção e Ordenação por Troca. Se Ordenar com um Tipo Específico é selecionado, então deve ser resolvido como um ponto de variação, por meio da seleção de suas variantes. Caso contrário, deve ser descartado juntamente com as suas variantes.

\subsubsection{SMartyProfile e Outras Abordagens de Representação de Variabilidade}

Nesta seção é apresentada uma comparação da abordagem SMarty, especificamente a representação de variabilidades, usando o perfil SMartyProfile, com duas abordagens de representação de variabilidade bastante difundidas na literatura: Halmans e Pohl (2003) e PLUS (Gomaa, 2005).

Halmans e Pohl (2003) estendem o metamodelo padrão da UML adicionando o estereótipo «variant» para representar variantes de LP, assim como faz o SMartyProfile. Eles afirmam que a representação de pontos de variação em diagramas de casos de uso não é possível e, para tanto, propõem a notação em triângulo, como mostra a Figura 4.5 .

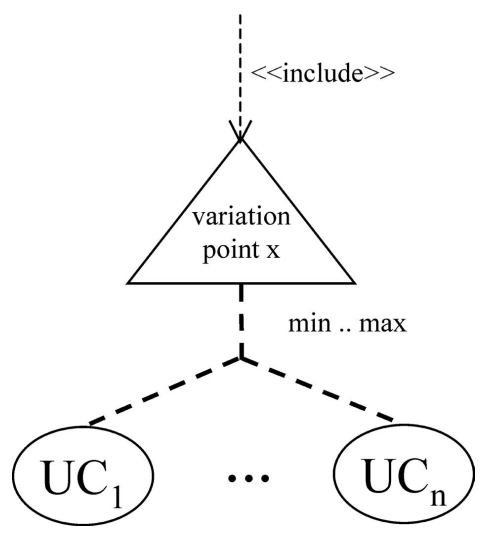

Figura 4.5: Representação de Pontos de Variação Usando a Notação em Triângulo (Halmans e Pohl, 2003). 
Na Figura 4.5, a relação entre um ponto de variação e as suas variantes é representada por meio de um triângulo, nomeado (variation point $x$ ), incluído por um caso de uso, que é um ponto de variação e relacionado a um conjunto de casos de uso variantes $\left\{\mathrm{UC}_{1}, \mathrm{UC}_{2}, \ldots\right.$, $\left.\mathrm{UC}_{n}\right\}$. Os casos de uso variantes são marcados com o estereótipo «variant》. Variantes inclusivas são indicadas por um círculo cinza junto ao triângulo, enquanto um círculo preto indica obrigatoriedade. A cardinalidade é indicada na relação entre o triângulo e os seus casos de uso variantes na forma min..max.

A Figura 4.6 apresenta uma parte de um Sistema de Reserva de Vôo segundo a abordagem de Halmans e Pohl (2003). Nesta figura, o ator User é um ponto de variação obrigatório que possui duas variantes associadas: o ator Customer (obrigatório) e o ator Card reader (opcional). Booking a flight é um ponto de variação e está relacionado às suas variantes inclusivas Booking by airline comp. e Booking by travel agency. Para resolver o ponto de variação, no mínimo zero e no máximo duas variantes $(0 . .2)$ devem ser selecionadas. Os demais casos de uso são obrigatórios e não são marcados.

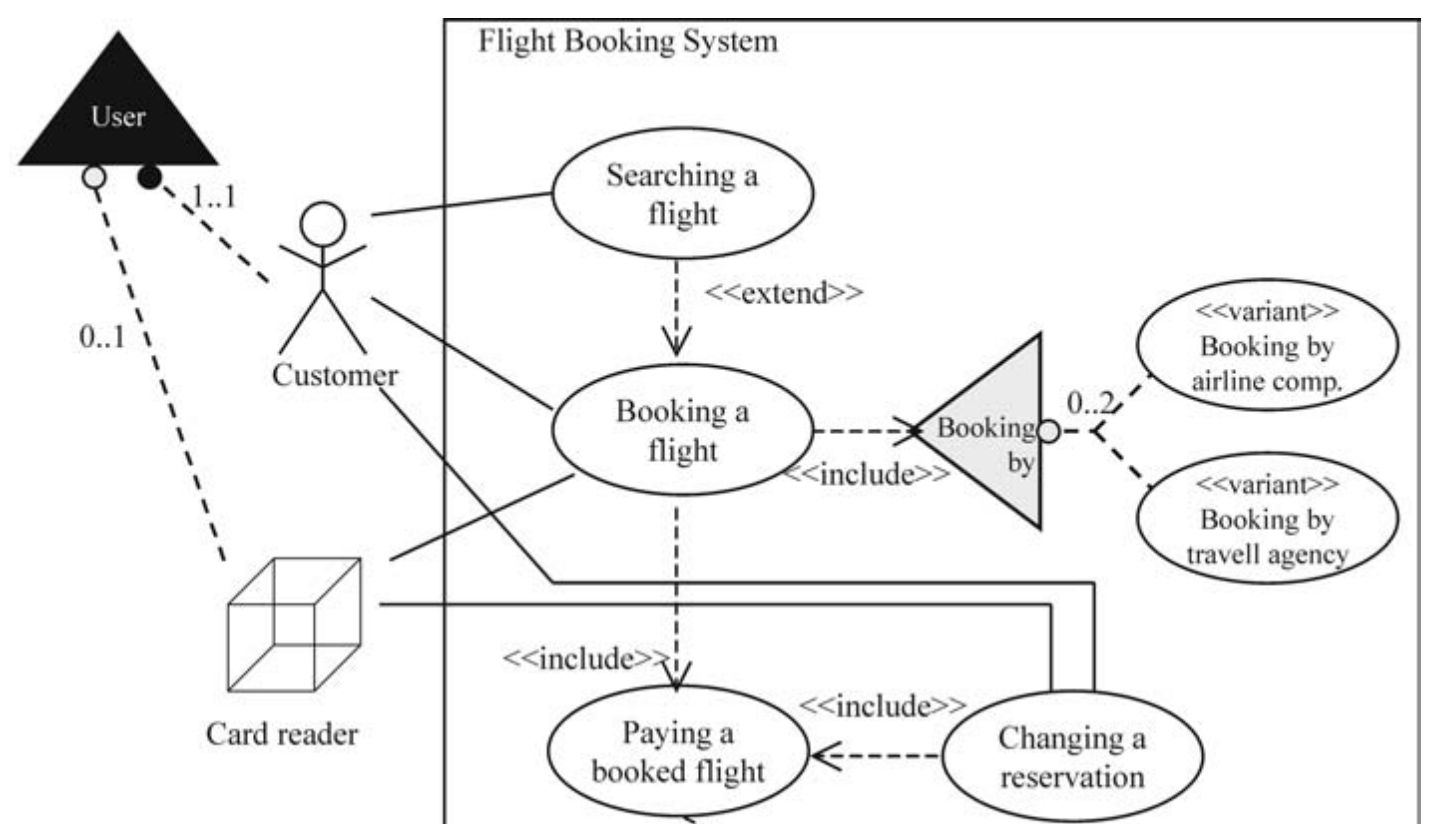

Figura 4.6: Sistema de Reserva de Vôo de Acordo com a Abordagem de Halmans e Pohl (2003).

Na notação em triângulo, o estereótipo «variant》 não indica o tipo de variante que está sendo tratada. Por exemplo, o caso de uso Booking by airline comp. poderia ser uma variante opcional, inclusiva ou exclusiva. No perfil SMartyProfile, «variant» é um estereótipo abstrato que é especializado pelos estereótipos «optional», «mandatory», «alternative_OR e «alternative_XOR》. Dessa forma, tais estereótipos tornam a 
modelagem de variantes explícita em casos de uso. Além disso, os quatro estereótipos herdam meta-atributos do estereótipo abstrato.

Por outro lado, o SMartyProfile usa o estereótipo «variationPoint》 para representar um ponto de variação em casos de uso, atores, classes e interfaces. Um ponto de variação está relacionado a uma nota UML, marcada com o estereótipo «variability» representando uma variabilidade. A nota UML contém todos os meta-atributos do estereótipo «variability» e seus valores, representando informações essenciais para a resolução de variabilidades.

Apesar da notação em triângulo ser uma notação interessante para pontos de variação, ela não faz parte do metamodelo da UML e, conseqüentemente, não é apoiada por ferramentas automatizadas que manipulam arquivos XML Metadata Interchange (XMI) contendo modelos UML. O perfil SMartyProfile se beneficia do conceito de pontos de extensão em casos de uso, para representar as relações entre pontos de variação e suas variantes. Além disso, a cardinalidade das variantes é representada na forma de um meta-atributo. Isso torna a representação de variabilidades totalmente compatível com os metamodelos da UML, sendo assim, apoiada por ferramentas de modelagem UML. A Figura 4.7 apresenta o modelo de casos de uso equivalente ao modelo de casos de uso do Sistema de Reserva de Vôo, ilustrado na Figura 4.6 e modelado de acordo com o SMartyProfile.

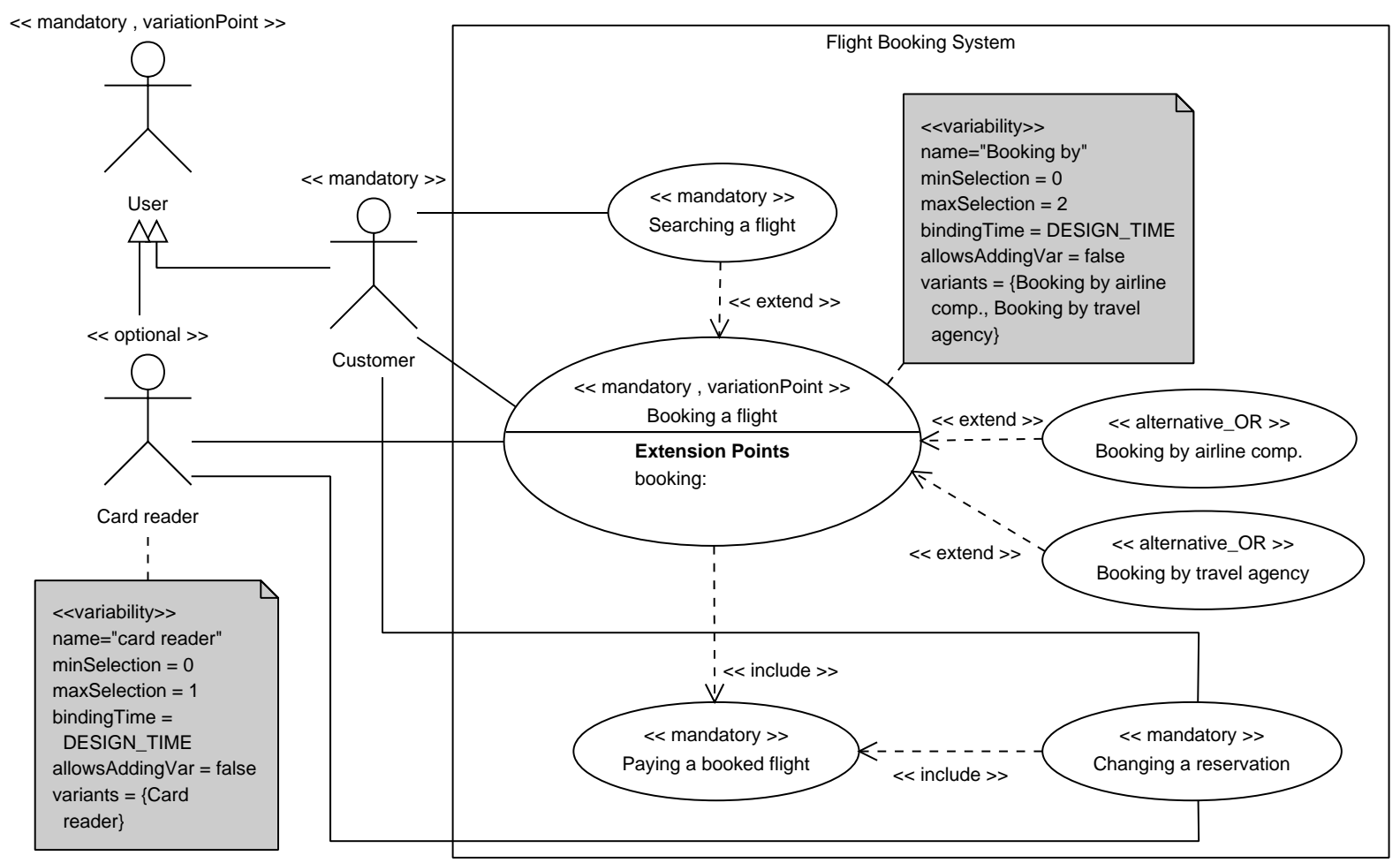

Figura 4.7: Sistema de Reserva de Vôo Segundo o Perfil SMartyProfile. 
Comparando a Figura 4.7 com a Figura 4.6 pode-se perceber que, além da primeira ser totalmente compatível com o metamodelo padrão da UML, fica evidente o tipo de relacionamento entre pontos de variação e variantes, suas cardinalidades e os valores dos meta-atributos de variabilidades. Dessa forma, a aplicação do SMartyProfile no modelo da Figura 4.6 não exigiu nenhuma mudança na estrutura de tal modelo e, ainda, possibilitou o uso da notação UML para pontos de extensão de forma apropriada. Ferramentas que apóiam os metamodelos UML podem identificar pontos de variação e variantes, bem como, automatizar o processo de resolução de variabilidades de acordo com os valores dos seus meta-atributos.

Gomaa (2005) usa o conceito de pontos de extensão para representar pontos de variação e suas variantes, em diagramas de casos de uso, assim como faz o SMartyProfile. A Figura 4.8 apresenta um exemplo da representação PLUS para a característica Check Out Customer. Nessa figura o caso de uso Check Out Customer é um elemento obrigatório («kernel») e possui duas extensões opcionais («optional»): Pay by Credit Card e Pay by Debit Card. Tais extensões adicionam ações específicas ao caso de uso estendido por meio do seu ponto de extensão payment.

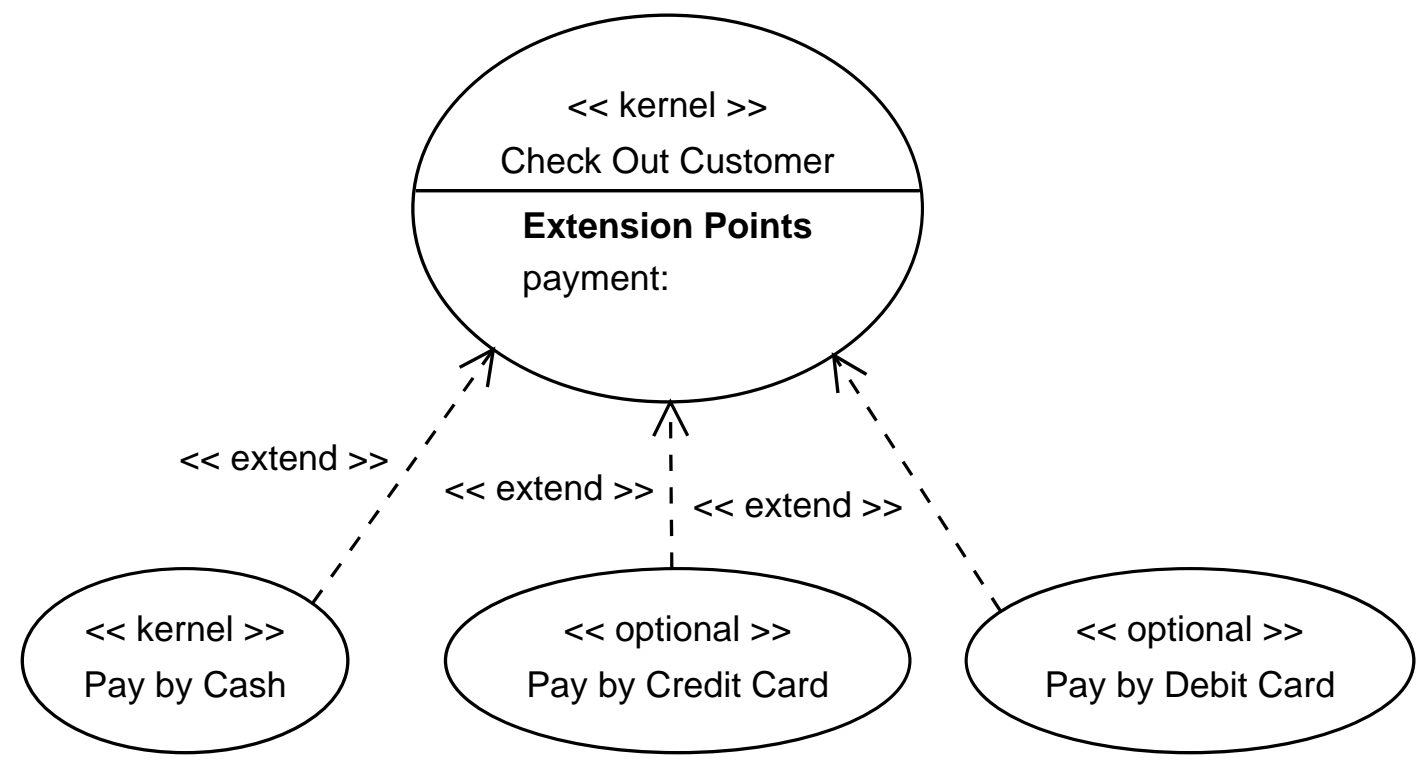

Figura 4.8: Característica "Check Out Customer" Segundo a Abordagem PLUS (Gomaa, 2005).

A representação de variabilidade proposta na abordagem PLUS é bastante similar à notação do SMartyProfile. Apesar da representação de acordo com a abordagem PLUS ser totalmente compatível com o metamodelo da UML, ela usa somente os estereótipos «kernel» e «optional» para representar variantes. Além disso, ela não representa 


\section{Capítulo 4. SMarty: Uma Abordagem UML para Gerenciamento de Variabilidade}

explicitamente pontos de variação por meio do uso de estereótipos, bem como, as informações com relação à resolução de pontos de variação, assim como faz o SMartyProfile. Por exemplo, um usuário poderia analisar a Figura 4.8 e questionar: em que momento a característica "Check Out Customer" deve ser resolvida? Ou, ainda, será que é possível adicionar outras variantes após resolver este ponto de variação? Assim, a Figura 4.9 apresenta a característica "Check Out Customer" de acordo com o SMartyProfile.

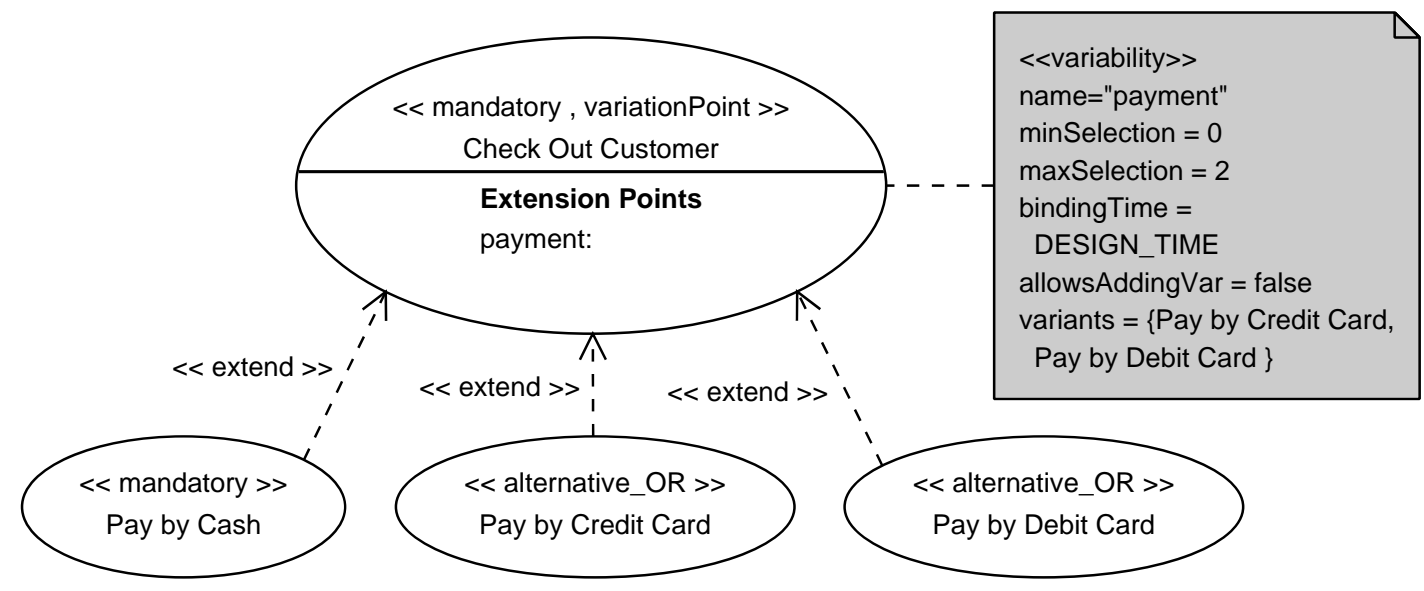

Figura 4.9: Característica "Check Out Customer" Segundo o SMartyProfile.

Pode-se identificar na Figura 4.9 qual caso de uso é um ponto de variação e as suas informações representadas na variabilidade associada, bem como, os casos de uso que são obrigatórios ou inclusivos. Além disso, o ponto de variação Check Out Customer é resolvido em tempo de projeto (DESIGN_TIME) e não permite a adição de novas variantes.

A Tabela 4.1 apresenta um resumo comparativo das três abordagens com relação aos principais conceitos de variabilidades consideradas pela abordagem SMarty.

Essas comparações fornecem indícios da abordagem SMarty com relação à sua efetividade de representação e gerenciamento de variabilidades. Contudo, entende-se que uma abordagem experimental mais ampla deve ser considerada para que seja possível comprovar tal efetividade. 
Tabela 4.1: Comparação das Abordagens com Relação aos Principais Conceitos de Variabilidade.

\begin{tabular}{|c|c|c|c|c|c|}
\hline \multirow{2}{*}{\multicolumn{3}{|c|}{ Conceitos }} & \multicolumn{3}{|c|}{ Abordagens } \\
\hline & & & Halmans et al. & PLUS & SMarty (SMartyProfile) \\
\hline \multirow{2}{*}{\multicolumn{2}{|c|}{ Ponto de Variação }} & Representação & Triângulo & $\begin{array}{l}\text { Caso de uso } \\
\text { estendido } \\
\text { (implícita) }\end{array}$ & $<<$ variationPoint $>>$ \\
\hline & & $\begin{array}{l}\text { Compatível } \\
\text { UML }\end{array}$ & & & \\
\hline \multirow{8}{*}{ Variante } & \multirow{2}{*}{ Obrigatória } & Representação & $\begin{array}{c}\text { Elementos sem } \\
\text { marcação }\end{array}$ & $<<$ kernel $>>$ & $<<$ mandatory $>>$ \\
\hline & & $\begin{array}{l}\text { Compatível } \\
\text { UML }\end{array}$ & & & \\
\hline & \multirow[b]{2}{*}{ Opcional } & Representação & \multirow{2}{*}{390} & $<<$ optional $>>$ & <<optional $>>$ \\
\hline & & $\begin{array}{l}\text { Compatível } \\
\text { UML }\end{array}$ & & & \\
\hline & \multirow{2}{*}{$\begin{array}{l}\text { Inclusiva } \\
\text { (OR) }\end{array}$} & Representação & $\begin{array}{c}<<\text { variant }>> \\
\text { Com círculo } \\
\text { cinza }\end{array}$ & \multirow{2}{*}{390} & <<alternative_OR $>>$ \\
\hline & & $\begin{array}{l}\text { Compatível } \\
\text { UML }\end{array}$ & & & \\
\hline & \multirow{2}{*}{$\begin{array}{c}\text { Exclusiva } \\
\text { (XOR) }\end{array}$} & Representação & $\begin{array}{c}<<\text { variant }>> \\
\text { Com círculo } \\
\text { preto }\end{array}$ & \multirow{2}{*}{390} & $<<$ alternative_XOR >> \\
\hline & & $\begin{array}{l}\text { Compatível } \\
\text { UML }\end{array}$ & & & \\
\hline \multirow{2}{*}{\multicolumn{2}{|c|}{ Variabilidade }} & Representação & \multirow{2}{*}{$39 \%$} & \multirow{2}{*}{ 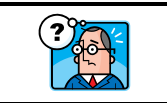 } & $<<$ variability $>>$ \\
\hline & & $\begin{array}{l}\text { Compatível } \\
\text { UML }\end{array}$ & & & \\
\hline \multirow{4}{*}{$\begin{array}{l}\text { Restrições } \\
\text { entre } \\
\text { Variantes }\end{array}$} & \multirow[b]{2}{*}{ Complemento } & Representação & \multirow{2}{*}{390} & \multirow{2}{*}{390} & $<<$ requires $>>$ \\
\hline & & $\begin{array}{l}\text { Compatível } \\
\text { UML }\end{array}$ & & & \\
\hline & \multirow{2}{*}{$\begin{array}{l}\text { Exclusão } \\
\text { Mútua }\end{array}$} & Representação & \multirow{2}{*}{390} & \multirow{2}{*}{ ?9: } & $<<$ mutex $>>$ \\
\hline & & $\begin{array}{l}\text { Compatível } \\
\text { UML }\end{array}$ & & & \\
\hline \multirow{2}{*}{\multicolumn{2}{|c|}{ Cardinalidade }} & Representação & $\begin{array}{c}\text { No triângulo } \\
0 . . n\end{array}$ & $\begin{array}{c}\text { Número de } \\
\text { casos de uso } \\
\text { que estendem }\end{array}$ & $\begin{array}{l}\text { Meta-atributo de } \\
<<\text { variability }>>\end{array}$ \\
\hline & & $\begin{array}{l}\text { Compatível } \\
\text { UML }\end{array}$ & & & (v) \\
\hline \multirow{2}{*}{\multicolumn{2}{|c|}{ Tempo de Resolução }} & Representação & \multirow{2}{*}{390} & \multirow[t]{2}{*}{300} & $\begin{array}{c}\text { Classe de Enumeração } \\
\text { BindingTime representado } \\
\text { por meta-atributo de } \\
<<\text { variability }>>\end{array}$ \\
\hline & & $\begin{array}{l}\text { Compatível } \\
\text { UML }\end{array}$ & & & (v) \\
\hline \multirow{2}{*}{\multicolumn{2}{|c|}{ Adição de Novas Variantes }} & Representação & \multirow{2}{*}{390} & \multirow{2}{*}{3} & $\begin{array}{c}\text { Meta-atributo de } \\
<<\text { variationPoint }>>>\end{array}$ \\
\hline & & $\begin{array}{l}\text { Compatível } \\
\text { UML }\end{array}$ & & & ( \\
\hline
\end{tabular}

Legenda:
(5) Possui representação e/ou é compatível com a UML.
D Não possui representação e/ou não é compatível com a UML.
3. Não é possível identificar representação e/ou compatibilidade com a UML.

\subsection{O Processo SMartyProcess}

As atividades do SMartyProcess estão diretamente relacionadas às atividades genéricas do processo de desenvolvimento de LP (Pohl et al., 2005, p. 19-38), (SEI, 2010a). 
A Figura 4.10 apresenta um diagrama de atividades da UML, ilustrando a interação entre o processo genérico de Desenvolvimento de Linha de Produto, representado pelas atividades verticalmente alinhadas no lado esquerdo e o SMartyProcess, representado pelas atividades dentro do retângulo à direita.

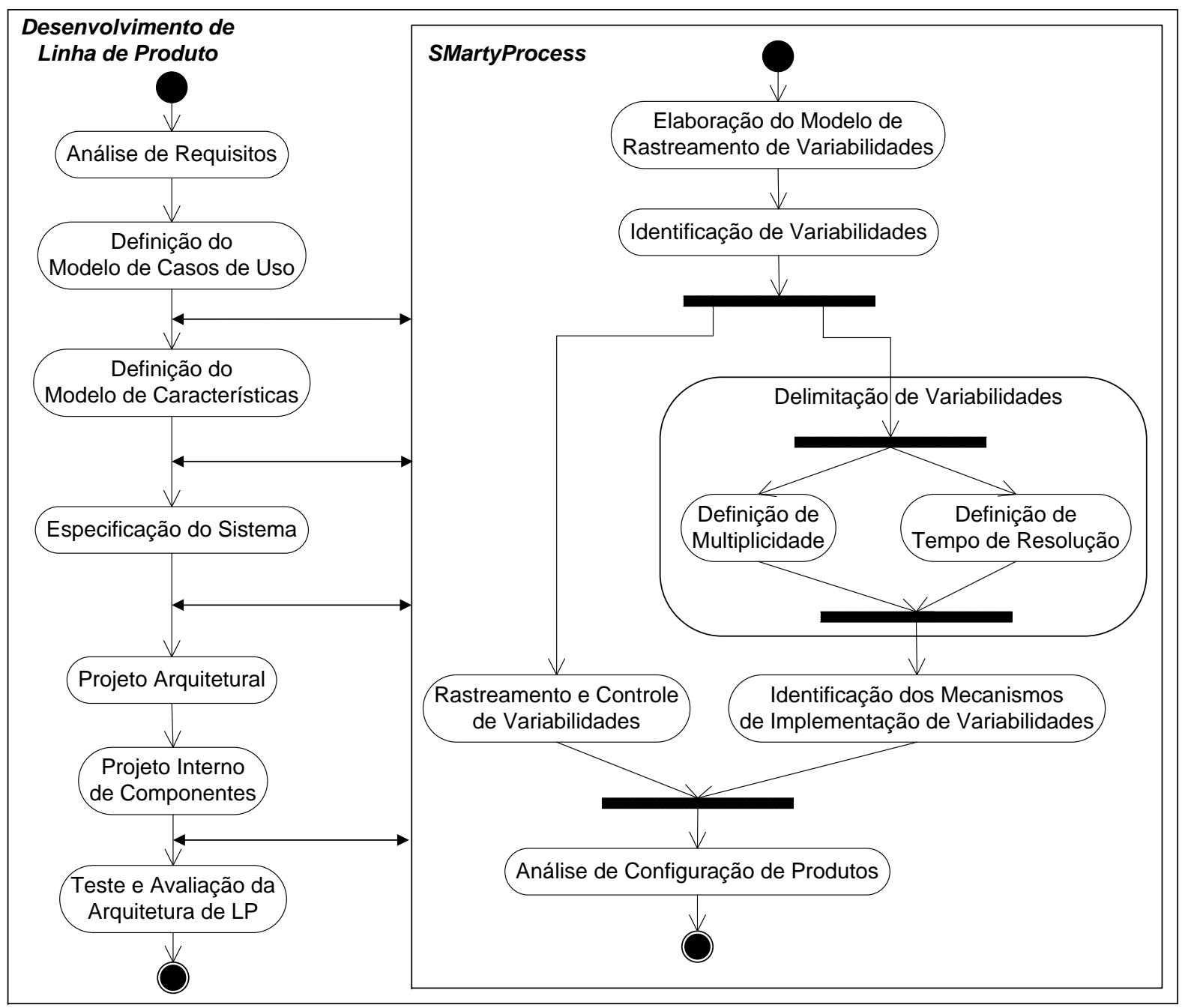

Figura 4.10: Interação entre as Atividades de Desenvolvimento de Linha de Produto e o SMartyProcess.

Oliveira Junior et al. (2005a) inicialmente propuseram um processo de gerenciamento de variabilidades, como prova de conceito, para a identificação de potenciais estereótipos e atividades com relação ao gerenciamento de variabilidades em LP. Nesta tese foram incorporadas definições formais a tais estereótipos por meio da proposta do SMartyProfile, bem como, da formalização da abordagem SMarty combinando o SMartyProfile e o SMartyProcess, em uma abordagem geral guiada por diretrizes para gerenciar sistematicamente variabilidades de LP. 
O processo SMartyProcess é realizado pelo engenheiro de LP e é iterativo e incremental, acontecendo em paralelo com o desenvolvimento de uma LP. Iterativo, pois após a execução de cada atividade do desenvolvimento de LP, o SMartyProcess progressivamente usa as saídas do desenvolvimento de LP como entradas para as suas atividades. Incremental, pois o número de variabilidades tende a crescer, à medida que as atividades do SMartyProcess são executadas. A Tabela 4.2 ilustra como as atividades, entradas e saídas do Desenvolvimento de Linha de Produto e do SMartyProcess estão relacionadas.

Tabela 4.2: Relacionamentos Entre Atividades, Entradas e Saídas do Desenvolvimento de Linha de Produto e do SMartyProcess.

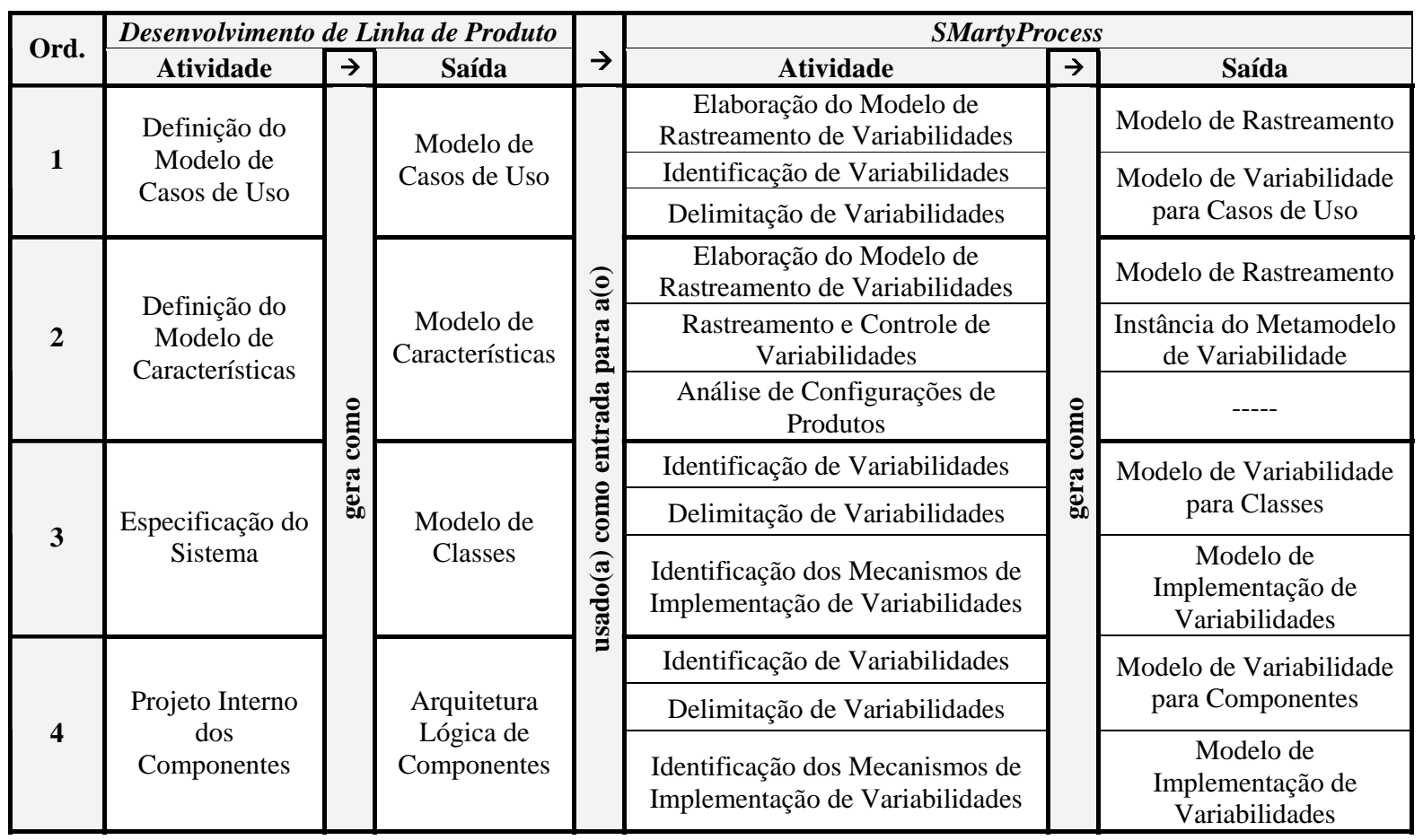

A leitura da Tabela 4.2 deve ser feita de acordo com o exemplo a seguir: na linha 1 a atividade de Definição do Modelo de Casos de Uso do Desenvolvimento de Linha de Produto gera como saída o Modelo de Casos de Uso que, então, é usado como entrada para a atividade de Identificação de Variabilidades que, por sua vez, gera como saída o Modelo de Variabilidade para Casos de Uso com as suas variabilidades identificadas e representadas graficamente.

Pelo fato do SMartyProcess ser iterativo, atualizações das variabilidades são permitidas a partir de qualquer uma de suas atividades. As atividades do SMartyProcess e suas respectivas entradas e saídas são apresentadas nas próximas seções. O SMartyProcess consome elementos do núcleo de artefatos de uma LP, bem como, o alimenta com outros. 
Os modelos de caso de uso e de classe, por exemplo, alimentam o SMartyProcess e retornam para o núcleo com as variabilidades identificadas e delimitadas. Alguns modelos como, por exemplo, os de rastreamento e implementação de variabilidades, são originados no SMartyProcess.

\subsubsection{Elaboração do Modelo de Rastreamento de Variabilidades}

Esta atividade recebe como entrada o modelo de casos de uso e o modelo de características, construídos no desenvolvimento de LP e tem como objetivo permitir que as variabilidades sejam rastreadas desde as características de uma LP, até os modelos de LP de mais baixo nível, como os de classes.

Assim, um modelo de rastreamento de variabilidade é construído de acordo com as seguintes diretrizes $(\mathrm{D})$ :

D.1.1 as características identificadas para uma LP são listadas;

D.1.2 os casos de uso identificados para uma LP são listados;

D.1.3 os relacionamentos entre características e casos de uso de uma LP são analisados; e

D.1.4 os inter-relacionamentos entre casos de uso e características são marcados com um "blob".

O modelo de rastreamento é apresentado de forma tabular. A característica Selection Sort é um exemplo de uma linha do modelo de rastreamento e está relacionada aos casos de uso (veja a Figura 4.2) Ordenar com Algoritmo Específico e Ordenação por Seleção. Assim, as colunas correspondentes do modelo são marcadas com um "•".

\subsubsection{Identificação de Variabilidades}

A cada interação entre o Desenvolvimento de LP e o SMartyProcess, a atividade de identificação de variabilidades recebe como entrada os modelos de características, casos de uso, classes e componentes. Esta atividade tem por objetivo identificar progressivamente as variabilidades associadas a esses modelos. O SMartyProfile apóia fortemente a realização da atividade de identificação de variabilidades, por meio da aplicação de seus estereótipos aos modelos UML e da definição dos valores dos meta-atributos.

A identificação de variabilidades é uma atividade que depende do domínio, o que exige habilidades dos gerentes e analistas de LP. Assim, algumas diretrizes são fornecidas como apoio à essa atividade, sendo elas: 
D.2.1 elementos de modelos de casos de uso relacionados aos mecanismos de extensão e de pontos de extensão円 (UML, 2010) sugerem pontos de variação com variantes associadas, as quais podem ser inclusivas ou exclusivas. Assim, os casos de uso estendidos representam pontos de variação, enquanto os casos de uso que estendem, representam variantes. Na Figura 4.2, por exemplo, os casos de uso Ordenar com Algoritmo Específico e Ordenar Elementos de um Tipo Específico representam variantes inclusivas associadas ao ponto de variação Ordenar Elementos (caso de uso estendido);

D.2.2 em modelos de classes, pontos de variação e suas variantes são identificadas nos seguintes relacionamentos (UML, 2010):

a) generalização, os classificadores mais gerais são os pontos de variação, enquanto os mais específicos são as variantes;

b) realização de interface, os "suppliers" (especificações) são os pontos de variação e as implementações (clientes) são as variantes;

c) agregação, as instâncias tipadas com losângulos não preenchidos são os pontos de variação e as instâncias associadas são as variantes; e

d) composição, as instâncias tipadas com losângulos preenchidos são os pontos de variação e as instâncias associadas são as variantes.

D.2.3 elementos de modelos de casos de uso relacionados com a associação de inclusão (《include») ou associados a atores (UML, 2010) sugerem variantes obrigatórias ou opcionais;

D.2.4 elementos de modelos de classes, relacionados à associações nas quais os seus atributos aggregationKind possuem valor none (UML, 2010), ou seja, não representam nem agregação nem composição, sugerem variantes obrigatórias ou opcionais. Na Figura 4.3. a classe ProgramaPrincipalOrdenacao é um exemplo de variante obrigatória;

D.2.5 variantes que, ao serem selecionadas para fazer parte de um produto, exigem a presença de outra(s) determinada(s) variante(s) devem ter seus relacionamentos de dependência marcados com o estereótipo «requires》;

D.2.6 variantes mutuamente exclusivas para um determinado produto devem ter seus relacionamentos de dependência marcados com o estereótipo «mutex》; e

\footnotetext{
${ }^{1} \mathrm{Na}$ abordagem SMarty, a generalização de casos de uso não é usada para representar pontos de variação, uma vez que não adicionam ações específicas a partir de casos de uso especializados, como a relação de extensão o faz (Bragança e Machado, 2006, UML, 2010).
} 
D.2.7 componentes formados por classes com variabilidades são marcados com o estereótipo $\ll$ variable».

\subsubsection{Delimitação de Variabilidades}

Esta atividade tem como objetivo definir os valores dos seguintes meta-atributos de uma variabilidade: minSelection, maxSelection, bindingTime, allowsAddingVar e variants.

Para tanto, as seguintes diretrizes devem ser seguidas:

D.3.1 variabilidades com variantes opcionais possuem multiplicidade minSelection $=0$ e maxSelection $=1$;

D.3.2 variabilidades com variantes exclusivas possuem multiplicidade minSelection = maxSelection $=1$;

D.3.3 variabilidades com variantes inclusivas possuem multiplicidade minSelection $=1 \mathrm{e}$ maxSelection $=$ size(variants) em que size (x) é uma função que retorna a quantidade de elementos da coleção $x$;

D.3.4 o valor de binding Time deve ser definido escolhendo-se um dos valores da classe de enumeração Binding Time da Figura 4.4,

D.3.5 o valor booleano do atributo allowsAddingVar deve ser analisado de acordo com a possibilidade de manter o ponto de variação aberto (true) ou fechado (false); e

D.3.6 o valor da coleção variants é o conjunto formado pelas instâncias das variantes associadas ao ponto de variação ou variabilidade.

A definição do tempo de resolução é essencial para determinar o mecanismo de implementação de variabilidades.

Na Figura 4.2, por exemplo, a variabilidade sort algorithms é delimitada como minSelection $=1$, maxSelection $=3$, bindingTime $=$ DESIGN_TIME, não permitindo a adição de novas variantes após o ponto de variação (Ordenar com Algoritmo Específico) ser resolvido.

\subsubsection{Identificação de Mecanismos de Implementação de Variabili- dade}

Esta atividade tem como objetivo permitir a escolha dos mecanismos a serem usados para implementar variabilidades. As entradas são os modelos de classe e componente, com as 
suas respectivas variabilidades representadas e delimitadas como resultado das atividades anteriores. A saída desta atividade é um modelo de implementação representado na forma de uma tabela. Cada linha da tabela indica o nome de uma variabilidade, o elemento no qual ocorre, o tempo de resolução, o mecanismo de implementação e uma estratégia de implementação. O modelo baseia-se nas técnicas de implementação de variabilidades propostas por Jacobson et al. (1997) e Svahnberg et al. (2005), mas não está restrito somente a estas. Dentre estas técnicas propostas por Jacobson et al. e Svahnberg et al. é possível citar: generalização, extensão e parametrização.

Para tanto, sugerem-se as seguintes diretrizes:

D.4.1 listar as variabilidades que ocorrem em classes ou componentes;

D.4.2 verificar se é permitido adicionar novas variantes após o ponto de variação ser resolvido, bem como, o seu tempo de resolução e selecionar os mecanismos de implementação mais apropriadas; e

D.4.3 para cada mecanismo escolhido, definir uma ou mais estratégias de implementação de variabilidade.

A Tabela 4.3 apresenta uma parte do modelo de implementação para a característica "Ordenação de Elementos" da Figura 4.3 .

Tabela 4.3: Exemplo de Modelo de Implementação para a Característica "Ordenação de Elementos".

\begin{tabular}{|c|c|c|c|c|}
\hline Variabilidade & Classe/Componente & Tempo de Resolução & Mecanismo & Estratégia \\
\hline sort insertion & OrdenacaoPorInsercao & $\begin{array}{c}\text { Projeto } \\
\text { (DESIGN_TIME) }\end{array}$ & $\begin{array}{c}\text { Variant Class } \\
\text { Specialization }\end{array}$ & $\begin{array}{c}\text { Padrão de Projeto } \\
\text { Template }\end{array}$ \\
\hline sorting element & ElementoOrdenacao & $\begin{array}{c}\text { Projeto } \\
\text { (DESIGN_TIME) }\end{array}$ & $\begin{array}{c}\text { Arquivo de } \\
\text { Propriedades }\end{array}$ & Parametrização \\
\hline
\end{tabular}

A primeira linha se refere à variabilidade chamada sort insertion, relacionada à classe OrdenacaoPorInsercao, resolvida em tempo de projeto, utilizando o mecanismo Variant Class Specialization (Svahnberg et al., 2005) que pode ser implementado por meio do padrão de projeto Template (Gamma et al., 1995).

\subsubsection{Rastreamento e Controle de Variabilidades}

O rastreamento e controle de variabilidades está baseado em um metamodelo de variabilidade, para descrever os relacionamentos entre artefatos variantes de uma LP e seus pontos 
de variação, variantes, tempo de resolução e mecanismos de implementação. Aliado ao modelo de rastreamento, esse metamodelo permite a associação de características com os casos de uso relacionados e, assim, com elementos de modelos de classe e componente. A execução dessa atividade consiste na instanciação do metamodelo para uma LP.

A Figura 4.11 apresenta o metamodelo de variabilidade. A instanciação deste metamodelo deve ser feita por uma ferramenta automatizada, de apoio ao gerenciamento de variabilidades e metamodelos UML.

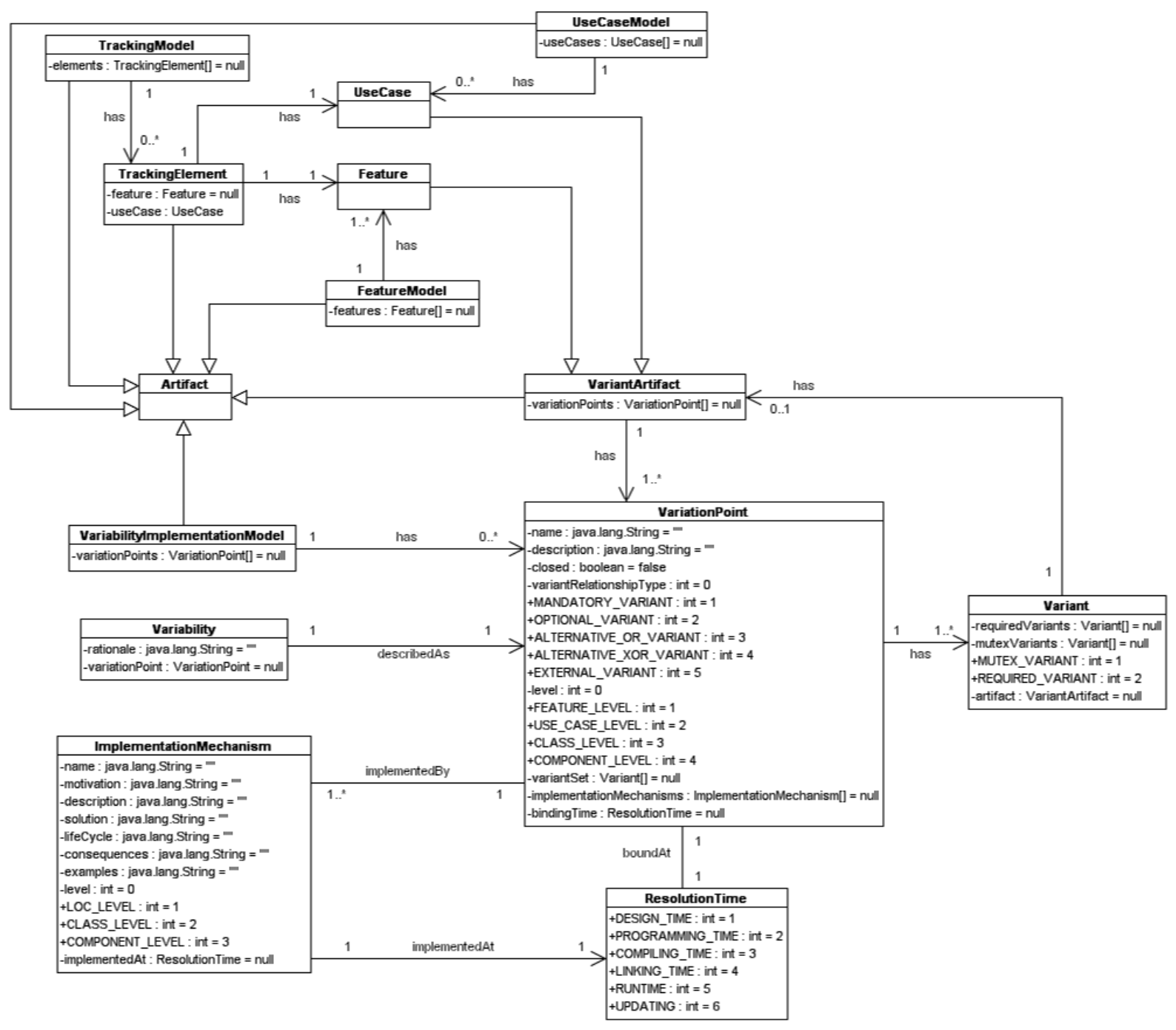

Figura 4.11: Metamodelo de Variabilidade Usado para Rastrear e Controlar Variabilidades.

\subsubsection{Análise de Configuração de Produtos}

A análise de configuração de produtos visa investigar o impacto da seleção de possíveis características de uma LP com o objetivo de analisar a viabilidade de produção de 
produtos específicos. A seleção de uma característica pode implicar na seleção de uma configuração de produto de acordo com pontos de variação descritos. Além disso, se um produto requer uma característica adicional, a introdução dessa característica deve ser analisada nos artefatos da LP.

Algumas ferramentas existentes apóiam a realização da análise de configuração de produtos, dentre elas, destaca-se a Software Product Line Online Tools (SPLOT) (Mendonça et al., 2009; SPLOT, 2010) que é um ambiente Web composto de um editor (Feature Model Editor) para a construção e depuração de modelos de características e um módulo automatizado de análise de modelos de características que informa, por exemplo, a quantidade de características de um modelo, as características comuns e variáveis, além de métricas relacionadas às variabilidades. A SPLOT ainda possui outros recursos interessantes como, por exemplo, um configurador de produtos que pode ser facilmente utilizado para apoiar esta atividade.

\subsection{Exemplo de Aplicação da Abordagem SMarty}

Esta seção apresenta como a LP AGM (Apêndice A) é modelada de acordo com a abordagem SMarty. A AGM também é utilizada para ilustrar o método SystEM-PLA no Capítulo 5 .

Para mostrar como a abordagem SMarty pode ser aplicada, os itens a seguir apresentam cada uma das atividades do SMartyProcess realizadas e os seus artefatos resultantes:

- Elaboração do Modelo de Rastreamento: para realizar esta atividade foram considerados como entrada os modelos de características e de casos de uso das figuras A.1 e A.2, produzindo como saída o modelo de rastreamento da Tabela 4.4. Como é possível notar nessa tabela, as características e casos de uso da AGM foram listados segundo as diretrizes D.1.1 e D.1.2, respectivamente, e suas inter-relações foram analisadas (diretriz D.1.3) e marcadas (diretriz D.1.4).

Por exemplo, a característica save está relacionada aos casos de uso Save Score e Save Game. O modelo de rastreamento permite, dessa forma, rastrear, a partir da característica save os seus casos de uso relacionados, enquanto operações de seleção de características, são realizadas durante as atividades de engenharia de aplicação da LP AGM. Assim, se a característica save for, por exemplo, removida de um determinado jogo, os casos de uso relacionados a ela também devem ser removidos. 
Tabela 4.4: Modelo de Rastreamento da LP AGM.

\begin{tabular}{|c|c|c|c|c|c|c|c|c|c|}
\hline \multirow{3}{*}{ Casos de Uso } & \multicolumn{9}{|c|}{ Características } \\
\hline & \multicolumn{3}{|c|}{ services } & \multicolumn{3}{|c|}{ rules } & \multicolumn{2}{|c|}{ action } & \multirow{2}{*}{ configuration } \\
\hline & play & pause & save & Brickles & Pong & Bowling & movement & collision & \\
\hline $\begin{array}{c}\text { Check Previous } \\
\text { Best Score }\end{array}$ & & $\bullet$ & & & & & & & \\
\hline Save Score & & & $\bullet$ & & & & & & \\
\hline Install Game & & & & & & & & & $\bullet$ \\
\hline Save Game & & & $\bullet$ & & & & & & \\
\hline Exit Game & & $\bullet$ & & & & & & & \\
\hline $\begin{array}{l}\text { Play Selected } \\
\text { Game }\end{array}$ & - & & & - & - & • & & & \\
\hline Uninstall Game & & & & & & & & & $\bullet$ \\
\hline Play Brickles & $\bullet$ & & & $\bullet$ & & & & & \\
\hline Play Pong & $\bullet$ & & & & $\bullet$ & & & & \\
\hline Play Bowling & $\bullet$ & & & & & $\bullet$ & & & \\
\hline Initialization & & & & & & & $\bullet$ & $\bullet$ & \\
\hline Animation Loop & & & & & & & - & - & \\
\hline
\end{tabular}

- Identificação e Delimitação de Variabilidades: seguindo as diretrizes para identificação (D.2.1 a D.2.7) e delimitação (D.3.1 a D.3.7) de variabilidades, foi possível gerar os modelos de variabilidade com base nos modelos de casos de uso e de classes da AGM.

Modelo de Variabilidade para Casos de Uso: para gerar o modelo da Figura 4.12, as seguintes diretrizes foram consideradas: 


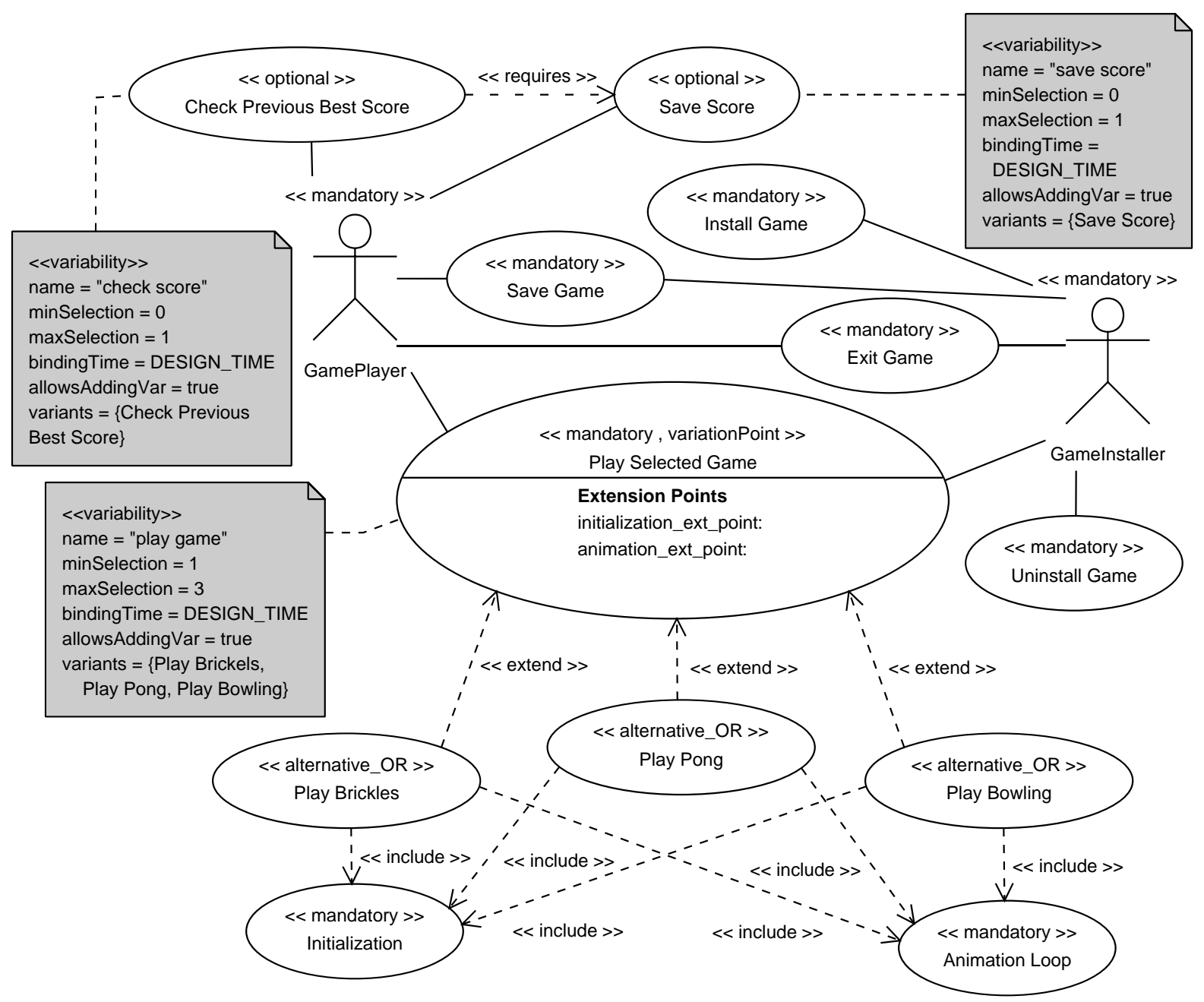

Figura 4.12: Modelo de Variabilidade para Casos de Uso da AGM de Acordo com SMarty.

- os casos de uso Play Brickles, Play Pong e Play Bowling estão relacionados ao caso de uso Play Selected Game, por meio da relação de extensão e pontos de extensão. Assim, a diretriz D.2.1 sugere que:

* o caso de uso Play Selected Game seja um ponto de variação; e

* os casos de uso Play Brickles, Play Pong e Play Bowling sejam variantes inclusivas, pois um ambiente AGM pode conter qualquer combinação de um, dois ou três jogos.

- os casos de uso Check Previous Best Score, Save Score, Save Game, Install Game, Exit Game e Uninstall Game estão relacionados diretamente com atores e, portanto, a diretriz D.2.3 sugere que sejam variantes obrigatórias ou opcionais. Dessa forma, os dois primeiros casos de uso foram modelados 
como sendo opcionais, já que um produto AGM pode não disponibilizar tais funcionalidades, enquanto os demais foram modelados como obrigatórios.

- os casos de uso Initialization e Animation Loop estão relacionados com os casos de uso Play Brickles, Play Pong e Play Bowling por meio de inclusão e, dessa forma, segundo a diretriz D.2.3 foram modelados como obrigatórios.

- as variabilidades nomeadas check score e save score possuem multiplicidades minSelection $=0$ e maxSelection $=1$. Isso significa que as suas variantes opcionais associadas podem ou não fazer parte de um produto AGM. Para estas variabilidades o tempo de resolução escolhido, segundo a diretriz D.3.4, foi DESIGN_TIME. Além disso, as variabilidades foram mantidas fechadas, não permitindo a adição de novas variantes, segundo a diretriz D.3.5. O conjunto de variantes da variabilidade check score é \{Check Previous Best Score\}, enquanto o da variabilidade save score é $\{$ Save Score\}, segundo a diretriz D.3.6.

- a variabilidade nomeada play game possui multiplicidade minSelection $=1$ e maxSelection $=3$. Isso significa que no mínimo uma e no máximo três das suas variantes inclusivas associadas devem ser escolhidas para um produto AGM. Para esta variabilidade o tempo de resolução escolhido segundo a diretriz D.3.4 foi DESIGN_TIME. Além disso, a variabilidade foi mantida fechada não permitindo a adição de novas variantes segundo a diretriz D.3.5. O conjunto de variantes da variabilidade play game é \{Play Brickles, Play Pong, Play Bowling\} segundo a diretriz D.3.6.

- o caso de uso Check Previous Best Score, ao ser selecionado para um produto AGM, exige a presença do caso de uso Save Score, assim, a dependência entre ambos foi marcada com o estereótipo «requires», segundo a diretriz D.2.5.

Modelo de Variabilidade para Classes: para gerar o modelo da Figura 4.13, as seguintes diretrizes foram aplicadas ao modelo de classes da AGM (Figura A.3): 


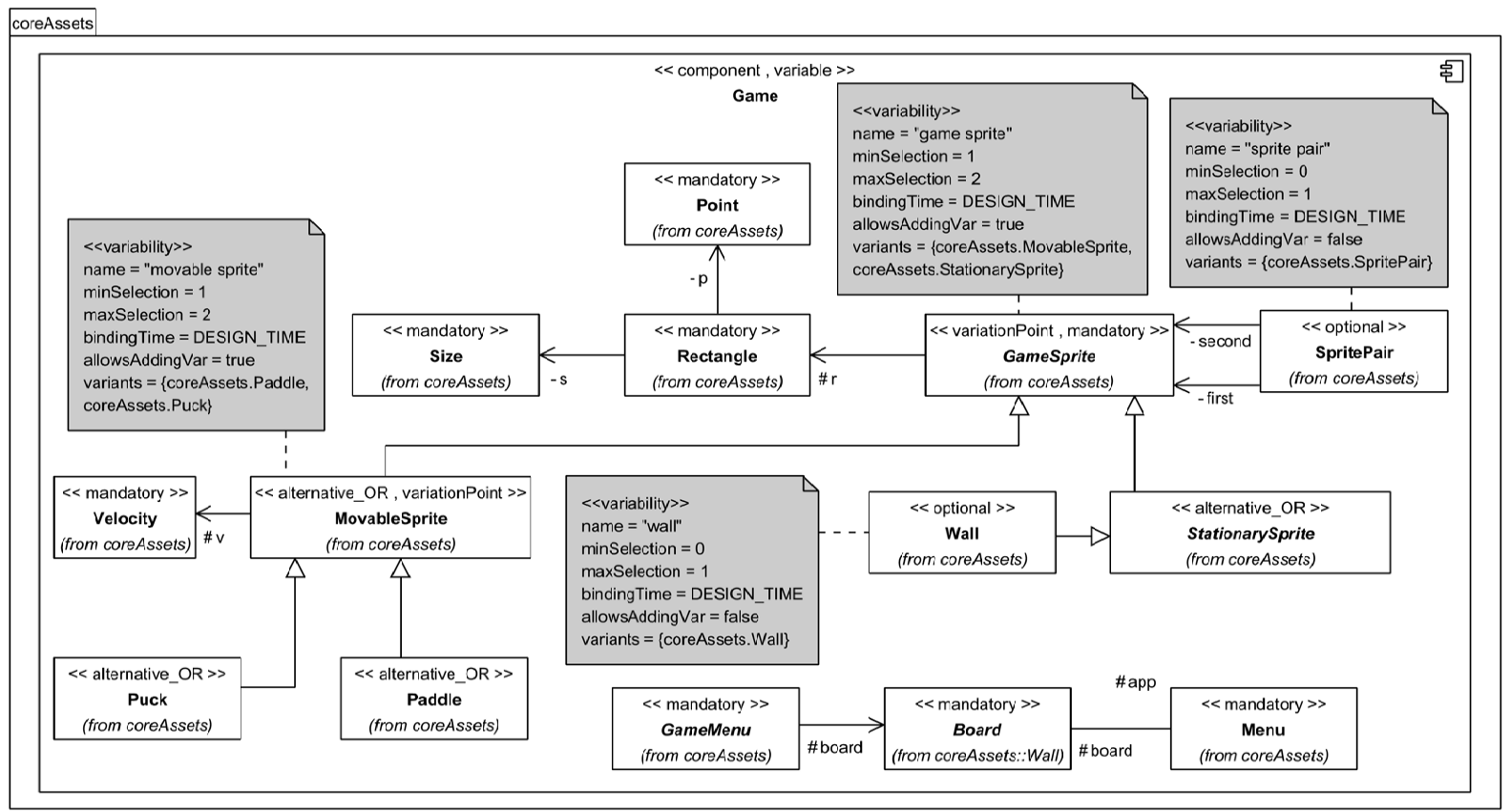

Figura 4.13: Modelo de Variabilidade para Classes da AGM de Acordo com SMarty.

- as classes MovableSprite e StationarySprite estão relacionados à classe GameSprite por meio de herança. Assim, a diretriz D.2.2 a) sugere que:

* a superclasse GameSprite seja um ponto de variação; e

* as subclasses MovableSprite e StationarySprite sejam variantes inclusivas, pois um produto AGM pode conter tanto elementos que se movimentam como elementos estáticos.

- as classes Puck e Paddle estão relacionadas à classe MovableSprite por meio de herança. Assim, a diretriz D.2.2 a) sugere que:

* a superclasse MovableSprite seja um ponto de variação; e

* as subclasses Puck e Paddle sejam variantes inclusivas.

- as classes SpritePair e Wall estão relacionadas a outras classes por meio de associações que não são nem agregações nem composições e, portanto, a diretriz D.2.4 sugere que sejam variantes obrigatórias ou opcionais. Dessa forma, foram modelados como sendo opcionais já que um produto AGM pode analisar as ações a elementos de forma isolada, ou seja, sem o uso de um par de elementos ação/reação (classe SpritePair) e não conter muros/paredes (classe Wall) como, por exemplo, o jogo Bowling.

- as demais classes foram modeladas como variantes obrigatórias, segundo a diretriz D.2.4. 
- as variabilidades nomeadas sprite pair e wall possuem multiplicidades minSelection $=0$ e maxSelection $=1$ segundo a diretriz D.3.1. Isso significa que suas variantes opcionais associadas podem ou não fazer parte de um produto AGM. Para estas variabilidades, o tempo de resolução escolhido, segundo a diretriz D.3.4 foi DESIGN_TIME. Além disso, as variabilidades foram mantidas fechadas, não permitindo a adição de novas variantes, segundo a diretriz D.3.5. O conjunto de variantes da variabilidade sprite pair é $\{$ SpritePair\}, enquanto o da variabilidade wall é $\{$ Wall $\}$, segundo a diretriz D.3.6.

- a variabilidade nomeada movable sprite possui multiplicidade minSelection $=1$ e maxSelection $=2$ segundo a diretriz D.3.3. Isso significa que no mínimo uma e no máximo duas das suas variantes inclusivas associadas, devem ser escolhidas para um produto AGM. Para esta variabilidade, o tempo de resolução escolhido, segundo a diretriz D.3.4 foi DESIGN_TIME. Além disso, a variabilidade foi mantida aberta, permitindo a adição de novas variantes, segundo a diretriz D.3.5. O conjunto de variantes da variabilidade movable sprite é $\{$ Puck, Paddle\}, segundo a diretriz D.3.6.

- a variabilidade nomeada game sprite possui multiplicidade minSelection = 1 e maxSelection $=2$ segundo a diretriz D.3.3. Isso significa que no mínimo uma e no máximo duas das suas variantes inclusivas associadas devem ser escolhidas para um produto AGM. Para esta variabilidade, o tempo de resolução escolhido, segundo a diretriz D.3.3 foi DESIGN_TIME. Além disso, a variabilidade foi mantida aberta, permitindo a adição de novas variantes, segundo a diretriz D.3.5. O conjunto de variantes da variabilidade game sprite é $\{$ MovableSprite, StationarySprite\}, segundo a diretriz D.3.6.

Modelo de Variabilidade para Componentes: o modelo da Figura 4.14 foi gerado considerando a diretriz D.2.7, a qual sugere que componentes formados por classes contendo variabilidades, devem ser marcados com o estereótipo «variable». 


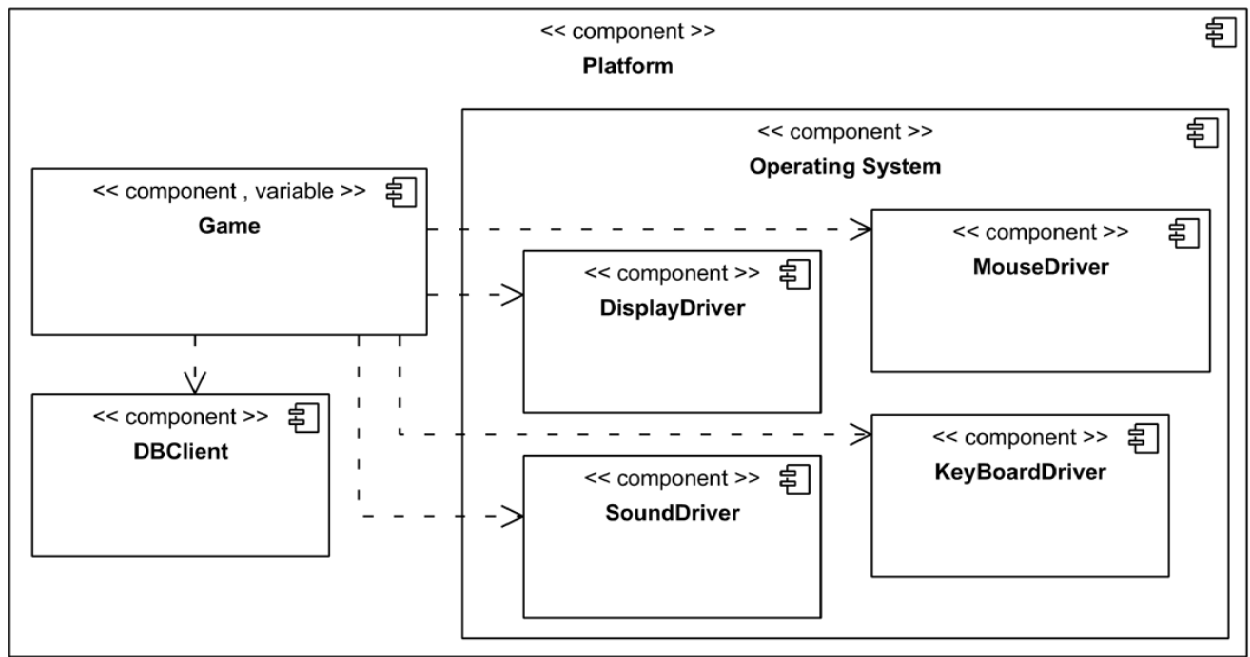

Figura 4.14: Arquitetura Lógica de Componentes da AGM de Acordo com SMarty.

- Mecanismos de Implementação: a definição do modelo de implementação para a LP AGM foi realizada com base nas classes que contêm variabilidade, bem como, nos mecanismos e estratégias de implementação de variabilidade, propostos por Svahnberg et al. (2005). Assim, a Tabela 4.5 apresenta os mecanismos e estratégias definidas para implementar as variabilidades em classes da AGM, considerando as seguintes diretrizes:

Tabela 4.5: Modelo de Implementação de Variabilidades da AGM.

\begin{tabular}{|c|c|c|c|c|}
\hline Variabilidade & Classe/Componente & Tempo de Resolução & Mecanismo & Estratégia \\
\hline movable sprite & MovableSprite & $\begin{array}{c}\text { Projeto } \\
\text { (DESIGN_TIME) }\end{array}$ & $\begin{array}{c}\text { Variant Class } \\
\text { Specialization }\end{array}$ & $\begin{array}{c}\text { Padrão de Projeto } \\
\text { Template }\end{array}$ \\
\hline wall & Wall & $\begin{array}{c}\text { Projeto } \\
\text { (DESIGN_TIME) }\end{array}$ & $\begin{array}{c}\text { Arquivo de } \\
\text { Propriedades }\end{array}$ & Parametrização \\
\hline game sprite & GameSprite & $\begin{array}{c}\text { Projeto } \\
\text { (DESIGN_TIME) }\end{array}$ & $\begin{array}{c}\text { Variant Class } \\
\text { Specialization }\end{array}$ & Java Generics \\
\hline sprite pair & SpritePair & $\begin{array}{c}\text { Projeto } \\
\text { (DESIGN_TIME) }\end{array}$ & $\begin{array}{c}\text { Arquivo de } \\
\text { Propriedades }\end{array}$ & $\begin{array}{c}\text { Padrão de Projeto } \\
\text { Strategy }\end{array}$ \\
\hline
\end{tabular}

- as variabilidades movable sprite, game sprite, sprite pair e wall foram listadas, segundo a diretriz D.4.1;

- o tempo de resolução de todas as variabilidades é DESIGN_TIME segundo a diretriz D.4.2, porém as variabilidades:

- sprite pair e wall não permitem a adição de variantes; e

- movable sprite e game sptire permitem a adição de variantes. 
- para o mecanismo "Variant Class Specialization" da variabilidade movable sprite, a estratégia "Padrão de Projeto Template" foi definida segundo a diretriz D.4.3;

- para o mecanismo "Arquivo de Propriedades" da variabilidade wall, a estratégia "Parametrização" foi definida segundo a diretriz D.4.3;

- para o mecanismo "Variant Class Specialization" da variabilidade game sprite, a estratégia "Java Generics" foi definida segundo a diretriz D.4.3; e

- para o mecanismo "Arquivo de Propriedades" da variabilidade sprite pair, a estratégia "Padrão de Projeto Strategy" foi definida segundo a diretriz D.4.3.

A atividade de Rastreamento e Controle de Variabilidade foi parcialmente apoiada pela ferramenta SPLOT, enquanto a atividade de Análise de Configuração de Produtos não foi realizada, por necessitar de um ambiente automatizado para tal.

\subsection{Considerações Finais}

A abordagem SMarty foi concebida, inicialmente, experimentando-se a aplicação de alguns estereótipos em modelos UML, com o objetivo de identificar e sanar as dificuldades previamente observadas na maioria das abordagens de gerenciamento de variabilidades analisadas.

O primeiro estudo foi realizado por Oliveira Junior et al. (2005a) e visava propor uma forma sistemática para identificar e representar graficamente as variabilidades em modelos UML. Esse estudo foi planejado e conduzido de acordo com os conceitos de engenharia de software experimental. Como resultado, foi constatado que a abordagem proposta na época para gerenciar variabilidades tinha potencial e que supria muitas das deficiências observadas em abordagens similares.

Um segundo estudo proposto por Oliveira Junior et al. (2008) foi realizado com vistas a utilizar os estereótipos experimentados com o objetivo de propor métricas, aplicá-las em modelos UML, coletar os seus valores e analisá-los. Assim, foi possível constatar que as métricas propostas poderiam ser utilizadas para compor métricas específicas para medir a complexidade de modelos UML de uma LP e, dessa forma, fazer uma análise dos potenciais produtos que uma ALP pode produzir acerca de sua complexidade. Métricas para extensibilidade também foram propostas com base nas métricas inicias para modelos UML de LP.

Como resultado desses estudos, foi proposto um novo perfil, estendendo o metamodelo padrão da UML, e formalizando as relações entre os estereótipos propostos e os seus 
meta-atributos, surgindo, assim, o perfil SMartyProfile. Porém, esse perfil precisava de atividades que guiassem a sua aplicação em modelos UML e, portanto, as atividades propostas inicialmente para os estudos de gerenciamento de variabilidades foram re-analisadas, dando origem ao SMartyProcess. A composição do perfil UML juntamente com esse processo deu origem à abordagem SMarty.

A abordagem SMarty pode ser adotada para ser utilizada em qualquer ciclo de vida de desenvolvimento de LP. A única exigência é que os artefatos gerados durante o ciclo de LP sejam modelos UML. Dessa forma, SMarty não interfere no desenvolvimento dos artefatos de LP. O SMartyProcess é executado em paralelo com as atividades de desenvolvimento de LP, utilizando somente as saídas do desenvolvimento como suas entradas para gerar os artefatos relacionados às variabilidades de uma LP. Pelo fato do SMartyProfile ser totalmente compatível com a UML, os artefatos UML gerados durante o desenvolvimento de LP não precisam sofrer alterações, nem serem adaptados. Na verdade, eles servem como base para gerar artefatos compatíveis com as variabilidades inerentes em uma LP. O SMartyProfile, quando aplicado, permite que as variabilidades sejam graficamente representadas, tornando o seu gerenciamento e análise mais intuitivos.

A abordagem SMarty não possui uma quantidade máxima de modelos que podem ser gerenciados. Além disso, qualquer ferramenta que apoie a importação e aplicação de perfis UML em seus modelos pode se beneficiar do SMartyProfile. Como a grande maioria das ferramentas possui tal apoio - dentre elas Poseidon (Gentleware, 2010), MagicDraw (No-Magic, 2010), Visual Paradigm (VP-International, 2010) - espera-se que o SMartyProfile não seja subutilizado.

Apesar de SMarty ser uma abordagem geral para gerenciar variabilidades, está limitada atualmente com relação ao apoio específico para certas áreas de pesquisa como, por exemplo, desenvolvimento orientado a aspectos (Aspect Oriented Development) e arquiteturas orientadas a modelos (Model-Driven Architecture - MDA). Porém, SMarty pode ser estendida para ser aplicada a esses domínios de pesquisa com a inclusão de, por exemplo, novos estereótipos e diretrizes, guiando a sua aplicação. 
92 Capítulo 4. SMarty: Uma Abordagem UML para Gerenciamento de Variabilidade 


$\frac{1}{5}$

\title{
SystEM-PLA: Um Método de Avaliação de Arquitetura de LP
}

\author{
"A descoberta consiste em ver o que \\ todos viram e em pensar o que \\ ninguém pensou." \\ Albert Szent-Györgyi (1893 - 1986), \\ Psicólogo, Prêmio Nobel (1937)
}

O objetivo deste capítulo é apresentar um método para avaliação de ALP, cujos modelos são especificados de acordo com a abordagem SMarty (Capítulo 4).

O método proposto permite aos engenheiros e arquitetos de LP terem um respaldo quanto à efetividade da ALP de um determinado domínio, além de possibilitar alguns tipos de análise, tais como:

- As variabilidades estão modeladas de forma apropriada?

- O que acontece se for modificado o local (elemento UML) no qual uma certa variabilidade está especificada?

- A quantidade de variabilidade afeta o número de produtos de uma LP? O que acontece, com relação ao número de produtos produzidos, se algumas variabilidades forem trocadas ou, simplesmente, se algumas variantes e suas restrições forem modificadas? 
- Dados os atributos de qualidade de uma ALP, qual deles deve ser priorizado ao desenvolver produtos de uma LP?

- Compensa continuar gerando produtos de uma certa LP, com base na análise de seus atributos de qualidade e o respaldo alcançado ou deve-se optar por reestruturar e, até mesmo, reespecificar a ALP para afetar os seus produtos?

No sentido de apoiar tais análises, o método proposto nesta tese conta com um conjunto de técnicas que podem ser aplicadas, desde a apresentação gráfica de dados até análises estatísticas e trade-offs. Diretrizes e métricas são também usadas para permitir avaliar uma ALP, bem como, apoiam a tomada de decisão por engenheiros e arquitetos de LP. A vantagem de o método ser apoiado por essas técnicas reside em não ser necessária a geração de vários produtos para se ter respaldo com relação à efetividade da ALP. Para tanto, o núcleo de artefatos deve ser desenvolvido. Assim, avaliações de ALP permitem identificar problemas arquiteturais que afetam o núcleo, corrigí-los para melhorar a qualidade dos produtos gerados.

As seções a seguir apresentam uma caracterização do método proposto, o perfil de usuário, as fases do método, o metaprocesso que deve ser instanciado para cada avaliação de ALP e as diretrizes que guiam uma avaliação.

\subsection{Caracterização do Método SystEM-PLA}

Systematic Evaluation Method for UML-based Software Product Line Architectures (SystEM-PLA) é um método de avaliação de ALP baseada em UML. Tal avaliação considera as variabilidades, identificadas e representadas, segundo a abordagem SMarty (Capítulo 4), em modelos UML de uma LP, sendo eles:

- o modelo de casos de uso, que representa a visão mais abstrata de uma LP; e

- os modelos de classes e de componentes, que representam a visão lógica da ALP.

O método SystEM-PLA tem sua fundamentação nos princípios dos seguintes métodos (Capítulo 3):

- ATAM (Seçao 3.1), herda a definição das metas de negócio (business drivers), a priorização de atributos de qualidade, cenários e o template para a escrita de um relatório ao final de cada avaliação; 
- EATAM (Seção 3.4.1), herda diretrizes de como definir cenários de variabilidade, para a geração de pontos de variação relacionados aos atributos de qualidade. Além disso, o EATAM apresenta e justifica a importância de alguns atributos de qualidade como, por exemplo, complexidade e extensibilidade, usados para mostrar como definir metas de negócio, cenários, questões gerenciais e técnicas e métricas segundo o método SystEM-PLA, além de ilustrar análises de trade-off;

- HoPLSAA (Seção 3.4.2), herda a forma como as variabilidades de uma LP se relacionam com os atributos de qualidade, permitindo assim, que decisões arquiteturais sejam tomadas por meio de análises de trade-off dos atributos de qualidade de uma ALP;

- GQM, herda a forma como se relacionam as metas de negócio (goal), as questões (question) gerenciais e técnicas e as métricas (metric) de atributos de qualidade. Esses elementos serão apresentados na Seção 5.2 .

O método SystEM-PLA analisa atributos de qualidade para validar as metas de negócio definidas para uma ALP, bem como, a precisão das variabilidades modeladas para um certo domínio. Além disso, o método pode ser usado como uma forma de verificar alternativas de projeto, fornecendo assim, apoio para a tomada de decisões e análise de trade-off que afetam os produtos a serem produzidos por uma LP.

SystEM-PLA é considerado parte das atividades de desenvolvimento de LP e possui três fases distintas, como mostra a Figura 5.1 na forma de um diagrama de atividades da UML: Planejamento (Seção 7.2), Coleta de Dados (Seção 5.1.2) e Análise de Dados e Documentação (Seção 5.1.3).

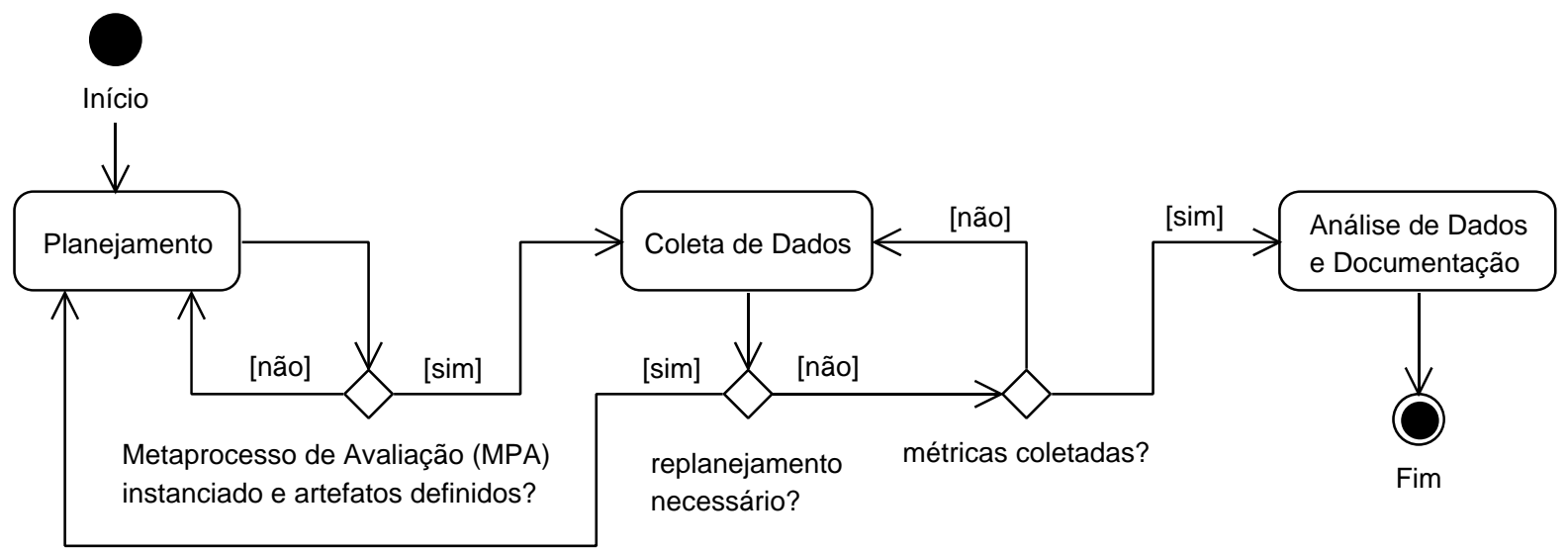

Figura 5.1: Fases do Método SystEM-PLA.

Na Figura 5.1, as ações (retângulos) representam as fases do SystEM-PLA, enquanto as decisões (losângulos) representam as pré e pós-condições de cada fase. Basicamente, o 
SystEM-PLA deve instanciar o Metaprocesso de Avaliação (MPA) (Seção 5.2) e definir os artefatos necessários. Em seguida, deve-se coletar as métricas definidas pelo SystEM-PLA. Por fim, os dados coletados são analisados e documentados.

O SystEM-PLA fornece um conjunto de diretrizes (Seção 5.3) que servem para guiar sistematicamente o usuário na realização das atividades de cada uma de suas fases. Também fornece um conjunto predefinido, porém extensível, de métricas básicas para avaliação de ALP. Esse conjunto serve para apoiar os usuários do método, na composição de métricas para atributos de qualidade e para encorajar os usuários a compartilhar novas métricas, por meio de um repositório de artefatos do método.

A Figura 5.2 representa graficamente o SystEM-PLA relacionando suas fases, diretrizes, artefatos e interações via fluxos de informação e de dados. As interações entre as fases do SystEM-PLA e o repositório de artefatos permitem o rastreamento e empacotamento dos dados gerados durante uma avaliação de ALP e suas possíveis replicações. 


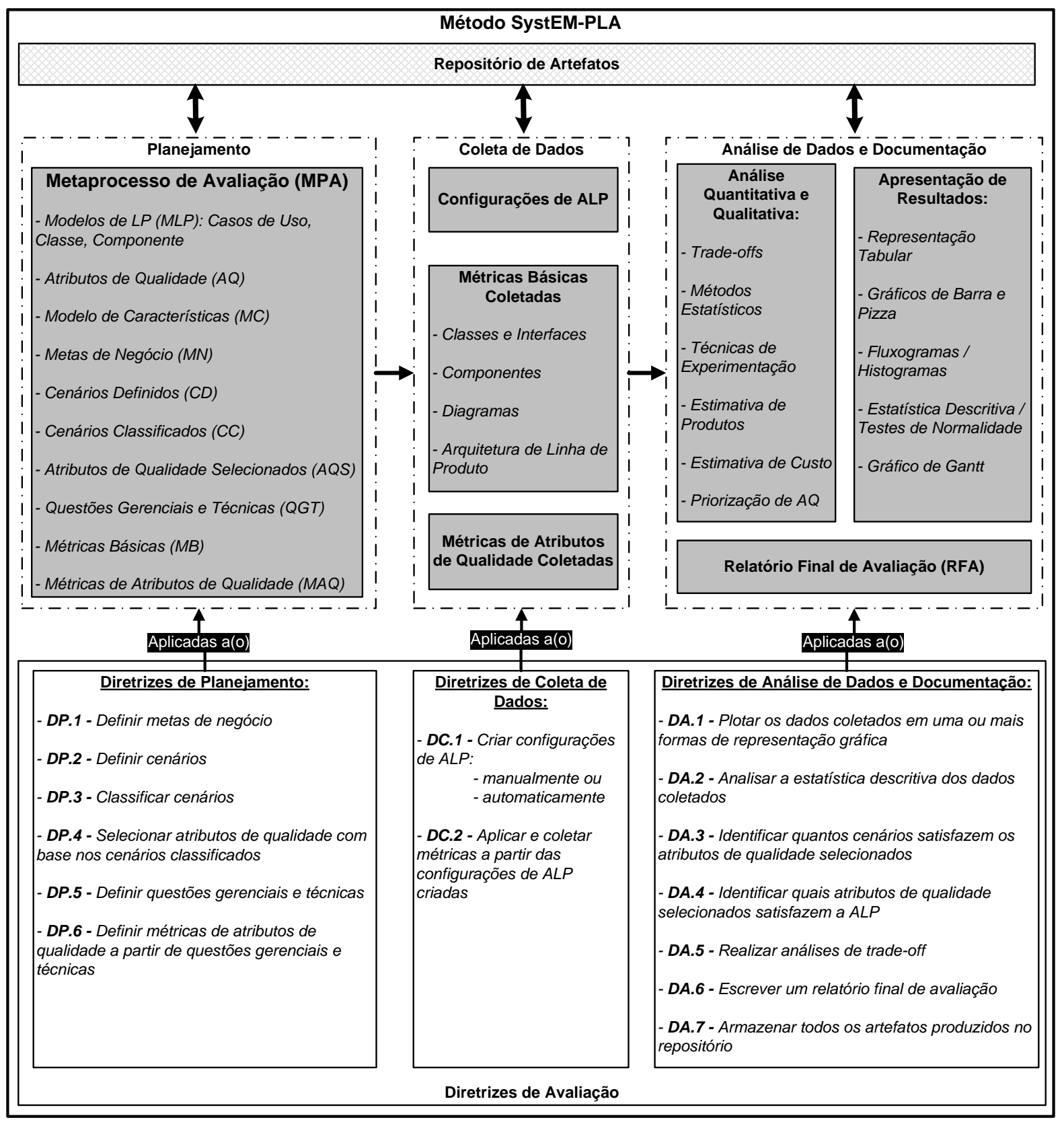

\begin{tabular}{|c|c|c|c|}
\hline & & Legenda: & \\
\hline$r \cdot-$ & Fase & & Fluxo de Informação \\
\hline$\square$ & Artefato & plicadas a & Diretriz Aplicada a uma Fase \\
\hline 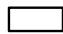 & Diretriz & & Fluxo de Dados \\
\hline$\square$ & Repositório de Artefatos & & \\
\hline
\end{tabular}

Figura 5.2: Representação Gráfica do Método SystEM-PLA Contendo suas Fases, Diretrizes e Artefatos.

O método SystEM-PLA inicia seguindo as diretrizes de planejamento, por meio da instanciação do MPA e da definição dos artefatos necessários para a avaliação de uma ALP como, por exemplo, metas de negócio, cenários e métricas de atributos de qualidade. 
Em seguida, configurações da ALP são geradas e as métricas básicas e de atributos de qualidade são aplicadas e coletadas de tais configurações, seguindo as devidas diretrizes para tal. Por fim, os dados coletados são analisados utilizando uma ou mais técnicas como, por exemplo, plotagem de dados em histogramas, análise de estatística descritiva e/ou análises de trade-off, e um relatório final de avaliação é escrito.

As subseções a seguir apresentam a descrição de cada uma das fases do SystEM-PLA, bem como, suas pré e pós-condições.

\subsubsection{Fase de Planejamento}

A fase de Planejamento tem como objetivo instanciar o MPA (Seção 5.2) e realizar as suas atividades para estabelecer os artefatos utilizados durante uma avaliação de ALP. Ela é essencial para a realização de uma avaliação de ALP, uma vez que os artefatos e técnicas/estratégias necessárias para tal são definidas.

Esta fase possui como pré-condições:

- a existência de um modelo de características de uma LP; e

- modelos de LP especificados de acordo com a abordagem SMarty. SystEM-PLA considera, pelo menos, os modelos de casos de uso, classes e componentes.

Esta fase possui como pós-condições o MPA instanciado e os seus artefatos definidos.

A seção 5.3.1 apresenta as diretrizes de planejamento a serem seguidas pelo usuário do método SystEM-PLA.

\subsubsection{Fase de Coleta de Dados}

Esta fase permite a aplicação de métricas orientadas a UML (Capítulo 6) aos artefatos estabelecidos pelo MPA. Além disso, fornece indicadores quantitativos e qualitativos para que o usuário possa articular a melhor forma de interpretar os dados coletados na fase seguinte.

Assim, basicamente, esta fase consiste em:

- gerar configurações de ALP, de forma manual ou automatizada, usando, por exemplo, um gerador de aplicações como o Captor (2010) ou uma ferramenta de gerenciamento de variantes como a pure::variants (Pure-Systems, 2010); e 
- aplicar e coletar as métricas básicas (Seção 6.1) e métricas de atributos de qualidade como, por exemplo, métricas de complexidade (Seção 6.2.1) e métricas de extensibilidade (Seção 6.2.2) às configurações geradas.

Esta atividade possui como pré-condição o MPA instanciado e os seus artefatos estabelecidos para conduzir uma avaliação de ALP e, como pós-condições, as configurações de ALP geradas e as métricas básicas e de atributos de qualidade coletadas.

A Seção 5.3 .2 apresenta as diretrizes de coleta de dados a serem seguidas pelo usuário do método SystEM-PLA.

\subsubsection{Fase de Análise de Dados e Documentação}

Esta fase permite interpretar os dados coletados tanto quantitativamente quanto qualitativamente, fornecendo respaldo com relação à ALP e seus atributos de qualidade avaliados. Assim, um ou mais relatórios são escritos para documentar a avaliação realizada, bem como, para permitir que a avaliação possa ser replicada. Além disso, representação tabular, gráficos de barra e pizza, fluxogramas/histogramas, estatística descritiva e gráficos de normalidade podem ser usados para melhorar a apresentação dos resultados da avaliação. O gráfico de Gantt (Kerzner, 2009) pode ser usado para planejar futuras replicações de uma avaliação.

A Seção 5.3 .3 apresenta as diretrizes de análise de dados e documentação a serem seguidas pelo usuário do método SystEM-PLA.

\subsection{Metaprocesso de Avaliação (MPA)}

O MPA tem como objetivo definir os artefatos que permitem a avaliação de uma ALP, bem como:

- a seleção de atributos de qualidade de uma ALP, para que análises de trade-off possam ser realizadas;

- a definição de questões gerenciais e técnicas a serem respondidas com relação aos atributos de qualidade selecionados; e

- a definição de métricas de atributos de qualidade para apoiar as fases de coleta e análise de dados, além de fornecer indicadores quantitativos sobre a ALP. 
O MPA possui como entrada os Modelos UML de LP, o Modelo de Características de uma LP e os Atributos de Qualidade inicialmente definidos para uma ALP.

Os artefatos definidos pelo MPA e as suas descrições são apresentadas a seguir:

- Metas de Negócio (MN): representam os objetivos de negócio que uma ALP deve atingir, com base nos seus atributos de qualidade de uma ALP;

- Cenários Definidos (CD): um conjunto de cenários é definido para cada atributo de qualidade de uma ALP, com o objetivo de apoiar a seleção dos atributos de qualidade para a avaliação de uma ALP;

- Cenários Classificados (CC): os cenários definidos são classificados com base em fatores importantes para a ALP, como importância e número de variabilidades;

- Atributos de Qualidade Selecionados (AQS): é um subconjunto não-vazio do conjunto de Atributos de Qualidade para os quais questões gerenciais e técnicas, bem como, métricas são definidas, para que análises de trade-off possam ser realizadas;

- Questões Gerenciais e Técnicas (QGT): são as questões que devem ser respondidas segundo as perspectivas gerencial e técnica, visando analisar uma ALP e apoiar a definição de métricas para análises quantitativas; e

- Métricas de Atributos de Qualidade (MAQ): são as métricas que devem ser definidas para apoiar a priorização de atributos de qualidade para uma ALP.

O diagrama de atividades da Figura 5.3 apresenta as atividades que devem ser realizadas para a definição dos artefatos do MPA, seguindo o método SystEM-PLA. No diagrama, as ações (retângulos com vértices arredondados) representam as atividades do metaprocesso e os objetos (retângulos com vértices retos) representam as entradas e as saídas das atividades.

Uma descrição de cada atividade do MPA e suas respectivas entradas e saídas é apresentada a seguir.

A Definição de Metas de Negócio possui como entrada os Modelos de LP e os Atributos de Qualidade de uma ALP, usados na definição das Metas de Negócio que uma ALP deve alcançar no desenvolvimento de seus produtos. As metas de negócio apoiam a definição de cenários e questões gerenciais e técnicas. Apesar da atividade de definição de metas de negócio estar baseada no método ATAM, ela considera as metas de negócio da ALP em vez das metas de arquiteturas de produtos únicos e, consequentemente, exige o uso das variabilidades modeladas em uma LP. 


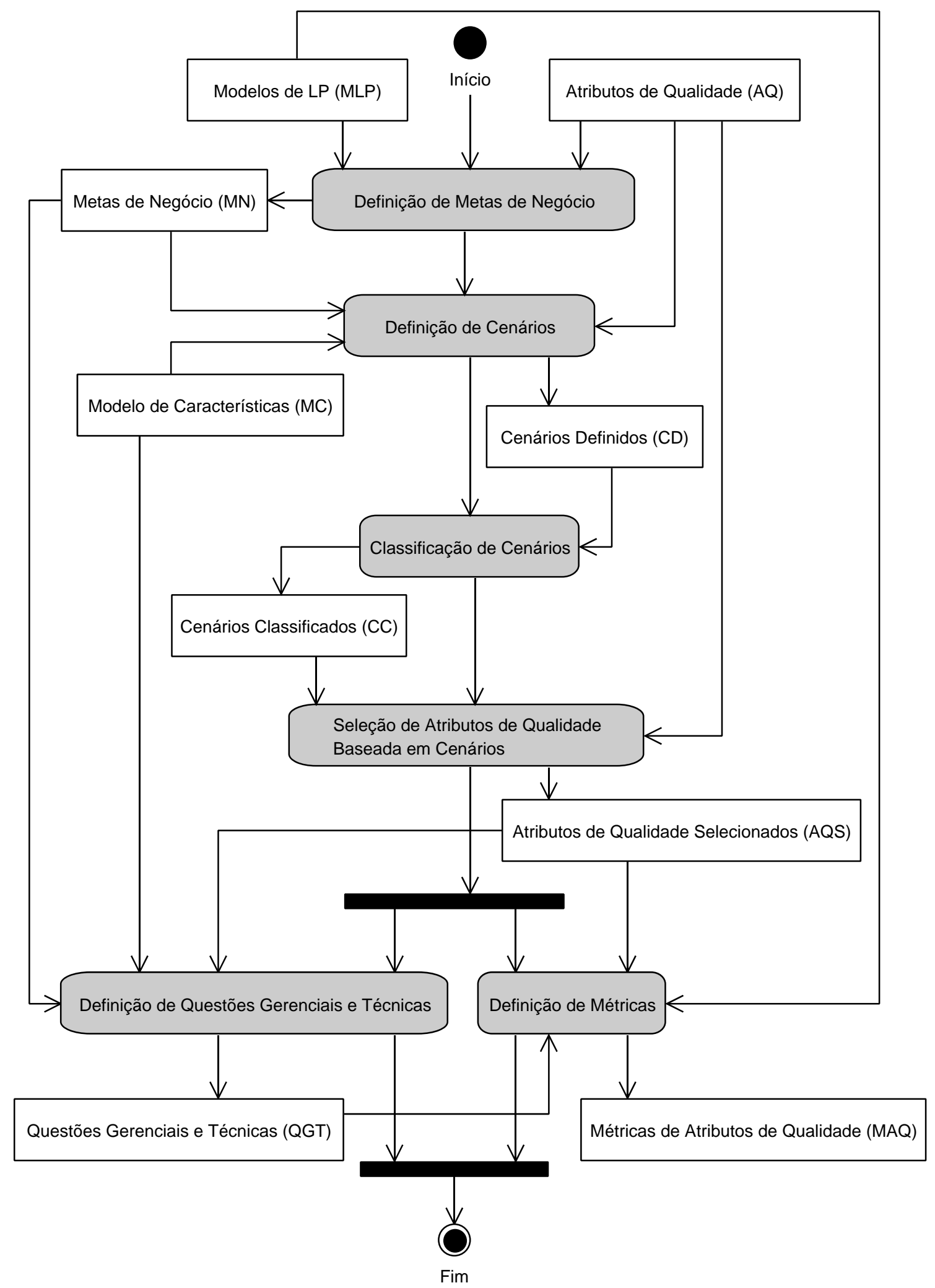

Figura 5.3: SystEM-PLA: Atividades do Metaprocesso de Avaliação (MPA). 
A Definição de Cenários possui como entrada as Metas de Negócio, o Modelo de Características da LP e os atributos de qualidade de uma ALP. Esta atividade estabelece os cenários para cada atributo de qualidade de uma ALP, com o objetivo de apoiar a atividade de seleção de tais atributos.

A Classificação de Cenários possui como entrada os Cenários Definidos e tem como objetivo classificá-los, de acordo com fatores importantes relacionados à ALP. Esta atividade gera como saída os Cenários Classificados.

A Seleção de Atributos Baseada em Cenários possui como entrada os Atributos de Qualidade de uma ALP e seus Cenários Classificados e tem como objetivo selecionar os atributos de qualidade que serão analisados para uma certa ALP. As saídas desta atividade são os Atributos de Qualidade Selecionados que formam um subconjunto dos Atributos de Qualidade de uma ALP.

A Definição de Questões Gerenciais e Técnicas possui como entrada as Metas de Negócio, o Modelo de Características de uma LP e os Atributos de Qualidade Selecionados de uma ALP. Esta atividade define Questões Gerenciais e Técnicas (QGT), que devem ser respondidas com base na definição de métricas, para apoiar a coleta e a análise de dados e documentação. Tais questões são definidas e consideram os papéis envolvidos no processo de desenvolvimento de LP como descrito por Chastek e Ferguson (2006). Os itens a seguir apresentam alguns exemplos de papéis e questões. Mais exemplos podem ser encontrados em (Taylor et al., 2009).

- Gerente de LP: realiza atividades como planejamento, monitoramento e controle de LP. Exemplos de questões relacionadas ao gerente de LP podem ser:

- Qual é o investimento efetivo, para a adoção da abordagem de LP de uma organização que está em processo de transição do desenvolvimento tradicional de software, para a abordagem de LP?

- Qual(is) configuração(ões) de uma ALP é(são) mais viável(eis) para um determinado domínio?

- Arquiteto de LP: responsável por gerenciar a evolução da ALP, bem como, fornecer apoio quantitativo e qualitativo à tomada de decisão. Exemplos de questões relacionadas ao arquiteto de LP são:

- Qual é a quantidade de esforço demandada para desenvolver um produto de uma LP, com base em seus artefatos e suas variabilidades?

- Qual é o impacto de adicionar, modificar ou remover características de uma LP sobre os atributos de qualidade de uma ALP? 
- Qual(is) configuração(ões) satisfaz(em) os atributos de qualidade definidos de uma ALP para um certo domínio? Além disso, como podem ser determinados os atributos de qualidade a serem priorizados em uma análise de custo-benefício?

- Programador/Desenvolvedor: Exemplos de questões são:

- Qual é o esforço exigido para implementar, manter ou remover uma certa variabilidade de uma LP? Com base no esforço exigido, vale a pena remover a variabilidade ou somente desativá-la?

- Quais técnicas de implementação de LP podem ser usadas, baseado no esforço estimado?

A Definição de Métricas possui como entrada os Modelos de LP, os Atributos de Qualidade Selecionados e as Questões Gerenciais e Técnicas. Esta atividade define Métricas de Atributos de Qualidade (MAQ) para responder as questões gerenciais e técnicas e apoiar a coleta de dados e análises quantitativas de uma ALP.

As atividades de Definição de Questões Gerenciais e Técnicas e Definição de Métricas são realizadas paralelamente. Assim que cada questão é definida, sua(s) métrica(s) já pode(m) ser proposta(s).

A Tabela 5.1 apresenta um resumo das entradas e saídas de cada atividade do MPA do método SystEM-PLA.

Tabela 5.1: Metaprocesso de Avaliação: Entradas e Saídas das Atividades.

\begin{tabular}{|l|c|c|}
\hline Atividades & Entrada(s) & Saída(s) \\
\hline Definição de Metas de Negócio & MLP e AQ & MN \\
\hline Definição de Cenários & MN, MC e AQ & CD \\
\hline Classificação de Cenários & CD & CC \\
\hline $\begin{array}{l}\text { Seleção de Atributos de Qualidade Baseada } \\
\text { em Cenários }\end{array}$ & CC e AQ & AQS \\
\hline Definição de Questões Gerenciais e Técnicas & MN, MC e AQS & QGT \\
\hline Definição de Métricas & MLP, AQS e QGT & MAQ \\
\hline
\end{tabular}

A seção a seguir apresenta as diretrizes que guiam a realização de uma avaliação de ALP, segundo o método SystEM-PLA.

\subsection{Diretrizes de Avaliação}

Esta seção apresenta as diretrizes de avaliação fornecidas pelo método SystEM-PLA, cujos usuários devem seguir para realizar, de forma apropriada, uma avaliação de ALP. Tais 
diretrizes são ilustradas com a LP AGM (Apêndice A) e os seus resultados obtidos são utilizados como referência para o estudo experimental de viabilidade do SystEM-PLA (Capítulo 8). Como propósito de ilustração, serão considerados somente os atributos de qualidade, complexidade e extensibilidade. Porém, o usuário pode definir/adicionar outros atributos de qualidade.

As seções a seguir apresentam as diretrizes para cada fase do método SystEM-PLA e exemplos baseados na LP AGM.

\subsubsection{Diretrizes de Planejamento (DP)}

As Diretrizes de Planejamento (DP) visam estabelecer os artefatos necessários para conduzir a avaliação de uma ALP. Assim, os itens a seguir apresentam tais diretrizes:

DP.1 Definir metas de negócio (MN): o usuário deve definir sempre as metas de negócio. A definição de metas de negócio do método ATAM pode apoiar esta atividade como descrito por Clements et al. (2002b). Para ilustrar esta atividade, foram definidas para a LP AGM as seguintes metas de negócio:

- MN.1 - manter o grau de complexidade dos jogos abaixo de 0.7 (70\%), comparado à complexidade geral da ALP, para, pelo menos, $\mathbf{5 0 \%}$ dos produtos produzidos: isso significa manter baixas as taxas de manutenibilidade e custo, concentrando-se em complexidade. O grau de complexidade pode fornecer um indicador da dificuldade para manter os produtos derivados de uma ALP. Assim, quanto maior é o grau de complexidade de um produto, mais difícil é mantê-lo e, consequentemente, mais alto é o seu custo; e

- MN.2 - manter o grau de extensibilidade dos jogos acima de 0.75 (75\%), comparado à extensibilidade geral da ALP, para, pelo menos, $\mathbf{5 0 \%}$ dos produtos produzidos: isso significa manter altas as taxas de reutilização, concentrando-se em extensibilidade. Graus de extensibilidade podem fornecer indicadores do quão reusável é um produto em termos de seus componentes. Quanto mais extensível é um produto, mais alta é a sua taxa de reusabilidade e mais baixo é o seu custo de manutenção/produção.

DP.2 Definir cenários: o usuário deve definir cenários para cada atributo de qualidade da ALP. Para tanto, a definição de cenários do método ATAM pode apoiar tal atividade como descrito por Barbacci (2002) e Clements et al. (2002b). Cada cenário definido deve indicar claramente o(s) atributo(s) de qualidade que ele afeta e a sua 
descrição. Além disso, o cenário deve ser representado usando a notação de Árvore de Utilidade, para facilitar sua seleção e apresentar as características relacionadas e suas subcaracterísticas, caso existam. As características de uma LP apoiam a especificação de cenários, por meio da ligação entre metas de negócio e um ou mais cenários. Por exemplo, as características da LP AGM services, rules e actions (Figura A.1) estão relacionadas aos cenários da Meta de Negócio MN.1. As Tabelas 5.2 e 5.3 apresentam as árvores de utilidade dos cenários definidos para os atributos de qualidade complexidade e extensibilidade.

Tabela 5.2: Cenários Definidos para Complexidade de Produtos da AGM.

\begin{tabular}{|c|l|l|}
\hline \multicolumn{2}{|c|}{ AGM - Árvore de Utilidade de Atributo de Qualidade } \\
\hline Atributo(s) de Qualidade & Complexidade \\
\hline $\begin{array}{c}\text { Característica(s) } \\
\text { Relacionada(s) }\end{array}$ & \multicolumn{2}{|c|}{ services, rules, actions } \\
\hline $\begin{array}{c}\text { Meta(s) de Negócio } \\
\text { Relacionada(s) }\end{array}$ & $\begin{array}{l}\text { MN.1: } \\
\text { complexidade geral da ALP, para, pelo menos, 50\% dos produtos produzidos }\end{array}$ \\
\hline \multirow{2}{*}{$\begin{array}{c}\text { Descrição do(s) } \\
\text { Cenário(s) }\end{array}$} & Cn.1 & $\begin{array}{l}\text { Pontos de variação e/ou variantes são adicionadas, modificadas ou removidas } \\
\text { mantendo a Meta de Negócio MN.1 verdadeira }\end{array}$ \\
\cline { 2 - 3 } & Cn.2 & $\begin{array}{l}50 \% \text { das variabilidades são removidas mantendo a Meta de Negócio MN.1 } \\
\text { verdadeira }\end{array}$ \\
\cline { 2 - 3 } & Cn.3 & $\begin{array}{l}\text { Ambientes com 1 (um) jogo possuem complexidade máxima de 0,65 (65\%) } \\
\text { com relação à arquitetura da AGM }\end{array}$ \\
\hline
\end{tabular}

Tabela 5.3: Cenários Definidos para Extensibilidade de Produtos da AGM.

\begin{tabular}{|c|l|l|}
\hline \multicolumn{2}{|c|}{ AGM - Árvore de Utilidade de Atributo de Qualidade } \\
\hline Atributo(s) de Qualidade & Extensibilidade \\
\hline $\begin{array}{c}\text { Característica(s) } \\
\text { Relacionada(s) }\end{array}$ & \multicolumn{2}{|c|}{ services, rules, actions } \\
\hline $\begin{array}{c}\text { Meta(s) de Negócio } \\
\text { Relacionada(s) }\end{array}$ & $\begin{array}{l}\text { MN.2: } \\
\text { à extensibilidade geral da ALP, para, pelo menos, 50\% dos produtos produzidos }\end{array}$ \\
\hline \multirow{2}{*}{$\begin{array}{c}\text { Descrição do(s) } \\
\text { Cenário(s) }\end{array}$} & Cn.4 & $\begin{array}{l}\text { pontos de variação e/ou variantes são adicionadas, modificadas ou } \\
\text { removidas mantendo a Meta de Negócio MN.2 verdadeira }\end{array}$ \\
\cline { 2 - 3 } & Cn.5 & $\begin{array}{l}\text { 50\% das variabilidades são removidas mantendo a Meta de Negócio MN.2 } \\
\text { verdadeira }\end{array}$ \\
\cline { 2 - 3 } & Cn.6 & $\begin{array}{l}\text { ambientes com 2 (dois) jogos possuem extensibilidade mínima de 0,8 (80\% ) } \\
\text { com relação à arquitetura da AGM }\end{array}$ \\
\hline
\end{tabular}

DP.3 Classificar cenários: o usuário deve classificar cada cenário como sendo Alto (A), Médio (M) ou Baixo (B), considerando cada um dos seguintes atributos de interesse: 
- a sua importância geral para a ALP e as suas metas de negócio;

- a generalidade do cenário com relação à ALP. O cenário deve ser classificado como obrigatório (Alto), alternativo (Médio) ou opcional (Baixo) como descrito por Olumofin (2007);

- o seu custo/risco, ou seja, o esforço envolvido para fornecer respostas aos cenários, bem como seu risco percebido; e

- o número de variabilidades contido em cada cenário.

A Tabela 5.4 apresenta a classificação dos cenários dos atributos de qualidade, Complexidade e Extensibilidade, relacionados ao exemplo da LP AGM.

Tabela 5.4: Cenários AGM Classificados para Complexidade e Extensibilidade.

\begin{tabular}{|c|c|c|c|c|c|c|c|c|}
\hline \multirow{2}{*}{\multicolumn{3}{|c|}{$\begin{array}{c}\text { Meta(s) de Negócio } \\
\text { Atributo(s) de Qualidade } \\
\end{array}$}} & \multicolumn{3}{|c|}{ MN.1 } & \multicolumn{3}{|c|}{ MN.2 } \\
\hline & & & \multicolumn{3}{|c|}{ Complexidade } & \multicolumn{3}{|c|}{ Extensibilidade } \\
\hline \multicolumn{3}{|c|}{ Cenário(s) } & Cn.1 & Cn.2 & Cn.3 & Cn.4 & Cn.5 & Cn.6 \\
\hline \multirow{12}{*}{ 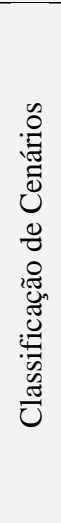 } & \multirow{3}{*}{ Importância } & $\mathrm{A}$ & $\mathbf{X}$ & & $\mathbf{X}$ & $\mathbf{X}$ & $\mathbf{X}$ & $\mathbf{X}$ \\
\hline & & $\mathrm{M}$ & & $\mathbf{X}$ & & & & \\
\hline & & $\mathrm{B}$ & & & & & & \\
\hline & \multirow{3}{*}{ Generalidade } & $\mathrm{A}$ & $\mathbf{X}$ & & & $\mathbf{X}$ & & \\
\hline & & $\mathrm{M}$ & & $\mathbf{X}$ & & & $\mathbf{X}$ & \\
\hline & & $\mathrm{B}$ & & & $\mathbf{X}$ & & & $\mathbf{X}$ \\
\hline & \multirow{3}{*}{ Custo/Risco } & A & & $\mathbf{X}$ & & & $\mathbf{X}$ & \\
\hline & & $\mathrm{M}$ & $\mathbf{X}$ & & & $\mathbf{X}$ & & \\
\hline & & $\mathrm{B}$ & & & $\mathbf{X}$ & & & $\mathbf{X}$ \\
\hline & \multirow{3}{*}{$\begin{array}{c}\text { Número de } \\
\text { Variabilidades }\end{array}$} & $\mathrm{A}$ & $\mathbf{X}$ & $\mathbf{X}$ & & $\mathbf{X}$ & $\mathbf{X}$ & $\mathbf{X}$ \\
\hline & & $\mathrm{M}$ & & & $\mathbf{X}$ & & & \\
\hline & & B & & & & & & \\
\hline
\end{tabular}

DP.4 Selecionar atributos de qualidade com base nos cenários classificados: como os cenários estão classificados, o usuário deve selecionar os atributos de qualidade por meio da definição de uma estratégia. Uma estratégia amplamente conhecida é o sistema de votação adotado pelo método ATAM (Barbacci, 2002), (Clements et al. 2002b). Para o exemplo da LP AGM, os cenários foram selecionados com base nas seguintes análises:

- os cenários Cn.1, Cn.4 e Cn.5 possuem um alto número de variabilidades e importância geral para a ALP. Tais cenários são obrigatórios para a ALP da AGM tendo um custo/risco médio;

- o cenário Cn.6 também possui um alto número de variabilidades envolvidas, alta importância para a ALP, porém um custo/risco baixo para a ALP da AGM, sendo opcional; e 
- o cenário Cn.2 possui um alto número de variabilidades envolvidas e um alto custo/risco para a ALP da AGM, além de média importância para a ALP, sendo alternativo;

- o cenário Cn.3 é alternativo, tendo alta importância para a ALP, baixo custo/risco e um baixo número de variabilidades envolvidas.

Assim, os cenários Cn.1, Cn.4 e Cn.5 caracterizam-se por serem os mais importantes para a LP AGM, como mostra a Tabela 5.5. O cenário Cn.1 está relacionado com a meta de negócio MN.1 e com o atributo de qualidade complexidade, os cenários Cn.4 e Cn.5 estão relacionados com a Meta de Negócio MN.2 e com o atributo de qualidade extensibilidade. Dessa forma, os atributos de qualidade, complexidade e extensibilidade foram selecionados para análise. Nota-se que nesse exemplo todos os atributos de qualidade foram selecionados com base nos cenários classificados. Porém, em uma avaliação envolvendo mais atributos de qualidade, pode acontecer de nem todos serem selecionados para serem avaliados.

Tabela 5.5: Seleção de Atributos de Qualidade AGM.

\begin{tabular}{|c|c|c|c|}
\hline $\begin{array}{c}\text { Meta(s) de } \\
\text { Negócio }\end{array}$ & $\begin{array}{c}\text { Atributo(s) de } \\
\text { Qualidade }\end{array}$ & Cenário(s) & Ordem de Seleção \\
\hline MN.1 & Complexidade & $\mathrm{Cn} .1$ & $1^{\mathbf{o}}$ a $3^{\mathbf{o}}$ \\
MN.2 & Extensibilidade & $\mathrm{Cn.4}$ & \\
MN.2 & Extensibilidade & $\mathrm{Cn} .5$ & $4^{\mathbf{o}}$ \\
\hline MN.2 & Extensibilidade & $\mathrm{Cn} .6$ & $5^{\mathbf{o}}$ \\
\hline MN.1 & Complexidade & $\mathrm{Cn} .2$ & $6^{\mathbf{o}}$ \\
\hline MN.1 & Complexidade & $\mathrm{Cn} .3$ & \\
\hline
\end{tabular}

DP.5 Definir questões gerenciais e técnicas: o usuário deve se basear nas metas de negócio, no modelo de características e nos atributos de qualidade selecionados, para definir tais questões. Para tanto, recomenda-se fortemente o uso do método GQM por causa de sua maturidade e consolidação. No método SystEM-PLA, as metas de negócio, os atributos de qualidade e as características podem ser mapeadas para as metas do GQM, sendo assim, usadas para definir as questões GQM. Tais questões devem indicar com qual(is) meta(s) de negócio, atributo(s) de qualidade selecionado(s) e/ou característica(s) estão relacionadas. Além disso, cada questão deve possuir um identificador único, bem como permitir a definição de métricas relacionadas. Assim, a Tabela 5.6 apresenta as questões gerenciais e técnicas definidas para as metas de negócio MN.1 e MN.2, estabelecidas pela diretriz DP.1, para a LP AGM. 
Tabela 5.6: Questões Gerenciais e Técnicas para as Metas de Negócio AGM.

\begin{tabular}{|c|l|l|}
\hline $\begin{array}{c}\text { Meta de Negócio / } \\
\text { Característica / } \\
\text { AQ Selecionado } \\
\text { (Metas) }\end{array}$ & \multicolumn{2}{|c|}{ Questões } \\
\hline \multirow{4}{*}{$\begin{array}{c}\text { MN.1 } \\
\text { (meta de negócio) }\end{array}$} & Q.01 & Qual a complexidade de uma classe/interface em um modelo de classes? \\
\cline { 2 - 3 } & Q.02 & $\begin{array}{l}\text { Qual a complexidade de uma classe/interface que é um ponto de variação } \\
\text { em um modelo de classes? }\end{array}$ \\
\cline { 2 - 3 } & $\begin{array}{l}\text { Qual a complexidade de uma classe/interface que é uma variabilidade em } \\
\text { um modelo de classes? }\end{array}$ \\
\cline { 2 - 3 } & Q.04 & Qual a complexidade de um componente variável em um modelo de componentes? \\
\cline { 2 - 3 } & Q.05 & Qual a complexidade de uma ALP com base em seu(s) modelo(s) de classes? \\
\hline \multirow{5}{*}{$\begin{array}{c}\text { MN.2 } \\
\text { (meta de negócio) }\end{array}$} & Q.06 & Qual a extensibilidade de uma classe/interface em um modelo de classes? \\
\cline { 2 - 3 } & Q.07 & $\begin{array}{l}\text { Qual a extensibilidade de uma classe/interface que é um ponto de variação } \\
\text { em um modelo de classes? }\end{array}$ \\
\cline { 2 - 3 } & Q.08 & $\begin{array}{l}\text { Qual a extensibilidade de uma classe/interface que é uma variabilidade em } \\
\text { um modelo de classes? }\end{array}$ \\
\cline { 2 - 3 } & Q.09 & Qual a extensibilidade de um componente variável em um modelo de componentes? \\
\cline { 2 - 3 } & Q.10 & Qual a extensibilidade de uma ALP baseada em seu(s) modelo(s) de classes? \\
\hline
\end{tabular}

DP.6 Definir métricas de atributos de qualidade: o usuário deve considerar os atributos de qualidade selecionados e as questões definidas, para estabelecer as métricas para os atributos de qualidade. Tais métricas respondem as questões gerenciais e técnicas, com relação aos atributos de qualidade selecionados. As métricas básicas (Seção 6.1) podem ser usadas para a composição das novas métricas. Cada métrica deve indicar com qual(is) atributo(s) de qualidade está relacionada e qual(is) questão(ões) responde. Além disso, cada métrica deve ter um nome simplificado e uma descrição associada. Para a LP AGM, foram definidas onze métricas, sendo cinco para medir complexidade e seis para medir extensibilidade, mostradas com mais detalhes na Seção 6.2. A Tabela 5.7 apresenta as métricas definidas e uma breve descrição de cada uma delas. 
Tabela 5.7: Métricas AGM para os Atributos de Qualidade Complexidade e Extensibilidade.

\begin{tabular}{|c|c|c|c|}
\hline \multirow{2}{*}{$\begin{array}{l}\text { Atributo de } \\
\text { Qualidade }\end{array}$} & \multirow{2}{*}{ Questão } & \multicolumn{2}{|r|}{ Métrica } \\
\hline & & Nome & Descrição \\
\hline \multirow{6}{*}{ Complexidade } & \multirow[t]{2}{*}{ Q.01 } & Compl nterface & $\begin{array}{l}\text { Sempre o valor } 0.0 \text {, pois não possuem métodos concretos para o cálculo } \\
\text { da métrica Weighted Methods per Class de McCabe. }\end{array}$ \\
\hline & & CompClass & $\begin{array}{l}\text { Valor da métrica Weighted Methods per Class de McCabe para uma } \\
\text { classe. }\end{array}$ \\
\hline & Q.02 & CompVarPointClass & $\begin{array}{l}\text { Soma do valor de CompClass de todas as variantes associadas, mais o } \\
\text { valor de CompClass do ponto de variação. }\end{array}$ \\
\hline & Q.03 & CompVariabilityClass & $\begin{array}{l}\text { Soma do valor de CompClass ou CompVarPointClass associado a todas as } \\
\text { variabilidades em modelos de classes. }\end{array}$ \\
\hline & Q.04 & CompVarComponent & $\begin{array}{l}\text { Soma de CompVariabilityClass para todas as variabilidades associadas a } \\
\text { classes que formam um componente. }\end{array}$ \\
\hline & Q.05 & CompPLA & Soma de CompVarComponent de todos os componentes de uma ALP. \\
\hline \multirow{6}{*}{ Extensibilidade } & \multirow[b]{2}{*}{ Q.06 } & ExtensI nterface & Sempre o valor 1.0 , pois é $100 \%$ extensível. \\
\hline & & ExtensClass & $\begin{array}{l}\text { Número de métodos abstratos dividido pelo número de métodos } \\
\text { abstratos, mais métodos concretos de uma classe. }\end{array}$ \\
\hline & Q.07 & ExtensVarPointClass & $\begin{array}{l}\text { Valor de ExtensClass de uma classe abstrata ou interface, multiplicado } \\
\text { pelo número de suas subclasses ou classes de implementação. }\end{array}$ \\
\hline & Q.08 & ExtensVariabilityClass & $\begin{array}{l}\text { Soma de ExtensClass ou ExtensVarPointClass associado com todas as } \\
\text { variabilidade em modelos de classes. }\end{array}$ \\
\hline & Q.9 & ExtensVarComponent & $\begin{array}{l}\text { Soma de ExtensVariabilityClass para todas as variabilidades associadas } \\
\text { com classes que formam um componente. }\end{array}$ \\
\hline & Q.10 & ExtensPLA & Soma de ExtensVarComponent de todos os componentes de uma ALP. \\
\hline
\end{tabular}


A Figura 5.4 mostra o modelo GQM, como sugerido pela diretriz DP.5, para a LP AGM, como resultado das diretrizes de planejamento. O modelo de interpretação do GQM para a LP AGM é estabelecido da seguinte forma: os valores coletados para cada métrica ajudam a responder as questões propostas que, por sua vez, ajudam a verificar se as metas de negócio estabelecidas para a LP em questão são satisfeitas. Além disso, a interpretação bottom-up do modelo GQM para a AGM permite ajustar, por meio das métricas definidas, as metas de negócio MN.1 2 MN.2.

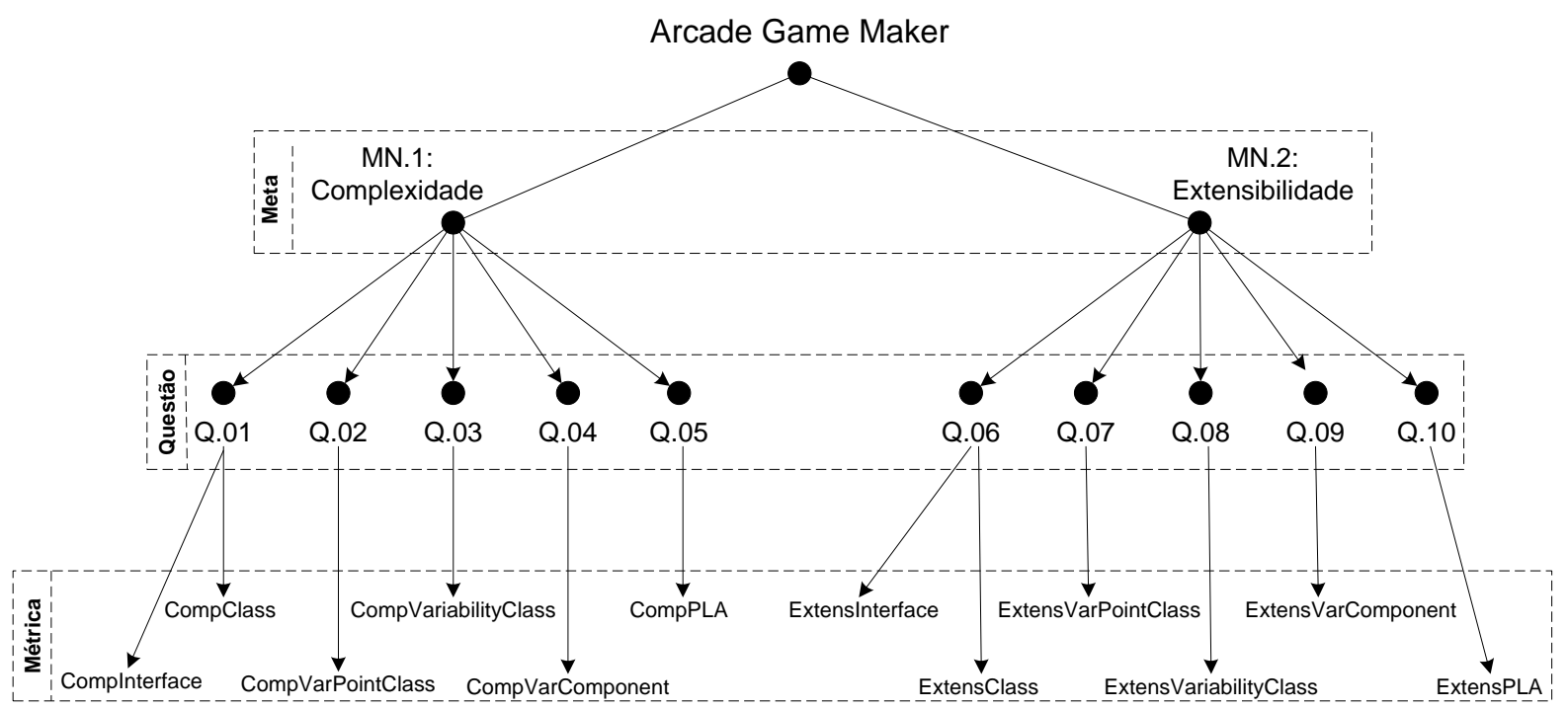

Figura 5.4: Modelo Goal-Question-Metric para a LP AGM.

Como mencionado na Seção 5.2, as pós-condições da fase de planejamento são: a instanciação do MPA e a definição dos artefatos para avaliar uma ALP, incluindo as métricas de atributos de qualidade definidas. As Seções 6.2.1 e 6.2.2 apresentam as definições formais de tais métricas para o exemplo da LP AGM. Essas métricas usam algumas das métricas básicas fornecidas pelo método SystEM-PLA, para as suas definições.

\subsubsection{Diretrizes de Coleta de Dados (DC)}

Uma configuração de ALP, ou simplesmente configuração, é uma instância da ALP que representa uma arquitetura de produtos únicos na qual, a maioria das suas variabilidades estão resolvidas. Para domínios específicos como, por exemplo, sistemas adaptativos (Salehie e Tahvildari, 2009), variabilidades em tempo de compilação, ligação e execução podem ser adiadas. Assim, o usuário pode realizar análises de trade-off de ALP com respeito aos seus produtos e aos seus atributos de qualidade.

Os seguintes itens apresentam as diretrizes para a coleta de dados (DC): 
DC.1 Criar configurações de ALP: pode ser realizada de forma manual ou automática. A primeira forma exige uma ou mais pessoas para ser realizada. Além disso, requer muito mais atenção, já que as pessoas envolvidas nesta atividade devem verificar se as configurações criadas são válidas com relação a certas restrições entre variabilidades. A outra forma é mais confiável, visto que podem ser usadas ferramentas como, por exemplo, Captor (2010), pure::variants (Pure-Systems, 2010) e SPLOT (Mendonça et al., 2009; SPLOT, 2010) para gerar configurações válidas. Contudo, pode ser necessário mais tempo para aprender todas as funcionalidades das ferramentas. O mais importante, porém, é criar o máximo possível de configurações para tornar as análises estatística e de trade-off mais confiáveis e precisas.

DC.2 Aplicar e coletar métricas a partir das configurações de ALP: isto é feito calculando as métricas de atributos de qualidade aplicadas às configurações de ALP criadas. Esta atividade pode ser realizada manual ou automaticamente. Recomenda-se fortemente o uso de uma ferramenta automatizada como, por exemplo, a SDMetrics (SDMetrics, 2010). Esse tipo de ferramenta automatizada fornece características para definir métricas customizadas e calculá-las, a partir de modelos UML exportados em arquivos XMI. Por exemplo, para as configurações da ALP AGM criadas por meio da diretriz DC.1 foram aplicadas as métricas de complexidade e extensibilidade (Seção 6.2). Assim, a Tabela 5.8 apresenta os valores observados para as métricas CompPLA e ExtensPLA.

Tabela 5.8: Valores Observados das Métricas de Complexidade e Extensibilidade para Configurações AGM.

\begin{tabular}{|c|c|c|}
\hline Configuração $\mathbf{N}^{\mathbf{0}}$ & CompPLA & ExtensPLA \\
\hline $\mathbf{0 1}$ & 0,51 & 0,61 \\
\hline $\mathbf{0 2}$ & 0,56 & 0,61 \\
\hline $\mathbf{0 3}$ & 0,51 & 0,81 \\
\hline $\mathbf{0 4}$ & 0,83 & 0,80 \\
\hline $\mathbf{0 5}$ & 0,91 & 1,00 \\
\hline $\mathbf{0 6}$ & 0,50 & 0,61 \\
\hline $\mathbf{0 7}$ & 0,47 & 0,61 \\
\hline $\mathbf{0 8}$ & 0,53 & 0,61 \\
\hline $\mathbf{0 9}$ & 0,67 & 0,80 \\
\hline $\mathbf{1 0}$ & 0,90 & 1,00 \\
\hline
\end{tabular}

\begin{tabular}{|c|c|c|}
\hline Configuração $^{\mathbf{0}}$ & CompPLA & ExtensPLA \\
\hline $\mathbf{1 1}$ & 0,53 & 0,61 \\
\hline $\mathbf{1 2}$ & 0,97 & 1,00 \\
\hline $\mathbf{1 3}$ & 0,48 & 0,61 \\
\hline $\mathbf{1 4}$ & 0,69 & 0,61 \\
\hline $\mathbf{1 5}$ & 0,74 & 0,80 \\
\hline $\mathbf{1 6}$ & 0,98 & 1,00 \\
\hline $\mathbf{1 7}$ & 0,77 & 0,80 \\
\hline $\mathbf{1 8}$ & 0,82 & 0,80 \\
\hline $\mathbf{1 9}$ & 0,52 & 0,61 \\
\hline $\mathbf{2 0}$ & 0,82 & 0,80 \\
\hline
\end{tabular}

\begin{tabular}{|c|c|c|}
\hline Configuração $\mathbf{N}^{\mathbf{0}}$ & CompPLA & ExtensPLA \\
\hline $\mathbf{2 1}$ & 0,49 & 0,61 \\
\hline $\mathbf{2 2}$ & 1,00 & 1,00 \\
\hline $\mathbf{2 3}$ & 0,52 & 0,61 \\
\hline $\mathbf{2 4}$ & 0,42 & 0,61 \\
\hline $\mathbf{2 5}$ & 0,62 & 0,80 \\
\hline $\mathbf{2 6}$ & 0,47 & 0,61 \\
\hline $\mathbf{2 7}$ & 0,53 & 0,61 \\
\hline $\mathbf{2 8}$ & 0,70 & 0,80 \\
\hline $\mathbf{2 9}$ & 0,40 & 0,61 \\
\hline $\mathbf{3 0}$ & 0,78 & 0,80 \\
\hline
\end{tabular}

\subsubsection{Diretrizes de Análise de Dados e Documentação (DA)}

A análise de dados é realizada com base nos artefatos produzidos e nos dados coletados em fases anteriores do SystEM-PLA.

Alguns desses artefatos levam o usuário a uma análise quantitativa como, por exemplo: 
- Quantos produtos são no máximo $15 \%$ menos complexos que a própria ALP? Um número alto para esta questão pode significar problemas de manutenção e desenvolvimento;

- Qual é o impacto, em termos do grau de extensibilidade para a ALP geral, ao substituir algumas classes abstratas (pontos de variação) por interfaces? Se o impacto for positivo, isso pode significar uma melhor aplicação dos conceitos de "program to interface", polimorfismo e dos padrões de projeto Template e Factory; e

- Quantos produtos do conjunto de configurações de ALP criadas, satisfazem os cenários dos atributos de qualidade selecionados? Quanto maior esse número, mais fácil é alcançar as metas de negócio da ALP e, consequentemente, menor é a complexidade e maior é a extensibilidade dos produtos de uma LP.

Alguns artefatos levam o usuário a uma análise qualitativa como, por exemplo:

- As metas de negócio são apropriadas aos atributos de qualidade de uma ALP? Caso sejam, é possível re-escrever tais metas de negócio para alcançar melhores produtos? Caso não sejam, elas devem ser redefinidas?

- Com base nos valores observados das métricas de atributos de qualidade, pode-se dizer que o atributo de qualidade "A" deve ser mais priorizado do que os atributos de qualidade "B", "C", ..., "N" durante o desenvolvimento de produtos de uma LP?

Assim, os próximos itens apresentam as diretrizes para análise de dados e documentação (DA):

DA.1 Plotar os dados coletados em uma ou mais formas de representação gráfica: apresentar os dados coletados usando diferentes representações gráficas, tais como: estatística descritiva e gráficos de distribuição de frequência que são extremamente importantes para análises estatísticas; gráficos em barra e pizza, pois fornecem informações com relação a valores observados sobre valores totais de uma medida; e histograma de dispersão, pois são úteis para comparar o comportamento de dois ou mais conjuntos diferentes de medidas, plotados em um mesmo gráfico.

Para a LP AGM, os dados coletados foram plotados em gráficos de distribuição de frequência e estatística descritiva, Figuras 5.5 e 5.6, e em um histograma de dispersão, Figura 5.7. Essas figuras são explicadas em detalhe no Capítulo 7. 


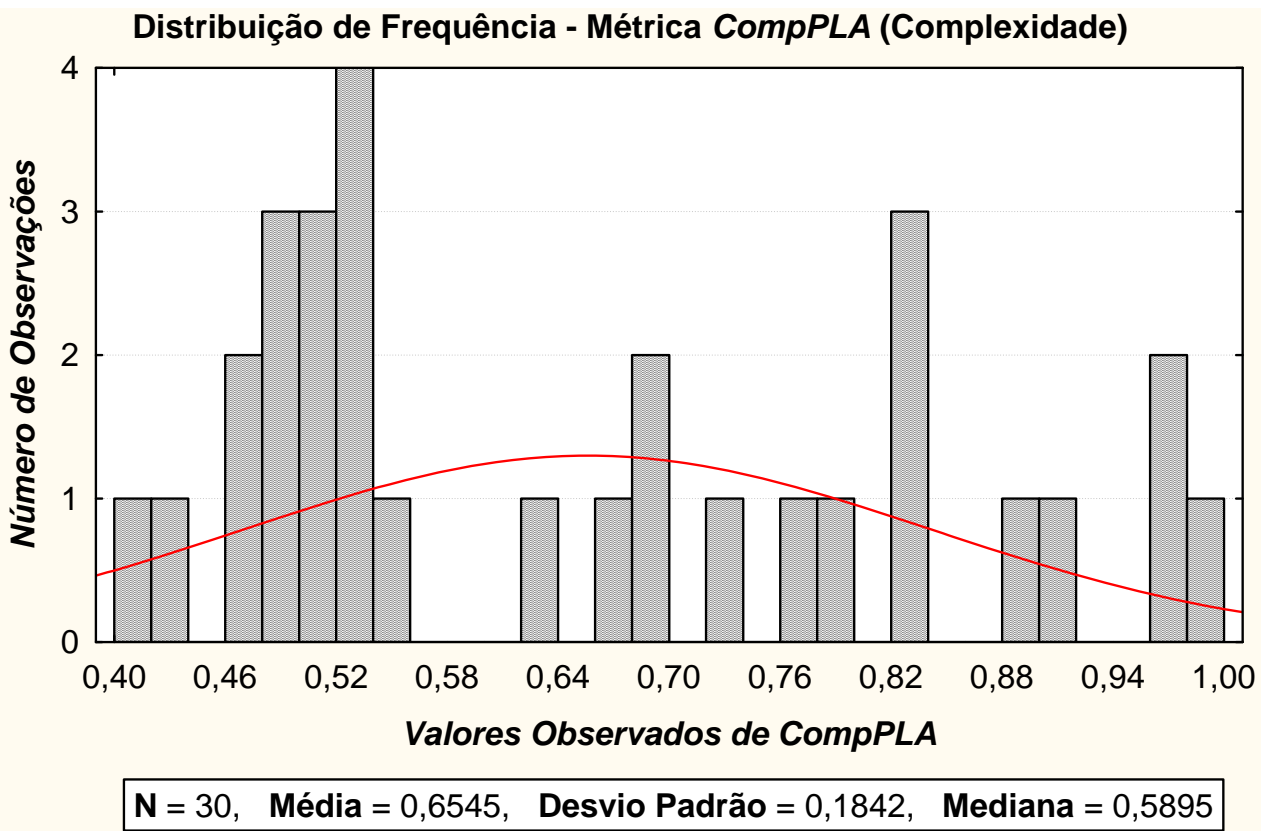

Figura 5.5: Estatística Descritiva e Distribuição de Frequência dos Valores Observados da Métrica CompPLA.

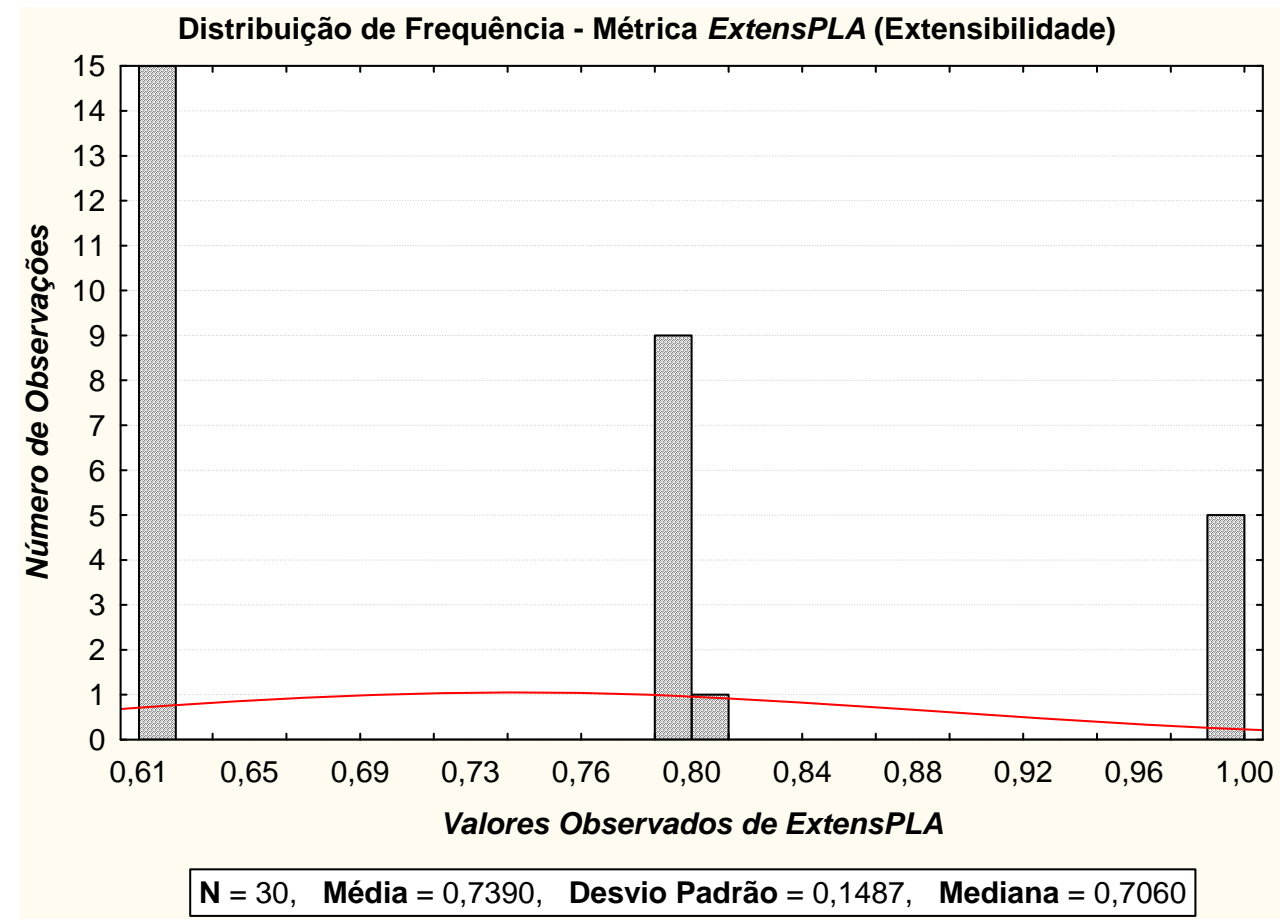

Figura 5.6: Estatística Descritiva e Distribuição de Frequência dos Valores Observados da Métrica ExtensPLA. 
DA.2 Analisar a estatística descritiva dos dados coletados: isto deve ser feito com base em algumas informações estatísticas importantes com relação aos dados coletados, tais como:

- número de elementos observados $(\mathrm{N})$;

- média aritmética $(\mu)$, que é a soma de todos os valores observados, dividido pelo número de valores observados $(\mathrm{N})$;

- desvio padrão $(\sigma)$, que mostra a quantidade de variação que existe com relação à média aritmética; e

- mediana $\left(\mu_{d}\right)$, que é um valor numérico central, separando a metade de maiores valores, da metade de menores valores.

Com base na estatística descritiva dos valores observados das métricas CompPLA e ExtensPLA para a LP AGM foi possível observar que:

- Análise $\mathrm{N}^{\mathrm{o}}$ 1: na Figura 5.5, referente à métrica CompPLA, o valor da mediana é 0,5895. Isso significa que:

- 15 configurações (50\%) possuem valores de CompPLA menores ou iguais a 0,5895 ; e

- 15 configurações (50\%) possuem valores de CompPLA maiores que 0,5895.

- Análise $\mathrm{N}^{\mathrm{o}}$ 2: na Figura 5.6, referente à métrica ExtensPLA, o valor da mediana é 0,7060. Isso significa que:

- 15 configurações (50\%) possuem valor de ExtensPLA menores ou iguais a 0,$7060 ; \mathrm{e}$

- 15 configurações (50\%) possuem valor de ExtensPLA maiores que 0,7060.

\section{DA.3 Identificar quantos cenários satisfazem os atributos de qualidade seleci-} onados: com base na análise realizada sobre as estatísticas descritivas dos dados coletados, é possível identificar quais cenários satisfazem os atributos de qualidade selecionados. Isso é muito importante para verificar se os cenários são apropriados aos atributos de qualidade ou se é necessário reescrevê-los. Com base no método SystEM-PLA, acredita-se que pelo menos 50\% dos cenários devem satisfazer os atributos de qualidade selecionados. Caso contrário, os cenários não fornecerão uma forma de realizar análises de trade-off confiáveis.

Para a LP AGM, a criação dos produtos exercita o cenário Cn.1, para complexidade, e os cenários Cn.4 e Cn.5, para extensibilidade. Assim, pode-se dizer que: 
- com base na Análise No 1 (diretriz DA.2), o cenário Cn.1 (Tabela 5.2) é satisfeito para o atributo de qualidade, complexidade. Durante a criação das configurações AGM, pontos de variação e variantes foram modificados ou removidos, de acordo com o tipo de produto criado. Assim, o cenário Cn.1 mantém a meta de negócio MN.1 verdadeira, já que 18 das 30 configurações (60,00\%) possuem valores de CompPLA menores que 0,70 (veja Figura 5.5);

- com base na Análise No 2 (diretriz DA.2), os cenários Cn.4 e Cn.5 (Tabela 5.3) são satisfeitos para o atributo de qualidade, extensibilidade. Durante a criação das configurações AGM, pontos de variação e variantes foram modificados ou removidos, de acordo com o tipo de produto criado. Assim, os cenários Cn.4 e Cn.5 mantém a meta de negócio MN.2 verdadeira, já que 15 das 30 configurações (50\%) possuem valores de ExtensPLA maiores que 0,75 (veja Figura 5.6);

\section{DA.4 Identificar qual(is) atributo(s) de qualidade selecionado(s) satisfaz(em) a}

ALP: considerando a porcentagem de cenários que satisfazem os atributos de qualidade selecionados, pode-se determinar qual(is) atributo(s) de qualidade satisfaz(em) a ALP.

Para a LP AGM, ambos os atributos de qualidade, complexidade e extensibilidade satisfazem a ALP, já que $100 \%$ de seus cenários são satisfeitos.

DA.5 Realizar análise(s) de trade-off: isto é feito levando em consideração os atributos selecionados que satisfazem a ALP, definidos a partir da diretriz DA.4, para decidir qual(is) deve(m) ser priorizado(s) para o desenvolvimento e evolução dos produtos de uma LP.

Para a LP AGM, essa análise foi realizada plotando os valores observados para as métricas CompPLA e ExtensPLA em um histograma de dispersão, apresentado na Figura 5.7. Pode-se observar nessa figura que os produtos mais interessantes são aqueles que possuem valores de CompPLA $<0,7$ (MN.1) e ExtensPLA $>$ 0,75 (MN.2). Assim, três principais produtos tornam-se interessantes para a LP AGM: o primeiro com CompPLA =0,50 e ExtensPLA $=0,81$; o segundo com CompPLA =0,67 e ExtensPLA =0,80; e o terceiro com CompPLA =0,62 e ExtensPLA $=0,80$. Assim, deve-se considerar que:

- o valor de ExtensPLA para os três produtos é 0,80 ou 0,81 , o que pode ser um indicador de que produtos similares devem priorizar complexidade em vez de extensibilidade; e 
- a porcentagem de satisfação, com base nos atributos de qualidade selecionados para complexidade $(60,00 \%)$ é maior que a porcentagem de satisfação do atributo de qualidade, extensibilidade (50\%). Isso significa que 60,00\% dos produtos gerados para a LP AGM satisfazem o atributo de qualidade complexidade, por meio do cenário Cn.1, enquanto 50\% dos produtos satisfazem extensibilidade, por meio dos cenários Cn.4 e Cn.5.

A região hachurada na Figura 5.7 com valores entre 0,70 e 0,75 contém produtos que não são interessantes para a LP AGM, já que não estão em conformidade com as metas de negócio estabelecidas. Assim, pode-se concluir, com base na análise de trade-off e seus indicadores, que, para a ALP da AGM, complexidade deve ser priorizada com relação à extensibilidade.

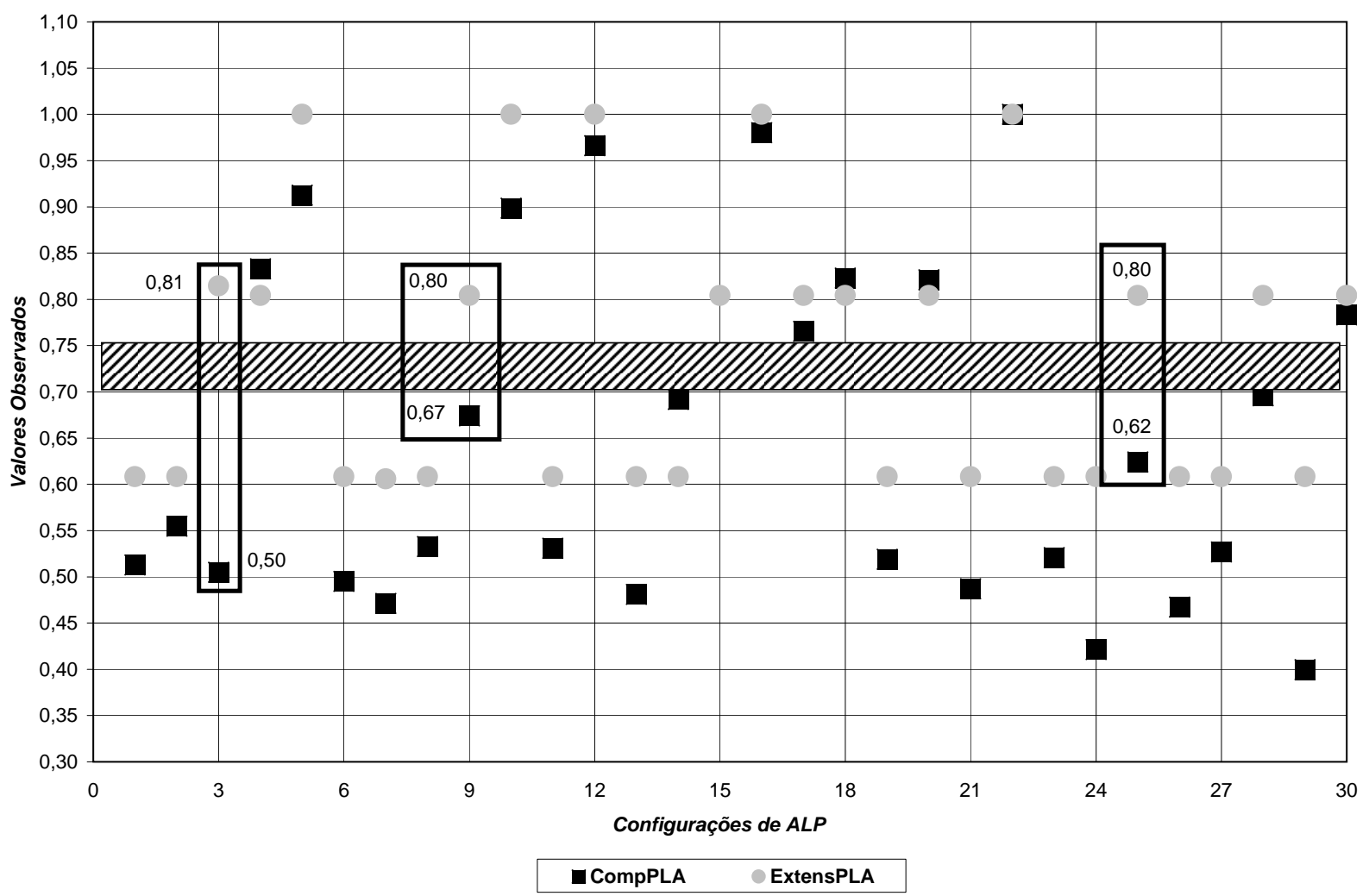

Figura 5.7: Histograma de Dispersão dos Valores Observados das Métricas CompPLA e ExtensPLA para as Configurações AGM.

DA.6 Escrever um relatório final de avaliação: para documentar todas as atividades de avaliação, bem como os artefatos produzidos, os dados coletados e os gráficos e tabelas geradas, recomenda-se escrever um relatório no estilo ATAM (Clements et al. 2002b), já que este é um padrão amplamente conhecido pela comunidade de avaliação de arquitetura de software. 
DA.7 Armazenar todos os artefatos produzidos no repositório: o método SystEM-PLA possui um repositório de artefatos que permite que esses sejam armazenados apoiando a replicação de avaliações.

\subsection{Considerações Finais}

A avaliação de uma ALP não é uma atividade simples, como se pode constatar no Capítulo 3 relacionado à revisão bibliográfica desta tese. Um dos grandes desafios na avaliação de uma ALP é a complexidade inerente de se avaliar todas as possíveis arquiteturas dos produtos únicos que uma LP é capaz de gerar. Além disso, grande parte das abordagens adotadas para o desenvolvimento de LP não se baseiam em notações consolidadas como, por exemplo, a UML, para estabelecer e representar as variabilidades de uma LP. Muito pelo contrário, métodos e processos particulares a determinados domínios são usados para tal. Outro fator que dificulta a realização de avaliações de ALP é a falta de métricas que permitam analisar quantitativa e experimentalmente uma ALP.

Dessa forma, este capítulo apresentou o SystEM-PLA como um método proposto para avaliar ALP baseada em UML, segundo a abordagem SMarty. O SystEM-PLA, como visto ao longo deste capítulo, permite que atributos de qualidade de uma ALP possam ser analisados e priorizados experimentalmente, por meio da definição de metas de negócio, cenários, questões técnicas e gerenciais e métricas de atributos de qualidade. Para tanto, o MPA deve ser instanciado, seguindo um conjunto de diretrizes de avaliação que guiam o usuário no planejamento, coleta de dados e análise de dados e documentação de avaliações de ALP. O SystEM-PLA é fortemente baseado nos conceitos de avaliação de arquiteturas de software do método ATAM e nos conceitos dos métodos EATAM e HoPLSAA.

Para a ilustração do SystEM-PLA foi utilizada a LP AGM (Apêndice A). Assim, as atividades do MPA, bem como as diretrizes do SystEM-PLA puderam ser ilustradas definindo artefatos para a AGM, permitindo mostrar como análises de trade-off podem ser realizadas para priorizar atributos de qualidade, para o desenvolvimento e evolução de produtos gerados a partir de uma ALP.

As métricas definidas para os atributos de qualidade complexidade e extensibilidade, usados para ilustrar este capítulo são definidas formalmente no próximo capítulo, bem como são apresentadas as métricas básicas que permitem a composição de novas métricas com base no SystEM-PLA. Além disso, o Capítulo 7 apresenta a validação experimental de tais métricas.

Ao final das avaliações, todos os artefatos produzidos e dados coletados devem ser armazenados no repositório de artefatos do SystEM-PLA. Utilizando tal repositório, re- 
plicações de avaliações podem ser feitas, bem como dados históricos podem ser recuperados para estudos experimentais de validação de métricas e configurações de ALP.

Um estudo de viabilidade do método SystEM-PLA é apresentado no Capítulo 8. 


ำ

\section{Métricas para Avaliação de Arquitetura de LP}

"A verdadeira medida de um homem

não é como ele se comporta em

momentos de conforto e conveniência, mas como ele se mantém em tempos de controvérsia e desafio."

M. Luther King Jr. (1929 - 1968), Ativ. Político, Prêmio Nobel (1964)

O método SystEM-PLA fornece um conjunto de métricas baseadas em UML, de apoio à avaliação de ALP. Tais métricas são aplicadas a modelos de LP com o objetivo de coletar dados que auxiliam na realização de análises quantitativas e qualitativas, além de trade-offs. Para tanto, dois tipos de métricas são considerados pelo método SystEM-PLA, sendo elas:

- Métricas Básicas: visam medir elementos UML essenciais aos modelos de LP como, por exemplo, classes e componentes, com o objetivo de apoiar a definição de métricas compostas para atributos de qualidade. Este tipo de métrica é apresentado na seção 6.1; e

- Métricas de Atributos de Qualidade: são compostas com base nas métricas básicas e visam medir atributos de qualidade de uma ALP. A apresentação das métricas desse tipo é feita Seção 6.2. 
A nomenclatura das métricas do SystEM-PLA é composta por cinco partes, separadas pelo caracter "_", sendo elas, respectivamente:

1. a sigla referente à metaclasse UML que está sendo medida;

2. a sigla do modelo UML, usado na medição da primeira parte;

3. a sigla do tipo de métrica que está sendo medida;

4. a sigla do tipo de elemento de variabilidade que está sendo medido; e

5. a sigla do tipo de medida que está sendo realizada.

Por exemplo, a métrica básica (BAS) $C L S \_C L S \_B A S \_V P T \_I S A$ indica se uma classe (CLS) é um (ISA) ponto de variação (VPT). A métrica $C L S \_I T F \_B A S \_I N C \_N U M$ é básica (BAS) e mede o número (NUM) de interfaces (ITF), que são variantes inclusivas (INC), implementadas por uma classe (CLS).

A Tabela 6.1 apresenta as siglas usadas para formar o nome das métricas baseadas em UML do método SystEM-PLA. O conjunto de siglas não é definitivo, permitindo que novas siglas sejam adicionadas à medida que novas métricas vão sendo definidas. Note que a sigla MDL refere-se ao conjunto de todos os modelos UML de uma LP.

Tabela 6.1: Siglas Usadas para Formar o Nome das Métricas Baseadas em UML.

\begin{tabular}{|c|c|c|c|c|}
\hline Sigla & Modelo UML & Tipo de Métrica & Elemento de Variabilidade & Tipo de Medida \\
\hline \hline ITF & Interface & - & - & - \\
\hline CLS & Classe & - & - & - \\
\hline CPT & Componente & - & - & - \\
\hline DGM & Diagrama & - & - & - \\
\hline MDL & Modelo & - & - & - \\
\hline \hline BAS & - & Básica & - & - \\
\hline CLX & - & Complexidade & - & - \\
\hline EXT & - & Extensibilidade & Variabilidade & - \\
\hline \hline VBT & - & - & Ponto de Variação & - \\
\hline VPT & - & - & Variação & - \\
\hline VTN & - & - & Variante Inclusiva & - \\
\hline INC & - & - & Variante Exclusiva & - \\
\hline EXC & - & - & Variante Opcional & - \\
\hline OPT & - & - & Variante Obrigatória & - \\
\hline MND & - & - & - & É um/uma \\
\hline \hline ISA & - & - & - & Possui um/uma \\
\hline HAS & - & - & - & Qúmero/Quantidade \\
\hline NUM & - & - & - & Quantia Total \\
\hline TOT & - & - & &
\end{tabular}


A Seção 6.1 apresenta as 52 métricas básicas fornecidas pelo SystEM-PLA, a Seção 6.2 enumera as métricas para os atributos de qualidade complexidade e extensibilidade, enquanto a Seção 6.3 mostra como as métricas são automatizadas usando a ferramenta SDMetrics. Um exemplo completo de aplicação e coleta das métricas de atributos de qualidade, com base nas configurações da LP AGM (Apêndice A) geradas como resultado do estudo piloto para a validação experimental de tais métricas, é apresentado na Seção 6.4. A validação experimental de tais métricas é apresentada no Capítulo 7.

\subsection{Métricas Básicas}

As métricas básicas visam medir modelos UML representados pelas seguintes metaclasses do metamodelo padrão da UML: Interface, Class, Component, Dependency e Comment. As métricas indicam quais modelos são pontos de variação e quais indicam variantes inclusivas, exclusivas, opcionais e obrigatórias. As métricas também medem o número de pontos de variação e variantes em cada diagrama dos modelos de LP e da ALP em geral Oliveira Junior et al. (2008).

As métricas básicas podem ser usadas para compor novas métricas para atributos de qualidade de uma ALP. Exemplos de composição de métricas para atributos de qualidade são apresentados na Seção 6.2 e em Oliveira Junior et al. (2008), que discorrem sobre as métricas e apresentam exemplos de coleta para uma LP de Workflow Management Systems.

Cada métrica está classificada em uma das seguintes categorias:

- variation point: indica métricas específicas à medição de pontos de variação;

- variant: indica métricas específicas à medição de variantes; e

- variability: indica métricas específicas à medição de variabilidades.

Os itens a seguir apresentam a descrição de cada uma das métricas básicas fornecidas pelo método SystEM-PLA, divididas em: métricas para classes e interfaces, diagramas, componentes e modelos de LP. O código XML de cada uma delas é apresentado no Apêndice B. Vale lembrar que o conjunto de métricas básicas aqui apresentado não é restrito e, portanto, permite que novas métricas sejam definidas e incorporadas às atuais.

\subsubsection{Métricas Básicas de Classes e Interfaces}

É definido um subconjunto de 32 métricas, sendo 16 para classes e 16 para interfaces. As 16 métricas básicas de classes são apresentadas nos itens a seguir: 
1. $\boldsymbol{C L} \boldsymbol{S} \_\boldsymbol{C L} \boldsymbol{S}_{-} \boldsymbol{B} \boldsymbol{A} \boldsymbol{S}_{-} \boldsymbol{V P T} \boldsymbol{T} \_\boldsymbol{I S A} \boldsymbol{A}$ : indica se uma classe é um Ponto de Variação. Esta métrica possui valor 1 para classes marcadas com o estereótipo «variationPoint》 e valor 0 , caso contrário;

2. $\boldsymbol{C L} \boldsymbol{S} \_\boldsymbol{C L} \boldsymbol{S} \_\boldsymbol{B} \boldsymbol{A} \boldsymbol{S} \_\boldsymbol{I} \boldsymbol{N} \boldsymbol{C} \_\boldsymbol{I S} \boldsymbol{A}$ : indica se uma classe é uma Variante Inclusiva. Esta métrica possui valor 1 para classes marcadas com o estereótipo «alternative_OR $\gg$ e valor 0 , caso contrário;

3. $\boldsymbol{C L} \boldsymbol{S} \_\boldsymbol{C L} \boldsymbol{S} \_\boldsymbol{B} \boldsymbol{A} \boldsymbol{S} \_\boldsymbol{E} \boldsymbol{X} \boldsymbol{C} \_\boldsymbol{I} \boldsymbol{S} \boldsymbol{A}$ : indica se uma classe é uma Variante Exclusiva. Esta métrica possui valor 1 para classes marcadas com o estereótipo «alternative_XOR $\gg$ e valor 0 , caso contrário;

4. $\boldsymbol{C L} \boldsymbol{S} \_\boldsymbol{C L} \boldsymbol{S}_{-} \boldsymbol{B} \boldsymbol{A} \boldsymbol{S} \_\boldsymbol{O P} \boldsymbol{T}_{-} \boldsymbol{I S} \boldsymbol{A}$ : indica se uma classe é uma Variante Opcional. Esta métrica possui valor 1 para classes marcadas com o estereótipo «optional» e valor 0 , caso contrário;

5. $\boldsymbol{C L} \boldsymbol{S} \_\boldsymbol{C L} \boldsymbol{S} \_\boldsymbol{B} \boldsymbol{A} \boldsymbol{S} \_\boldsymbol{M N D} \boldsymbol{I} \boldsymbol{S} \boldsymbol{A}$ : indica se uma classe é uma Variante Obrigatória. Esta métrica possui valor 1 para classes marcadas com o estereótipo «mandatory》 e valor 0 , caso contrário;

6. $\boldsymbol{C L} \boldsymbol{S} \_\boldsymbol{C L} \boldsymbol{S} \_\boldsymbol{B} \boldsymbol{A} \boldsymbol{S} \_\boldsymbol{I N} \boldsymbol{C} \_\boldsymbol{N} \boldsymbol{U} \boldsymbol{M}$ : número de subclasses, que são Variantes Inclusivas, de uma classe que é Ponto de Variação. Esta métrica é representada pela Equação (7.1):

$$
\left.\begin{array}{l}
\boldsymbol{C L} \boldsymbol{S} \_\boldsymbol{C L} \boldsymbol{S} \_\boldsymbol{B} \boldsymbol{A} \boldsymbol{S} \_\boldsymbol{I N} \boldsymbol{C} \_\boldsymbol{N} \boldsymbol{U} \boldsymbol{M}\left(\boldsymbol{C}_{v p}\right)=\sum_{i=1}^{n} C L S_{-} C L S_{-} B A S_{-} I N C_{-} I S A\left(S C_{i}\right), \\
\text { tal que: } \\
n=\text { número de subclasses }(S C) \text { da classe } C_{v p} \text { que é ponto de variação }
\end{array}\right\}
$$

7. $\boldsymbol{C L} \boldsymbol{S} \_\boldsymbol{C L} \boldsymbol{S} \_\boldsymbol{B} \boldsymbol{A} \boldsymbol{S} \_\boldsymbol{E} \boldsymbol{X} \boldsymbol{C} \_\boldsymbol{N} \boldsymbol{U} \boldsymbol{M}$ : número de subclasses, que são Variantes Exclusivas, de uma classe que é um Ponto de Variação. Esta métrica é representada pela Equação (7.2):

$$
\left.\begin{array}{l}
\boldsymbol{C L} \boldsymbol{S} \_\boldsymbol{C L} \boldsymbol{S} \_\boldsymbol{B} \boldsymbol{A} \boldsymbol{S} \_\boldsymbol{E} \boldsymbol{X} \boldsymbol{C} \_\boldsymbol{N} \boldsymbol{U} \boldsymbol{M}\left(\boldsymbol{C}_{v p}\right)=\sum_{i=1}^{n} C L S \_C L S \_B A S \_E X C \_I S A\left(S C_{i}\right), \\
\text { tal que: } \\
n=\text { número de subclasses }(S C) \text { da classe } C_{v p} \text { que é ponto de variação }
\end{array}\right\}
$$


8. $\boldsymbol{C L} \boldsymbol{S} \_\boldsymbol{C L} \boldsymbol{S} \_\boldsymbol{B} \boldsymbol{A} \boldsymbol{S} \_\boldsymbol{O P} \boldsymbol{T}_{-} \boldsymbol{N} \boldsymbol{U} \boldsymbol{M}$ : número de classes, que são Variantes Opcionais, associadas a uma determinada classe. Esta métrica é representada pela Equação (7.3):

$$
\left.\begin{array}{l}
\boldsymbol{C L} \boldsymbol{S}_{-} \boldsymbol{C L S} \boldsymbol{S} \boldsymbol{B} \boldsymbol{A} \boldsymbol{S}_{-} \boldsymbol{O P} \boldsymbol{T}_{-} \boldsymbol{N} \boldsymbol{U} \boldsymbol{M}(\boldsymbol{C})=\sum_{i=1}^{n} C L S_{-} C L S_{-} B A S_{-} O P T_{-} I S A\left(C l s_{i}\right), \\
\text { tal que: } \\
n=\text { número de classes }(C l s) \text { associadas à classe } C
\end{array}\right\}
$$

9. $\boldsymbol{C L} \boldsymbol{S} \_\boldsymbol{C L} \boldsymbol{S} \_\boldsymbol{B} \boldsymbol{A} \boldsymbol{S}_{-} \boldsymbol{M} \boldsymbol{N} \boldsymbol{D} \_\boldsymbol{N} \boldsymbol{U} \boldsymbol{M}$ : número de classes, que são Variantes Obrigatórias, associadas a uma determinada classe. Esta métrica é representada pela Equação (7.4):

$$
\left.\begin{array}{l}
\boldsymbol{C L} \boldsymbol{S} \_\boldsymbol{C} \boldsymbol{L} \boldsymbol{S} \_\boldsymbol{B} \boldsymbol{A} \boldsymbol{S} \_\boldsymbol{M} \boldsymbol{N} \boldsymbol{D} \_\boldsymbol{N} \boldsymbol{U} \boldsymbol{M}(\boldsymbol{C})=\sum_{i=1}^{n} C L S_{-} C L S \_B A S \_M N D \_I S A\left(C l s_{i}\right), \\
\text { tal que: } \\
n=\text { número de classes }(C l s) \text { associadas à classe } C
\end{array}\right\}
$$

10. $\boldsymbol{C L} \boldsymbol{S} \_\boldsymbol{C L} \boldsymbol{S} \_\boldsymbol{B} \boldsymbol{A} \boldsymbol{S} \_\boldsymbol{V P T} \boldsymbol{T} \boldsymbol{N} \boldsymbol{U} \boldsymbol{M}$ : número de classes, que são Pontos de Variação, associadas a uma determinada classe. Esta métrica é representada pela Equação (7.5):

$$
\left.\begin{array}{l}
\boldsymbol{C L} \boldsymbol{S}_{-} \boldsymbol{C L} \boldsymbol{S} \_\boldsymbol{B} \boldsymbol{A} \boldsymbol{S}_{-} \boldsymbol{V P P} \boldsymbol{T}_{-} \boldsymbol{N} \boldsymbol{U M}(\boldsymbol{C})=\sum_{i=1}^{n} C L S_{-} C L S_{-} B A S_{-} V P T_{-} I S A\left(C l s_{i}\right), \\
\text { tal que: } \\
n=\text { número de classes }(C l s) \text { associadas à classe } C
\end{array}\right\}
$$


11. $\boldsymbol{C} \boldsymbol{L} \boldsymbol{S} \_\boldsymbol{I} \boldsymbol{T} \boldsymbol{F} \_\boldsymbol{B} \boldsymbol{A} \boldsymbol{S} \_\boldsymbol{I N} \boldsymbol{C} \_\boldsymbol{N} \boldsymbol{U} \boldsymbol{M}$ : número de interfaces, que são Variantes Inclusivas, associadas a uma determinada classe. Esta métrica é representada pela Equação (6.6):

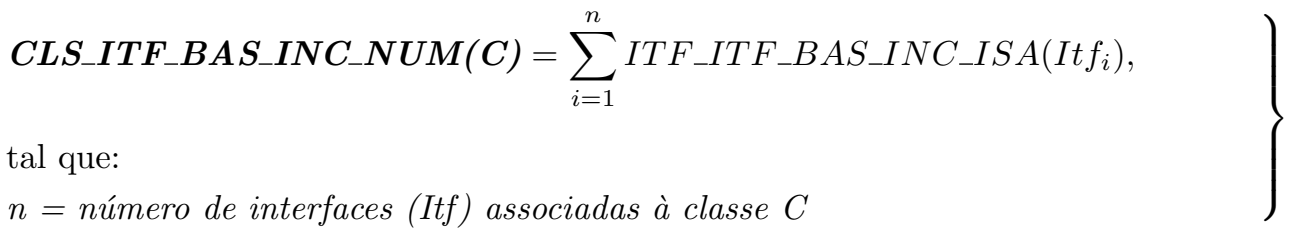

12. $\boldsymbol{C} \boldsymbol{L} \boldsymbol{S} \_\boldsymbol{I} \boldsymbol{T} \boldsymbol{F} \_\boldsymbol{B} \boldsymbol{A} \boldsymbol{S} \_\boldsymbol{E} \boldsymbol{X} \boldsymbol{C} \_\boldsymbol{N} \boldsymbol{U} \boldsymbol{M}$ : número de interfaces, que são Variantes Exclusivas, associadas a uma determinada classe. Esta métrica é representada pela Equação (6.7):

$$
\left.\begin{array}{l}
\boldsymbol{C L} \boldsymbol{S}_{-} \boldsymbol{I} \boldsymbol{T} \boldsymbol{F}_{-} \boldsymbol{B} \boldsymbol{A} \boldsymbol{S}_{-} \boldsymbol{E} \boldsymbol{X} \boldsymbol{C}_{-} \boldsymbol{N} \boldsymbol{U} \boldsymbol{M}(\boldsymbol{C})=\sum_{i=1}^{n} I T F_{-} I T F_{-} B A S_{-} E X C_{-} I S A\left(I t f_{i}\right), \\
\text { tal que: } \\
n=\text { número de interfaces (Itf) associadas à classe } C
\end{array}\right\}
$$

13. $\boldsymbol{C L} \boldsymbol{S} \_\boldsymbol{I} \boldsymbol{T F} \_\boldsymbol{B} \boldsymbol{A} \boldsymbol{S} \_\boldsymbol{O P} \boldsymbol{T}_{-} \boldsymbol{N} \boldsymbol{U} \boldsymbol{M}$ : número de interfaces, que são Variantes Opcionais, associadas a uma determinada classe. Esta métrica é representada pela Equação (6.8):

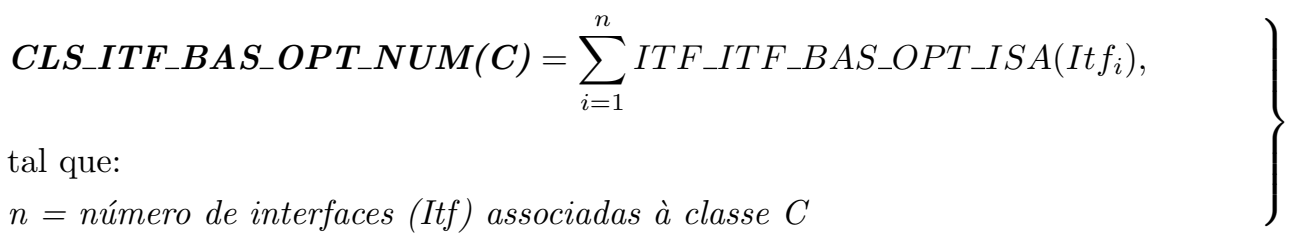

14. $\boldsymbol{C L} \boldsymbol{S} \_\boldsymbol{I} \boldsymbol{T} \boldsymbol{F} \_\boldsymbol{B} \boldsymbol{A} \boldsymbol{S} \_\boldsymbol{M N D} \boldsymbol{D} \boldsymbol{N} \boldsymbol{U} \boldsymbol{M}$ : número de interfaces, que são Variantes Obrigatórias, associadas a uma determinada classe. Esta métrica é representada pela Equação (6.9): 
$\left.\begin{array}{l}\boldsymbol{C L} \boldsymbol{S} \_\boldsymbol{I T F} \_\boldsymbol{B} \boldsymbol{A} \boldsymbol{S} \_\boldsymbol{M N} \boldsymbol{N} \_\boldsymbol{N} \boldsymbol{U} \boldsymbol{M}(\boldsymbol{C})=\sum_{i=1}^{n} I T F_{-} I T F \_B A S \_M N D \_I S A\left(I t f_{i}\right), \\ \text { tal que: } \\ n=\text { número de interfaces (Itf) associadas à classe } C\end{array}\right\}$

15. $\boldsymbol{C} \boldsymbol{L} \boldsymbol{S} \_\boldsymbol{I} \boldsymbol{T} \boldsymbol{F} \_\boldsymbol{B} \boldsymbol{A} \boldsymbol{S}_{-} \boldsymbol{V P} \boldsymbol{P} \_\boldsymbol{N} \boldsymbol{U} \boldsymbol{M}$ : número de interfaces, que são Pontos de Variação, associadas a uma determinada classe. Esta métrica é representada pela Equação 6.10):

$\left.\begin{array}{l}\boldsymbol{C L} \boldsymbol{S}_{-} \boldsymbol{I} T \boldsymbol{F}_{-} \boldsymbol{B} \boldsymbol{A} \boldsymbol{S}_{-} \boldsymbol{V P} \boldsymbol{T}_{-} \boldsymbol{N} \boldsymbol{U} \boldsymbol{M}(\boldsymbol{C})=\sum_{i=1}^{n} I T F_{-} I T F_{-} B A S_{-} V P T_{-} I S A\left(I t f_{i}\right), \\ \text { tal que: } \\ n=\text { número de interfaces (Itf) associadas à classe } C\end{array}\right\}$

16. $\boldsymbol{C} \boldsymbol{L} \boldsymbol{S} \_\boldsymbol{C L} \boldsymbol{S} \_\boldsymbol{B} \boldsymbol{A} \boldsymbol{S} \_\boldsymbol{V} \boldsymbol{B} \boldsymbol{T}_{-} \boldsymbol{N} \boldsymbol{U} \boldsymbol{M}$ : número de variabilidades de uma determinada classe. Esta métrica é representada pela Equação 6.11):

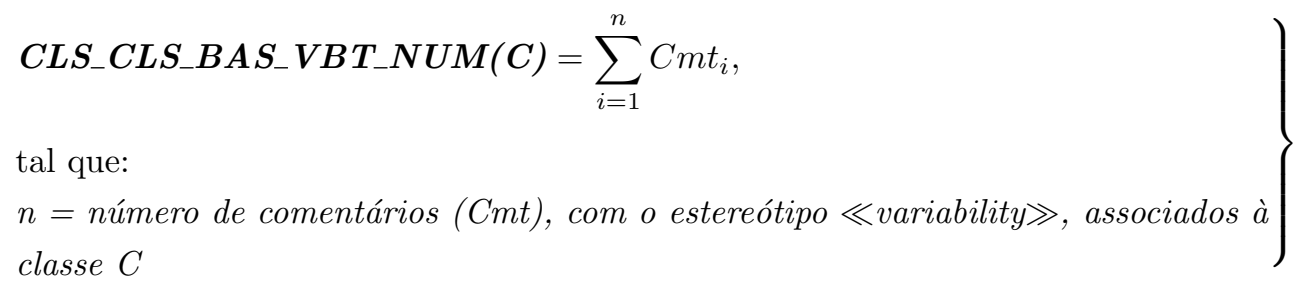

A Tabela 6.2 apresenta as métricas definidas para classes e suas respectivas categorias. 
Tabela 6.2: Métricas Básicas para Classes.

\begin{tabular}{|c|l|l|}
\hline Ord. & Métrica & Categoria \\
\hline 01 & CLS_CLS_BAS_VPT_ISA & variation point \\
\hline 02 & CLS_CLS_BAS_INC_ISA & variant \\
\hline 03 & CLS_CLS_BAS_EXC_ISA & variant \\
\hline 04 & CLS_CLS_BAS_OPT_ISA & variant \\
\hline 05 & CLS_CLS_BAS_MND_ISA & variant \\
\hline 06 & CLS_CLS_BAS_INC_NUM & variant \\
\hline 07 & CLS_CLS_BAS_EXC_NUM & variant \\
\hline 08 & CLS_CLS_BAS_OPT_NUM & variant \\
\hline 09 & CLS_CLS_BAS_MND_NUM & variant \\
\hline 10 & CLS_CLS_BAS_VPT_NUM & variation point \\
\hline 11 & CLS_ITF_BAS_INC_NUM & variant \\
\hline 12 & CLS_ITF_BAS_EXC_NUM & variant \\
\hline 13 & CLS_ITF_BAS_OPT_NUM & variant \\
\hline 14 & CLS_ITF_BAS_MND_NUM & variant \\
\hline 15 & CLS_ITF_BAS_VPT_NUM & variation point \\
\hline 16 & CLS_CLS_BAS_VBT_NUM & variability \\
\hline
\end{tabular}

As 16 métricas básicas de interfaces são apresentadas nos itens a seguir:

17. $\boldsymbol{I} \boldsymbol{T} \boldsymbol{F}_{-} \boldsymbol{I} \boldsymbol{T} \boldsymbol{F}_{-} \boldsymbol{B} \boldsymbol{A} \boldsymbol{S}_{-} \boldsymbol{V} \boldsymbol{P} \boldsymbol{T}_{-} \boldsymbol{I} \boldsymbol{S} \boldsymbol{A}$ : indica se uma interface é um Ponto de Variação. Esta métrica possui valor 1 para interfaces que estão marcadas com o estereótipo «variationPoint 》 e valor 0 , caso contrário;

18. $\boldsymbol{I} \boldsymbol{T} \boldsymbol{F}_{-} \boldsymbol{I} \boldsymbol{T} \boldsymbol{F} \_\boldsymbol{B} \boldsymbol{A} \boldsymbol{S} \_\boldsymbol{I} \boldsymbol{N} \boldsymbol{C}_{-} \boldsymbol{I} \boldsymbol{S} \boldsymbol{A}$ : indica se uma interface é uma Variante Inclusiva. Esta métrica possui valor 1 para interfaces que estão marcadas com o estereótipo «alternative_OR $\gg$ e valor 0 , caso contrário;

19. $\boldsymbol{I} \boldsymbol{T} \boldsymbol{F} \_\boldsymbol{I} \boldsymbol{T} \boldsymbol{F}_{-} \boldsymbol{B} \boldsymbol{A} \boldsymbol{S} \_\boldsymbol{E} \boldsymbol{X} \boldsymbol{C} \_\boldsymbol{I} \boldsymbol{S} \boldsymbol{A}$ : indica se uma interface é uma Variante Exclusiva. Esta métrica possui valor 1 para interfaces que estão marcadas com o estereótipo «alternative_XOR》e valor 0 , caso contrário;

20. $\boldsymbol{I} \boldsymbol{T} \boldsymbol{F} \_\boldsymbol{I} \boldsymbol{T} \boldsymbol{F}_{-} \boldsymbol{B} \boldsymbol{A} \boldsymbol{S} \_\boldsymbol{O P} \boldsymbol{T} \_\boldsymbol{I S A}$ : indica se uma interface é uma Variante Opcional. Esta métrica possui valor 1 para interfaces que estão marcadas com o estereótipo «optional» e valor 0 , caso contrário;

21. $\boldsymbol{I} \boldsymbol{T} \boldsymbol{F} \_\boldsymbol{I} \boldsymbol{T} \boldsymbol{F} \_\boldsymbol{B} \boldsymbol{A} \boldsymbol{S} \_\boldsymbol{M} \boldsymbol{N} \boldsymbol{D} \_\boldsymbol{I} \boldsymbol{S} \boldsymbol{A}$ : indica se uma interface é uma Variante Obrigatória. Esta métrica possui valor 1 para interfaces que estão marcadas com o estereótipo $\ll$ mandatory e valor 0 , caso contrário; 
22. $\boldsymbol{I} \boldsymbol{T} \boldsymbol{F} \_\boldsymbol{I} \boldsymbol{T} \boldsymbol{F} \_\boldsymbol{B} \boldsymbol{A} \boldsymbol{S} \_\boldsymbol{I} \boldsymbol{N} \boldsymbol{C} \_\boldsymbol{N} \boldsymbol{U} \boldsymbol{M}:$ número de interfaces, que são Variantes Inclusivas, associadas a uma determinada interface. Esta métrica é representada pela Equação 6.12):

$$
\left.\begin{array}{l}
\boldsymbol{I} \boldsymbol{T} \boldsymbol{F}_{-} \boldsymbol{I} \boldsymbol{T} \boldsymbol{F}_{-} \boldsymbol{B} \boldsymbol{A} \boldsymbol{S}_{-} \boldsymbol{I N} \boldsymbol{N}_{-} \boldsymbol{N} \boldsymbol{U M}(\boldsymbol{I})=\sum_{i=1}^{n} I T F_{-} I T F_{-} B A S_{-} I N C_{-} I S A\left(I t f_{i}\right), \\
\text { tal que: } \\
n=\text { número de interfaces (Itf) associadas à interface } I
\end{array}\right\}
$$

23. $\boldsymbol{I} \boldsymbol{T} \boldsymbol{F} \_\boldsymbol{I} \boldsymbol{T} \boldsymbol{F}_{-} \boldsymbol{B} \boldsymbol{A} \boldsymbol{S} \_\boldsymbol{E} \boldsymbol{X} \boldsymbol{C} \_\boldsymbol{N} \boldsymbol{U} \boldsymbol{M}$ : número de interfaces, que são Variantes Exclusivas, associadas a uma determinada interface. Esta métrica é representada pela Equação 6.13):

$$
\left.\begin{array}{l}
\boldsymbol{I} \boldsymbol{T} \boldsymbol{F}_{-} \boldsymbol{I} \boldsymbol{T} \boldsymbol{F}_{-} \boldsymbol{B} \boldsymbol{A} \boldsymbol{S} \_\boldsymbol{E} \boldsymbol{X} \boldsymbol{C} \_\boldsymbol{N} \boldsymbol{U M}(\boldsymbol{I})=\sum_{i=1}^{n} I T F_{-} I T F_{-} B A S_{-} E X C_{-} I S A\left(I t f_{i}\right), \\
\text { tal que: } \\
n=\text { número de interfaces (Itf) associadas à interface } I
\end{array}\right\}
$$

24. $\boldsymbol{I} \boldsymbol{T F} \_\boldsymbol{I} \boldsymbol{T F} \_\boldsymbol{B} \boldsymbol{A} \boldsymbol{S} \_\boldsymbol{O P} \boldsymbol{T}_{-} \boldsymbol{N} \boldsymbol{U} \boldsymbol{M}$ : número de interfaces, que são Variantes Opcionais, associadas a uma determinada interface. Esta métrica é representada pela Equação 6.14):

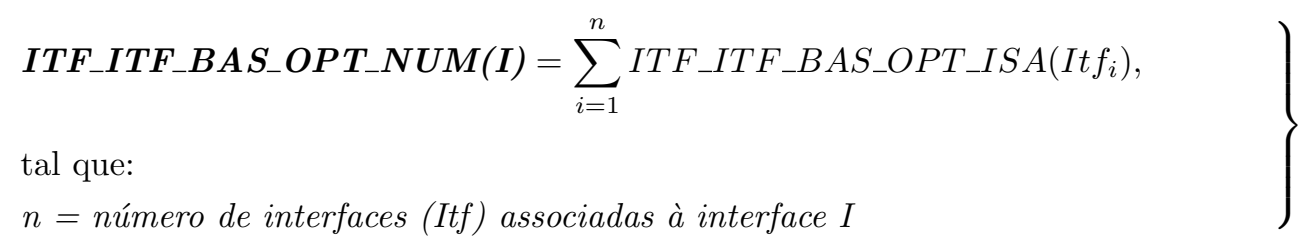

25. $\boldsymbol{I} \boldsymbol{T} \boldsymbol{F} \_\boldsymbol{I} \boldsymbol{T} \boldsymbol{F}_{-} \boldsymbol{B} \boldsymbol{A} \boldsymbol{S} \_\boldsymbol{M} \boldsymbol{N} \boldsymbol{D} \_\boldsymbol{N} \boldsymbol{U} \boldsymbol{M}$ : número de interfaces, que são Variantes Obrigatórias, associadas a uma determinada interface. Esta métrica é representada pela Equação 6.15): 


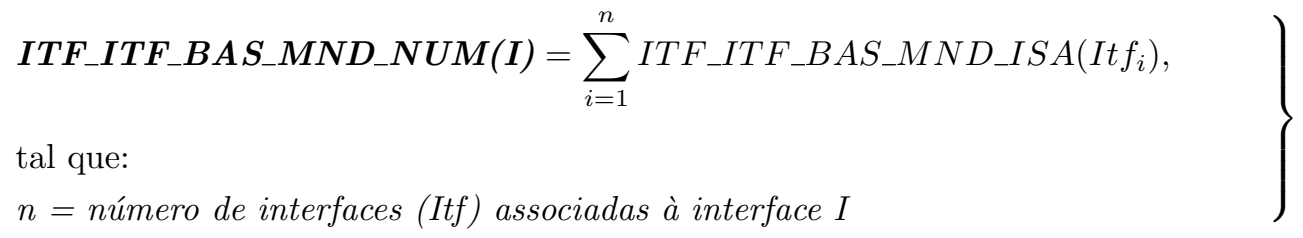

26. $\boldsymbol{I} \boldsymbol{T} \boldsymbol{F}_{-} \boldsymbol{I} \boldsymbol{T} \boldsymbol{F} \_\boldsymbol{B} \boldsymbol{A} \boldsymbol{S} \_\boldsymbol{V P} \boldsymbol{T}_{-} \boldsymbol{N} \boldsymbol{U} \boldsymbol{M}$ : número de interfaces, que são Pontos de Variação, associadas a uma determinada interface. Esta métrica é representada pela Equação 6.16):

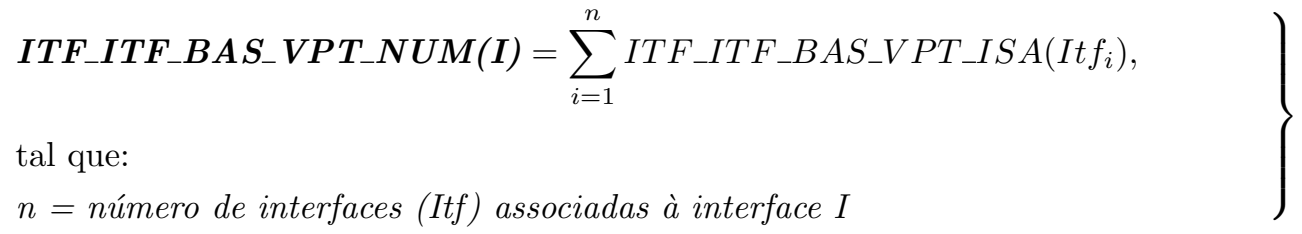

27. $\boldsymbol{I} \boldsymbol{T} \boldsymbol{F} \_\boldsymbol{C L} \boldsymbol{S} \_\boldsymbol{B} \boldsymbol{A} \boldsymbol{S} \_\boldsymbol{I} \boldsymbol{N} \boldsymbol{C}_{-} \boldsymbol{N} \boldsymbol{U} \boldsymbol{M}$ : número de classes, que são Variantes Inclusivas, associadas a uma determinada interface. Esta métrica é representada pela Equação (6.17):

$\left.\begin{array}{l}\boldsymbol{I T F} \_\boldsymbol{C L} \boldsymbol{S} \_\boldsymbol{B} \boldsymbol{A} \boldsymbol{S} \_\boldsymbol{I N} \boldsymbol{N} \_\boldsymbol{N} \boldsymbol{U} \boldsymbol{M}(\boldsymbol{I})=\sum_{i=1}^{n} C L S \_C L S \_B A S \_I N C \_I S A\left(C l s_{i}\right), \\ \text { tal que: } \\ n=\text { número de classes }(C l s) \text { associadas à interface } I\end{array}\right\}$

28. $\boldsymbol{I} \boldsymbol{T} \boldsymbol{F} \_\boldsymbol{C L} \boldsymbol{S} \_\boldsymbol{B} \boldsymbol{A} \boldsymbol{S} \_\boldsymbol{E} \boldsymbol{X} \boldsymbol{C} \_\boldsymbol{N} \boldsymbol{U} \boldsymbol{M}$ : número de classes, que são Variantes Exclusivas, associadas a uma determinada interface. Esta métrica é representada pela Equação (6.18):

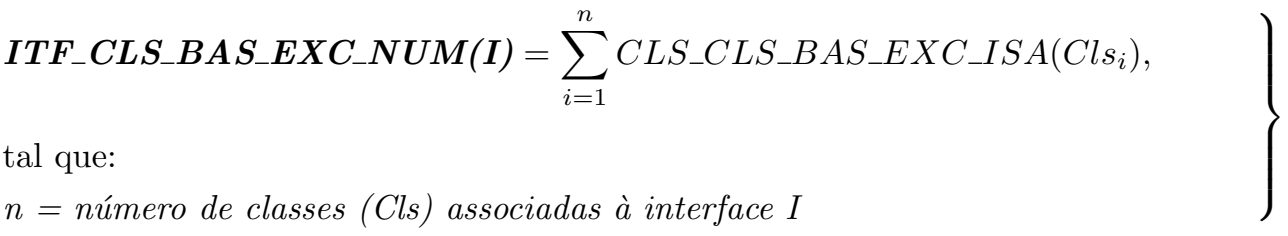


29. $\boldsymbol{I} \boldsymbol{T} \boldsymbol{F} \_\boldsymbol{C L} \boldsymbol{S} \_\boldsymbol{B} \boldsymbol{A} \boldsymbol{S}_{-} \boldsymbol{O P} \boldsymbol{T}_{-} \boldsymbol{N} \boldsymbol{U} \boldsymbol{M}$ : número de classes, que são Variantes Opcionais, associadas a uma determinada interface. Esta métrica é representada pela Equação (6.19):

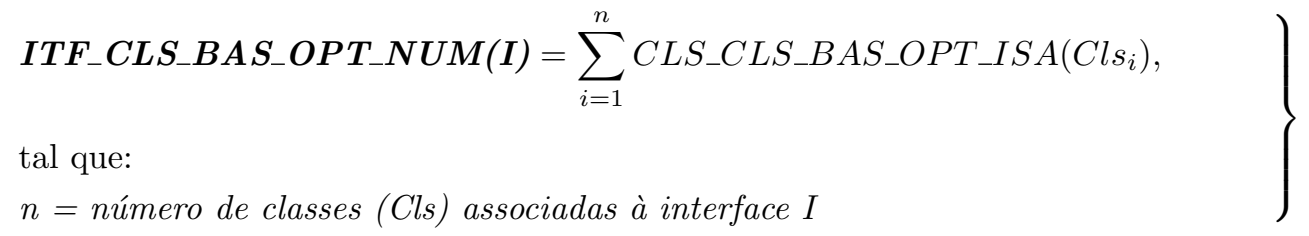

30. $\boldsymbol{I} \boldsymbol{T} \boldsymbol{F} \_\boldsymbol{C L} \boldsymbol{S} \_\boldsymbol{B} \boldsymbol{A} \boldsymbol{S}_{-} \boldsymbol{M} \boldsymbol{N} \boldsymbol{D} \_\boldsymbol{N} \boldsymbol{U} \boldsymbol{M}$ : número de classes, que são Variantes Obrigatórias, associadas a uma determinada interface. Esta métrica é representada pela Equação 6.20):

$$
\left.\begin{array}{l}
\boldsymbol{I} \boldsymbol{T} \boldsymbol{F}_{-} \boldsymbol{C} \boldsymbol{L} \boldsymbol{S} \_\boldsymbol{B} \boldsymbol{A} \boldsymbol{S} \_\boldsymbol{M} \boldsymbol{N} \boldsymbol{D} \_\boldsymbol{N} \boldsymbol{U M}(\boldsymbol{I})=\sum_{i=1}^{n} C L S_{-} C L S \_B A S \_M N D \_I S A\left(C l s_{i}\right), \\
\text { tal que: } \\
n=\text { número de classes }(C l s) \text { associadas à interface } I
\end{array}\right\}
$$

31. $\boldsymbol{I} \boldsymbol{T} \boldsymbol{F} \_\boldsymbol{C L} \boldsymbol{S} \_\boldsymbol{B} \boldsymbol{A} \boldsymbol{S}_{-} \boldsymbol{V} \boldsymbol{P} \boldsymbol{T}_{-} \boldsymbol{N} \boldsymbol{U} \boldsymbol{M}$ : número de classes, que são Pontos de Variação, associadas a uma determinada interface. Esta métrica é representada pela Equação (6.21):

$$
\left.\begin{array}{l}
\boldsymbol{I} \boldsymbol{T} \boldsymbol{F}_{-} \boldsymbol{C} \boldsymbol{L} \boldsymbol{S}_{-} \boldsymbol{B} \boldsymbol{A} \boldsymbol{S}_{-} \boldsymbol{V P} \boldsymbol{T}_{-} \boldsymbol{N} \boldsymbol{U} \boldsymbol{M}(\boldsymbol{I})=\sum_{i=1}^{n} C L S_{-} C L S_{-} B A S_{-} V P T_{-} I S A\left(C l s_{i}\right), \\
\text { tal que: } \\
n=\text { número de classes }(C l s) \text { associadas à interface } I
\end{array}\right\}
$$

32. $\boldsymbol{I} \boldsymbol{T} \boldsymbol{F}_{-} \boldsymbol{I} \boldsymbol{T} \boldsymbol{F}_{-} \boldsymbol{B} \boldsymbol{A} \boldsymbol{S}_{-} \boldsymbol{V} \boldsymbol{B} \boldsymbol{T}_{-} \boldsymbol{N} \boldsymbol{U} \boldsymbol{M}$ : número de variabilidades de uma determinada interface. Esta métrica é representada pela Equação 6.22): 
$\left.\begin{array}{l}\boldsymbol{I T F} \_\boldsymbol{I T F} \boldsymbol{F}_{-} \boldsymbol{B} \boldsymbol{A} \boldsymbol{S}_{-} \boldsymbol{V} \boldsymbol{B} \boldsymbol{T}_{-} \boldsymbol{N} \boldsymbol{U} \boldsymbol{M}(\boldsymbol{I})=\sum_{i=1}^{n} C m t_{i}, \\ \text { tal que: } \\ \begin{array}{l}n=\text { número de comentários }(\mathrm{Cmt}), \text { com o estereótipo } \ll \text { variability», associados } \grave{a} \\ \text { interface } I\end{array}\end{array}\right\}$

A Tabela 6.3 apresenta as métricas definidas para interfaces e suas respectivas categorias.

Tabela 6.3: Métricas Básicas para Interfaces.

\begin{tabular}{|c|l|l|}
\hline Ord. & Métrica & Categoria \\
\hline 17 & ITF_ITF_BAS_VPT_ISA & variation point \\
\hline 18 & ITF_ITF_BAS_INC_ISA & variant \\
\hline 19 & ITF_ITF_BAS_EXC_ISA & variant \\
\hline 20 & ITF_ITF_BAS_OPT_ISA & variant \\
\hline 21 & ITF_ITF_BAS_MND_ISA & variant \\
\hline 22 & ITF_ITF_BAS_INC_NUM & variant \\
\hline 23 & ITF_ITF_BAS_EXC_NUM & variant \\
\hline 24 & ITF_ITF_BAS_OPT_NUM & variant \\
\hline 25 & ITF_ITF_BAS_MND_NUM & variant \\
\hline 26 & ITF_ITF_BAS_VPT_NUM & variation point \\
\hline 27 & ITF_CLS_BAS_INC_NUM & variant \\
\hline 28 & ITF_CLS_BAS_EXC_NUM & variant \\
\hline 29 & ITF_CLS_BAS_OPT_NUM & variant \\
\hline 30 & ITF_CLS_BAS_MND_NUM & variant \\
\hline 31 & ITF_CLS_BAS_VPT_NUM & variation point \\
\hline 32 & ITF_ITF_BAS_VBT_NUM & variability \\
\hline
\end{tabular}

\subsubsection{Métricas Básicas de Diagramas}

As métricas de diagrama visam medir os totais relacionados aos elementos que pertencem a um determinado tipo de diagrama. Por exemplo, em um diagrama de classes, esse tipo de métrica mede a quantidade total de interfaces e classes que são pontos de variação ou variantes. Em um diagrama de componentes, mede quantos componentes são variáveis.

As 13 métricas básicas de diagramas são apresentadas nos itens a seguir:

33. $\boldsymbol{D} \boldsymbol{G} \boldsymbol{M}_{-} \boldsymbol{C L} \boldsymbol{S}_{-} \boldsymbol{B} \boldsymbol{A} \boldsymbol{S}_{-} \boldsymbol{V P T} \boldsymbol{T} \boldsymbol{T} \boldsymbol{T}$ : número total de classes que são Pontos de Variação em um diagrama de classes. Esta métrica é representada pela Equação (6.23): 


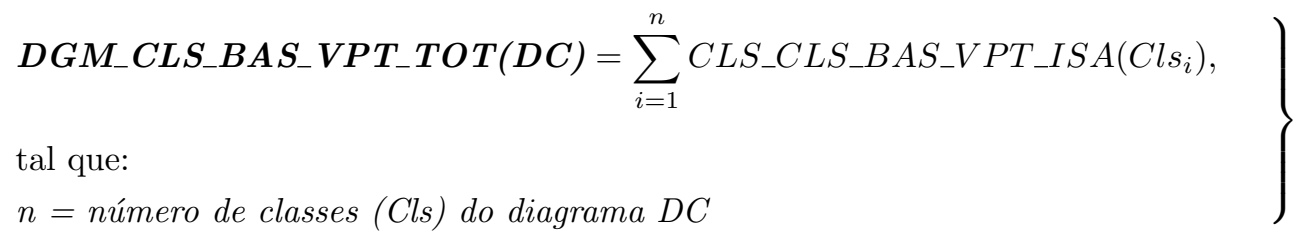

34. $\boldsymbol{D} \boldsymbol{G} \boldsymbol{M} \_\boldsymbol{C L} \boldsymbol{S} \_\boldsymbol{B} \boldsymbol{A} \boldsymbol{S} \_\boldsymbol{I N} \boldsymbol{C} \_\boldsymbol{T O} \boldsymbol{T}:$ número total de classes que são Variantes Inclusivas em um diagrama de classes. Esta métrica é representada pela Equação 6.24):

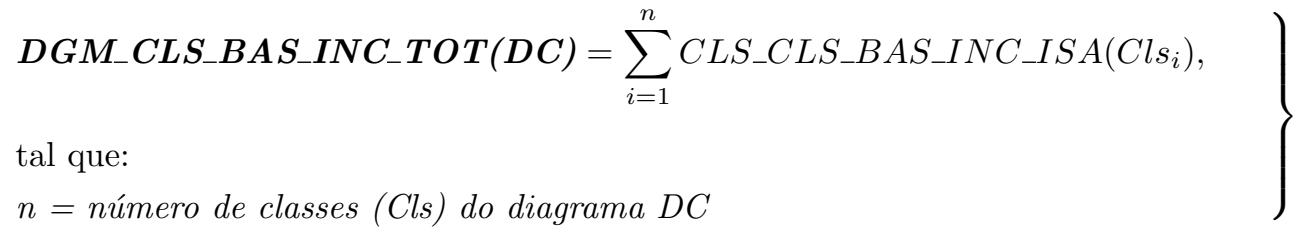

35. $\boldsymbol{D} G \boldsymbol{M}_{-} \boldsymbol{C L} \boldsymbol{S} \_\boldsymbol{B} \boldsymbol{A} \boldsymbol{S}_{-} \boldsymbol{E} \boldsymbol{X} \boldsymbol{C}_{-} \boldsymbol{T} \boldsymbol{O} \boldsymbol{T}$ : número total de classes que são Variantes Exclusivas em um diagrama de classes. Esta métrica é representada pela Equação (6.25):

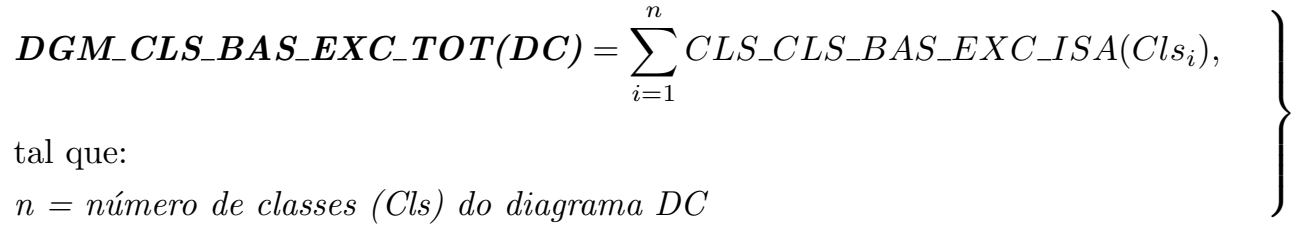

36. $\boldsymbol{D} \boldsymbol{G} \boldsymbol{M}_{-} \boldsymbol{C L} \boldsymbol{S} \_\boldsymbol{B} \boldsymbol{A} \boldsymbol{S}_{-} \boldsymbol{O P} \boldsymbol{T}_{-} \boldsymbol{T} \boldsymbol{O} \boldsymbol{T}$ : número total de classes que são Variantes Opcionais em um diagrama de classes. Esta métrica é representada pela Equação (6.26):

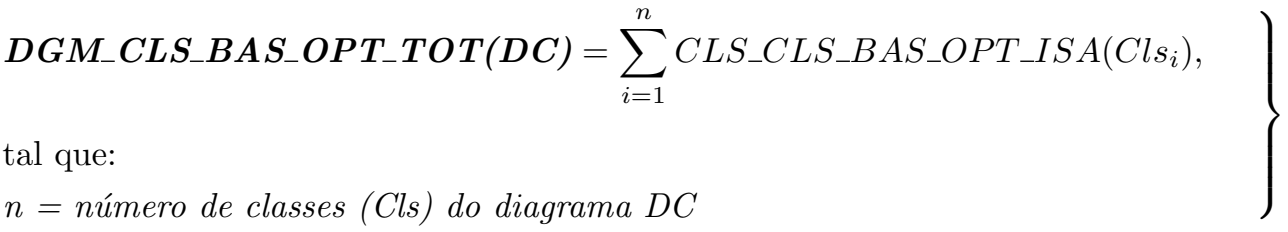


37. $\boldsymbol{D} G \boldsymbol{M} \_\boldsymbol{C L} \boldsymbol{S} \_\boldsymbol{B} \boldsymbol{A} \boldsymbol{S} \_\boldsymbol{M N D} \boldsymbol{D} \boldsymbol{T} \boldsymbol{O} \boldsymbol{T}$ : número total de classes que são Variantes Obrigatórias em um diagrama de classes. Esta métrica é representada pela Equação (6.27):

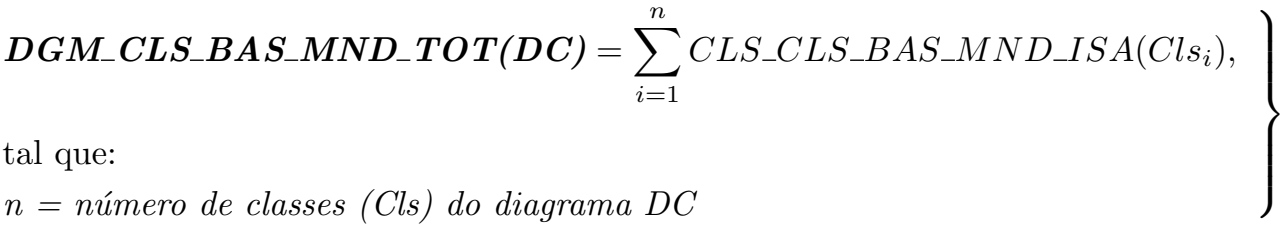

38. $\boldsymbol{D} \boldsymbol{G} \boldsymbol{M}_{-} \boldsymbol{C L} \boldsymbol{S}_{-} \boldsymbol{B} \boldsymbol{A} \boldsymbol{S}_{-} \boldsymbol{V} \boldsymbol{B} \boldsymbol{T}_{-} \boldsymbol{T} \boldsymbol{O} \boldsymbol{T}$ : número total de Variabilidades em classes em um diagrama de classes. Esta métrica é representada pela Equação (6.28):

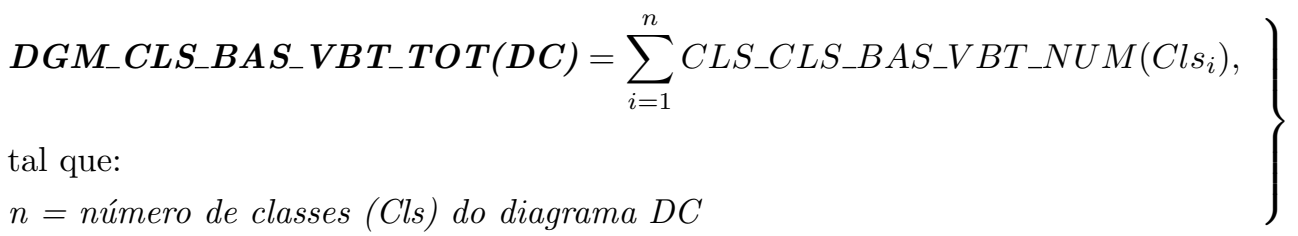

39. $\boldsymbol{D} \boldsymbol{G} \boldsymbol{M} \_\boldsymbol{I} \boldsymbol{T} \boldsymbol{F}_{-} \boldsymbol{B} \boldsymbol{A} \boldsymbol{S} \_\boldsymbol{V P T} \boldsymbol{T} \boldsymbol{T} \boldsymbol{T}:$ número total de interfaces que são Pontos de Variação em um diagrama de classes. Esta métrica é representada pela Equação (6.29):

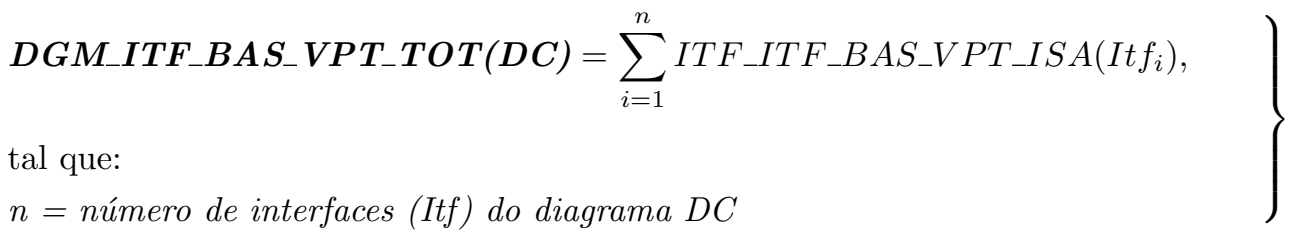

40. $\boldsymbol{D} \boldsymbol{G} \boldsymbol{M} \_\boldsymbol{I} \boldsymbol{T F} \_\boldsymbol{B} \boldsymbol{A} \boldsymbol{S} \_\boldsymbol{I N} \boldsymbol{C} \_\boldsymbol{T} \boldsymbol{O} \boldsymbol{T}:$ número total de interfaces que são Variantes Inclusivas em um diagrama de classes. Esta métrica é representada pela Equação 6.30): 


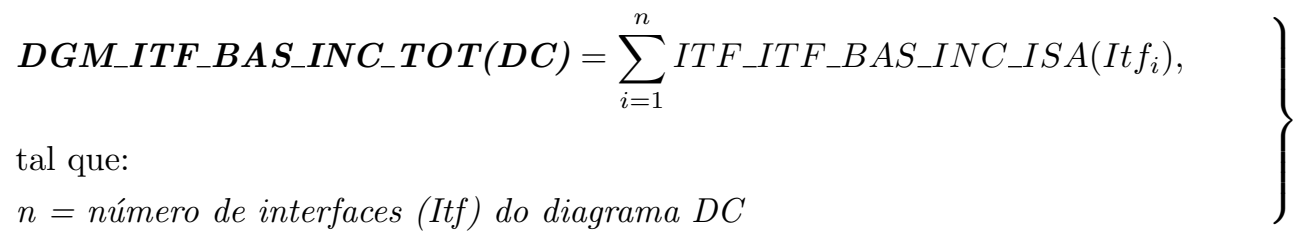

41. $\boldsymbol{D} \boldsymbol{G} \boldsymbol{M} \_\boldsymbol{I} \boldsymbol{T F} \_\boldsymbol{B} \boldsymbol{A} \boldsymbol{S} \_\boldsymbol{E} \boldsymbol{X} \boldsymbol{C} \_\boldsymbol{T} \boldsymbol{O} \boldsymbol{T}:$ número total de interfaces que são Variantes Exclusivas em um diagrama de classes. Esta métrica é representada pela Equação 6.31:

$\boldsymbol{D} \boldsymbol{G M} \boldsymbol{M}_{-} \boldsymbol{I} \boldsymbol{T} \boldsymbol{F}_{-} \boldsymbol{B} \boldsymbol{A} \boldsymbol{S}_{-} \boldsymbol{E} \boldsymbol{X} \boldsymbol{C}_{-} \boldsymbol{T} \boldsymbol{O} \boldsymbol{T}(\boldsymbol{D C})=\sum_{i=1}^{n} I T F_{-} I T F_{-} B A S_{-} E X C_{-} I S A\left(I t f_{i}\right)$,

tal que:

$n=$ número de interfaces (Itf) do diagrama $D C$

42. $\boldsymbol{D} \boldsymbol{G} \boldsymbol{M}_{-} \boldsymbol{I} \boldsymbol{T} \boldsymbol{F}_{-} \boldsymbol{B} \boldsymbol{A} \boldsymbol{S}_{-} \boldsymbol{O P} \boldsymbol{T}_{-} \boldsymbol{T} \boldsymbol{O T}$ : número total de interfaces que são Variantes Opcionais em um diagrama de classes. Esta métrica é representada pela Equação (6.32):

$\boldsymbol{D G} \boldsymbol{G} \_\boldsymbol{I T F} \boldsymbol{F}_{-} \boldsymbol{B} \boldsymbol{A} \boldsymbol{S}_{-} \boldsymbol{O P} \boldsymbol{T}_{-} \boldsymbol{T O T}(\boldsymbol{D C})=\sum_{i=1}^{n} I T F_{-} I T F_{-} B A S_{-} O P T_{-} I S A\left(I t f_{i}\right)$,

tal que:

$n=$ número de interfaces (Itf) do diagrama $D C$

43. $\boldsymbol{D} \boldsymbol{G} \boldsymbol{M} \_\boldsymbol{I} \boldsymbol{T} \boldsymbol{F} \_\boldsymbol{B} \boldsymbol{A} \boldsymbol{S} \_\boldsymbol{M N D} \boldsymbol{N} \boldsymbol{T} \boldsymbol{O} \boldsymbol{T}:$ número total de interfaces que são Variantes Obrigatórias em um diagrama de classes. Esta métrica é representada pela Equação (6.33):

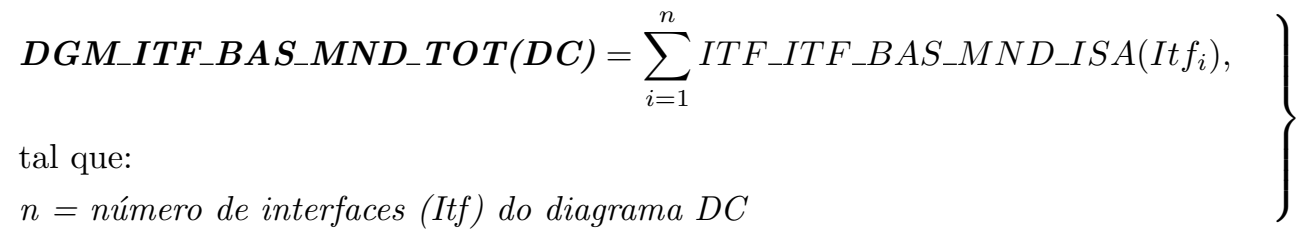


44. $\boldsymbol{D} \boldsymbol{G} \boldsymbol{M} \_\boldsymbol{I} \boldsymbol{T} \boldsymbol{F}_{-} \boldsymbol{B} \boldsymbol{A} \boldsymbol{S}_{-} \boldsymbol{V} \boldsymbol{B} \boldsymbol{T}_{-} \boldsymbol{T} \boldsymbol{O} \boldsymbol{T}:$ número total de Variabilidades em interfaces em um diagrama de classes. Esta métrica é representada pela Equação 6.34):

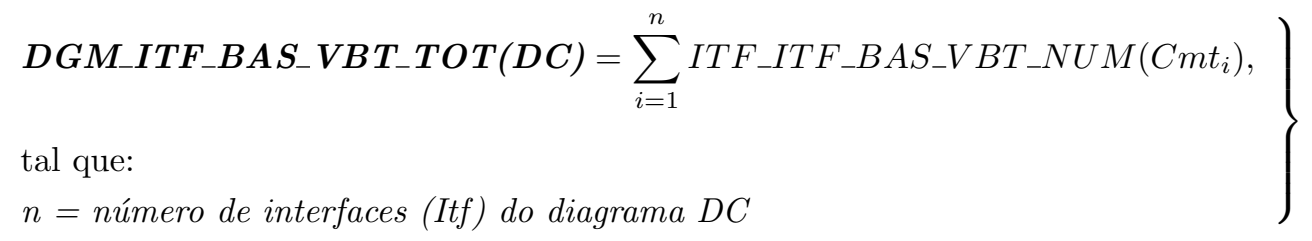

45. $\boldsymbol{D} \boldsymbol{G} \boldsymbol{M}_{-} \boldsymbol{C P} \boldsymbol{T}_{-} \boldsymbol{B} \boldsymbol{A} \boldsymbol{S}_{-} \boldsymbol{V} \boldsymbol{B} \boldsymbol{T}_{-} \boldsymbol{T} \boldsymbol{O} \boldsymbol{T}$ : número total de Variabilidades em componentes em um diagrama de componentes. Esta métrica é representada pela Equação (6.35):

$$
\left.\begin{array}{l}
\boldsymbol{D G} \boldsymbol{M}_{-} \boldsymbol{C P} \boldsymbol{T}_{-} \boldsymbol{B} \boldsymbol{A} \boldsymbol{S}_{-} \boldsymbol{V} \boldsymbol{B} \boldsymbol{T}_{-} \boldsymbol{T O} \boldsymbol{O}(\boldsymbol{D C})=\sum_{i=1}^{n} C P T_{-} C P T_{-} B A S_{-} V B T_{-} N U M\left(C p t_{i}\right), \\
\text { tal que: } \\
n=\text { número de componentes }(C p t) \text { do diagrama } D C
\end{array}\right\}
$$

A Tabela 6.4 apresenta as métricas definidas para diagramas e suas respectivas categorias. 
Tabela 6.4: Métricas Básicas para Diagramas.

\begin{tabular}{|c|l|l|}
\hline Ord. & Métrica & Categoria \\
\hline 33 & DGM_CLS_BAS_VPT_TOT & variation point \\
\hline 34 & DGM_CLS_BAS_INC_TOT & variant \\
\hline 35 & DGM_CLS_BAS_EXC_TOT & variant \\
\hline 36 & DGM_CLS_BAS_OPT_TOT & variant \\
\hline 37 & DGM_CLS_BAS_MND_TOT & variant \\
\hline 38 & DGM_CLS_BAS_VBT_TOT & variability \\
\hline 39 & DGM_ITF_BAS_VPT_TOT & variation point \\
\hline 40 & DGM_ITF_BAS_INC_TOT & variant \\
\hline 41 & DGM_ITF_BAS_EXC_TOT & variant \\
\hline 42 & DGM_ITF_BAS_OPT_TOT & variant \\
\hline 43 & DGM_ITF_BAS_MND_TOT & variant \\
\hline 44 & DGM_ITF_BAS_VBT_TOT & variability \\
\hline 45 & DGM_CPT_BAS_VBT_TOT & variability \\
\hline
\end{tabular}

\subsubsection{Métricas Básicas de Componentes e Modelos}

As 7 métricas básicas de componentes e modelos são apresentadas nos itens a seguir:

46. $\boldsymbol{C P} \boldsymbol{T}_{-} \boldsymbol{C P} \boldsymbol{T}_{-} \boldsymbol{B} \boldsymbol{A} \boldsymbol{S}_{-} \boldsymbol{V} \boldsymbol{T} \boldsymbol{N}_{-} \boldsymbol{H} \boldsymbol{A} \boldsymbol{S}$ : indica se um componente possui Variação. Esta métrica possui valor 1 para componentes marcados com o estereótipo «variable», e valor, 0 caso contrário.

47. $\boldsymbol{M D L} \boldsymbol{L}_{-} \boldsymbol{C L} \boldsymbol{S}_{-} \boldsymbol{B} \boldsymbol{A} \boldsymbol{S}_{-} \boldsymbol{V P T} \boldsymbol{T}_{-} \boldsymbol{T} \boldsymbol{O} \boldsymbol{T}$ : número total de Pontos de Variação em classes de uma ALP. Esta métrica é representada pela Equação (6.36):

$$
\begin{aligned}
& \boldsymbol{M D L} \boldsymbol{C} \boldsymbol{C} \boldsymbol{S}_{-} \boldsymbol{B} \boldsymbol{A} \boldsymbol{S}_{-} \boldsymbol{V P} \boldsymbol{P} \boldsymbol{T}_{-} \boldsymbol{T O T}(\boldsymbol{L P})=\sum_{i=1}^{n} D G M_{-} C L S_{-} B A S_{-} V P T_{-} N U M\left(D C_{i}\right), \\
& \text { tal que: } \\
& n=\text { número de diagramas de classes }(D G) \text { da linha de produto } L P
\end{aligned}
$$

48. $\boldsymbol{M D L} \boldsymbol{I} \boldsymbol{T} \boldsymbol{F}_{-} \boldsymbol{B} \boldsymbol{A} \boldsymbol{S}_{-} \boldsymbol{V P} \boldsymbol{T}_{-} \boldsymbol{T} \boldsymbol{O} \boldsymbol{T}$ : número total de Pontos de Variação em interfaces de uma ALP. Esta métrica é representada pela Equação 6.37): 
$\left.\begin{array}{l}\boldsymbol{M D L} \boldsymbol{I} \boldsymbol{T} \boldsymbol{F}_{-} \boldsymbol{B} \boldsymbol{A} \boldsymbol{S}_{-} \boldsymbol{V P T} \boldsymbol{T} \boldsymbol{T} \boldsymbol{T}(\boldsymbol{L P})=\sum_{i=1}^{n} D G M_{-} I T F_{-} B A S_{-} V P T_{-} N U M\left(D C_{i}\right), \\ \text { tal que: } \\ n=\text { número de diagramas de classes }(D G) \text { da linha de produto } L P\end{array}\right\}$

49. $\boldsymbol{M D L} \boldsymbol{D} \boldsymbol{M} \boldsymbol{D} \boldsymbol{L}_{-} \boldsymbol{B} \boldsymbol{A} \boldsymbol{S} \_\boldsymbol{V} \boldsymbol{P} \boldsymbol{T}_{-} \boldsymbol{T} \boldsymbol{O} \boldsymbol{T}$ : número total de Pontos de Variação em uma ALP. Esta métrica é resultado da soma da equação 6.36 com a equação 6.37. representado pela Equação (6.38):

$\boldsymbol{M D L} \_\boldsymbol{M D L} \boldsymbol{B} \boldsymbol{A} \boldsymbol{S} \_\boldsymbol{V P T} \boldsymbol{T} \boldsymbol{T O T}(\boldsymbol{L P})=M D L \_C L S \_B A S_{-} V P T \_T O T(L P)+$ $M D L \_I T F \_B A S \_V P T \_T O T(L P)$

50. $\boldsymbol{M D L} \boldsymbol{D} \boldsymbol{C L} \boldsymbol{S} \_\boldsymbol{B} \boldsymbol{A} \boldsymbol{S}_{-} \boldsymbol{V} \boldsymbol{B} \boldsymbol{T}_{-} \boldsymbol{T} \boldsymbol{O} \boldsymbol{T}$ : número total de Variabilidades em classes de uma ALP. Esta métrica é representada pela Equação (6.39):

$\left.\begin{array}{l}\boldsymbol{M D} \boldsymbol{L}_{-} \boldsymbol{C L} \boldsymbol{S}_{-} \boldsymbol{B} \boldsymbol{A} \boldsymbol{S}_{-} \boldsymbol{V} \boldsymbol{B} \boldsymbol{T}_{-} \boldsymbol{T} \boldsymbol{O} \boldsymbol{T}(\boldsymbol{L P})=\sum_{i=1}^{n} D G M_{-} C L S_{-} B S_{-} V B T_{-} N U M\left(D C_{i}\right), \\ \text { tal que: } \\ n=\text { número de diagramas de classes }(D G) \text { da linha de produto } L P\end{array}\right\}$

51. $\boldsymbol{M D L} \boldsymbol{I} \boldsymbol{T} \boldsymbol{F}_{-} \boldsymbol{B} \boldsymbol{A} \boldsymbol{S}_{-} \boldsymbol{V} \boldsymbol{B} \boldsymbol{T}_{-} \boldsymbol{T} \boldsymbol{O} \boldsymbol{T}:$ número total de Variabilidades em interfaces de uma ALP. Esta métrica é representada pela Equação 6.40):

$$
\begin{aligned}
& \left.\begin{array}{l}
\boldsymbol{M D L} \boldsymbol{I} \boldsymbol{T} \boldsymbol{F}_{-} \boldsymbol{B} \boldsymbol{A} \boldsymbol{S}_{-} \boldsymbol{V B} \boldsymbol{T} \boldsymbol{T}_{-} \boldsymbol{T} \boldsymbol{T}(\boldsymbol{L P})=\sum_{i=1}^{n} D G M_{-} I T F_{-} B A S_{-} V B T_{-} N U M\left(D C_{i}\right), \\
\text { tal que: } \\
n=\text { número de diagramas de classes }(D G) \text { da linha de produto } L P
\end{array}\right\}
\end{aligned}
$$


52. $\boldsymbol{M D L} \boldsymbol{D} \boldsymbol{M} \boldsymbol{D} \boldsymbol{L}_{-} \boldsymbol{B} \boldsymbol{A} \boldsymbol{S}_{-} \boldsymbol{V} \boldsymbol{B} \boldsymbol{T}_{-} \boldsymbol{T} \boldsymbol{O} \boldsymbol{T}:$ número total de Variabilidades em uma ALP. Esta métrica é resultado da soma das Equações 6.39 e 6.40, representada pela Equação (6.41):

$\boldsymbol{M D L} \_\boldsymbol{M D L} \boldsymbol{L}_{-} \boldsymbol{B} \boldsymbol{A} \boldsymbol{S}_{-} \boldsymbol{V} \boldsymbol{B} \boldsymbol{T}_{-} \boldsymbol{T O} \boldsymbol{T}(\boldsymbol{L P})=M D L_{-} C L S_{-} B A S_{-} V B T_{-} T O T(L P)+$ $M D L_{-} I T F_{-} B A S_{-} V B T_{-} T O T(L P)$

A Tabela 6.5 apresenta as métricas e suas categorias definidas para componentes e modelos.

Tabela 6.5: Métricas Básicas para Componentes e Modelos.

\begin{tabular}{|c|l|l|}
\hline Ord. & Métrica & Categoria \\
\hline 46 & CPT_CPT_BAS_VTN_HAS & variant \\
\hline 47 & MDL_CLS_BAS_VPT_TOT & variation point \\
\hline 48 & MDL_ITF_BAS_VPT_TOT & variation point \\
\hline 49 & MDL_MDL_BAS_VPT_TOT & variation point \\
\hline 50 & MDL_CLS_BAS_VBT_TOT & variability \\
\hline 51 & MDL_ITF_BAS_VBT_TOT & variability \\
\hline 52 & MDL_MDL_BAS_VBT_TOT & variability \\
\hline
\end{tabular}

\subsection{Métricas para Atributos de Qualidade}

Esta seção apresenta as métricas definidas para os atributos de qualidade complexidade e extensibilidade, utilizadas para ilustrar o método SystEM-PLA. Essas métricas consideram as variabilidades representadas em modelos UML de LP e representam um exemplo de como métricas para atributos de qualidade podem ser definidas, formalizadas, aplicadas, coletadas e validadas para que avaliações de ALP possam ser realizadas.

As subseções a seguir apresentam as métricas de complexidade e extensibilidade para ALP. A Seção 6.4 apresenta um exemplo de aplicação e coleta de tais métricas, tomando como base o estudo piloto realizado para a validação experimental (Capítulo 7) de tais métricas. 


\subsubsection{Métricas de Complexidade}

A compreensão da complexidade de uma LP é fundamental do ponto de vista de adoção da abordagem de LP, uma vez que o gerente de LP pode fazer uma análise da complexidade potencial de uma LP e dos tipos de produtos que podem ser produzidos.

Organizações que possuem o núcleo de artefatos já desenvolvido para um determinado domínio podem analisar a complexidade de configurações distintas do núcleo para o desenvolvimento e evolução de seus possíveis produtos e, dessa forma, optar por uma ou mais configurações viáveis para o desenvolvimento de uma LP.

As métricas compostas a partir das métricas básicas para classes, visam medir a complexidade de uma ALP e são definidas com base na complexidade ciclomática (CC) de McCabe (1976). A CC mede a quantidade de lógica de decisão de um módulo de software representada pelo número de caminhos que devem ser testados. Outra métrica relacionada à complexidade ciclomática, porém específica da abordagem orientada a objetos, é o número de Métodos Ponderados por Classe (Weighted Methods per Class - WMC) (Chidamber e Kemerer, 1994), que indica a soma da CC de todos os métodos de uma classe.

As métricas compostas de complexidade para classes e componentes são apresentadas nos itens a seguir, assim como suas descrições e definições formais.

- CompInterface: tem sempre o valor 0.0, pois não possui métodos concretos para computar a métrica WMC de McCabe.

- CompClass: é o valor da métrica WMC para uma determinada classe. Esta métrica é representada pela Equação (6.42):

$$
\left.\begin{array}{l}
\text { CompClass }(\mathbf{C l s})=W M C(C l s)=\sum_{i=1}^{n} W M C\left(M t d_{i}\right), \\
\text { tal que: } \\
\quad-n=\text { número de métodos }(M t d) \text { da classe Cls }
\end{array}\right\}
$$

- CompVarPointClass: é o valor da métrica CompClass (6.42), da classe que é um ponto de variação mais a soma do valor da métrica CompClass $(6.42)$ de cada variante associada à classe. Esta métrica é representada pela Equação (6.43): 


$$
\begin{aligned}
& \text { CompVarPointClass }(\mathbf{C l s})=\operatorname{CompClass}(C l s)+\sum_{i=1}^{n} \operatorname{CompClass}\left(C_{\text {s }} \text { Ass }_{i}\right) \text {, } \\
& \text { tal que: } \\
& -n=C L S \_C L S \_B A S \_I N C \_N U M(C l s)+C L S \_C L S \_B A S \_E X C \_N U M(C l s) \\
& +\quad C L S \_C L S \_B A S \_O P T \_N U M(C l s) \quad+\quad C L S \_C L S \_B A S \_M N D \_N U M(C l s) \\
& +\quad I T F \_I T F \_B A S \_I N C \_N U M(C l s) \quad+\quad I T F_{-} I T F_{-} B A S_{-} E X C_{-} N U M(C l s)+ \\
& I T F \_I T F \_B A S \_O P T \_N U M+I T F \_I T F \_B A S \_M N D \_N U M(C l s)
\end{aligned}
$$

- Comp VariabilityClass: é a soma da medida da métrica CompVarPointClass (6.43), de cada ponto de variação de uma determinada variabilidade. Esta métrica é representada pela Equação (6.44):

$$
\left.\begin{array}{l}
\text { CompVariabilityClass }(\mathbf{V b t})=\sum_{i=1}^{n V P} \operatorname{CompVarPointClass}\left(C l s_{i}\right), \\
\text { tal que: } \\
\quad-n V P=C L S \_C L S \_B A S_{-} V P T \_N U M+C L S \_I T F_{-} B A S S_{-} V P T_{-} N U M
\end{array}\right\}
$$

- CompVarComponent: é a soma da medida da métrica CompVariabilityClass (6.44), de cada classe que forma um componente. Esta métrica é representada pela Equação (6.45):

$$
\left.\begin{array}{l}
\text { CompVarComponent }(\mathbf{C p t})=\sum_{i=1}^{n C l s} \text { CompVariabilityClass }\left(C l s_{i}\right), \\
\text { tal que: } \\
\quad-n C l s=\text { número de classes que formam o componente Cpt }
\end{array}\right\}
$$

- CompPLA: é a soma dos valores da métrica CompVarComponent 6.45 para cada componente de uma ALP. Esta métrica é representada pela Equação (6.46): 
$\left.\begin{array}{l}\text { CompPLA(ALP) }=\sum_{i=1}^{n C p t} \text { CompVarComponent }\left(C p t_{i}\right), \\ \text { tal que: } \\ \quad-n C p t=\text { número de componentes da ALP } \\ \quad-C p t_{i} \text { é o i-ésimo componente da ALP }\end{array}\right\}$

\subsubsection{Métricas de Extensibilidade}

Um dos conceitos mais importantes e de maior impacto em uma aplicação que segue o paradigma de orientação a objetos, é a herança entre classes. A herança tem por característica permitir a extensão de uma aplicação em termos de suas funcionalidades com base nas interfaces e implementações de suas classes (Batory et al., 2002; Freeman et al., 2004; Nystrom et al., 2004; Shalloway e Trott, 2002). Porém, um dos problemas da herança é a necessidade de a cada nova extensão, criar-se novos tipos de classes, acarretando em mudanças estruturais da aplicação. Para amenizar o impacto da herança na estrutura de uma aplicação durante a sua manutenção, utiliza-se o conceito de classes abstratas (Sane e Birchenough, 1999; Woolf, 1997). Tais classes possuem uma interface, formada por métodos abstratos, e uma implementação-padrão, formada por métodos concretos. Isso faz com que a aplicação não possua uma estrutura fixa voltada somente às classes concretas, mas define um conjunto de classes que representam pontos de extensão da aplicação, além dos hot spots de um arcabouço (Arango et al., 1988).

Os conceitos apresentados até aqui, nesta seção, formam a base para se entender como extensibilidade é medida, no nível de classes e componentes.

As métricas compostas de extensibilidade para classes e componentes, são apresentadas nos itens a seguir, assim como suas descrições e definições formais.

- ExtensInterface: é o nível de extensibilidade de uma interface, o qual é sempre o valor 1.0 já que interfaces são compostas $100 \%$ por métodos abstratos. Esta métrica é representada pela Equação 6.47): 


$$
\begin{aligned}
& \text { ExtensInterface }(\mathbf{I t f})=\frac{I T F_{-} I T F_{-} E X T_{-} M T D_{-} N U M(\text { Itf })}{I T F_{-} I T F_{-} E X T_{-} M T D_{-} N U M(\text { Itf })}=1.0, \\
& \text { tal que: } \\
& \quad \quad \text { ITF_ITF_EXT_MTD_NUM(Itf) }=\text { número de métodos da interface Itf }
\end{aligned}
$$

- ExtensClass: é o nível de extensibilidade de uma classe. Fornece a porcentagem de métodos abstratos com relação ao total de métodos (abstratos mais os concretos) de uma classe. Esta métrica é representada pela Equação (6.48):

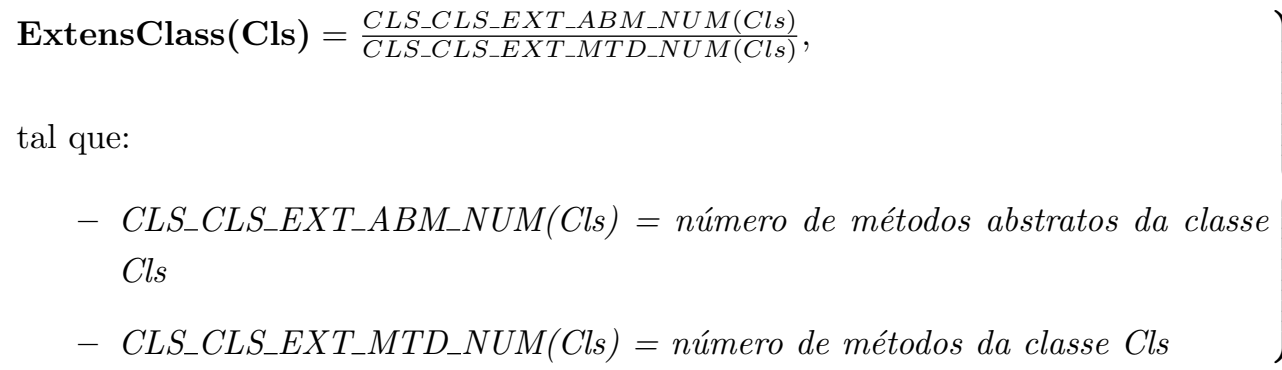

- Extens VarPointClass: é o valor da métrica ExtensClass (6.48), da classe que é um ponto de variação, mais a soma do valor da métrica ExtensClass (6.48) de cada variante associada à classe. Esta métrica é representada pela Equação (6.49):

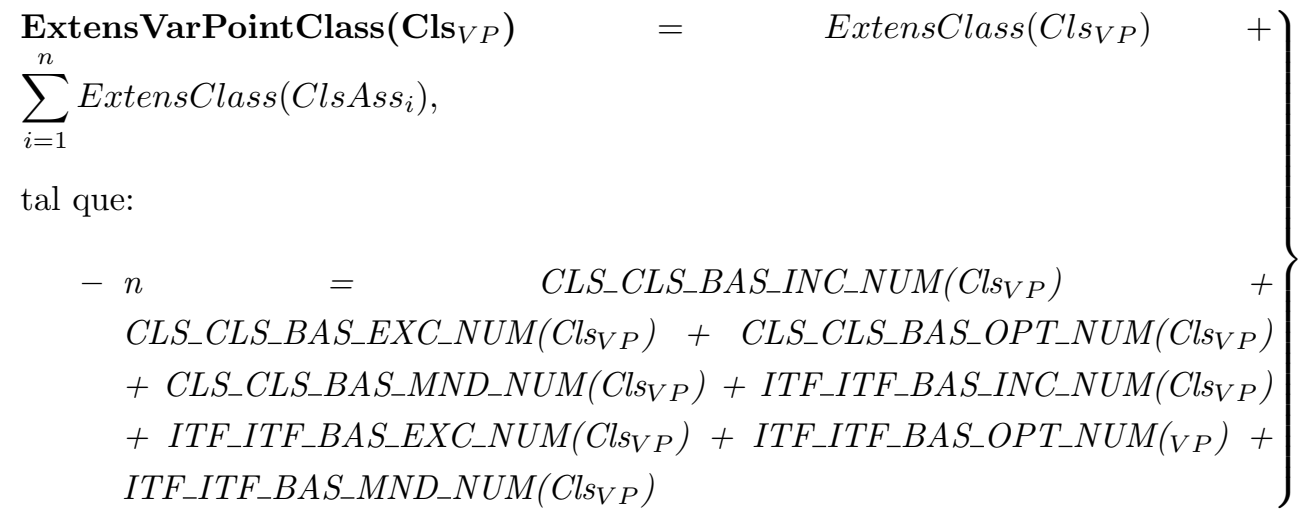


- Extens VariabilityClass: é a soma da medida da métrica Extens VarPointClass 6.49 de cada ponto de variação, de uma determinada variabilidade. Esta métrica é representada pela Equação 6.50):

$$
\left.\begin{array}{l}
\text { ExtensVariabilityClass }(\mathbf{V b t})=\sum_{i=1}^{n V P} \operatorname{ExtensV\operatorname {Var}PointClass}\left(C l s_{i}\right), \\
\text { tal que: } \\
\quad-n V P=C L S \_C L S \_B A S_{-} V P T_{-} N U M+C L S \_I T F_{-} B A S S_{-} V P T_{-} N U M
\end{array}\right\}
$$

- Extens VarComponent: é a soma da medida da métrica Extens VariabilityClass 6.50 de cada classe que forma um componente. Esta métrica é representada pela Equação 6.51):

$$
\left.\begin{array}{l}
\text { ExtensVarComponent }(\mathbf{C p t})=\sum_{i=1}^{n C l s} \text { ExtensVariabilityClass }\left(\mathrm{Cls}_{i}\right), \\
\text { tal que: } \\
\quad-n C l s=\text { número de classes que formam o componente } C p t
\end{array}\right\}
$$

- ExtensPLA: é o nível geral de extensibilidade da ALP, sendo a soma dos valores da métrica ExtensVarComponent (6.51) de cada componente da ALP. Esta métrica é representada pela Equação 6.52:

$$
\begin{aligned}
& \text { ExtensPLA }(\mathbf{A L P})=\sum_{i=1}^{n C p t} \text { ExtensVarComponent }\left(C p t_{i}\right) \\
& \text { tal que: } \\
& \quad-n C p t=\text { número de componentes da } A L P \\
& \quad-C p t_{i} \text { é o i-ésimo componente da } A L P
\end{aligned}
$$




\subsection{Automatização das Métricas Usando a Ferramenta} SDMetrics

Grande parte das métricas baseadas em UML do SystEM-PLA é automatizada por meio da ferramenta SDMetrics (2010). Tal ferramenta aceita como entrada:

- um arquivo $\boldsymbol{X} \boldsymbol{M I}$, que é um formato intercambiável, com modelos UML exportados a partir de ferramentas de modelagem como, por exemplo, Poseidon (Gentleware, 2010);

- um arquivo XMI Transformation, que possui as regras de transformação a partir de marcações XMI e que é dependente da versão XMI e da ferramenta UML utilizada;

- um arquivo Metamodel Definitions com os metamodelos para uma versão específica da UML; e

- um arquivo XML de métricas com a definição de métricas, segundo operações matemáticas de projeção e relação fornecidas pela SDMetrics.

A Listagem 6.1 apresenta um exemplo de definição de uma métrica que indica se uma classe é um ponto de variação.

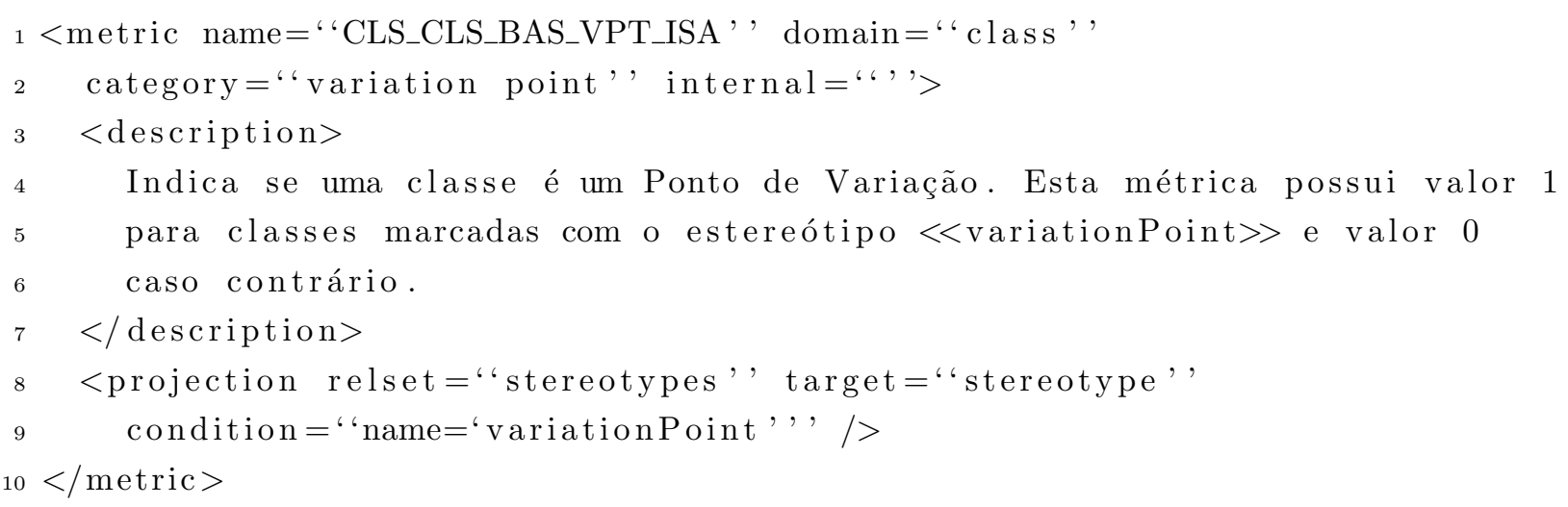

Listagem 6.1: Exemplo de Definição de Métrica Usando a Ferramenta SDMetrics.

A métrica da Listagem 6.1 define:

- um nome (linha 1);

- um domínio, que representa a metaclasse UML a ser medida (linha 1);

- uma categoria (linha 2); 
- se ela é uma métrica auxiliar (internal="true") usada para a composição de outras métricas (linha 2);

- uma descrição (linhas 3 a 7); e

- a relação usada para medir os modelos UML (linhas 8 e 9).

Para a métrica da Listagem 6.1, está sendo realizada uma projeção (projection), no conjunto (relset) de estereótipos da classe medida, cuja condição (condition) é verificar se existe pelo menos um estereótipo (target) cujo nome é variationPoint segundo a abordagem SMarty. Caso positivo, será atribuído o valor 1 (um) para a métrica em questão, indicando que a classe é um ponto de variação. Caso contrário, será atribuído o valor 0 (zero), indicando que a classe não é um ponto de variação.

A Figura 6.1 mostra a tela principal da SDMetrics com métricas para diagramas, coletadas a partir de modelos UML de uma LP para Workflow Management Systems (WfMS) (Gimenes et al., 2004, 2003). A SDMetrics permite exportar tanto as métricas coletadas, quanto os modelos UML em um dos seguintes formatos: Tab-separated text (TXT), Comma-separated vectors (CSV), HTML File (HTM), OpenOffice.org Calc $(S X C)$, ou Excel XML File (XML) Assim, ambientes automatizados de avaliação de ALP podem ler tais arquivos e processar os dados exportados. Além disso, a SDMetrics permite comparar dois conjuntos de modelos UML distintos, apresentar e exportar estatísticas sobre os modelos e exportar gráficos.

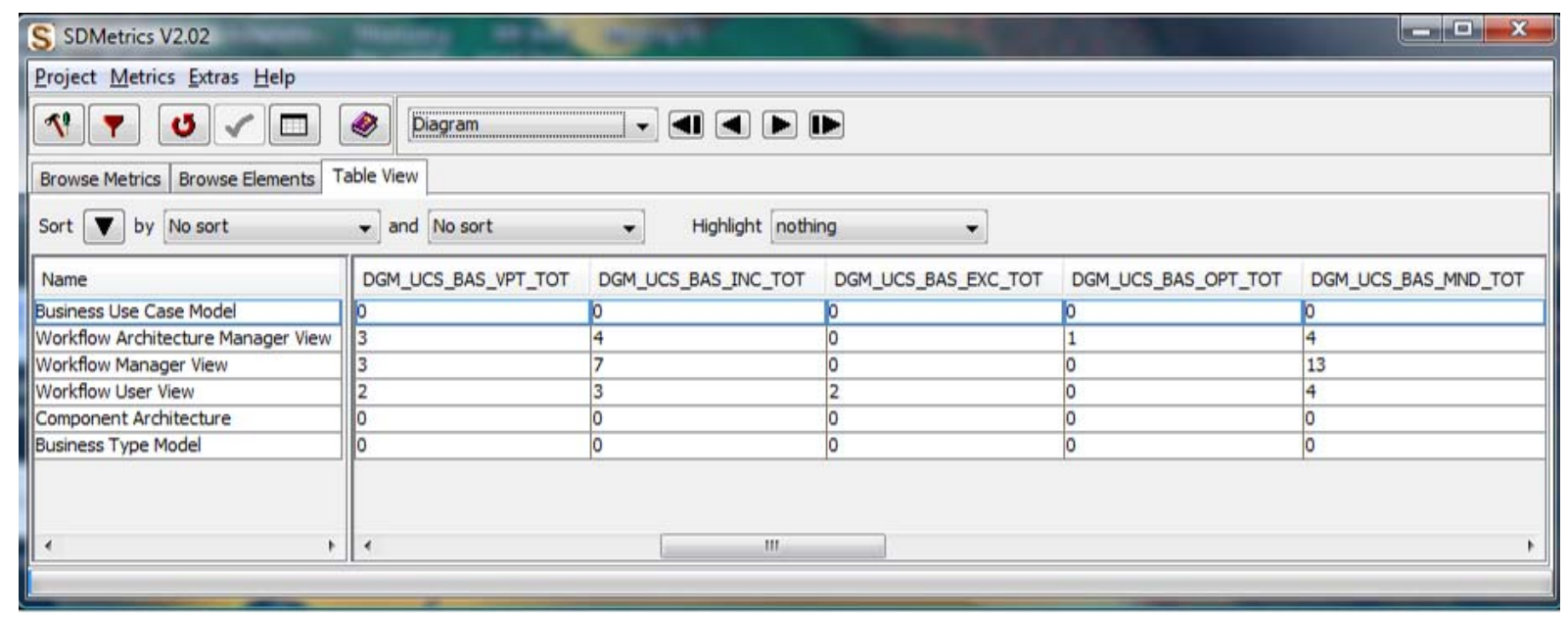

Figura 6.1: Tela Principal da SDMetrics Versão 2.02. na Visão Tabular (Table View)

A Figura 6.2 apresenta um exemplo de coleta de métricas básicas de classes para o diagrama da Figura 4.13 . 


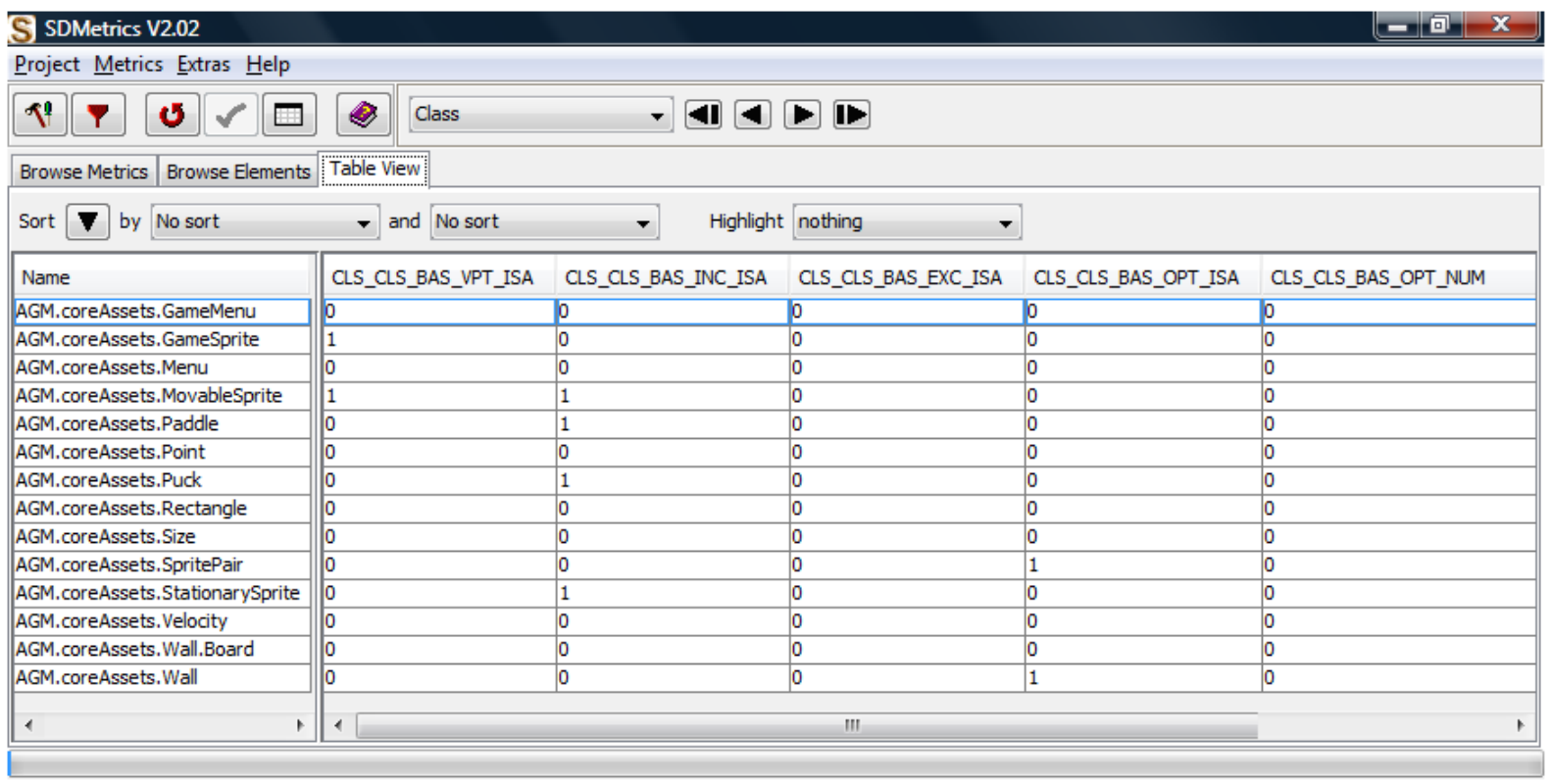

Figura 6.2: Exemplo de Coleta de Métricas Básicas de Classes Usando a Ferramenta SDMetrics.

Pode-se identificar no exemplo da Figura 6.2 que:

- a classe GameSprite é um ponto de variação ( $\left.C L S \_C L S \_B A S_{-} V P T_{-} I S A=1\right)$;

- a classe MovableSprite é uma variante inclusiva (CLS_CLS_BAS_INC_ISA=1); e

- a classe SpritePair é uma variante opcional (CLS_CLS_BAS_OPT_ISA=1).

\subsection{Exemplo de Aplicação e Coleta de Métricas de Com- plexidade e Extensibilidade}

Para ilustrar a aplicação das métricas de atributos de qualidade, esta seção utiliza as configurações da ALP AGM, geradas durante um estudo piloto (Capítulo 7) para a validação experimental de métricas de complexidade e extensibilidade. Tais configurações, suas descrições e seus modelos de classes são apresentados nas subseções a seguir. Note que a ALP da AGM (Apêndice A) possui somente um único componente variável: Game (Figura 4.14).

\subsubsection{Config.1: Jogo Brickles com Características Restritas}

A primeira configuração (Config.1) gerou um produto com as seguintes características: 
- ambiente arcade formado pelo jogo Brickles;

- o jogo não permite salvar o placar corrente;

- o jogo não permite verificar o melhor placar registrado anteriormente;

- é possível salvar o jogo e sair do ambiente; e

- é possível instalar e desinstalar jogos.

O modelo de classes desta configuração é apresentado na Figura 6.3.

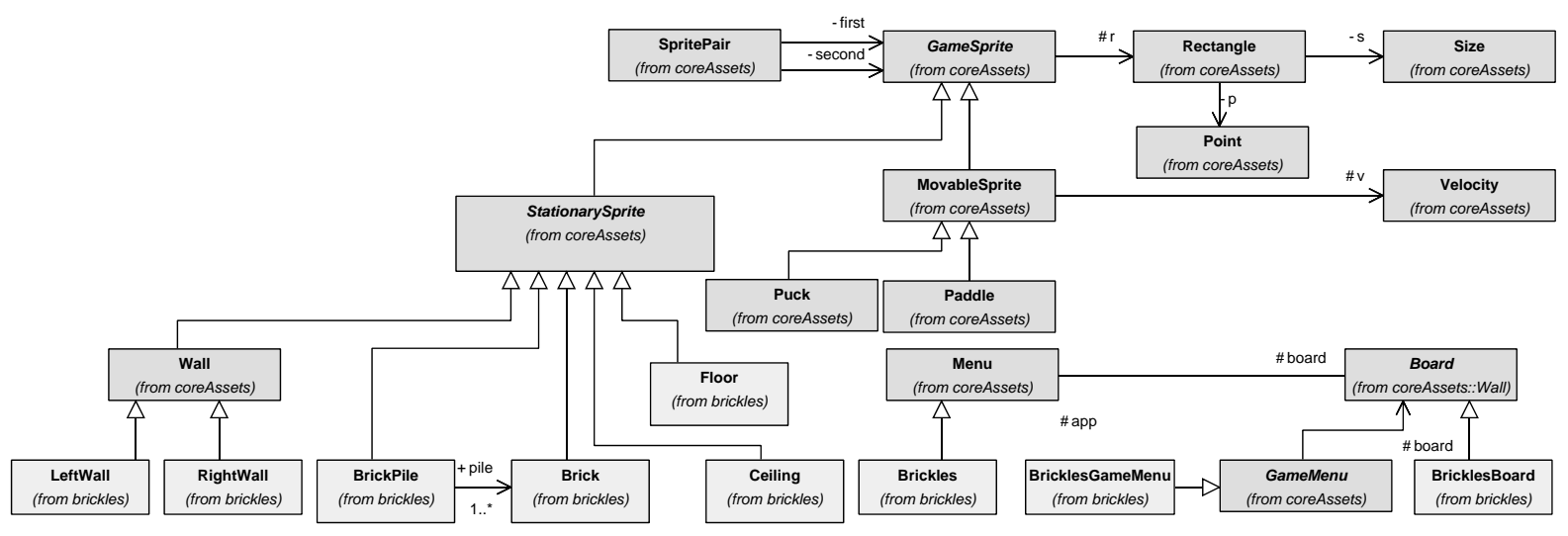

Figura 6.3: Modelo de Classes AGM Config.1.

As métricas de complexidade coletadas para a primeira configuração foram:

- Métrica CompClass: aplicando a Equação (6.42), obtem-se a Tabela 6.6.

Tabela 6.6: Métrica CompClass Aplicada às Classes e Interfaces da Config.1

\begin{tabular}{|c|c|}
\hline CompClass $($ Board $)=47$ & CompClass $($ GameMenu $)=20$ \\
\hline CompClass $($ GameSprite $)=6$ & CompClass $($ Menu $)=11$ \\
\hline CompClass $($ MovableSprite $)=11$ & CompClass $($ Paddle $)=11$ \\
\hline CompClass $($ Point $)=9$ & CompClass $($ Puck $)=9$ \\
\hline CompClass $($ Rectangle $)=20$ & CompClass $($ Size $)=5$ \\
\hline CompClass $($ SpritePair $)=3$ & CompClass $($ StationarySprite $)=1$ \\
\hline CompClass $\left({ }_{\text {Velocity }}\right)=36$ & CompClass $($ Wall $)=5$ \\
\hline CompClass $($ Brick $)=12$ & CompClass $($ Brickles $)=1$ \\
\hline CompClass $($ BricklesBoard $)=28$ & CompClass $($ BricklesGameMenu $)=28$ \\
\hline CompClass $($ BrickPile $)=25$ & CompClass $($ Ceiling $)=5$ \\
\hline CompClass $($ Floor $)=5$ & CompClass $($ LeftWall $)=1$ \\
\hline CompClass $($ RightWall $)=1$ & \\
\hline
\end{tabular}


- Métrica CompVarPointClass: aplicando a Equação (6.43) para cada ponto de variação, obtem-se:

- Comp VarPointClass $\left({ }_{\text {Board }}\right)=$ CompClass $\left._{(\text {Board }}\right)+$ CompClass $($ BricklesBoard $)=47+28=\mathbf{7 5}$;

- Comp VarPointClass $\left(\right.$ GameMenu $\left._{1}\right)=$ CompClass $($ GameMenu $)+$ CompClass $($ BricklesGameMenu $)=20+28=\mathbf{4 8}$;

- CompVarPointClass (GameSprite $)=$ CompClass $($ GameSprite $)+$ $\operatorname{CompClass}($ MovableSprite $)+\operatorname{CompClass}($ StationarySprite $)=6+11+1=\mathbf{1 8}$;

- Comp VarPointClass $\left.{ }_{\text {Menu }}\right)=$ CompClass $\left._{(\text {Menu }}\right)+$ CompClass $($ Brickles $)=11+1=\mathbf{1 2}$;

- Comp VarPointClass (MovableSprite $)=$ CompClass $($ MovableSprite $)+$ $\left.\operatorname{CompClass}_{\text {Paddle }}\right)+$ CompClass $\left._{(\text {Puck }}\right)=11+11+9=\mathbf{3 1}$;

- CompVarPointClass $($ Paddle $)=\operatorname{CompClass}($ Paddle $)=\mathbf{1 1}$;

- Comp VarPointClass $($ StationarySprite $)=$ CompClass $\left(\right.$ StationarySprite $\left._{\text {Stat }}\right)+$

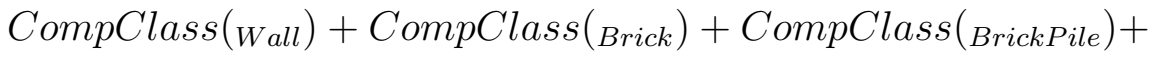
CompClass $($ Floor $)+$ CompClass $($ Ceiling $)=$ $1+5+12+25+5+5=\mathbf{5 3} ; \mathrm{e}$

- Comp VarPointClass $\left({ }_{\text {Wall }}\right)=$ CompClass $($ Wall $)+$ CompClass $($ RightWall $)+\operatorname{CompClass}($ LeftWall $)=6+1+1=\mathbf{7}$.

- Métrica Comp VariabilityClass: aplicando a Equação (6.44), obtem-se:

- Comp VariabilityClass $($ game sprite $)=$ CompVarPointClass $($ GameSprite $)=\mathbf{1 8}$;

- CompVariabilityClass $($ movable sprite $)=$ CompVarPointClass $($ MovableSprite $)=$ 31 ;

- CompVariabilityClass $\left(_{\text {paddle }}\right)=$ CompVarPointClass $($ Paddle $)=11$;

- Comp VariabilityClass $\left(_{\text {тепи }}\right)=$ CompVarPointClass $\left._{(\text {мепи }}\right)=\mathbf{1 2}$;

- Comp VariabilityClass $\left(\right.$ board $\left._{1}\right)=$ CompVarPointClass $\left({ }_{\text {Board }}\right)=\mathbf{7 5}$;

- Comp VariabilityClass (brickles stat. sprite) $=$ CompVarPointClass $($ StationarySprite $)=\mathbf{5 3}$;

- CompVariabilityClass $($ game menu $)=$ CompVarPointClass $\left(\right.$ GameMenu $\left._{\text {- }}\right)=\mathbf{4 8}$; $\mathrm{e}$

- Comp VariabilityClass $($ brickles wall $)=$ CompVarPointClass $\left({ }_{\text {Wall }}\right)=\mathbf{7}$. 
- Métrica Comp VarComponent: aplicando a Equação 6.45), obtem-se:

- CompVarComponent $($ Game $)=$ CompVariabilityClass $($ game sprite $)+$ CompVariabilityClass $\left({ }_{\text {movable sprite }}\right)+$ CompVariabilityClass $\left({ }_{\text {paddle }}\right)+$ CompVariabilityClass $\left({ }_{\text {menu }}\right)+$ CompVariabilityClass $($ board $)+$ CompVariabilityClass (brickles stat. sprite $)+$ CompVariabilityClass (game menu $)+$ CompVariabilityClass $($ brickles wall $)+$ CompVariabilityClass $($ sprite pair $)=$ $18+31+11+12+75+53+48+7+3=\mathbf{2 5 8}$.

- Métrica CompPLA: aplicando a Equação 6.46), obtem-se:

- $\boldsymbol{C o m p P L A}\left(\right.$ Config.1 $\left._{1}\right)=$ CompVarComponent $\left({ }_{\text {Game }}\right)=\mathbf{2 5 8}$.

As métricas de extensibilidade coletadas para a primeira configuração foram:

- Métrica ExtensClass: aplicando a Equação (6.48), obtem-se:

- ExtensClass $($ Board $)=0,13$;

- ExtensClass $($ GameMenu $)=0,50 ; \mathrm{e}$

- ExtensClass $($ GameSprite $)=0,67$.

- Métrica Extens VarPointClass: aplicando a Equação (6.49), obtem-se:

- ExtensVarPointClass $($ Board $)=$ ExtensClass $($ Board $) *$ $\left(C L S \_C L S \_B A S \_I N C \_N U M\left(_{\text {Board }}\right)+C L S \_C L S \_B A S \_E X C \_N U M(\right.$ Board $\left.)\right)=$ $0,13 *(1+0)=\mathbf{0 , 1 3}$;

- ExtensVarPointClass $($ GameMenu $)=$ ExtensClass $\left(\right.$ GameMenu $\left._{1}\right) *$ $\left(C L S \_C L S \_B A S \_I N C \_N U M(\right.$ GameMenu $)+$ $C L S \_C L S \_B A S \_E X C \_N U M($ GameMenu $\left.)\right)=0,50 *(1+0)=\mathbf{0 , 5 0} ; \mathrm{e}$

- ExtensVarPointClass $\left({ }_{\text {GameSprite }}\right)=$ ExtensClass $($ GameSprite $) *$ $\left(C L S \_C L S \_B A S \_I N C \_N U M(\right.$ GameSprite $)+$ $C L S \_C L S \_B A S \_E X C \_N U M($ GameSprite $\left.)\right)=0,67 *(2+0)=\mathbf{1 , 3 3}$.

- Métrica Extens VariabilityClass: aplicando a Equação 6.50, obtem-se:

- ExtensVariabilityClass $\left({ }_{\text {sprite pair }}\right)=$ ExtensVarPointClass $\left({ }_{\text {SpritePair }}\right)=\mathbf{0 , 0}$;

- ExtensVariabilityClass $($ game sprite $)=$ ExtensVarPointClass $($ GameSprite $)=$ 1,33 ; 
- ExtensVariabilityClass $\left({ }_{\text {movable sprite }}\right)=$ ExtensVarPointClass $($ MovableSprite $)=$ 0,0

- ExtensVariabilityClass $\left({ }_{\text {paddle }}\right)=$ ExtensVarPointClass $\left({ }_{\text {Paddle }}\right)=\mathbf{0 , 0}$;

- ExtensVariabilityClass $\left({ }_{\text {menu }}\right)=$ ExtensVarPointClass $\left({ }_{\text {Menu }}\right)=\mathbf{0 , 0}$;

- ExtensVariabilityClass $\left({ }_{\text {board }}\right)=$ ExtensVarPointClass $\left._{(\text {Board }}\right)=\mathbf{0 , 1 3}$;

- ExtensVariabilityClass(brickes stat. sprite) $=$ ExtensVar PointClass (StationarySprite $)=\mathbf{0 , 0}$; e

- ExtensVariabilityClass $($ game menu $)=$ ExtensVarPointClass $\left({ }_{\text {GameMenu }}\right)=\mathbf{0 , 5 0}$;

- ExtensVariabilityClass $($ wall $)=$ ExtensVarPointClass $\left({ }_{\text {Wall }}\right)=\mathbf{0 , 0 .}$

- Métrica Extens VarComponent: aplicando a Equação 6.51, obtem-se:

- ExtensVarComponent $\left({ }_{\text {Game }}\right)=$ ExtensVariabilityClass $($ sprite pair $)+$ ExtensVariabilityClass( game sprite $)+$ ExtensVariabilityClass $($ movable sprite $)+$ ExtensVariabilityClass $\left({ }_{\text {paddle }}\right)+$ ExtensVariabilityClass $\left({ }_{\text {menu }}\right)+$ ExtensVariabilityClass( board $)+$ ExtensVariabilityClass (brickes stat. sprite $)+$ ExtensVariabilityClass $($ game menu $)+$ ExtensVariabilityClass $($ wall $)=$ $0,0+1,33+0,0+0,0+0,0+0,13+0,0+0,50+0,0=\mathbf{1 , 9 7}$.

- Métrica ExtensPLA: aplicando a Equação (6.52), obtem-se:

- ExtensPLA $\left({ }_{\text {Config. } 1}\right)=$ ExtensVarComponent $\left({ }_{\text {Game }}\right)=\mathbf{1 , 9 7 .}$

\subsubsection{Config.2: Jogos Brickles e Pong com Todas as Características}

A segunda configuração (Config.2) gerou um produto com as seguintes características:

- ambiente arcade formado pelos jogos Brickles e Pong;

- o jogo permite salvar o placar corrente e recuperar o melhor placar registrado anteriormente;

- é possível salvar o jogo e sair do ambiente; e

- é possível instalar e desinstalar outros jogos.

O modelo de classes desta configuração é apresentado na Figura 6.4. 


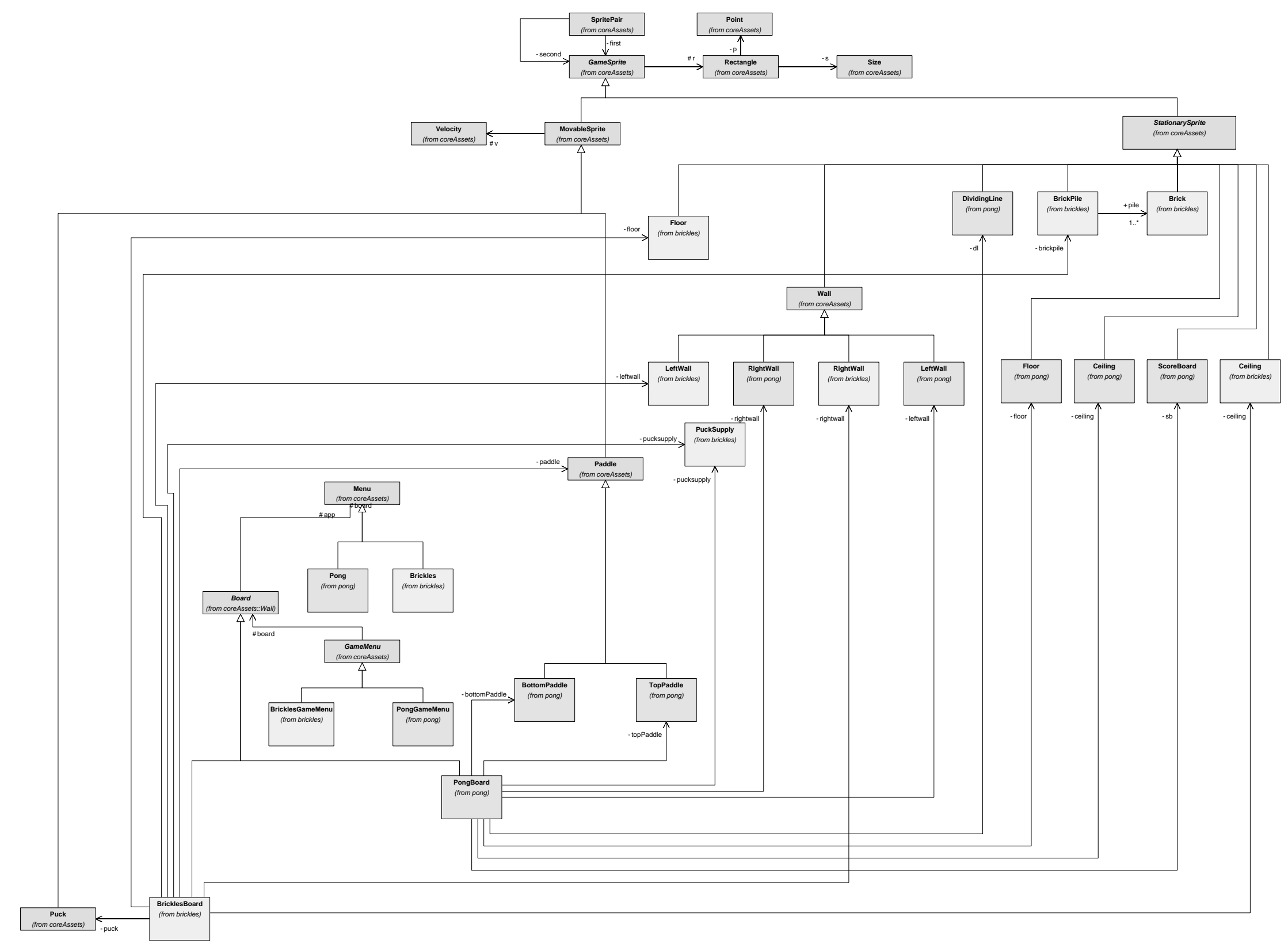

Figura 6.4: Modelo de Classes AGM Config.2. 
As métricas de complexidade coletadas para a segunda configuração foram:

- Métrica CompClass: aplicando a Equação 6.42, obtem-se a Tabela 6.7.

Tabela 6.7: Métrica CompClass Aplicada às Classes e Interfaces da Config.2

\begin{tabular}{|c|c|}
\hline CompClass $($ Board $)=47$ & CompClass $($ GameMenu $)=20$ \\
\hline CompClass $($ GameSprite $)=6$ & $\operatorname{CompClass}($ Menu $)=11$ \\
\hline CompClass $($ MovableSprite $)=11$ & CompClass $($ Paddle $)=11$ \\
\hline CompClass $($ Point $)=9$ & CompClass $($ Puck $)=9$ \\
\hline CompClass $($ Rectangle $)=20$ & $\operatorname{CompClass}($ size $)=5$ \\
\hline CompClass $($ SpritePair $)=3$ & CompClass $($ StationarySprite $)=1$ \\
\hline CompClass $($ Velocity $)=36$ & CompClass $($ Wall $)=5$ \\
\hline CompClass $($ Brick $)=12$ & CompClass $($ Brickles $)=1$ \\
\hline CompClass $($ BricklesBoard $)=28$ & CompClass $($ BricklesGameMenu $)=28$ \\
\hline CompClass $($ BrickPile $)=25$ & CompClass $($ Ceiling $)=5$ \\
\hline CompClass $($ Floor $)=5$ & CompClass $($ LeftWall $)=1$ \\
\hline CompClass $($ RightWall $)=1$ & CompClass $($ BottomPaddle $)=1$ \\
\hline CompClass $($ Ceiling $)=5$ & CompClass $($ DividingLine $)=3$ \\
\hline CompClass $($ Floor $)=5$ & CompClass $($ LeftWall $)=1$ \\
\hline CompClass $($ Pong $)=1$ & CompClass $($ PongBoard $)=34$ \\
\hline CompClass $($ PongGameMenu $)=30$ & CompClass $($ RightWall $)=1$ \\
\hline CompClass $($ ScoreBoard $)=7$ & CompClass $($ TopPaddle $)=1$ \\
\hline
\end{tabular}

- Métrica CompVarPointClass:

- Comp VarPointClass $\left({ }_{\text {Board }}\right)=$ CompClass $\left._{(\text {Board }}\right)+$ CompClass $($ BricklesBoard $)+$ CompClass $\left._{(\text {PongBoard }}\right)=$ $47+28+34=\mathbf{1 0 9}$

- Comp VarPointClass $\left(\right.$ GameMenu $\left._{1}\right)=$ CompClass $\left(\right.$ GameMепu $\left._{1}\right)+$ CompClass $($ BricklesGameMenu $)+$ CompClass $($ PongGameMenu $)=20+28+30=$ 78 ;

- CompVarPointClass $($ GameSprite $)=$ CompClass $($ GameSprite $)+$ CompClass $($ MovableSprite $)+\operatorname{CompClass}($ StationarySprite $)=6+11+1=\mathbf{1 8}$;

- Comp VarPointClass $\left.\left(_{\text {Menu }}\right)=\operatorname{CompClass}_{(\text {мепu }}\right)+$ $\left.\operatorname{CompClass}_{(\text {Pong }}\right)+$ CompClass $_{(\text {Brickles })}=11+1+1=\mathbf{1 3}$;

- Comp VarPointClass (MovableSprite $)=$ CompClass $($ MovableSprite $)+$ CompClass $($ Paddle $)+$ CompClass $($ Puck $)=11+11+9=\mathbf{3 1}$;

- CompVarPointClass (Paddle $)=$ CompClass $($ Paddle $)+$ CompClass $($ BottomPadle $)+$ CompClass $\left({ }_{\text {TopPaddle }}\right)=11+1+1 \mathbf{1 3}$; 


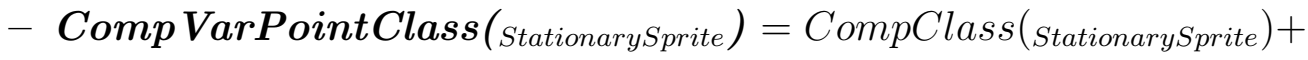
CompClass $\left(\right.$ Wall $\left._{1}\right)+$ CompClass $\left._{(\text {Brick }}\right)+$ CompClass $($ BrickPile $)+$ CompClass $($ Floor $)+$ CompClass $($ Ceiling $)+$ CompClass $($ Floor $)+$ CompClass $($ Ceiling $)+$ CompClass $($ ScoreBoard $)+$ CompClass $($ DividingLine $)=$ $1+5+12+25+5+5+5+5+7+3=73$; e

- Comp VarPointClass $\left({ }_{\text {Wall }}\right)=$ CompClass $($ Wall $)+$ CompClass $($ RightWall $)+$ CompClass $($ LeftWall $)+$ $\operatorname{CompClass}\left({ }_{\text {RightWall }}\right)+\operatorname{CompClass}\left({ }_{\text {LeftWall }}\right)=5+1+1+1+1=\mathbf{9}$.

\section{- Métrica Comp VariabilityClass:}

- Comp VariabilityClass $($ sprite pair $)=$ CompVarPointClass $\left({ }_{\text {SpritePair }}\right)=\mathbf{3}$;

- CompVariabilityClass $($ game sprite $)=$ CompVarPointClass $($ GameSprite $)=\mathbf{1 8}$;

- CompVariabilityClass $($ movable sprite $)=$ CompVarPointClass $($ MovableSprite $)=$ 31 ;

- Comp VariabilityClass $\left(_{\text {puck supply }}\right)=$ CompVarPointClass $($ PuckSupply $)=\mathbf{6}$;

- CompVariabilityClass $\left(_{\text {paddle }}\right)=$ CompVarPointClass $\left({ }_{\text {Paddle }}\right)=\mathbf{1 3}$;

- Comp VariabilityClass $\left._{(\text {mеnu }}\right)=$ CompVarPointClass $\left({ }_{\text {мепи }}\right)=\mathbf{1 3}$;

- CompVariabilityClass $\left(_{\text {board }}\right)=$ CompVarPointClass $($ Board $)=\mathbf{1 0 9}$;

- Comp VariabilityClass (brickles stat. sprite) $=$ CompVarPointClass $($ StationarySprite $)=\mathbf{7 3}$;

- Comp VariabilityClass $($ gате тепu $)=$ CompVarPointClass $\left(\right.$ GameMenu $\left._{\text {G }}\right)=\mathbf{7 8}$; e

- Comp VariabilityClass $($ brickles wall $)=$ CompVarPointClass $($ Wall $)=\mathbf{9}$.

- Métrica Comp VarComponent:

- CompVarComponent $\left({ }_{\text {Game }}\right)=$ CompVariabilityClass $($ game sprite $)+$ CompVariabilityClass (movable sprite $)+$ CompVariabilityClass $\left({ }_{\text {paddle }}\right)+$

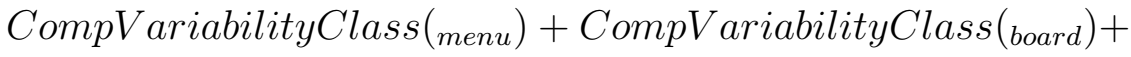
CompVariabilityClass (brickles stat. sprite $)+$ CompVariabilityClass (game menu $)+$ CompVariabilityClass $($ brickles wall $)+$ CompVariabilityClass $\left({ }_{\text {sprite pair }}\right)=$ $18+31+6+13+13+109+73+78+9+3=\mathbf{3 5 3}$.

- Métrica CompPLA: 
- $\boldsymbol{C o m p P L A}$ Config. $\left.1_{1}\right)=$ CompVarComponent $\left({ }_{\text {Game }}\right)=353$

As métricas de extensibilidade coletadas para a segunda configuração foram:

\section{- Métrica ExtensClass:}

- ExtensClass $($ Board $)=0,13$;

- ExtensClass $($ GameMenu $)=0,50 ; \mathrm{e}$

- ExtensClass $($ GameSprite $)=0,67$.

\section{- Métrica Extens VarPointClass:}

- ExtensVarPointClass $($ Board $)=$ ExtensClass $\left({ }_{\text {Board }}\right) *$ $\left(C L S \_C L S \_B A S \_I N C \_N U M\left(_{\text {Board }}\right)+C L S \_C L S \_B A S \_E X C \_N U M(\right.$ Board $\left.)\right)=$ $0,13 *(2+0)=\mathbf{0 , 2 7}$

- ExtensVarPointClass $\left(\right.$ GameMenu $\left._{1}\right)=$ ExtensClass $\left(\right.$ GameMenu $\left._{\text {Gam }}\right)$ $\left(C L S \_C L S \_B A S \_I N C \_N U M(\right.$ GameMenu $)+$ $\left.C L S \_C L S \_B A S \_E X C \_N U M\left({ }_{\text {GameMenu }}\right)\right)=0,50 *(2+0)=\mathbf{1 , 0 0} ; \mathrm{e}$

- ExtensVarPointClass $\left({ }_{\text {GameSprite }}\right)=$ ExtensClass $($ GameSprite $) *$ $\left(C L S \_C L S \_B A S \_I N C \_N U M(\right.$ GameSprite $)+$ $C L S \_C L S \_B A S \_E X C \_N U M($ GameSprite $\left.)\right)=0,67 *(2+0)=\mathbf{1 , 3 3}$.

\section{- Métrica Extens VariabilityClass:}

- ExtensVariabilityClass $\left({ }_{\text {sprite pair }}\right)=$ ExtensVarPointClass $($ SpritePair $)=\mathbf{0 , 0}$;

- ExtensVariabilityClass $($ game sprite $)=$ ExtensVarPointClass $($ GameSprite $)=$ 1,33 ;

- ExtensVariabilityClass $\left({ }_{\text {movable sprite }}\right)=$ ExtensVarPointClass $($ MovableSprite $)=$ 0,0 ;

- ExtensVariabilityClass $\left({ }_{\text {paddle }}\right)=$ ExtensVarPointClass $\left({ }_{\text {Paddle }}\right)=\mathbf{0 , 0}$;

- ExtensVariabilityClass $\left({ }_{\text {menu }}\right)=$ ExtensVarPointClass $\left({ }_{\text {Menu }}\right)=\mathbf{0 , 0}$;

- ExtensVariabilityClass $\left({ }_{\text {board }}\right)=$ ExtensVarPointClass $\left._{(\text {Board }}\right)=\mathbf{0 , 2 7}$;

- ExtensVariabilityClass (brickes stat. sprite) $=$ ExtensVarPointClass $($ StationarySprite $)=\mathbf{0 , 0}$;

- ExtensVariabilityClass $($ game menu $)=$ ExtensVarPointClass $($ GameMenu $)=\mathbf{1 , 0 0}$; e 
- ExtensVariabilityClass $($ wall $)=$ ExtensVarPointClass $\left({ }_{\text {Wall }}\right)=\mathbf{0 , 0 .}$

- Métrica Extens VarComponent:

- ExtensVarComponent $\left({ }_{\text {Game }}\right)=$ ExtensVariabilityClass $($ sprite pair $)+$ ExtensVariabilityClass (game sprite $)+$ ExtensVariabilityClass $\left({ }_{\text {movable sprite }}\right)+$ ExtensVariabilityClass $\left({ }_{\text {paddle }}\right)+$ ExtensVariabilityClass $\left({ }_{\text {menu }}\right)+$ ExtensVariabilityClass( board $\left._{1}\right)+$ ExtensVariabilityClass (brickes stat. sprite $)+$ ExtensVariabilityClass $($ game menu $)+$ ExtensVariabilityClass $\left({ }_{\text {wall }}\right)=$ $0,0+1,33+0,0+0,0+0,0+0,27+0,0+1,00+0,0=\mathbf{2 , 6 0 .}$

- Métrica ExtensPLA:

- ExtensPLA $\left({ }_{\text {Config. } 2}\right)=$ ExtensVarComponent $\left({ }_{\text {Game }}\right)=\mathbf{2 , 6 0 .}$

\subsubsection{Análise Acerca do Exemplo}

Ao comparar as duas configurações geradas, Config.1 e Config.2, pode-se fazer uma análise quanto aos valores observados para complexidade e extensibilidade:

- Métrica CompPLA: a Config.1 apresentou o valor 258 para a métrica CompPLA, enquanto a Config.2 apresentou o valor 353 para a mesma métrica. Assim,

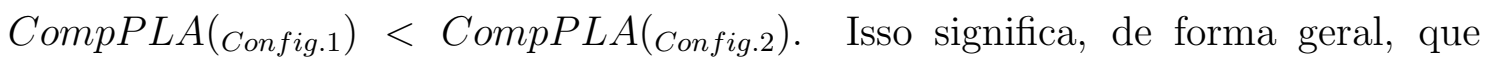
produtos similares à Config.2, a partir da ALP da AGM, são mais complexos do que produtos similares à Config.1.

- Métrica ExtensPLA: a Config.1 apresentou o valor 1,97 para a métrica ExtensPLA, enquanto a Config.2 apresentou o valor 2,60 para a mesma métrica. Assim, Extens Config.1 $_{\text {C }}<$ ExtensPLA(Config.2). Isso significa, de forma geral, que produtos similares à Config.2, desenvolvidos a partir da ALP da AGM, são mais extensíveis do que produtos similares à Config.1.

Percebe-se que produtos similares à Config.1 são interessantes à LP AGM, pois possuem baixos valores de complexidade. Porém, produtos similares à Config.2 também são interessantes à LP AGM, pois permitem produtos mais extensíveis do que os similares à Config.1. Uma questão certamente relevante seria: Qual atributo de qualidade deve ser priorizado no desenvolvimento de produtos AGM?

Uma forma de responder a esta questão, é gerar um número suficientemente grande de configurações para que se possa analisar estatisticamente, os valores coletados para cada métrica e, dessa forma, decidir experimentalmente qual atributo de qualidade priorizar tal como demonstrado no Capítulo 5, por meio de análises de trade-off. 


\subsection{Considerações Finais}

Este capítulo apresentou o conjunto de métricas básicas de modelos UML, utilizadas para a composição de métricas para atributos de qualidade.

As métricas básicas visam a medição de elementos UML, incluindo: classes e interfaces, componentes, diagramas e modelos UML que representam uma LP como um todo.

As métricas de complexidade baseiam-se na medição de complexidade ciclomática por meio da métrica WMC para sistemas orientados a objetos. Já as métricas para extensibilidade estão fundamentadas nos conceitos de herança e polimorfismo, em especial ao relacionamento entre classes abstratas e concretas e entre métodos abstratos e concretos.

Um exemplo de aplicação e coleta das métricas básicas e de atributos de qualidade foi apresentado, em que duas configurações da ALP da AGM foram geradas.

Com base no exemplo apresentado, pode-se dizer que a priorização de atributos de qualidade por meio do método SystEM-PLA se torna mais interessante a partir do momento em que incorporam-se mais atributos de qualidade à tais análises. Desse modo, fica evidente a necessidade de análises quantitativas apoiadas pela definição e coleta de métricas e aplicação de métodos estatísticos.

Outro fator que fundamenta a necessidade de avaliação experimental de uma ALP é a capacidade de uma LP gerar centenas ou milhares de produtos diferentes, o que torna inviável e, muitas vezes impossível, analisar todos os possíveis produtos de tal LP. Dessa forma, métricas de atributos de qualidade se fazem necessárias para possibilitar tais análises experimentais, sendo consideradas essenciais à uma efetiva avaliação de ALP, corroborando com a literatura existente. 


\section{Validação Experimental das Métricas de Complexidade e Extensibilidade}

"No campo da observação, o acaso

favorece somente as mentes

preparadas."

Louis Pasteur (1822 - 1895),

Bacteriologista Francês

Demonstrar que uma medida realmente mede o atributo para o qual foi definida é a forma mais básica de validação. Além disso, é necessário demonstrar a sua utilidade. Assim, uma medida é válida se:

- realmente mede o que se propõe a medir; e

- está relacionada a algum atributo externo, contribuindo para alcançar alguma meta de avaliação ou predição.

Duas abordagens para validação de métricas são apresentadas e discutidas por Briand et al. (1995): validação teórica e validação experimental. Esses dois tipos de validação são usados para demonstrar, respectivamente, que uma métrica: realmente mede o atributo com o qual está relacionada; e é útil no sentido de que está relacionada à outras variáveis de acordo com a sua teoria definida. 
Validação experimental é fundamental para o sucesso de atividades de medição (Basili et al., 1999; Fenton e Pfleeger, 1996; Kitchenham et al., 1995; Schneidewind, 1992). Por meio da validação experimental é possível demonstrar com real evidência que as medidas servem ao propósito para o qual foram propostas e que são viáveis na prática (Briand et al., 1995; Genero et al., 2002).

Este capítulo descreve o experimento realizado para validar experimentalmente as métricas de complexidade CompPLA (Seção 6.2.1) e de extensibilidade ExtensPLA (Seção 6.2.2 para ALP. Para tanto, as sugestões apresentadas por Wohlin et al. (2000), Perry et al. (2000) e Briand et al. (2001) para a definição e condução de experimentos foram seguidas.

As próximas seções estão divididas em definição, planejamento, execução, análise e interpretação dos resultados, avaliação de validade e apresentação e empacotamento do estudo experimental; além de lições aprendidas com a condução do estudo experimental.

\subsection{Definição do Estudo Experimental}

Com base no template GQM (Basili e Rombach, 1988), o objetivo do experimento é apresentado a seguir:

Analisar métricas coletadas de modelos UML e código fonte

Com o propósito de validação

Referente à capacidade de serem usadas como indicadores de complexidade e extensibilidade de ALP

Do ponto de vista do arquiteto de $L P$

No contexto de professores e alunos de mestrado e doutorado da área de Engenharia de Software da University of Waterloo (ECE-UWaterloo), Universidade de São Paulo (ICMC-USP) e Universidade Estadual de Maringá (DIN-UEM).

\subsection{Planejamento do Estudo Experimental}

Contexto Global: para avaliar uma LP é necessário um conjunto de métricas (Dincel et al., 2001). Essas métricas devem evidenciar tanto a qualidade da LP como também servir de base para analisar o valor gerencial e econômico de uma LP (Böckle et al., 2004). A avaliação de uma LP inclui sua arquitetura e os elementos que a compõem. A arquitetura de uma LP difere da arquitetura de um produto único e específico, pois deve tornar explícitos os aspectos comuns e os aspectos variáveis, normalmente chamados de 
variabilidades de uma família de produtos. Um dos elementos principais do gerenciamento de uma LP é o gerenciamento de variabilidades (Becker, 2003; Oliveira Junior, 2005; Oliveira Junior et al., 2005a) que inicia na análise de requisitos e tem efeito na maioria dos artefatos da LP. A análise de impacto das variabilidades, no desenvolvimento dos produtos de uma LP, pode determinar o valor agregado desta para uma organização. As métricas de uma LP se aplicam a um conjunto de artefatos flexível (núcleo de artefatos de uma LP), a partir do qual, várias configurações podem ser geradas, em vez de um produto concreto, o que é mais comum na aplicação de métricas na área de software.

Contexto Local: este estudo tem como objetivo validar a aplicação de métricas de modelos UML e código fonte na avaliação de ALP. Tais métricas levam em consideração as variabilidades de uma LP e, portanto, mostram-se importantes na análise do valor gerencial e econômico de uma LP. Os participantes deverão entender os modelos UML de uma LP, entender suas variabilidades identificadas, resolvê-las e gerar configurações da LP para que as métricas possam ser coletadas.

Treinamento: nenhum treinamento será realizado para este estudo experimental.

Projeto Piloto: antes da execução real do estudo, será realizado um estudo piloto com vistas a avaliar a instrumentação que será utilizada no estudo experimental. Para tanto, somente um participante será utilizado. O participante utilizará os mesmos instrumentos do estudo experimental. Não será usado nenhum dado coletado pelo estudo piloto para complementar o estudo experimental.

Participantes: os participantes do estudo, além de terem pelo menos graduação na área de computação, deverão possuir conhecimentos mínimos sobre:

- a notação UML, mais especificamente sobre modelos de classes e de componentes - para que possam entender os modelos de uma determinada LP e, a partir destes, gerar as configurações de LP (produtos) necessárias; e

- a abordagem de LP, gerenciamento de variabilidades, tempo de resolução de variabilidades e relacionamento entre pontos de variação e variantes.

O estudo não leva em consideração o ambiente ao qual o participante está associado. Portanto, não faz diferença se o participante é oriundo da academia ou da indústria. 
Instrumentação: todos os participantes receberão um conjunto de documentos (Apêndice C), sendo eles:

- uma cópia do termo de adesão ao estudo experimental;

- uma cópia do questionário de caracterização, no qual o participante indicará a sua formação acadêmica, o seu nível de experiência com a notação UML e com a abordagem de LP;

- uma cópia do documento com a descrição geral da LP AGM;

- uma cópia do documento apresentando os principais estereótipos e suas respectivas descrições, do perfil SMartyProfile, o qual é aplicado nos diagramas UML da LP AGM;

- cinco cópias do diagrama de classes e de componentes da LP AGM; e

- cinco cópias do modelo de resolução de variabilidades da LP AGM.

Formulação das Hipóteses: as seguintes hipóteses são propostas para o estudo experimental em questão:

- Hipótese Nula $\left(\mathbf{H}_{0}\right)$ : não existe correlação significante entre a métrica CompPLA e o valor de complexidade associado pelo participante, e nem entre a métrica Extens$P L A$ e o valor de extensibilidade associado pelo participante, segundo o participante. $H_{0}: \mu_{C o m p P L A} \nRightarrow \mu_{\text {Complexidade(Participante) }}$ e $\mu_{\text {ExtensPLA }} \nRightarrow \mu_{\text {Extensibilidade(Participante) }}$

- Hipótese Alternativa $\left(\mathbf{H}_{1}\right)$ : existe correlação significante entre a métrica CompPLA e o valor de complexidade associado pelo participante, mas não existe correlação significante entre a métrica ExtensPLA e o valor de extensibilidade associado pelo participante.

$$
H_{1}: \mu_{C o m p P L A} \Leftrightarrow \mu_{\text {Complexidade(Participante) }} \text { e } \mu_{\text {ExtensPLA }} \nRightarrow \mu_{\text {Extensibilidade(Participante) }}
$$

- Hipótese Alternativa $\left(\mathbf{H}_{2}\right)$ : não existe correlação significante entre a métrica CompPLA e a o valor de complexidade associado pelo participante, mas existe correlação significante entre a métrica ExtensPLA e o valor de extensibilidade associado pelo participante.

$H_{2}: \mu_{\text {CompPLA }} \leftrightarrow \mu_{\text {Complexidade(Participante) }}$ e $\mu_{\text {ExtensPLA }} \Leftrightarrow \mu_{\text {Extensibilidade(Participante) }}$ 
- Hipótese Alternativa $\left(\mathbf{H}_{3}\right)$ : existe correlação significante entre as métricas CompPLA e ExtensPLA e os valores de complexidade e extensibilidade, respectivamente, associados pelos participantes.

$H_{3}: \mu_{\text {CompPLA }} \Leftrightarrow \mu_{\text {Complexidade(Participante) }}$ e $\mu_{\text {ExtensPLA }} \Leftrightarrow \mu_{\text {Extensibilidade(Participante) }}$

Variáveis Dependentes: complexidade e extensibilidade de uma ALP.

Variáveis Independentes: métricas CompPLA e ExtensPLA para complexidade e extensibilidade, respectivamente.

Análise Qualitativa: tem o objetivo de avaliar a complexidade e a extensibilidade de uma ALP por meio da geração de configurações de ALP, aplicação e coleta de métricas e a sua correlação com os valores de complexidade e extensibilidade associados pelos participantes do estudo.

Capacidade Aleatória: a seleção de participantes não será de forma aleatória dentro do universo de candidatos, já que tal universo é bastante restrito.

Classificação em Bloco: não há necessidade de dividir os participantes em blocos, pois o estudo avaliará apenas um fator que é a validação das métricas de complexidade e extensibilidade. Contudo, após aplicado o questionário de caracterização de participantes, tais informações poderão ser classificadas e organizadas em blocos durante a análise dos dados.

Balanceamento: serão distribuídas tarefas em números iguais para um número similar de participantes.

Mecanismos de Análise: o experimento proposto verifica a existência de uma correlação significante entre a métrica de complexidade e o valor de complexidade associado pelo participante para uma ALP. O mesmo acontece para a métrica de extensibilidade. Assim, acredita-se que os possíveis mecanismos de análise sejam:

- os testes de normalidade de Kolmogorov-Smirnov e Shapiro-Wilk que serão aplicados aos valores observados para cada métrica; 
- caso as distribuições de frequência dos valores observados sejam normais, será aplicada a Correlação de Pearson. Caso contrário, será aplicada a Correlação de Spearman. Tais métodos estatísticos fornecerão indícios para aceitar ou refutar a Hipótese Nula $\left(\mathrm{H}_{0}\right)$, definida para este estudo; e

- caso a Hipótese Nula seja rejeitada, a técnica de análise de regressão linear será usada para obter a equação de correlação entre as métricas.

Validade Interna: Para garantir a validade interna deste estudo serão tomadas as seguintes medidas:

- é prevista a utilização de 6 (seis) participantes, todos realizando o estudo de forma isolada. Assim, não terão oportunidade de trocar idéias a respeito do estudo entre si, durante a realização das tarefas;

- foi incluído no termo de adesão ao estudo experimental, o total sigilo das informações relevantes ao estudo e a troca de idéias sobre este entre os participantes.

Validade Externa: A validade externa deste estudo é considerada suficiente, já que os participantes atuam diretamente em seus cargos possuindo conhecimento mínimo dos conceitos de LP e variabilidades, além de modelagem UML. Assim, a falta de motivação não afetará a validade externa de tal estudo.

Validade de Construção: Acredita-se que a validade de construção esteja garantida, uma vez que a abordagem de LP e seus conceitos de modelagem e resolução de variabilidade em UML, no nível em que será aplicado, não exigem ampla experiência dos participantes. A notação UML é amplamente conhecida, o que contribui para garantir a validade de construção do estudo.

Validade de Conclusão: Acredita-se que a capacidade de conclusão do estudo esteja garantida, uma vez que a análise dos dados poderá ser realizada por meio da utilização de métodos de correlação entre dois conjuntos de dados. Além disso, as métricas são medidas objetivas e de fácil coleta, o que diminui a influência da complexidade de entendimento e cálculo. 


\subsection{Execução do Estudo Experimental}

Seleção dos Participantes: para este estudo experimental foram selecionados alunos de cursos de Mestrado e Doutorado em Engenharia de Software dos programas de pósgraduação em Ciência da Computação das seguintes universidades: University of Waterloo (UWaterloo), Universidade de São Paulo (USP) e Universidade Estadual de Maringá (UEM). Os participantes selecionados satisfazem as restrições apresentadas no planejamento deste estudo (Seção 7.2). Os participantes formam um subconjunto dos alunos de tais instituições.

Instrumentação: o principal instrumento é o modelo de resolução de variabilidades que foi preenchido para cada configuração gerada por cada participante do estudo. A tarefa principal de cada participante foi ler e entender: a descrição geral da LP AGM, o perfil UML SMartyProfile e os modelos de classes e de componentes. Em seguida, o modelo de resolução de variabilidades foi resolvido para cada configuração por meio da resposta "Sim" ou "Não" às questões de tal modelo (Apêndice C). Além disso, para cada configuração, o usuário associou um valor de complexidade e extensibilidade, segundo o seu julgamento e de acordo com a Figura 7.1. Dessa forma, cada participante gerou 5 configurações, num totalde 30 .

\begin{tabular}{|c|c|c|c|c|}
\hline $\begin{array}{c}\text { Extremamente } \\
\text { Baixa }\end{array}$ & Baixa & $\begin{array}{c}\text { Nem Baixa } \\
\text { Nem Alta }\end{array}$ & Alta & $\begin{array}{c}\text { Extremamente } \\
\text { Alta }\end{array}$ \\
\hline
\end{tabular}

Figura 7.1: Valores de Complexidade e Extensibilidade Associados pelos Participantes às Configurações AGM.

Procedimentos de Participação: um único procedimento de participação foi adotado para cada participante do estudo. Os itens a seguir apresentam, em ordem cronológica, cada procedimento:

1. participante comparece ao local em que o estudo será realizado;

2. experimentador entrega ao participante o Termo de Adesão ao estudo experimental;

3. participante lê, esclarece possíveis dúvidas e assina o Termo de Adesão ao estudo experimental;

4. um identificador (ID) único é associado ao participante; 
5. experimentador anota o ID do participante no Questionário de Caracterização de Participante;

6. experimentador entrega ao participante o Questionário de Caracterização de Participante;

7. participante lê, esclarece possíveis dúvidas e assina o Questionário de Caracterização de Participante;

8. experimentador entrega o documento com a Descrição Geral da LP AGM;

9. participante lê e esclarece possíveis dúvidas com relação à Descrição Geral da LP AGM;

10. experimentador entrega ao participante os Modelos de Classes e de Componentes da LP AGM;

11. participante lê e esclarece possíveis dúvidas com relação aos Modelos de Classes e de Componentes da LP AGM;

12. experimentador entrega ao participante o Modelo de Resolução de Variabilidades da LP AGM;

13. participante lê e esclarece possíveis dúvidas com relação ao Modelo de Resolução de Variabilidades da LP AGM;

14. participante resolve as variabilidades e gera 5 produtos distintos para a LP AGM;

15. experimentador verifica se o produto gerado é consistente com relação às suas variabilidades e restrições;

16. para cada configuração gerada, o participante associa um valor de complexidade e extensibilidade, segundo a Figura 7.1;

17. participante entrega o modelo de resolução de cada configuração gerada ao experimentador; e

18. experimentador confere os 5 modelos de resolução entregues pelo participante e os armazena em uma pasta apropriada. 
Execução: a Tabela 7.1 apresenta as informações sobre os participantes do estudo experimental. Para cada critério foram usados os seguintes fatores de classificação:

- Formação Acadêmica: Mestrando (Mn), Mestre (Ms), Doutorando (Dn), Doutor (Dr);

- Experiência com UML: Básica (B), Moderada (M), Avançada (A); e

- Experiência com LP e Variabilidade: Básica (B), Moderada (M), Avançada (A).

Tabela 7.1: Dados Detalhados dos Participantes do Estudo Experimental.

\begin{tabular}{|c|c|c|c|c|c|c|c|c|c|c|}
\hline ID & \multicolumn{4}{|c|}{ Formação Acadêmica } & \multicolumn{3}{|c|}{ Experiência com U. } & \multicolumn{3}{|c|}{ Experiência com LP } \\
\hline Exp-AGM-01 & $\operatorname{Mn}(\mathrm{x})$ & $\overline{\mathrm{Ms}()}$ & $\overline{\operatorname{Dn}()}$ & $\overline{D \operatorname{Dr}()}$ & $\overline{\mathrm{B}(\mathrm{)})}$ & $\overline{\mathrm{M}(\mathrm{x})}$ & $\overline{\mathrm{A}(\mathrm{)})}$ & $\mathrm{B}(\mathrm{)}$ & $\overline{\mathrm{M}(\mathrm{)})}$ & $\mathrm{A}(\mathrm{x})$ \\
\hline Exp-AGM-02 & $\operatorname{Mn}()$ & $\mathrm{Ms}()$ & $\operatorname{Dn}(\mathrm{x})$ & $\operatorname{Dr}()$ & $\mathrm{B}(\mathrm{)}$ & $\mathrm{M}(\mathrm{)}$ & $\mathrm{A}(\mathrm{x})$ & $\mathrm{B}(\mathrm{)}$ & $\mathrm{M}(\mathrm{x})$ & $\mathrm{A}()$ \\
\hline Exp-AGM-03 & $\operatorname{Mn}()$ & $\operatorname{Ms}(\mathrm{x})$ & $\operatorname{Dn}()$ & $\operatorname{Dr}()$ & $\mathrm{B}(\mathrm{)}$ & $\mathrm{M}(\mathrm{)}$ & $\mathrm{A}(\mathrm{x})$ & $\mathrm{B}(\mathrm{)}$ & $\mathrm{M}(\mathrm{x})$ & $\mathrm{A}(\mathrm{)})$ \\
\hline Exp-AGM-04 & $\operatorname{Mn}(x)$ & $\operatorname{Ms}()$ & $\operatorname{Dn}()$ & $\operatorname{Dr}()$ & $\mathrm{B}(\mathrm{x})$ & $\mathrm{M}(\mathrm{)}$ & $\mathrm{A}(\mathrm{)}$ & $\mathrm{B}(\mathrm{x})$ & $\mathrm{M}()$ & $\mathrm{A}(\mathrm{)})$ \\
\hline Exp-AGM-05 & $\operatorname{Mn}()$ & $\mathrm{Ms}($ & $\operatorname{Dn}(\mathrm{x})$ & $\operatorname{Dr}()$ & $\mathrm{B}(\mathrm{x})$ & $\mathrm{M}()$ & $\mathrm{A}(\mathrm{)}$ & $\mathrm{B}(\mathrm{x})$ & $\mathrm{M}()$ & $\mathrm{A}(\mathrm{)})$ \\
\hline Exp-AGM-06 & $\operatorname{Mn}()$ & $\mathrm{Ms}()$ & $\operatorname{Dn}(\mathrm{x})$ & $\operatorname{Dr}()$ & $\mathrm{B}(\mathrm{)}$ & $\mathrm{M}(\mathrm{x})$ & $\mathrm{A}(\mathrm{)}$ & $\mathrm{B}(\mathrm{x})$ & $\mathrm{M}(\mathrm{)}$ & $\mathrm{A}(\mathrm{)})$ \\
\hline
\end{tabular}

Seis pessoas participaram do estudo experimental, sendo cinco alunos de mestrado e doutorado e um professor de Engenharia de Software. Aos participantes foram distribuídos todos os documentos necessários para a realização das tarefas. Cada participante solucionou o modelo de resolução de variabilidades gerando cinco produtos distintos, aos quais foram aplicadas e coletadas as métricas de complexidade e extensibilidade. Além disso, os participantes avaliaram a complexidade e extensibilidade associadas à cada produto gerado.

Ao final, trinta produtos distintos foram gerados, além de trinta valores de métricas coletadas (Tabela 7.2), as quais foram analisadas com métodos estatísticos apropriados, como mostra a Seção 7.4 . 
166 Capítulo 7. Validação Experimental das Métricas de Complexidade e Extensibilidade

Tabela 7.2: Arcade Game Maker: Métricas Coletadas e Estatística Descritiva.

\begin{tabular}{|c|c|c|}
\hline Configurações & CompPLA & ExtensPLA \\
\hline Config. 01 & 0,51 & 0,61 \\
\hline Config. 02 & 0,56 & 0,61 \\
\hline Config. 03 & 0,51 & 0,81 \\
\hline Config. 04 & 0,83 & 0,80 \\
\hline Config. 05 & 0,91 & 1,00 \\
\hline Config. 06 & 0,50 & 0,61 \\
\hline Config. 07 & 0,47 & 0,61 \\
\hline Config. 08 & 0,53 & 0,61 \\
\hline Config. 09 & 0,67 & 0,80 \\
\hline Config. 10 & 0,90 & 1,00 \\
\hline Config. 11 & 0,53 & 0,61 \\
\hline Config. 12 & 0,97 & 1,00 \\
\hline Config. 13 & 0,48 & 0,61 \\
\hline Config. 14 & 0,69 & 0,61 \\
\hline Config. 15 & 0,74 & 0,80 \\
\hline Config. 16 & 0,98 & 1,00 \\
\hline Config. 17 & 0,77 & 0,80 \\
\hline Config. 18 & 0,82 & 0,80 \\
\hline Config. 19 & 0,52 & 0,61 \\
\hline Config. 20 & 0,82 & 0,80 \\
\hline Config. 21 & 0,49 & 0,61 \\
\hline Config. 22 & 1,00 & 1,00 \\
\hline Config. 23 & 0,52 & 0,61 \\
\hline Config. 24 & 0,42 & 0,61 \\
\hline Config. 25 & 0,62 & 0,80 \\
\hline Config. 26 & 0,47 & 0,61 \\
\hline Config. 27 & 0,53 & 0,61 \\
\hline Config. 28 & 0,70 & 0,80 \\
\hline Config. 29 & 0,40 & 0,61 \\
\hline Config. 30 & 0,78 & 0,80 \\
\hline Média Aritm. $(\mu)$ & 0,6545 & 0,7390 \\
\hline Desvio Padrão $(\sigma)$ & 0,1842 & 0,1487 \\
\hline Mediana & 0,5895 & 0,7060 \\
\hline
\end{tabular}

\subsection{Análise e Interpretação dos Resultados do Estudo Experimental}

Com base nas configurações geradas e nas métricas CompPLA e ExtensPLA, coletadas para cada configuração, as seguintes etapas foram realizadas:

- aplicação de testes de normalidade baseados em hipóteses, Kolmogorov-Smirnov e Shapiro-Wilk, com o objetivo de verificar se o conjunto de valores observados para cada métrica (Tabela 7.2 possui comportamento normal; 
- aplicação da Correlação de Spearman (Spearman, 1904), que é um método estatístico não paramétrico usado para verificar se existe uma correlação significante entre dois conjuntos não normais de valores; e

- análise linear de regressão para obter as equações que representam a correlação entre duas variáveis, no caso, entre as métricas de complexidade e extensibilidade.

\subsubsection{Testes de Normalidade para as Métricas CompPLA e Extens- PLA}

Antes de aplicar efetivamente um método estatístico, é necessário saber se a amostra de valores observados para cada métrica, possui comportamento semelhante ao de uma distribuição normal. Para tanto, os testes de normalidade baseados em hipóteses de Kolmogorov-Smirnov (Corder e Foreman, 2009) e de Shapiro-Wilk (Shapiro e Wilk, 1965) foram aplicados. As subseções a seguir apresentam os resultados da aplicação de tais testes, em cada uma das métricas da Tabela 7.2 .

Para ambos os testes de normalidade foram propostas as seguintes hipóteses:

- Hipótese Nula $\left(\mathbf{H}_{0}\right)$ : a distribuição dos valores observados para a métrica em questão é normal.

- Hipótese Alternativa $\left(\mathbf{H}_{1}\right)$ : a distribuição dos valores observados para a métrica em questão não é normal.

\section{Teste de Normalidade para a Métrica CompPLA}

Conforme pode ser observado na Figura 7.2, para uma amostra de tamanho $(N)$ 30, com média $(\mu)$ 0,6545, desvio padrão $(\sigma)$ 0,1842 e mediana 0,5895, a métrica CompPLA obteve:

- $p=0,1500$ para o teste de Kolmogorov-Smirnov; e

- $p=0,0118$ para o teste de Shapiro-Wilk. 


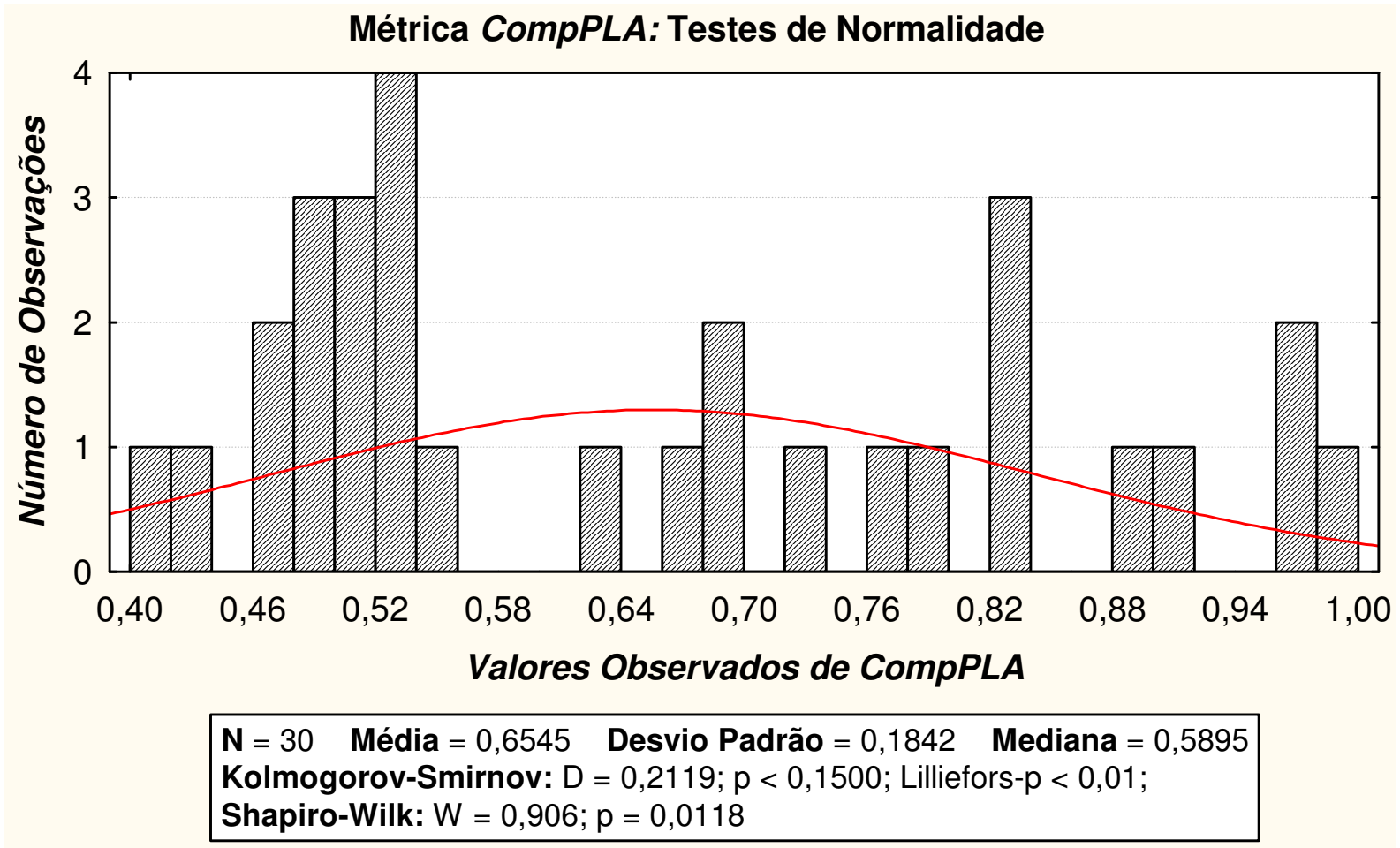

Figura 7.2: Métrica CompPLA: Estatística Descritiva e Testes de Kolmogorov-Smirnov e Shapiro-Wilk.

Segundo o teste de Kolmogorov-Smirnov (Corder e Foreman, 2009), para uma amostra de tamanho 30 com $95 \%$ de segurança $(\alpha=0,05)$ e baseado no valor de $p$ obtido $(0,1500<$ 0,2400), a hipótese nula deve ser rejeitada.

Com base no teste de Shapiro-Wilk (Shapiro e Wilk, 1965), para uma amostra de tamanho 30 com 95\% de segurança $(\alpha=0,05), p=0,0118(0,0118<0,05)$ e valor calculado $W=0,906$ menor que $W=0,912$ (esperado), a hipótese nula deve ser rejeitada.

Dessa forma, para ambos os testes, há indícios para se rejeitar a hipótese nula $\left(\mathrm{H}_{0}\right)$, não considerando a distribuição dos valores observados para a métrica CompPLA normal. Um método estatístico não paramétrico deve ser utilizado para a análise de tal métrica.

\section{Teste de Normalidade para a Métrica ExtensPLA}

Conforme pode ser observado na Figura 7.3. para uma amostra de tamanho $(N)$ 30, com média $(\mu)$ 0,7390, desvio padrão $(\sigma)$ 0,1487 e mediana 0,7060, a métrica ExtensPLA obteve:

- $p=$ 0,0100 para o teste de Kolmogorov-Smirnov; e

- $p=0,00001$ para o teste de Shapiro-Wilk. 
Métrica ExtensPLA: Testes de Normalidade

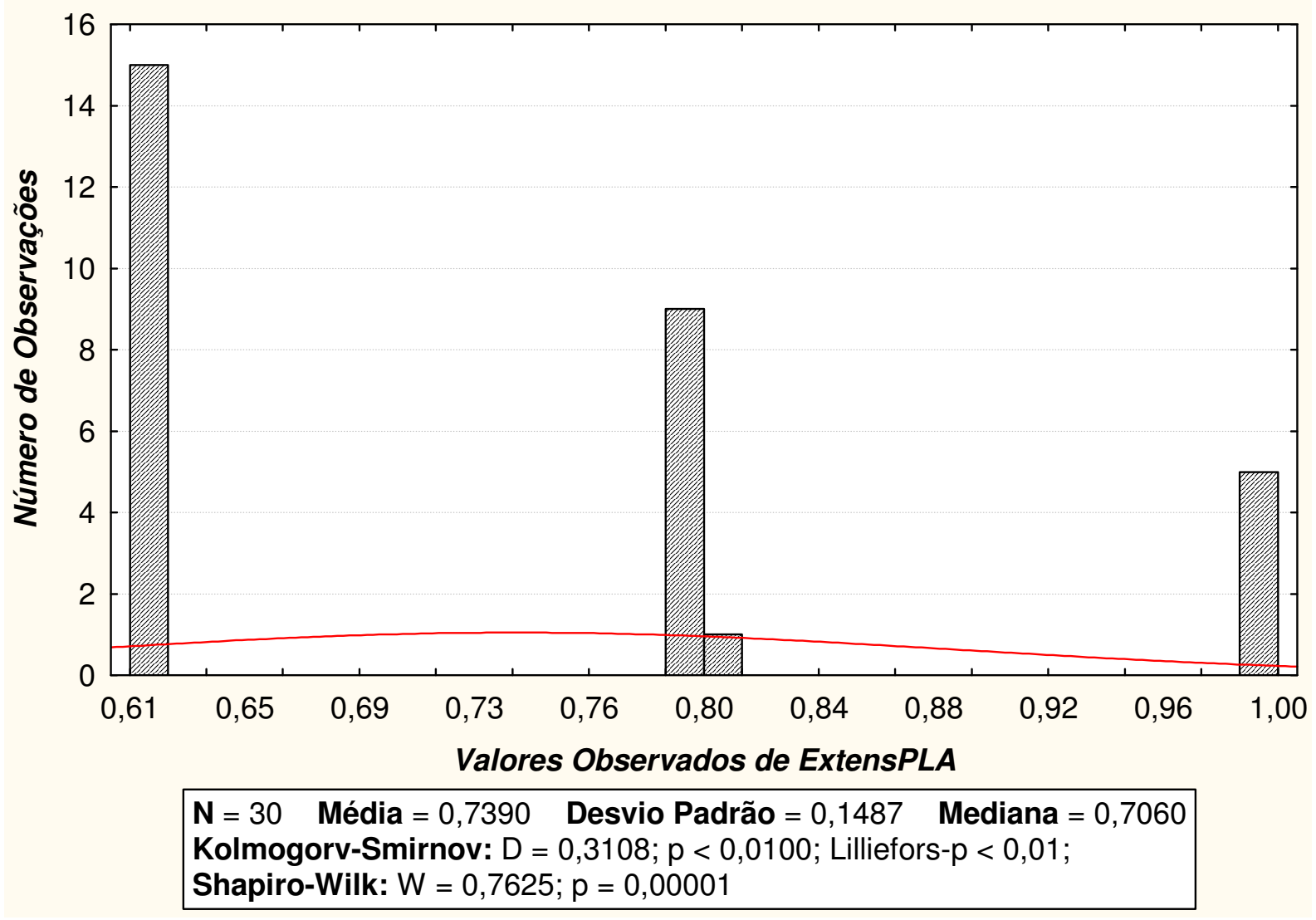

Figura 7.3: Métrica ExtensPLA: Estatística Descritiva e Testes de Kolmogorov-Smirnov e Shapiro-Wilk.

Segundo o teste de Kolmogorov-Smirnov (Corder e Foreman, 2009), para uma amostra de tamanho 30 com $95 \%$ de segurança $(\alpha=0,05)$ e baseado no valor de $p$ obtido $(0,0100<$ 0,2400), a hipótese nula deve ser rejeitada.

Com base no teste de Shapiro-Wilk (Shapiro e Wilk, 1965), para uma amostra de tamanho 30 com $95 \%$ de segurança $(\alpha=0,05), p=0,00001(0,00001<0,05)$ e valor calculado $W=0,7625$ menor que $W=0,912$ (esperado), a hipótese nula deve ser rejeitada.

Dessa forma, para ambos os testes, há indícios para se rejeitar a hipótese nula $\left(\mathrm{H}_{0}\right)$, não considerando a distribuição dos valores observados para a métrica ExtensPLA normal. Um método estatístico não paramétrico deve ser utilizado para a análise de tal métrica. 


\subsubsection{Correlação de Spearman para as Métricas CompPLA e Extens-} PLA

Como ambas as distribuições das métricas CompPLA e ExtensPLA não são normais, o método não paramétrico Correlação de Spearman foi aplicado para que fosse possível rejeitar ou aceitar a hipótese nula do estudo experimental. Esse método permite estabelecer se existe uma correlação entre dois conjuntos de dados.

O coeficiente $(\rho)$ da Correlação de Spearman é calculado executando os seguintes passos:

1. criar uma tabela a partir dos dois conjuntos de dados a serem correlacionados;

2. classificar cada um dos conjuntos. A classificação é realizada associando o valor "1" ao maior valor do conjunto (coluna), "2" para o segundo maior valor e, assim por diante. O menor valor do conjunto recebe o mais alto valor de classificação. Isto deve ser feito para ambos os conjuntos de dados. Valores iguais de um conjunto recebem a média do valor da classificação;

3. encontrar a diferença (d) entre a classificação dos valores dos dois conjuntos para cada linha da tabela;

4. elevar ao quadrado o valor da diferença (d);

5. somar as diferenças elevadas ao quadrado $\left(\mathrm{d}^{2}\right)$; e

6. calcular o coeficiente $(\rho)$ usando a Equação (7.1). A resposta sempre será um valor entre 1,0 e -1,0, como apresentado na Figura 7.4, indicando o tipo de correlação existente ou a sua ausência.

$\rho=1-\frac{6}{n\left(n^{2}-1\right)} \sum_{i=1}^{n} d_{i}^{2}$

tal que $n$ é o tamanho da amostra $(N)$

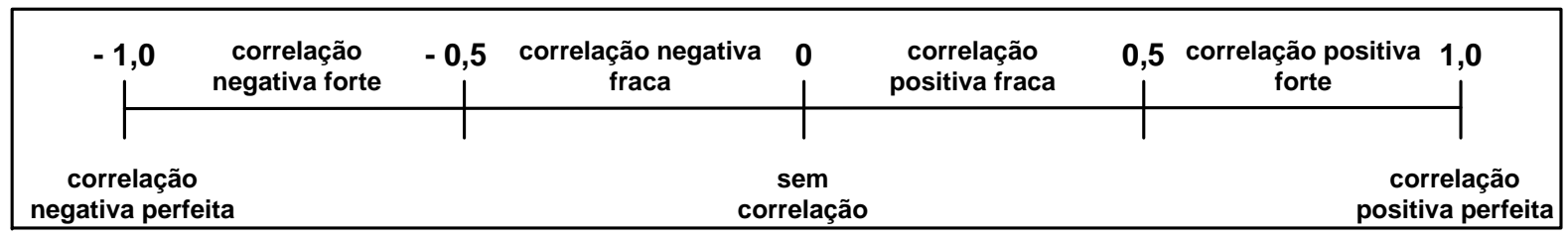

Figura 7.4: Escalas da Correlação de Spearman. 
Para a validação das métricas de complexidade e extensibilidade, foram realizadas três correlações (Corr.):

Corr.1 CompPLA e o valor de complexidade associado pelo participante, mostrando que o entendimento de complexidade pelos participantes corrobora com a métrica CompPLA, estabelecendo como medir complexidade em ALP;

Corr.2 ExtensPLA e o valor de extensibilidade associado pelo participante, mostrando que o entendimento de extensibilidade pelos participantes corrobora com a métrica ExtensPLA, estabelecendo como medir extensibilidade em ALP; e

Corr.3 CompPLA e ExtensPLA que mostra se existe uma correlação significante entre complexidade e extensibilidade, em termos de ALP.

A Tabela 7.3 mostra a correlação de Spearman para Corr.1. O coeficiente de Spearman $\rho$ (Equação 7.1) para Corr.1 é calculado como segue:

$$
\rho(\text { Corr. } 1)=1-\frac{6}{30\left(30^{2}-30\right)} \times 293,5=1-\frac{6}{26970} \times 293,5=1-0,07=\mathbf{0 , 9 3}
$$

Tabela 7.3: Correlação de Spearman para Corr.1: CompPLA e o Valor de Complexidade Associado pelos Participantes.

\begin{tabular}{|c|c|c|c|c|c|c|}
\hline $\begin{array}{c}\text { Configuração } \\
\mathbf{N}^{\mathbf{0}}\end{array}$ & CompPLA & $\mathbf{r}_{\mathbf{a}}$ & $\begin{array}{c}\text { Complexidade } \\
\text { Associada }\end{array}$ & $\mathbf{r}_{\mathbf{b}}$ & $\begin{array}{c}\mathbf{d} \\
\left|\mathbf{r}_{\mathbf{a}}-\mathbf{r}_{\mathbf{b}}\right|\end{array}$ & $\mathbf{d}^{2}$ \\
\hline 1 & 0,51 & 22,5 & $\begin{array}{c}\text { nem pouca } \\
\text { nem muita }\end{array}$ & 22,5 & 0 & 0 \\
\hline 2 & 0,56 & 16 & $\begin{array}{c}\text { nem pouca } \\
\text { nem muita }\end{array}$ & 22,5 & 6,5 & 42,25 \\
\hline 2 & 0,51 & 22,5 & $\begin{array}{c}\text { nem pouca } \\
\text { nem muita }\end{array}$ & 22,5 & 0 & 0 \\
\hline 4 & 0,83 & 6 & extrema & 4,5 & 1,5 & 2,25 \\
\hline 5 & 0,91 & 4 & extrema & 4,5 & 0,5 & 0,25 \\
\hline 6 & 0,50 & 24 & $\begin{array}{c}\text { nem pouca } \\
\text { nem muita }\end{array}$ & 22,5 & 1,5 & 2,25 \\
\hline 7 & 0,47 & 27,5 & $\begin{array}{c}\text { nem pouca } \\
\text { nem muita }\end{array}$ & 22,5 & 5 & 25 \\
\hline 8 & 0,53 & 18 & $\begin{array}{c}\text { nem pouca } \\
\text { nem muita }\end{array}$ & 22,5 & 4,5 & 20,25 \\
\hline 9 & 0,67 & 14 & muita & 12 & 2 & 4 \\
\hline 10 & 0,90 & 5 & extrema & 4,5 & 0,5 & 0,25 \\
\hline 11 & 0,53 & 18 & $\begin{array}{c}\text { nem pouca } \\
\text { nem muita }\end{array}$ & 22,5 & 4,5 & 20,25 \\
\hline 12 & 0,97 & 3 & extrema & 4,5 & 1,5 & 2,25 \\
\hline 13 & 0,48 & 26 & $\begin{array}{c}\text { nem pouca } \\
\text { nem muita }\end{array}$ & 22,5 & 3,5 & 12,25 \\
\hline 14 & 0,69 & 13 & muita & 12 & 1 & 1 \\
\hline 15 & 0,74 & 11 & muita & 12 & 1 & 1 \\
\hline
\end{tabular}

\begin{tabular}{|c|c|c|c|c|c|c|}
\hline $\begin{array}{c}\text { Configuração } \\
\boldsymbol{N}^{\mathbf{0}}\end{array}$ & CompPLA & $\mathbf{r}_{\mathbf{a}}$ & $\begin{array}{c}\text { Complexidade } \\
\text { Associada }\end{array}$ & $\mathbf{r}_{\mathbf{b}}$ & $\begin{array}{c}\mathbf{d} \\
\left|\mathbf{r}_{\mathbf{a}}-\mathbf{r}_{\mathbf{b}}\right|\end{array}$ & $\mathbf{d}^{2}$ \\
\hline 16 & 0,98 & 2 & extrema & 4,5 & 2,5 & 6,25 \\
\hline 17 & 0,77 & 10 & muita & 12 & 2 & 4 \\
\hline 18 & 0,82 & 7,5 & extrema & 4,5 & 3 & 9 \\
\hline 19 & 0,52 & 20,5 & $\begin{array}{c}\text { nem pouca } \\
\text { nem muita }\end{array}$ & 22,5 & 2 & 4 \\
\hline 20 & 0,82 & 7,5 & extrema & 4,5 & 3 & 9 \\
\hline 21 & 0,49 & 25 & $\begin{array}{c}\text { nem pouca } \\
\text { nem muita }\end{array}$ & 22,5 & 2,5 & 6,25 \\
\hline 22 & 1,00 & 1 & extrema & 4,5 & 3,5 & 12,25 \\
\hline 23 & 0,52 & 20,5 & $\begin{array}{c}\text { nem pouca } \\
\text { nem muita }\end{array}$ & 22,5 & 2 & 4 \\
\hline 24 & 0,42 & 29 & $\begin{array}{c}\text { nem pouca } \\
\text { nem muita }\end{array}$ & 22,5 & 6,5 & 42,25 \\
\hline 25 & 0,62 & 15 & muita & 12 & 3 & 9 \\
\hline 26 & 0,47 & 27,5 & $\begin{array}{c}\text { nem pouca } \\
\text { nem muita }\end{array}$ & 22,5 & 5 & 25 \\
\hline 27 & 0,53 & 18 & $\begin{array}{c}\text { nem pouca } \\
\text { nem muita }\end{array}$ & 22,5 & 4,5 & 20,25 \\
\hline 28 & 0,70 & 12 & muita & 12 & 0 & 0 \\
\hline 29 & 0,40 & 30 & pouca & 30 & 0 & 0 \\
\hline 30 & 0,78 & 9 & muita & 12 & 3 & 9 \\
\hline
\end{tabular}

Assim, de acordo com a Figura 7.4, existe uma forte e positiva correlação $(\rho($ corr.1 $)=$ 0,93) entre a métrica CompPLA e o valor de complexidade associado pelo participante. 
A Tabela 7.4 mostra a correlação de Spearman para Corr.2. O coeficiente de Spearman $\rho$ (Equação 7.1) para Corr.2 é calculado como segue:

$$
\rho(\text { Corr. } 2)=1-\frac{6}{30\left(30^{2}-30\right)} \times 841,5=1-\frac{6}{26970} \times 841,5=1-0,19=\mathbf{0 , 8 1}
$$

Tabela 7.4: Correlação de Spearman para Corr.2: ExtensPLA e o Valor de Extensibilidade Associado pelos Participantes.

\begin{tabular}{|c|c|c|c|c|c|c|}
\hline $\begin{array}{c}\text { Configuração } \\
\mathbf{N}^{\mathbf{o}}\end{array}$ & ExtensPLA & $\mathbf{r}_{\mathbf{a}}$ & $\begin{array}{c}\text { Extensibilidade } \\
\text { Associada }\end{array}$ & $\mathbf{r}_{\mathbf{b}}$ & $\begin{array}{c}\mathbf{d} \\
\mid \mathbf{r}_{\mathbf{a}}-\mathbf{r}_{\mathbf{b}} \mathbf{l}\end{array}$ & $\mathbf{d}^{\mathbf{2}}$ \\
\hline 1 & 0,61 & 23 & muita & 17,5 & 5,5 & 30,25 \\
\hline 2 & 0,61 & 23 & muita & 17,5 & 5,5 & 30,25 \\
\hline 3 & 0,81 & 6 & extrema & 3,5 & 2,5 & 6,25 \\
\hline 4 & 0,80 & 11 & muita & 17,5 & 6,5 & 42,25 \\
\hline 5 & 0,61 & 23 & muita & 17,5 & 5,5 & 30,25 \\
\hline 6 & 1,00 & 3 & extrema & 3,5 & 0,5 & 0,25 \\
\hline 7 & 0,61 & 23 & muita & 17,5 & 5,5 & 30,25 \\
\hline 8 & 0,61 & 23 & muita & 17,5 & 5,5 & 30,25 \\
\hline 9 & 0,80 & 11 & muita & 17,5 & 6,5 & 42,25 \\
\hline 10 & 1,00 & 3 & extrema & 3,5 & 0,5 & 0,25 \\
\hline 11 & 1,00 & 3 & extrema & 3,5 & 0,5 & 0,25 \\
\hline 12 & 0,61 & 23 & muita & 17,5 & 5,5 & 30,25 \\
\hline 13 & 0,61 & 23 & muita & 17,5 & 5,5 & 30,25 \\
\hline 14 & 0,61 & 23 & muita & 17,5 & 5,5 & 30,25 \\
\hline 15 & 0,80 & 11 & muita & 17,5 & 6,5 & 42,25 \\
\hline
\end{tabular}

\begin{tabular}{|c|c|c|c|c|c|c|}
\hline $\begin{array}{c}\text { Configuração } \\
\mathbf{N}^{\mathbf{0}}\end{array}$ & ExtensPLA & $\mathbf{r}_{\mathbf{a}}$ & $\begin{array}{c}\text { Extensibilidade } \\
\text { Associada }\end{array}$ & $\mathbf{r}_{\mathbf{b}}$ & $\begin{array}{c}\mathbf{d} \\
\left|\mathbf{r}_{\mathbf{a}}-\mathbf{r}_{\mathbf{b}}\right|\end{array}$ & $\mathbf{d}^{\mathbf{2}}$ \\
\hline 16 & 1,00 & 3 & extrema & 3,5 & 0,5 & 0,25 \\
\hline 17 & 0,80 & 11 & muita & 17,5 & 6,5 & 42,25 \\
\hline 18 & 0,80 & 11 & muita & 17,5 & 6,5 & 42,25 \\
\hline 19 & 0,61 & 23 & muita & 17,5 & 5,5 & 30,25 \\
\hline 20 & 0,80 & 11 & muita & 17,5 & 6,5 & 42,25 \\
\hline 21 & 0,61 & 23 & muita & 17,5 & 5,5 & 30,25 \\
\hline 22 & 1,00 & 3 & extrema & 3,5 & 0,5 & 0,25 \\
\hline 23 & 0,61 & 23 & muita & 17,5 & 5,5 & 30,25 \\
\hline 24 & 0,61 & 23 & muita & 17,5 & 5,5 & 30,25 \\
\hline 25 & 0,80 & 11 & muita & 17,5 & 6,5 & 42,25 \\
\hline 26 & 0,61 & 23 & muita & 17,5 & 5,5 & 30,25 \\
\hline 27 & 0,61 & 23 & muita & 17,5 & 5,5 & 30,25 \\
\hline 28 & 0,80 & 11 & muita & 17,5 & 6,5 & 42,25 \\
\hline 29 & 0,61 & 23 & muita & 17,5 & 5,5 & 30,25 \\
\hline 30 & 0,80 & 11 & muita & 17,5 & 6,5 & 42,25 \\
\hline
\end{tabular}

Assim, de acordo com a Figura 7.4, existe uma forte e positiva correlação $(\rho($ corr.2 $)=$ 0,81) entre a métrica ExtensPLA e o valor de extensibilidade associado pelo participante.

A Tabela 7.5 mostra a correlação de Spearman para Corr.3. O coeficiente de Spearman $\rho$ (Equação 7.1) para Corr.3 é calculado como segue:

$$
\rho(\text { Corr. } 3)=1-\frac{6}{30\left(30^{2}-30\right)} \times 2139=1-\frac{6}{26970} \times 2139=1-0,48=\mathbf{0 , 5 2}
$$

Tabela 7.5: Correlação de Spearman para Corr.3: CompPLA e ExtensPLA.

\begin{tabular}{|c|c|c|c|c|c|c|}
\hline $\begin{array}{c}\text { Configuração } \\
\mathbf{N}^{\mathbf{0}}\end{array}$ & CompPLA & $\mathbf{r}_{\mathbf{a}}$ & ExtensPLA & $\mathbf{r}_{\mathbf{b}}$ & $\begin{array}{c}\mathbf{d} \\
\left\langle\mathbf{r}_{\mathbf{a}}-\mathbf{r}_{\mathbf{b}}\right|\end{array}$ & $\mathbf{d}^{\mathbf{2}}$ \\
\hline 1 & 0,51 & 22,5 & 0,61 & 23,0 & 0,5 & 0,25 \\
\hline 2 & 0,56 & 16,0 & 0,61 & 23,0 & 7,0 & 49,00 \\
\hline 2 & 0,51 & 22,5 & 0,81 & 6,0 & 16,5 & 272,25 \\
\hline 4 & 0,83 & 6,0 & 0,80 & 11,0 & 5,0 & 25,00 \\
\hline 5 & 0,91 & 4,0 & 0,61 & 23,0 & 19,0 & 361,00 \\
\hline 6 & 0,50 & 24,0 & 1,00 & 3,0 & 21,0 & 441,00 \\
\hline 7 & 0,47 & 27,5 & 0,61 & 23,0 & 4,5 & 20,25 \\
\hline 8 & 0,53 & 18,0 & 0,61 & 23,0 & 5,0 & 25,00 \\
\hline 9 & 0,67 & 14,0 & 0,80 & 11,0 & 3,0 & 9,00 \\
\hline 10 & 0,90 & 5,0 & 1,00 & 3,0 & 2,0 & 4,00 \\
\hline 11 & 0,53 & 18,0 & 1,00 & 3,0 & 15,0 & 225,00 \\
\hline 12 & 0,97 & 3,0 & 0,61 & 23,0 & 20,0 & 400,00 \\
\hline 13 & 0,48 & 26,0 & 0,61 & 23,0 & 3,0 & 9,00 \\
\hline 14 & 0,69 & 13,0 & 0,61 & 23,0 & 10,0 & 100,00 \\
\hline 15 & 0,74 & 11,0 & 0,80 & 11,0 & 0,0 & 0,00 \\
\hline
\end{tabular}

\begin{tabular}{|c|c|c|c|c|c|c|}
\hline $\begin{array}{c}\text { Configuração } \\
\mathbf{N}^{\mathbf{o}}\end{array}$ & CompPLA & $\mathbf{r}_{\mathbf{a}}$ & ExtensPLA & $\mathbf{r}_{\mathbf{b}}$ & $\begin{array}{c}\mathbf{d} \\
\left|\mathbf{r}_{\mathbf{a}}-\mathbf{r}_{\mathbf{b}}\right|\end{array}$ & $\mathbf{d}^{\mathbf{2}}$ \\
\hline 16 & 0,98 & 2,0 & 1,00 & 3,0 & 1,0 & 1,00 \\
\hline 17 & 0,77 & 10,0 & 0,80 & 11,0 & 1,0 & 1,00 \\
\hline 18 & 0,82 & 7,5 & 0,80 & 11,0 & 3,5 & 12,25 \\
\hline 19 & 0,52 & 20,5 & 0,61 & 23,0 & 2,5 & 6,25 \\
\hline 20 & 0,82 & 7,5 & 0,80 & 11,0 & 3,5 & 12,25 \\
\hline 21 & 0,49 & 25,0 & 0,61 & 23,0 & 2,0 & 4,00 \\
\hline 22 & 1,00 & 1,0 & 1,00 & 3,0 & 2,0 & 4,00 \\
\hline 23 & 0,52 & 20,5 & 0,61 & 23,0 & 2,5 & 6,25 \\
\hline 24 & 0,42 & 29,0 & 0,61 & 23,0 & 6,0 & 36,00 \\
\hline 25 & 0,62 & 15,0 & 0,80 & 11,0 & 4,0 & 16,00 \\
\hline 26 & 0,47 & 27,5 & 0,61 & 23,0 & 4,5 & 20,25 \\
\hline 27 & 0,53 & 18,0 & 0,61 & 23,0 & 5,0 & 25,00 \\
\hline 28 & 0,70 & 12,0 & 0,80 & 11,0 & 1,0 & 1,00 \\
\hline 29 & 0,40 & 30,0 & 0,61 & 23,0 & 7,0 & 49,00 \\
\hline 30 & 0,78 & 9,0 & 0,80 & 11,0 & 2,0 & 4,00 \\
\hline
\end{tabular}

Assim, de acordo com a Figura 7.4, existe uma forte e positiva correlação $(\rho($ corr.3 $)=$ 0,52) entre as métricas CompPLA e ExtensPLA. 
Com base nas três correlações feitas, tem-se evidências para se rejeitar a hipótese nula $\mathrm{H}_{0}$ do estudo e aceitar a hipótese alternativa $\mathrm{H}_{3}$ (Seção 7.2), corroborando para que as métricas CompPLA e ExtensPLA estejam significativamente correlacionadas com a complexidade e extensibilidade de ALP.

\subsubsection{Análise de Regressão Linear}

A técnica de Análise de Regressão Linear (Figueiredo et al., 2007) foi usada para mostrar a equação que representa cada uma das correlações realizadas.

\section{Análise de Regressão Linear - Corr.1}

A Figura 7.5 mostra o gráfico da regressão linear para a métrica CompPLA e o valor de complexidade associado pelo participante.

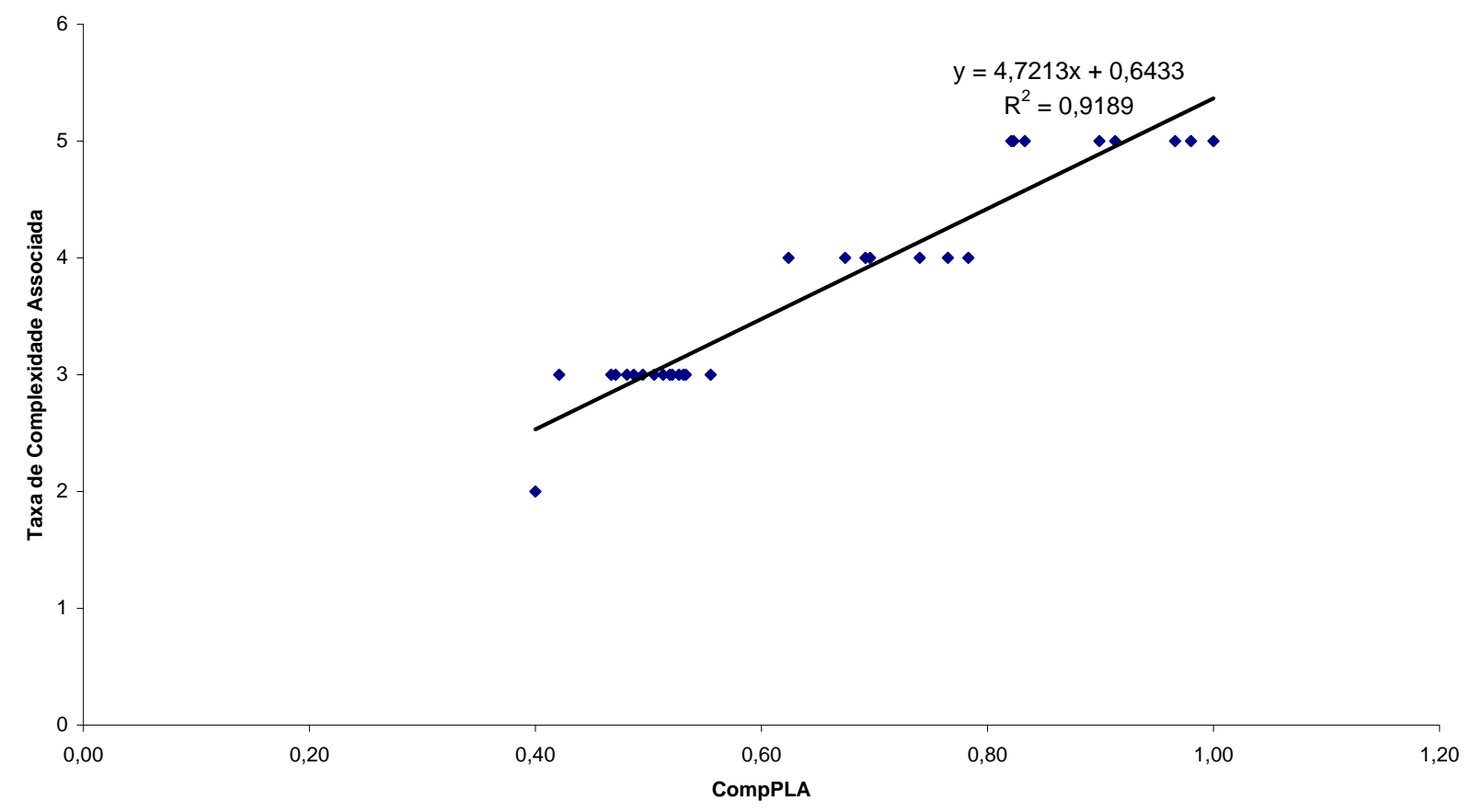

Figura 7.5: Análise de Regressão Linear da Correlação Corr.1.

A correlação Corr.1 pode ser expressa em termos da seguinte equação:

$y=4,7213 x+0,6433$, sendo que

$x$ é o valor de CompPLA

y é o valor de complexidade associado pelo participante 
Com base na Equação (7.2), obtida com a análise de regressão linear da correlação Corr.1, é proposta uma escala para medir a complexidade de uma configuração de ALP, apresentada na Figura 7.6 .

\begin{tabular}{|c|c|c|c|c|c|c|c|c|c|c|}
\hline 0,64 & & 2,53 & & 2,63 & & 3,27 & & 4,52 & & 5,36 \\
\hline 1 & $\begin{array}{c}\text { Extremamente } \\
\text { Baixa }\end{array}$ & I & Baixa & & $\begin{array}{l}\text { Nem Baixa } \\
\text { Nem Alta }\end{array}$ & & Alta & & $\begin{array}{l}\text { Extremamente } \\
\text { Alta }\end{array}$ & \\
\hline
\end{tabular}

Figura 7.6: Escala de Complexidade Proposta para Medir Configurações de ALP.

Para medir a complexidade de uma determinada configuração de ALP, basta substituir o valor de CompPLA pelo "x" na Equação (7.2). Em seguida, comparar o resultado obtido (o valor de $y$ ) com a escala de complexidade (Figura 7.6) e encontrar quão complexa é tal configuração. Por exemplo, considere um valor de CompPLA para uma configuração hipotética sendo 0,64. Resolvendo a Equação (7.2), encontra-se $y=3,66$. Assim, pode-se afirmar que a configuração possui alta complexidade com base na escala de complexidade proposta (Figura 7.6).

\section{Análise de Regressão Linear - Corr.2}

A Figura 7.7 mostra o gráfico da regressão linear para a métrica ExtensPLA e o valor de extensibilidade associado pelo participante.

A correlação Corr.2 pode ser expressa em termos da seguinte equação:

$y=2,1522 x+2,6091$, sendo que

$x$ é o valor de ExtensPLA

y é o valor de extensibilidade associado pelo participante

Com base na Equação (7.3), obtida com a análise de regressão linear da correlação Corr.2, é proposta uma escala para medir a extensibilidade de uma configuração de ALP, apresentada na Figura 7.8 . 


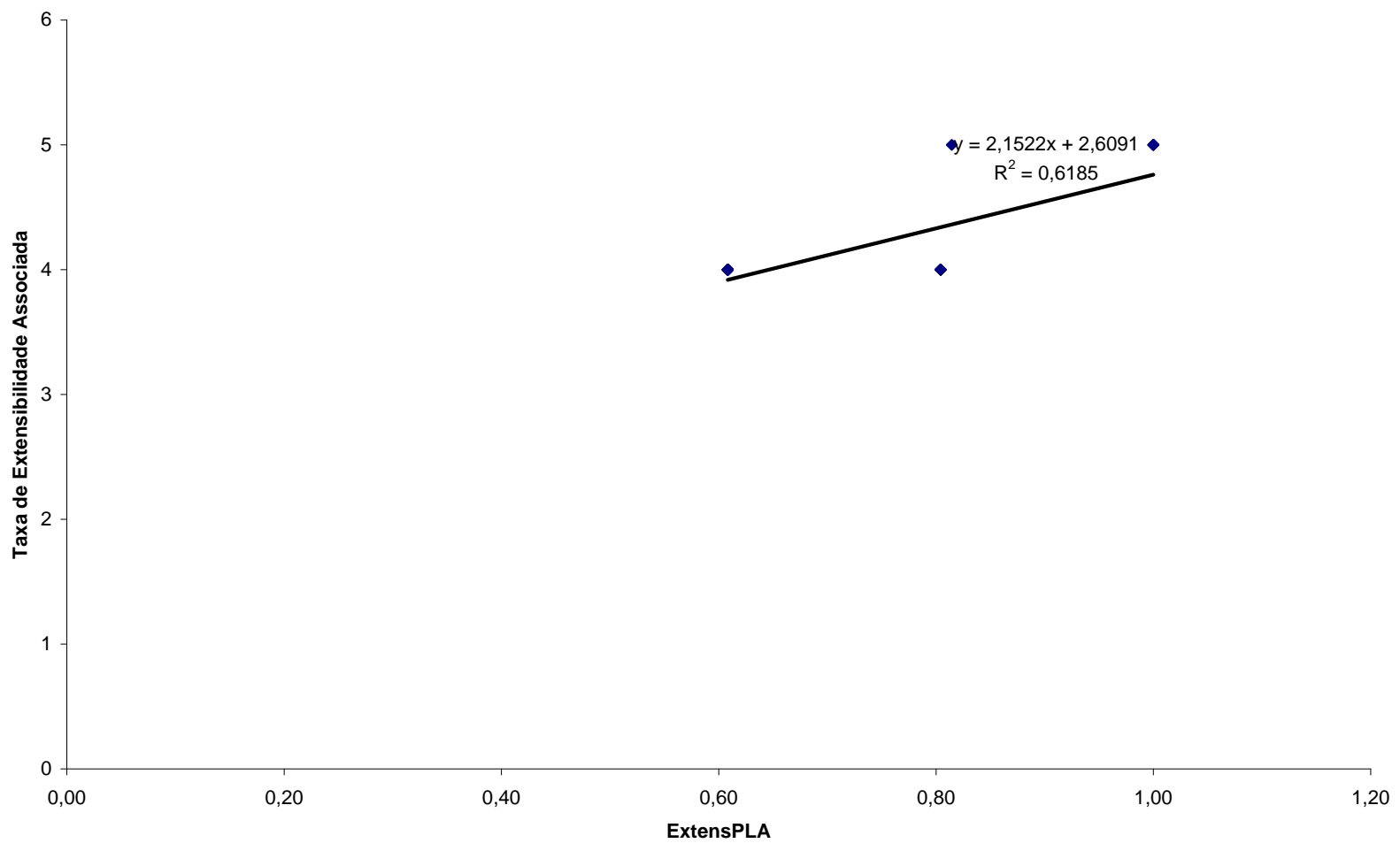

Figura 7.7: Análise de Regressão Linear da Correlação Corr.2.

\begin{tabular}{|c|c|c|c|c|c|c|c|c|c|}
\hline 2,66 & & 3,08 & & 3,50 & & 3,92 & & 4,34 & 4,76 \\
\hline & $\begin{array}{c}\text { Extremamente } \\
\text { Baixa }\end{array}$ & & Baixa & & $\begin{array}{l}\text { Nem Baixa } \\
\text { Nem Alta }\end{array}$ & & Alta & & $\begin{array}{l}\text { Extremamente } \\
\text { Alta }\end{array}$ \\
\hline
\end{tabular}

Figura 7.8: Escala de Extensibilidade Proposta para Medir Configurações de ALP.

\section{Análise de Regressão Linear - Corr.3}

As Figuras 7.9 e 7.10 mostram os gráficos de regressão linear da Corr.3. 


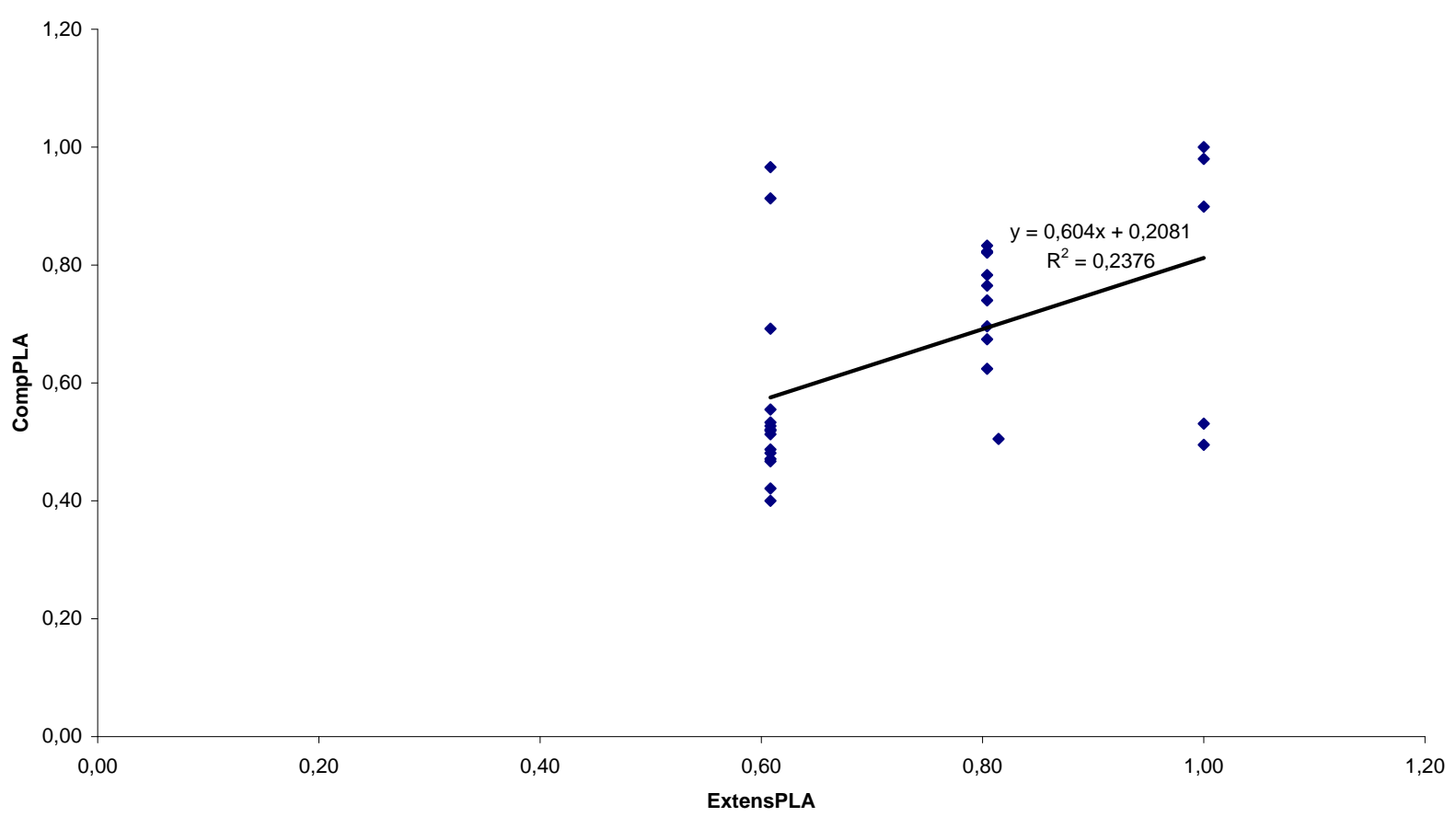

Figura 7.9: CompPLA vs. ExtensPLA: Análise de Regressão Linear.

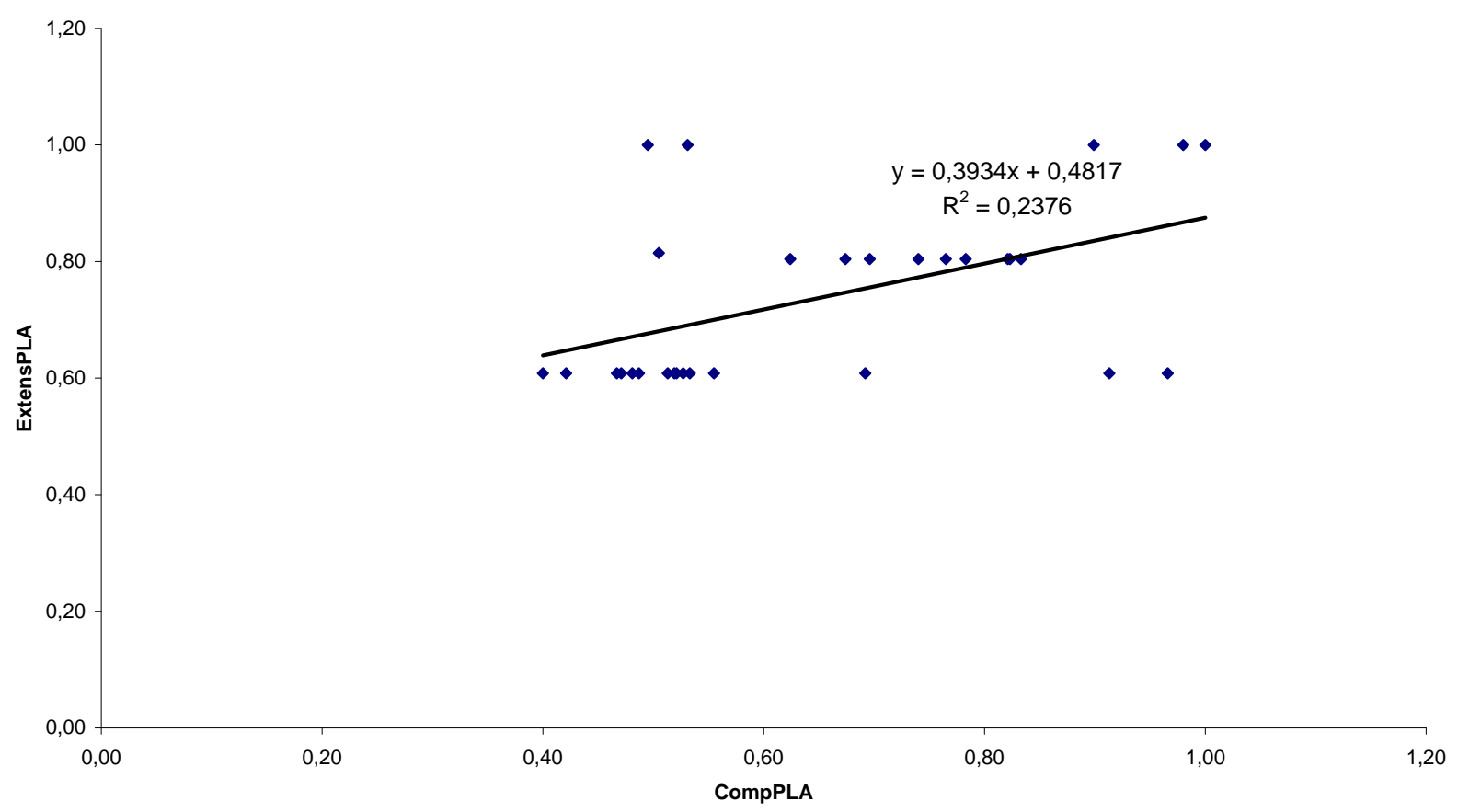

Figura 7.10: ExtensPLA vs. CompPLA: Análise de Regressão Linear.

A correlação da Figura 7.9 pode ser expressa em termos da seguinte equação:

CompPLA $=(0,604 \times$ ExtensPLA $)+0,2081$ 
A correlação da Figura 7.10 pode ser expressa em termos da seguinte equação:

$$
\text { ExtensPLA }=(0,3934 \times \text { CompPLA })+0,4817
$$

Dessa forma, fica simples calcular o valor da métrica CompPLA, com base no valor da métrica ExtensPLA (Equação 7.4) e calcular o valor da métrica ExtensPLA, com base no valor da métrica CompPLA (Equação 7.5), para essa amostra. Porém, com a replicação deste experimento e a geração de novas configurações, o cálculo dos valores das métricas CompPLA e ExtensPLA torna-se mais ajustado, uma vez que o tamanho da amostra tende a crescer.

\subsection{Avaliação de Validade do Estudo Experimental}

Nesta seção são discutidas as ameaças à validade do estudo experimental e como tais ameaças foram minimizadas.

\subsubsection{Ameaças à Validade de Conclusão}

A validade de conclusão define a extensão para qual as conclusões acerca do estudo são estatisticamente válidas.

A única preocupação considerada como um risco para afetar a validade estatística deste estudo é o tamanho da amostra, a qual pode ser incrementada em replicações futuras, para que seja possível alcançar a normalidade dos valores observados.

\subsubsection{Ameaças à Validade de Construção}

A validade de construção é o grau para o qual variáveis dependentes e independentes são medidas pelos instrumento apropriados.

As variáveis dependentes deste estudo são complexidade e extensibilidade. Métricas subjetivas para complexidade e extensibilidade foram propostas e coletadas, com base na experiência dos participantes, na forma de valores de complexidade e extensibilidade 
associados pelos participantes à cada configuração de ALP. Como os participantes possuem experiência suficiente em modelagem de sistemas orientados a objeto, usando pelo menos diagramas de classes, tais valores são consideradas significantes.

A validade de construção das métricas usadas para as variáveis independentes é garantida por alguns ensaios realizados em estudos anteriores de métricas para ALP (Oliveira Junior et al., 2008).

\subsubsection{Ameaças à Validade Interna}

A validade interna é o grau para o qual conclusões podem ser estabelecidas sobre causa-efeito de variáveis independentes sobre variáveis dependentes. Neste estudo, as seguintes dificuldades foram encontradas:

- Diferenças entre os participantes. Como foi considerada uma pequena amostra, variações com relação às habilidades dos participantes foram reduzidas, aplicando o formato de tarefas "whithin-subject". Nesse formato, todos os participantes realizam todas as tarefas definidas na mesma ordem. Assim, a experiência dos participantes teve aproximadamente o mesmo nível com relação à modelagem UML e conceitos de LP e variabilidades;

- Acurácia das respostas dos participantes. Complexidade e extensibilidade foram medidas por cada participante. Como possuem pelo menos experiência média com modelagem UML e conceitos de LP e variabilidades, considera-se que suas respostas são válidas;

- Efeitos de fadiga. Em média, o experimento durou 69 minutos para cada participante. Assim, a fadiga não foi considerada relevante. Além disso, o modelo de resolução de variabilidades contribuiu para reduzir tal efeito, sendo formatado de forma simples e direta; e

- Outros fatores importantes. Influência entre os participantes não foi possível ser efetivamente controlada. Os participantes realizaram o experimento com a supervisão de um observador humano. Dessa forma, acredita-se que esses problemas não afetaram a validade do estudo. 


\subsubsection{Ameaças à Validade Externa}

Considerando que, quanto maior for a validade externa, mais resultados de um estudo experimental podem ser generalizados para práticas de Engenharia de Software, duas ameaças de validade externa foram identificadas:

- Instrumentação. Tentou-se usar diagramas de classes e componentes representativos de casos reais. Porém, a LP usada no experimento não é comercial, e algumas suposições podem ser feitas sobre esta ameaça. Assim, mais estudos experimentais devem ser conduzidos utilizando LP reais desenvolvidas por organizações de software; e

- Participantes. Obter participantes qualificados foi uma das grandes dificuldades do estudo. Assim, professores e estudantes em nível avançado da academia de Engenharia de Software foram utilizados. Mais experimentos com profissionais da indústria devem ser conduzidos, permitindo generalizar os resultados do estudo.

\subsection{Apresentação e Empacotamento do Estudo Experi- mental}

Todos os documentos relacionados ao estudo estão disponíveis no endereço eletrônico http://edsonjr.pro.br/expAGM01, uma vez que é importante a difusão dos dados experimentais para replicações externas do estudo atual (Brooks et al., 1996) e o compartilhamento do conhecimento (Shull et al., 2004).

\subsection{Considerações Finais}

A literatura existente indica a necessidade de métricas que permitam arquitetos de LP analisar experimentalmente o potencial de uma ALP, assim como gerentes de LP analisar o valor gerencial e econômico agregado à uma LP, por meio de seus produtos.

A realização de validações experimentais de métricas é essencial para demonstrar sua utilidade prática. As métricas propostas para os atributos de qualidade de ALP complexidade (CompPLA) e extensibilidade (ExtensPLA) foram validadas experimentalmente. Na validação, as métricas foram aplicadas a um conjunto de trinta produtos para a LP AGM, gerados por participantes do estudo. Os valores observados foram submetidos aos testes de normalidade de Shapiro-Wilk e Kolmogorov-Smirnov. A técnica não paramétrica de Correlação de Spearman foi usada para demonstrar a correlação das métricas, sendo elas: 
- CompPLA possui uma correlação forte e positiva com o valor de complexidade associado pelo participante;

- ExtensPLA possui uma correlação forte e positiva com o valor de extensibilidade associado pelo participante; e

- CompPLA e ExtensPLA possuem correlação forte e positiva entre si.

A técnica de Análise de Regressão Linear foi usada para obter as equações que representam as correlações observadas no estudo.

Os resultados obtidos com este estudo experimental levam a concluir que as métricas CompPLA e ExtensPLA são indicadores relevantes de complexidade e extensibilidade de ALP, respectivamente. Apesar da correlação entre CompPLA e ExtensPLA possuir quase que um valor limite $(0,52)$, pode-se concluir que tais métricas estão fortemente correlacionadas como mostrado nas Equações (7.4) e (7.5).

Experimentos adicionais devem ser conduzidos, assim como mais configurações de ALP devem ser geradas e incorporadas para melhorar os resultados deste estudo. Além disso, é necessário aplicar as métricas propostas à uma LP comercial para que seja possível reduzir as ameaças à validação externa e obter evidências reais de que elas podem ser usadas como indicadores de complexidade e extensibilidade de ALP. 


\section{Estudo Experimental de Viabilidade do Método SystEM-PLA}

"Onde se encontram mentes abertas, sempre haverá uma fronteira."

Charles F. Kettering (1876-1958),

Engenheiro e Inventor Americano

Organizações de um modo geral, buscam melhorar seus processos de produção de software por meio da adoção de novas tecnologias e modelos, normalmente propostos pela academia. A academia possui maneiras peculiares de avaliar a qualidade de seus processos e produtos, tornando a indústria, de certo modo, dissociada da academia. Dessa forma, a transição da nova tecnologia/modelo dos laboratórios de pesquisa para a indústria para o seu efetivo uso é prejudicada (Zelkowitz et al., 2003).

Mafra e Travassos (2005) afirmam que a imaturidade na escolha de processos e tecnologias por parte da indústria, gera incertezas e falta de credibilidade nos engenheiros de software, com relação às novas propostas e à adoção de tecnologias como, por exemplo saber em quais tecnologias investir, quando todas prometem sanar os problemas existentes e qual o ROI sobre a tecnologia adotada. Assim, decisões equivocadas podem ser tomadas por causa da falta de métodos que comprovem a efetiva adoção e investimento nas tecnologias emergentes.

As seções a seguir apresentam um estudo experimental de análise da viabilidade do método SystEM-PLA, proposto no Capítulo 5. 


\subsection{Definição do Estudo Experimental}

Com base no template GQM (Basili e Rombach, 1988), o objetivo do experimento é apresentado a seguir:

Analisar o método SystEM-PLA

Com o propósito de estabelecer a sua viabilidade

Referente à capacidade de ser usado como um método sistemático para avaliar ALP e priorizar atributos de qualidade

Do ponto de vista do gerente e arquiteto de $L P$

No contexto de profissionais da área de Engenharia de Software e Tecnologia da Informação de uma empresa de grande porte.

\subsection{Planejamento do Estudo Experimental}

Contexto Global: avaliar uma ALP requer a realização de um conjunto de atividades, entradas e saídas, cujo objetivo principal é permitir que gerentes e arquitetos possam analisar o valor agregado da LP, bem como, permitir que atributos de qualidade sejam priorizados (Clements e Northrop, 2001; Linden et al., 2007). Dentre as atividades pode-se citar as principais: (i) definição das metas de negócio; (ii) definição de cenários; (iii) classificação de cenários; e (iv) definição de métricas. Tais atividades estão baseadas em métodos de avaliação de arquitetura de software como, por exemplo, o método ATAM (Clements et al., 2002b) e modelos de análise como, por exemplo, o modelo GQM. Com base nesses conceitos, o método SystEM-PLA (Capítulo 5) foi proposto. Esse método é composto por um metaprocesso de avaliação, cujas atividades são responsáveis por instanciar os artefatos necessários para a avaliação de uma ALP, um conjunto de diretrizes que guia o usuário do método em como realizar tais atividades e um conjunto de métricas básicas e de atributos de qualidade (Capítulos 6 e 7).

Contexto Local: este estudo tem como objetivo analisar a viabilidade da aplicação do método SystEM-PLA. Para tanto, o método será aplicado à ALP da AGM (Apêndice A) com o objetivo de verificar se os artefatos definidos para avaliar tal ALP, conduzem a resultados similares aos resultados obtidos no Capítulo 5, que serviram para ilustrar as atividades e diretrizes do método SystEM-PLA (Seção 5.3).

Treinamento: para esse estudo foi necessário treinar os participantes na aplicação do método SystEM-PLA e análises de trade-off para atributos de qualidade. 
Projeto Piloto: antes da execução real do estudo, será realizado um estudo piloto com vistas à avaliar a instrumentação que será utilizada no estudo experimental. Para tanto, somente um participante será utilizado. O participante utilizará os mesmos instrumentos do estudo experimental. Os dados obtidos pelo estudo piloto não serão usados para complementar o estudo.

Participantes: os participantes do estudo, além de terem pelo menos graduação na área de computação, deverão estar inseridos no contexto industrial e possuir conhecimentos mínimos sobre:

- a notação UML, mais especificamente sobre modelos de classes e de componentes - para que possam entender os modelos de uma determinada LP e, a partir desses, gerar as configurações de ALP necessárias;

- a abordagem de LP, sobre gerenciamento de variabilidades, tempo de resolução de variabilidade e relacionamento entre pontos de variação e variantes; e

- metas de negócio, cenários e métricas.

O estudo leva em consideração o ambiente no qual o participante está inserido que, no caso, é o ambiente industrial.

Instrumentação: todos os participantes receberão um conjunto de documentos (Apêndice $\mathrm{D}]$ :

- uma cópia do termo de adesão ao estudo experimental;

- uma cópia do questionário de caracterização, no qual o participante indicará sua formação acadêmica e seu nível de experiência com a notação UML e com a abordagem de LP;

- uma cópia do Capítulo 5 desta tese, versando sobre o método SystEM-PLA, não contendo o estudo piloto e os resultados obtidos;

- uma cópia do documento com a descrição geral da LP AGM, idêntico ao contido no Apêndice C:

- uma cópia do documento apresentando o perfil SMartyProfile, os principais estereótipos e suas respectivas descrições, o qual é aplicado nos diagramas UML da LP AGM, idêntico ao contido no Apêndice C: 
- dez cópias dos diagramas de classes e de componentes da LP AGM;

- dez cópias do modelo de resolução de variabilidades da LP AGM, idêntico ao contido no Apêndice C:

- uma cópia do Capítulo 6 desta tese, apresentando as métricas básicas e de atributos de qualidade (complexidade e extensibilidade) do método SystEM-PLA;

- uma cópia do documento contendo as metas de negócio, os atributos de qualidade e os cenários definidos para este estudo experimental;

- uma cópia do documento contendo uma tabela com os cenários definidos para o participante classificar com base em uma lista de fatores; e

- gráficos com a descrição estatística dos valores observados para as métricas CompPLA e ExtensPLA coletadas a partir das dez configurações geradas por cada participante.

Formulação das Hipóteses: as seguintes hipóteses são propostas para o estudo em questão:

- Hipótese Nula $\left(\mathbf{H}_{0}\right)$ : os resultados obtidos por este estudo experimental não são similares aos previamente obtidos no Capítulo 5, utilizados como referência para a aplicação do método SystEM-PLA à arquitetura da LP AGM.

$H_{0}: \mu_{\text {Resultados Previamente Obtidos }} \nRightarrow \mu_{\text {Resultados deste Estudo Experimental }}$

- Hipótese Alternativa $\left(\mathbf{H}_{1}\right)$ : os resultados obtidos por este estudo experimental são similares aos previamente obtidos no Capítulo 5, utilizados como referência para a aplicação do método SystEM-PLA à arquitetura da LP AGM.

$H_{1}: \mu_{\text {Resultados Previamente Obtidos }} \Leftrightarrow \mu_{\text {Resultados deste Estudo Experimental }}$

Variáveis Dependentes: os atributos de qualidade complexidade e extensibilidade, as metas de negócio MN.1 e MN.2 e os cenários Cn.1, Cn.2, Cn.3, Cn.4, Cn.5 e Cn.6 (Apêndice D).

Variáveis Independentes: as configurações AGM geradas por cada participante e as métricas CompPLA e ExtensPLA coletadas a partir das configurações. 
Análise Qualitativa: tem o objetivo de avaliar os resultados obtidos neste estudo, com relação aos resultados previamente obtidos, por meio de análises de estatística descritiva e de trade-off, baseadas nas configurações AGM geradas e nas métricas CompPLA e ExtensPLA coletadas.

Capacidade Aleatória: a seleção de participantes não será de forma aleatória dentro do universo de candidatos, já que tal universo é bastante restrito. A capacidade aleatória será exercida com relação à distribuição dos objetos de análise para cada participante.

Classificação em Bloco: não há necessidade de dividir os participantes em blocos, pois o estudo avaliará apenas um fator que é a viabilidade de aplicação do método SystEM-PLA, em função dos resultados obtidos neste estudo experimental, confrontados com os resultados previamente esperados. Contudo, após aplicado o questionário de caracterização de participante, tais informações poderão ser classificadas e organizadas em blocos durante a análise dos dados.

Balanceamento: serão distribuídas tarefas em números iguais para um número similar de participantes.

Mecanismos de Análise: o estudo proposto analisa a viabilidade do método SystEM-PLA com base nas métricas coletadas e nos atributos de qualidade, metas de negócio e cenários definidos para a LP AGM. Assim, os possíveis mecanismos de análise são:

- análises de estatísticas descritivas acerca das métricas coletadas a partir das configurações AGM geradas, por cada participante, combinadas com análises dos gráficos de dispersão das métricas CompPLA e ExtensPLA; e

- análises de trade-off com o objetivo de priorizar atributos de qualidade para o desenvolvimento e evolução da LP AGM.

Tais análises fornecerão indícios para se aceitar ou rejeitar a Hipótese Nula $\left(\mathrm{H}_{0}\right)$ do estudo e contribuir para generalizar conclusões acerca dos resultados alcançados.

Validade Interna: Para garantir a validade interna deste estudo serão tomadas as seguintes medidas:

- é prevista a utilização de 3 (três) participantes, todos realizando o estudo de forma isolada. Assim, não terão oportunidade de trocar idéias a respeito do estudo entre si, durante a realização das tarefas; e 
- foi incluído no termo de adesão ao estudo experimental, o total sigilo das informações relevantes ao estudo e a troca de idéias sobre este, entre os participantes.

Validade Externa: a validade externa do estudo experimental, mede a sua capacidade de refletir o mesmo comportamento, em outros grupos de participantes e profissionais da indústria, além daquele em que o estudo foi aplicado. A validade externa deste estudo é considerada suficiente, já que os participantes atuam diretamente em seus cargos com os conceitos de modelagem UML, processos de software e arquitetura de software. Assim, a falta de motivação não afetará a validade externa de tal estudo.

Validade de Construção: a validade de construção do estudo se refere à relação entre os instrumentos e participantes do estudo e a teoria que está sendo provada. Acredita-se que a validade de construção esteja garantida, uma vez que a abordagem de LP e seus conceitos de modelagem e resolução de variabilidade em UML, no nível em que será aplicado, não exigem ampla experiência dos participantes. A notação UML é amplamente conhecida, o que contribui para garantir a validade de construção do estudo.

Validade de Conclusão: a validade de conclusão mede a relação entre os tratamentos e os resultados, determinando a capacidade do estudo em generalizar os resultados. Acredita-se que a capacidade de conclusão do estudo esteja garantida, uma vez que a análise dos dados poderá ser realizada por meio de estatísticas descritivas e de análises de trade-off, sendo quantitativas e qualitativas e, portanto, podendo ser comparadas com análises anteriores para se apurar a conclusão do estudo. Além disso, as configurações são fáceis de ser geradas e as métricas são medidas objetivas e de fácil coleta, o que diminui a influência da complexidade de entendimento de geração e cálculo.

\subsection{Execução do Estudo Experimental}

Seleção dos Participantes: para este estudo experimental, foram selecionados profissionais de Tecnologia da Informação de uma empresa de grande porte. Os participantes selecionados estão de acordo com as restrições apresentadas no planejamento deste estudo (Seção 8.2).

Instrumentação: para a execução deste estudo experimental, os documentos, que formam a instrumentação deste estudo experimental, foram entregues a cada participante, todos eles relacionados no Apêndice $\mathrm{D}$. 
As principais tarefas de cada participante foram:

- ler e entender um documento descrevendo os atributos de qualidade, as metas de negócio e os cenários definidos para a ALP da AGM;

- ler e entender um documento apresentando os cenários pré-definidos para este estudo experimental para que fossem classificados por cada participante, segundo os atributos de interesse, descritos na Seção 5.3.1.

- responder a quatro questões relacionadas às metas de negócio, cenários e priorização de atributos de qualidade;

- gerar dez configurações da ALP da AGM;

- analisar a estatística descritiva das métricas coletadas para as dez configurações geradas; e

- fazer uma análise de trade-off com relação à priorização dos atributos de qualidade complexidade e extensibilidade para a ALP da AGM, indicando qual(is) atributo(s) de qualidade priorizar.

Procedimentos de Participação: os itens a seguir apresentam em ordem cronológica, cada procedimento:

1. participante comparece ao local em que o estudo será realizado;

2. experimentador ministra treinamento e esclarece possíveis dúvidas sobre o método SystEM-PLA, apresentando o texto do Capítulo 5 e análises de trade-off para atributos de qualidade, com base em exemplos do livro de Clements et al. (2002b);

3. experimentador entrega ao participante o Termo de Adesão ao estudo experimental;

4. participante lê, esclarece possíveis dúvidas e assina o Termo de Adesão ao estudo experimental;

5. um identificador (ID) único é associado ao participante;

6. experimentador anota o ID do participante no Questionário de Caracterização de Participante;

7. experimentador entrega ao participante o Questionário de Caracterização de Participante; 
8. participante lê, esclarece possíveis dúvidas e assina o Questionário de Caracterização de Participante;

9. experimentador entrega o documento descrevendo os atributos de qualidade, as metas de negócio e os cenários definidos para a ALP da AGM;

10. participante lê e esclarece possíveis dúvidas com relação ao documento que descreve os atributos de qualidade, as metas de negócio e os cenários definidos para a ALP da AGM;

11. experimentador entrega ao participante o documento utilizado para classificar os cenários definidos para a LP AGM e questões sobre atributos de qualidade, metas de negócio e cenários;

12. participante lê e esclarece possíveis dúvidas com relação ao documento utilizado para classificar os cenários definidos para a LP AGM e questões sobre atributos de qualidade, metas de negócio e cenários;

13. experimentador entrega ao participante o Modelo de Classes e de Componentes representando a ALP da AGM;

14. participante lê e esclarece possíveis dúvidas com relação ao Modelo de Classes e de Componentes representando a ALP da AGM;

15. experimentador entrega ao participante o Modelo de Resolução de Variabilidades da LP AGM;

16. participante lê e esclarece possíveis dúvidas com relação ao Modelo de Resolução de Variabilidades da LP AGM;

17. participante resolve as variabilidades e gera dez produtos distintos para a LP AGM;

18. participante entrega o modelo de resolução de cada configuração gerada ao experimentador;

19. experimentador confere os dez modelos de resolução entregues pelo participante e os armazena em uma pasta apropriada;

20. experimentador verifica se os produtos gerados são consistentes com relação às suas variabilidades e restrições;

21. experimentador coleta as métricas de cada produto e gera gráficos representando a estatística descritiva dos valores observados de cada métrica; 
22. experimentador entrega e explica ao participante os gráficos gerados;

23. participante esclarece possíveis dúvidas sobre os gráficos e suas interpretações;

24. experimentador pede para que o participante faça uma análise de trade-off com relação aos atributos de qualidade complexidade e extensibilidade, apoiada pelas metas de negócio, cenários classificados e os gráficos gerados;

25. participante realiza a análise de trade-off;

26. experimentador discute a análise de trade-off realizada, esclarecendo possíveis dúvidas;

27. participante finaliza a análise e entrega um documento à "mão-livre" ao experimentador; e

28. experimentador armazena o documento em uma pasta apropriada.

Execução: a Tabela 8.1 apresenta as informações sobre os participantes do estudo. Para cada critério foram usados os seguintes fatores de classificação:

- Formação Acadêmica: Mestrando (Mn), Mestre (Ms), Doutorando (Dn), Doutor $(\mathrm{Dr})$;

- Experiência com UML: Básica (B), Moderada (M), Avançada (A); e

- Experiência com LP e Variabilidade: Básica (B), Moderada (B), Avançada (A).

Tabela 8.1: Dados Detalhados dos Participantes do Estudo.

\begin{tabular}{|c|c|c|c|c|c|c|c|c|c|c|}
\hline ID & \multicolumn{4}{|c|}{ Formação Acadêmica } & \multicolumn{3}{|c|}{ Experiência com UML } & \multicolumn{3}{|c|}{ Experiência com LP } \\
\hline 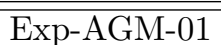 & $\overline{\mathrm{Mn}()}$ & $\overline{\mathrm{Ms}(\mathrm{C}}$ & $\overline{\overline{\operatorname{Dn}(x)}}$ & 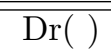 & $\overline{\overline{\mathrm{B}()}}$ & $\overline{\mathrm{M}(\mathrm{)})}$ & $\overline{\mathrm{A}(\mathrm{x})}$ & $\overline{\mathrm{B}(\mathrm{)})}$ & $\mathrm{M}(\mathrm{x}$ & $\overline{\mathrm{A}(\mathrm{(})}$ \\
\hline Exp-AGM-02 & $\operatorname{Mn}()$ & $\mathrm{Ms}($ & $\operatorname{Dn}()$ & $\operatorname{Dr}(\mathrm{x})$ & $\mathrm{B}(\mathrm{)})$ & $\mathrm{M}()$ & $\mathrm{A}(\mathrm{x})$ & $\mathrm{B}()$ & $\mathrm{M}()$ & $\mathrm{A}(\mathrm{x})$ \\
\hline Exp-AGM-03 & $\operatorname{Mn}()$ & $\mathrm{Ms}($ & $\operatorname{Dn}()$ & $\operatorname{Dr}(\mathrm{x})$ & $\mathrm{B}(\mathrm{)})$ & $\mathrm{M}(\mathrm{)}$ & $\mathrm{A}(\mathrm{x})$ & $\mathrm{B}(\mathrm{)}$ & $\mathrm{M}(\mathrm{x}$ & $\mathrm{A}()^{\prime}$ \\
\hline
\end{tabular}

Aos participantes foram distribuídos todos os documentos necessários para a realização das tarefas. Basicamente, cada participante:

- classificou os cenários definidos; 
- solucionou o modelo de resolução de variabilidades gerando dez produtos distintos, aos quais foram aplicadas e coletadas as métricas de complexidade e extensibilidade; e

- realizou uma análise de trade-off com relação aos atributos de qualidade complexidade e extensibilidade, com o apoio de metas de negócio, cenários, estatística descritiva e gráfico de dispersão das métricas coletadas.

As metas de negócio definidas para ilustrar as diretrizes do método SystEM-PLA são:

- MN.1 - manter o grau de complexidade dos jogos, abaixo de 0.7 (70\%), comparado à complexidade geral da ALP, para, pelo menos, $50 \%$ dos produtos produzidos. Isso significa manter baixas as taxas de manutenibilidade e custo, concentrando-se em complexidade. O grau de complexidade pode fornecer um indicador de dificuldade para manter os produtos derivados de uma ALP. Assim, quanto maior é o grau de complexidade de um produto, mais difícil é mantê-lo e, consequentemente, mais alto é o seu custo; e

- MN.2 - manter o grau de extensibilidade dos jogos, acima de 0.75 (75\%), comparado à extensibilidade geral da ALP, para, pelo menos, 50\% dos produtos produzidos. Isso significa manter altas taxas de reutilização, concentrando-se em extensibilidade. Graus de extensibilidade podem fornecer indicadores do quão reusável é um produto em termos de seus componentes. Quanto mais extensível é um produto, mais alta é a sua taxa de reusabilidade e mais baixo é o seu custo de manutenção/produção.

Os cenários definidos para ilustrar as diretrizes do método SystEM-PLA são:

- Cn.1 - pontos de variação e/ou variantes são adicionadas, modificadas ou removidas, mantendo a Meta de Negócio MN.1 verdadeira;

- Cn.2 - 50\% das variabilidades são removidas, mantendo a Meta de Negócio MN.1 verdadeira;

- Cn.3 - ambientes com 1 (um) jogo possuem complexidade máxima de 0,65 (65\%) com relação à arquitetura da AGM;

- Cn.4 - pontos de variação e/ou variantes são adicionadas, modificadas ou removidas, mantendo a Meta de Negócio MN.2 verdadeira;

- Cn.5 - 50\% das variabilidades são removidas, mantendo a Meta de Negócio MN.2 verdadeira; e 
- Cn.6 - ambientes com 2 (dois) jogos possuem extensibilidade mínima de 0,8 (80\%) com relação à arquitetura da AGM.

Os itens a seguir apresentam os resultados obtidos com a realização das tarefas, pelos três participantes do estudo:

\section{- Participante $\mathrm{N}^{\circ} 1$ (Part.1):}

- classificação dos cenários: com base nas metas de negócio, atributos de qualidade e conhecimento da LP AGM e do seu domínio, a Tabela 8.2 apresenta a classificação dos cenários pelo participante Part.1:

Tabela 8.2: Part.1: Classificação dos Cenários.

\begin{tabular}{|c|c|c|c|c|c|c|c|c|}
\hline \multirow{3}{*}{\multicolumn{3}{|c|}{$\begin{array}{c}\text { Meta(s) de Negócio } \\
\text { Atributo(s) de Qualidade } \\
\text { Cenário(s) }\end{array}$}} & \multirow{2}{*}{\multicolumn{3}{|c|}{$\begin{array}{c}\text { MN.1 } \\
\text { Complexidade }\end{array}$}} & \multirow{2}{*}{\multicolumn{3}{|c|}{$\begin{array}{c}\text { MN.2 } \\
\text { Extensibilidade }\end{array}$}} \\
\hline & & & & & & & & \\
\hline & & & \multirow{2}{*}{$\frac{C n .1}{\mathrm{X}}$} & \multirow[t]{2}{*}{ Cn. 2} & \multirow[t]{2}{*}{ Cn.3 } & \multirow{2}{*}{$\begin{array}{c}\text { Cn.4 } \\
X\end{array}$} & \multirow{2}{*}{$\frac{C n .5}{\mathrm{X}}$} & \multirow[t]{2}{*}{ Cn.6 } \\
\hline \multirow{12}{*}{ 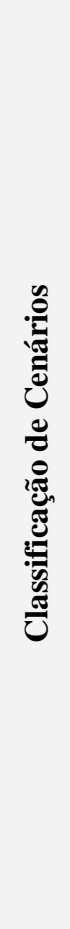 } & \multirow{3}{*}{ Importância } & A & & & & & & \\
\hline & & $\mathbf{M}$ & & $\mathbf{X}$ & $\mathbf{X}$ & & & $\mathbf{X}$ \\
\hline & & B & & & & & & \\
\hline & \multirow{3}{*}{ Generalidade } & A & $\mathbf{X}$ & $\mathbf{X}$ & & $\mathbf{X}$ & $\mathbf{X}$ & $\mathbf{X}$ \\
\hline & & $\mathbf{M}$ & & & $\mathbf{X}$ & & & \\
\hline & & B & & & & & & \\
\hline & \multirow{3}{*}{ Custo/Risco } & A & & & & & & $\mathbf{X}$ \\
\hline & & $\mathbf{M}$ & $X$ & $\mathbf{X}$ & $\mathbf{X}$ & $\mathbf{X}$ & $\mathbf{X}$ & \\
\hline & & B & & & & & & \\
\hline & \multirow{3}{*}{$\begin{array}{c}\text { Número de } \\
\text { Variabilidades }\end{array}$} & A & $\mathbf{X}$ & & $\mathbf{X}$ & & & $\mathbf{X}$ \\
\hline & & $\mathbf{M}$ & & $\mathbf{X}$ & & & $\mathbf{X}$ & \\
\hline & & B & & & & $\mathbf{X}$ & & \\
\hline
\end{tabular}

- questões sobre os artefatos da AGM: o Part.1 respondeu às seguintes questões, com base no seu conhecimento e entendimento de metas de negócio, cenários e atributos de qualidade, considerando o método SystEM-PLA e a LP AGM:

1. Você considera que as metas de negócio contribuem para entender melhor os atributos de qualidade da ALP da AGM? 
* Resp.: "Serviu, pois as metas especificam as margens esperadas para cada atributo de qualidade."

2. Você considera que os cenários definidos para a arquitetura da AGM permitem uma melhor compreensão das suas metas de negócio?

* Resp.: "Sim. Exercitam diferentes situações de geração de produtos."

3. Você considera que os cenários são elementos importantes definidos para uma arquitetura de linha de produto e, por isso, são essenciais para priorizar atributos de qualidade?

* Resp.: "Sim, pois os cenários exercitam diferentes situações visando as metas de negócio."

4. Faça um mapeamento hierárquico (forma de árvore) dos seguintes elementos (ordenados alfabeticamente) definidos para a arquitetura da AGM: atributos de qualidade, cenários e metas de negócio.

* Resp.: "atributos de qualidade $\Rightarrow$ metas de negócio $\Rightarrow$ cenários"

- geração das configurações AGM: o Part.1 gerou dez configurações para a ALP AGM. A Tabela 8.3 apresenta as métricas coletadas para cada configuração gerada e a estatística descritiva dos valores observados:

Tabela 8.3: Part.1: Valores Observados para as Métricas CompPLA e ExtensPLA.

\begin{tabular}{|c|c|c|}
\hline${\text { Configuração } \mathbf{N}^{\mathbf{}}}^{\text {CompPLA }}$ & ExtensPLA \\
\hline 01 & 0,51 & 0,61 \\
\hline 02 & 0,56 & 0,61 \\
\hline 03 & 0,83 & 0,80 \\
\hline 04 & 0,53 & 0,61 \\
\hline 05 & 0,67 & 0,80 \\
\hline 06 & 0,87 & 1,00 \\
\hline 07 & 0,82 & 0,80 \\
\hline 08 & 0,62 & 0,80 \\
\hline 09 & 0,53 & 0,61 \\
\hline 10 & 0,40 & 0,61 \\
\hline Média & 0,63 & 0,73 \\
\hline Mediana & 0,59 & 0,71 \\
\hline Desvio Padrão & 0,16 & 0,14 \\
\hline Variância & 0,03 & 0,02 \\
\hline
\end{tabular}

A Figura 8.1 apresenta o gráfico de dispersão dos valores observados para as métricas CompPLA e ExtensPLA, a partir das configurações geradas pelo Part.1. 


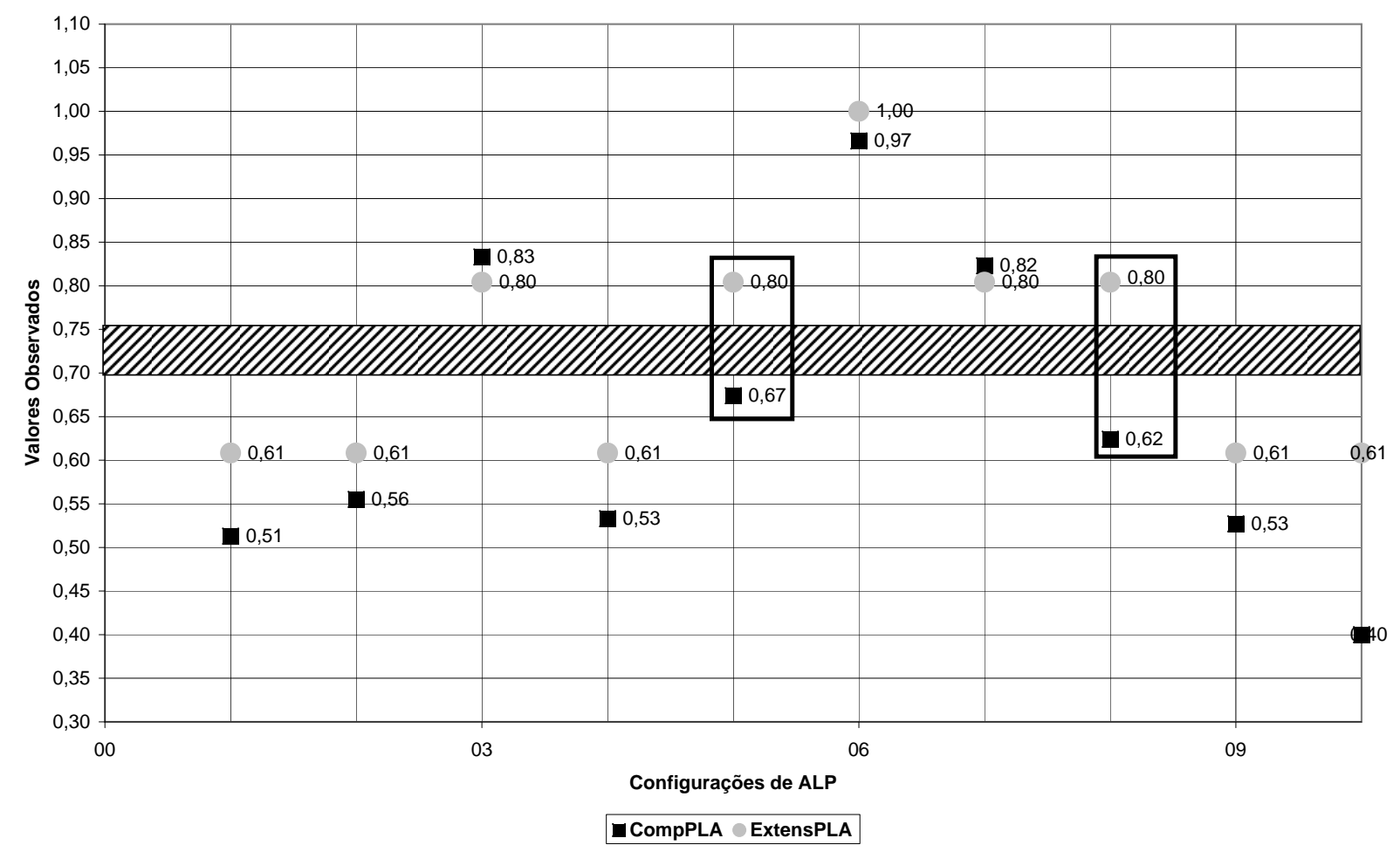

Figura 8.1: Part.1: Gráfico de Dispersão para as Métricas CompPLA e ExtensPLA.

- análise de trade-off: com base nas metas de negócio, atributos de qualidade, cenários (Tabela 8.2), configurações geradas, métricas coletadas (Tabela 8.3 e Figura 8.1), o Part.1 realizou uma análise de trade-off com o objetivo de identificar qual(is) atributo(s) de qualidade deve(m) ser priorizado(s) no desenvolvimento e evolução da LP AGM. Assim, tal análise é apresentada a seguir:

* tomando como base a Tabela 8.2 com a classificação dos cenários, pode-se observar claramente que:

• os cenários Cn.1 e Cn.6 são os mais importantes, pois possuem valores altos (A) para três dos quatro fatores de classificação;

- os cenários Cn.4 e Cn.5 são menos importantes que os cenários Cn.1 e Cn.6, pois possuem valores altos (A) para apenas dois, dos quatro fatores de classificação. Além disso, são mais importantes que os cenários Cn.2 e Cn.3; e

- como, dos quatro cenários mais importantes (Cn1, Cn.6, Cn.4 e Cn.5), três são cenários de extensibilidade e um é de complexidade, sugere-se que a priorização desses atributos de qualidade, seja realizada por meio 
de uma análise da estatística descritiva e dos possíveis produtos da AGM.

* pode-se observar que a meta de negócio MN.1 é mantida verdadeira, ao analisar o número de configurações geradas. Sete configurações, $70 \%$ das configurações geradas, possuem complexidade inferior a $0,7(70 \%)$. O mesmo acontece para a meta de negócio MN.2; cinco configurações, 50\% das configurações geradas, possuem extensibilidade superior a 0,75 (75\%); $\mathrm{e}$

* como as duas metas de negócio são satisfeitas, uma análise dos dez produtos gerados para a AGM deve ser realizada. Assim, observando o gráfico de dispersão da Figura 8.1 é possível identificar dois produtos que são interessantes: a configuração $\mathrm{N}^{0} 5$ (Config.5) com valores CompPLA = 0,67 e ExtensPLA $=0,80$; e a configuração $N^{\circ} 8$ (Config.8) com valores CompPLA $=0,62$ e ExtensPLA $=0,80$. Nesse caso, as duas configurações possuem valores de extensibilidade iguais $(0,80)$, porém valores de complexidade diferentes. Dessa forma, pode-se concluir que com base nas metas de negócio e cenários definidos e nos dez produtos gerados para a AGM, deve-se priorizar complexidade no desenvolvimento e evolução da LP, uma vez que os valores de extensibilidade alcançados mantêm a meta de negócio MN.1 verdadeira. Assim, o objetivo é dar prioridade para a produção de produtos AGM com extensibilidade e complexidade similar à Config.8.

\section{- Participante $\mathrm{N}^{\circ} 2$ (Part.2):}

- classificação dos cenários: com base nas metas de negócio, atributos de qualidade e conhecimento da LP AGM e do seu domínio, a Tabela 8.4 apresenta a classificação dos cenários pelo participante Part.2: 
Tabela 8.4: Part.2: Classificação dos Cenários.

\begin{tabular}{|c|c|c|c|c|c|c|c|c|}
\hline \multirow{3}{*}{\multicolumn{3}{|c|}{$\begin{array}{c}\text { Meta(s) de Negócio } \\
\text { Atributo(s) de Qualidade } \\
\text { Cenário(s) }\end{array}$}} & \multirow{2}{*}{\multicolumn{3}{|c|}{$\begin{array}{c}\text { MN.1 } \\
\text { Complexidade }\end{array}$}} & \multirow{2}{*}{\multicolumn{3}{|c|}{$\begin{array}{c}\text { MN.2 } \\
\text { Extensibilidade }\end{array}$}} \\
\hline & & & & & & & & \\
\hline & & & \multirow{2}{*}{$\begin{array}{c}\text { Cn.1 } \\
\mathrm{X}\end{array}$} & \multirow[t]{2}{*}{ Cn.2 } & \multirow{2}{*}{$\begin{array}{c}\text { Cn.3 } \\
X\end{array}$} & \multirow[t]{2}{*}{ Cn.4 } & \multirow{2}{*}{$\begin{array}{c}\text { Cn.5 } \\
\mathrm{X}\end{array}$} & \multirow[t]{2}{*}{ Cn.6 } \\
\hline \multirow{12}{*}{ 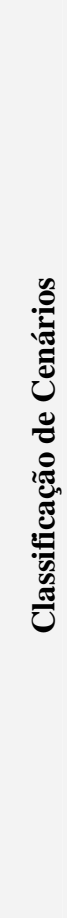 } & \multirow{3}{*}{ Importância } & A & & & & & & \\
\hline & & $\mathbf{M}$ & & & & $\mathbf{X}$ & & $\mathbf{X}$ \\
\hline & & B & & $\mathbf{X}$ & & & & \\
\hline & \multirow{3}{*}{ Generalidade } & A & & & $\mathbf{X}$ & $\mathbf{X}$ & & \\
\hline & & $\mathbf{M}$ & $\mathbf{X}$ & $\mathbf{X}$ & & & $\mathbf{X}$ & $\mathbf{X}$ \\
\hline & & B & & & & & & \\
\hline & \multirow{3}{*}{ Custo/Risco } & A & $\mathbf{X}$ & $\mathbf{X}$ & & $\mathbf{X}$ & $\mathbf{X}$ & $\mathbf{X}$ \\
\hline & & M & & & $\mathbf{X}$ & & & \\
\hline & & B & & & & & & \\
\hline & \multirow{3}{*}{$\begin{array}{c}\text { Número de } \\
\text { Variabilidades }\end{array}$} & A & $\mathbf{X}$ & & $\mathbf{X}$ & & & $\mathbf{X}$ \\
\hline & & M & & & & $\mathbf{X}$ & & \\
\hline & & B & & $\mathbf{X}$ & & & $\mathbf{X}$ & \\
\hline
\end{tabular}

- questões sobre os artefatos da AGM: o Part.2 respondeu às seguintes questões, com base no seu conhecimento e entendimento de metas de negócio, cenários e atributos de qualidade, considerando o método SystEM-PLA e a LP AGM:

1. Você considera que as metas de negócio contribuem para entender melhor os atributos de qualidade da ALP da AGM?

- Resp.: "As metas de negócio deixam claro os objetivos da LP em termos gerais, porém os atributos de qualidade ficam mais detalhados com a apresentação das metas de negócio."

2. Você considera que os cenários definidos para a arquitetura da AGM permitem uma melhor compreensão das suas metas de negócio?

- Resp.: "As metas de negócio são bem claras. Vejo os cenários como uma forma de entender melhor o comportamento esperado pela ALP da AGM e valores que podem ser medidos."

3. Você considera que os cenários são elementos importantes definidos para uma arquitetura de linha de produto e, por isso, são essenciais para priorizar atributos de qualidade? 
- Resp.: "Sem dúvida. Cenários são importantes em qualquer metodologia de avaliação de arquitetura de software."

4. Faça um mapeamento hierárquico (forma de árvore) dos seguintes elementos (ordenados alfabeticamente) definidos para a arquitetura da AGM: atributos de qualidade; cenários; e metas de negócio.

- Resp.1: "atributos de qualidade $\Rightarrow$ metas de negócio $\Rightarrow$ cenários"

- Resp.2: "atributos de qualidade $\Rightarrow$ cenários $\Rightarrow$ metas de negócio"

- geração das configurações AGM: o Part.2 gerou dez configurações para a ALP AGM. A Tabela 8.5 apresenta as métricas coletadas para cada configuração gerada e a estatística descritiva dos valores observados:

Tabela 8.5: Part.2: Valores Observados para as Métricas CompPLA e ExtensPLA.

\begin{tabular}{|c|c|c|}
\hline Configuração N $^{\mathbf{0}}$ & CompPLA & ExtensPLA \\
\hline 01 & 0,49 & 0,61 \\
\hline 02 & 0,68 & 0,79 \\
\hline 03 & 0,55 & 0,82 \\
\hline 04 & 0,98 & 1,00 \\
\hline 05 & 0,63 & 0,79 \\
\hline 06 & 0,74 & 0,80 \\
\hline 07 & 1,00 & 1,00 \\
\hline 08 & 0,40 & 0,61 \\
\hline 09 & 0,53 & 0,61 \\
\hline 10 & 0,48 & 0,61 \\
\hline Média & 0,65 & 0,76 \\
\hline Mediana & 0,59 & 0,79 \\
\hline Desvio Padrão & 0,21 & 0,15 \\
\hline Variância & 0,04 & 0,02 \\
\hline
\end{tabular}

A Figura 8.2 apresenta o gráfico de dispersão dos valores observados para as métricas CompPLA e ExtensPLA, a partir das configurações geradas pelo Part.2. 


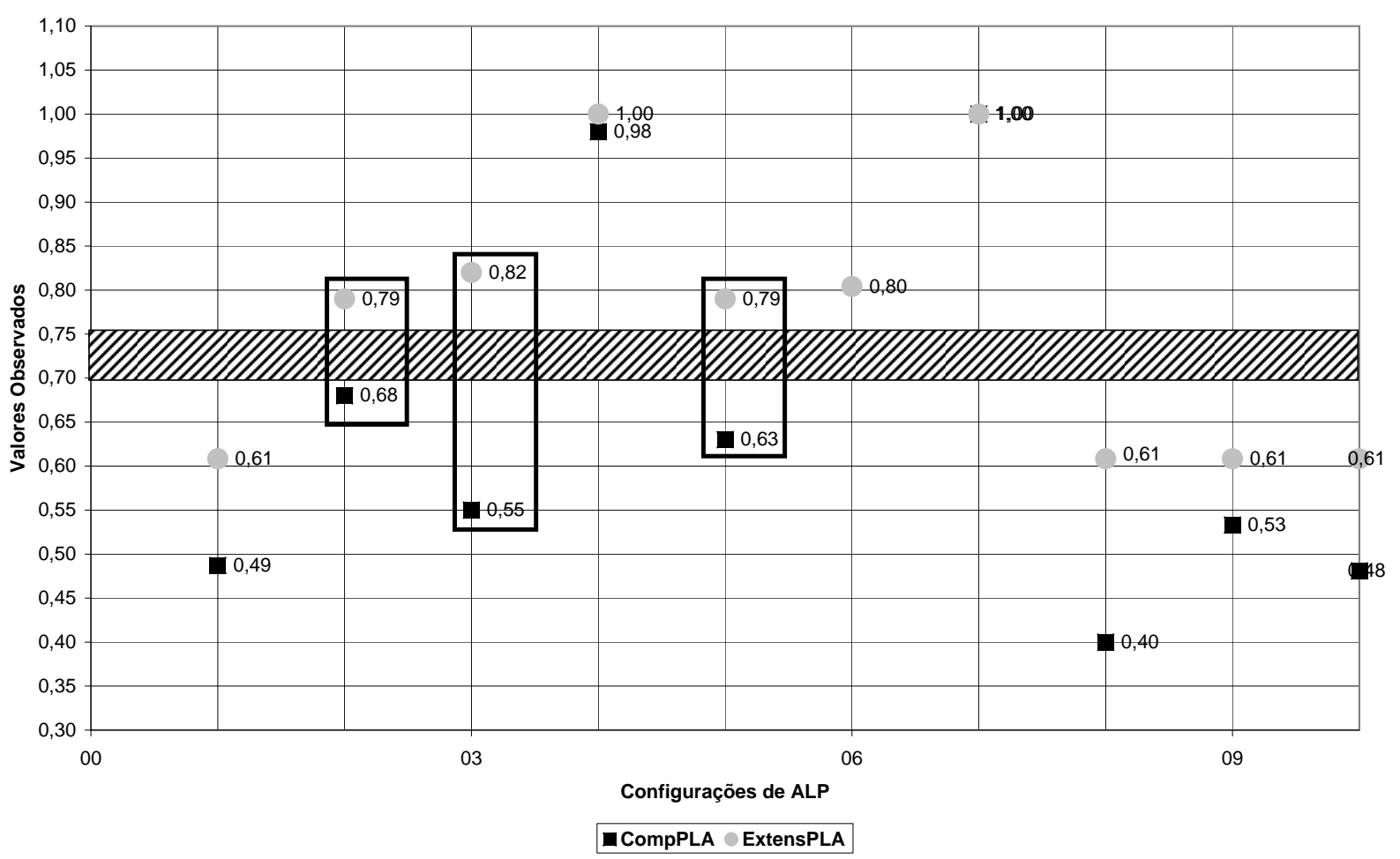

Figura 8.2: Part.2: Gráfico de Dispersão para as Métricas CompPLA e ExtensPLA.

- análise de trade-off: com base nas metas de negócio, atributos de qualidade, cenários (Tabela 8.4), configurações geradas, métricas coletadas (Tabela 8.5 e Figura 8.2), o Part.2 realizou uma análise de trade-off com o objetivo de identificar qual(is) atributo(s) de qualidade deve(m) ser priorizado(s) no desenvolvimento e evolução da LP AGM. Assim, tal análise é apresentada a seguir:

- tomando como base a Tabela 8.4 com a classificação dos cenários, pode-se observar claramente que:

* os cenários Cn.1 e Cn.3 são os mais importantes, pois possuem valores altos (A) para três, dos quatro fatores de classificação;

* os cenários Cn.4 e Cn.6 são menos importantes que os cenários Cn.1 e Cn.3, pois possuem valores altos (A) para apenas dois, dos quatro fatores de classificação. Além disso, são mais importantes que os cenários Cn.5 e Cn.2; e

* como, dos quatro cenários mais importantes (Cn.1, Cn.3, Cn.4 e Cn.6), dois são cenários de complexidade e dois são de extensibilidade, sugere-se que a priorização desses atributos de qualidade seja realizada por meio de uma análise da estatística descritiva e dos possíveis produtos da AGM. 
- pode-se observar que a meta de negócio MN.1 é mantida verdadeira, ao analisar o número de configurações geradas. Sete configurações, $70 \%$ das configurações geradas, possuem complexidade inferior a 0,7 (70\%). O mesmo acontece para a meta de negócio MN.2, seis configurações, $60 \%$ das configurações geradas, possuem extensibilidade superior a 0,75 (75\%); e

- como as duas metas de negócio são satisfeitas, uma análise dos dez produtos gerados para a AGM deve ser realizada. Assim, observando o gráfico de dispersão da Figura 8.2 é possível identificar três produtos que são interessantes: a configuração $\mathrm{N}^{\circ} 2$ (Config.2) com valores CompPLA $=0,68$ e ExtensPLA $=$ 0,79; a configuração No 3 (Config.3) com valores CompPLA $=0,55$ e ExtensPLA $=0,82 ;$ e a configuração $\mathrm{N}^{\circ} 5$ (Config.5) com valores CompPLA=0,63 e ExtensPLA $=0,79$. Nesse caso, as três configurações possuem valores de extensibilidade com 0.3 pontos percentuais de proximidade, porém, valores de complexidade possuem uma diferença de 0,13 pontos percentuais. Dessa forma, pode-se concluir que, com base nas metas de negócio e cenários definidos, nos dez produtos gerados para a AGM e na diferença dos valores observados, deve-se priorizar complexidade no desenvolvimento e evolução da LP. Assim, o objetivo é dar prioridade para a produção de produtos AGM com extensibilidade e complexidade similar à Config.3, com baixa complexidade e alta extensibilidade.

\section{- Participante N $^{\mathrm{a}} 3$ (Part.3):}

- classificação dos cenários: com base nas metas de negócio, atributos de qualidade e conhecimento da LP AGM e do seu domínio, a Tabela 8.6 apresenta a classificação dos cenários pelo participante Part.3: 
Tabela 8.6: Part.3: Classificação dos Cenários.

\begin{tabular}{|c|c|c|c|c|c|c|c|c|}
\hline \multirow{3}{*}{\multicolumn{3}{|c|}{\begin{tabular}{|c|} 
Meta(s) de Negócio \\
Atributo(s) de Qualidade \\
Cenário(s) \\
\end{tabular}}} & \multirow{2}{*}{\multicolumn{3}{|c|}{$\begin{array}{c}\text { MN.1 } \\
\text { Complexidade }\end{array}$}} & \multirow{2}{*}{\multicolumn{3}{|c|}{$\begin{array}{c}\text { MN.2 } \\
\text { Extensibilidade }\end{array}$}} \\
\hline & & & & & & & & \\
\hline & & & Cn.1 & Cn.2 & Cn.3 & Cn.4 & Cn.5 & Cn.6 \\
\hline \multirow{12}{*}{ 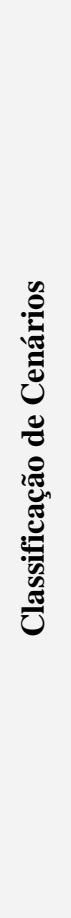 } & \multirow{3}{*}{ Importância } & A & & $\mathbf{X}$ & & $\mathbf{X}$ & & \\
\hline & & $\mathbf{M}$ & $\mathbf{X}$ & & $\mathbf{X}$ & & $\mathbf{X}$ & \\
\hline & & B & & & & & & $\mathbf{X}$ \\
\hline & \multirow{3}{*}{ Generalidade } & A & & $\mathbf{X}$ & & $\mathbf{X}$ & & $\mathbf{X}$ \\
\hline & & $\mathbf{M}$ & $\mathbf{X}$ & & $\mathbf{X}$ & & $\mathbf{X}$ & \\
\hline & & B & & & & & & \\
\hline & \multirow{3}{*}{ Custo/Risco } & $\mathbf{A}$ & & & & & & $\mathbf{X}$ \\
\hline & & $\mathbf{M}$ & $\mathbf{X}$ & $\mathbf{X}$ & & $\mathbf{X}$ & $\mathbf{X}$ & \\
\hline & & B & & & $\mathbf{X}$ & & & \\
\hline & \multirow{3}{*}{$\begin{array}{c}\text { Número de } \\
\text { Variabilidades }\end{array}$} & A & $\mathbf{X}$ & $\mathbf{X}$ & & & & \\
\hline & & $\mathbf{M}$ & & & $\mathbf{X}$ & $\mathbf{X}$ & $\mathbf{X}$ & $\mathbf{X}$ \\
\hline & & B & & & & & & \\
\hline
\end{tabular}

- questões sobre os artefatos da AGM: o Part.3 respondeu às seguintes questões, com base no seu conhecimento e entendimento de metas de negócio, cenários e atributos de qualidade, considerando o método SystEM-PLA e a LP AGM:

1. Você considera que as metas de negócio contribuem para entender melhor os atributos de qualidade da ALP da AGM?

- Resp.: "Sim, apesar de serem bem intuitivas. Os atributos de qualidade ficam mais explícitos."

2. Você considera que os cenários definidos para a arquitetura da AGM permitem uma melhor compreensão das suas metas de negócio?

- Resp.: "Sim. Mas os cenários são mais específicos do ponto de vista arquitetural do que as metas de negócio, que são mais amplas."

3. Você considera que os cenários são elementos importantes definidos para uma arquitetura de linha de produto e, por isso, são essenciais para priorizar atributos de qualidade?

- Resp.: "Sim, porém acho que a utilização de uma ADL contribuiria." 
- geração das configurações AGM: o Part.3 gerou dez configurações para a ALP AGM. A Tabela 8.7 apresenta as métricas coletadas para cada configuração gerada e a estatística descritiva dos valores observados:

Tabela 8.7: Part.3: Valores Observados para as Métricas CompPLA e ExtensPLA.

\begin{tabular}{|c|c|c|}
\hline${\text { Configuração } \mathbf{N}^{\mathbf{0}}}^{\text {CompPLA }}$ & ExtensPLA \\
\hline 01 & 0,56 & 0,61 \\
\hline 02 & 0,83 & 0,80 \\
\hline 03 & 0,50 & 0,61 \\
\hline 04 & 0,50 & 0,77 \\
\hline 05 & 0,90 & 1,00 \\
\hline 06 & 0,98 & 1,00 \\
\hline 07 & 0,52 & 0,61 \\
\hline 08 & 0,49 & 0,61 \\
\hline 09 & 0,42 & 0,61 \\
\hline 10 & 0,82 & 0,80 \\
\hline Média & 0,65 & 0,74 \\
\hline Mediana & 0,54 & 0,69 \\
\hline Desvio Padrão & 0,21 & 0,16 \\
\hline Variância & 0,04 & 0,03 \\
\hline
\end{tabular}

A Figura 8.3 apresenta o gráfico de dispersão gerado a partir dos valores observados para as métricas CompPLA e ExtensPLA, a partir das configurações geradas. 


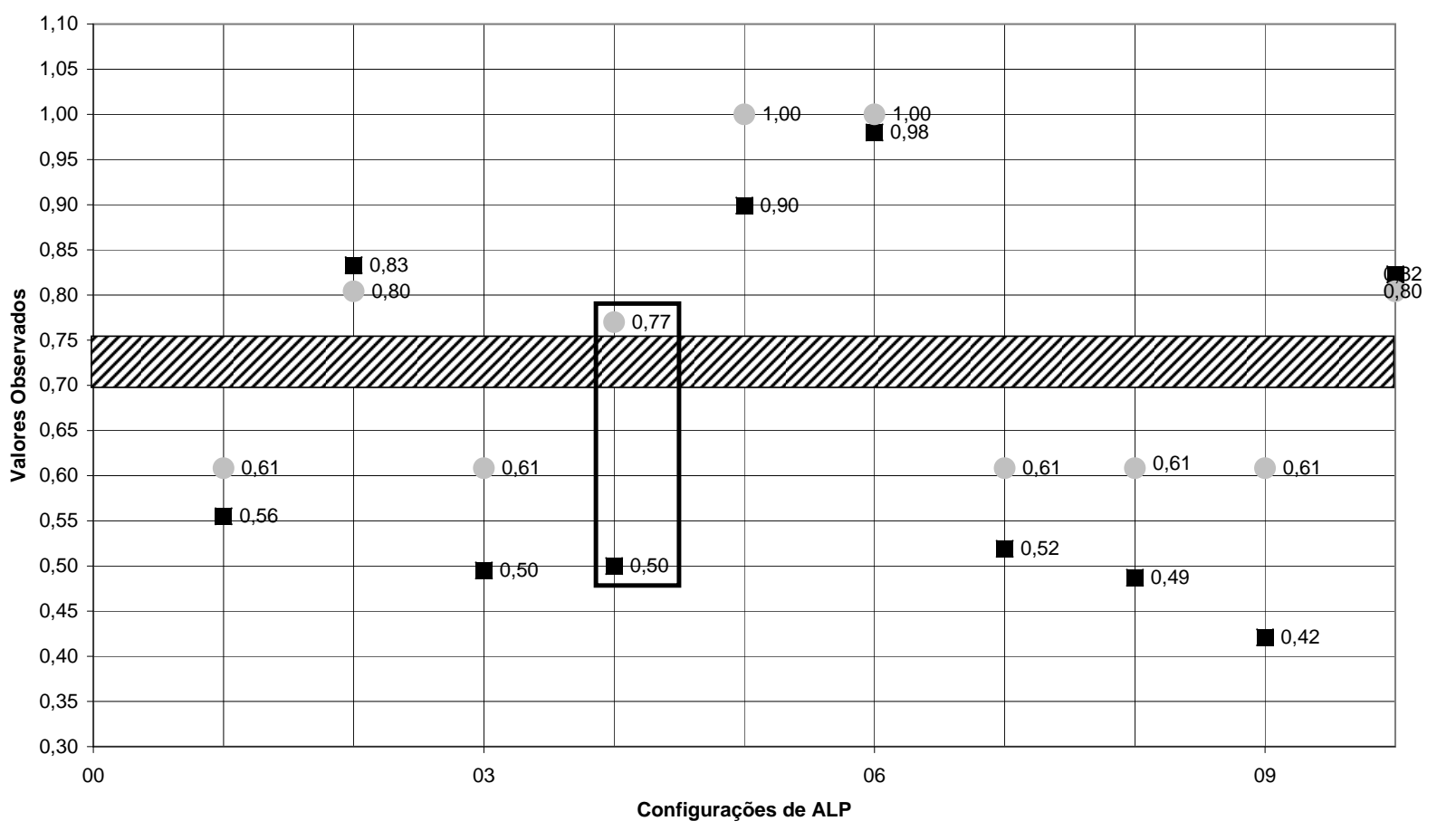

- CompPLA ExtensPLA

Figura 8.3: Part.3: Gráfico de Dispersão para as Métricas CompPLA e ExtensPLA.

- análise de trade-off: com base nas metas de negócio, atributos de qualidade, cenários (Tabela 8.6), configurações geradas, métricas coletadas (Tabela 8.7 e Figura 8.3), o Part.3 realizou uma análise de trade-off com o objetivo de identificar qual(is) atributo(s) de qualidade deve(m) ser priorizado(s) no desenvolvimento e evolução da LP AGM. Assim, tal análise é apresentada a seguir:

- tomando como base a Tabela 8.6 com a classificação dos cenários, pode-se observar claramente que:

* os cenários Cn.2 e Cn.4 são os mais importantes, pois possuem valores altos (A) para os fatores de classificação;

* os cenários Cn.6 e Cn.1 são menos importantes que os cenários Cn.2 e Cn.4, pois possuem menos valores altos (A) para os quatro fatores de classificação. Além disso, são mais importantes que os cenários Cn.5 e Cn.3; e

* como, dos quatro cenários mais importantes (Cn.2, Cn.4, Cn.6 e Cn.1), dois são cenários de complexidade e dois são de extensibilidade, sugere-se que a priorização desses atributos de qualidade seja realizada por meio de uma análise da estatística descritiva e dos possíveis produtos da AGM. 
- pode-se observar que a meta de negócio MN.1 é mantida verdadeira, ao analisar o número de configurações geradas. Seis configurações, $60 \%$ das configurações geradas, possuem complexidade inferior a 0,7 (70\%). O mesmo acontece para a meta de negócio MN.2, cinco configurações, $50 \%$ das configurações geradas, possuem extensibilidade superior a 0,75 (75\%); e

- como as duas metas de negócio são satisfeitas, uma análise dos dez produtos gerados para a AGM deve ser realizada. Assim, observando o gráfico de dispersão da Figura 8.3 é possível identificar um produto que é interessante, a configuração $\mathrm{N}^{\circ} 4$ (Config.4) com valores CompPLA $=0,50$ e ExtensPLA $=$ 0,77. Nesse caso, como somente a Config.4 é um produto interessante para a LP AGM, recomenda-se, com base nas metas de negócio e cenários definidos e nos dez produtos gerados para a AGM, priorizar os dois atributos de qualidade no desenvolvimento e evolução da LP. Além disso, deve-se dar prioridade para a produção de produtos AGM com extensibilidade e complexidade similar à Config.4, com baixa complexidade e alta extensibilidade.

\subsection{Análise e Interpretação dos Resultados do Estudo Experimental}

Para analisar e interpretar os resultados obtidos com os procedimentos de execução deste estudo, tais resultados foram comparados aos resultados previamente obtidos no Capítulo 5. os quais são apresentados a seguir.

\section{Resultados Previamente Obtidos:}

1. as duas metas de negócio MN.1 e MN.2 devem ser satisfeitas com relação aos produtos gerados;

2. identificar quais os cenários mais importantes a partir da classificação desses. Caso os melhores classificados estejam relacionados a somente um atributo de qualidade, esse deve ser priorizado;

3. caso contrário, deve-se analisar a estatística descritiva e o gráfico de dispersão gerados a partir dos valores observados das métricas coletadas. Assim, deve-se identificar o(s) produto(s) mais importante(s) para a LP. Isso é feito listando os produtos gerados que satisfazem todas as metas de negócio, nesse caso, as metas MN.1 e MN.2; e 
4. os produtos mais interessantes da LP devem ser analisados e, como mostrado no Capítulo 5, para os produtos AGM, complexidade deve ser priorizada.

Dessa forma, os itens a seguir apresentam sucintamente os resultados obtidos com a execução deste estudo. Em seguida, uma análise acerca das hipóteses definidas para esse estudo é apresentada.

\section{- Resultados Obtidos pelo Part.1:}

1. as metas MN.1 e MN.2 foram totalmente satisfeitas com relação aos produtos gerados;

2. os cenários classificados pelo participante, em ordem de importância, são: Cn.1, Cn.6, Cn.4, Cn.5, Cn.2 e Cn.3. Os cenários mais importantes referem-se a complexidade e extensibilidade;

3. os produtos mais importantes para a LP AGM são: Config.5 e Config.8; e

4. complexidade é priorizada, pois os valores de ExtensPLA dos produtos mais importantes é 0,80 , enquanto os valores de CompPLA possuem uma variação maior.

\section{- Resultados Obtidos pelo Part.2:}

1. as metas MN.1 e MN.2 foram totalmente satisfeitas com relação aos produtos gerados;

2. os cenários classificados pelo participante, em ordem de importância, são: Cn.1, Cn.3, Cn.4, Cn.6, Cn.5 e Cn.2. Os cenários Cn.1 e Cn.3 referem-se à complexidade e os cenários Cm.4 e Cn.6 à extensibilidade;

3. os produtos mais importantes para a LP AGM são: Config.2, Config.3 e Config.5; e

4. complexidade é priorizada, pois os valores de ExtensPLA dos produtos mais importantes são muito próximos, enquanto os valores de CompPLA se diferem em maior escala.

\section{- Resultados Obtidos pelo Part.3:}

1. as metas MN.1 e MN.2 foram totalmente satisfeitas com relação aos produtos gerados;

2. os cenários classificados pelo participante, em ordem de importância, são: Cn.2, Cn.4, Cn.6, Cn.1, Cn.5 e Cn.3. Os cenários mais importantes referem-se a complexidade e a extensibilidade, portanto os seus produtos devem ser analisados; 
3. o produto mais importante para a LP AGM é a Config.4; e

4. ambos os atributos de qualidade complexidade e extensibilidade devem ser priorizados, já que somente um produto mostra-se interessante à LP, dificultando a priorização de somente um deles.

Comparando os resultados obtidos neste estudo experimental com os resultados previamente obtidos no Capítulo 5, tem-se que:

- somente o quarto resultado obtido pelo Part.3 não está totalmente de acordo com o resultado previamente obtido. O resultado obtido pelo Part.3 indica a priorização dos dois atributos de qualidade definidos, enquanto o resultado previamente obtido espera que somente complexidade seja priorizada. Isso acontece por causa das configurações geradas pelo Part.3. Essas configurações apresentam somente um produto interessante à LP AGM, com valores de CompPLA abaixo de 0,70 (70\%) e valores de ExtensPLA acima de 0,75 (75\%);

- a análise das respostas às questões apresentadas por cada participante após a classificação dos cenários fornece indícios para concluir que os artefatos produzidos durante a aplicação do método SystEM-PLA são importantes e viáveis para a condução de avaliações de ALP, bem como, para permitir uma maior compreensão dos demais artefatos gerados pelo método; e

- é possível concluir que os resultados obtidos por este estudo experimental são similares aos resultados previamente obtidos. Assim, há evidências para se rejeitar a Hipótese Nula $\left(\mathrm{H}_{0}\right)$ e aceitar a Hipótese Alternativa $\left(\mathrm{H}_{1}\right)$.

Com base nos resultados deste estudo experimental, conclui-se que o método SystEM-PLA é viável, gerando artefatos que contribuem para a correta compreensão do método e da realização das suas atividades. Porém, fica clara a necessidade de experimentos adicionais aplicando o método SystEM-PLA à LP comerciais e a participação de pessoal altamente qualificado da indústria.

\subsection{Avaliação de Validade do Estudo Experimental}

\subsubsection{Ameaças à Validade de Conclusão}

A única preocupação considerada capaz de afetar a validade de conclusão deste estudo é o tamanho da amostra, três participantes, a qual deve ser incrementada em replicações 
futuras. Essa ameaça se dá por causa da extrema dificuldade de se obter participantes qualificados para o estudo.

\subsubsection{Ameaças à Validade de Construção}

As variáveis dependentes deste estudo, são os atributos de complexidade e extensibilidade, as metas de negócio MN.1 e MN.2, os cenários Cn.1, Cn.2, Cn.3, Cn.4, Cn.5 e Cn.6. Configurações AGM e métricas de complexidade e extensibilidade foram geradas e coletadas com base na experiência dos participantes. Como os participantes possuem experiência suficiente em modelagem de sistemas orientados a objeto, usando pelo menos diagramas de classes, e em LP, a geração das configurações e as análises de trade-off são consideradas significantes.

A validade de construção das configurações geradas e das métricas usadas para as variáveis independentes é garantida pela validação das métricas, conforme descrito no Capítulo 7.

\subsubsection{Ameaças à Validade Interna}

Neste estudo, as seguintes dificuldades foram encontradas:

- Diferenças entre os participantes. Como foi considerada uma pequena amostra, variações com relação às habilidades dos participantes foram reduzidas, aplicando o formato de tarefas "whithin-subject". Nesse formato, todos os participantes realizam todas as tarefas definidas na mesma ordem. A experiência dos participantes teve aproximadamente o mesmo nível com relação à modelagem UML e conceitos de LP e variabilidades;

- Acurácia das respostas dos participantes. Uma vez entendido o método SystEM-PLA, somado à experiência dos participantes com modelagem UML, conceitos de LP e variabilidades, e arquitetura de software, considera-se que suas respostas são válidas;

- Efeitos de fadiga. Em média, o experimento durou 117 minutos para cada participante. Assim, a fadiga não foi considerada relevante. Além disso, o texto sobre o método SystEM-PLA, com exemplos, contribui para reduzir tal efeito; e

- Outros fatores importantes. Influência entre os participantes não pôde ser efetivamente controlada. Os participantes realizaram o experimento com a supervisão 
de um observador humano, em dias diferentes. Dessa forma, acredita-se que esses problemas não afetaram a validade do estudo.

\subsubsection{Ameaças à Validade Externa}

Duas ameaças de validade externa foram identificadas:

- Instrumentação. Tentou-se usar documentos padronizados relacionados ao método SystEM-PLA e à LP AGM. Porém, a LP usada no experimento não é comercial e, algumas suposições podem ser feitas sobre essa ameaça. Assim, estudos experimentais adicionais devem ser conduzidos utilizando LP reais, desenvolvidas por organizações de software; e

- Participantes. Obter participantes qualificados foi uma das grandes dificuldades do estudo. Assim, profissionais em nível avançado da indústria de Engenharia de Software foram utilizados. Mais experimentos, aumentando o número de participantes provenientes da indústria devem ser conduzidos, permitindo generalizar os resultados do estudo.

\subsection{Apresentação e Empacotamento do Estudo Experi- mental}

Todos os documentos relacionados ao estudo estão disponíveis no endereço eletrônico http://edsonjr.pro.br/expSystEM-PLA, uma vez que é importante a difusão dos dados experimentais para replicações externas do estudo atual (Brooks et al., 1996) e o compartilhamento do conhecimento (Shull et al., 2004).

\subsection{Considerações Finais}

A literatura existente mostra a necessidade de se estabelecer métodos experimentais para provar as teorias de Engenharia de Software, apoiar a transferência de tecnologia da academia para a indústria e estabelecer uma bancada experimental de apoio à avaliação de ALP.

Nesse sentido, a realização deste estudo experimental forneceu parâmetros e indícios da viabilidade do método SystEM-PLA com base na LP AGM. O estudo foi realizado em ambiente industrial, corroborando com a necessidade de maior participação e validação 
por parte da indústria em projetos acadêmicos, além de permitir a colaboração entre esses setores, podendo resultar em uma efetiva transferência de tecnologia.

Experimentos adicionais são necessários, principalmente por dois motivos: dificuldade de captação de profissionais qualificados para a participação e a necessidade de realização de experimentos apoiados por uma LP comercial, com um número representativo de produtos gerados e em produção. Outro fator que pode contribuir para o sucesso de replicações deste estudo é a concepção de um ambiente automatizado para avaliações ALP e realização de experimentos. 


\begin{tabular}{l|l}
\hline & Capítulo \\
\hline & 9 \\
\hline
\end{tabular}

\section{Conclusões}

"O que eu faço é uma gota no meio

de um oceano. Mas sem ela o oceano será menor."

Md. Teresa de Calcutá (1910 - 1997), Religiosa Humanitária, Prêmio Nobel

(1979)

\subsection{Propósito da Pesquisa}

Esta tese propõe um método sistemático para avaliação de ALP baseada em UML, o SystEM-PLA. Esse método tem seus princípios fundamentados em conceitos de arquiteturas para produtos únicos de sistemas e do método ATAM como, por exemplo, a definição de metas de negócio e de cenários e a classificação dos cenários por parte dos stakeholders e da equipe de avaliação. Outros dois métodos contribuíram para a proposta do SystEM-PLA: o método HoPLSAA, que define cenários de variabilidades para uma ALP; e o método EATAM, para a compreensão da correlação entre os atributos de qualidade de uma ALP e as suas variabilidades.

O SystEM-PLA é composto por um metaprocesso de avaliação que possui atividades para a definição dos artefatos necessários para avaliar uma ALP como, por exemplo, metas de negócio, cenários e métricas. Esse processo é instanciado e suas atividades 
são executadas de acordo com as diretrizes fornecidas pelo SystEM-PLA. Apesar do SystEM-PLA possuir um conjunto de diretrizes, é possível utilizar técnicas específicas de acordo com as atividades realizadas. Isso torna o método flexível o suficiente para acomodar eventuais adaptações das técnicas utilizadas.

Métricas básicas para modelos UML e específicas para atributos de qualidade são fornecidas pelo método SystEM-PLA. Essas métricas permitem que configurações de uma ALP possam ser analisadas para medir a qualidade da ALP por meio de seus produtos. Para tanto, métricas de complexidade e extensibilidade foram propostas para o método. Tais métricas foram validadas por meio de um estudo experimental que contou com a participação de seis profissionais da área de Engenharia de Software, gerando um total de trinta configurações diferentes para a ALP da AGM.

ALP avaliadas pelo método SystEM-PLA possuem suas variabilidades explícitas com a aplicação da abordagem SMarty, proposta neste trabalho. A abordagem é composta por um perfil UML, o SMartyProfile, que permite a identificação, representação explícita e o gerenciamento de variabilidades em LP, e um processo, o SMartyProcess, composto por diretrizes para o gerenciamento de variabilidades.

Um estudo experimental de viabilidade foi realizado com o objetivo de analisar o método SystEM-PLA com relação à sua aplicação e os artefatos gerados durante a avaliação de uma ALP. O estudo contou com a participação de três profissionais de uma organização de grande porte do ramo de desenvolvimento de software.

\subsection{Resultados e Contribuições}

Os itens a seguir listam os demais resultados e contribuições deste trabalho.

\section{Resultados e Contribuições com relação à Abordagem SMarty:}

- a proposta de uma abordagem sistemática e completa, SMarty, para o gerenciamento de variabilidades em LP, composta pelo perfil UML SMartyProfile e o processo SmartyProcess. SMartyProfile é uma extensão do metamodelo padrão da UML que permite a representação de variabilidades por meio de estereótipos, meta-atributos e as inter-relações entre esses elementos. SMartyProcess é um processo que contém diretrizes de como identificar e representar variabilidade em modelos UML com o apoio do SMartyProfile;

- a representação não ambígua dos conceitos de variabilidade em modelos UML; 
- a interação entre o gerenciamento de variabilidades e as atividades essenciais de desenvolvimento de LP;

- a capacidade de utilizar ferramentas UML para exportar modelos de LP de acordo com SMArty por meio de arquivos XMI (XML Metadata Interchange);

- a definição de um conjunto de métricas básicas para modelos UML utilizadas para a composição de métricas para atributos de qualidade de ALP; e

- a comparação de SMarty com duas abordagens de gerenciamento de variabilidades com relação à efetividade de representação dos conceitos de variabilidade.

\section{Resultados e Contribuições com relação às Métricas de Complexidade e Extensibi- lidade:}

- a proposta de métricas para os atributos de qualidade complexidade e extensibilidade. Tais métricas permitem a realização de análise de trade-off entre atributos de qualidade de ALP, cujos modelos UML seguem a abordagem SMarty;

- a validação das métricas de complexidade e extensibilidade por meio de um estudo experimental. Nesse estudo seis participantes geraram cinco configurações cada, sendo as métricas aplicadas às configurações da LP AGM e os valores coletados analisados. Testes de normalidade, correlação de Spearman e análise de regressão linear foram utilizadas para interpretar os dados do estudo;

- a proposta de escalas para a medição de complexidade e extensibilidade de produtos de uma ALP a partir dos valores das métricas CompPLA e ExtensPLA; e

- a proposta de uma correlação entre complexidade e extensibilidade para ALP, com base no experimento realizado para a validação das métricas de atributos de qualidade.

\section{Resultados e Contribuições com relação ao Método SystEM-PLA:}

- a análise e constatação inicial da viabilidade do método SystEM-PLA por meio de um estudo experimental envolvendo participantes de uma organização de grande porte. Os participantes realizaram algumas das atividades do MPA e avaliaram a efetividade dos artefatos utilizados para a realização de cada tarefa;

- a proposta de um metaprocesso para a definição de artefatos necessários para uma avaliação de ALP de forma sistemática, de acordo com diretrizes específicas; 
- a utilização de elementos do método ATAM, já consolidado na literatura, para a realização de avaliações de ALP. Destaque para um dos principais elementos: as metas de negócio;

- a tomada de decisão por parte do engenheiro e/ou do arquiteto de LP com base nos resultados da aplicação do método SystEM-PLA; e

- a proposta de métricas para atributos de qualidade, utilizadas para a realização de análises de trade-off e priorização de atributos de qualidade de uma ALP.

\section{Resultados e Contribuições com relação à Replicação de Experimentos com o Mé- todo SystEM-PLA:}

- a definição de um conjunto contendo sessenta configurações da LP AGM. Tais configurações podem ser usadas como parâmetro para a realização de outros experimentos, bem como, somadas a futuras configurações, até mesmo de outras LP, com o objetivo de ajustar as escalas de medição de complexidade e extensibilidade propostas durante o estudo experimental de validação das métricas de atributos de qualidade.

\section{Resultados e Contribuições com relação ao Estado da Arte sobre Avaliação de LP:}

- a realização de duas revisões sistemáticas com o objetivo de apresentar o estado da arte com relação à avaliação de LP na forma de um panorama, classificando os estudos recuperados da seguinte maneira: (i) avaliação de atributos de qualidade de ALP; (ii) avaliação estrutural de ALP; e (iii) definição e avaliação de escopo de LP.

\subsection{Dificuldades e Limitações}

Este trabalho possui algumas limitações como, por exemplo, a necessidade de um ambiente automatizado para o uso do método SystEM-PLA, a dificuldade de captação de profissionais qualificados e a baixa disponibilidade de LP comerciais, dificultando a análise de viabilidade do método proposto.

Os itens a seguir listam as dificuldades e limitações deste trabalho em mais detalhes:

- a abordagem SMarty está limitada, atualmente, à representação de variabilidades em modelos UML de casos de uso, classes e componentes. Porém, sabe-se da necessidade de representação em outros modelos UML como diagramas de sequência e colaboração e diagramas de atividades; 
- o método SystEM-PLA concentra-se na avaliação de ALP baseada em UML, não considerando outras abordagens de desenvolvimento de software como orientação a aspectos e Model-Driven Development (MDD);

- o método SystEM-PLA fornece métricas para os atributos de qualidade complexidade e extensibilidade, o que acaba limitando, de certa forma, as análises de trade-off realizadas para ilustrar as diretrizes do método, bem como, o estudo experimental realizado para avaliar a sua viabilidade. Assim, à medida que avaliações vão sendo realizadas, novas métricas devem ser compartilhadas por meio de uma ferramenta automatizada;

- a dificuldade de captar profissionais qualificados para participar dos experimentos realizados neste trabalho é um fator que, de certa forma, impede a generalização dos resultados obtidos com tais experimentos;

- a falta de um ambiente automatizado para avaliações de ALP é uma limitação quanto ao uso do SystEM-PLA e à possibilidade de realizar experimentos adicionais em direção à garantia de viabilidade do método. Acredita-se que com um ambiente automatizado, mais experimentos poderão ser realizados em menos tempo, contribuindo com a efetiva aplicação e viabilidade do método proposto; e

- a baixa disponibilidade de LP comerciais para serem usadas em experimentos limitou, de certa forma, a garantia de viabilidade do método com relação à abrangência deste considerando outras LP além da AGM, que não é comercial.

\subsection{Trabalhos Futuros}

Os itens a seguir apresentam as sugestões de trabalhos futuros como continuidade deste trabalho:

- a realização de um estudo experimental para avaliar a efetividade da abordagem SMarty levando em consideração as abordagens de gerenciamento de variabilidades apresentadas na revisão sistemática intitulada "Variability Management in Software Product Lines: a Systematic Review", realizada por Chen et al. (2009). Neste trabalho, a efetividade de SMarty foi comparada a duas consolidadas abordagens (Seção 4.2.1). Porém, sabe-se da necessidade de comparar SMarty com as principais abordagens existentes; 
- ampliar o conjunto de métricas para atributos de qualidade, validá-las e utilizá-las em estudos experimentais;

- ajustar as escalas de medição de complexidade e extensibilidade, além de propor novas escalas para outros atributos de qualidade como resultado de estudos experimentais de validação de métricas para tais atributos;

- investigar a possibilidade de aplicar o método SystEM-PLA em LP comerciais com o objetivo de generalizar os resultados obtidos sobre a viabilidade do método;

- analisar a capacidade do método SystEM-PLA de ser incorporado como uma etapa das abordagens de desenvolvimento de LP existentes como, por exemplo, PLUS Gomaa, 2005) e a abordagem de Halmans e Pohl (2003), com mínimas mudanças na estrutura de desenvolvimento da abordagem de LP adotada;

- associar um modelo de custos ao método SystEM-PLA para que o retorno de investimento possa ser analisado com base nos resultados da avaliação de uma ALP;

- estender o método SystEM-PLA para LP dinâmicas, sistemas self-adaptive, arquiteturas orientadas a aspectos e Model-Driven Architectures (MDA);

- projetar e propor a abordagem SysTEM-PL, a Systematic Testing and Evaluation Method for Software Product Lines, para a avaliação e teste de LP. Assim, SystEM$P L A$ será um método de apoio à abordagem SysTEM-PL; e

- projetar e implementar o SysTEM-Env, um ambiente automatizado de apoio à abordagem Sys TEM-PL, que permitirá o gerenciamento de variabilidades, a geração de configurações de LP, a definição dos artefatos necessários para testar e avaliar LP, a aplicação e a coleta de métricas, o planejamento e a condução de estudos experimentais e a documentação de testes e avaliações; 


\section{Referências Bibliográficas}

Ahmed, F.; Capretz, L. A Business Maturity Model of Software Product Line Engineering. Information Systems Frontiers, v. 1, n. 1, p. 1-18, 2010a.

Ahmed, F.; Capretz, L. F. An Organizational Maturity Model of Software Product Line Engineering. Software Quality Control, v. 18, n. 2, p. 195-225, 2010b.

Ahmed, F.; Capretz, L. F.; Samarabandu, J. Fuzzy Inference System for Software Product Family Process Evaluation. Information and Science, v. 178, n. 13, p. 2780-2793, 2008.

Arango, G.; Baxter, I.; Freeman, P. A Framework for Incremental Progress in the Application of AI to Software Engineering. SIGSOFT Software Engineering Notes, v. 13, n. 1, p. 46-50, 1988.

Barbacci, M. R. SEI Architecture Analysis Techniques and When to Use Them. Relatório Técnico CMU/SEI-2002-TN-005, Software Engineering Institute (SEI), Pittsburgh, USA, 2002.

Disponível em http://www.sei.cmu.edu/pub/documents/02.reports/pdf/ 02tn005.pdf (Acessado em 22/03/2010)

Barbacci, M. R.; Clements, P.; Lattanze, A.; Northrop, L.; Wood, W. Using the Architecture Tradeoff Analysis Method (ATAM) to Evaluate the Software Architecture for a Product Line of Avionic Systems: a Case Study. Relatório Técnico CMU/SEI-2003-TN-012, Software Engineering Institute (SEI), Pittsburgh, USA, 2003. Disponível em http://www.sei.cmu.edu/pub/documents/01.reports/pdf/ 01tn022.pdf (Acessado em 03/03/2010) 
Basili, V.; Rombach, H. The TAME Project: Towards Improvement-Oriented Software Environments. IEEE Transactions on Software Engineering, v. 14, n. 6, p. $758-773,1988$.

Basili, V. R.; Shull, F.; Lanubille, F. Building Knowledge Through Families of Experiments. IEEE Transactions on Software Engineering, v. 25, n. 4, p. 456-473, 1999.

Bass, L.; Clements, P.; Kazman, R. Software Architecture in Practice. Boston, MA, USA: Addison-Wesley, 2005.

Batory, D.; Johnson, C.; MacDonald, B.; Heeder, D. Achieving Extensibility Through Product-Lines and Domain-Specific Languages: a Case Study. ACM Transactions on Software Engineering Methodologies, v. 11, n. 2, p. 191-214, 2002.

Böckle, G.; Clements, P.; McGregor, J. D.; Muthig, D.; Schmid, K. Calculating ROI for Software Product Lines. IEEE Software, v. 21, n. 3, p. 23-31, 2004.

Becker, M. Towards a General Model of Variability in Product Families. In: Proceedings of the Software Variability Management Workshop, Groningen, The Netherlands: University of Groningen, 2003, p. 19-27.

Bell, P. A Practical High Volume Software Product Line. In: Companion to the ACM SIGPLAN Conference on Object-Oriented Programming, Systems, and Applications, New York, NY, USA: ACM, 2007, p. 994-1003.

Bernardo, C.; Fernandes, D.; Dias, L.; Montini, D.; Silva, D.; Cunha, A. Using GQM for Testing Design Patterns in Real-Time and Embedded Systems on a Software Production Line. In: Proceedings of the International Conference on Information Technology: New Generations, Washington, DC, USA: IEEE Computer Society, 2009, p. 1397-1404.

Booch, G.; Rumbaugh, J.; Jacobson, I. The Unified Modeling Language User Guide. Redwood City, CA, USA: Addison Wesley Longman Publishing Co., Inc., 1999.

Bosch, J. Design and Use of Software Architectures: Adopting and Evolving a Product-Line Approach. New York, NY, USA: Addison-Wesley, 2000. 
Bosch, J.; Bosch-Sijtsema, P. From Integration to Composition: On the Impact of Software Product Lines, Global Development, and Ecosystems. Journal of Systems and Software, v. 83, n. 1, p. 67-76, 2010.

BraganÇA, A.; Machado, R. J. Extending UML 2.0 Metamodel for Complementary Usages of the «extend》 Relationship within Use Case Variability Specification. In: Proceedings of the Software Product Line Conference, Washington, DC, USA: IEEE Computer Society, 2006, p. 123-130.

Briand, L.; Emam, K. E.; Morasca, S.; El, K.; Morasca, E. S. Theoretical and Empirical Validation of Software Product Measures. ISERN-95-03, International Software Engineering Research Network, 1995.

Briand, L. C.; Bunse, C.; Daly, J. W. A Controlled Experiment for Evaluating Quality Guidelines on the Maintainability of Object-Oriented Designs. IEEE Transactions on Software Engineering, v. 27, n. 6, p. 513-530, 2001.

Brito, P.; Lemos, R.; Martins, E.; Moraes, R.; Rubira, C. Architectural-Based Validation of Fault-Tolerant Software. In: Fourth Latin-American Symposium on Dependable Computing, Washington, DC, USA: IEEE Computer Society, 2009, p. 103-110.

Brooks, A.; Daly, J.; Miller, J.; Roper, M.; Wood, M. Replication of Experimental Results in Software Engineering. Relatório Técnico ISERN-96-10, International Software Engineering Research Network, Germany, 1996.

Buschmann, F.; Meunier, R.; Rohnert, H.; Sommerlad, P.; Stal, M. Pattern-Oriented Software Architecture: a System of Patterns. Chichester, England: John Wiley \& Sons Ltd, 1996.

CAptor Captor-AO Application Generator. online, 2010.

Disponível em http://code.google.com/p/captor (Acessado em 04/03/2010)

Chastek, G.; Ferguson, R. Toward Measures for Software Architectures. SEI Technical Note CMU/SEI-2006-TN-013, Software Engineering Institute (SEI), Pittsburgh, USA, 2006.

Disponível em http://www.sei.cmu.edu/pub/documents/06.reports/pdf/ 06tn013.pdf (Acessado em 03/03/2010)

Chen, L.; Babar, M. A.; Ali, N. Variability Management in Software Product Lines: a Systematic Review. In: Proceedings of the Software Product Line Conference, Pittsburgh, PA, USA: Carnegie Mellon University, 2009, p. 81-90. 
Chidamber, S. R.; Kemerer, C. F. A Metrics Suite for Object Oriented Design. IEEE Transactions on Software Engineering, v. 20, n. 6, p. 476-493, 1994.

Clauss, M. Generic Modeling Using UML Extensions for Variability. In: Proceedings of Workshop on Domain Specific Visual Languages, Jyvaskylae, Finland: Jyvaskylae University Printing House, 2001, p. 11-18.

Clements, P.; Garlan, D.; Bass, L.; Stafford, J.; Nord, R.; Ivers, J.; Little, R. Documenting Software Architectures: Views and Beyond. Boston, MA, USA: Addison-Wesley Professional, 2002a.

Clements, P.; Kazman, R.; Klein, M. Evaluating Software Architectures: Methods and Case Studies. Boston, MA, USA: Addison-Wesley Longman Publishing Co., Inc., $2002 \mathrm{~b}$.

Clements, P.; Northrop, L. Software Product Lines: Practices and Patterns. Boston, MA, USA: Addison-Wesley Longman Publishing Co., Inc., 2001.

Corder, G. W.; Foreman, D. I. Nonparametric Statistics for Non-Statisticians: A Step-by-Step Approach. Boston, MA, USA: Wiley, 2009.

Decker, S. G.; Dager, J. Software Product Lines Beyond Software Development. In: Proceedings of the Software Product Line Conference, Washington, DC, USA: IEEE Computer Society, 2007, p. 275-280.

Deelstra, S.; Sinnema, M.; Bosch, J. Variability Assessment in Software Product Families. Information and Software Technology, v. 51, n. 1, p. 195-218, 2009.

Dincel, E.; Medvidovic, N.; Hoek, A. V. D. Measuring Product Line Architectures. In: Proceedings of the International Workshop on Product Family Engineering, London, UK: Springer-Verlag, 2001, p. 346-352.

DobricA, L.; Niemelä, E. A Survey on Software Architecture Analysis Methods. IEEE Transactions on Software Engineering, v. 28, n. 7, p. 638-653, 2002.

Dolan, T.; Weterings, R.; Wortmann, J. C. Stakeholder-Centric Assessment of Product Family Architecture. In: Proceedings of the International Workshop on Software Architectures for Product Families, London, UK: Springer-Verlag, 2000, p. 225-245.

Eskenazi, E. M.; Fioukov, A. V.; Hammer, D. K.; Obbink, H.; Pronk, B. Analysis and Prediction of Performance for Evolving Architectures. In: Proceedings of 
the EUROMICRO Conference, Washington, DC, USA: IEEE Computer Society, 2004, p. $22-31$.

Etxeberria, L.; Sagardui, G. Product-Line Architecture: New Issues for Evaluation. In: Proceedings of the Software Product Line Conference, Berlin, Germany: Springer-Verlag, 2005, p. 174-185.

Etxeberria, L.; Sagardui, G. Evaluation of Quality Attribute Variability in Software Product Families. In: Proceedings of the Annual IEEE International Conference and Workshop on the Engineering of Computer Based Systems, Washington, DC, USA: IEEE Computer Society, 2008a, p. 255-264.

Etxeberria, L.; Sagardui, G. Variability Driven Quality Evaluation in Software Product Lines. In: Proceedings of the Software Product Line Conference, Washington, DC, USA: IEEE Computer Society, 2008b, p. 243-252.

Fenton, N. E.; Pfleeger, S. Software Metrics: a Rigorous and Practical Approach. Boston, MA, USA: International Thomson Computer Press, 1996.

Ferber, S.; Heidl, P.; Lutz, P. Reviewing Product Line Architectures: Experience Report of ATAM in an Automotive Context. In: Proceedings of the International Workshop on Software Product-Family Engineering, London, UK: Springer-Verlag, 2002, p. 364-382.

Figueiredo, F.; Figueiredo, A.; Ramos, A.; Teles, P. Estatística Descritiva e Probabilidades. São Paulo-SP: Escolar, 2007.

Freeman, E.; Freeman, E.; Bates, B.; Sierra, K. Head First Design Patterns. Sebastopol, CA, USA: O’ Reilly \& Associates, Inc., 2004.

Fritsch, C.; Lehn, A.; Strohm, T.; Gmbh, R. B. Evaluating Variability Implementation Mechanisms. In: Proceedings of International Workshop on Product Line Engineering, Seattle, USA: Springer, 2002, p. 59-64.

Gacek, C.; Anastasopoules, M. Implementing Product Line Variabilities. SIGSOFT Software Engineering Notes, v. 26, n. 3, p. 109-117, 2001.

Gamma, E.; Helm, R.; Johnson, R. E.; Vlissides, J. Design Patterns. Elements of Reusable Object-Oriented Software. Boston, MA, USA: Addison-Wesley, 1995. 
Gannod, G. C.; Lutz, R. R. An Approach to Architectural Analysis of Product Lines. In: Proceedings of the International Conference on Software Engineering, New York, NY, USA: ACM, 2000, p. 548-557.

Genero, M.; Piattini, M.; Calero, C. Empirical Validation of Class Diagram Metrics. In: Proceedings of the International Symposium on Empirical Software Engineering, Washington, DC, USA: IEEE Computer Society, 2002, p. 195.

Gentleware Model to Business: Poseidon for UML. online, 2010.

Disponível em http://www.gentleware.com/products.html (Acessado em $02 / 03 / 2010)$

Geppert, B.; Weiss, D. M. Goal-Oriented Assessment of Product-Line Domains. In: Proceedings of the International Symposium on Software Metrics, Washington, DC, USA: IEEE Computer Society, 2003, p. 180.

Gimenes, I. M. S.; Lazilha, F. R.; Oliveira Junior, E. A.; Barroca, L. A Component-based Product Line for Workflow Management Systems. CLEI Electronic Journal - Special Issue of Best Papers Presented at CLEI 2003, v. 7, n. 2, p. 1-20, 2004.

Gimenes, I. M. S.; Oliveira Junior, E. A.; Lazilha, F. R.; Barroca, L. A Product Line Architecture for Workflow Management Systems According to the Component-based Development Approach. In: Proceedings of the IEEE International Conference on Information Reuse and Integration, Las Vegas, USA: ACM, 2003, p. 112-119.

GomaA, H. Designing Software Product Lines with UML: from Use Cases to Pattern-based Software Architectures. Boston, MA, USA: Addison-Wesley, 2005.

Gurp, J. V.; Bosch, J.; Svahnberg, M. On the Notion of Variability in Software Product Lines. In: Proceedings of the Working IEEE/IFIP Conference on Software Architecture, Washington, DC, USA: IEEE Computer Society, 2001, p. 45.

Halmans, G.; Pohl, K. Communicating the Variability of a Software-Product Family to Customers. Software and System Modeling, v. 2, n. 1, p. 15-36, 2003.

Harsu, M. A Survey of Product-Line Architectures. Relatório Técnico 23, Institute of Software Systems, Tampere University of Technology, Finland, 2001.

Disponível em http://practise2.cs.tut.fi/pub/papers/arkki.pdf (Acessado em $01 / 07 / 2010)$ 
Heymans, P.; Trigaux, J. C. Software Product Line: State of the Art. Relatório Técnico EPH3310300R0462/215315, Product Line ENgineering of food TraceabilitY software (PLENTY) Project, Institut d'Informatique, FUNDP, Namur, 2003. Disponível em http://www.fundp.ac.be/en/research (Acessado em 01/07/2010)

Hoek, A. V. D.; Dincel, E.; Medvidovic, N. Using Service Utilization Metrics to Assess the Structure of Product Line Architectures. In: Proceedings of the International Symposium on Software Metrics, Washington, DC, USA: IEEE Computer Society, 2003, p. 298-308.

Jacobson, I.; Griss, M. L.; Jonsson, P. Software Reuse: Architecture, Process, and Organization for Business Success. Boston, MA, USA: Addison-Wesley Professional, 1997.

Jazayeri, M.; Ran, A.; Linden, F. V. D. Software Architecture for Product Families. Boston, MA, USA: Addison-Wesley, 2000.

Jensen, P. Experiences with Software Product Line Development. Crosstalk, v. 22, n. 1, p. 11-14, 2003.

Kahsai, T.; Roggenbach, M.; Schlingloff, B. Specification-Based Testing for Software Product Lines. In: Proceedings of the IEEE International Conference on Software Engineering and Formal Methods, Washington, DC, USA: IEEE Computer Society, 2008, p. 149-158.

Kang, K. C.; Cohen, S. G.; Hess, J. A.; Novak, W. E.; Peterson, A. S. Feature-Oriented Domain Analysis (FODA) Feasibility Study. Relatório Técnico CMU/SEI-90-TR-21, Carnegie-Mellon University - Software Engineering Institute (SEI), Pittsburgh, USA, 1990.

Disponível em http://web.njit.edu/〜aab25/cs673/download/Documents/FODA. pdf (Acessado em 01/07/2010)

Kang, K. C.; Kim, S.; Lee, J.; Kim, K.; Kim, G. J.; Shin, E. FORM: a Feature-Oriented Reuse Method with Domain-Specific Reference Architectures. Annals of Software Engineering, v. 5, n. 1, p. 143-168, 1998.

Kazman, R.; BAss, L. Categorizing Business Goals for Software Architectures. Relatório Técnico CMU/SEI-2005-TR-021, Software Engineering Institute (SEI), Pittsburgh, USA, 2005.

Disponível em http://www.sei.cmu.edu/pub/documents/05.reports/pdf/ 05tr021.pdf (Acessado em 01/07/2010) 
Kerzner, H. Project Management: A Systems Approach to Planning, Scheduling, and Controlling. 10 ed. Boston, MA, USA: Wiley, 2009.

KIM, K. A Case Study on Architectural Maturity Evaluation: Experience in the Consumer Electronics Domain. In: Proceedings of the OTM Confederated International Workshops and Posters on On the Move to Meaningful Internet Systems, Berlin, Heidelberg: Springer-Verlag, 2008, p. 364-373.

Kim, K.; KIm, H.; Kım, S.; Chang, G. A Case Study on SW Product Line Architecture Evaluation: Experience in the Consumer Electronics Domain. In: Proceedings of the International Conference on Software Engineering Advances, Washington, DC, USA: IEEE Computer Society, 2008a, p. 192-197.

Kim, T.; Ko, I. Y.; Kang, S. W.; Lee, D. H. Extending ATAM to Assess Product Line Architecture. In: Proceedings of the IEEE International Conference on Computer and Information Technology, USA: ACM Press, 2008b, p. 790-797.

Kitchenham, B.; Pfleeger, S. L.; Fenton, N. Towards a Framework for Software Measurement Validation. IEEE Transactions on Software Engineering, v. 21, n. 12, p. 929-944, 1995.

Kolb, R.; John, I.; Knodel, J.; Muthig, D.; Haury, U.; Meier, G. Experiences with Product Line Development of Embedded Systems at Testo AG. In: Proceedings of the Software Product Line Conference, Washington, DC, USA: IEEE Computer Society, 2006, p. 172-181.

Korherr, B.; List, B. A UML 2 Profile for Variability Models and their Dependency to Business Processes. In: Proceedings of the International Conference on Database and Expert Systems Applications, Washington, DC, USA: IEEE Computer Society, 2007, p. 829-834.

Lamine, S. B. A. B.; Jilani, L. L.; Ghézala, H. H. B. Cost Estimation for Product Line Engineering Using COTS Components. In: Proceedings of the Software Product Line Conference, Berlin, Heidelberg: Springer-Verlag, 2005, p. 113-123.

Linden, F. J. V. D.; Bosch, J.; Kamsties, E.; Känsälä, K.; Krzanik, L.; ObBink, J. H. Software Product Family Evaluation. In: Proceedings of the International Workshop on Software Product-Family Engineering, Berlin, Heidelberg: Springer-Verlag, 2004, p. 352-369. 
Linden, F. J. V. D.; Schmid, K.; Rommes, E. Software Product Lines in Action: The Best Industrial Practice in Product Line Engineering. Secaucus, NJ, USA: Springer-Verlag New York, Inc., 2007.

Lutz, R. R.; Gannod, G. C. Analysis of a Software Product Line Architecture: an Experience Report. Journal of Systems and Software, v. 66, n. 3, p. 253-267, 2003.

MACCARI, A. Experiences in Assessing Product Family Software Architecture for Evolution. In: Proceedings of the International Conference on Software Engineering, New York, NY, USA: ACM Press, 2002, p. 585-592.

Mafra, S. N.; Travassos, G. H. Estudos Primários e Secundários Apoiando a Busca por Evidência em Engenharia de Software. Relatório Técnico RT-ES 687/06, PESC COPPE/UFRJ, Brasil, 2005.

Matinlassi, M. Comparison of Software Product Line Architecture Design Methods: COPA, FAST, FORM, KobrA, and QADA. In: Proceedings of the International Conference on Software Engineering, Washington, DC, USA: IEEE Computer Society, 2004a, p. 127-136.

Matinlassi, M. Evaluating the Portability and Maintainability of Software Product Family Architecture: Terminal Software Case Study. In: Proceedings of the Working IEEE/IFIP Conference on Software Architecture, Washington, DC, USA: IEEE Computer Society, 2004b, p. 295.

MCCABE, T. J. A Complexity Measure. IEEE Transactions on Software Engineering, v. 2, n. 4, p. 308-320, 1976.

McGregor, J. D. Arcade Game Maker Product Line - Architecture Evaluation Report. 2005.

Disponível em http://wWw.cs.clemson.edu/〜johnmc/productLines/example/ ATAMFinalReport.pdf (Acessado em 13/09/2007)

McGregor, J. D.; Muthig, D.; Yoshimura, K.; Jensen, P. Successful Software Product Line Practices. IEEE Software, v. 27, n. 3, p. 16-21, 2010.

Mendonça, M.; Branco, M.; Cowan, D. S.P.L.O.T.: Software Product Lines Online Tools. In: Proceedings of the ACM SIGPLAN Conference on Object Oriented Programming, Systems, Languages, and Applications, New York, NY, USA: ACM, 2009, p. $761-762$. 
Montagud, S.; Abrahão, S. Gathering Current Knowledge About Quality Evaluation in Software Product Lines. In: Proceedings of the Software Product Line Conference, Pittsburgh, PA, USA: Carnegie Mellon University, 2009, p. 91-100.

Morisio, M.; Travassos, G. H.; Stark, M. E. Extending UML to Support Domain Analysis. In: Proceedings of the IEEE International Conference on Automated Software Engineering, Washington, DC, USA: IEEE Computer Society, 2000, p. 321-324.

Muccini, H.; Hoek, A. V. D. Towards Testing Product Line Architectures. Electronic Notes in Theoretical Computer Science, v. 82, n. 6, 2003.

Niemelä, E.; Ihme, T. Product Line Software Engineering of Embedded Systems. In: Proceedings of the Symposium on Software Reusability, New York, NY, USA: ACM Press, 2001, p. 118-125.

Niemelä, E.; Matinlassi, M.; Taulavuori, A. Practical Evaluation of Software Product Family Architectures. In: Proceedings of the Software Product Line Conference, Berlin, Heidelberg: Springer-Verlag, 2004, p. 130-145.

No-Magic MagicDraw - Architecture Made Simple. online, 2010.

Disponível em http://www.magicdraw.com (Acessado em 02/03/2010)

Nobrega, J.; Almeida, E.; Meira, S. InCoME: Integrated Cost Model for Product Line Engineering. In: Proceedings of the EUROMICRO Conference on Software Engineering and Advanced Applications, Washington, DC, USA: IEEE Computer Society, 2008, p. 27-34.

Northrop, L. M. SEI's Software Product Line Tenets. IEEE Software, v. 19, n. 4, p. $32-40,2002$.

Nystrom, N.; Chong, S.; Myers, A. C. Scalable Extensibility via Nested Inheritance. In: Proceedings of the Annual ACM SIGPLAN Conference on Object-Oriented Programming, Systems, Languages, and Applications, New York, NY, USA: ACM, 2004, p. $99-115$.

Oliveira Junior, E. A. Um Processo de Gerenciamento de Variabilidade para Linha de Produto de Software. Dissertação de Mestrado, Programa de Pós-Graduação em Ciência da Computação, Universidade Estadual de Maringá, Maringá, PR, Brasil, 2005.

Oliveira Junior, E. A.; Gimenes, I. M. S.; Huzita, E. H. M.; Maldonado, J. C. A Variability Management Process for Software Product Lines. In: Proceedings of the 
Conference of the Centre for Advanced Studies on Collaborative Research, Toronto, ON, Canada: IBM Press, 2005a, p. 225-241.

Oliveira Junior, E. A.; Gimenes, I. M. S.; Huzita, E. H. M.; Maldonado, J. C.; Alencar, P. Adding Variability Management to UML-based Software Product Lines. Relatório Técnico CS-2005-33, Electrical and Computer Engineering Department (ECE), University of Waterloo (UWaterloo), Waterloo, Ontario, Canada, $2005 b$.

Disponível em http://www.cs.uwaterloo.ca/research/tr/2005/cs-2005-33.pdf (Acessado em 08/07/2010)

Oliveira Junior, E. A.; Gimenes, I. M. S.; Maldonado, J. C. A Metric Suite to Support Software Product Line Architecture Evaluation. In: Proceedings of the Conferencia Latinoamericana de Informática, Santa Fé, Argentina, 2008, p. 489-498.

Oliveira Junior, E. A.; Maldonado, J. C.; Gimenes, I. M. S. Uma Revisão Sistemática sobre Avaliação de Linha de Produto de Software. Relatório Técnico No. 310, Instituto de Ciências Matemáticas e de Computação (ICMC) - Universidade de São Paulo (USP), São Carlos, SP, Brasil, 2007.

Disponível em http://www.icmc.usp.br/ ^biblio/BIBLIOTECA/rel_tec/RT_310. pdf (Acessado em 01/07/2010)

Oliveira Junior, E. A.; Maldonado, J. C.; Gimenes, I. M. S. Uma Revisão Sistemática sobre Avaliação de Linha de Produto de Software: Iteração Jan/2008 a Jul/2010. Relatório Técnico No. 355, Instituto de Ciências Matemáticas e de Computação (ICMC) - Universidade de São Paulo (USP), São Carlos, SP, Brasil, 2010. Disponível em http://www.icmc.usp.br/〜biblio/BIBLIOTECA/rel_tec/RT_355. pdf (Acessado em 01/07/2010)

Olumofin, F. A Holistic Method for Assessing Software Product Line Architectures. Saarbrücken, Germany, Germany: VDM Verlag, 2007.

Olumofin, F. G.; Misic, V. B. Extending the ATAM Architecture Evaluation to Product Line Architectures. In: Proceedings of the Working IEEE/IFIP Conference on Software Architecture, Washington, DC, USA: IEEE Computer Society, 2005a, p. $45-56$.

Olumofin, F. G.; Misic, V. B. Extending the ATAM Architecture Evaluation to Product Line Architectures. Relatório Técnico TR 05/02, Department of Computer Science, University of Manitoba, Winnipeg, Manitoba, Canada, 2005b. 
Disponível em http://citeseerx.ist.psu.edu/viewdoc/summary?doi=10.1.1.95. 1814 (Acessado em 01/07/2010)

Parsons, D.; Rashid, A.; Speck, A.; Telea, A. A Framework for Object Oriented Frameworks Design. In: Proceedings of the Technology of Object-Oriented Languages and Systems, Washington, DC, USA: IEEE Computer Society, 1999, p. 141.

Perry, D. E.; Porter, A. A.; Votta, L. G. Empirical Studies of Software Engineering: a Roadmap. In: Proceedings of the International Conference on Software Engineering, New York, NY, USA: ACM, 2000, p. 345-355.

Peter In, H.; Baik, J.; Kim, S.; YAng, Y.; Boenm, B. A Quality-based Cost Estimation Model for the Product Line Life Cycle. Communications of the ACM, v. 49, n. 12, p. 85-88, 2006.

Pohl, K.; Böckle, G.; Linden, F. J. V. D. Software Product Line Engineering: Foundations, Principles, and Techniques. Secaucus, NJ, USA: Springer-Verlag, 2005.

Poulin, J. S. Measuring Software Reuse: Principles, Practices, and Economic Models. Boston, MA, USA: Addison-Wesley Longman Publishing Co., Inc., 1996.

Pree, W. Design Patterns for Object-Oriented Software Development. New York, NY, USA: ACM Press/Addison-Wesley Publishing Co., 1995.

Pure-Systems pure::variants - Variant Management. online, 2010.

Disponível em http://www .pure-systems.com/pure_variants.49.0.html (Acessado em 22/03/2010)

Rahman, A. Metrics for the Structural Assessment of Product Line Architecture. Dissertação de Mestrado, School of Engineering - Blekinge Institute of Technology, Sweden, 2004.

Riva, C.; Rosso, C. D. Experiences with Software Product Family Evolution. In: Proceedings of the International Workshop on Principles of Software Evolution, Washington, DC, USA: IEEE Computer Society, 2003, p. 161-170.

Rosso, C. D. The Process of and the Lessons Learned from Performance Tuning of a Product Family Software Architecture for Mobile Phones. In: Proceedings of the EUROMICRO Working Conference on Software Maintenance and Reengineering, Washington, DC, USA: IEEE Computer Society, 2004, p. 270. 
Rosso, C. D. Software Performance Tuning of Software Product Family Architectures: Two Case Studies in the Real-Time Embedded Systems Domain. Journal of Systems and Software, v. 81, n. 1, p. 1-19, 2008.

Salehie, M.; TAhvildari, L. Self-Adaptive Software: Landscape and Research Challenges. ACM Transactions on Autonomous and Adaptive Systems, v. 4, n. 2, p. 1-42, 2009.

Sane, A.; Birchenough, A. First Class Extensibility for UML - Packaging of Profiles, Stereotypes, Patterns. In: Proceedings of the International Conference on the Unified Modeling Language, Berlin, Heidelberg: Springer-Verlag, 1999, p. 265-277.

Schmid, K. An Assessment Approach to Analyzing Benefits and Risks of Product Lines. In: Proceedings of the International Computer Software and Applications Conference on Invigorating Software Development, Washington, DC, USA: IEEE Computer Society, 2001, p. 525-530.

Schmid, K.; John, I. Developing, Validating and Evolving an Approach to Product Line Benefit and Risk Assessment. In: Proceedings of the EUROMICRO Conference, Los Alamitos, CA, USA: IEEE Computer Society, 2002, p. 272-283.

Schmid, K.; Verlage, M. The Economic Impact of Product Line Adoption and Evolution. IEEE Software, v. 19, n. 4, p. 50-57, 2002.

SchneIdewind, N. F. Methodology for Validating Software Metrics. IEEE Transactions on Software Engineering, v. 18, n. 5, p. 410-422, 1992.

SDMetrics The UML Design Quality Metrics Tool. 2010.

Disponível em http://www.sdmetrics.com (Acessado em 15/03/2010)

Segura, S.; Hierons, R. M.; Benavides, D.; Ruiz-Corté ands, A. Automated Test Data Generation on the Analyses of Feature Models: a Metamorphic Testing Approach. In: Proceedings of the International Conference on Software Testing, Verification, and Validation, Los Alamitos, CA, USA: IEEE Computer Society, 2010, p. 35-44.

SEI A Framework for Software Product Line Practice. online, 2010a.

Disponível em http://www.sei.cmu.edu/productlines/frame_report/index.html (Acessado em 01/03/2010) 
SEI Arcade Game Maker Pedagogical Product Line. online, 2010b.

Disponível em http://www.sei.cmu.edu/productlines/ppl (Acessado em $25 / 02 / 2010)$

SEI Hall of Fame. online, 2010c.

Disponível em http://www.sei.cmu.edu/productlines/plp_hof.html (Acessado em $29 / 06 / 2010)$

Shalloway, A.; Trott, J. R. Design Patterns Explained: a New Perspective on Object-Oriented Design. Boston, MA, USA: Addison-Wesley Longman Publishing Co., Inc., 2002.

Shapiro, S. S.; Wilk, M. B. An Analysis of Variance Test for Normality (Complete Samples). Biometrika, v. 3, n. 52, p. 591-611, 1965.

Shaw, M.; Garlan, D. Software Architecture: Perspectives on an Emerging Discipline. Upper Saddle River, NJ, USA: Prentice-Hall, Inc., 1996.

Shull, F.; Mendonça, M. G.; Basili, V.; Carver, J.; Maldonado, J. C.; Fabbri, S.; Travassos, G. H.; Ferreira, M. C. Knowledge-Sharing Issues in Experimental Software Engineering. Empirical Software Engineering, v. 9, n. 1-2, p. 111-137, 2004.

Silva, L.; Soares, S. Analyzing Structure-based Techniques for Test Coverage on a J2ME Software Product Line. In: Proceedings of the Latin American Test Workshop, Buzios, Rio de Janeiro, Brasil, 2009, p. 1-6.

SPC Reuse-Driven Software Processes Guidebook. Relatório Técnico SPC-92019-CMC, SPC - Software Productivity Consortuim, USA, 1993.

Disponível em http://oai.dtic.mil/oai/oai?verb=getRecord\&metadataPrefix= html\&identifier=ADA273644 (Acessado em 01/07/2010)

Spearman, C. The Proof and Measurement of Association Between Two Things. American Journal of Psychology, v. 15, n. 1, p. 72-101, 1904.

SPLOT Software Product Line Online Tools. online, 2010.

Disponível em http://www.splot-research.org (Acessado em 25/02/2010)

Steger, M.; Tischer, C.; Boss, B.; Müller, A.; Pertler, O.; Stolz, W.; Ferber, S. Introducing PLA at Bosch Gasoline Systems: Experiences and Practices. In: Proceedings of the Software Product Line Conference, Berlin, Germany: Springer-Verlag, 2004, p. 34-50. 
Stoermer, C.; O'Brien, L. MAP - Mining Architectures for Product Line Evaluations. In: Proceedings of the Working IEEE/IFIP Conference on Software Architecture, Washington, DC, USA: IEEE Computer Society, 2001, p. 35-44.

SvahnberG, M.; Gurp, J. V.; Bosch, J. A Taxonomy of Variability Realization Techniques: Research Articles. Software Practice and Experience, v. 35, n. 8, p. $705-754,2005$.

Takebe, Y.; Fukaya, N.; Chikahisa, M.; Hanawa, T.; Shirai, O. Experiences with Software Product Line Engineering in Product Development Oriented Organization. In: Proceedings of the Software Product Line Conference, Pittsburgh, PA, USA: Carnegie Mellon University, 2009, p. 275-283.

Taylor, R. N.; Medvidovic, N.; Dashofy, E. M. Software Architecture: Foundations, Theory, and Practice. USA: John Wiley \& Sons, 2009.

Toft, P. The HP Owen Firmware Cooperative - a Software Product Line Success Story. online, 2004.

Disponível em www.softwareproductlines.com/successes/hp.html (Acessado em $30 / 06 / 2010)$

Toft, P.; Coleman, D.; Ohta, J. A Cooperative Model for Cross-Divisional Product Development for a Software Product Line. In: Proceedings of the Software Product Line Conference, Norwell, MA, USA: Kluwer Academic Publishers, 2000, p. 111-132.

UML OMG - UML Specification - Superstructure v2.2. online, 2010.

Disponível em http://www.omg.org/cgi-bin/doc?formal/09-02-02 (Acessado em $22 / 02 / 2010)$

VP-International Visual Paradigm - Tool for UML. online, 2010.

Disponível em http://www.visual-paradigm.com/product/vpuml (Acessado em $02 / 03 / 2010)$

Weiss, D. M.; LAI, C. T. R. Software Product-Line Engineering: a Family-based Software Development Process. Boston, MA, USA: Addison-Wesley Longman Publishing Co., Inc., 1999.

Wohlin, C.; Runeson, P.; Hust, M.; Ohlsson, M. C.; Regnell, B.; Wesslun, A. Experimentation in Software Engineering: an Introduction. Norwell, MA, USA: Kluwer Academic Publishers, 2000. 
Woolf, B. The Abstract Class Pattern. In: Proceedings of the Pattern Languages of Programming Conference, 1997, p. 1-8.

Yoshimura, K.; Ganesan, D.; Muthig, D. Defining a Strategy to Introduce a Software Product Line Using Existing Embedded Systems. In: Proceedings of the ACM $\&$ IEEE International Conference on Embedded Software, New York, NY, USA: ACM Press, 2006, p. 63-72.

Zelkowitz, M. V.; Wallace, D. R.; Binkley, D. W. Experimental Validation of New Software Technology. Lecture Notes on Empirical Software Engineering, v. 12, n. 1, p. 229-263, 2003.

Zhang, H.; Jarzabek, S.; Yang, B. Quality Prediction and Assessment for Product Lines. In: Proceedings of the International Conference on Advanced Information Systems Engineering, Berlin, Heidelberg: Springer-Verlag, 2003, p. 681-695.

Ziadi, T.; HÉlouët, L.; JÉzÉquel, J. M. Towards a UML Profile for Software Product Lines. Lecture Notes in Computer Science, v. 3014, n. 1, p. 129-139, 2004. 


$\bar{A}$

\section{A Linha de Produto Arcade Game Maker}

Arcade Game Maker (AGM) (SEI, 2010b) é uma LP pedagógica para jogos, criada pelo Software Engineering Institute (SEI) para apoiar o aprendizado e a experimentação de conceitos de LP. Possui um conjunto completo de documentos e modelos UML, bem como um conjunto de classes testadas e código-fonte para três jogos diferentes, sendo eles: Pong, Bowling e Brickles. Apesar de não ser uma LP comercial, a AGM tem sido usada para ilustrar os conceitos de várias abordagens distintas de LP e estudos de caso e avaliação de arquiteturas de LP.

Os artefatos essenciais da AGM são: o modelo de características, o modelo de casos de uso, o modelo de classes e a arquitetura lógica de componentes. Tais modelos e suas respectivas descrições são apresentadas a seguir.

Características: o modelo de características da AGM é composto por quatro características principais (Figura A.1), sendo elas: 


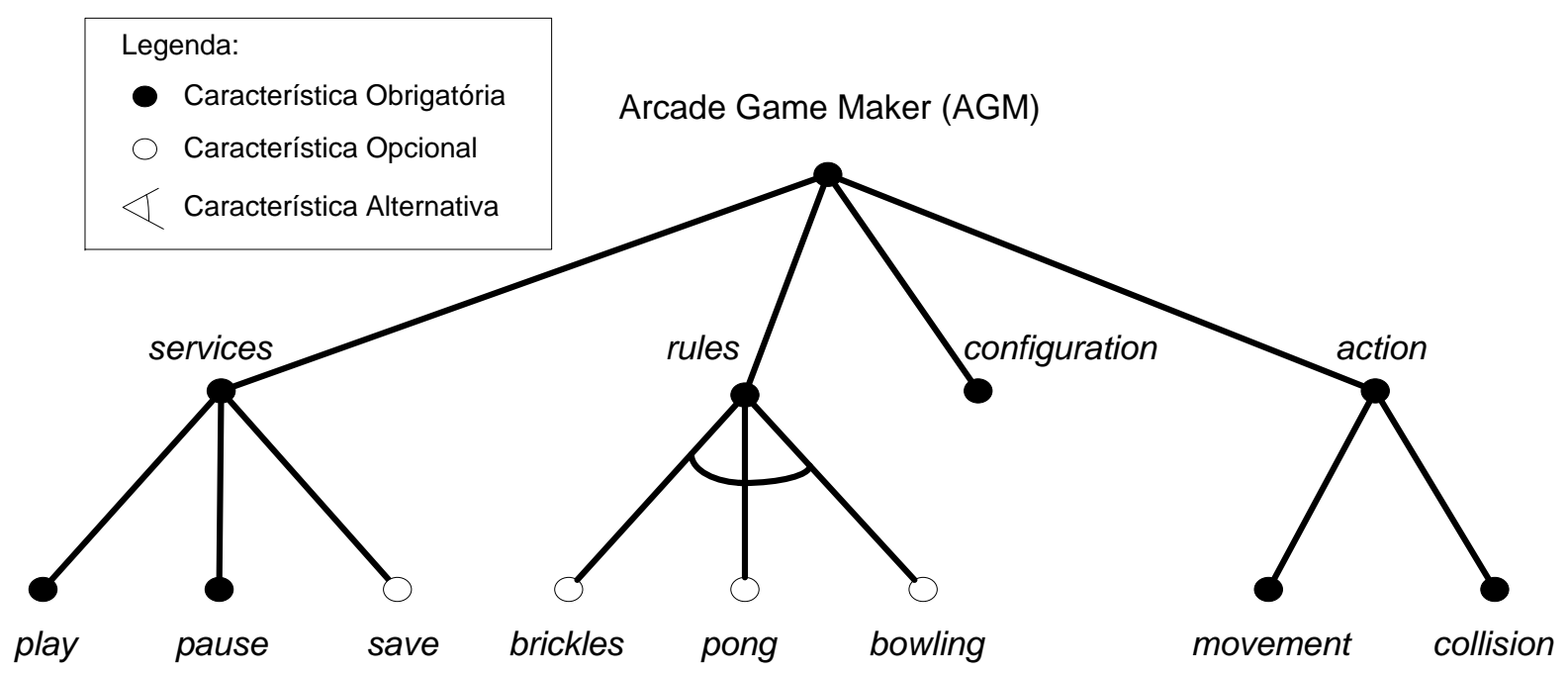

Figura A.1: Modelo de Características da LP Arcade Game Maker (SEI, 2010b).

- services, que define os seguintes serviços para cada jogo: play, pause e save;

- rules, que define as regras que devem ser seguidas pelos jogos brickles, pong e bowling;

- configuration, que define as configurações básicas do ambiente e dos seus jogos;

- action, que define cada ação necessária para movimentação (movement) e colisão (collision) dos elementos de um jogo.

As subcaracterísticas save, brickles, pong e bowling são opcionais, enquanto as demais são obrigatórias.

Atores e Casos de Uso: os itens a seguir apresentam os atores e casos de uso da AGM e as suas principais ações. A Figura A.2 apresenta o modelo de casos de uso da LP AGM. 


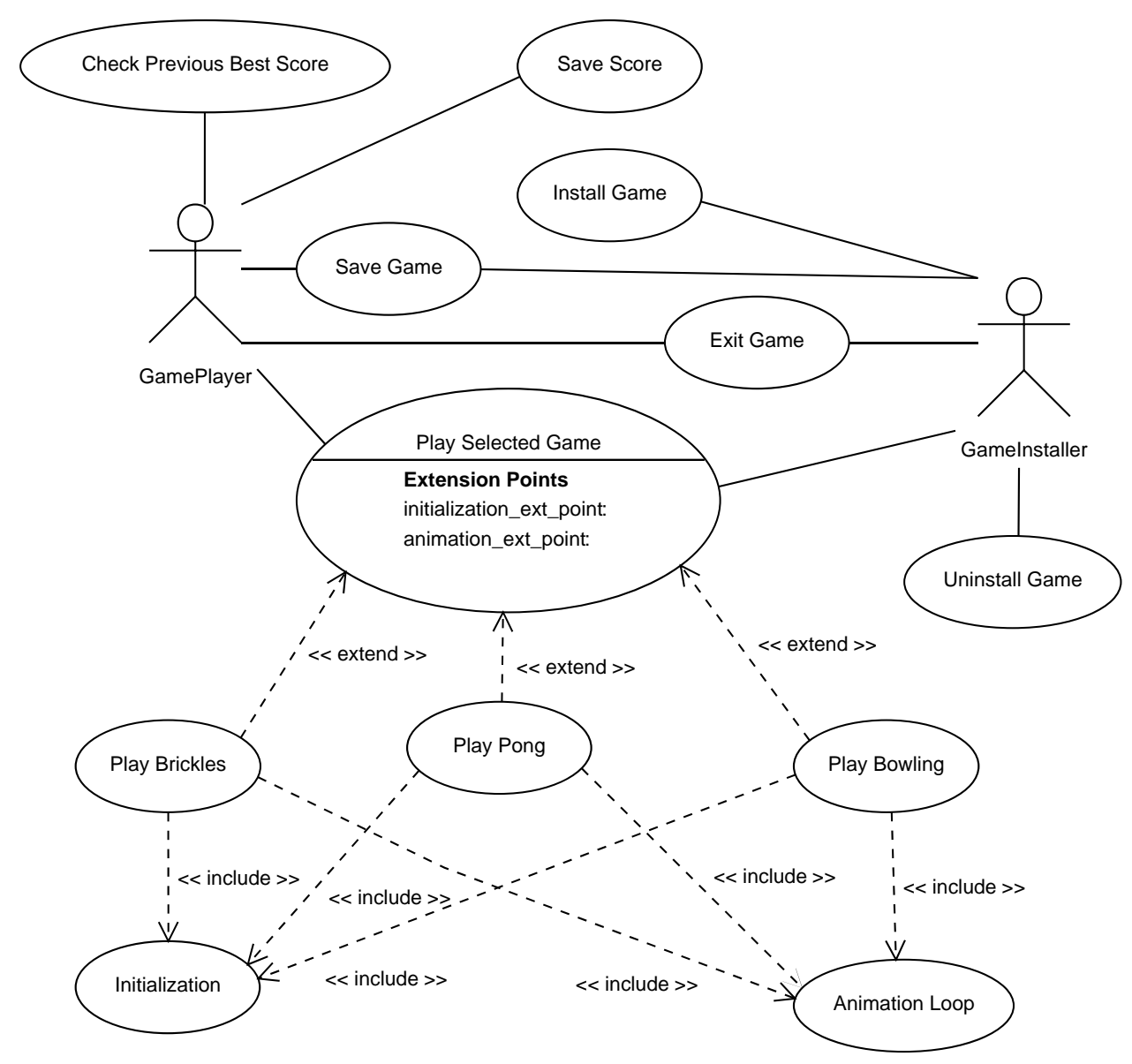

Figura A.2: Modelo de Casos de Uso da LP AGM (SEI, 2010b).

1. GamePlayer: ator responsável por executar as principais ações de um jogo produzido pela AGM.

2. GameInstaller: ator responsável por ações de configuração dos jogos (instalação e desinstalação) produzidos pela AGM.

3. Check Previous Best Score: verifica e apresenta a melhor pontuação registrada anteriormente.

(a) Ator seleciona a opção CHECK PREVIOUS BEST SCORE do menu do sistema. Sistema pede para fornecer o nome do arquivo, lê o arquivo e retorna o placar (score) à caixa de diálogo.

(b) Ator seleciona $O K$ na caixa de diálogo para continuar. Sistema retorna ao estado anterior.

4. Save Score: salva a pontuação corrente do jogador. 
(a) Ator seleciona SAVE SCORE no menu do sistema. Sistema pede um nome de arquivo (cria um novo se não existe), escreve o score no arquivo e retorna ao estado pré-salvo do jogo.

5. Save Game: salva o jogo em andamento.

(a) Ator seleciona a opção $S A V E$ GAME no menu do sistema. Sistema permite ao ator especificar um nome de arquivo e, em seguida, escreve os dados do jogo no arquivo especificado, retornando ao estado pré-salvo do jogo.

6. Install Game: instala o jogo escolhido.

(a) Ator escolhe o instalador do jogo para ser executado. Sistema apresenta uma caixa de diálogo para escolher o diretório em que serão armazenados os arquivos do jogo.

(b) Ator escolhe o diretório. Sistema armazena os arquivos no diretório escolhido.

7. Exit Game: encerra o jogo em andamento.

(a) Ator seleciona EXIT no Menu do sistema. Sistema apresenta a caixa de diálogo para salvar ou sair do jogo.

(b) Ator salva o jogo. Sistema salva e sai ou cancela saída do jogo.

(c) Sistema retorna à ação suspensa.

8. Uninstall Game: remove o jogo selecionado.

(a) Ator escolhe a opção UNINSTALL do menu do sitema. Sistema apresenta uma caixa de diálogo ao ator.

(b) Ator seleciona o diretório do jogo a ser removido. Sistema exclui os arquivos do diretório e apresenta uma caixa de diálogo de remoção concluída.

(c) Ator seleciona a opção $O K$ da caixa de diálogo. Sistema fecha a caixa de diálogo.

9. Play Selected Game: um ator seleciona o jogo e inicia a sua execução.

(a) Ator seleciona a opção $P L A Y$ a partir do menu. Sistema inicializa o jogo e apresenta o GameBoard.

(b) Ator clica com o botão esquerdo e inicia o jogo. Sistema inicia a ação do jogo.

(c) Ator clica com o botão esquerdo ou usa o teclado para enviar comandos. Sistema responde aos comandos. 
(d) Ator responde à caixa de diálogo Won/Lost/Even clicando com o botão esquerdo. Sistema retorna o GameBoard para ser inicializado.

(e) A qualquer instante o ator pode selecionar EXIT, via menu.

10. Play Bowling: inicia o jogo Bowling.

(a) Ator seleciona PLAY do Menu do sistema. Sistema inicializa o jogo e apresenta o GameBoard.

(b) Ator clica com o botão esquerdo para jogar. Sistema inicia a ação do jogo.

(c) Ator repete as ações seguintes 10 vezes mais um lance de bônus (opcional)

(d) Ator posiciona o mouse e clica com o botão esquerdo para lançar a BowlingBall pela Alley (pista). Sistema move a BowlingBall pela Alley usando um algoritmo randômico. Se há colisões com os BowlingPins, o sistema move os BowlingPins, segundo as leis físicas de colisão. Sistema conta o número de pinos derrubados. Sistema computa o score.

11. Play Brickles: inicia o jogo Brickles.

(a) Ator seleciona $P L A Y$ do menu do sistema. Sistema inicializa o jogo e apresenta o GameBoard.

(b) Ator clica com o botão esquerdo para iniciar o jogo. Sistema inicia a ação do jogo.

(c) Ator usa o botão esquerdo ou o teclado para enviar comandos ao jogo. Sistema move o Paddle horizontalmente, seguindo o rastro do mouse. A cada movimento do Puck, o sistema verifica se houve colisão com outro objeto. Se o Puck colide com o Ceiling (teto) ou com uma Wall, o Puck volta para a área de jogo. Se o Puck colide com o Floor, deixa de existir. Se o número máximo de Pucks não foi alcançado, um novo é criado, caso contrário a caixa de diálogo Lost é apresentada. Se o Puck colide com um Brick, a ação a ser tomada depende do Brick. Se for o último Brick, a caixa de diálogo Won é apresentada.

(d) Ator responde à caixa de diálogo Won/Lost clicando com o botão esquerdo. Sistema retorna o GameBoard ao estado inicializado e pronto para jogar.

12. Play Pong: inicia o jogo Pong.

(a) Ator seleciona PLAY do menu do sistema. Sistema inicializa o jogo e apresenta o GameBoard. 
(b) Ator clica com o botão esquerdo para iniciar o jogo. Sistema inicia a ação do jogo.

13. Animation Loop: executa as ações de animação dos jogos.

(a) Sistema gera periódicamente sinais e os envia para o jogo.

(b) Sistema move todos os objetos passo a passo de acordo com os seus algoritmos de movimentação.

(c) Sistema verifica se há colisões e executa os algoritmos de colisão dos objetos.

14. Initialization: inicializa o jogo selecionado e apresenta o GameBoard.

(a) Sistema cria as instâncias-padrão para as classes requeridas.

(b) Sistema entra no estado READY.

Classes: a Tabela A.1 apresenta as classes da AGM e uma breve descrição de cada uma delas. A Figura A.3 apresenta o modelo de classes da AGM. 
Tabela A.1: Pacotes e Descrição das Classes da LP AGM.

\begin{tabular}{|c|c|c|}
\hline Pacote & Classe & Descrição \\
\hline \multirow{14}{*}{ coreAssets } & Board & Borda de um jogo \\
\hline & GameMenu & Menu com as opcões de um determinado jogo \\
\hline & GameSprite & Elementos dos jogos com os quais o jogador interage \\
\hline & Menu & Menu com as principais opções dos jogos \\
\hline & MovableSprite & Elementos que se movem em um jogo \\
\hline & Paddle & $\begin{array}{l}\text { Elemento utilizado em um jogo para colocar um Puck } \\
\text { em movimento }\end{array}$ \\
\hline & Point & Determinado ponto em um retângulo \\
\hline & Puck & $\begin{array}{l}\text { Representa o principal elemento de um jogo como, } \\
\text { por exemplo, a bola que derruba os } \\
\text { BowlingPins no jogo Bowling }\end{array}$ \\
\hline & Rectangle & Um retângulo que demarca uma área em um jogo \\
\hline & Size & Tamanho de um retângulo \\
\hline & SpritePair & Par de elementos de um jogo que reagem à uma ação \\
\hline & StationarySprite & Elementos que não se movem em um jogo \\
\hline & Velocity & Velocidade de um MovableSprite \\
\hline & Wall & Representa as paredes de um jogo \\
\hline \multirow{10}{*}{ bowl } & Bowling & Classe com a inicialização do jogo \\
\hline & BowlingBall & Bola de boliche \\
\hline & BowlingBoard & Borda do jogo Bowling \\
\hline & BowlingGameMenu & Menu com as opções específicas do jogo \\
\hline & BowlingPin & Pino do jogo de boliche \\
\hline & Edge & Limites esquerdo e direito da canaleta de boliche \\
\hline & EndOfAlley & Fim da pista de boliche \\
\hline & Gutter & Canaleta da pista de boliche \\
\hline & Lane & Pista de boliche \\
\hline & RackOfPins & Local onde os pinos são posicionados \\
\hline \multirow{11}{*}{ pong } & BottomPaddle & $\begin{array}{l}\text { Elemento que movimenta a Puck do jogo, localizado } \\
\text { na parte inferior da PongBoard }\end{array}$ \\
\hline & Ceiling & Teto do jogo \\
\hline & DividingLine & Linha divisória dos Paddles \\
\hline & Floor & Chão do jogo \\
\hline & LeftWall & Parede à esquerda do jogo \\
\hline & Pong & Classe com a inicialização do jogo \\
\hline & PongBoard & Borda do jogo Pong \\
\hline & PongGameMenu & Menu com as opções específicas do jogo \\
\hline & RightWall & Parede à direita \\
\hline & ScoreBoard & Placar do jogo \\
\hline & TopPaddle & $\begin{array}{l}\text { Elemento que movimenta a Puck do jogo, localizado na } \\
\text { parte superior da PongBoard }\end{array}$ \\
\hline \multirow{10}{*}{ brickles } & Brick & Tijolo a ser quebrado pelo elemento Puck \\
\hline & Brickles & Classe com a inicialização do jogo \\
\hline & BricklesBoard & Borda do jogo Pong \\
\hline & BricklesGameMenu & Menu com as opções específicas do jogo \\
\hline & BrickPile & Pilha de tijolos \\
\hline & Ceiling & Teto do jogo \\
\hline & Floor & Chão do jogo \\
\hline & LeftWall & Parede à esquerda \\
\hline & PuckSupply & Quantidade de Pucks que o jogador tem direito \\
\hline & RightWall & Parede à direita \\
\hline
\end{tabular}




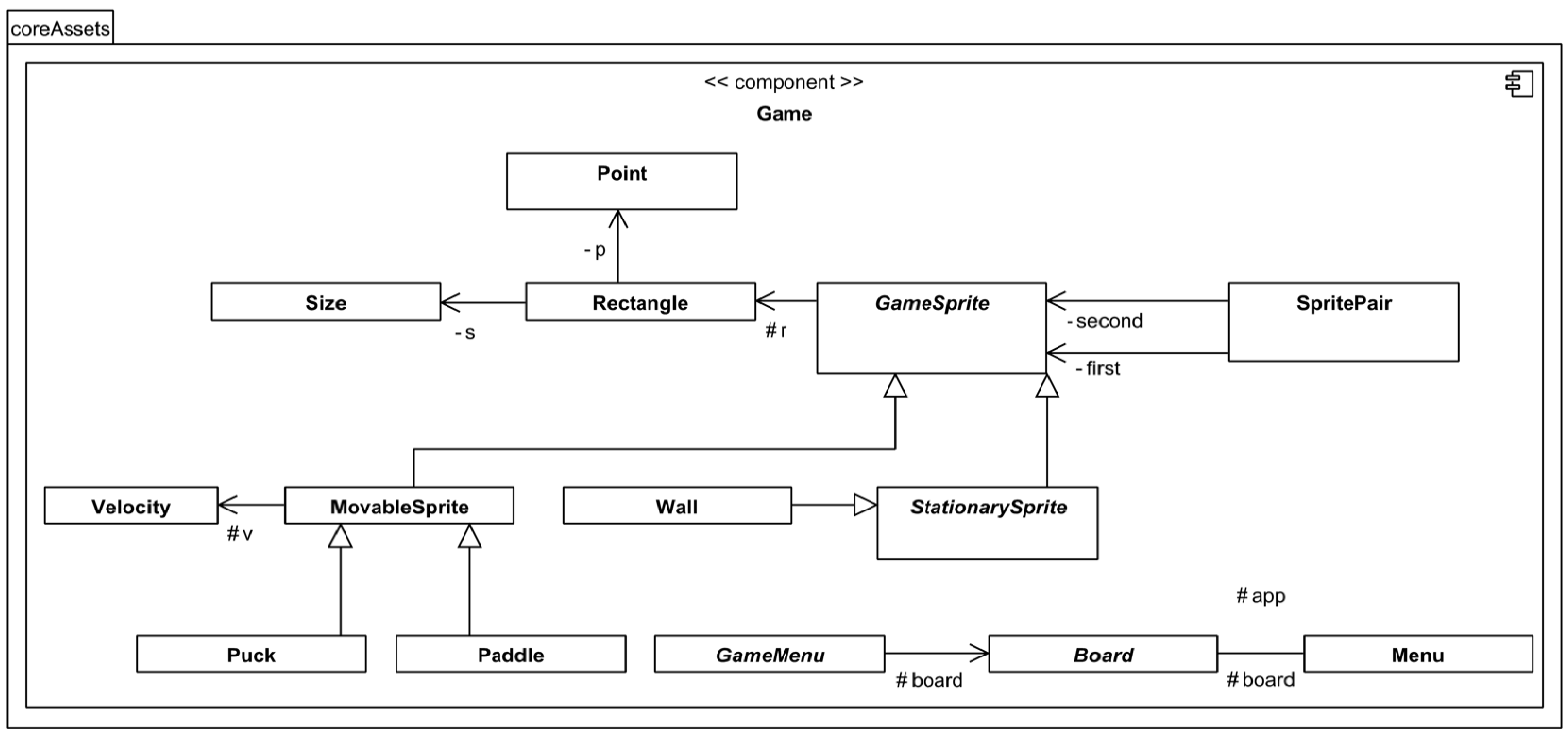

Figura A.3: Modelo de Classes da LP AGM (SEI, 2010b).

Componentes: a arquitetura lógica de componentes da LP AGM é composta por vários componentes. Porém, somente um deles, Game, é formado a partir das classes do núcleo de artefatos (Figura A.3). A Figura A.4 apresenta tal arquitetura.

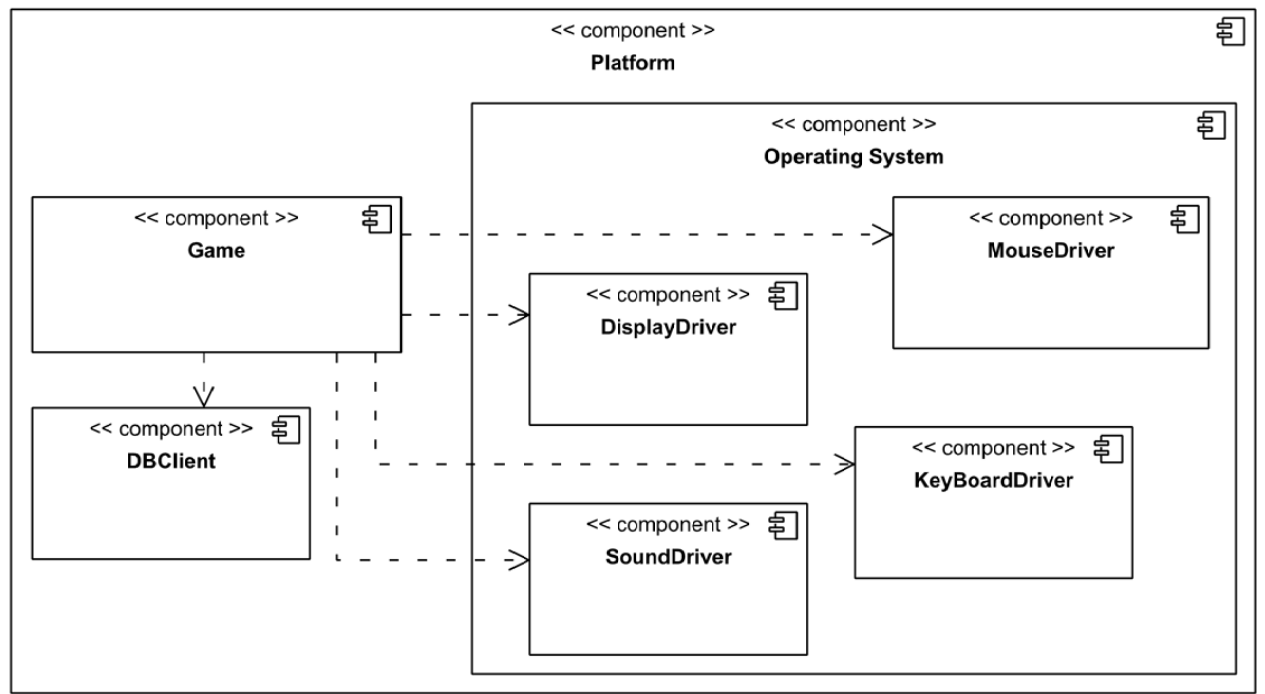

Figura A.4: Arquitetura Lógica de Componentes da AGM (SEI, 2010b). 


\section{Código XML das Métricas Básicas de Avaliação de ALP}

Este apêndice apresenta o código XML das métricas básicas (Seção 6.1) para avaliação de ALP definidas com o auxílio da ferramenta SDMetrics.

\section{B.1 Métricas Básicas de Classes}

\section{1. $C L S \_C L S \_B A S \_V P T \_I S A$}

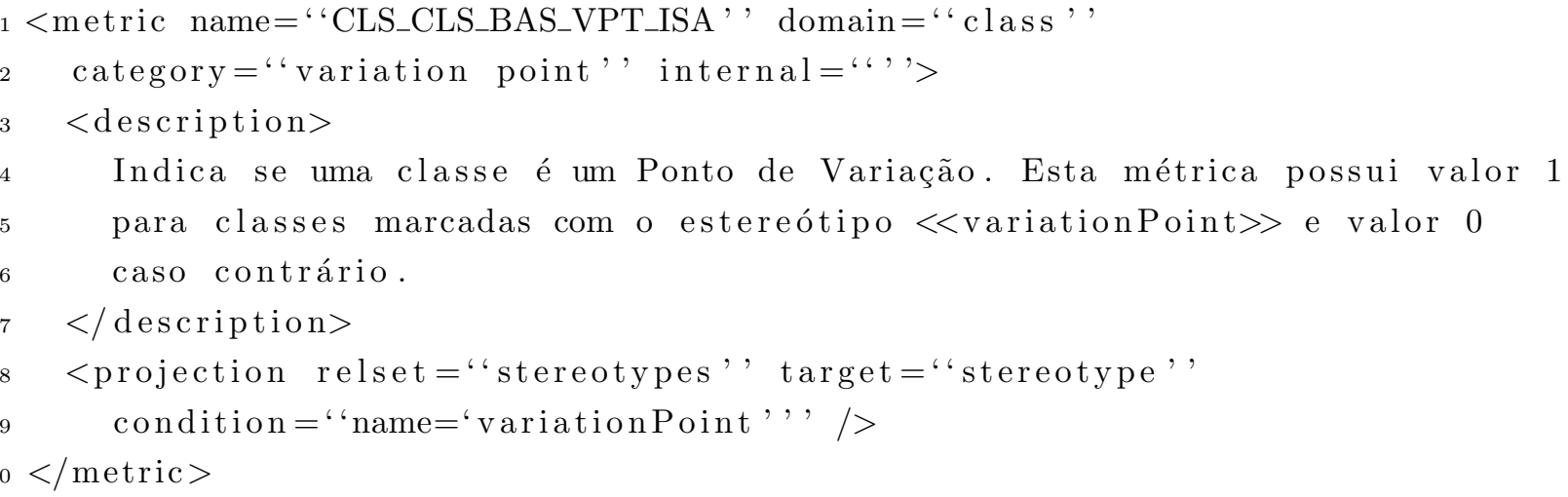

Listagem B.1: Código XML da Métrica $C L S \_C L S \_B A S_{-} V P T \_I S A$.

\section{2. $C L S \_C L S \_B A S \_I N C \_I S A$}

$1<$ metric name="CLS_CLS_BAS_INC_ISA" domain=" class" category="variant" 


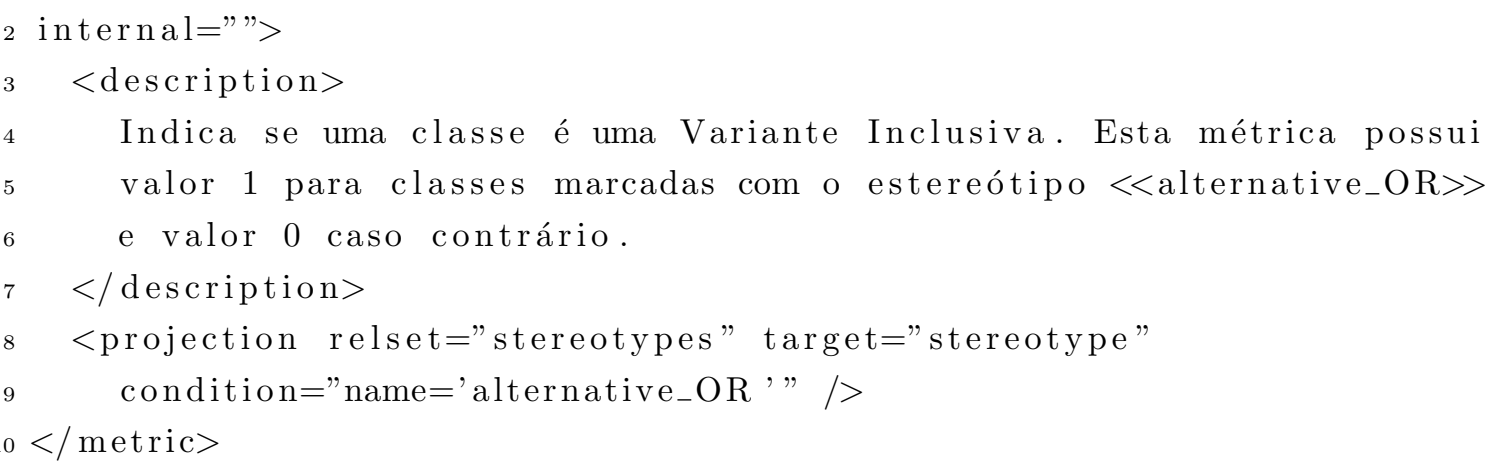

Listagem B.2: Código XML da Métrica $C L S \_C L S \_B A S_{-} I N C \_I S A$.

\section{3. $C L S \_C L S \_B A S \_E X C \_I S A$}

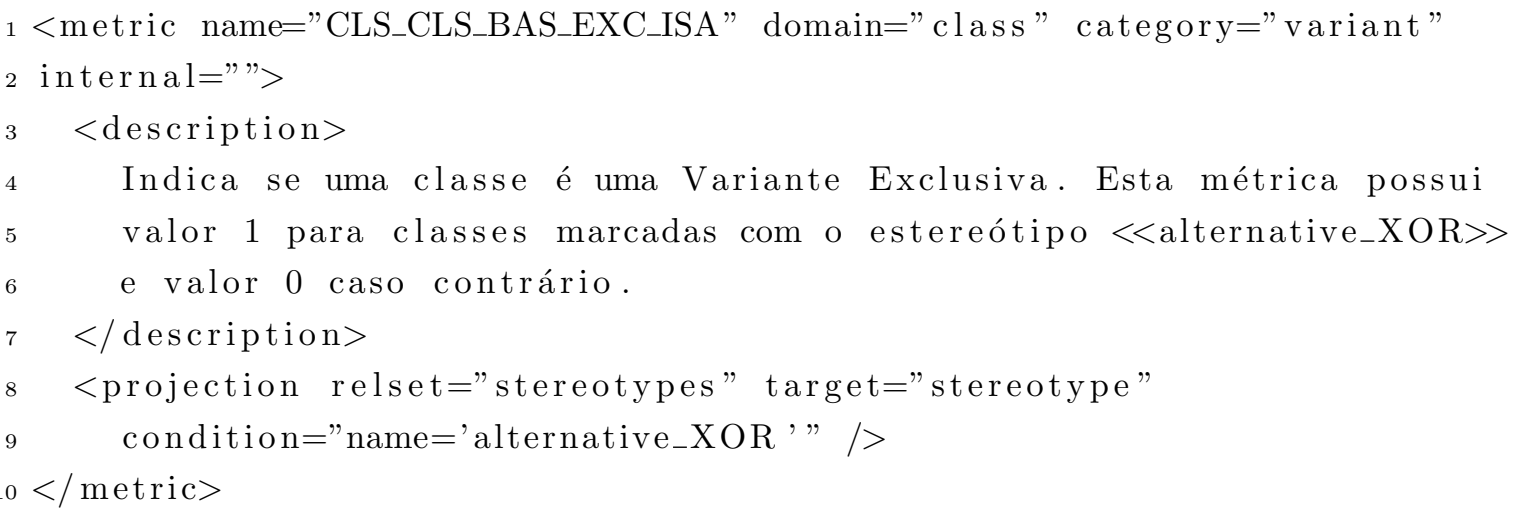

Listagem B.3: Código XML da Métrica $C L S \_C L S \_B A S \_E X C_{-} I S A$.

\section{4. $C L S \_C L S \_B A S \_O P T \_I S A$}

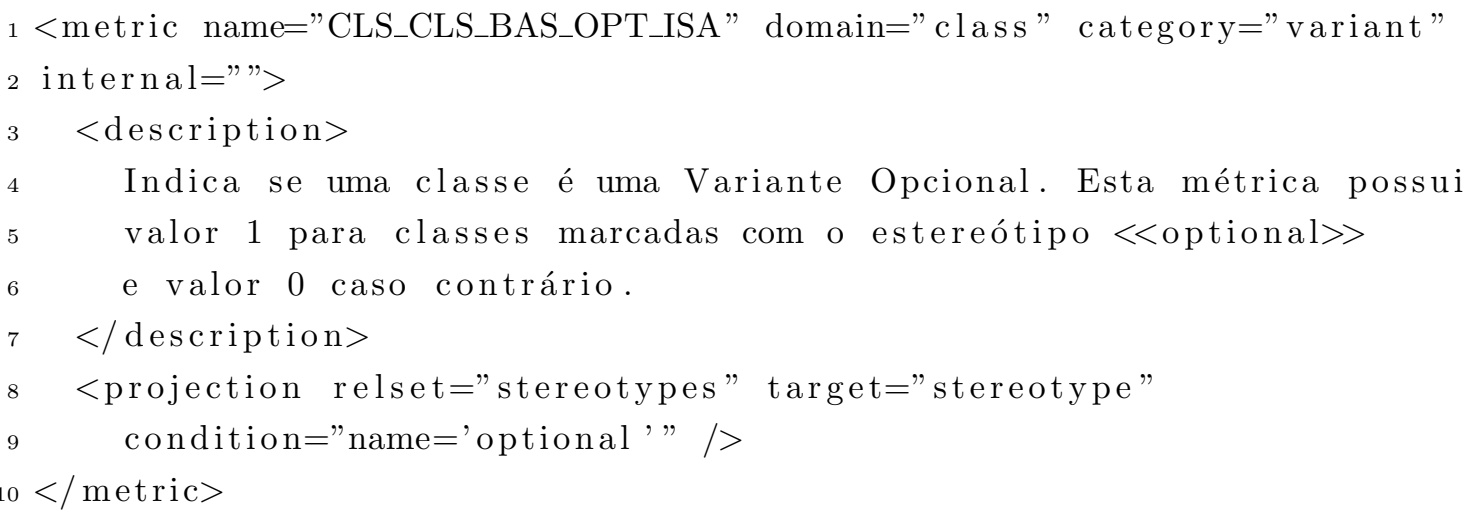

Listagem B.4: Código XML da Métrica CLS_CLS_BAS_OPT_ISA.

\section{5. $C L S \_C L S \_B A S \_M N D \_I S A$}

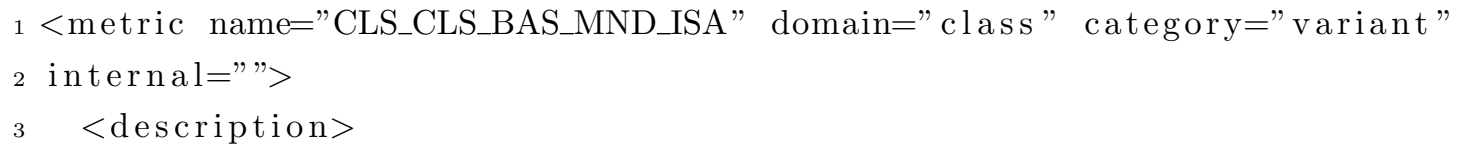




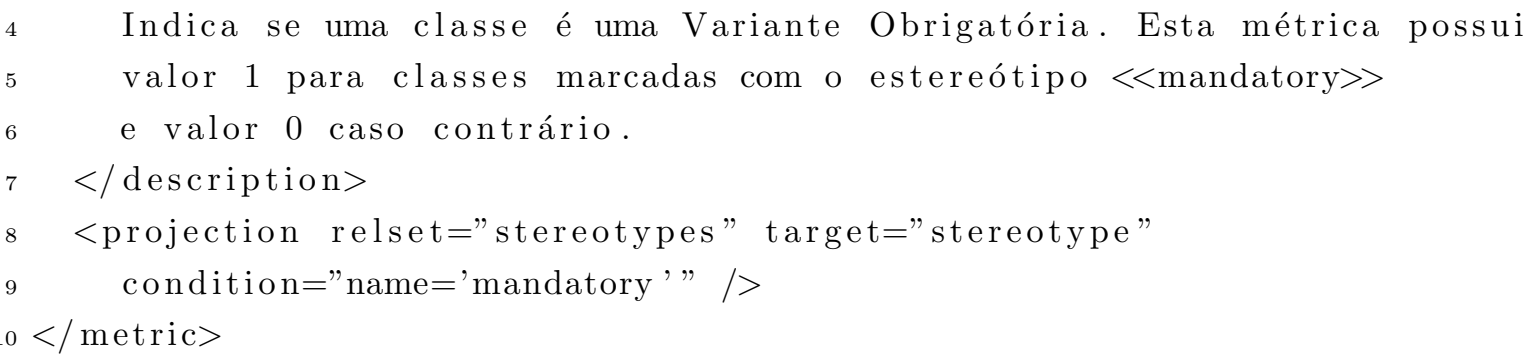

Listagem B.5: Código XML da Métrica $C L S \_C L S \_B A S \_M N D \_I S A$.

\section{6. $C L S \_C L S \_B A S \_I N C \_N U M$}

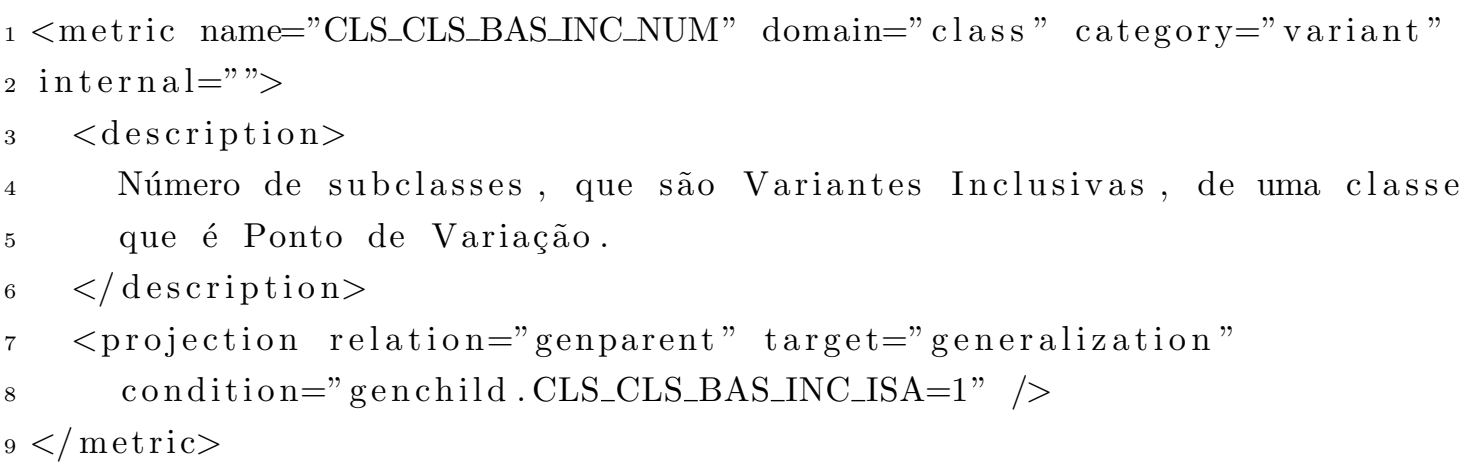

Listagem B.6: Código XML da Métrica $C L S \_C L S \_B A S \_I N C \_N U M$.

\section{7. $C L S \_C L S \_B A S \_E X C \_N U M$}

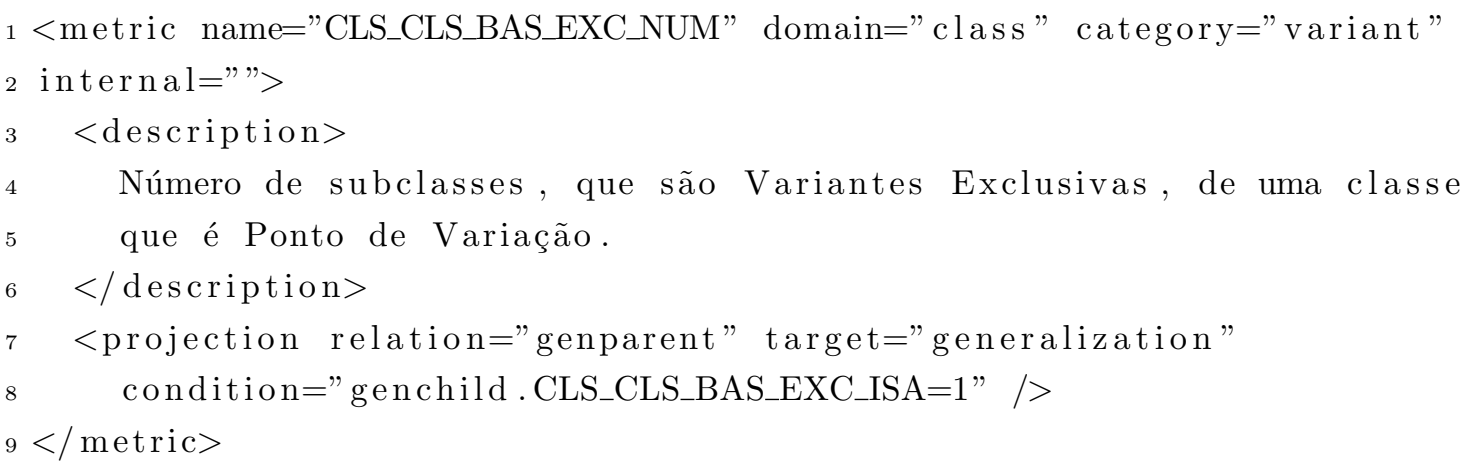

Listagem B.7: Código XML da Métrica $C L S \_C L S \_B A S \_E X C_{-} N U M$.

\section{8. $C L S \_C L S \_B A S \_O P T \_N U M$}

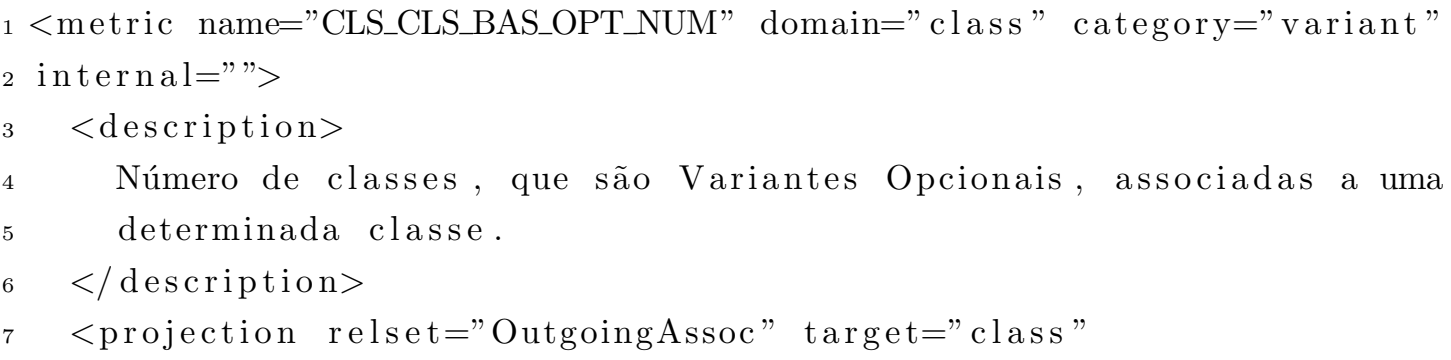


$8 \quad$ condition="CLS_CLS_BAS_OPT_ISA=1" $/>$

$9</$ metric $>$

Listagem B.8: Código XML da Métrica $C L S_{-} C L S_{-} B A S_{-} O P T \_N U M$.

\section{9. $C L S \_C L S \_B A S \_M N D \_N U M$}

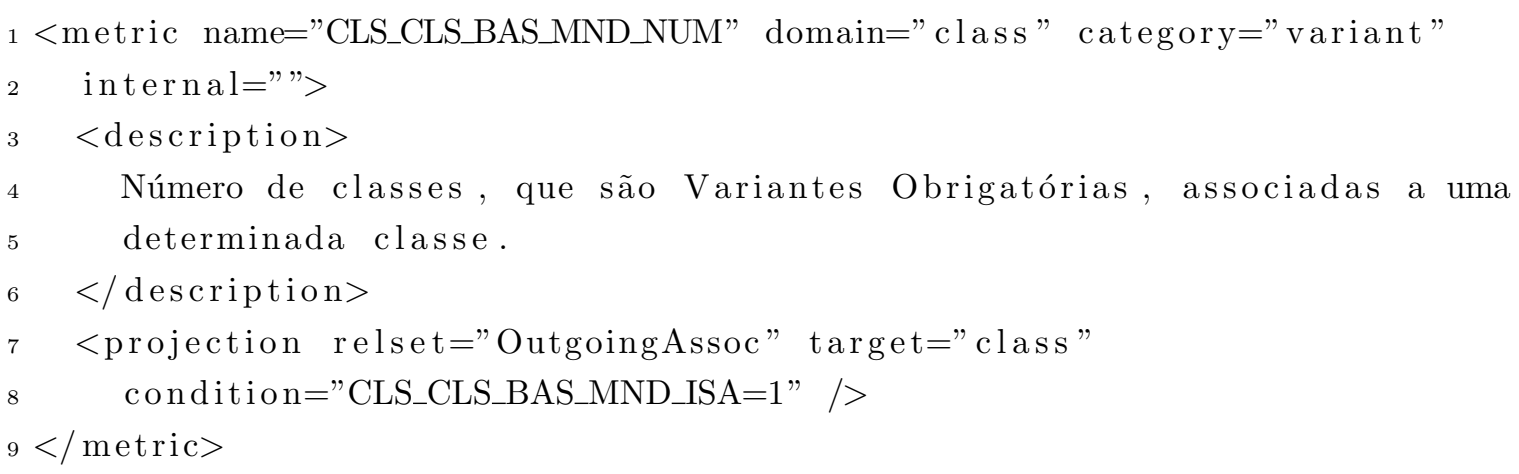

Listagem B.9: Código XML da Métrica $C L S \_C L S \_B A S \_M N D \_N U M$.

10. $C L S \_C L S \_B A S \_V P T \_N U M$

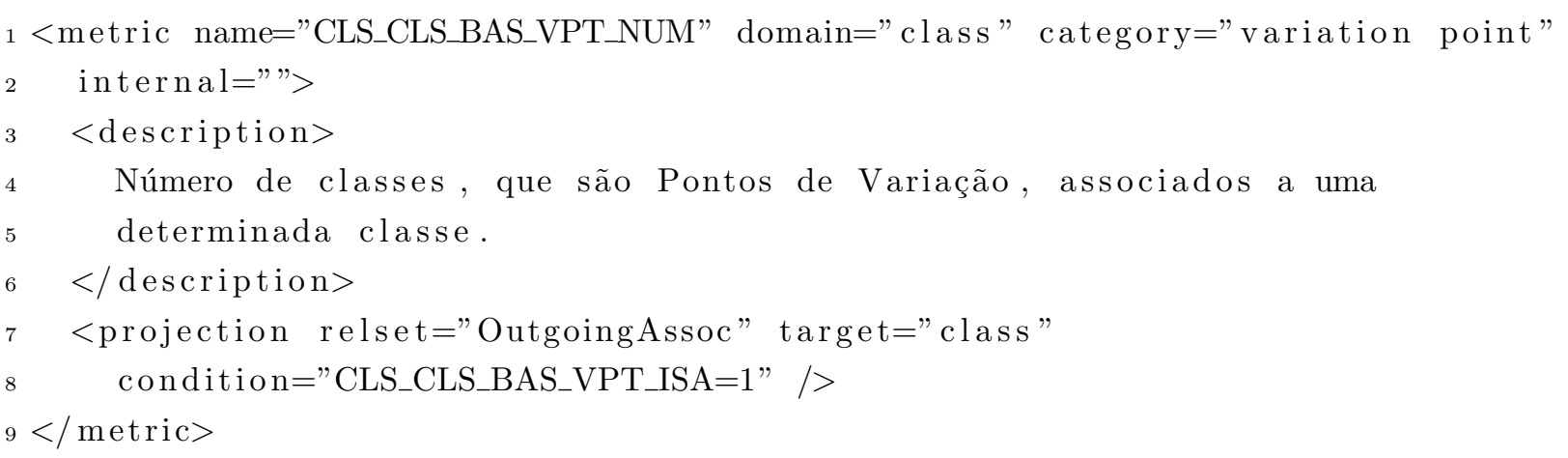

Listagem B.10: Código XML da Métrica $C L S_{-} C L S_{-} B A S_{-} V P T_{-} N U M$.

\section{1. $C L S \_I T F \_B A S \_I N C \_N U M$}

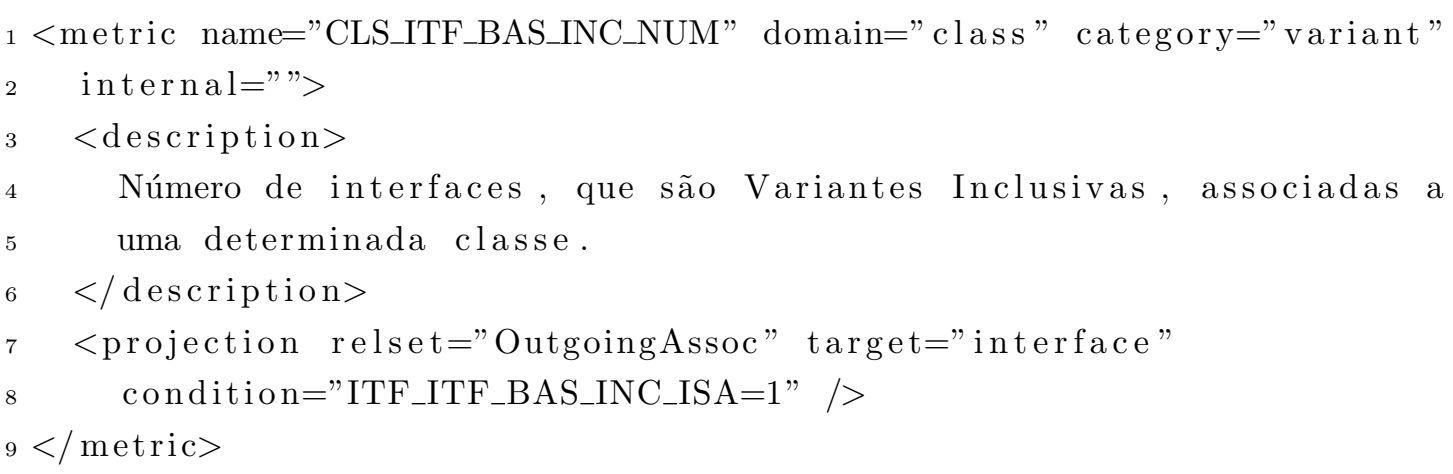

Listagem B.11: Código XML da Métrica $C L S \_I T F \_B A S \_I N C \_N U M$. 


\section{2. $C L S \_I T F \_B A S \_E X C \_N U M$}

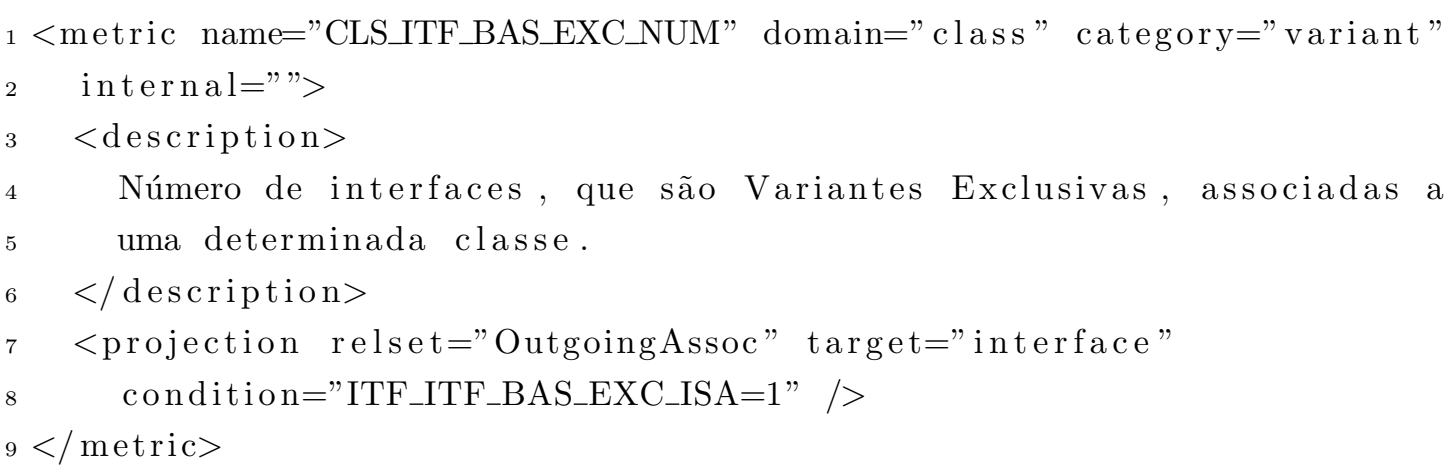

Listagem B.12: Código XML da Métrica $C L S \_I T F \_B A S \_E X C \_N U M$.

\section{3. $C L S \_I T F \_B A S \_O P T \_N U M$}

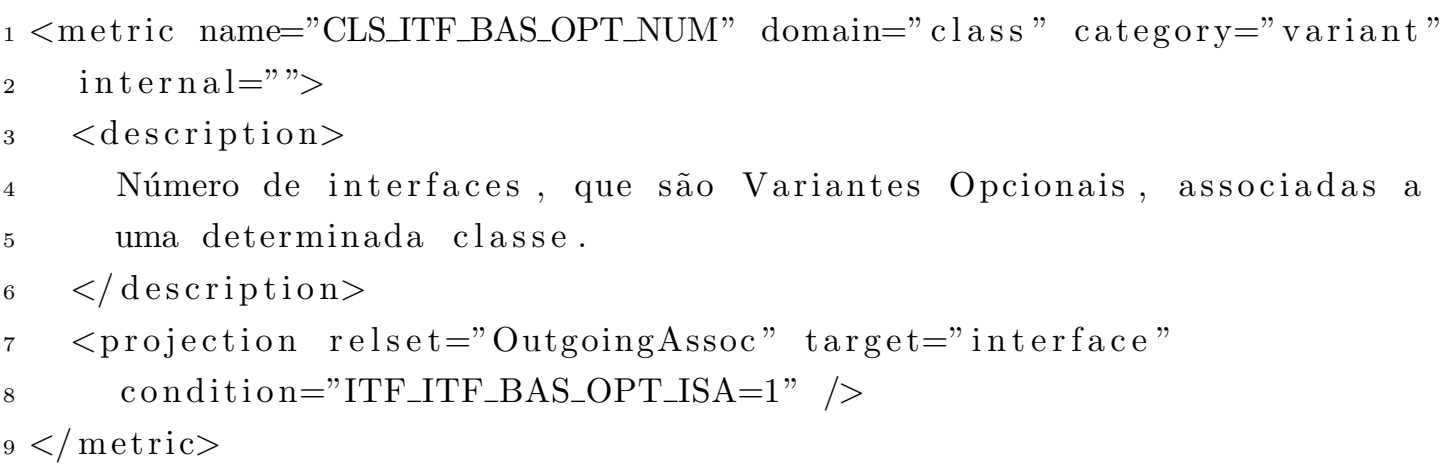

Listagem B.13: Código XML da Métrica $C L S_{-} I T F_{-} B A S_{-} O P T_{-} N U M$.

\section{4. $C L S \_I T F \_B A S \_M N D \_N U M$}

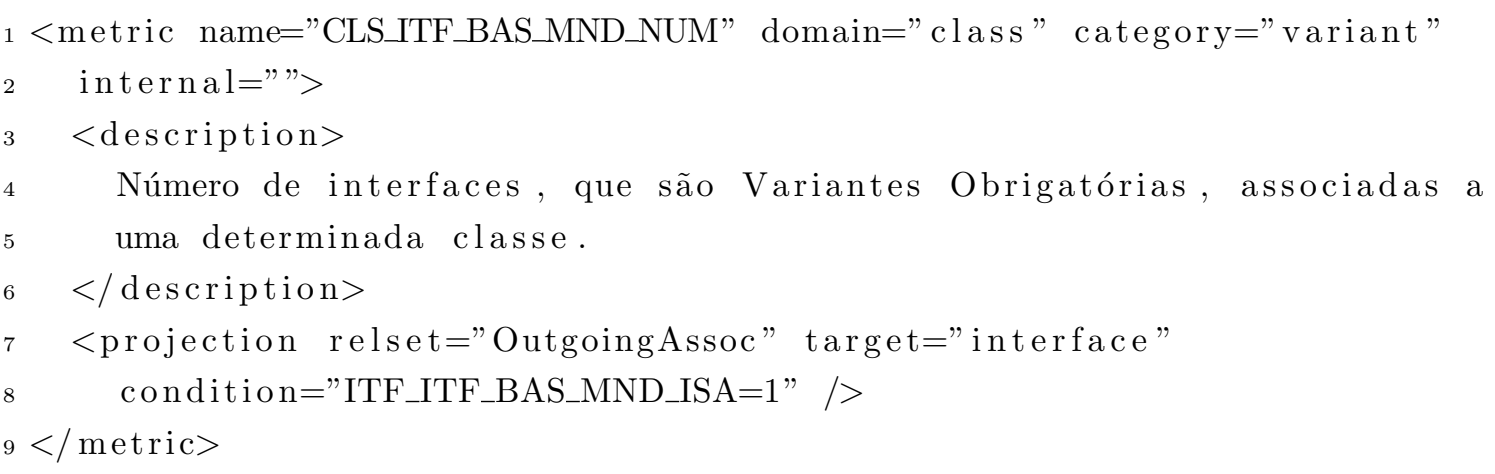

Listagem B.14: Código XML da Métrica $C L S \_I T F \_B A S \_M N D \_N U M$.

\section{5. $C L S \_I T F \_B A S \_V P T \_N U M$}

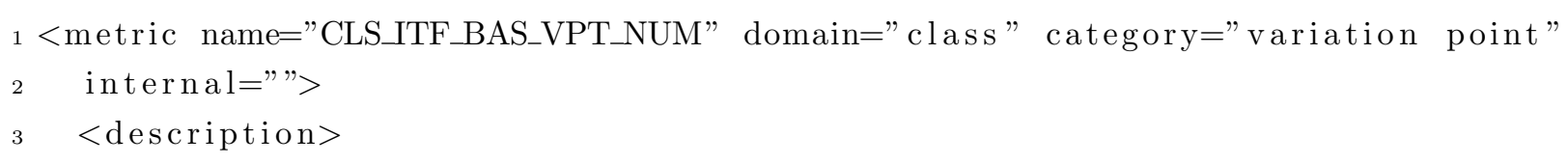




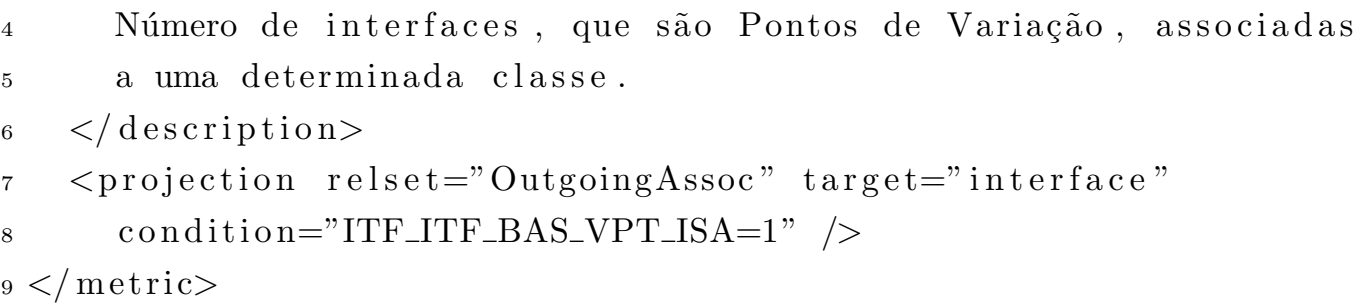

Listagem B.15: Código XML da Métrica $C L S \_I T F \_B A S \_V P T \_N U M$.

\section{6. $C L S \_C L S \_B A S \_V B T \_N U M$}

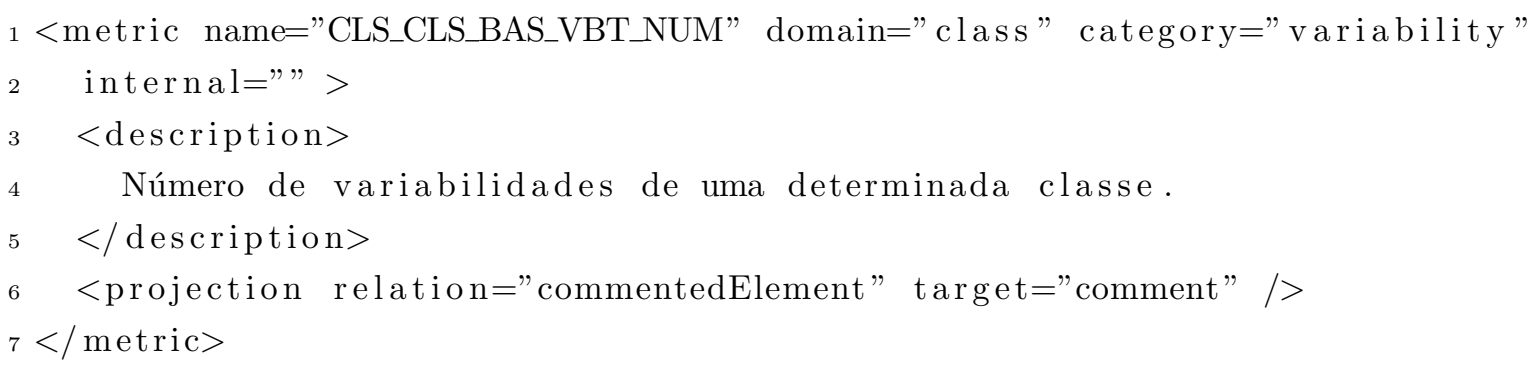

Listagem B.16: Código XML da Métrica $C L S_{-} C L S_{-} B A S_{-} V B T_{-} N U M$.

\section{B.2 Métricas Básicas de Interfaces}

\section{7. $I T F_{-} I T F_{-} B A S S_{-} V P T_{-} I S A$}

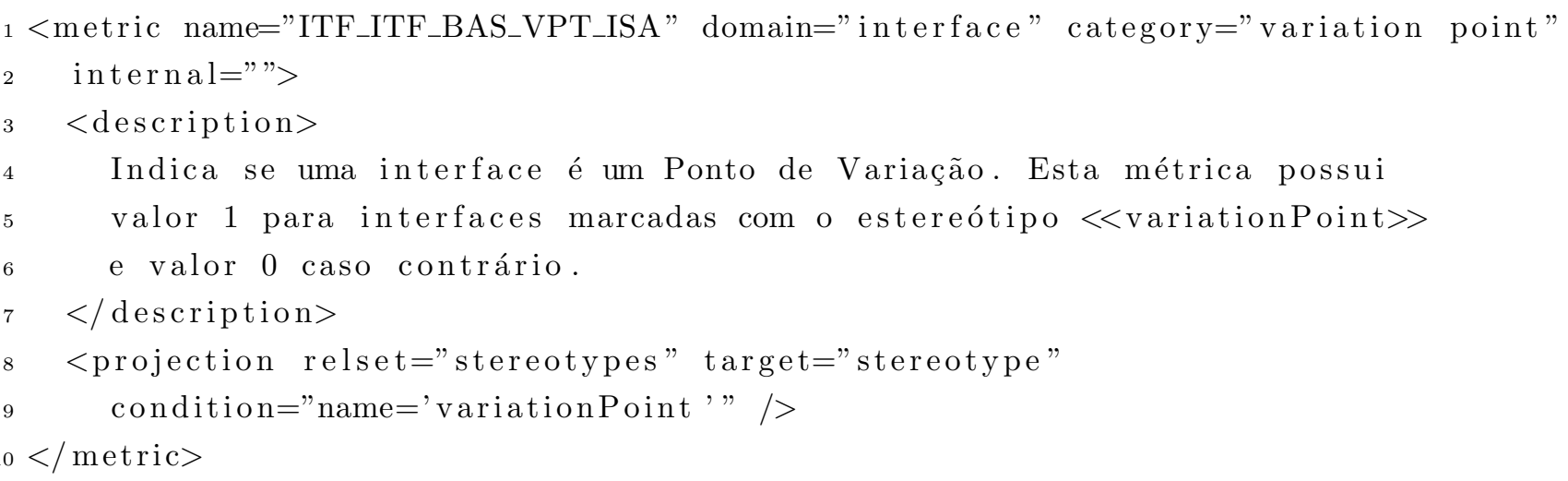

Listagem B.17: Código XML da Métrica ITF_ITF_BAS_VPT_ISA.

\section{ITF_ITF_BAS_INC_ISA}

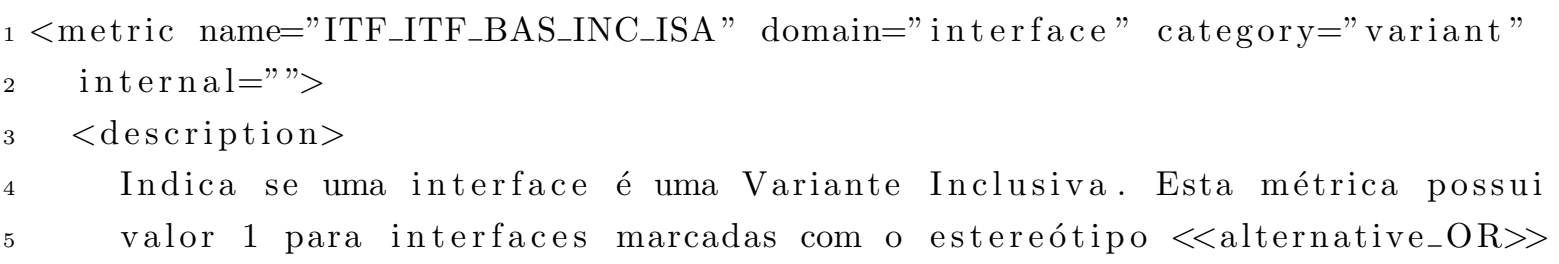




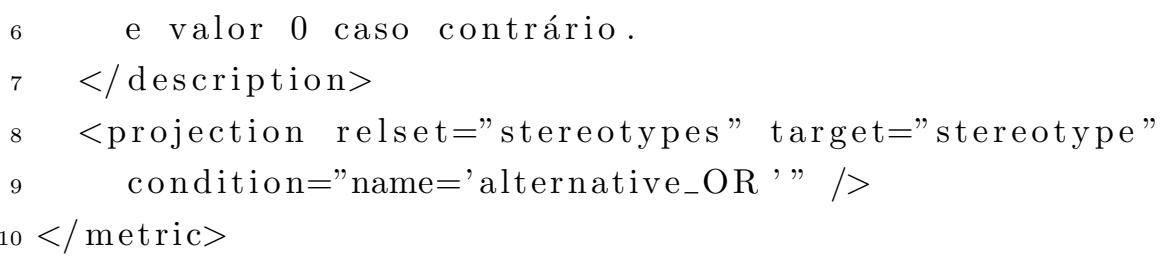

Listagem B.18: Código XML da Métrica ITF_ITF_BAS_INC_ISA.

\section{9. $I T F \_I T F \_B A S \_E X C \_I S A$}

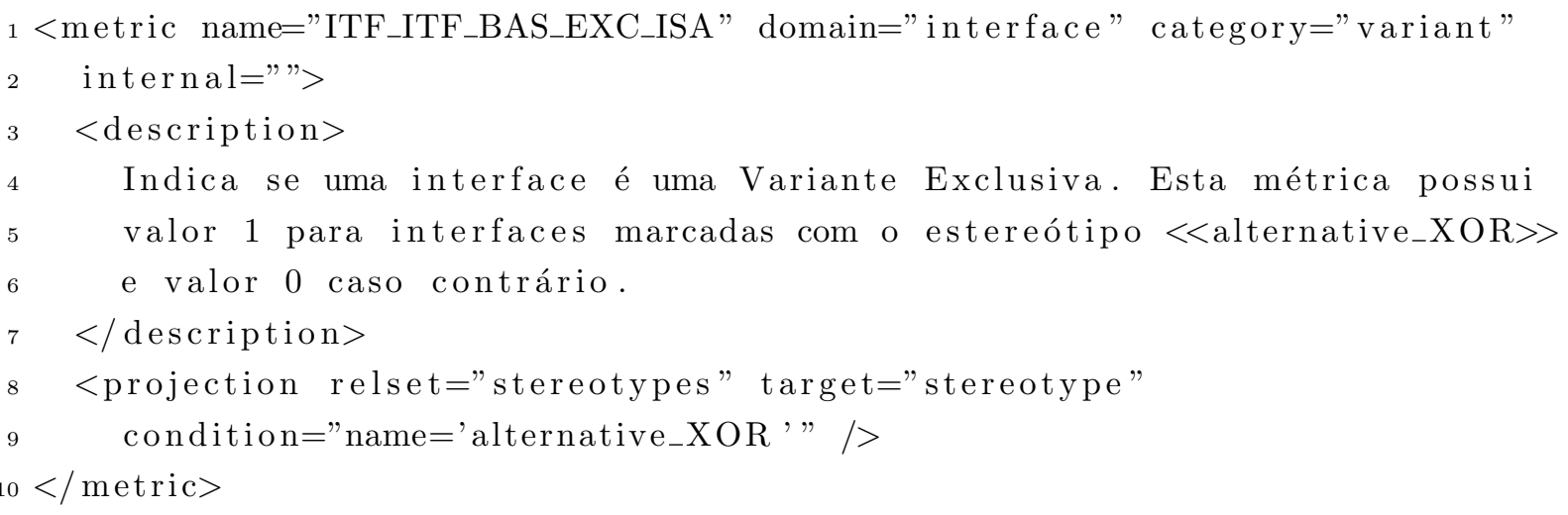

Listagem B.19: Código XML da Métrica $I T F \_I T F \_B A S \_E X C \_I S A$.

\section{0. $I T F \_I T F \_B A S \_O P T \_I S A$}

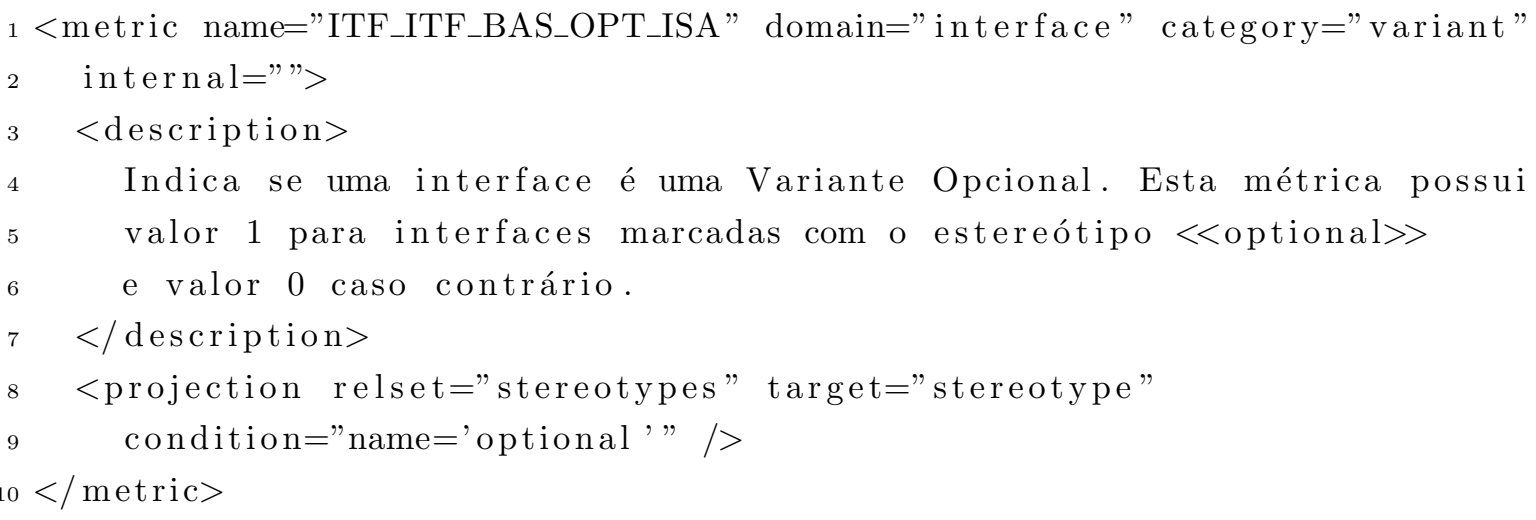

Listagem B.20: Código XML da Métrica ITF_ITF_BAS_OPT_ISA.

\section{1. $I T F \_I T F \_B A S \_M N D \_I S A$}

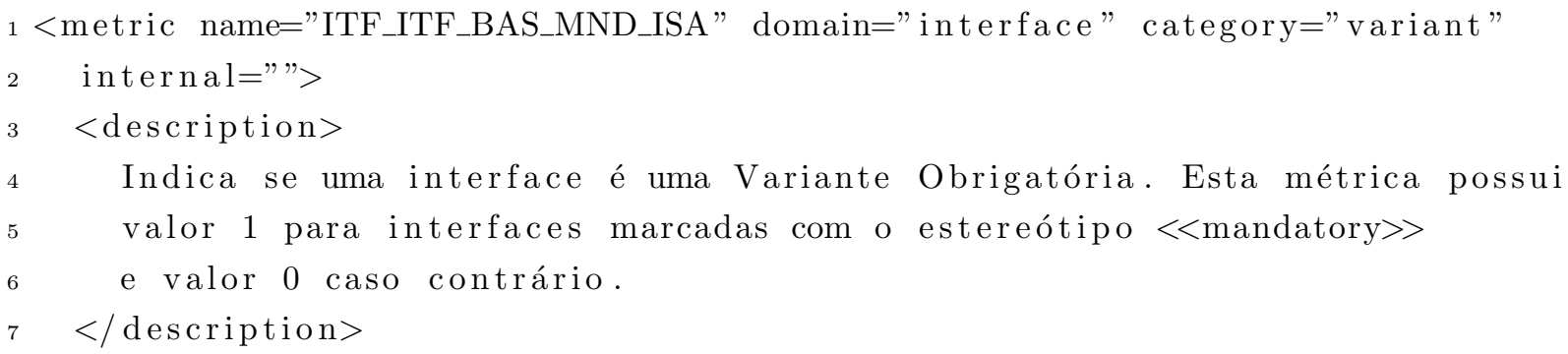




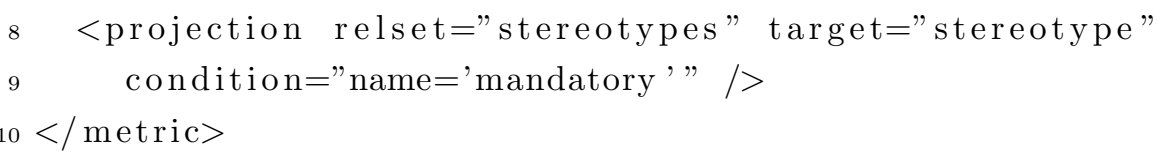

Listagem B.21: Código XML da Métrica $I T F \_I T F \_B A S \_M N D \_I S A$.

\section{2. $\boldsymbol{I} T \boldsymbol{T F} \_\boldsymbol{I} T F_{-} \boldsymbol{B} \boldsymbol{A} \boldsymbol{S} \_I N \boldsymbol{C}_{-} \boldsymbol{N} \boldsymbol{U} \boldsymbol{M}$}

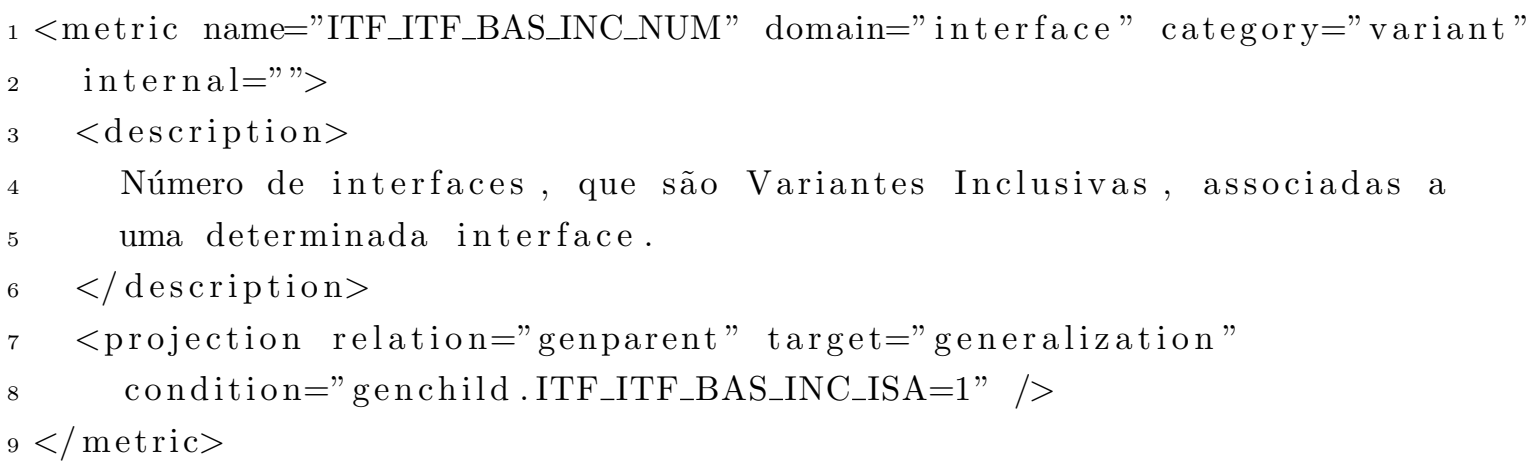

Listagem B.22: Código XML da Métrica $I T F_{-} I T F_{-} B A S_{-} I N C_{-} N U M$.

\section{3. $\boldsymbol{I T F} \_\boldsymbol{I} \boldsymbol{T F} \_\boldsymbol{B} \boldsymbol{A} \boldsymbol{S} \_\boldsymbol{E} \boldsymbol{X} \boldsymbol{C} \_\boldsymbol{N} \boldsymbol{U} \boldsymbol{M}$}

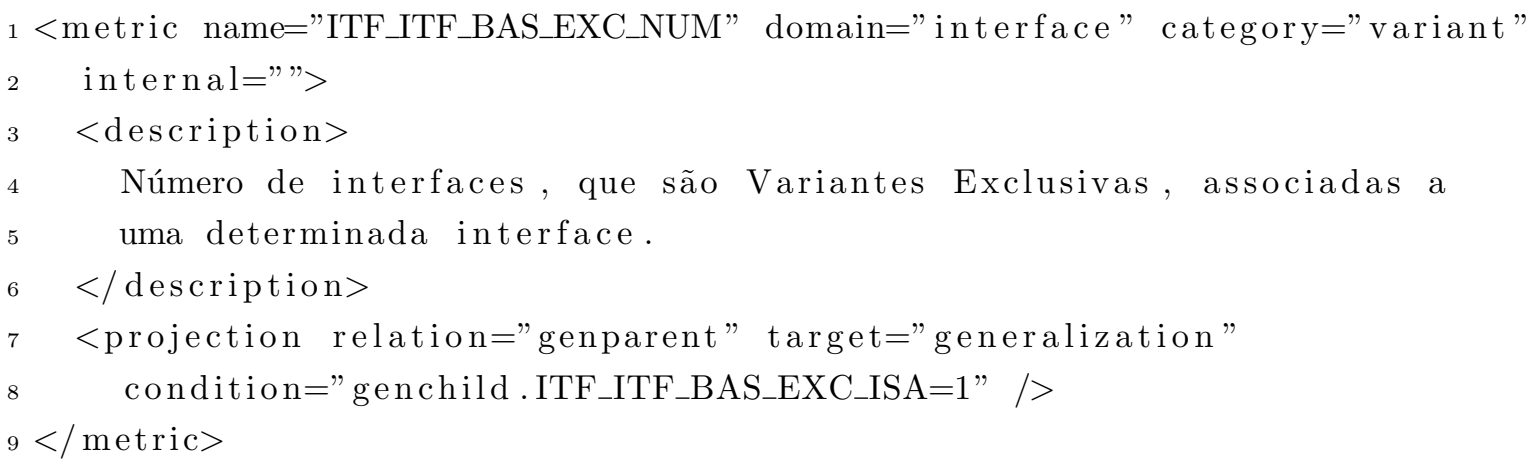

Listagem B.23: Código XML da Métrica ITF_ITF_BAS_EXC_NUM.

\section{4. $\boldsymbol{I T F} \boldsymbol{I T}_{-} \boldsymbol{T} \_\boldsymbol{B} \boldsymbol{A} \boldsymbol{S} \_\boldsymbol{O P T} \boldsymbol{T}_{-} \boldsymbol{N} \boldsymbol{U} \boldsymbol{M}$}

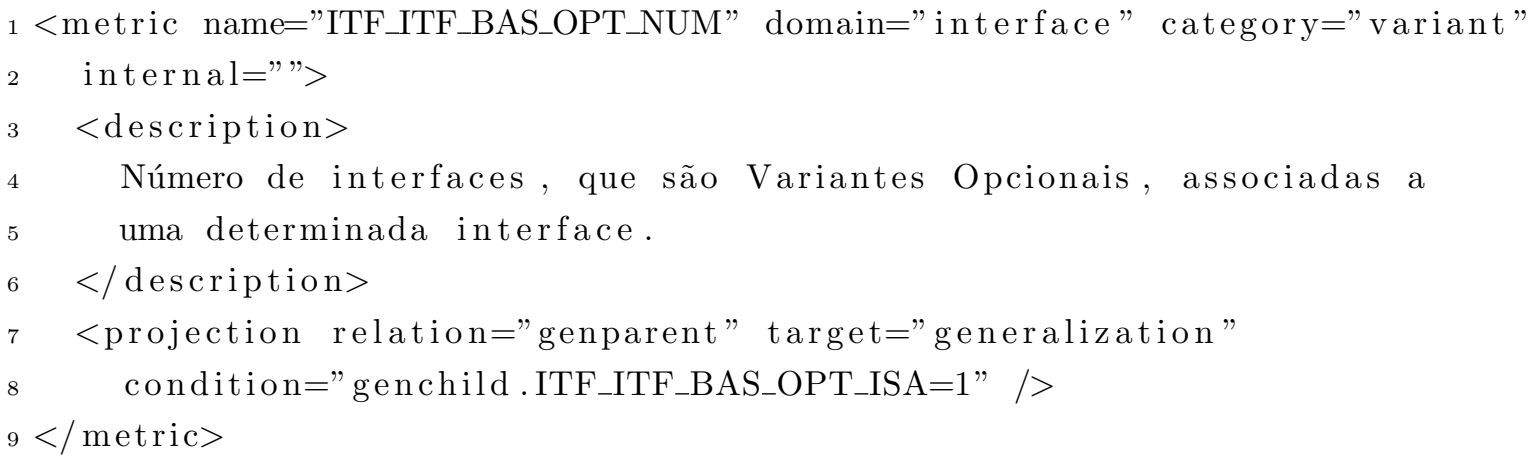

Listagem B.24: Código XML da Métrica $I T F_{-} I T F_{-} B A S \_O P T \_N U M$. 


\section{5. $I T F \_I T F \_B A S \_M N D \_N U M$}

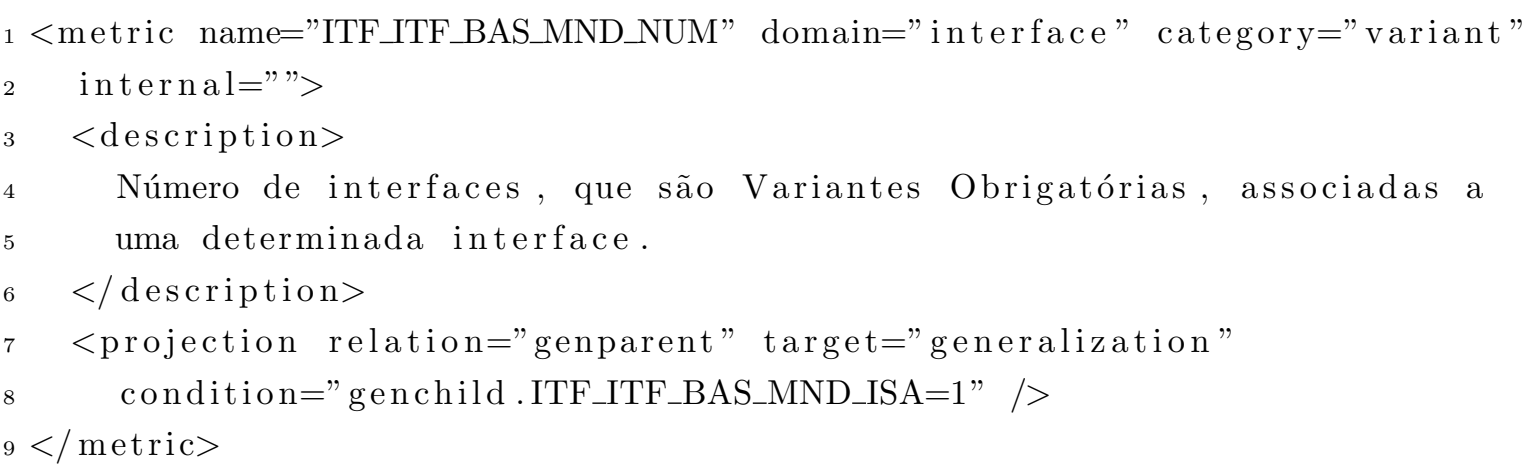

Listagem B.25: Código XML da Métrica ITF_ITF_BAS_MND_NUM.

\section{6. $\boldsymbol{I T F} \_\boldsymbol{I T F} \boldsymbol{F}_{-} \boldsymbol{B} \boldsymbol{A} \boldsymbol{S}_{-} \boldsymbol{V} \boldsymbol{P} \boldsymbol{T}_{-} \boldsymbol{N} \boldsymbol{U} \boldsymbol{M}$}

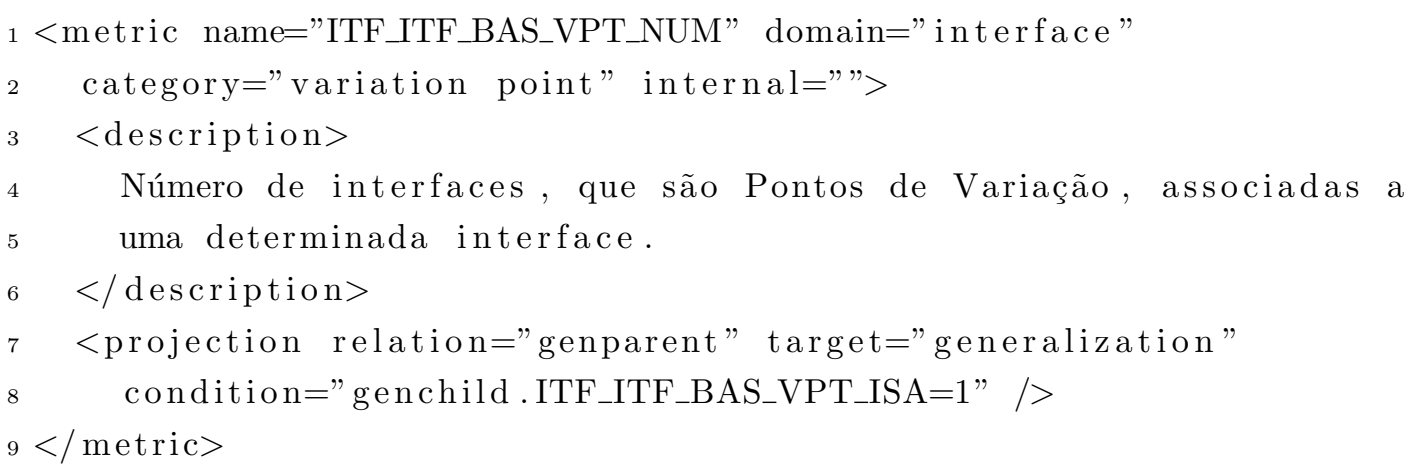

Listagem B.26: Código XML da Métrica ITF_ITF_BAS_VPT_NUM.

\section{ITF_CLS_BAS_INC_NUM}

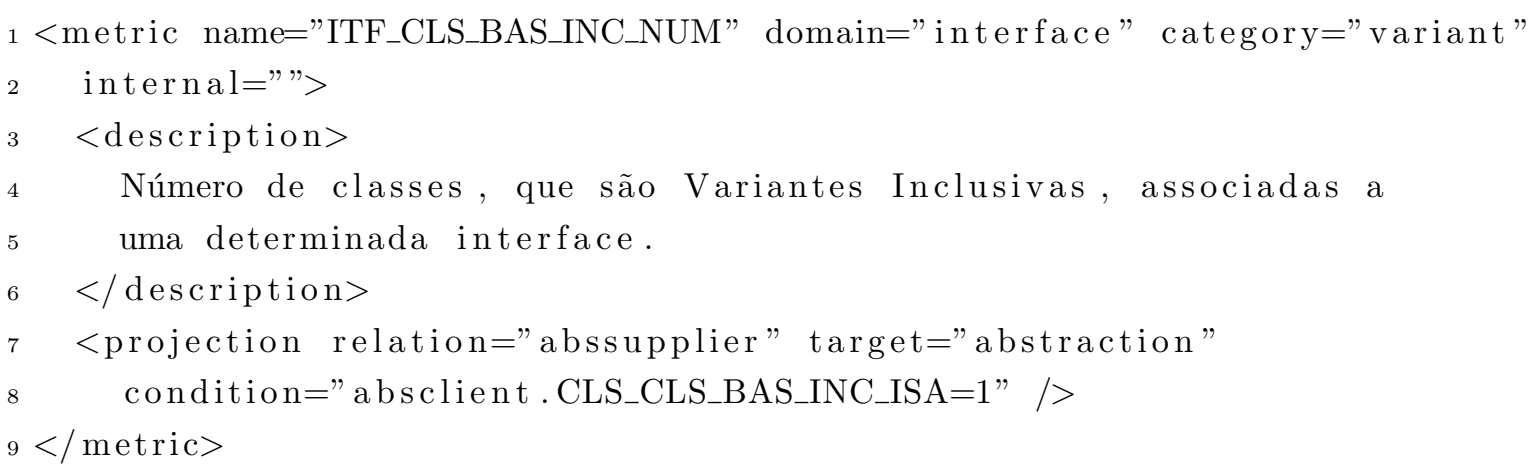

Listagem B.27: Código XML da Métrica ITF_CLS_BAS_INC_NUM.

\section{8. $\boldsymbol{I} T \boldsymbol{T}$ - $\boldsymbol{C L} \boldsymbol{S} \_\boldsymbol{B} \boldsymbol{A} \boldsymbol{S} \_\boldsymbol{E} X \boldsymbol{C} \_\boldsymbol{N} U \boldsymbol{M}$}

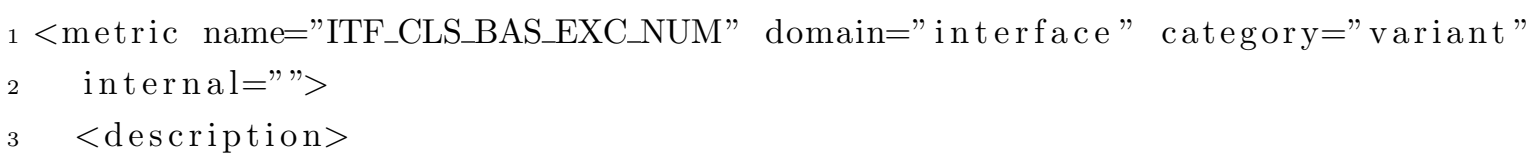




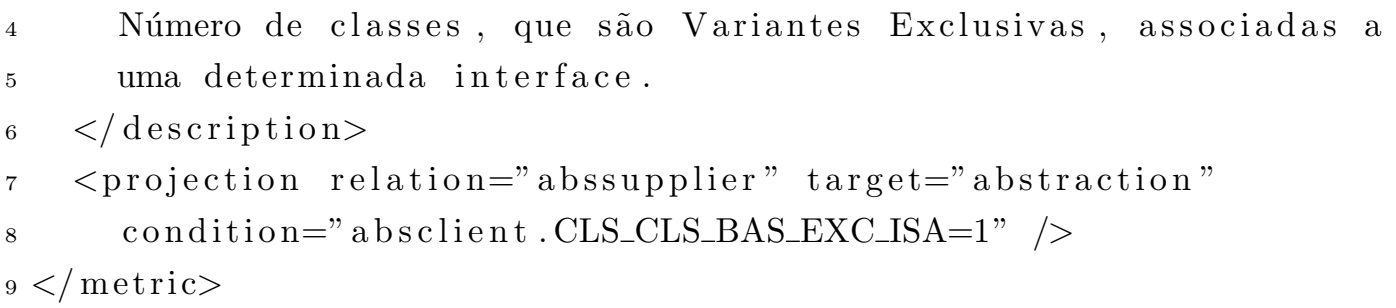

Listagem B.28: Código XML da Métrica ITF_CLS_BAS_EXC_NUM.

\section{9. $\boldsymbol{I T F} \boldsymbol{T} \boldsymbol{C L} \boldsymbol{S} \_\boldsymbol{B} \boldsymbol{A} \boldsymbol{S} \_\boldsymbol{O P T} \boldsymbol{T} \boldsymbol{N} U \boldsymbol{M}$}

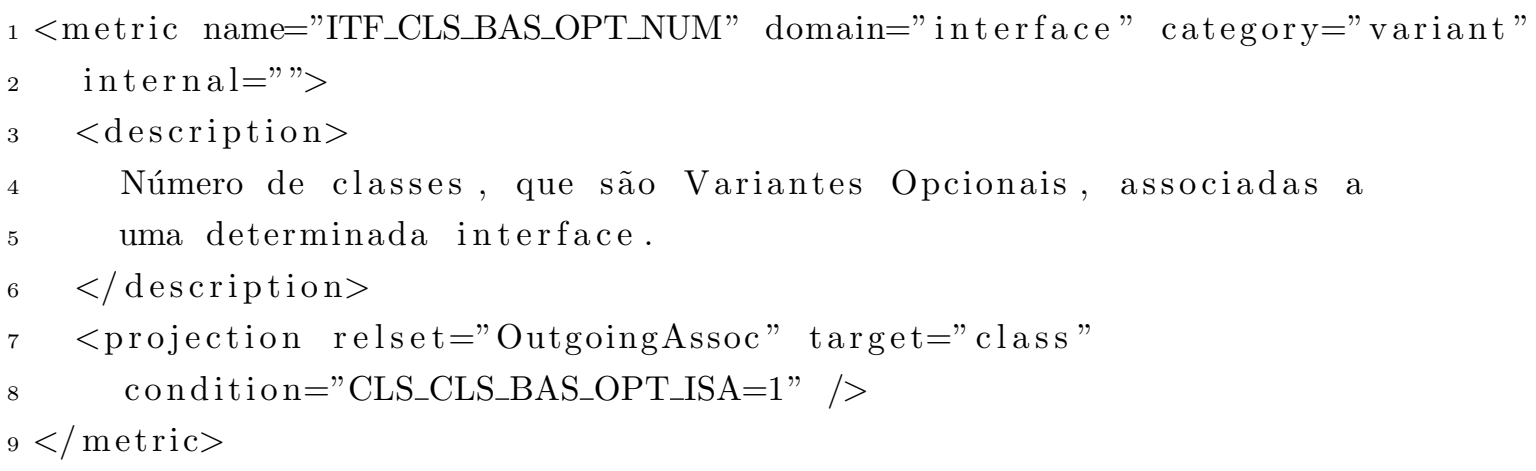

Listagem B.29: Código XML da Métrica ITF_CLS_BAS_OPT_NUM.

\section{ITF_CLS_BAS_MND_NUM}

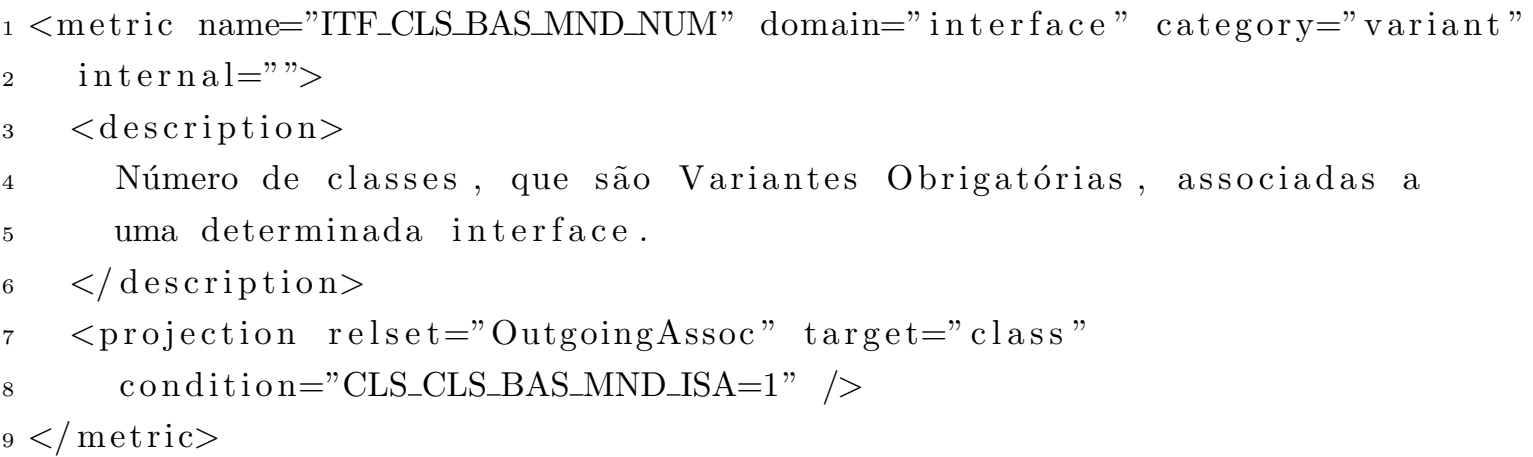

Listagem B.30: Código XML da Métrica $I T F \_C L S \_B A S \_M N D \_N U M$.

\section{1. $\boldsymbol{I T F} \boldsymbol{F}_{-} \boldsymbol{C L} \boldsymbol{S}_{-} \boldsymbol{B} \boldsymbol{A} \boldsymbol{S}_{-} \boldsymbol{V P T} \boldsymbol{T}_{-} \boldsymbol{N} \boldsymbol{U} \boldsymbol{M}$}

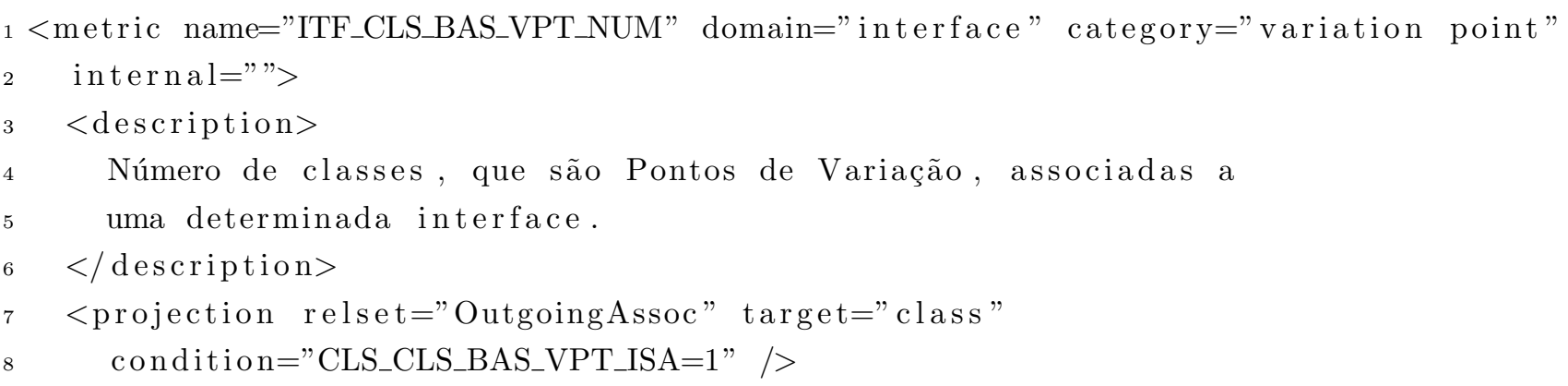


$9</$ metric $>$

Listagem B.31: Código XML da Métrica $I T F_{-} C L S_{-} B A S_{-} V P T \_N U M$.

32. $\boldsymbol{I T F} \_\boldsymbol{I T F} \_\boldsymbol{B} \boldsymbol{A} \boldsymbol{S}_{-} \boldsymbol{V} \boldsymbol{B} \boldsymbol{T}_{-} \boldsymbol{N} \boldsymbol{U} \boldsymbol{M}$

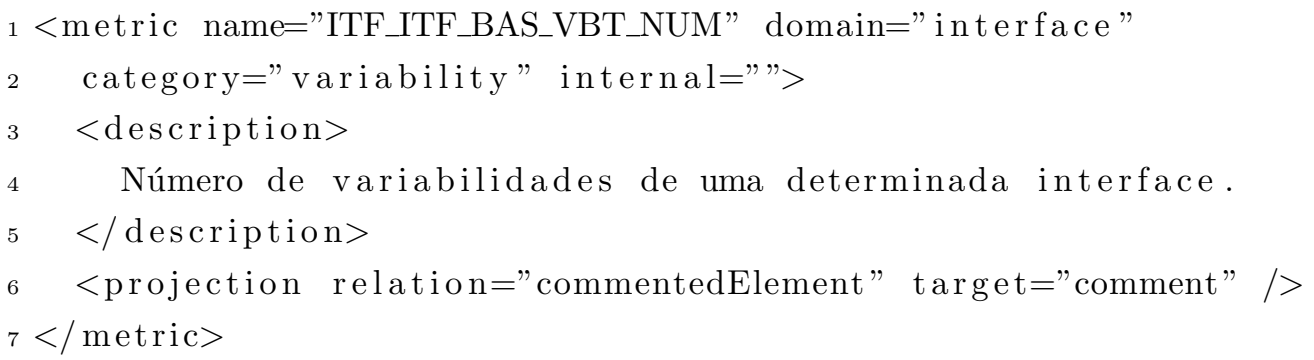

Listagem B.32: Código XML da Métrica $I T F \_I T F \_B A S \_V B T \_N U M$.

\section{B.3 Métricas Básicas de Diagramas}

33. DGM_CLS_BAS_VPT_TOT

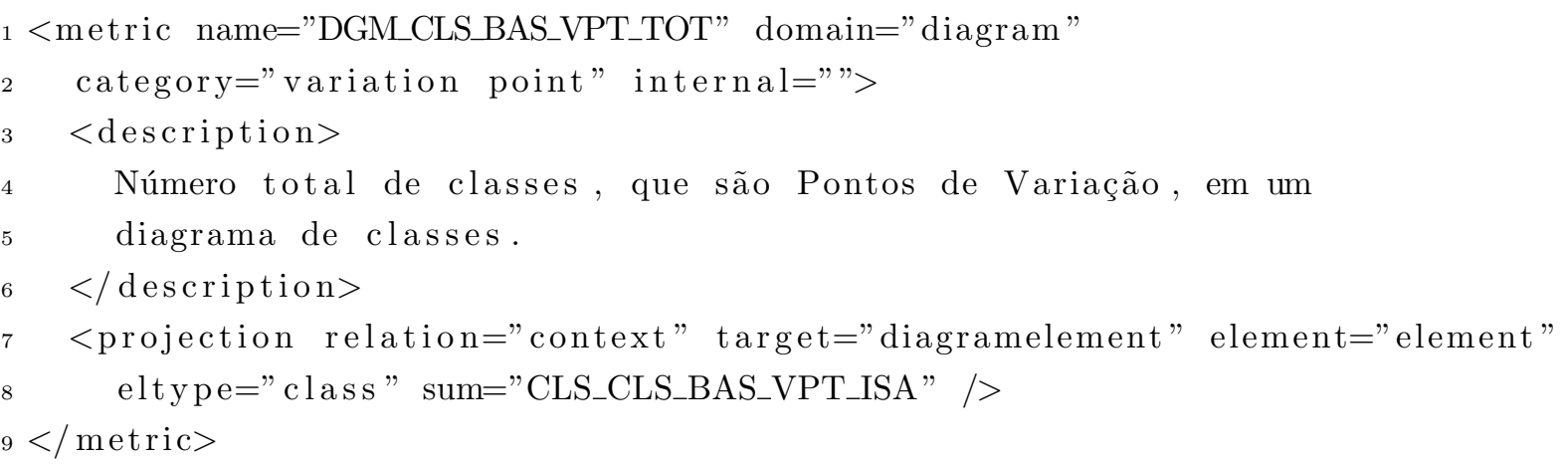

Listagem B.33: Código XML da Métrica $D G M_{-} C L S_{-} B A S_{-} V P T \_T O T$.

\section{4. $D G M \_C L S \_B A S \_I N C \_T O T$}

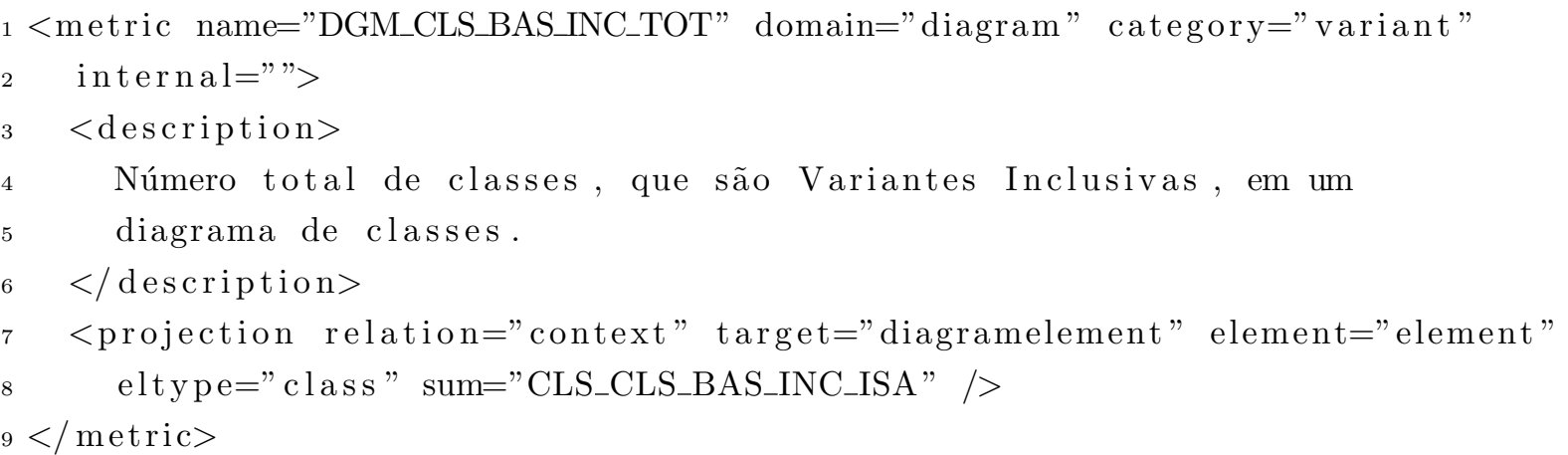

Listagem B.34: Código XML da Métrica $D G M_{-} C L S \_B A S \_I N C_{-} T O T$. 
35. DGM_CLS_BAS_EXC_TOT

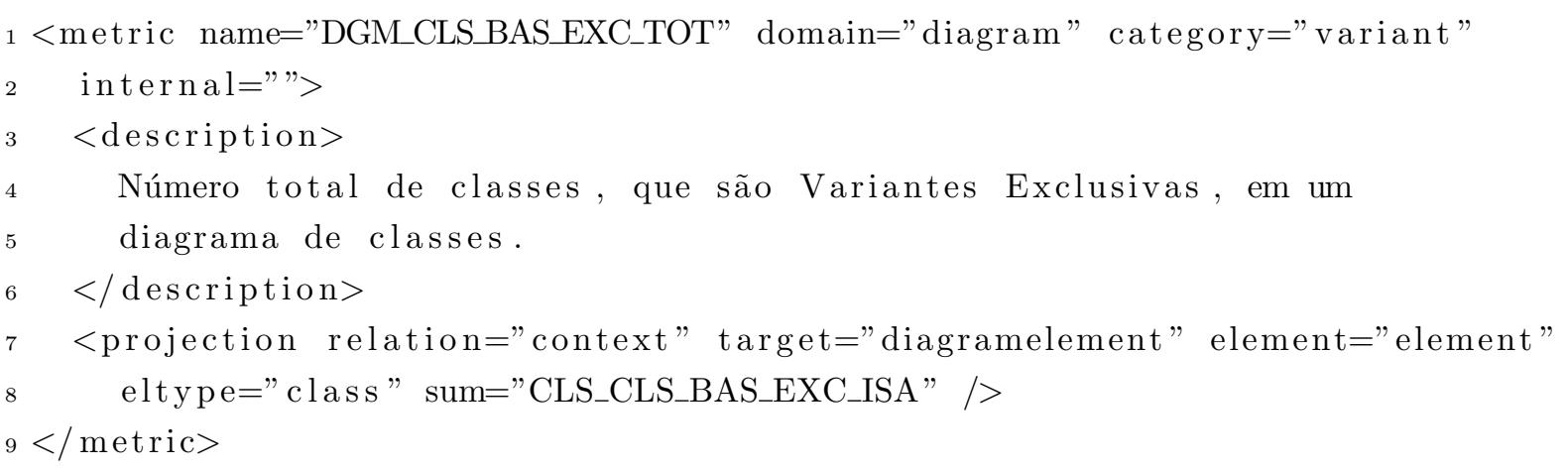

Listagem B.35: Código XML da Métrica DGM_CLS_BAS_EXC_TOT.

\section{DGM_CLS_BAS_OPT_TOT}

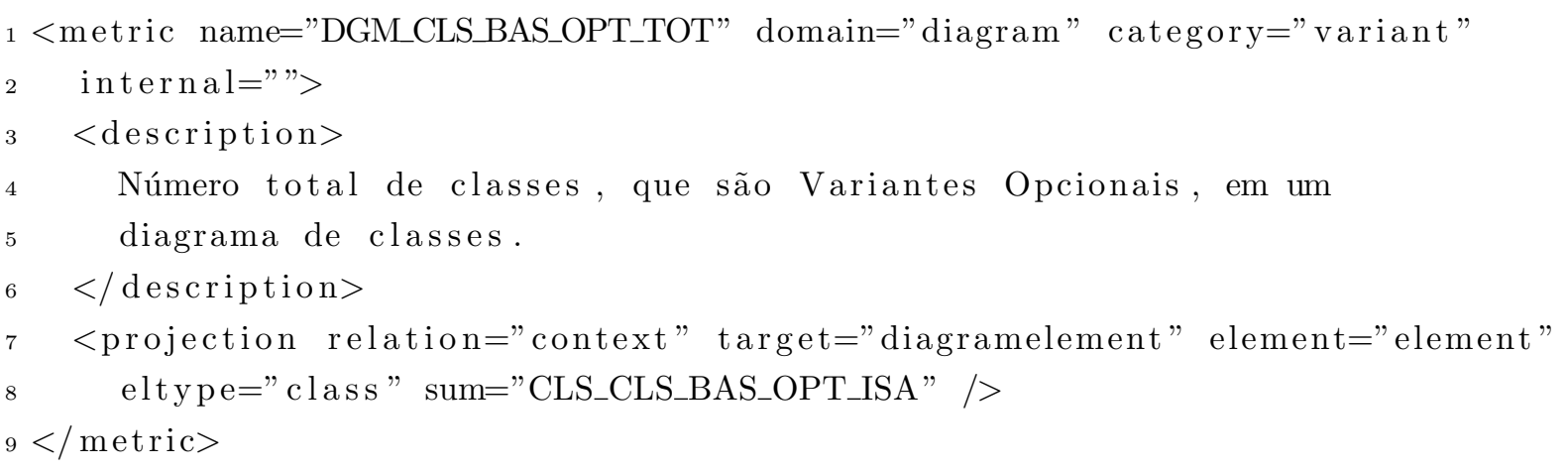

Listagem B.36: Código XML da Métrica DGM_CLS_BAS_OPT_TOT.

\section{7. $D G M \_C L S \_B A S \_M N D \_T O T$}

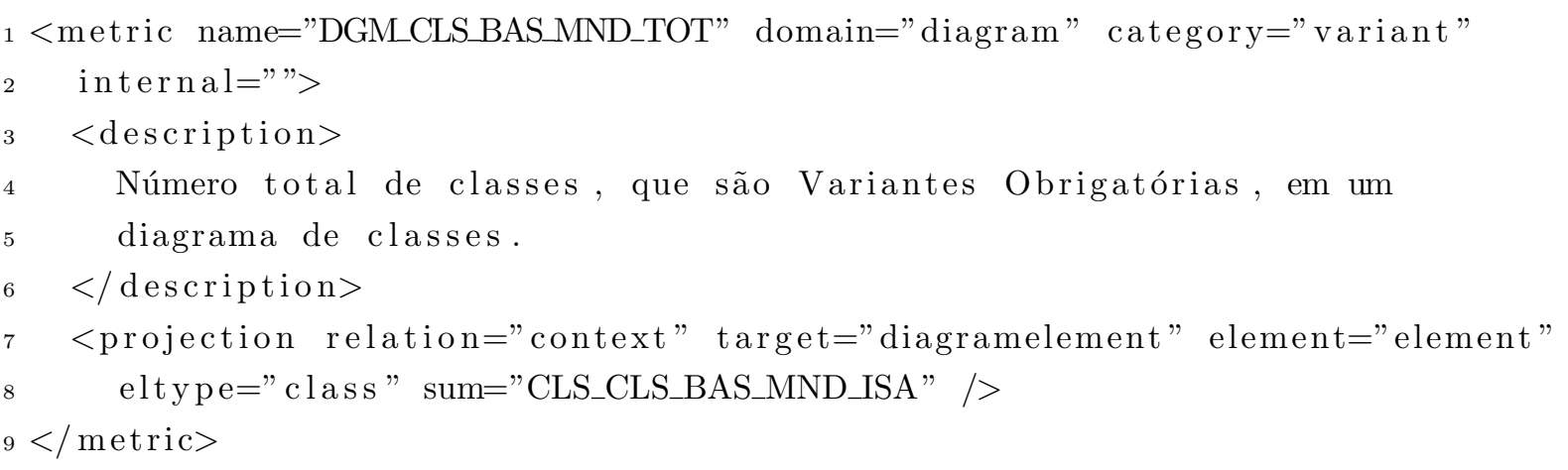

Listagem B.37: Código XML da Métrica DGM_CLS_BAS_MND_TOT.

\section{8. $D G M \_C L S \_B A S_{-} V B T_{-} T O T$}

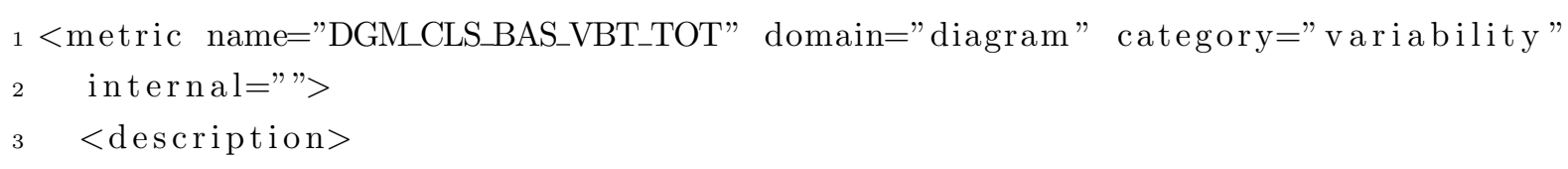




$$
5
$$

Número total de Variabilidades em classes em um diagrama de classes. $</$ description $>$

$<$ projection relation=" context" target="diagramelement" element="element" elty pe=" class" condition="CLS_CLS_BAS_VBT_NUM!=0" $/>$

Listagem B.38: Código XML da Métrica $D G M_{-} C L S_{-} B A S_{-} V B T_{-} T O T$.

\section{9. $\boldsymbol{D G M} \boldsymbol{I} T \boldsymbol{F}_{-} \boldsymbol{B} \boldsymbol{A} \boldsymbol{S}_{-} \boldsymbol{V P T} \boldsymbol{T}_{-} \boldsymbol{T} \boldsymbol{O T}$}

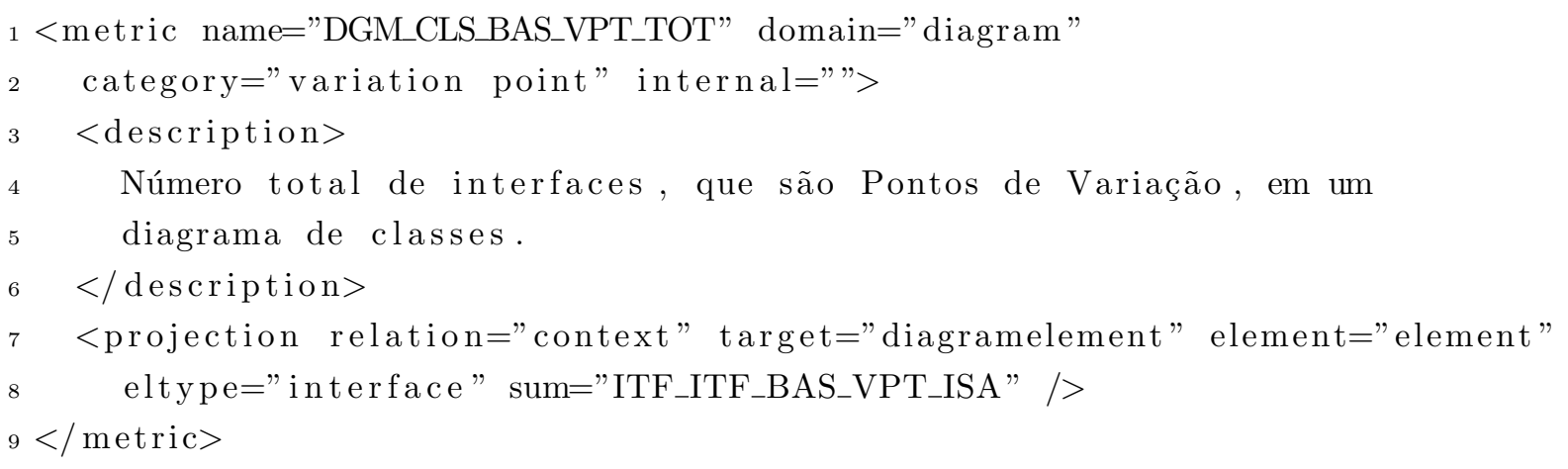

Listagem B.39: Código XML da Métrica DGM_ITF_BAS_VPT_TOT.

\section{0. $\boldsymbol{D} G M_{-} I T F_{-} B A S S_{-} I N C_{-} T \boldsymbol{O} T$}

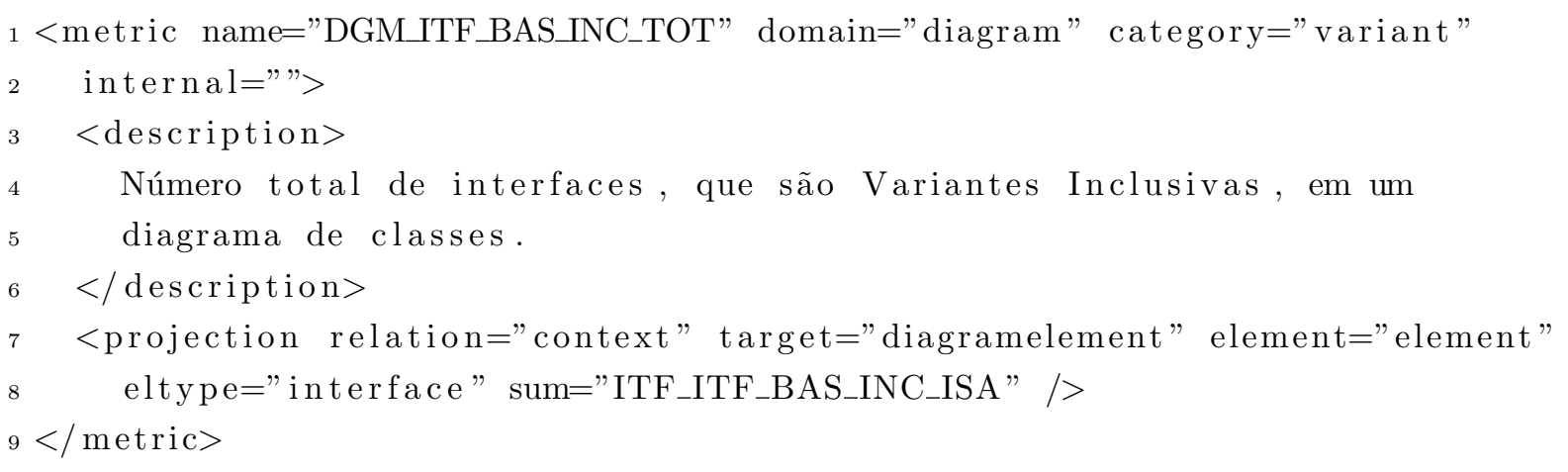

Listagem B.40: Código XML da Métrica DGM_ITF_BAS_INC_TOT.

\section{1. $\boldsymbol{D} G M \_I T F \_B A S \_E X C_{-} T \boldsymbol{O T}$}

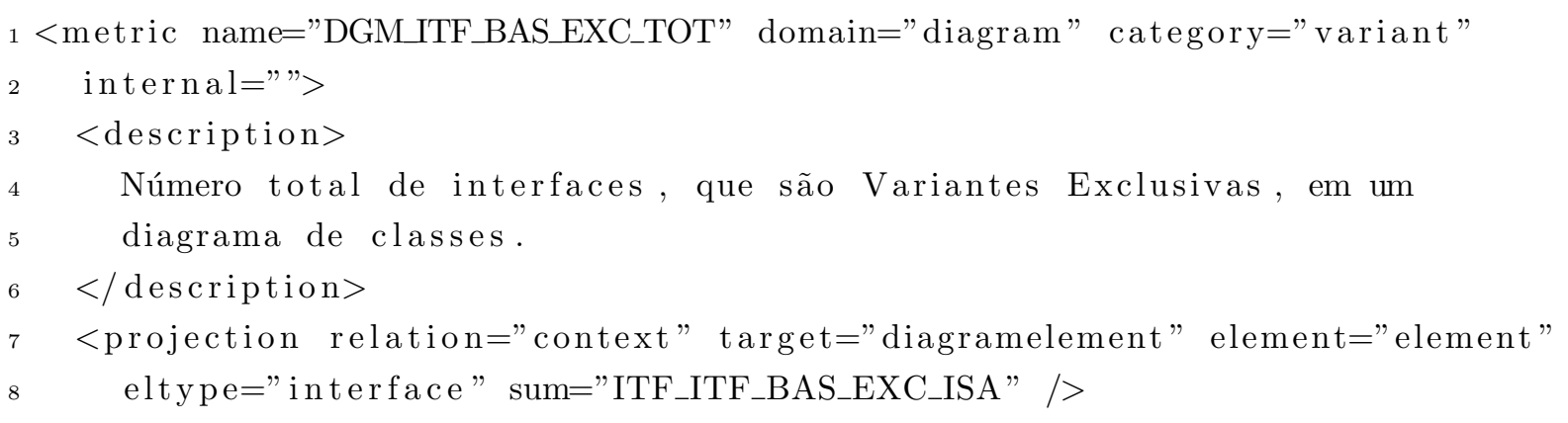


$9</$ metric $>$

Listagem B.41: Código XML da Métrica DGM_ITF_BAS_EXC_TOT.

42. $\boldsymbol{D} G \boldsymbol{M}_{-} \boldsymbol{I} \boldsymbol{T} \boldsymbol{F}_{-} \boldsymbol{B} \boldsymbol{A} \boldsymbol{S} \_\boldsymbol{O P} \boldsymbol{T}_{-} \boldsymbol{T} \boldsymbol{O T}$

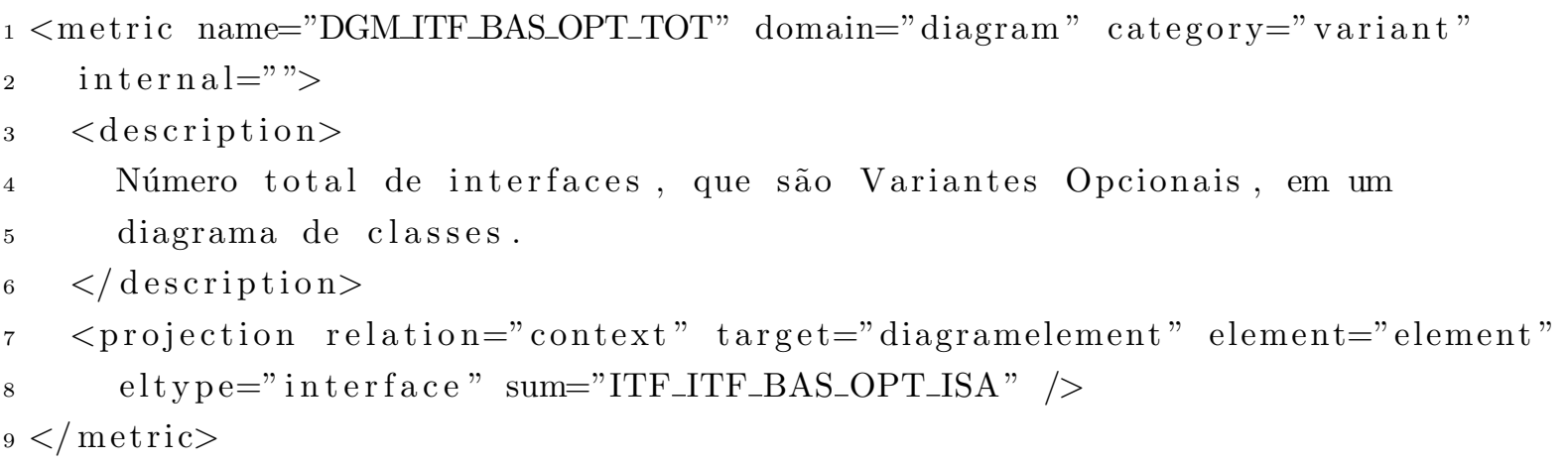

Listagem B.42: Código XML da Métrica DGM_ITF_BAS_OPT_TOT.

43. $\boldsymbol{D} G M \_I T F \_B A S \_M N D \_T O T$

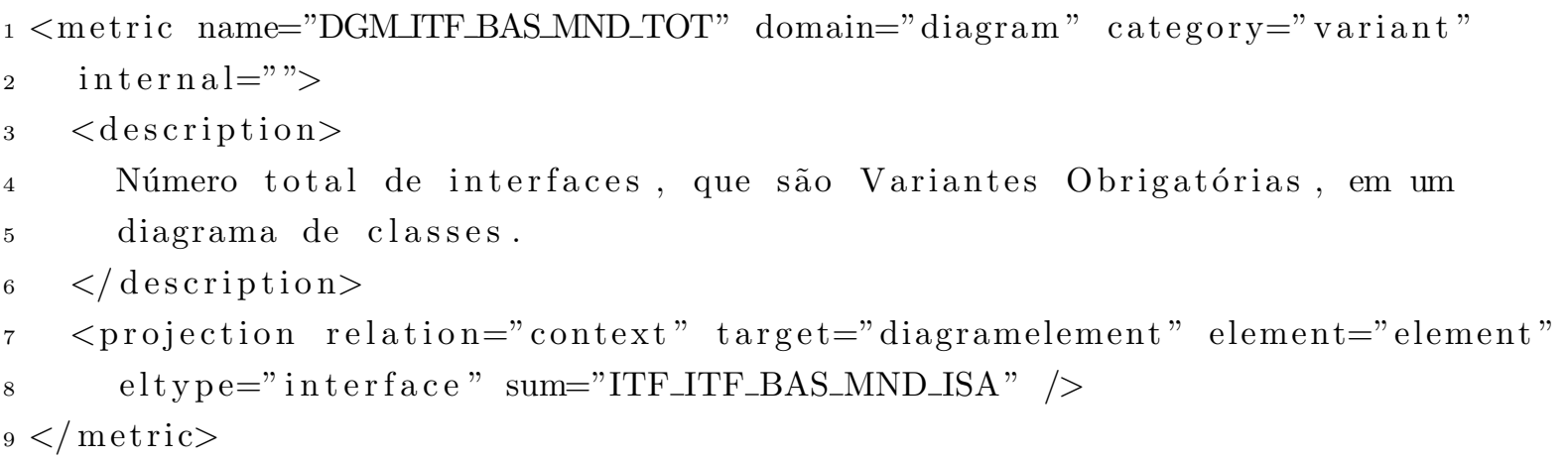

Listagem B.43: Código XML da Métrica $D G M \_I T F \_B A S \_M N D \_T O T$.

\section{4. $D G M \_I T F \_B A S \_V B T+T O T$}

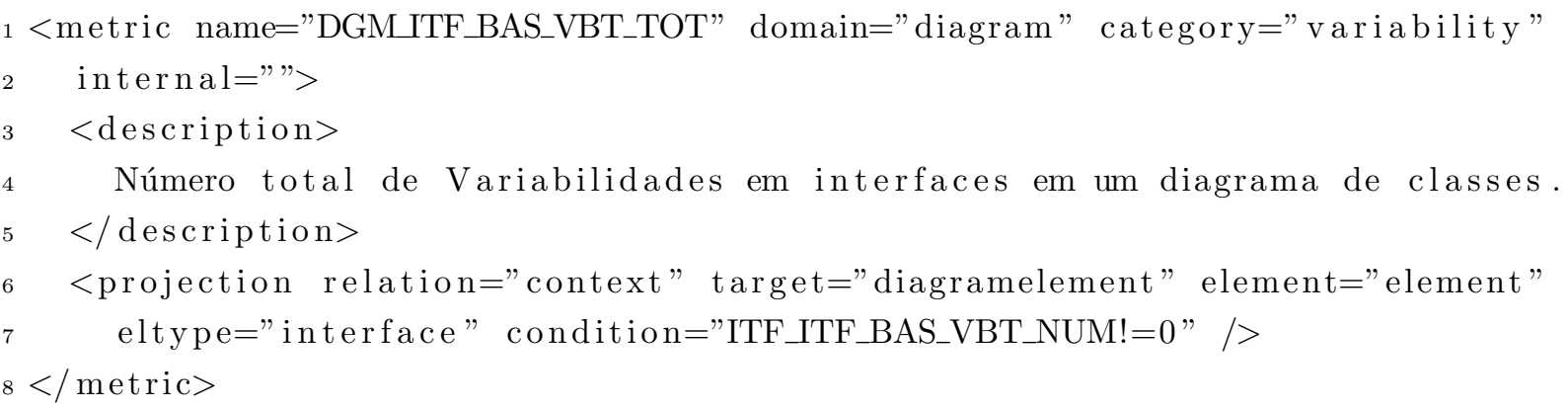

Listagem B.44: Código XML da Métrica DGM_ITF_BAS_VBT_TOT. 


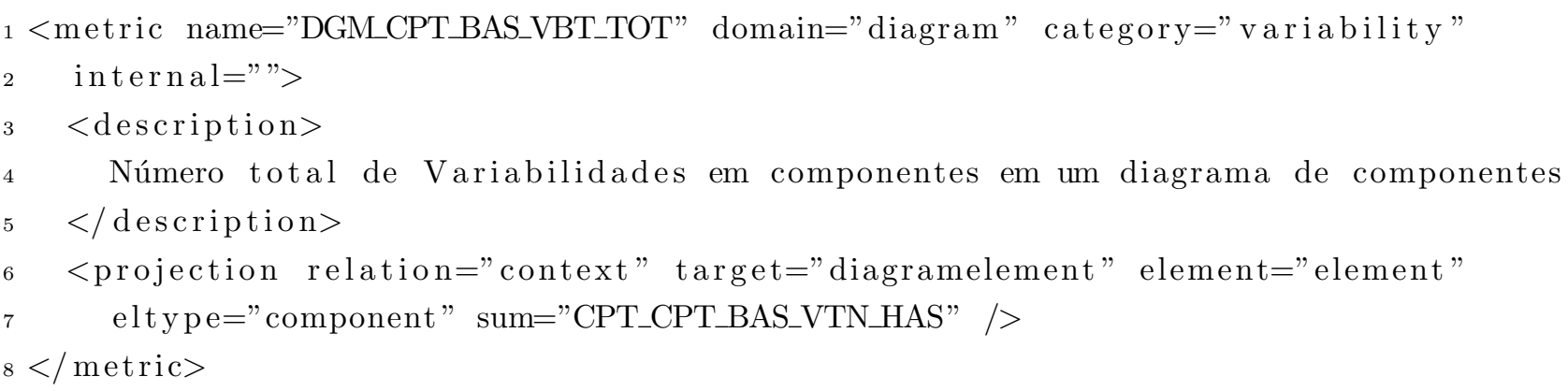

Listagem B.45: Código XML da Métrica DGM_CPT_BAS_VBT_TOT.

\section{B.4 Métrica Básica de Componentes}

46. $C P T_{-} C P T_{-} B A S_{-} V T N_{-} H A S$

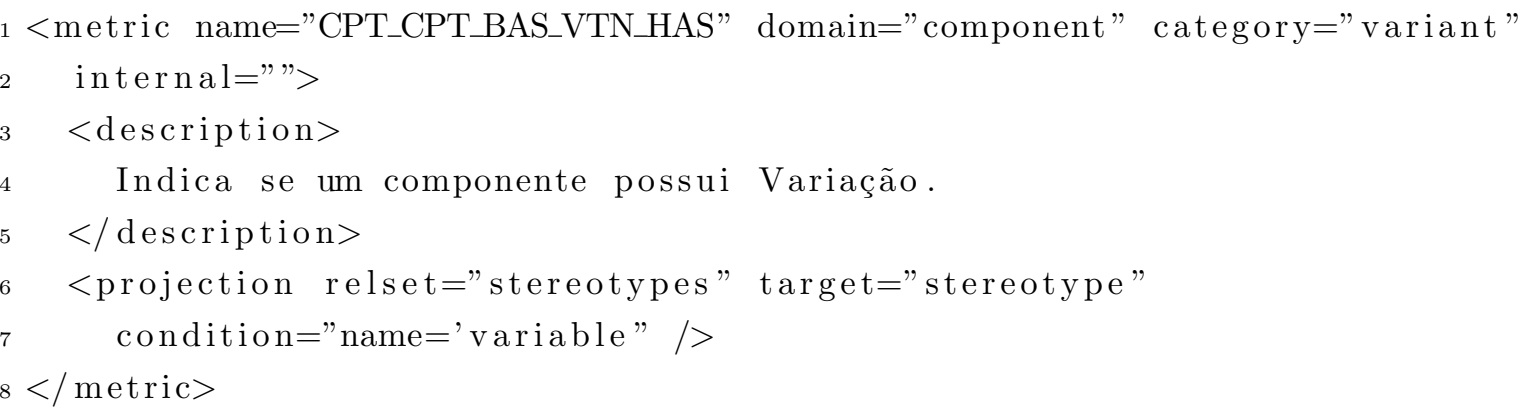

Listagem B.46: Código XML da Métrica $C P T_{-} C P T_{-} B A S_{-} V T N_{-} H A S$.

\section{B.5 Métricas Básicas de Modelos (LP)}

47. $M D L \_C L S \_B A S \_V P T \_T O T$

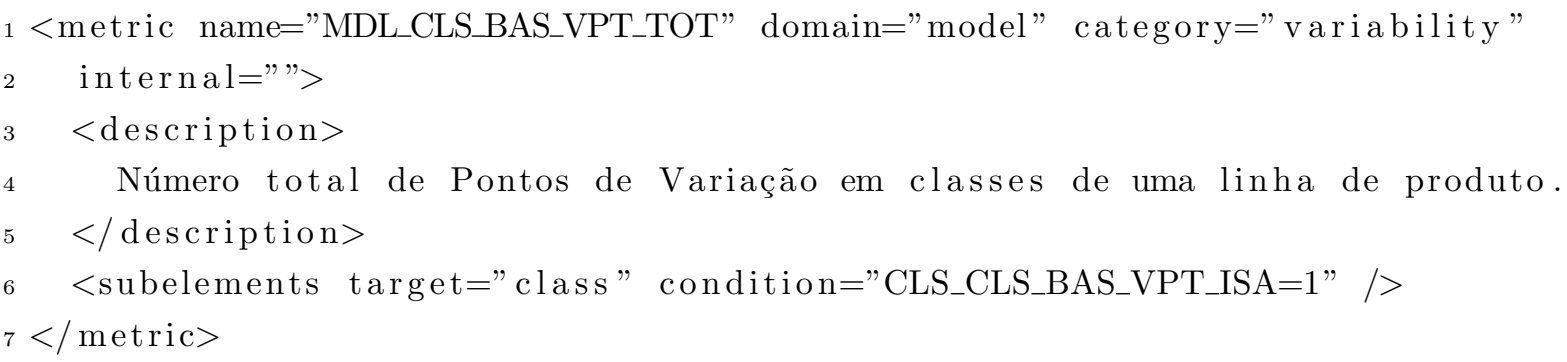

Listagem B.47: Código XML da Métrica MDL_CLS_BAS_VPT_TOT.

48. $\boldsymbol{M D L} \_\boldsymbol{I T F} \_\boldsymbol{B} \boldsymbol{A} \boldsymbol{S}_{-} \boldsymbol{V P T} \boldsymbol{T}_{-} \boldsymbol{T} \boldsymbol{O T}$

$1<$ metric name="MDL_ITF_BAS_VPT_TOT" domain="model" category=" variation point" 


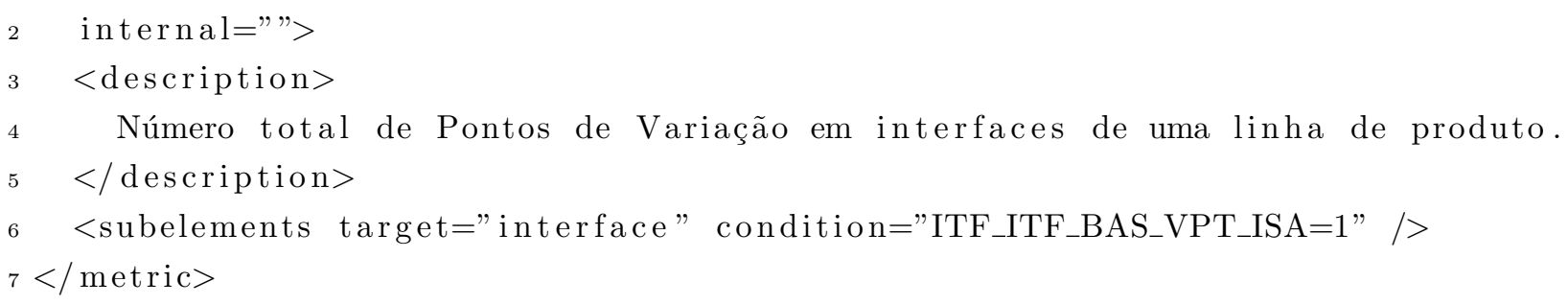

Listagem B.48: Código XML da Métrica MDL_ITF_BAS_VPT_TOT.

49. $M D L \_M D L \_B A S \_V P T \_T O T$

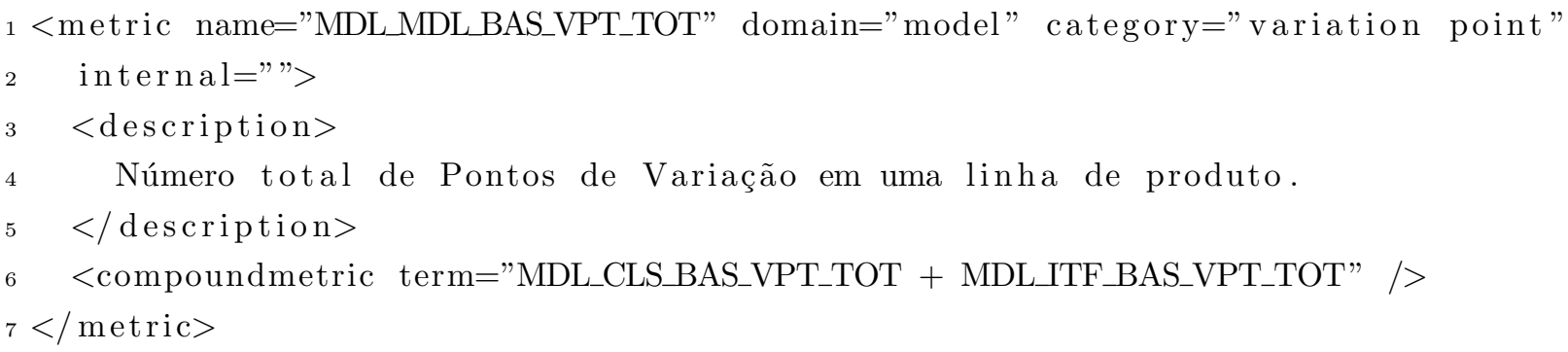

Listagem B.49: Código XML da Métrica $M D L_{-} M D L_{-} B A S_{-} V P T \_T O T$.

\section{0. $M D L \_C L S \_B A S \_V B T_{-} T O T$}

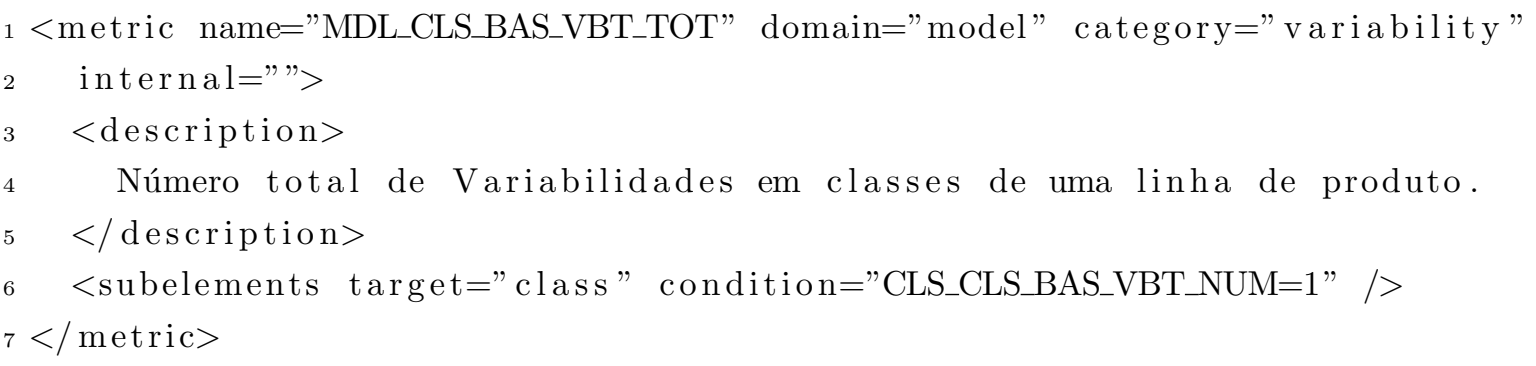

Listagem B.50: Código XML da Métrica $M D L_{-} C L S_{-} B A S_{-} V B T_{-} T O T$.

\section{1. $M D L \_I T F \_B A S \_V B T \_T O T$}

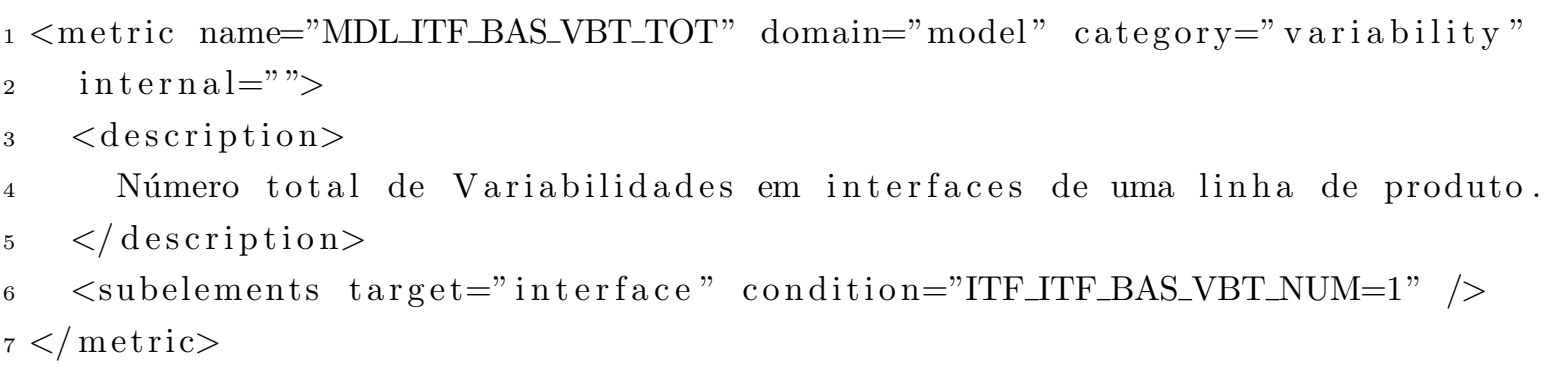

Listagem B.51: Código XML da Métrica $M D L_{-} I T F_{-} B A S_{-} V B T \_T O T$. 


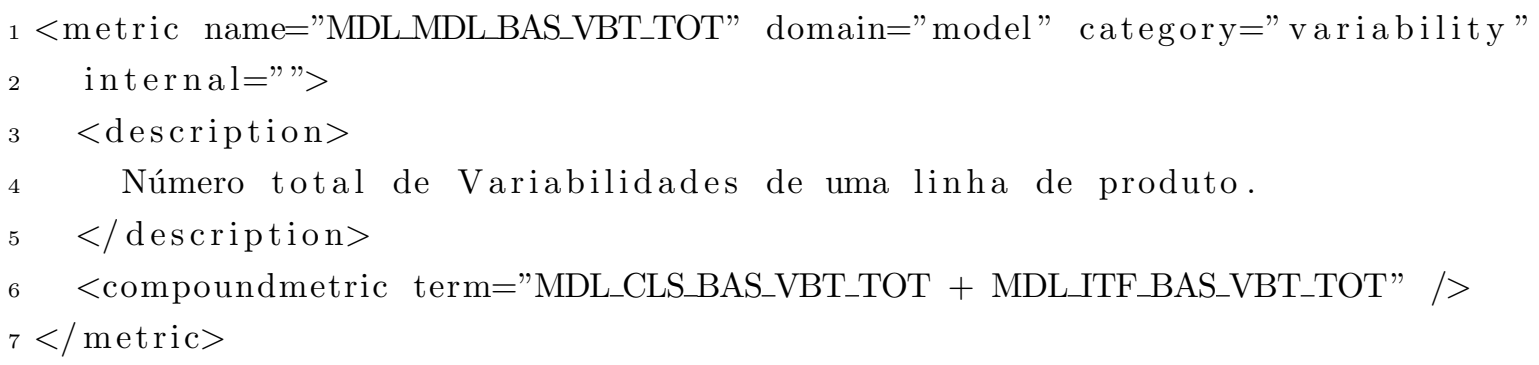

Listagem B.52: Código XML da Métrica $M D L \_M D L \_B A S_{-} V B T_{-} T O T$. 



$\bar{c}$

\section{Validação Experimental de Métricas de ALP:} Instrumentação

Este apêndice apresenta os documentos utilizados para a realização do estudo experimental (Capítulo 7) de validação das métricas de complexidade e extensibilidade propostas para o método SystEM-PLA. Tais documentos são apresentados obedecendo a seguinte ordem:

1. Termo de Adesão ao estudo experimental;

2. Questionário de Caracterização do Participante;

3. Descrição Geral da LP Arcade Game Maker (AGM);

4. Documento descrevendo de forma geral o perfil UML SMartyProfile;

5. Modelo de classes da LP AGM;

6. Modelo de Resolução de Variabilidades da LP AGM. 


\section{Termo de Adesão a Estudo Experimental}

"Validação de Métricas UML e de Código Fonte para Arquiteturas de Linhas de Produto de Software"

Declaro estar ciente de participar de um estudo experimental, denominado validação de métricas UML e código fonte para arquiteturas de linhas de produto de software, a ser coordenado pelo aluno de doutorado Edson A. de Oliveira Junior (ICMC-USP) e pelos professores José C. Maldonado (ICMC-USP) e Itana M. S. Gimenes (DIN-UEM). Neste estudo utilizarei modelos de classes UML da linha de produto Arcade Game Maker (AGM), desenvolvida pelo SEI (Software Engineering Institute), nos quais deverei resolver as suas variabilidades com o objetivo de gerar 05 (cinco) configurações distintas de produtos. Deverei ainda preencher um questionário sucinto declarando minha formação, minha experiência com a notação UML e com a abordagem de Linha de Produto de Software, além de um parecer a respeito do estudo após sua realização. Declaro estar ciente de que os resultados coletados a meu respeito serão confidenciais.

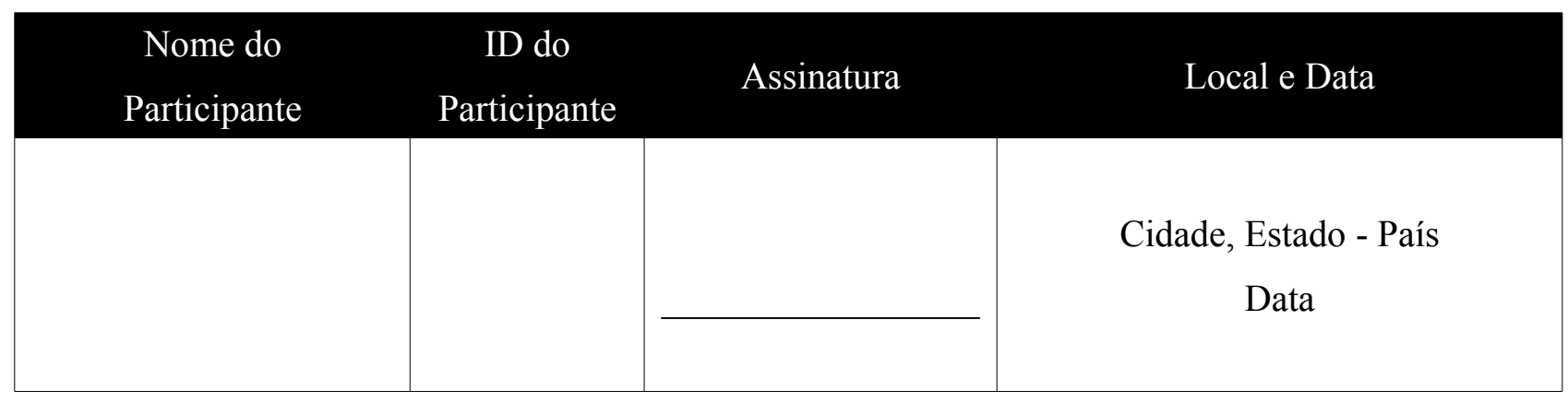




\section{Questionário de Caracterização de Participante em Estudo Experimental}

\section{"Validação de Métricas UML e Código Fonte para Arquiteturas de Linhas de Produto de} Software"

\section{ID do Participante}

Nas perguntas a seguir, quando duas ou mais alternativas forem válidas, marque a alternativa que mais se aplica ao seu caso.
1. Qual o seu nível de formação?
[ ] Graduando
[ ] Graduado
[ ] Mestrando
[ ] Mestre
[ ] Doutorando
[ ] Doutor

2. Qual a sua experiência com a notação UML com relação aos diagramas de casos de uso e de classes?

[ ] Eu nunca modelei um software usando a UML.

[ ] Minha experiência com a notação UML é básica.

Eu modelo softwares somente no nível dos elementos mais comuns da UML como casos de uso e atores; classes e herança.

[ ] Minha experiência com a notação UML é moderada.

Eu modelo softwares no nível dos elementos da opção anterior, além de: relacionamentos de dependência include e extend, e extension points em diagramas de casos de uso; e polimorfismo, associação (uni e bi-direcionais), dependência, agregação e composição em classes.

[ ] Minha experiência com a notação UML é avançada.

Eu modelo softwares que exigem a utilização de todos os elementos de diagramas de casos de uso e classes, além de outros diagramas da UML como, por exemplo, diagramas de 
colaboração, sequência, e componentes.

3. Qual a sua experiência com relação à abordagem de Linha de Porduto de Software (LP) e

\section{Gerenciamento de Variabilidade?}

[ ] Eu nunca ouvi falar a respeito de LP.

[ ] Já lí, de forma superficial, algo a respeito de LP.

[ ] Minha experiência com LP é básica.

Eu conheço os seguintes conceitos da abordagem: ciclo de desenvolvimento de LP e suas atividades (engenharia de domínio e engenharia de aplicação). Porém, não tenho experiência com gerenciamento de variabilidades.

[ ] Minha experiência com LP é moderada.

Eu conheço os conceitos da opção anterior, e com relação ao gerenciamento de variabilidades, eu sei o conceito de pontos de variação, variantes e os seus relacionamentos, além dos conceitos de resolução de variabilidades e tempos de resolução (design time, link time, runtime, entre outros).

\section{[ ] Minha experiência com LP é avançada.}

$\mathrm{Eu}$ conheço os conceitos da opção anterior, além de alguns processos existentes de desenvolvimento de LP (FODA, PLP, PLUS, PuLSE, entre outros). Com relação ao gerenciamento de variabilidades, eu sei os conceitos da opção anterior, além de: modelos de resolução; abordagens existentes para o gerenciamento de variabilidades, e representação de variabilidades (usando a UML, modelos de características, entre outras). 


\section{Arcade Game Maker: Descrição Geral da Linha de Produto}

\section{I dentificação}

A linha de produto (LP) Arcade Game Maker (AGM) produz uma série de jogos arcade. Cada jogo é jogado por um único jogador que controla, parcialmente, os objetos que se movem. O objetivo é marcar pontos acertando obstáculos estáticos. Os jogos vão desde aqueles com obstáculos baixos até obstáculos altos e estão disponíveis para uma variedade de diferentes plataformas.

\section{Similaridades e Variabilidades}

\section{I.1 Similaridades}

- todo jogo possui um conjunto de Sprites (seção II.3);

- todo jogo possui um conjunto de Rules (seção II.3);

- todos os jogos envolvem movimentação.

\section{I .2 Variabilidades}

- Tipos de Regras: é a maior diferença entre os jogos. Algumas regras estão relacionadas às leis da física (gravidade, colisões, etc) e podem ser aplicáveis a múltiplos jogos. Outras regras estão especificamente relacionadas a um jogo e podem ser usadas em todas as implementações do jogo, mas não se aplicam a outros jogos;

- Tipos de Movimentação: em alguns jogos a movimentação é inerente à operação do jogo. Isto acontece periodicamente e é orientada pelo tempo. Em outros jogos, o jogador escolhe e inicia a movimentação, sendo ações dirigidas pelo ator.

\section{I.3 Conceitos I mportantes}

- Sprite: são os elementos do jogo que os jogadores vêem e com os quais eles interagem.

- Rule: são as regras que regem as ações dos jogos. Por exemplo, um jogo pode ter uma regra em que um objeto em movimento ao colidir com um objeto estático deve obedecer às leis da física.

\section{Casos de Uso}

1) Check Previous Best Score: verifica e apresenta o melhor score registrado anteriormente.

a) Ator seleciona a opção CHECK PREVIOUS BEST SCORE do Menu do sistema. Sistema pede para fornecer o nome do arquivo, lê o arquivo e retorna o score à caixa de diálogo.

b) Ator seleciona OK na caixa de diálogo para continuar. Sistema retorna ao estado anterior.

2) Save Score: salva a pontuação corrente do jogador.

a) Ator seleciona SAVE SCORE no Menu do sistema. Sistema pede um nome de arquivo ao ator (cria um novo se não existe), escreve o score no arquivo e retorna ao estado pré-salvo do jogo.

3) Save Game: salva o jogo em andamento. 
a) Ator seleciona a opção SAVE no Menu do sistema. Sistema permite ao ator especificar um nome de arquivo e, em seguida, escreve os dados do jogo no arquivo especificadao e retorna ao estado pré-salvo do jogo.

4) Install Game: instala o jogo escolhido.

a) Ator escolhe o instalador do jogo para ser executado. Sistema apresenta uma caixa de diálogo para escolher o diretório em que serão armazenados os arquivos do jogo.

b) Ator escolhe o diretório. Sistema armazena os arquivos no diretório escolhido.

5) Exit Game: encerra o jogo em andamento.

a) Ator seleciona EXIT no Menu do sistema. Sistema apresenta a caixa de diálogo para salvar ou sair do jogo.

b) Ator salva o jogo. Sistema salva e sai ou cancela saída do jogo.

c) Sistema retorna à ação suspensa.

6) Uninstall Game: remove o jogo selecionado.

a) Ator escolhe a opção UNISTALL do Menu do sitema. Sistema apresenta uma caixa de diálogo ao ator.

b) Ator seleciona o diretório do jogo a ser removido. Sistema exclui os arquivos do diretório e apresenta uma caixa de diálogo de remoção concluída.

c) Ator seleciona a opção OK da caixa de diálogo. Sistema fecha a caixa de diálogo.

7) Play Selected Game: ator seleciona o jogo e inicia a sua execução.

a) Ator seleciona a opção PLAY a partir do Menu. Sistema inicializa o jogo e apresenta o GameBoard.

b) Ator clica com o botão esquerdo e inicia o jogo. Sistema inicia a ação do jogo.

c) Ator clica com o botão esquerdo ou usa o teclado para enviar comandos. Sistema responde aos comandos.

d) Ator responde à caixa de diálogo Won/Lost/Even clicando com o botão esquerdo. Sistema retorna o GameBoard para ser inicializado.

e) A qualquer instante o ator pode selecionar EXIT a partir do Menu.

8) Play Bowling: inicia o jogo Bowling.

a) Ator seleciona PLAY do Menu do sistema. Sistema inicializa o jogo e apresenta o GameBoard.

b) Ator clica com o botão esquerdo para jogar. Sistema inicia a ação do jogo.

c) Ator repete as ações a seguir 10 vezes mais um lance bônus (opcional)

d) Ator posiciona o mouse e clica com o botão esquerdo para lançar a Ball pela Alley (pista). Sistema move a Ball pela Alley usando um algoritmo randômico. Se há colisões com os Pins, o sistema move os Pins segundo as leis físicas de colisão. Sistema conta o número de Pins derrubados. Sistema computa o score.

9) Play Brickles: inicia o jogo Brickles.

a) Ator seleciona PLAY do Menu do sistema. Sistema inicializa o jogo e apresenta o GameBoard.

b) Ator clica com o botão esquerdo para iniciar o jogo. Sistema inicia a ação do jogo.

c) Ator usa o botão esquerdo ou o teclado para enviar comandos ao jogo. Sistema move o Paddle horizontalmente, seguindo o rastro do mouse. A cada movimento do Puck, o sistema verifica se houve colisão com outro objeto. Se o Puck colide com o Ceiling (teto) ou com uma Wall o Puck volta para a área de jogo. Se o Puck colide com o Floor, ele deixa de existir. Se o número máximo de Pucks não foi alcançado, um novo é criado, senão a caixa de diálogo Lost é apresentada. Se o Puck colide com um Brick, a ação a ser tomada depende do Brick. Se for o último Brick, a caixa de diálogo Won é apresentada.

d) Ator responde à caixa de diálogo Won/Lost clicando com o botão esquerdo. Sistema retorna o GameBoard ao estado inicializado e pronto para jogar.

10) Play Pong: inicia o jogo Pong.

a) Ator seleciona PLAY do Menu do sistema. Sistema inicializa o jogo e apresenta o GameBoard.

b) Ator clica com o botão esquerdo para iniciar o jogo. Sistema inicia a ação do jogo.

11) Animation Loop: executa as ações de animação dos jogos.

a) Sistema gera periódicamente sinais e os envia para o jogo. 
b) Sistema move todos os objetos passo-a-passo de acordo com os seus algoritmos de movimentação.

c) Sistema verifica se há colisões e executa os algoritmos de colisão dos objetos.

12) I nitialization: inicializa o jogo selecionado e apresenta o GameBoard.

a) Sistema cria as instâncias-padrão para as classes requeridas.

b) Sistema entra no estado READY.

\section{Classes}

\begin{tabular}{|c|c|c|}
\hline Pacote & Classe & Descrição \\
\hline & Board & Borda de um jogo \\
\hline & GameMenu & Menu com as opcões de um determinado jogo \\
\hline & GameSprite & Elementos dos jogos com os quais o jogador interage \\
\hline & Menu & Menu com as principais opções dos jogos \\
\hline & Movablesprite & Elementos que se movem em um jogo \\
\hline & Paddle & $\begin{array}{l}\text { Elemento utilizado em um jogo para colocar um Puck em } \\
\text { movimento }\end{array}$ \\
\hline & Point & Determinado ponto em um retângulo \\
\hline coreAssets & Puck & $\begin{array}{l}\text { Representa o principal elemento de um jogo como, por } \\
\text { exemplo, a bola que derruba os BowlingPins no jogo } \\
\text { Bowling, a bolinha que destrói os BrickPile no jogo Brickles, } \\
\text { etc }\end{array}$ \\
\hline & Rectangle & Um retângulo que demarca uma área em um jogo \\
\hline & Size & Tamanho de um retângulo \\
\hline & SpritePair & Par de elementos de um jogo que reagem à uma ação \\
\hline & StationarySprite & Elementos que não se movem em um jogo \\
\hline & Velocity & Velocidade de um MovableSprite \\
\hline & Wall & Representa as paredes de um jogo \\
\hline \multirow{10}{*}{ bowl } & Bowling & Classe com a inicialização do jogo \\
\hline & BowlingBall & Bola de boliche \\
\hline & BowlingBoard & Borda do jogo Bowling \\
\hline & BowlingGameMenu & Menu com as opções específicas do jogo \\
\hline & BowlingPin & Pino do jogo de boliche \\
\hline & Edge & Limites esquerdo e direito da canaleta de boliche \\
\hline & EndOfAlley & Fim da pista de boliche \\
\hline & Gutter & Canaleta da pista de boliche \\
\hline & Lane & Pista de boliche \\
\hline & RackOfPins & Local onde os pinos são posicionados \\
\hline pong & BottomPaddle & $\begin{array}{l}\text { Elemento que movimenta a Puck do jogo, localizado na parte } \\
\text { inferior da PongBoard }\end{array}$ \\
\hline
\end{tabular}




\begin{tabular}{|c|c|c|}
\hline & Ceiling & Teto do jogo \\
\hline & DividingLine & Linha divisória dos Paddles \\
\hline & Floor & Chão do jogo \\
\hline & LeftWall & Parede à esquerda do jogo \\
\hline & Pong & Classe com a inicialização do jogo \\
\hline & PongBoard & Borda do jogo Pong \\
\hline & PongGameMenu & Menu com as opções específicas do jogo \\
\hline & RightWall & Parede à direita \\
\hline & ScoreBoard & Placar do jogo \\
\hline & TopPaddle & $\begin{array}{l}\text { Elemento que movimenta a Puck do jogo, localizado na parte } \\
\text { superior da PongBoard }\end{array}$ \\
\hline \multirow{10}{*}{ brickles } & Brick & Tijolo a ser quebrado pelo elemento Puck \\
\hline & Brickles & Classe com a inicialização do jogo \\
\hline & BricklesBoard & Borda do jogo Pong \\
\hline & BricklesGameMenu & Menu com as opções específicas do jogo \\
\hline & BrickPile & Pilha de tijolos \\
\hline & Ceiling & Teto do jogo \\
\hline & Floor & Chão do jogo \\
\hline & LeftWall & Parede à esquerda \\
\hline & PuckSupply & Quantidade de Pucks que o jogador tem direito em um jogo \\
\hline & RightWall & Parede à direita \\
\hline
\end{tabular}

\section{Telas dos Jogos}

\section{V.1 Brickles}

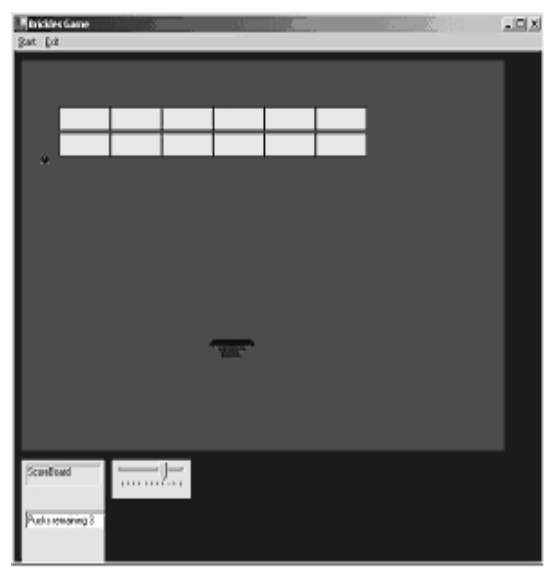


V. 2 Pong

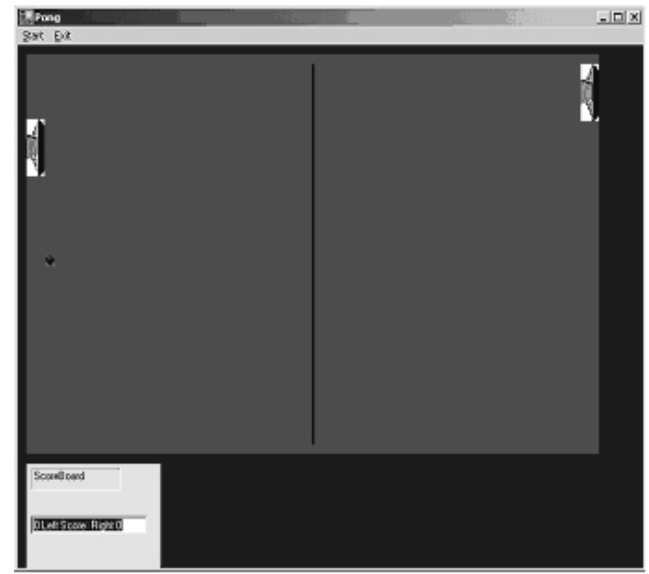

V.3 Bowling

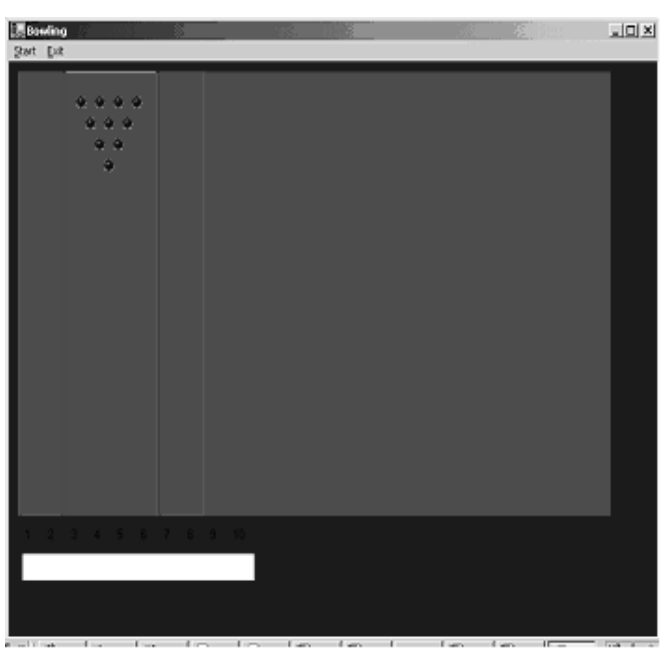




\section{O Perfil SMartyProfile:}

\section{Modelagem de Variabilidades de LP em UML}

As variabilidades são representadas usando a notação UML com base nos seguintes estereótipos:

- <<variationPoint $>>$ : representa o local em que ocorre uma variabilidade. Um ponto de variação está sempre associado à uma ou mais variantes.

- Exemplo: a classe GameMenu representa um ponto de variação e as classes BricklesGameMenu, PongGameMenu e BowlingGameMenu representam as suas variantes associadas.

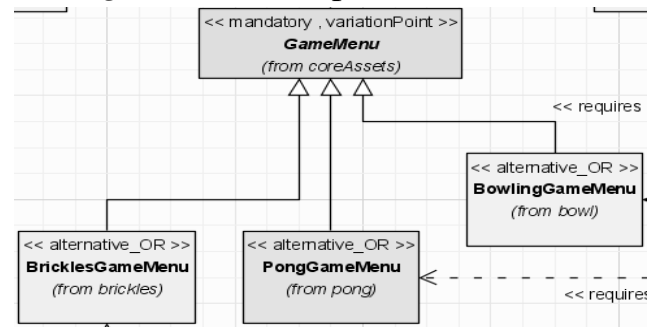

- $\quad<<$ mandatory $>>$ : a variante estará obrigatoriamente presente na configuração de qualquer produto da linha de produto.

- Exemplo: o caso de uso Install Game sempre fará parte dos produtos da linha de produto à qual pertence.

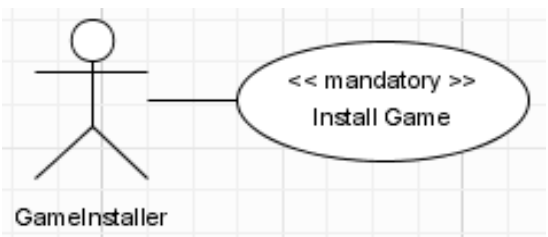

- <<optional>> : a variante pode ou não estar presente na configuração de um produto da linha de produto. Variantes opcionais também podem ou não estar associadas a um ponto de variação.

- Exemplo: a classe SpritePair pode ou não fazer parte da configuração de um produto da linha de produto à qual pertence, ou seja, pode ou não ser escolhida para resolver o ponto de variação GameSprite.

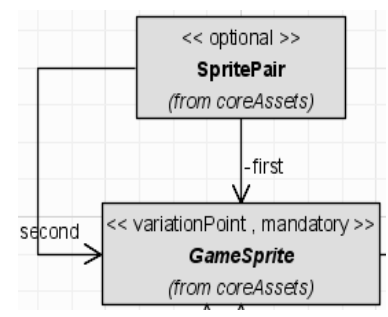


- <<alternative_OR>> : estão sempre associadas aos pontos de variação. Pelo menos uma das variantes deverá ser escolhida para resolver o ponto de variação, ou seja, para estar presente na configuração de um produto da linha de produto.

- Exemplo: pelo menos um dos casos de uso Play Brickles e Play Pong deve ser escolhido para resolver o ponto de variação Play Selected Game.

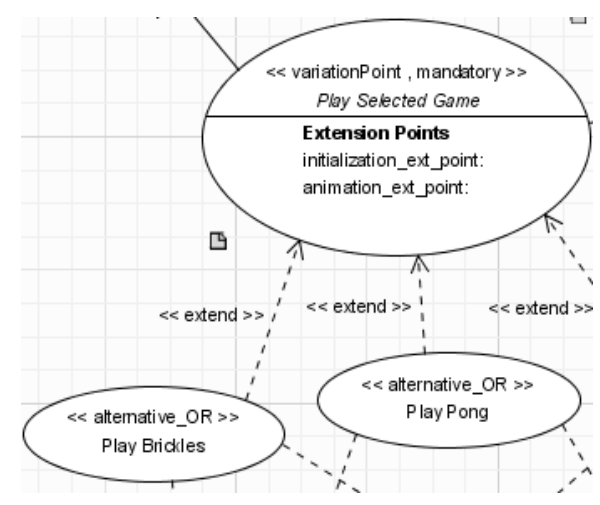

- <<alternative_XOR>> : estão sempre associadas aos pontos de variação. Somente uma das variantes deverá ser escolhida para resolver o ponto de variação.

- Exemplo: o ponto de variação GameMenu é resolvido pela escolha de somente uma única variante: ou BricklesGameMenu ou PongGameMenu.

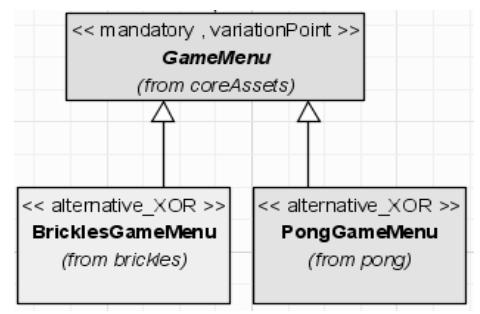

- <<variability >> : indica uma variabilidade existente em um modelo UML.

- Exemplo: a LP possui uma variabilidade chamada "check score" associada ao caso de uso opcional Check Previous Best Score. 


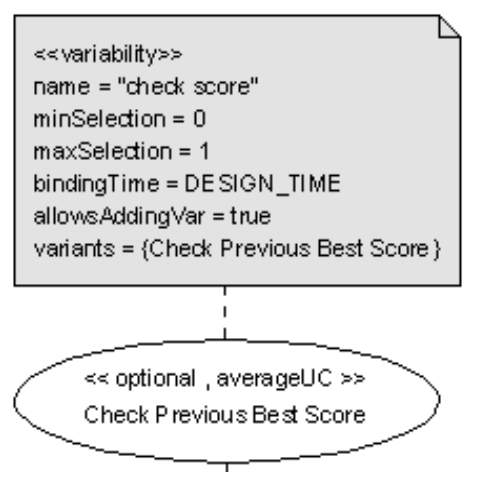

- <<requires >> : indica um relacionamento de dependência (em UML) entre variantes no qual a variante dependente (origem da dependência) só existirá em uma configuração se a variante relacionada (destino da dependência) existir.

- $\quad<<$ mutex $>>$ : indica um relacionamento de dependência (em UML) entre variantes no qual a variante dependente (origem da dependência) só existirá em uma configuração se a variante relacionada (destino da dependência) obrigatoriamente não existir. São conhecidas como variantes mutuamente exclusivas.

A Figura a seguir apresenta o diagrama do perfil VMS-Profile.

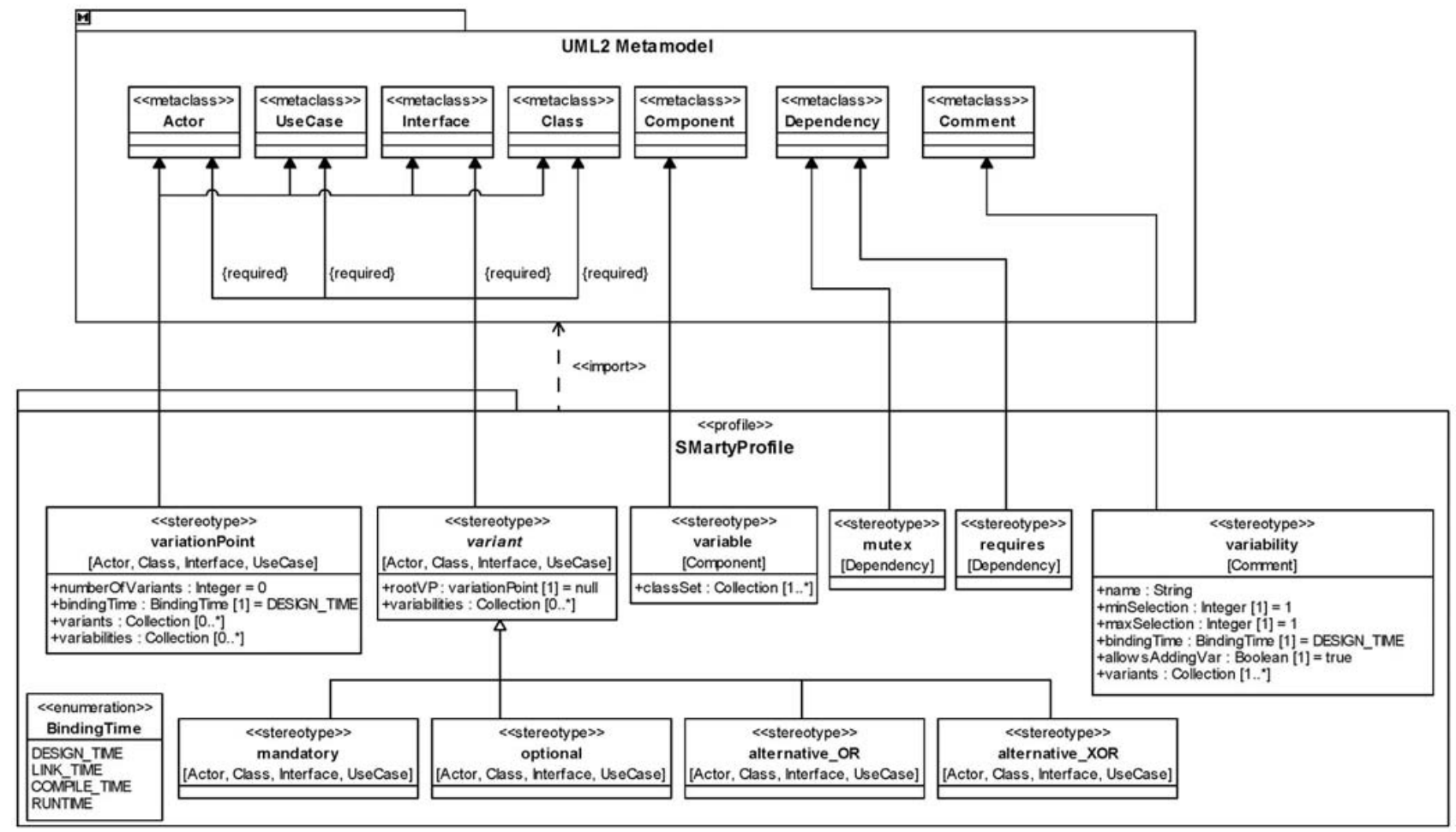




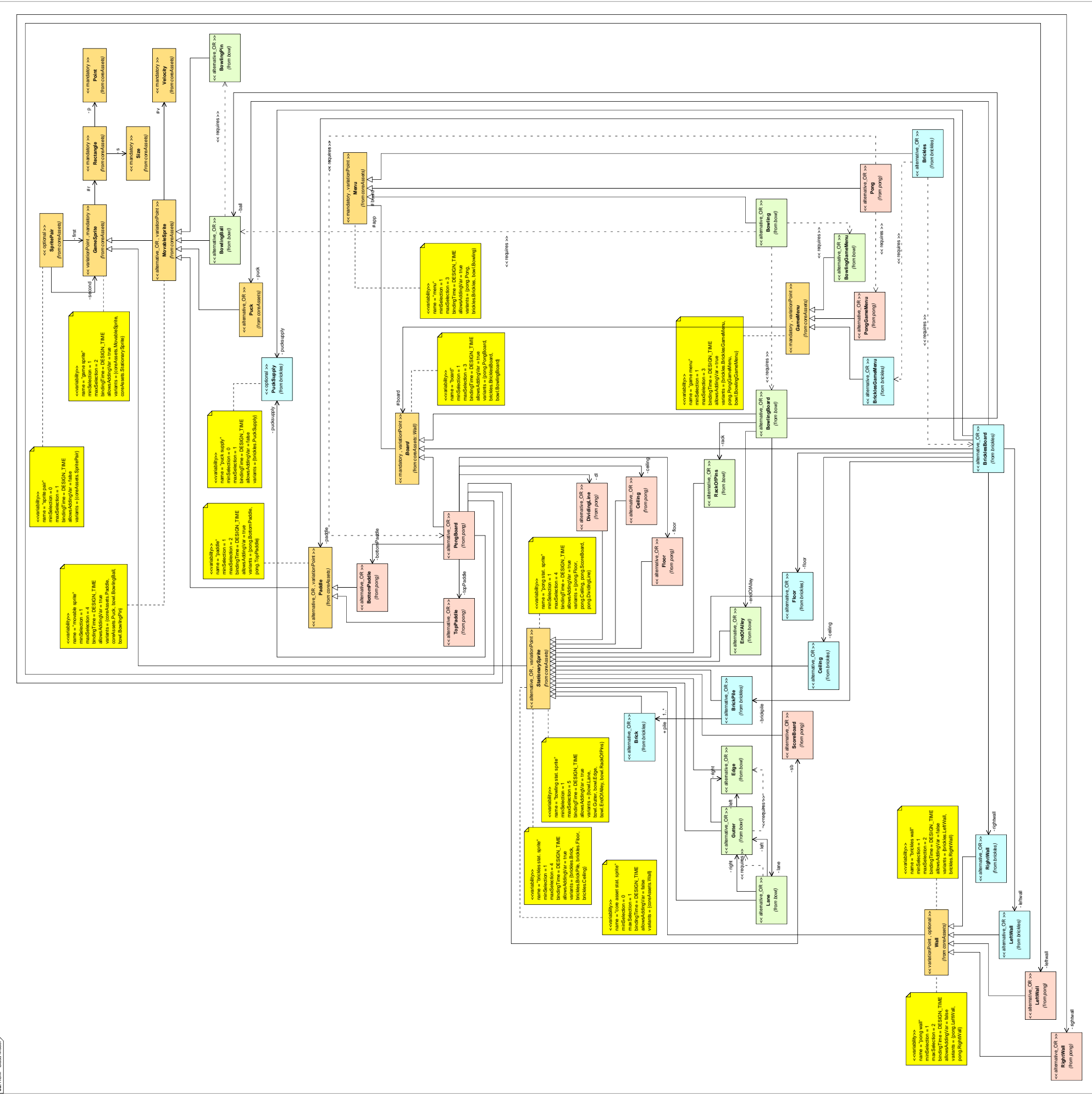


ID do

Participante:

\section{Arcade Game Maker (AGM)}

Configuração Número:

Modelo de Resolução de Variabilidades em Classes

\begin{tabular}{|c|c|c|c|c|c|c|c|}
\hline \multicolumn{8}{|c|}{ Variabilidades } \\
\hline Variabilidade & Ponto de Variação & Variante & $\begin{array}{c}\text { Relacionamento Variante / Ponto de } \\
\text { Variação }\end{array}$ & Selecionar & Variant & ira & Configuração? \\
\hline \multirow{3}{*}{ "game sprite" } & \multirow{3}{*}{ GameSprite } & MovableSprite & alternative_OR & I & ] Sim & [ & ] Não \\
\hline & & StationarySprite & alternative_OR & I & ] Sim & [ & ] Não \\
\hline & & SpritePair & optional & I & ] Sim & [ & ] Não \\
\hline \multirow{4}{*}{ “movable sprite” } & \multirow{4}{*}{ MovableSprite } & Paddle & alternative_OR & I & ] Sim & I & ] Não \\
\hline & & Puck & alternative_OR & I & ] Sim & I & ] Não \\
\hline & & BowlingBall & alternative_OR & I & I Sim & I & ] Não \\
\hline & & BowlingPin & alternative_OR & I & ] Sim & [ & ] Não \\
\hline \multirow{3}{*}{ “menu” } & \multirow{3}{*}{ Мenu } & Bowling & alternative_OR & I & ] Sim & I & ] Não \\
\hline & & Pong & alternative_OR & I & ] Sim & I & ] Não \\
\hline & & Brickles & alternative_OR & I & ] Sim & [ & ] Não \\
\hline \multirow{3}{*}{ “game mеnu” } & \multirow{3}{*}{ GameMenu } & BricklesGameMenu & alternative_OR & I & I Sim & I & ] Não \\
\hline & & BowlingGameMenu & alternative_OR & I & l Sim & I & ] Não \\
\hline & & PongMenu & alternative_OR & I & ] Sim & [ & ] Não \\
\hline \multirow{4}{*}{ "pong stat. sprite" } & \multirow{4}{*}{ StationarySprite } & ScoreBoard & alternative_OR & I & l Sim & I & ] Não \\
\hline & & Ceiling (pong) & alternative_OR & I & ] Sim & I & ] Não \\
\hline & & Floor (pong) & alternative_OR & I & ] Sim & [ & ] Não \\
\hline & & DividingLine & alternative_OR & I & ] Sim & [ & ] Não \\
\hline \multirow{5}{*}{ "bowling stat. sprite" } & \multirow{5}{*}{ StationarySprite } & Lane & alternative_OR & I & I Sim & I & ] Não \\
\hline & & Gutter & alternative_OR & I & l Sim & I & ] Não \\
\hline & & Edge & alternative_OR & I & ] Sim & [ & ] Não \\
\hline & & EndOfAlley & alternative_OR & I & I Sim & I & ] Não \\
\hline & & RackOfPins & alternative_OR & I & ] Sim & I & ] Não \\
\hline
\end{tabular}




\begin{tabular}{|c|c|c|c|c|c|c|c|}
\hline \multirow{4}{*}{ "brickles stat. sprite” } & \multirow{4}{*}{ StationarySprite } & Floor (brickles) & alternative_OR & I & I Sim & I & ] Não \\
\hline & & Ceiling (brickles) & alternative_OR & I & ] Sim & I & ] Não \\
\hline & & BrickPile & alternative_OR & I & I Sim & I & ] Não \\
\hline & & Brick & alternative_OR & I & I Sim & I & ] Não \\
\hline "core asset stat. sprite" & StationarySprite & Wall & optional & I & I Sim & I & ] Não \\
\hline \multirow{2}{*}{ "pong wall” } & \multirow{2}{*}{ Wall } & RightWall (pong) & alternative_OR & I & I Sim & I & ] Não \\
\hline & & LeftWall (pong) & alternative_OR & I & I Sim & I & ] Não \\
\hline \multirow{2}{*}{ "brickles wall" } & \multirow{2}{*}{ Wall } & RightWall (brickles) & alternative_OR & I & I Sim & I & ] Não \\
\hline & & LeftWall (brickles) & alternative_OR & I & I Sim & I & ] Não \\
\hline \multirow{2}{*}{ "paddle" } & \multirow{2}{*}{ Paddle } & TopPaddle & alternative_OR & I & Sim & I & ] Não \\
\hline & & BottomPaddle & alternative_OR & I & I Sim & I & ] Não \\
\hline \multirow[t]{3}{*}{ "board" } & \multirow[t]{3}{*}{ Board } & PongBoard & alternative_OR & I & I Sim & I & ] Não \\
\hline & & BowlingBoard & alternative_OR & I & I Sim & I & ] Não \\
\hline & & BricklesBoard & alternative_OR & I & Sim & I & ] Não \\
\hline "puck supply" & $\ldots-\ldots$ & PuckSupply & optional & I & I Sim & I & ] Não \\
\hline
\end{tabular}

1. Considerando a sua experiência com UML e Linha de Produto de Software, qual a complexidade desta configuração com relação à Arquitetura de Linha de Produto da AGM?

Marque com um " $X$ " somente uma alternativa.

\begin{tabular}{|c|c|c|c|c|}
\hline Extremamente Baixa & Baixa & Nem Baixa Nem Alta & Alta & Extremamente Alta \\
\hline & & & & \\
\hline
\end{tabular}

2. Considerando a sua experiência com UML e Linha de Produto de Software, qual a extensibilidade desta configuração com relação à Arquitetura de Linha de Produto da AGM?

Marque com um " $X$ " somente uma alternativa.

\begin{tabular}{|c|c|c|c|c|}
\hline Extremamente Baixa & Baixa & Nem Baixa Nem Alta & Alta & Extremamente Alta \\
\hline & & & & \\
\hline
\end{tabular}





\section{Estudo Experimental de Viabilidade do Método SystEM-PLA: Instrumentação}

Este apêndice apresenta os principais documentos utilizados no estudo experimental de viabilidade do método SystEM-PLA (Capítulo 8). Tais documentos são apresentados obedecendo a seguinte ordem:

1. Termo de Adesão ao estudo experimental;

2. Questionário de Caracterização do Participante;

3. Documento descrevendo os atributos de qualidade, as metas de negócio e os cenários definidos para a ALP da AGM;

4. Documento utilizado para classificar os cenários definidos para a LP AGM e questões sobre atributos de qualidade, metas de negócio e cenários. 


\section{Termo de Adesão a Estudo Experimental}

"Estudo de Viabilidade do Método SystEM-PLA para Avaliação de Arquiteturas de Linhas de Produtos Baseadas em UML"

Declaro estar ciente de participar de um estudo experimental, denominado Estudo de Viabilidade do Método SvstEM-PLA para Avaliação de Arquiteturas de Linhas de Produtos. Baseadas em UML, a ser coordenado pelo aluno de doutorado Edson A. de Oliveira Junior (ICMC-USP) e pelos professores José C. Maldonado (ICMC-USP) e Itana M. S. Gimenes (DIN-UEM). Neste estudo utilizarei modelos UML (classes e componentes) da linha de produto Arcade Game Maker (AGM), desenvolvida pelo SEI (Software Engineering Institute), nos quais deverei resolver as suas variabilidades com o objetivo de gerar 10 (dez) configurações distintas de produtos. Deverei ainda classificar cenários que exercitam AGM com vistas a realizar uma análise de trade-off acerca dos atributos de qualidade complexidade e extensibilidade definidos para a AGM, além da efetividade das metas de negócio definidas para a arquitetura da AGM. Devo preencher, também, questionários declarando minha formação, minha experiência com a notação UML e com a abordagem de Linha de Produto de Software, além de um parecer a respeito de cada tarefa do estudo realizada. Declaro estar ciente de que os resultados coletados a meu respeito (perfil) serão divulgados como parte do estudo sem vinculá-los ao meu nome. Declaro, também, estar ciente de que as informações obtidas/produzidas neste estudo podem ser divulgadas/publicadas única e exclusivamente pelo coordenador deste estudo. Finalmente, estou ciente de que não receberei nenhum benefício/pagamento pela participação neste estudo, além do conhecimento adquirido contribuindo com a minha formação profissional.

\begin{tabular}{|c|c|c|c|}
\hline $\begin{array}{c}\text { Nome do } \\
\text { Participante }\end{array}$ & $\begin{array}{c}\text { ID do } \\
\text { Participante }\end{array}$ & Assinatura & Local e Data \\
\hline & & & $\begin{array}{c}\text { Cidade, Estado - País } \\
\text { Data }\end{array}$ \\
\hline & & & \\
\hline
\end{tabular}




\title{
Questionário de Caracterização de Participante em Estudo Experimental
}

\author{
"Estudo de Viabilidade do Método SystEM-PLA para Avaliação de Arquiteturas de Linhas \\ de Produtos Baseadas em UML"
}

\section{ID do Participante}

Nas perguntas a seguir, quando duas ou mais alternativas forem válidas, marque a alternativa que mais se aplica ao seu caso.

1. Qual o seu nível de formação?

[ ] Mestrando [ ] Mestre

[ ] Doutorando [ ] Doutor

2. Qual a sua experiência com a notação UML com relação aos diagramas de classes e de componentes?

[ ] Minha experiência com a notação UML é básica.

Eu modelo softwares somente no nível dos elementos mais comuns da UML como classes e herança.

[ ] Minha experiência com a notação UML é moderada.

Eu modelo softwares no nível dos elementos da opção anterior, além de: polimorfismo, associação (uni e bi-direcionais), dependência, agregação e composição em classes; e componentes, interfaces requeridas e fornecidas, além de seus relacionamentos.

[ ] Minha experiência com a notação UML é avançada.

Eu modelo softwares que exigem a utilização de todos os elementos de diagramas de classes e componentes, além de outros diagramas da UML como, por exemplo, diagramas de colaboração e sequência. Além disso, conheço o metamodelo padrão da UML e sei como definir novos estereótipos, meta-atributos e restrições.

\section{Qual a sua experiência com relação à Arquitetura de Software?}

[ ] Minha experiência com Arquitetura de Software é básica.

$\mathrm{Eu}$ conheço os seguintes conceitos: estilos arquiteturais (camadas, pipes and filters, etc.), representação de uma arquitetura de software usando alguma notação e atributos de qualidade. Porém, não tenho experiência com avaliação de arquitetura de software. 


\section{[ ] Minha experiência com Arquitetura de Software é moderada.}

Eu conheço os conceitos da opção anterior, além de cenários, paradigmas arquiteturais (arquiteturas OO, orientadas a aspecto, etc), Architectural Description Languages (ADL), metas de negócio e avaliação de arquiteturas de software por meio do método ATAM (Architectural Trade-off Analysis Method) e documentação de arquiteturas incluindo visão lógica em UML.

\section{[ ] Minha experiência com Arquitetura de Software é avançada.}

Eu conheço os conceitos da opção anterior, além de já ter conduzido, pelo menos, uma avaliação de arquitetura usando o método ATAM.

4. Qual a sua experiência com relação à abordagem de Linha de Produto de Software (LP) e Gerenciamento de Variabilidade?

[ ] Eu nunca ouvi falar a respeito de LP.

[ ] Já lí, de forma superficial, algo a respeito de LP.

[ ] Minha experiência com LP é básica.

Eu conheço os seguintes conceitos da abordagem: ciclo de desenvolvimento de LP e suas atividades (engenharia de domínio e engenharia de aplicação). Porém, não tenho experiência com gerenciamento de variabilidades.

\section{[ ] Minha experiência com LP é moderada.}

Eu conheço os conceitos da opção anterior, e com relação ao gerenciamento de variabilidades, eu sei o conceito de pontos de variação, variantes e os seus relacionamentos, além dos conceitos de resolução de variabilidades e tempos de resolução (design time, link time, runtime, entre outros).

\section{[ ] Minha experiência com LP é avançada.}

Eu conheço os conceitos da opção anterior, além de alguns processos existentes de desenvolvimento de LP (FODA, PLP, PLUS, PuLSE, entre outros). Com relação ao gerenciamento de variabilidades, eu sei os conceitos da opção anterior, além de: modelos de resolução; abordagens existentes para o gerenciamento de variabilidades, e representação de variabilidades (usando a UML, modelos de características, entre outras). 


\section{Linha de Produto Arcade Game Maker (AGM): Atributos de Qualidade, Metas de Negócio e Cenários}

\section{Arquitetura Lógica em UML:}

- Componente Game: é o mais importante da arquitetura, pois possui classes com variabilidades que ao serem resolvidas resultam nos diversos produtos que a linha de produto pode produzir.

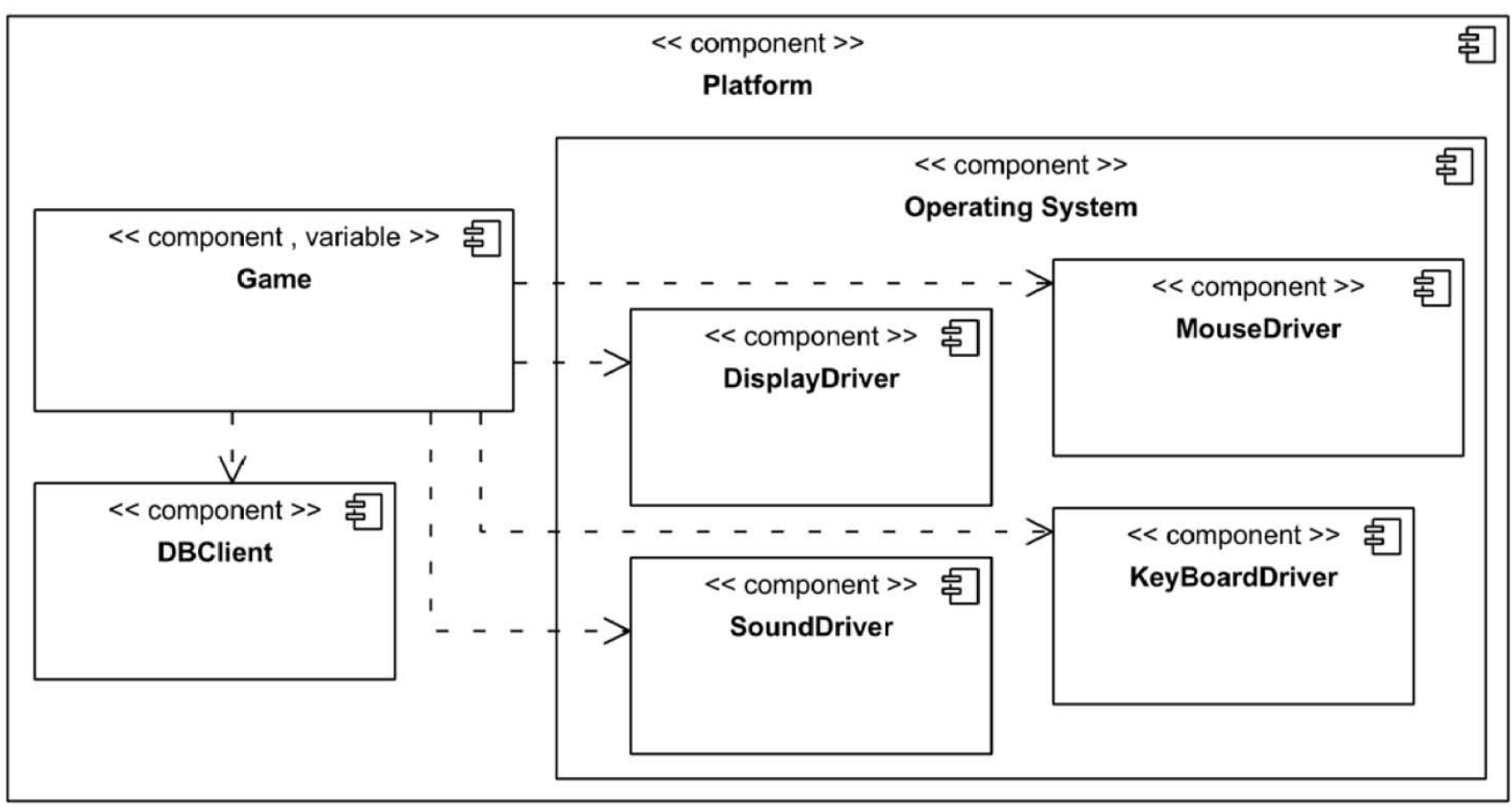

Atributos de Qualidade:

- Complexidade: medida com base na métrica de Complexidade Ciclomática de McCabe.

- Extensibilidade: relação entre classes/métodos abstratos e classes/métodos concretos

Metas de Negócio (MN):

- MN.1 - manter o grau de complexidade dos jogos abaixo de 0.7 (70\%), comparado à complexidade geral da ALP, para, pelo menos, $50 \%$ dos produtos produzidos:

o isto significa manter baixas as taxas de manutenibilidade e custo concentrando-se em complexidade. O grau de complexidade pode fornecer um indicador de dificuldade para manter os produtos derivados de uma ALP. Assim, quanto maior é o grau de complexidade de um produto, mais difícil é mantê-lo e, conseqüentemente, mais alto é o seu custo. 
- MN.2 - manter o grau de extensibilidade dos jogos acima de 0.75 (75\%), comparado à extensibilidade geral da ALP, para, pelo menos, $50 \%$ dos produtos produzidos:

0 isto significa manter altas taxas de reuso concentrando-se em extensibilidade. Graus de extensibilidade podem fornecer indicadores do quão reusável é um produto em termos de seus componentes. Quanto mais extensível é um produto, mais alta é a sua taxa de reusabilidade e mais baixo é o seu custo de manutenção/produção.

Cenários (Cn) Definidos para a Arquitetura da AGM:

- Definição de cenário:

- uma sentença simples descrevendo uma interação de um dos atores com o sistema.

- Cenários de Complexidade:

o Cn.1 - Pontos de variação e/ou variantes são adicionadas, modificadas ou removidas mantendo a Meta de Negócio MN.1 verdadeira;

o Cn.2 - 50\% das variabilidades são removidas mantendo a Meta de Negócio MN.1 verdadeira;

o Cn.3 - ambientes com 1 (um) jogo possuem complexidade máxima de 0.5 (50\%) com relação à arquitetura da AGM.

\section{- Cenários de Extensibilidade:}

o Cn.4 - Pontos de variação e/ou variantes são adicionadas, modificadas ou removidas mantendo a Meta de Negócio MN.2 verdadeira;

o Cn.5 - 50\% das variabilidades são removidas mantendo a Meta de Negócio MN.1 verdadeira;

o Cn.6 - ambientes com 2 (dois) jogos possuem extensibilidade mínima de 0.6 (50\%) com relação à arquitetura da AGM.

\section{Atributos para Classificação de Cenários:}

1. importância geral para a ALP e as suas metas de negócio;

2. generalidade do cenário com relação à ALP. O cenário deve ser classificado como obrigatório (Alto), alternativo (Médio) ou opcional (Baixo);

3. custo/risco, ou seja, o esforço envolvido para fornecer respostas aos cenários, bem como seu risco;

4. número de variabilidades contido em cada cenário. 


\section{ID do Participante}

Tarefa 1: Classificar os cenários a seguir sendo: A para Alto(a), M para médio(a) e B para baixo(a).

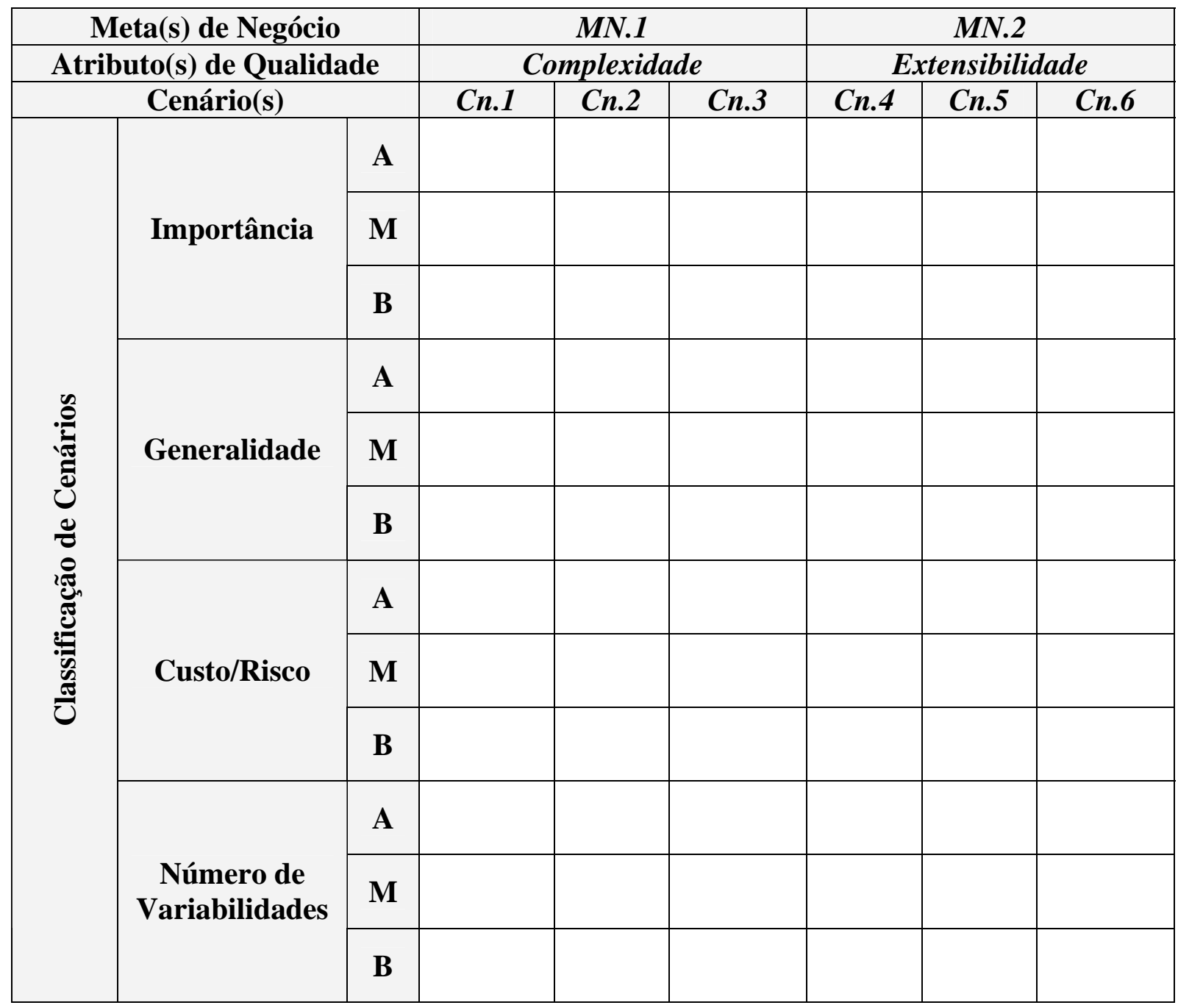


Tarefa 2: Responder as questões a seguir:

a) Você considera que as metas de negócio contribuem para entender melhor os atributos de qualidade da AGM?

b) Você considera que os cenários definidos para a arquitetura da AGM permitem uma melhor compreensão das suas metas de negócio?

c) Você considera que os cenários são elementos importantes definidos para uma arquitetura de linha de produto e, por isso, são essenciais para priorizar atributos de qualidade? 
d) Faça um mapeamento hierárquico (forma de árvore) dos seguintes elementos (ordenados alfabeticamente) definidos para a arquitetura da AGM:

- atributos de qualidade;

- cenários;

- metas de negócio. 